Andreas Schade

\title{
Ganzjährige \\ Beschäftigung in der \\ Bauwirtschaft - Eine \\ Wirkungsanalyse
}

Analyse und Ansätze für eine Reform

derWinterbauförderung 
Andreas Schade

\section{Ganzjährige Beschäftigung in der Bauwirtschaft - Eine Wirkungsanalyse}

Das Thema der ganzjährigen Beschäftigung durch Winterbau ist seit einigen Jahrzehnten Gegenstand der wirtschafts- und sozialpolitischen Diskussion. Andreas Schade analysiert die Auswirkungen der für die Bauwirtschaft konzipierten gesetzlichen Regelungen im Hinblick auf die Zielgrößen Produktion, Einkommen und Beschäftigung und zeigt Alternativen auf. Das Buch stellt einen wichtigen Beitrag zur aktuellen Auseinandersetzung um eine Reform des Förderprogramms für den Bausektor (Wegfall des Schlechtwettergeldes) dar.

Andreas Schade wurde 1964 in Hoya/Weser geboren. Von 1984 bis 1991 studierte er Wirtschaftsingenieurwesen der Fachrichtung Maschinenbau an der Technischen Hochschule Darmstadt. Von 1991 bis 1992 studierte er an der University of Colorado at Boulder/USA. 1995 erfolgte die Promotion. 
Ganzjährige Beschäftigung in der Bauwirtschaft Eine Wirkungsanalyse

Analyse und Ansätze für eine Reform der Winterbauförderung 


\section{Sozialökonomische Schriften}

Herausgegeben von Bert Rürup

Band 8

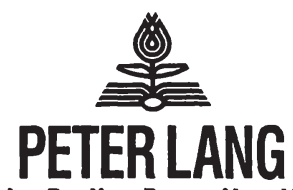

Frankłurt am Main. Berlin · Bern · New York. Paris · Wien 


\section{Andreas Schade}

\section{Ganzjährige Beschäftigung in der Bauwirtschaft - Eine Wirkungsanalyse Analyse und Ansätze für eine Reform der Winterbauförderung}

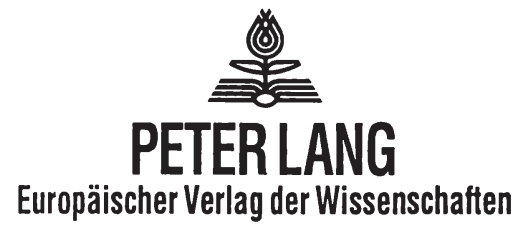


Die Deutsche Bibliothek - CIP-Einheitsaufnahme

Schade, Andreas:

Ganzjährige Beschäftigung in der Bauwirtschaft : eine Wirkungsanalyse ; Analyse und Ansätze für eine Reform der Winterbauförderung / Andreas Schade. - Frankfurt am Main ; Berlin ; Bern ; New York ; Paris ; Wien : Lang, 1995

(Sozialökonomische Schriften ; Bd. 8)

Zugl.: Darmstadt, Techn. Hochsch., Diss., 1995

ISBN 3-631-48878-5

Open Access: The online version of this publication is published on www.peterlang.com and www.econstor.eu under the international Creative Commons License CC-BY 4.0. Learn more on how you can use and share this work: http://creativecommons. org/licenses/by/4.0.

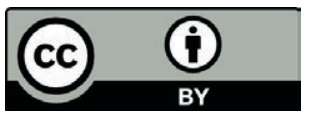

This book is available Open Access thanks to the kind support of ZBW - Leibniz-Informationszentrum Wirtschaft.

NE: GT

\author{
D 17 \\ ISSN 0172-1747 \\ ISBN 3-631-48878-5 \\ ISBN 978-3-631-75046-9 (eBook) \\ (C) Peter Lang $\mathrm{GmbH}$ \\ Europäischer Verlag der Wissenschaften \\ Frankfurt am Main 1995 \\ Alle Rechte vorbehalten.
}

Das Werk einschließlich aller seiner Teile ist urheberrechtlich geschützt. Jede Verwertung außerhalb der engen Grenzen des

Urheberrechtsgesetzes ist ohne Zustimmung des Verlages unzulässig und strafbar. Das gilt insbesondere für Vervielfältigungen, Übersetzungen, Mikroverfilmungen und die Einspeicherung und Verarbeitung in elektronischen Systemen.

Printed in Germany 1234567 


\section{Geleitwort}

Fertigstellung und Erscheinung dieser Arbeit zu Beginn des Jahres 1995 wird man angesichts der Auseinandersetzung um den Wegfall des "Schlechtwettergeldes" und des beginnenden Dialoges zwischen Bauwirtschaft und der Gewerkschaft IG BauSteine-Erden um eine "tarifliche" Lösung der typischen witterungsbedingter Lohnausfälle dieser Branche - als einen "Glücksfall" bezeichnen müssen, da mit dieser von Herrn Schade vorgelegten Analyse ein wichtiger Beitrag zur Rationalisierung der Diskussion über diese für die Baubranche wichtigen Frage geleistet wird.

Dieser Rationalisierungsbeitrag besteht darin, daß Herr Schade in der ganzjährigen Beschäftigung nicht eine a prioristische Notwendigkeit sieht, sondern er sich darum bemüht, diese zunächst nur "plausible" Forderung sozialpolitisch, betriebswirtschaftlich und volkswirtschaftlich zu begründen und er zudem eine in dieser Form neue Wirkungsanalyse der derzeitigen Regelung hinsichtlich ihrer Auswirkung auf die Arbeitslosenzahlen und das Arbeitsvolumen sowie die korrespondierenden eini-ommensmäßigen Effekte vorlegt.

Der Verfasser gibt sich ferner - erfreulicherweise - nicht mit einer analytischen Durchdringung und empirischen Aufhellung der bisherigen Regelungen zufrieden, sondern hat zudem den "politischen" Mut, ein eigenständiges Tarifmodell vorzulegen.

Es ist der Arbeit und dem Verfasser zu wünschen, daß sowohl die Ergebnisse seiner Arbeit, als auch sein tarifpolitischer Vorschlag in der laufenden Auseinandersetzung die gebührende Beachtung finden mögen.

Prof. Dr. Dr. h.c. Bert Rürup 
Andreas Schade - 978-3-631-75046-9

Downloaded from PubFactory at 01/11/2019 08:54:32AM

via free access 


\section{INHALTSVERZEICHNIS}

Seite

INHALTSVERZEICHNIS................................................................... VII

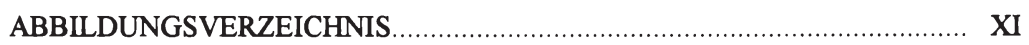

ABKÜRZUNGSVERZEICHNIS..................................................... XV

\section{Kapitel 1}

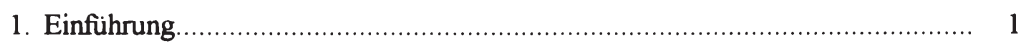

1.1. Begriffliche Bestimmungen und Abgrenzungen............................... 3

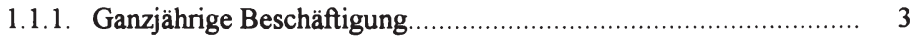

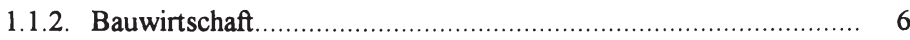

1.1.3. Bauhaupt- und Ausbaugewerbe ......................................... 8

1.2. Die Notwendigkeit der ganzjährigen Beschäftigung in der Bauwirtschaft............................................................................. 10

1.2.1. Die sozialpolitische Sichtweise ....................................... 11

1.2.2. Die betriebswirtschaftliche Sichtweise ................................. 18

1.2.3. Die volkswirtschaftliche Sichtweise..................................... 23

1.3. Problemstellung..................................................................... 29

1.4. Zielsetzung ................................................................... 31

1.5. Vorgehensweise und Abgrenzung ............................................ 32

\section{Kapitel 2}

2. Bauwirtschaft in Deutschland ......................................................... 36

2.1. Strukturanalyse und Bedeutung der Bauwirtschaft......................... 36

2.1.1. Die Bauwirtschaft im Rahmen der Gesamtwirtschaft............... 37

2.1.2. Betriebsstrukturelle Entwicklung .................................... 40

2.1.3. Baukonjunkturelle Entwicklung und Prognose...................... 42

2.1.4. Besonderheiten in der Bauwirtschaft................................... 47

2.2. Saisonbewegungen und deren Problematik für die Bauwirtschaft........... 50

2.2.1. Saisonschwankung ................................................... 50

2.2.2. Ursachen der Saisonschwankungen................................ 53 
2.2.2.1. Marktbedingte Saisonschwankungen........................ 54

2.2.2.2. Produktionsbedingte Saisonschwankungen.................. 56

2.2.3. Wirkungen der Saisonschwankungen................................ 58

2.3. Die konzeptionellen Möglichkeiten zur Realisierung der ganzjährigen Beschäftigung in der Bauwirtschaft.................................... 60

2.4. Zeitlicher Abriß der Förderungsmaßnahmen zur ganzjährigen

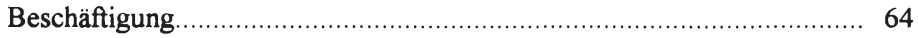

2.4.1. Gesetzliche Regelungen.................................................. 65

2.4.1.1. 1954-59: Der Zeitraum "Vorher"................................ 65

2.4.1.2. 1960-68: Das zweite Änderungsgesetz zum AVAVG.... 67

2.4.1.3. 1969-71: Das Arbeitsförderungsgesetz.................... 70

2.4.1.4. 1972-85: Die Winterbaunovelle................................ 71

2.4.1.5. 1986-92: Aussetzung der Förderung von IKZ und MKZ.. 73

2.4.2. Tarifvertragliche Leistungen und Regelungen.......................... 74

2.4.3. Sonstige Maßnahmen......................................................... 76

2.5. Vorstellungen der Beteiligten von den Förderungsmaßnahmen zur ganzjährigen Beschäftigung ................................................................ 79

2.5.1. Ziele des Gesetzgebers....................................................... 79

2.5.1.1. AVAVG ................................................. 80

2.5.1.2. AFG ............................................................ 83

2.5.1.3. Winterbaunovelle .............................................. 84

2.5.1.4. IKZ und MKZ ............................................ 87

2.5.2. Ziele der Arbeitgeber..................................................... 88

2.5.3. Ziele der IG Bau-Steine-Erden............................................. 90

\section{Kapitel 3}

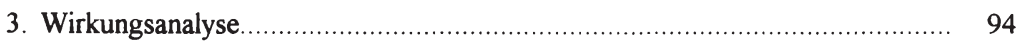

3.1. Einschränkungen in der Untersuchung....................................... 95

3.1.1. Statistik ................................................................... 95

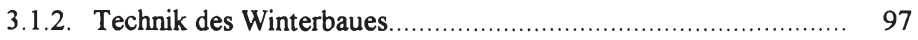

3.1.3. Schutzmaßnahmen.................................................. 98

3.1.4. Witterungsbedingungen............................................... 101

3.1.5. Zur Berechnung der Saisonschwankungen.............................. 107

3.1.5.1. Exkurs: Zeitreihenanalyse................................... 107

3.1.5.2. Das Phasendurchschnittsverfahren.......................... 110 
3.1.6. Sonstige Einschränkungen............................................... 111

3.1.7. Zusammenfassung der Einschränkungen............................... 112

3.2. Formulierung der Untersuchungskriterien aus den Zielvorstellungen...... 113

3.2.1. Primärkriterien.............................................................. 114

3.2.2. Sekundärkriterien.......................................................... 115

3.3. Ergebnisse der Wirkungsanalyse................................................. 116

3.3.1. Arbeitsmarktpolitische Effekte der getroffenen Förderungsmaßnahmen................................................................ 117

3.3.1.1. Wirkungen auf die Arbeitslosenzahlen....................... 117

3.3.1.2. Wirkungen auf die Beschäftigtenzahlen.................... 128

3.3.1.3. Erklärungsmöglichkeiten..................................... 132

3.3.2. Wirtschaftspolitische Effekte der getroffenen Förderungsmaßnahmen.............................................................. 138

3.3.2.1. Wirkungen auf die Produktionsschwankungen............. 138

3.3.2.1.1. Geleistete Arbeitsstunden......................... 141

3.3.2.1.2. Nettoproduktion für das Bauhauptgewerbe... 146

3.3.2.2. Wirkungen auf das Jahresbauvolumen......................... 153

3.3.2.3. Wirkungen auf die Verstetigung der Bautätigkeit.......... 159

3.3.3. Einkommenswirksame Effekte der getroffenen Förderungs-

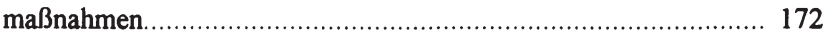

3.3.3.1. Wirkungen auf das Einkommen der Bauarbeiter............ 172

3.3.3.2. Erklärungsmöglichkeiten..................................... 181

3.4. Zusammenfassung der Ergebnisse der Wirkungsanalyse....................... 186

\section{Kapitel 4}

4. Diskussion alternativer Maßnahmen zur Förderung der ganzjährigen Beschäftigung 192

4.1. Gesetzliche Alternativmaßnahmen............................................. 193

4.1.1. Die SWG-Regelung...................................................... 196

4.1.1.1. Einkommenseffekte.......................................... 207

4.1.1.2. Fiskalische Effekte......................................... 213

4.1.1.3. Folgen der Streichung des SWG.......................... 220

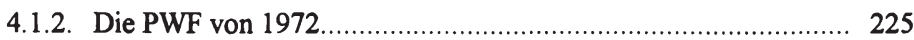

4.1.2.1. Wintergeld...................................................... 225

4.1.2.2. IKZ und MKZ .................................................. 228 
4.2. Tarifvertragliche Alternativmaßnahmen..................................... 231

4.3. Sonstige Alternativmaßnahmen................................................. 235

4.4. Fazit und Tarifmodellansatz................................................. 237

\section{Anhang}

I. Erläuterungen zu den gesetzlichen Vorschriften von 1960-68 243

II. Erläuterungen zu den gesetzlichen Vorschriften von 1969-71 245

III. Erläuterungen zu den gesetzlichen Vorschriften von 1972-85 247

IV. Witterungsbedingter Arbeitsausfall nach Ausfalltagewerken 257

LITERATURVERZEICHNIS XIX 


\section{ABBILDUNGSVERZEICHNIS}

Seite

Abbildung 1: Systematik der Wirtschaftszweige für das Baugewerbe

Abbildung 2: Erwerbstätige in 1.000 (JD) in der gesamten Wirtschaft und in der Bauwirtschaft......................................................... 37

Abbildung 3: Beschäftigte in bauabhängigen Wirtschaftszweigen................... 38

Abbildung 4: Gesamtwirtschaftliche Bedeutung der Bauwirtschaft in Mrd. DM.. 40

Abbildung 5: Betriebsgrößenklassen in \% .............................................. 41

Abbildung 6: Bauzweige des Bauhauptgewerbes in \%................................ 42

Abbildung 7: Reale Veränderung von Bauvolumen und BSP zum Vorjahr in \%.. 43

Abbildung 8: Zusammensetzung des Bauvolumens in \%.............................. 43

Abbildung 9: Gesamter Baubedarf der Jahre 1991 bis 2005 in Preisen von

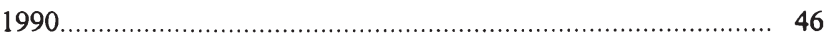

Abbildung 10: Die Komponenten einer Zeitreihe ....................................... 52

Abbildung 11: 1960-68: Tage mit Witterungserscheinungen, die die Fortführung der Bauarbeiten sehr erschweren................................. 104

Abbildung 12: 1969-71: Tage mit Witterungserscheinungen, die die Fortführung der Bauarbeiten sehr erschweren. 104

Abbildung 13: 1972-85: Tage mit Witterungserscheinungen, die die Fortführung der Bauarbeiten sehr erschweren. 105

Abbildung 14: 1986-92: Tage mit Witterungserscheinungen, die die Fortführung der Bauarbeiten sehr erschweren................................... 106

Abbildung 15: Vergleich der Witterungserscheinungen in Zeiträumen............... 106

Abbildung 16: Arbeitslose in den Bauberufen 1954 - 1959............................ 118

Abbildung 17: Saisonausschlag der Arbeitslosigkeit 1954 - 1959................... 119

Abbildung 18: Anteil der Arbeitslosigkeit in den Bauberufen an der Gesamtarbeitslosigkeit............................................................. 119

Abbildung 19: Arbeitslose in den Bauberufen 1960 - 1968........................ 120

Abbildung 20: Arbeitslose in den Bauberufen 1969 - 1971 ........................... 121

Abbildung 21: Arbeitslose in den Bauberufen 1972 - 1981............................. 122

Abbildung 22: Arbeitslose in den Bauberufen 1982 - 1985 ........................... 122

Abbildung 23: Arbeitslose in den Bauberufen 1986 - 1992 ......................... 123

Abbildung 24: Saisonausschlag der Arbeitslosigkeit $1960-1968 \ldots \ldots \ldots \ldots \ldots \ldots . . \ldots \ldots$ 
Abbildung 25: Saisonausschlag der Arbeitslosigkeit $1969-1971 \ldots \ldots \ldots \ldots \ldots \ldots \ldots . \ldots 125$

Abbildung 26: Saisonausschlag der Arbeitslosigkeit 1972 - 1985................... 125

Abbildung 27: Saisonausschlag der Arbeitslosigkeit 1986 - 1992................... 126

Abbildung 28: Saisonfaktoren der Arbeitslosen in den Bauberufen.................. 127

Abbildung 29: Beschäftigte im Bauhauptgewerbe 1954 - 1959..................... 128

Abbildung 30: Beschäftigte im Bauhauptgewerbe 1960 - 1968....................... 129

Abbildung 31: Beschäftigte im Bauhauptgewerbe 1969 - 1971 ....................... 130

Abbildung 32: Beschäftigte im Bauhauptgewerbe 1972 - 1985 ..................... 130

Abbildung 33: Beschäftigte im Bauhauptgewerbe 1986 - 1992 .................... 131

Abbildung 34: Saisonfaktoren der Beschäftigten im Bauhauptgewerbe.............. 131

Abbildung 35: Ausgaben der BA für die Bauwirtschaft an Arbeitslosengeld und SWG in Mio. DM.................................................... 136

Abbildung 36: Geleistete Arbeitsstunden in 1.000 Stunden im Bauhauptgewerbe 1954 - 1959.

Abbildung 37: Geleistete Arbeitsstunden in 1.000 Stunden im Bauhauptgewerbe 1960 - 1968.

Abbildung 38: Geleistete Arbeitsstunden in 1.000 Stunden im Bauhauptgewerbe 1969 - 1971

Abbildung 39: Geleistete Arbeitsstunden in 1.000 Stunden im Bauhauptgewerbe 1972 - 1985 .

Abbildung 40: Geleistete Arbeitsstunden in 1.000 Stunden im Bauhauptgewerbe $1986-1992$.

Abbildung 41: Saisonfaktoren der Arbeitsstunden im Bauhauptgewerbe. 145

Abbildung 42: Index der Nettoproduktion für das Bauhauptgewerbe 1954-1959.. 146

Abbildung 43: Saisonfaktoren der Nettoproduktion für das Bauhauptgewerbe 1954 - 1959.

Abbildung 44: Index der Nettoproduktion für das Bauhauptgewerbe 1960-1968.. 147

Abbildung 45: Saisonfaktoren der Nettoproduktion für das Bauhauptgewerbe 1960 - 1968

Abbildung 46: Index der Nettoproduktion für das Bauhauptgewerbe 1969-1971.. 148

Abbildung 47: Saisonfaktoren der Nettoproduktion für das Bauhauptgewerbe 1969 - 1971.

Abbildung 48: Index der Nettoproduktion für das Bauhauptgewerbe 1972-1985.. 149

Abbildung 49: Saisonfaktoren der Nettoproduktion für das Bauhauptgewerbe 1972 - 1985.

Abbildung 50: Index der Nettoproduktion für das Bauhauptgewerbe 1986-1992.. 150 
Abbildung 51: Saisonfaktoren der Nettoproduktion für das Bauhauptgewerbe $1986-1992$ 150

Abbildung 52: Saisonfaktoren der Nettoproduktion im Bauhauptgewerbe. 151

Abbildung 53: Vergleich der geleisteten Arbeitsstunden in 1.000 Stunden im Bauhauptgewerbe zwischen "Sommer" und "Winter". 155

Abbildung 54: Vergleich der geleisteten Arbeitsstunden je Beschäftigten und Tag im Bauhauptgewerbe. 162

Abbildung 55: Zusammenhang zwischen Arbeitsstundendifferenz und Witterung.. 167

Abbildung 56: Tägliche Arbeitszeitentwicklung je Beschäftigten....................... 170

Abbildung 57: Zusammenhang zwischen Arbeitsstundendifferenz und Witterung.. 171

Abbildung 58: Bruttolohnsumme in Mio. DM im Bauhauptgewerbe 1954-1959... 173

Abbildung 59: Bruttolohnsumme in Mio. DM im Bauhauptgewerbe 1960-1968 ... 174

Abbildung 60: Bruttolohnsumme in Mio. DM im Bauhauptgewerbe 1969-1971 ... 174

Abbildung 61: Bruttolohnsumme in Mio. DM im Bauhauptgewerbe 1972-1985 .. 175

Abbildung 62: Bruttolohnsumme in Mio. DM im Bauhauptgewerbe 1986-1992 .. 175

Abbildung 63: Saisonfaktoren der Bruttolohnsumme im Bauhauptgewerbe. 176

Abbildung 64: Bruttolohnsumme in DM/Beschäftigten im Bauhauptgewerbe 1954 - 1959 177

Abbildung 65: Bruttolohnsumme in DM/Beschäftigten im Bauhauptgewerbe 1960 - 1968 178

Abbildung 66: Bruttolohnsumme in DM/Beschäftigten im Bauhauptgewerbe 1969 - 1971 178

Abbildung 67: Bruttolohnsumme in DM/Beschäftigten im Bauhauptgewerbe 1972 - 1985 179

Abbildung 68: Bruttolohnsumme in DM/Beschäftigten im Bauhauptgewerbe 1986 - 1992 179

Abbildung 69: Saisonfaktoren der Bruttolohnsumme in DM/Beschäftigten. 180

Abbildung 70: Gegenüberstellung von Zahlungen und Stunden im Rahmen der Förderungsmaßnahmen zur "Ganzjährigen Beschäftigung".. 194

Abbildung 71: Ausfallstunden und Lohnausgleich je Bauarbeiter. 198

Abbildung 72: Zusammenhang zwischen Ausfallstunden je Bauarbeiter und Witterungsverlauf. 200

Abbildung 73: Zusammenhang zwischen Ausfallstunden je Bauarbeiter und Witterungsverlauf. 201

Abbildung 74: Einkommenseffekte der SWG-Regelung 208

Abbildung 75: Entwicklung von SWG je Ausfallstunde zum Ecklohn in \% 210 
Abbildung 76: Ausgaben der BA an Arbeitslosen- und Schlechtwettergeld getrennt nach Wirtschaftszweigen in Prozent.....

Abbildung 77: Einnahmen und Ausgaben aus der WB-Umlage in Mio. DM. 219

Abbildung 78: Wintergeld je Baustellenbeschäftigten und Gesamtergebnis. 226

Abbildung 79: Verteilung des witterungsbedingten Arbeitsausfalles von 90 Stunden auf die Monate November bis März 240

Abbildung 80: Witterungsbedingter Arbeitsausfall 1960-1968 257

Abbildung 81: Witterungsbedingter Arbeitsausfall 1969-1971 257

Abbildung 82: Witterungsbedingter Arbeitsausfall 1972-1985 258

Abbildung 83: Witterungsbedingter Arbeitsausfall 1986-1992. 258 


\section{ABKÜRZUNGSVERZEICHNIS}

Abb.

Abs.

a.F.

AFG

ANBA

AO

ArbStättV

Aufl.

AVAVG

Az

B

BA

BAVAV

Betr.

BGB

BGBI

BR-Drucks.

BRTV

BSE

BSP

BT-Drucks.

BT-Drs.

bzw.

C

d.h.

DIW

EG

EStG

f.

FAZ
Abbildung

Absatz

alte Fassung

Arbeitsförderungsgesetz

Amtliche Nachrichten der Bundesanstalt für Arbeit(svermittlung und Arbeitslosenversicherung)

Anordnung

Arbeitsstättenverordnung

Auflage

Gesetz über Arbeitsvermittlung und Arbeitslosenversicherung

Aktenzeichen

Beobachtung(en)

Bundesanstalt für Arbeit

Bundsanstalt für Arbeitsvermittlung und Arbeitslosenversicherung

Betreff

Bürgerliches Gesetzbuch

Bundesgesetzblatt

Bundesratsdrucksache

Bundesrahmentarifvertrag

Bau-Steine-Erden

Bruttosozialprodukt

Bundestagsdrucksache

Bundestagsdrucksache

beziehungsweise

Celsius

das heißt

Deutsches Institut für Wirtschaftsforschung

Europäische Gemeinschaft

Einkommenssteuergesetz

folgende Seite

Frankfurter Allgemeine Zeitung 


\begin{tabular}{|c|c|}
\hline ff. & folgende Seiten \\
\hline Hrsg. & Herausgeber \\
\hline $\mathrm{IAB}$ & Interministerieller Arbeitsausschuß Bauwirtschaft \\
\hline i.d.F. & in der Fassung \\
\hline insbes. & insbesondere \\
\hline i.S. & im Sinne \\
\hline i.V.m. & in Verbindung mit \\
\hline IG-Bau & Industriegewerkschaft Bau-Steine-Erden \\
\hline $\mathrm{IKZ}$ & Investitionskostenzuschuß \\
\hline $\mathbf{J}$ & $\operatorname{Jahr}(\mathrm{e})$ \\
\hline J & Jahresdurchschnitt (Gesamtdurchschnitt) \\
\hline Jg. & Jahrgang \\
\hline Kap. & Kapitel (Abschnitt) \\
\hline LStDV & Lohnsteuerdurchführungsverordnung \\
\hline M & Monat(e) \\
\hline $\mathrm{MD}$ & Monatsdurchschnitt (Phasendurchschnitt) \\
\hline Mio. & Million(en) \\
\hline MKZ & Mehrkostenzuschuß \\
\hline Mrd. & Milliarde(n) \\
\hline ND & Niederschlagsdauer \\
\hline n.F. & neue Fassung \\
\hline NM & Niederschlagsmenge \\
\hline Nr. & Nummer \\
\hline o. V. & ohne Verfasserangabe \\
\hline PWF & Produktive Winterbauförderung \\
\hline Rd.Erl. & Runderlaß der Bundesanstalt für Arbeit \\
\hline RG & Rationalisierungs-Gemeinschaft \\
\hline RKW & Rationalisierungs-Kuratorium der Deutschen Wirtschaft \\
\hline RVO & Reichsversicherungsordnung \\
\hline S. & Seite \\
\hline SA & Saisonausschlag (Schwankungsdifferenz, Variationsbreite) \\
\hline SF & Saisonfaktor \\
\hline sog. & sogenannt \\
\hline Sp. & Spalte \\
\hline SWG & Schlechtwettergeld \\
\hline SYPRO & Systematik der Wirtschaftszweige für das Baugewerbe \\
\hline
\end{tabular}


SZ Sommerzeit (Monatsdurchschnittszahlen der Monate April bis Oktober)

TV Tarifvertrag

u.a. und andere, unter anderem

UKB Urlaubskasse des Bayerischen Baugewerbes

ULAK Urlaubs- und Lohnausgleichskasse

usw. und so weiter

u.U.

vgl. unter Umständen

v.H. vergleiche vom Hundert

VO Verordnung

VTV Tarifvertrag über das Sozialkassenverfahren im Baugewerbe

WB

Winterbau

WG Wintergeld

WZ Winterzeit (Monatsdurchschnittszahlen der Monate November bis März)

z.B. zum Beispiel

Ziff. Ziffer

ZVK Zusatzversorgungskasse 
Andreas Schade - 978-3-631-75046-9

Downloaded from PubFactory at 01/11/2019 08:54:32AM

via free access 


\section{KAPITEL 1}

\section{Einführung}

Die Erkenntnis, daß witterungsbedingte Einflüsse die Bauwirtschaft in ihrer ganzjährigen kontinuierlichen Beschäftigung erheblich behindern, ist nicht neu. Bereits im vorigen Jahrhundert hat es in Deutschland unter den Sozialpolitikern immer wieder Diskussionen über die Problematik der saisonalen oder auch "berufsüblichen" Arbeitslosigkeit in der Bauwirtschaft gegeben. ${ }^{1}$

Auch in zahlreichen anderen Ländern befaßte man sich mit dem Problem des Bauens im Winter. Beispielsweise gab es in Nordamerika schon um die Jahrhundertwende eine umfangreiche Winterbautätigkeit zur Bewältigung großer Bauaufgaben. Insbesondere militärische Bauten sind hier zu nennen, da deren Fertigstellung durch Witterungseinflüsse nicht verzögert werden durfte. In der ehemaligen Sowjetunion sind Winterbauten aus dem Jahr 1929 bekannt, bei denen unter Vollschutz ${ }^{2}$ und bis zu Außentemperaturen von $-40^{\circ} \mathrm{C}$ gearbeitet worden ist. ${ }^{3}$

Die in Deutschland geführte Diskussion über den "Winterbau" bzw. die "Ganzjährige Beschäftigung in der Bauwirtschaft" hat erst nach 1945 wegen des enorm gesteigerten Baubedarfs infolge der Kriegszerstörungen eine erhöhte Bedeutung gewonnen. Erste Ergebnisse der einsetzenden Diskussion gehen auf den Winter 1948/49 im Gebiet des heutigen Landes Baden-Württemberg zurück. Hier wurden erstmalig Unterstützungsleistungen aus Mitteln der Arbeitslosenversicherung für Arbeitslose des Baugewerbes eingefuhrt; d.h. "...die Betriebe zahlten bei Arbeitsausfall in den Wintermonaten für mindestens 16 Stunden in der Doppelwoche Lohn und die Arbeitsämter leisteten eine nach Steuerklassen abgestufte Ausfallunterstützung." 4

Verfolgt man die Geschichte der diesbezüglichen Bestrebungen und Maßnahmen weiter, so läßt sich erkennen, daß erst ab Mitte der 50er Jahre ernsthafte und prakti-

1 vgl. Schleicher, E., Ratgeber für das Bauen im Winter, S.9.

2 Umhüllung des gesamten Bauwerkes zum Schutz vor Witterungseinflüssen, vgl. hierzu ausführlich Kap. 3.1.3. Schutzmaßnahmen, S.98ff.

3 vgl. Hampe, K.-H., Winterbau-Technologie, S.7.

4 vgl. Heberer, O./Kuhn, A./Wagner, H.-G., Kurzarbeitergeld/Winterbauforderung, S.84. 
sche Anstrengungen unternommen wurden, den winterlichen Arbeitsausfall zu überwinden. Der Grund für das verhältnismäßig späte Interesse am kontinuierlichen Bauen in Deutschland lag einerseits in der hohen Arbeitslosigkeit, die den Arbeitsmarkt noch Ende der 40er und Anfang der 50er Jahre kennzeichnete. Bis dahin galt die vielfach anzutreffende Meinung, daß es zumindest vom sozialen Standpunkt aus betrachtet nicht notwendig sei, sich um den Winterbau zu bemühen, "...weil es bei gleichem Produktionsvolumen immer noch wichtiger ist, einer größeren Anzahl von Bauarbeitern in der Saison die Chance der Arbeitsaufnahme zu geben, als einer kleineren Zahl von Bauarbeitern eine ganzjährige Beschäftigung zu garantieren."

Andererseits werden auch ökonomische Gründe für das verhältnismäßig späte Interesse am kontinuierlichen Bauen in Deutschland angefuhrt. So ist beispielsweise Riester der Auffassung, daß die Behandlung des Problems der saisonalen Arbeitslosigkeit traditionell mehr die ökonomische, als die sozialpolitische Problematik ins Auge gefaßt hatte. ${ }^{6}$

Schon allein die Tatsache, daß die Problematik der Saisonarbeitslosigkeit vorwiegend nur in Zeiten wirtschaftlicher Prosperität aufgegriffen wurde, wenn infolge Arbeitskräftemangels die Entwicklungskurve der Produktionsleistung zu stagnieren begann, ist für Riester bezeichnend. Erst jetzt erinnerte man sich der saisonalen Kräftereserven und glaubte, sie ohne weiteres für den erwünschten Kapazitätszuwachs nutzbar machen zu können.

Besonders in der Bauwirtschaft spielen solche Bestrebungen eine traditionsreiche Rolle. Bereits Ende der zwanziger Jahre, als die Baukonjunktur einen gewissen Höhepunkt erreichte, wurde untersucht, "...ob man nicht die für die Bauwirtschaft typischen winterlichen Produktionslücken unter den Bedingungen einer normalen Marktwirtschaft zum Zwecke eines nachhaltigen Kapazitätszuwachses schließen könnte."

5 vgl. Petz, G., Lohnausgleich bei Arbeitsausfall im Winter, S.511ff.

6 Anmerkung: Dies gilt insbesondere für den Zeitraum vor 1959.

7 vgl. Riester, F., Die Verhütung und Überwindung saisonaler Arbeitslosigkeit, insbesondere im Baugewerbe, als arbeitsmarktpolitische Aufgabe, S.1. 


\subsection{Begriffliche Bestimmungen und Abgrenzungen}

An dieser Stelle soll eine Begriffsbestimmung und -abgrenzung vorgenommen werden. Dies ist notwendig, weil in der Literatur eine Vielzahl unterschiedlicher Definitionen zur "Winterbauterminologie" existieren und die Abgrenzung häufig nicht eindeutig ist. Deshalb wird eine Auseinandersetzung mit der Terminologie einerseits dazu beitragen, mögliche und noch vorhandene Begriffsverwirrungen zu beseitigen. Andererseits soll eine Basis für eine einheitliche und exakte Ausdrucksweise geschaffen und die Verwendung möglicher Synonyme aufgezeigt werden. Die folgenden untrennbar mit dieser Arbeit verbundenen Begriffe werden daher näher erläutert und machen auch die Schwierigkeiten einer scharfen Abgrenzung der Termini untereinander deutlich.

\subsubsection{Ganzjährige Beschäftigung}

Schon die Definition des Begriffes "Ganzjährige Beschäftigung" bringt erhebliche Probleme mit sich. Begründet vor allem durch die Tatsache, daß der Begriff Beschäftigung in unterschiedlichem Sinne, d.h. betriebswirtschaftlich, volkswirtschaftlich oder sozialpolitisch zu verstehen ist.

Die betriebswirtschaftliche Betrachtungsweise, insbesondere bei unternehmenspolitischen Entscheidungen, meint mit Beschäftigung häufig nur die "...Beschäftigung von Menschen." 8 Die Volkswirtschaftslehre hingegen differenziert weiter und versteht unter dem Begriff Beschäftigung die "...Ausnutzung der vorhandenen Produktionsfaktoren Arbeit und Kapital einschließlich Boden. Der Bestand an Arbeitskräften und die Kapazität der Produktionsanlagen bestimmen die volkswirtschaftlichen Produktionsmöglichkeiten."9 Eine weitere Definitionsmöglichkeit liefert die Sozialpolitik, die Beschäftigung meist als Pendant zur Arbeitslosigkeit sieht und den Begriff somit als "...Vermeidung von Arbeitslosigkeit"10 charakterisiert, wobei Arbeitslosigkeit hier wie folgt verstanden werden soll: "...Als Arbeitslose gelten Personen ohne Arbeitsverhältnis, die als Arbeitssuchende beim Arbeitsamt registriert sind. Nach §102

8 vgl. Mellerowics, K., Beschäftigungspolitik, Sp.719ff.

9 vgl. Henrichsmeyer, W./Gans, O./Evers, I., Einfürung in die Volkswirtschaftslehre, S.319.

10 vgl. Willeke, E., Arbeitslosigkeit. (I) Allgemeines, S.305ff. 
AFG sind Personen dann als arbeitslos zu registrieren, wenn sie vorübergehend ohne Beschäftigungsverhältnis sind oder nur eine geringfügige Beschäftigung ausüben."11

Aufgrund der unterschiedlichen Begriffsdefinitionen stellt sich nun die Frage, was den Gesetzgeber bewogen hat, im AFG den Titel "Förderung der ganzjährigen Beschäftigung in der Bauwirtschaft" zu verwenden. Hier bietet sich die Schlußfolgerung an, den Beschäftigungsbegriff im sozialpolitischen Sinne anzuwenden, da das AFG der Sozialgesetzgebung zuzurechnen ist. Dieser Interpretation widerspricht allerdings die Tatsache, daß es nicht Aufgabe des Gesetzgebers sein kann, wenn er von einer "Förderung der ganzjährigen Beschäftigung in der Bauwirtschaft" spricht, jegliche im Jahresverlauf auftetende Arbeitslosigkeit dieses Wirtschaftszweiges zu bekämpfen. Vielmehr müssen hier wirtschafts- und sozialpolitische Maßnahmen gemeint sein, die mit dem Ziel eingesetzt werden sollen, die für die Bauwirtschaft typische Saisonarbeitslosigkeit zu beseitigen.

Ohne an dieser Stelle näher auf die Meinungsverschiedenheiten über die Bedeutung des Wortes "Saison"12 eingehen zu wollen, sollen unter "Saisonarbeitslosigkeit" entsprechend der Definition Willekes "...alle periodischen, ins Negative gehenden Beschäftigungsschwankungen, die in ihrer zeitlichen Dauer begrenzt und zugleich an bestimmte Zeitabschnitte im Jahr gebunden sind"13, verstanden werden. Diese Saisonarbeitslosigkeit kann auf unterschiedlichen Ursachen beruhen und tritt in einer Reihe von Wirtschaftszweigen mehr oder weniger ausgeprägt auf. ${ }^{14}$ Von besonderer Bedeutung ist sie in der Bauwirtschaft, wo sie alljährlich mit Einsetzen des Winters ein ungewöhnlich hohes Ausmaß annimmt und im allgemeinen Sprachgebrauch deshalb auch als "Winterarbeitslosigkeit" bezeichnet wird.

Eine nähere Betrachtung der Förderungsmaßnahmen des AFG belegt ebenfalls die Tatsache, daß der Gesetzgeber unter "Ganzjähriger Beschäftigung" offenbar nicht nur die Vermeidung von Saisonarbeitslosigkeit versteht, sondern vielmehr "...durch Leistungen der Produktiven Winterbauförderung"15 die ganzjährige Beschäftigung fördern will. D.h. der Gesetzgeber bezieht in den Beschäftigungsbegriff die produk-

\footnotetext{
11 vgl. Brümmerhoff, D., Volkswirtschaftliche Gesamtrechnungen, S.171.

12 vgl. hierzu ausführlich Kap. 2.2.1. Saisonschwankung, S.50ff.

13 vgl. Willeke, E., Arbeitslosigkeit. (I) Allgemeines, S.307.

14 vgl. hierzu ausführlich Kap. 2.2.2. Ursachen der Saisonschwankungen, S.53ff.

15 §74 AFG, Allgemeines, Absatz 2.
} 
tive Komponente ein und lehnt sich somit dem volkswirtschaftlichen Sprachgebrauch an.

Diese produktive Komponente des Begriffes "Ganzjährige Beschäftigung" wird auch als "Winterbau" bezeichnet, wobei unter Winterbau die "...Durchfürung von Bauarbeiten während der Winterbauzeit mit Hilfe von Winterbauschutzmaßnahmen", ${ }^{16}$ verstanden wird. Allerdings ist hier klar herauszustellen, daß mit "Winter" nicht die kalendarische Jahreszeit gemeint ist, sondern ein willkürlich festgelegter Zeitraum. ${ }^{17}$

Nach dem Umfang der einzusetzenden Schutzmaßnahmen unterscheidet man noch zwischen "Schlechtwetterbau" und "Frostbau". Bei ersterem werden Bauleistungen in der winterlichen Jahreszeit unter Witterungsbedingungen ausgeführt, die nur Maßnahmen geringeren Umfanges (z.B. Einzelschutz) zum Schutz der Arbeiten gegen die Einwirkung von Nässe, Kälte und Schnee erfordern. Der Frostbau hingegen benötigt zur Weiterführung der Arbeiten zusätzliche Maßnahmen, insbesondere gegen die Einwirkungen des Frostes. ${ }^{18}$

Die Ausführungen belegen die Vielfalt der möglichen Bezeichnungen zur "Ganzjährigen Beschäftigung." In der Literatur finden sich noch weitere Begriffe, wie beispielsweise "Ganzjähriges Bauen", "Bauen ohne Winterpause", "Ganzjahresbau", "Bauen in der witterungsungünstigen Jahreszeit", "Kontinuierliche Bautätigkeit" und "Winterbau". ${ }^{19}$ Die Bemühungen, die unternommen worden sind, einen passenderen Begriff zu finden, führten allerdings auch zu keiner ausschließlich geeigneten Bezeichnung. ${ }^{20}$

16 vgl. Schönberg, G./Dobler, M./Werthwein, R., Untersuchungen über Winterbauschutzmaßnahmen: Die Wirtschaftlichkeit wird positiv beeinflußt, S.16.

17 Zur Definition der Winterbauzeit vgl. auch Schönberg/Dobler/Werthwein, Untersuchungen über Winterbauschutzmaßnahmen: Die Wirtschaftlichkeit wird positiv beeinflußt, S. 16 und Institut für Arbeits- und Baubetriebswissenschaft (ifA), Betriebswirtschaftlicher Nutzen des Winterbaues, Anhang, Januar 1984: Zeit, in der über die in der Arbeitsschutzverordnung für Winterbaustellen vom 1.8.1968 festgelegten Maßnahmen hinaus Winterbauschutzmaßnahmen erforderlich sind. Sie kann über die gesetzlich festgelegte Schlechtwetterzeit (Zweites Gesetz zur Änderung und Ergänzung des Arbeitsförderungsgesetzes vom 19.5.1972 bzw. Arbeitsschutzverordnung für Winterbaustellen \$1 Abs. 1: 1.11. bis 31.3.) hinausgehen und beginnt mit dem vom Auftraggeber $b z w$. Auftragnehmer festgelegten bzw. zwischen Auftraggeber und Auftragnehmer vereinbarten Termin zu dem alle zu diesem Zeitpunkt für den Winterbau erforderlichen Maßnahmen einsatzbereit sein müssen und sind. Sie endet zu dem vereinbarten Zeitpunkt.

18 vgl. Eyerich, J./Lenz, J./Witschel, K., Einsparungen beim Bauen im Winter, S.44-46 und auch Kap. 3.1.2. Technik des Winterbaues, S.97-98.

19 Hinweis: $\mathrm{Zu}$ den verschiedenen Bezeichnungen und den Assoziationen, die sie möglicherweise hervorrufen; vgl. auch Böhler, H., Zur Winterbauterminologie, S.298ff. 
Nach Ansicht des Verfassers ist mit der Bezeichnung "Kontinuierliche Bautätigkeit" die "Ganzjährige Beschäftigung" am treffendsten charakterisiert, weil eine gleichmäBige und kontinuierliche Bautätigkeit während des ganzen Jahres sowohl die produktive als auch die beschäftigende Komponente berücksichtigt. ${ }^{21} \mathrm{Da}$ die Bezeichnung "Kontinuierliche Bautätigkeit" die Produktionsseite betont, erscheint unerheblich, weil eine kontinuierliche Bautätigkeit automatisch eine Verminderung der Saisonarbeitslosigkeit mit sich bringt, während der Umkehrschluß, wie sich noch zeigen wird, nicht unbedingt gilt. 22 Genau gesehen ist der Winterbau dann nur ein Teil der kontinuierlichen Bautätigkeit. Eine ähnliche Interpretation findet sich auch in Ansätzen bei anderen Autoren. ${ }^{23}$

Der Verfasser verzichtet jedoch, um sich nicht allzusehr in Widerspruch zum allgemeinen Sprachgebrauch zu setzen, auf eine scharfe Abgrenzung der verschiedenen Termini untereinander und versteht diese daher als Synonyme.

\subsubsection{Bauwirtschaft}

Die Ausführungen haben gezeigt, daß eine einheitliche und exakte Ausdrucksweise nicht immer gegeben ist und deshalb auch Synonyme ihre Verwendung finden. Inwieweit diese für den Begriff Bauwirtschaft eine Rolle spielen, soll nun erläutert werden, da insbesondere die Untersuchung des Zahlenmaterials der vorhandenen Baustatistiken im Rahmen dieser Arbeit von großer Bedeutung sein wird und daher eine klare Abgrenzung zu Begriffen wie Baugewerbe und Bauhauptgewerbe erforderlich macht.

Nach einer sehr weiten Begriffsbestimmung "...umfaßt die Bauwirtschaft alles, was zur Versorgung der Menschen mit Bauten gehört."24 In diesem Sinne würde jeder

$20 \mathrm{vgl}$. Semler, R., Laßt uns nicht von Winterbau sprechen, S.477ff.

21 vgl. hierzu auch Kap. 2.5.1. Ziele des Gesetzgebers, S.79ff.

22 Die erreichte Verringerung der Saisonarbeitslosigkeit führte nicht automatisch zur "kontinuierlichen Bautätigkeit", vgl. hierzu Kap. 3.3.1.3. Erklärungsmöglichkeiten, S.132ff. und Kap. 3.3.2.3. Wirkungen auf die Verstetigung der Bautätigkeit, S.159ff.

23 vgl. auch Schattenberg, H. H., Das kontinuierliche Bauen in wirtschaftspolitischer Schau, S.25ff; Kranz, G., Die jüngsten Bemühungen um ein kontinuierliches ganzjähriges Bauen, S.97ff. und Schleicher, E., Ist das Thema Winterbau noch aktuell?, S.1483f.

24 vgl. Kresling, H., Bauwirtschaft, S.687ff. 
Betrieb, der einen zur Errichtung eines Bauwerkes benötigten Artikel herstellt, zur Bauwirtschaft gehören.

Eine enger gefaßte Definition liefert Hesser. Er unterscheidet zwischen Bauwirtschaft und Baugewerbe. Unter Bauwirtschaft versteht er den "...Inbegriff aller Planungen, Tätigkeiten und Einrichtungen, die der Bereitstellung von Baulichkeiten dienen" und unter Baugewerbe "...die produktionswirtschaftliche Seite der Bauwirtschaft". ${ }^{25}$

Im Gegensatz dazu will Ehrler die Anwendung des Begriffes Bauwirtschaft auf diejenigen Wirtschaftszweige begrenzt wissen, die ausschließlich die Bauproduktion durchführen. ${ }^{26}$ Ähnlich wie Ehrler definiert auch Willeke den Begriff Bauwirtschaft, indem er die Bauwirtschaft an den "...von Unternehmen unmittelbar her- oder fertiggestellten Bauwerken orientiert." Hierzu zählen vor allem jene Unternehmen, die gemäß der Fassung für die Statistik im Produzierenden Gewerbe (SYPRO) ${ }^{27}$ in der Gruppe des Baugewerbes zusammengefaßt sind. Unternehmen, die keinen unmittelbaren Beitrag zur Erstellung eines Bauwerkes leisten, gehören somit nicht zur Bauwirtschaft. ${ }^{28}$

Beide zuletzt genannten Autoren setzen durch ihren Bezug zum produzierenden Gewerbe die Begriffe "Bauwirtschaft" und "Baugewerbe" gleich und klammern aufgrund ihrer Abgrenzung die anders strukturierte Baustoffindustrie aus. Ein Vergleich dieser Definition mit den Bezeichnungen in den Gesetzestexten, unterstützt die gefundene Übereinstimmung der Begriffe ebenfalls. So lautet beispielsweise die Überschrift des 2. Unterabschnittes im 3. Abschnitt des AFG: Förderung der ganzjährigen Beschäftigung in der Bauwirtschaft. Die Tatsache, daß in der Überschrift die Bezeichnung "Bauwirtschaft" zu finden ist, in den folgenden Paragraphen aber stets von "Baugewerbe" gesprochen wird, ${ }^{29}$ läßt es nicht nur gerechtfertigt, sondern auch sinnvoll erscheinen, in Anlehnung an Ehrler und Willeke, "Bauwirtschaft" und "Baugewerbe" zu Synonymen zu erklären. ${ }^{30}$

25 vgl. Hesser, W., Beschäftigung und Beschaftigungsgrad des Baugewerbes, S.11.

26 vgl. Ehrler, K., Die statistische Erfassung der Bauwirtschaft, S. 10.

27 vgl. Hauptverband der Deutschen Bauindustrie, Systematik der Wirtschaftszweige für das Baugewerbe, Erläuterungen Abschnitt D.

28 vgl. Willeke, R., Möglichkeiten zur Verstetigung der Baunachfrage durch Konjunkturprogramme, S.11.

29 vgl. \$74 AFG, Abs. 1 Satz 2 und Abs. 3 Satz 1 und 2.

30 Auch andere Autoren verwenden diese beiden Begriffe "gleichwertig" nebeneinander; vgl. z.B. Ruckgaber, H., Probleme der sozialen Sicherheit im Baugewerbe unter besonderer Berück- 


\subsubsection{Bauhaupt- und Ausbaugewerbe}

Nachdem der Begriff "Bauwirtschaft" bzw. "Baugewerbe" definiert und abgegrenzt wurde, sollen die Möglichkeiten seiner weiteren Untergliederung dargestellt werden. Dies ist deshalb von Bedeutung, weil sich die nachfolgenden statistischen Untersuchungen nicht immer auf die gesamte Bauwirtschaft, sondern lediglich auf Teile davon beziehen. Die Kenntnis und die Rangordnung dieser statistischen Teilbereiche innerhalb der Bauwirtschaft ist notwendig, um die Relevanz des zur Verfügung stehenden Zahlenmaterials beurteilen zu können.

In der amtlichen deutschen Statistik umfaßt das Baugewerbe die beiden Bereiche Bauhauptgewerbe ${ }^{31}$ und Ausbaugewerbe. Für die Gliederung dieser Bereiche galt bis 1976 die vom Statistischen Bundesamt herausgegebene "Systematik der Wirtschaftszweige". Inzwischen ist diese Systematik im Zuge der Modernisierung und Vereinheitlichung der Statistiken in der EG revidiert worden.

Die in der folgenden Abbildung dargestellte "Systematik der Wirtschaftszweige für das Baugewerbe" oder auch "Fassung für die Statistik im Produzierenden Gewerbe (SYPRO)" wird nunmehr bei den jährlichen Erhebungen im Bauhaupt- und im Ausbaugewerbe angewendet. ${ }^{32}$

Abschließend sei noch auf die Gliederungsmöglichkeit des Baugewerbes in Bauindustrie auf der einen und Bauhandwerk auf der anderen Seite hingewiesen. Diese Aufteilung bietet sich aufgrund der verbandsorganisatorischen Trennung der beiden Bereiche ${ }^{33}$ einerseits an, wirft aber andererseits kaum überwindbare Abgren-

sichtigung der winterlichen Arbeitslosigkeit, S.23 und Ifo-Institut für Wirtschaftsforschung, Die konjunkturelle Schlüsselstellung der Bauwirtschaft, S.17ff.

31 Hinweis: Der statistische Begriff Bauhauptgewerbe ist nicht identisch mit dem fachlichen Geltungsbereich der Tarifverträge für das Baugewerbe. Letztere erstrecken sich nicht auf die Dachdecker, andererseits schließen sie das Fliesen- und Plattenlegergewerbe ein.

32 Neuerung für das Bauhauptgewerbe war die vollständige Einbeziehung der Unternehmen/Betriebe, die überwiegend Fertigteilbauten herstellen und/oder montieren. Ferner sind die Zweige Gerüstbau, Fassadenreinigung und Gebäudetrocknung, die früher als Bauhilfsgewerbe galten, in das Bauhauptgewerbe übernommen worden. Diese Änderungen bedeuten gegenüber der alten Systematik Einschränkungen in der Vergleichbarkeit der Ergebnisse ab 1977.

33 Anmerkung: Einerseits Industrie- und Handelskammer für die Industriebetriebe organisiert im Hauptverband der Deutschen Bauindustrie und andererseits Handwerkskammer für die Handwerksbetriebe organisiert im Zentralverband des Deutschen Baugewerbes. 


\begin{tabular}{|c|c|}
\hline \multicolumn{2}{|r|}{ Systematil, der Wirtschaftsweige für das Baugewerbe ${ }^{34}$} \\
\hline SYPRO-Nr. & Wirtschaftszweig \\
\hline & Bauhauptgewerbe \\
\hline 72 & Hoch- und Tiefbau \\
\hline 7210 & Hoch-und Tiefbau, ohne ausgeprägten Schwerpunkt \\
\hline 7220 & Hochbau (ohne Fertigteilbau) \\
\hline 7231 & Herstellung von Fertigbauteilen aus Beton im Hochbau \\
\hline 7233 & Montage von Fertigbauteilen aus Beton im Hochbau \\
\hline 7235 & Herstellung von Fertigbauteilen aus Holz im Hochbau \\
\hline 7237 & Montage von Fertigbauteilen aus Holz im Hochbau \\
\hline 7241 & Erdbewegungsarbeiten, Landeskulturbau \\
\hline 7242 & Wasser- und Wasserspezialbau \\
\hline 7243 & Straßenbau \\
\hline 7244 & Brunnenbau, nichtbergbauliche Tiefbohrung \\
\hline 7245 & Bergbauliche Tiefbohrung und ähnliches (ohne Erdölbohrung) \\
\hline 7249 & Tiefbau, anderweitig nicht genannt \\
\hline 7251 & Gerüstbau \\
\hline 7255 & Fassadenreinigung \\
\hline 73 & Spezialbau \\
\hline 7301 & Schornstein-, Feuerungs- und Industrieofenbau \\
\hline 7302 & Gebäudetrocknung \\
\hline 7303 & Abdichtung gegen Wasser, Feuchtigkeit \\
\hline 7304 & Dämmung gegen Kälte, Wärme, Schall und ähnliches \\
\hline 7305 & Abbruch-, Spreng- und Enttrümmerungsgewerbe \\
\hline 74 & Stukkateurgewerbe, Gipserei, Verputzerel \\
\hline 75 & Zimmerei, Dachdeckerei \\
\hline 7510 & Zimmerei, Ingenieurholzbau \\
\hline 7550 & Dachdeckerei \\
\hline & A us b a u g w e r be \\
\hline 76 & Bauinstallation \\
\hline 7610 & Klempnerei, Gas- und Wasserinstallation \\
\hline 7640 & $\begin{array}{l}\text { Installation von Heizungs-, Lüftungs-, Klima und gesundheitstechnischen } \\
\text { Anlagen }\end{array}$ \\
\hline 7670 & Elektroinstallation \\
\hline 77 & Ausbaugewerbe (ohne Bauinstallation) \\
\hline 7731 & Glasergewerbe \\
\hline 7734 & Maler- und Lackierergewerbe \\
\hline 7737 & Tapetenkleberei \\
\hline 7751 & Bautischlerei \\
\hline 7755 & Parkettlegerei \\
\hline 7771 & Fliesen-, Platten- und Mosaiklegerei \\
\hline 7774 & Estrichlegerei \\
\hline 7777 & Sonstige Fußbodenlegerei und -kleberei \\
\hline 7791 & Ofen- und Herdsetzerei \\
\hline 7799 & Sonstiges Ausbaugewerbe (ohne Ofen- und Herdsetzerei) \\
\hline
\end{tabular}

Quelle: Die Deutsche Bauindustrie, Baustatistisches Jahrbuch 1992, Erläuterungen: D

34 Hinweis: Mit Beginn des Gemeinsamen Binnenmarktes in der EG gilt grundsätzlich ab 1993 die durch Verordnung des EG-Ministerrates für alle Mitglieder verbindlich angeordnete neue Systematik "NACE Rev. 1.": Für die Abteilung "Baugewerbe" sind dann folgende fünf Gruppen vorgesehen: 1.Vorbereitende Baustellenarbeiten, 2.Hoch- und Tiefbau, 3.Bauinstallation, 4.Sonstiges Ausbaugewerbe, 5. Vermietung. 
zungsschwierigkeiten auf, da die Grenzen zwischen handwerklichen und industriellen Baubetrieben fließend und in aller Regel nicht exakt bestimmbar sind.

Im Rahmen dieser Untersuchung ist die Gliederungsmöglichkeit nur insofern von Bedeutung, weil eine Reihe von Statistiken entweder nur die Bauindustrie oder nur das Bauhandwerk umfassen. In diesen Fällen handelt es sich um Zahlenmaterial, dessen statistische Abgrenzung auf rein formalen Kriterien beruht, wie der Mitgliedschaft bei den jeweiligen Fachverbänden, der Zugehörigkeit zur Industrie- und Handelskammer, oder der Eintragung in die Handwerksrolle. ${ }^{35}$

Eine Einschränkung muß an dieser Stelle allerdings gemacht werden, da in den vorhandenen Baustatistiken spezielles Zahlenmaterial fur das Baugewerbe großenteils nur für den Bereich des Bauhauptgewerbes existiert, so daß die vorliegende Untersuchung in weiten Teilen zwangsläufig auf diesen Teil der Bauwirtschaft beschränkt bleiben muß. ${ }^{36}$ Während der Verfasser in den aufgefuhrten Statistiken stets vermerkt, worauf Bezug genommen wird, verwendet er im fortlaufenden Text in Anlehnung an die gebräuchliche Terminologie die Bezeichnung Baugewerbe auch dort, wo lediglich das Bauhauptgewerbe angesprochen ist.

Nachdem wesentliche mit dieser Arbeit verbundene Begriffe und deren Abgrenzungsschwierigkeiten näher erläutert worden sind, soll das folgende Kapitel darüber Auskunft geben, warum eine Förderung der ganzjährigen Beschäftigung in der Bauwirtschaft überhaupt notwendig ist.

\subsection{Die Notwendigkeit der ganzjährigen Beschäftigung in der Bauwirtschaft}

Die Diskussion des Begriffes "Ganzjährige Beschäftigung" hat aufgezeigt, daß dieser als Kombination aus einer produktiven und beschäftigenden Komponente, d.h. winterlicher Bautätigkeit und Vermeidung von Saisonarbeitslosigkeit, verstanden werden muß und nach Ansicht des Verfassers mit der Bezeichnung "Kontinuierliche Bautätigkeit" am treffendsten charakterisiert wird. ${ }^{37}$

35 vgl. Schneider, H. K., Struktur und volkswirtschaftliche Bedeutung der Bauwirtschaft, S.7ff.

36 vgl. Betriebswirtschaftliches Institut der Westdeutschen Bauindustrie, Bauunternehmen und Baumarkt in der Statistik; Stand und Probleme, S. 17.

37 vgl. Kap. 1.1.1. Ganzjährige Beschäftigung, S.3ff. 
Obwohl bereits viel über die Notwendigkeit einer "Ganzjährigen Beschäftigung" bzw. "Kontinuierlichen Bautätigkeit" geschrieben und gesprochen worden ist, sollen die folgenden Ausführungen wesentliche sozialpolitische, betriebswirtschaftliche und volkswirtschaftliche Gründe, die aus qualitativen Gesichtspunkten für eine Förderung bzw. Realisierung der ganzjährigen Beschäftigung in der Bauwirtschaft sprechen, aufzeigen.

\subsubsection{Die sozialpolitische Sichtweise}

Um die Bedeutung der "Ganzjährigen Beschäftigung" aus sozialpolitischer Sicht verstehen und beurteilen zu können, ist es zunächst erforderlich, über die Ursachen und die Notwendigkeit staatlicher Sozialpolitik grundsätzlich nachzudenken.

Die Entstehung der Sozialpolitik ist vor allem auf die Existenz von Unterschieden in den politischen, persönlichen und wirtschaftlichen Rechten sowie in den Verfügungsmöglichkeiten über wirtschaftliche Güter (Einkommen, Vermögen) zwischen sozialen Gruppen (Schichten, Ständen, Klassen) zurückzuführen. Die Existenz dieser Unterschiede kann im Extremfall derartige soziale Spannungszustände verursachen, daß der innere Frieden und damit die Existenz einer Gesellschaft bzw. eines Staates bedroht werden, wenn nicht durch eine entsprechende Sozialpolitik die allgemeine "Soziale Frage", d.h. "...die Frage des friedlichen Zusammenlebens und Zusammenwirkens der in ihren wirtschaftlichen Lebensbedingungen, Lebensgewohnheiten und Lebensanschauungen weit voneinander entfernten Schichten, Ständen, Klassen eines Volkes", gelöst wird. ${ }^{38}$

Im Verlauf der geschichtlichen Entwicklung wurde diese elementare soziale Frage grundsätzlich gelöst, als im Zuge der allmählichen Verwirklichung der Ideen der Aufklärung und des Liberalismus die vorindustriellen Gesellschaftsstrukturen mit ihren für die überwiegende Mehrheit der Bevölkerung eingeschränkten Rechts- und einseitigen Abhängigkeitsverhältnissen aufgelöst wurden. Eine wesentliche Rolle spielten dabei die Aufhebung der Leibeigenschaft und Hörigkeit sowie die Einfürung und Sicherung elementarer Grundrechte wie Vertragsfreiheit, Freizügigkeit, Koalitionsfreiheit, Freiheit der Berufs- und Arbeitsplatzwahl und freies Wahlrecht. ${ }^{39}$

38 vgl. Tönnies, F., Die Entwicklung der sozialen Frage, S.7. 
Mit Beginn des Industriezeitalters entwickelte sich, unterstützt durch die eben angeführten Maßnahmen, eine schnell wachsende Schicht persönlich freier, aber vermögens- und besitzloser Menschen, die ihren Lebensunterhalt nur durch die vertragliche Verwertung ihrer Arbeitskraft sichern konnten. Dies geschah allerdings unter menschenunwürdigen wirtschaftlichen und sozialen Bedingungen, so daß diese Menschen am Rande des Existenzminimums leben mußten, gesellschaftlich nicht akzeptiert und politisch ohne Einfluß waren. Ihre Existenz und die ihrer Familien war im Falle von Arbeitslosigkeit, Krankheit, Invalidität, Altersschwäche oder Tod unmittelbar bedroht. Vor diesem Hintergrund wurde die Notwendigkeit staatlicher Sozialpolitik deutlich, die sich unmittelbar aus der Schutzlosigkeit der Arbeiter im Falle des Eintritts der oben genannten Risiken ergab. ${ }^{40}$

Betrachtet man die Auffassungen über das, was die Sozialpolitik bewirken soll, so sind im Laufe der Zeit sicherlich Veränderungen in den Zielvorstellungen der Sozialpolitik festzustellen. Die Sicherung des Existenzminimums für den Fall der oben genannten Notlagen war das Hauptziel zu Beginn des Industriezeitalters. Im Verlauf ihrer weiteren Entwicklung trat insbesondere die Arbeiterfrage ${ }^{41}$, als neue soziale Frage, in den Mittelpunkt der Sozialpolitik. ${ }^{42}$ Hier wurde auf der Grundlage eines starken wirtschaftlichen Wachstums vor allem der Auf- und Ausbau der Arbeitnehmerschutzpolitik und der Arbeitsmarktpolitik vorangetrieben.

$\mathrm{Da}$ die Sicherung der Existenz bei fehlenden Möglichkeiten oder Fähigkeiten zum Erwerb ausreichenden Arbeitseinkommens jedoch nur ein Teilbereich staatlicher Sozialpolitik ist, zeigen Art, Umfang und Niveau der sozialpolitischen Leistungen der Gegenwart. Diese haben sich in den vergangenen Jahrzehnten in einer Weise entwikkelt, daß nahezu alle Lebensbereiche durch sozialpolitische Vorschriften und Maßnahmen reguliert bzw. beeinflußt werden. So gehören beispielsweise auch Wohnungs-,

39 vgl. Lampert, H., Lehrbuch der Sozialpolitik, S.13ff.

40 vgl. Patsch, M., Prinzipien und Formen sozialer Sicherung in nichtindustriellen Gesellschaften, S.56ff. und Fischer, W., Soziale Unterschichten im Zeitalter der Frühindustrialisierung, S.242ff.

41 Anmerkung: Die Arbeiterfrage läßt sich vereinfacht umschreiben, "... als die soziale und sozialpolitische Problematik, die sich aus den wirtschaftlichen, sozialen und gesellschaftlichen Lebensumständen der in Deutschland entstehenden Schicht der Industriearbeiter ergab", vgl. hierzu Lampert, H., Lehrbuch der Sozialpolitik, S.19.

42 vgl. Tennstedt, F., Sozialgeschichte der Sozialpolitik in Deutschland, S.47ff. 
Familien- und Bildungspolitik sowie Einkommens- und Vermögensumverteilungspolitik und Sozialhilfepolitik zur staatlichen Sozialpolitik der Gegenwart. ${ }^{43}$

Trotz unterschiedlicher Zielsetzungen im Zeitablauf wird es die wichtigste Aufgabe der Sozialpolitik bleiben, die menschliche Existenz bestmöglich abzusichern. Dabei ergibt sich die Notwendigkeit der staatlichen Sozialpolitik der Gegenwart im Grunde aus den folgenden drei Tatsachen: ${ }^{44}$

- Die überwiegende Mehrheit der Bevölkerung ist auf das Arbeitseinkommen als Existenzgrundlage angewiesen. Bei Eintritt vorübergehender oder dauernder Erwerbsunfähigkeit oder bei Auftreten unplanmäßiger Ausgaben durch Krankheit, Arbeitslosigkeit, Unfall, Invalidität und Alter wäre diese Existenzgrundlage gefährdet, wenn nicht soziale staatliche Sicherungseinrichtungen bestünden.

- Es gibt Gesellschaftsmitglieder, die überhaupt nicht oder nur sehr begrenzt in der Lage sind, ihre Existenz durch Arbeitsleistungen und den damit verbundenen Erwerb von Ansprüchen auf staatliche Sozialleistungen abzusichern.

- Die Verwirklichung sozialer Gerechtigkeit durch eine gleichmäßigere Verteilung der Chancen für den Erwerb von Bildung, Einkommen und Vermögen sowie eine Verringerung nicht leistungsgebundener Einkommens- und Vermögensunterschiede gehört zur gesellschaftspolitischen Zielsetzung.

Aufgrund der beschriebenen sozialen Notlagen und Risiken, die jeden einzelnen betreffen können, erklärt sich die Bedeutung der Sozialpolitik auch für unsere Gesellschaft. Dies zeigt sich vor allem in der Summe der sozialpolitischen Leistungen, die rund ein Drittel des Sozialproduktes ausmachen und damit sehr nachhaltig die Lebenslage von Millionen Menschen beeinflussen. Infolgedessen steht die ökonomische und politische Auseinandersetzung um die Sozialpolitik häufig im Mittelpunkt des Interesses. Unstrittig ist allerdings die Tatsache, daß Arbeitslosigkeit als ein zentrales soziales Risiko angesehen wird, weil sie die materielle Existenz der Betroffenen unmittel-

43 vgl. Bäcker, G./Bispinck, R./Hofemann, K./Naegele, G., Sozialpolitik und soziale Lage in der Bundesrepublik Deutschland, Band 1: Arbeit, Einkommen, Qualifikation, S.28ff.

44 vgl. hierzu auch Widmaier, H. P., Klassifikation sozialpolitischer Bedürfnisse, in: Sozialpolitik und Wohlfahrtsstaat, S.47ff. und Lampert, H., Lehrbuch der Sozialpolitik, S.112ff. 
bar gefährdet. Daher ist es ein Hauptanliegen der Sozialpolitik, dem Arbeitnehmer die Sicherheit des Arbeitsplatzes bestmöglich zu garantieren. ${ }^{45}$

In der Bauwirtschaft spielt das zentrale soziale Risiko der Arbeitslosigkeit, mit allen negativen Folgewirkungen für die betroffenen Bauarbeiter, eine besondere Rolle. Hervorgerufen durch Saisonschwankungen, insbesondere durch den Rückgang der winterlichen Bautätigkeit, steigt in diesem Wirtschaftszweig in den Wintermonaten regelmäßig die saisonale Arbeitslosigkeit so stark an, daß nahezu jeder zweite männliche Arbeiter des Baugewerbes bei Winterbeginn seinen Arbeitsplatz verliert und im Durchschnitt etwa acht bis zehn Wochen arbeitslos bleibt. ${ }^{46}$ Durch diese winterlichen Produktions- und Beschäftigungsrückgänge werden Einkommenskontinuität und -situation der Bauarbeiter besonders negativ beeinflußt. Dabei ist zu unterscheiden, ob das Arbeitsverhältnis des Bauarbeiters fortbesteht oder aufgelöst wird.

Für den Fall des winterlichen Produktionsrückganges, in dem das Arbeitsverhältnis des Bauarbeiters fortbesteht, entfällt der Lohnanspruch für ausgefallene Arbeitsstunden. Nach $\S 4 \mathrm{Nr} .1$ BRTV-Bau wird "...der Lohn nur für die wirklich geleistete Arbeitszeit gezahlt." 47 Dies gilt auch dann, wenn die Arbeitsleistung infolge ungünstiger Witterung unmöglich wird ${ }^{48} \mathrm{D}$.h. bei Arbeitsausfall aus Witterungsgründen entstehen dem Betrieb, abgesehen von den vollen Krankenkassenbeiträgen (Arbeitgeberund Arbeitnehmeranteil) für Schlechtwetterausfallzeiten, keine Personal- bzw. Lohnkosten. Ausnahmen von diesem Grundsatz sind in $§ 4$ BRTV-Bau erschöpfend aufgezählt. Die Aufzählung zeigt, daß selbst für den Fall des Arbeitsmangels kein Lohnanspruch des Arbeitnehmers existiert, da Arbeitsmangel nicht zu den in §4 BRTV-Bau aufgezählten Ausnahmen von dem Grundsatz des $\S 4$ Nr.1 BRTV-Bau gehört. Im Extremfall - d.h. keine Arbeitsleistung aufgrund von Arbeitsmangel und/oder witterungsbedingtem Arbeitsausfall - ist es also möglich, daß der Lohnanspruch des Bauarbeiters bei bestehendem Arbeitsverhältnis entfältt.

45 vgl. hierzu Lampert, H., Ein wesentliches sozialpolitisches Ziel (Finalziel) ist "...die Sichenung und Erhöhung der materiellen Freiheit für alle durch Absicherung individueller Erwerbschancen", in: Lehrbuch der Sozialpolitik, S.328.

46 Hinweis: Diese Aussage gilt nur bis zur Einführung der SWG-Regelung im Dezember 1959, vgl. hierzu auch Kap. 3.3.1. Arbeitsmarktpolitische Effekte der getroffenen Förderungsmaßnahmen, S.117ff.

47 Anmerkung: In Abweichung von $\$ 616$ BGB (Vorübergehende Verhinderung) und vom Lohnfortzahlungsgesetz besteht der Lohnanspruch in der Bauwirtschaft nach $\$ 4$ BRTV-Bau (Arbeitsversäumnis und Arbeitsausfall, 1.Allgemeines) nur für wirklich geleistete Arbeitszeit.

48 § Nr.5.1 BRTV-Bau. 
Falls das Arbeitsverhältnis aufgelöst wird, erhält der arbeitslose Bauarbeiter anstelle des Arbeitseinkommens Arbeitslosengeld. Die Höhe dieses Arbeitslosengeldes, das zur finanziellen Überbrückung der winterlichen Arbeitslosigkeit aus Mitteln der Sozialversicherung gezahlt wird, beträgt im Durchschnitt nur etwa $65 \%$ des normalen Arbeitsentgeltes (63\% bzw.68\% des Nettolohnes), und das, obwohl das Arbeitslosengeld in der Regel nach dem durchschnittlichen Lohn der letzten dreizehn Wochen errechnet wird, in denen der Verdienst aufgrund der im Herbst üblichen Überstunden überdurchschnittlich hoch ist. ${ }^{49}$

Die Beschäftigungspause bewirkt zusätzlich eine erhebliche Verminderung der Altersrenten bei den Bauarbeitern, weil Ausfallzeiten durch Arbeitslosigkeit bei der Rentenberechnung als geminderte Beitragszeiten in Höhe des Arbeitslosengeldes gewertet werden. Ferner erhalten die Bauarbeiter im Krankheitsfall während der Arbeitslosigkeit nur ein Krankengeld in Höhe des Arbeitslosengeldes und nicht in Höhe ihres letzten Verdienstes. ${ }^{50}$ Das Urlaubsgeld wird ebenfalls gemindert und betriebliche Ansprüche auf Treueprämien für langjährige Betriebszugehörigkeit, auf Zuschüsse zur Altersversorgung etc. kann sich der Bauarbeiter aufgrund der winterlichen Arbeitspause in der Regel nicht erwerben. Die arbeitslosen Bauarbeiter werden gezwungenermaßen versuchen, diese Lohnausfälle durch anderweitige Nebenverdienste zu kompensieren. Daher muß damit gerechnet werden, daß die erhöhte Arbeitslosenzahl auch zu mehr Schwarzarbeit führt, die mit weiteren Mindereinnahmen an Steuern und Sozialbeiträgen verbunden ist.

Der Rückgang der winterlichen Bautätigkeit bzw. der Anstieg der Saisonarbeitslosigkeit hat aber nicht nur Auswirkungen auf die Einkommensverhältnisse sondern beeinflußt die gesamte Lebenssituation des einzelnen Bauarbeiters und seines sozialen Umfeldes. So führt die Einschränkung des materiellen Lebensstandards, ausgelöst durch den Verlust bzw. die Verringerung des Arbeitseinkommens, zu einer Einengung der sozialen und politischen Betätigungsmöglichkeiten und einer Belastung des Familienlebens. Denn selbst ein relativ gut ausgebautes Netz sozialer Sicherungsmaßnahmen kann ein kontinuierliches Arbeitseinkommen nie vollständig ersetzen. Die

49 vgl. Ewald, N., Der Angriff auf das Schlechtwettergeld, S.17, in: Rundschreiben der IG BauSteine-Erden, Abteilung Bundesvorsitzender vom 10.8.93.

50 Hinweis: Als Folge der Förderungsmaßnahmen zur ganzjährigen Beschăftigung in der Bauwirtschaft haben sich die finanziellen Bezüge im Krankheitsfall und die Ansprüche aus der Rentenversicherung erheblich verbessert, vgl. hierzu Kap. 3.3.3.2. Erklärungsmöglichkeiten, S. 183f. 
Ursachen hierfür liegen vor allem in der Tatsache, daß der erreichte Lebensstand weitgehend durch fixe Kosten bestimmt wird und nicht mehr finanziert werden kann. ${ }^{51}$

Das Risiko der latenten Unsicherheit und Unstetigkeit des Arbeitseinkommens macht eine längerfristige Lebensplanung ohne soziale Absicherung unmöglich. In dem Maße, wie das Arbeitseinkommen unsicher ist oder ganz ausfallt, wird auch der Unterhalt der unterhaltsberechtigten Familienangehörigen gefährdet, denn in einer hochindustrialisierten, arbeitsteiligen Gesellschaft wie der Bundesrepublik Deutschland müssen die meisten, für die persönliche Lebensführung notwendigen Sachgüter und Dienstleistungen gekauft werden. Eigenproduktion und Naturaltausch spielen heute so gut wie keine Rolle mehr. Damit wird die Verfügung über Geld zu einer entscheidenden Voraussetzung für den individuellen Lebensstandard. Je höher das Einkommen, um so besser ist die Versorgung mit materiellen (Nahrungsmittel und Bekleidung, Wohnung, Kraftfahrzeug, Medien etc.) und immateriellen (soziale Kontakte und Kommunikation, Bildung und kulturelle Betätigung etc.) Gütern. ${ }^{52}$

Ganz allgemein läßt sich sagen, daß heute eine Teilhabe am sozialen und kulturellen Leben ohne ausreichendes Einkommen nicht möglich ist. Dabei ist nicht nur die Höhe des Einkommens für die Lebenslage entscheidend, sondern auch die Tatsache auf welche Weise die Bauarbeiter ihr Einkommen erhalten. Es macht einen qualitativen Unterschied, ob ein eigenes, kontinuierliches Arbeitseinkommen bezogen wird oder ob die Existenzsicherung auf staatlichen Sozialleistungen beruht.

Im Fall der staatlich unterstützten Existenzsicherung lassen sich weitere negative Auswirkungen für den Arbeitnehmer des Baugewerbes erkennen. Durch die permanente soziale und wirtschaftliche Unsicherheit wird ein gewisses Minderwertigkeitsgefühl der Bauarbeiter im Vergleich zu anderen Berufsgruppen verstärkt und das Sozialprestige geschwächt. ${ }^{53}$

51 vgl. Riester, F., Die Verhütung und Überwindung saisonaler Arbeitslosigkeit, insbesondere im Baugewerbe, als arbeitsmarktpolitische Aufgabe, S.38ff. und Bäcker, G./Bispinck, R./Hofemann, K.Naegele, G., Sozialpolitik und soziale Lage in der Bundesrepublik Deutschland, Band 1: Arbeit, Einkommen, Qualifikation, S.83ff.

52 vgl. Bäcker, G./Welzmüller, R., Materielle Sicherung durch Arbeits- und Sozialeinkommen Strukturelle Veränderungen und verteilungspolitische Konsequenzen, in: Perspektiven der Vollbeschäftigung, S.23ff.

53 vgl. Ifo-Institut für Wirtschaftsforschung, Soziale und wirtschaftliche Auswirkungen der Winterbauförderung, S.25ff. 
Im einzelnen wirken sich die winterlichen Arbeitseinschränkungen und Arbeitsunterbrechungen vor allem auf die Schaffung und Pflege der sog. "human relations" äußerst ungünstig und störend aus, zumal deren Zustandekommen im Baugewerbe durch den nicht-stationären Charakter der Produktionsstätten ohnehin erheblich beeinträchtigt wird. Desweiteren werden durch die zu Beginn des Winters üblichen und zahlreichen Entlassungen nicht nur einzelne Arbeitsgruppen, sondern oftmals ganze Betriebsgemeinschaften aufgelöst, so daß die geknüpften Kontakte zwischen den Arbeitskräften, sowie ihr Verhältnis zu den Vorgesetzten und Unternehmern immer wieder unterbzw. abgebrochen werden. Ein betriebliches Zusammengehörigkeitsgefühl kann nicht aufkommen und Arbeitsfreude bzw. Arbeitswilligkeit werden nicht gerade gefördert. Außerdem behindert eine hohe Fluktuation die Möglichkeiten, die "...Arbeitnehmer im Betrieb organisch und rationell in die Willensbildung einzubauen, um dadurch die nachteiligen Folgen der Fremdbestimmtheit der Arbeitsverhältnisse für die Arbeitnehmer zu überwinden." 54

Die Ausführungen haben die negativen Folgewirkungen für den Bauarbeiter und sein soziales Umfeld, ausgelöst durch die Saisonarbeitslosigkeit in der Bauwirtschaft, aus sozialpolitischer Sicht aufgezeigt. Zusammenfassend läßt sich feststellen, daß die zentrale Voraussetzung für ein stetiges, zur individuellen Verwirklichung erforderliches Einkommen eine kontinuierliche Beschäftigung ist. Die Möglichkeit dieser kontinuierlichen Beschäftigung ist jedoch den auf den Verkauf ihrer Arbeitskraft angewiesenen Bauarbeitern faktisch verwehrt, so daß eine eigenständige, selbstverantwortliche Problemlösung unmöglich wird. Aus diesem Grund ist eine solidarische Risikoabsicherung nicht nur sinnvoll, sondern für den Bestand der Gesellschaftsordnung notwendig. Inwieweit diese Absicherung dem Markt, d.h. der individuellen Vorsorge überlassen werden kann, welche Leistungen für wen erbracht werden sollen und wie sie zu finanzieren sind, ist Gegenstand der Sozialpolitik. Mit der Sozialpolitik kommen somit soziale Interessen und Bedürfnisse der abhängig Beschäftigten zur Geltung.

$\mathrm{Da} ß$ eine Beschäftigungskontinuität aber nicht nur günstige Auswirkungen auf die sozialen Verhältnisse der Bauarbeiter ausübt, sondern auch betriebs- und volkswirtschaftliche Gründe für eine Förderung der ganzjährigen Beschäftigung in der Bauwirtschaft sprechen, sollen die folgenden Ausführungen belegen.

54 vgl Schwarzfischer, J., "Aufgaben, Möglichkeiten und Grenzen der betrieblichen Sozialpolitik" in: Betriebliche Sozialpolitik und soziale Betriebspolitik", S.53. 


\subsubsection{Die betriebswirtschaftliche Sichtweise}

Nachdem die Gründe aus sozialpolitischer Sicht für eine Förderung der ganzjährigen Beschäftigung in der Bauwirtschaft aufgezeigt wurden, darf die betriebswirtschaftliche Sichtweise nicht vernachlässigt werden. Infolge des marktwirtschaftichen Wirtschaftssystems der Bundesrepublik Deutschland kommt ihr sogar eine besondere Bedeutung zu, da letztendlich die Marktteilnehmer, also Bauherr und Bauunternehmer, entscheiden, ob im Winter gebaut wird oder nicht. ${ }^{55}$ Die folgenden Ausfürungen sollen daher klären, welche positiven Aspekte unter betriebswirtschaftlichen Gesichtspunkten von einer Förderung der ganzjährigen Beschäftigung in der Bauwirtschaft ausgehen.

Bei der Untersuchung des betriebswirtschaftlichen Nutzens der ganzjährigen Beschäftigung ist zwischen einem qualitativen und quantitativem Aspekt zu unterscheiden. Die Ermittlung des qualitativen Nutzens erstreckt sich auf die Untersuchung der die Unternehmensziele ${ }^{56}$ fördernden oder hemmenden Einflußfaktoren einer ganzjährigen Beschäftigung. Das Ergebnis ist zwar in Geldeinheiten nicht bewertbar, jedoch bei der Entscheidung für oder gegen den Winterbau von Bedeutung.

Ein kurz-, mittel oder langfristiger qualitativer Nutzen der "Kontinuierlichen Bautätigkeit" bzw. "Ganzjährigen Beschäftigung" kann grundsätzlich durch alle Maßnahmen entstehen, die dazu dienen, Unternehmensziele zu erreichen bzw. zu sichern. D.h. betriebswirtschaftlicher Nutzen ist immer dann festzustellen, wenn Unternehmensziele mehr gefördert als beeinträchtigt werden. Die der qualitativen Nutzenbetrachtung zugrunde liegenden positiven Effekte des Winterbaues sollen hier anhand der folgenden Unternehmensziele bezüglich des Absatzmarktes, des Personalwesens und der Produktion aufgezeigt werden: ${ }^{57}$

- Absatzziele: Die ganzjährige Bautätigkeit ermöglicht eine Vergrößerung der Bauleistung insgesamt. Falls eine Umsatzausweitung nicht realisiert werden kann, so erlaubt doch die Verteilung der Bauleistung auf die Wintermonate eine Reduzie-

55 vgl. Kießling, A., Winterbau lohnt sich - Wirtschaftlichkeit spielt die wichtigste Rolle, in: Beratende Ingenieure, Heft 12, 1974, S.4.

56 Zur ausfuhrlichen Diskussion von Unternehmenszielen vgl. Heinen, E., Grundlage betriebswirtschaftlicher Entscheidungen, S.89ff.

57 vgl. hierzu ausführlich Hampe, K.-H., Winterbau-Technologie, Planung, Vergabe, Ausführung, S.67ff. 
rung der vorzuhaltenden Kapazitäten und damit ihre gleichmäßigere und bessere Auslastung. Das Angebot von Winterbauleistungen kann von entscheidender Bedeutung für die Auftragserteilung sein, weil der Auftraggeber dadurch zu einem entsprechend früheren Zeitpunkt sein Bauobjekt nutzen kann. Schließlich kann ein Unternehmen, das Winterbau betreibt, seine Marktposition ausbauen.

- Personalziele: Erhebliche saisonale Schwankungen im Arbeitsanfall und damit im Bedarf an Arbeitskräften führen zu negativen Auswirkungen durch eine erhöhte Fluktuationsrate, die durch Winterbau vermindert werden kann. Im einzelnen reduziert eine kleinere Fluktuationsrate vor allem den Aufwand furr Entlassungen und Einstellungen sowie den Aufwand für Ausbildung und Einarbeitung neuer Mitarbeiter. ${ }^{58}$

- Produktionsziele: Winterliche Bautätigkeit fördert wesentliche Produktionsziele, wie vertragsgerechte, fristgemäße und wirtschaftliche Herstellung der geforderten Leistungen. So entfält beispielsweise der Aufwand für die turnusmäßige Überwachung von stillgelegten Baustellen sowie für deren gegebenenfalls mehrmaliges Aus- und Anlaufen. ${ }^{59}$ Durch Schutzmaßnahmen kann auch an Tagen weitergearbeitet werden, an denen auf ungeschützten Baustellen die Arbeiten ruhen. Dadurch werden die Kapazitäten besser genutzt und die Fertigungszeiten verkürzt, weil der Leistungsgrad auf geschützten Baustellen in der Regel höher ist als auf den ungeschützten. Insgesamt werden die Störungen im Bauablauf durch die Reduzierung der Witterungsabhängigkeit verringert und damit die Termineinhaltung positiv beeinflußt und erleichtert. Falls trotz Schutzmaßnahmen extreme Witterungsbedingungen die Stillegung einer Baustelle erforderlich machen, sind die Bedingungen beim Wiederanlaufen wesentlich günstiger als auf einer ungeschützten Baustelle.

Bei der Entscheidung für oder gegen eine "Kontinuierliche Bautätigkeit" aus betriebswirtschaftlichen Gesichtspunkten spielen aber nicht nur die genannten qualitativen Aspekte, sondern vor allem auch der quantitative - aus der Differenz von Aufwand und Ertrag errechnete - Nutzen einer winterlichen Baumaßnahme eine ent-

58 Eine Verringerung der Fluktuationsrate hat auch in sozial- und wirtschaftspolitischer Hinsicht positive Auswirkungen, vgl. hierzu Ifo-Institut für Wirtschaftsforschung: Soziale und wirtschaftliche Auswirkungen der Winterbauförderung, S.55ff.

59 Durch eine "...kontinuierliche Beschăftigung werden die zusătzlichen Kosten eines "Stop-andgo"-Betriebes der Baustelle vermieden", vgl. hierzu Nolte, R., Winterbau verbessert Rentabilităt und Wirtschaftlichkeit - Eine Chance zum Überleben, in: Bauwirtschaft, Heft 41, Oktober 1984, S.1409. 
scheidende Rolle. D.h. für den Baubetrieb bzw. den Bauunternehmer ist es in erster Linie von Bedeutung, zu wissen, ob und gegebenenfalls in welchem Umfang eine ganzjährige Beschäftigung bzw. kontinuierliche Bautätigkeit die Kostenstruktur positiv beeinflußt und damit für den Betrieb insgesamt ökonomische Vorteile bringt ${ }^{60}$ Aus diesem Grund beschränken sich die folgenden Betrachtungen vorwiegend auf die Darstellung und Beurteilung der verschiedenen Kosteneffekte einer verstärkten Winterbautätigkeit.

$\mathrm{Daß}$ eine erhöhte winterliche Bauproduktion das Kostengefüge in den Baubetrieben beeinflußt, ist unbestritten. So entstehen durch das Bauen im Winter sowohl zusätzliche Kosten als auch Minderkosten. Zu den Mehrkosten, die aufgrund spezifischer Aufwendungen des Winterbaues nötig sind, gehören beispielsweise:

- Einmalige Kosten für die Baustelleneinrichtung, d.h. für An- und Abtransport sowie Auf- und Abbau der Schutzeinrichtungen zum Winterfestmachen der Baustelle.

- Zeitabhängige Kosten, z.B. Vorhalte- bzw. Mietkosten für die Winterbaugeräte und Schutzeinrichtungen.

- Leistungsabhängige Kosten, z.B. Mehraufwendungen für Energie (Beleuchtung und Heizung) und zusätzliche Arbeiten ( $\mathrm{Zu}$ - und Abdecken der Baustoffe, Schneeräumen, Enteisen, etc.).

Demgegenüber stehen die folgenden Minderkosten und/oder Erträge, die sich teilweise auch aus der qualitativen Nutzenbetrachtung der Unternehmensziele ableiten lassen:

- Zusätzliche Deckungsbeiträge: D.h. eine kontinuierliche Bautätigkeit bzw. eine Verringerung der witterungsbedingten Stillstandszeiten führt zu kontinuierlichen Rechnungslegungen und Zahlungseingängen und daher zur Vermeidung von $\mathrm{Li}$ quiditätsengpässen.

60 vgl. Sommer, M., Winterbau - Kriterium ist die Wirtschaflichkeit, S.82, in: bau-zentralblatt, Heft 21, 1981. 
- Leistungsabhängige Minderaufwendungen: Verringerung unrentierlicher Stillstands- und Wiederanlaufkosten ("Stop-and-go-Betrieb") ${ }^{61}$ und Steigerung der Arbeitsproduktivität durch Winterbauschutzmaßnahmen.

- Vermeidung von Kostenremanenz: Darunter versteht man im allgemeinen den Tatbestand, daß kurzfristige bewegliche Kosten sich in ihrer Höhe an Änderungen des Beschäftigungsgrades des Betriebes nicht sofort, sondern erst mit einer zeitlichen Verzögerung anpassen. ${ }^{62}$ Insbesondere hat man festgestellt, daß sich die Kosten bei einem Rückgang der Beschäftigung nicht im erwartetem Umfang vermindern. ${ }^{63}$ Die unmittelbaren Ursachen hierfür können sehr vielfältiger Natur sein. Ein möglicher Entstehungsgrund liegt in der unternehmenspolitischen Entscheidung, die höhere Betriebsbereitschaft in Erwartung eines Wiederanstiegs der Beschäftigung beizubehalten, auch wenn sie während des Winters nicht vollständig ausgelastet ist. Mit anderen Worten: Fixe Kosten werden nicht abgebaut, obwohl dies technisch und organisatorisch grundsätzlich möglich wäre. ${ }^{64}$

- Sonstige Minderkosten: Verringerung der Fluktuationskosten durch ganzjährige Beschäftigung, d.h. insbesondere Verringerung des Mehraufwandes furr Inserate, Kosten der Personalabteilung und Kosten, die aus der Anlernzeit der häufig ungelernten Arbeitskräfte resultieren. ${ }^{65}$ Ferner weist das Ifo-Institut darauf hin, daß die Unternehmer infolge der Tatsache, daß die witterungsbedingten Ausfallzeiten nicht annähernd vorauszuschätzen sind, für diese Stillstandszeiten einen erhöhten Wagniszuschlag einkalkulieren, der bei kontinuierlicher Bautätigkeit entfallen könnte. ${ }^{66}$

61 So müssen bei Stillegung der Baustelle die Baumaschinen entweder zum Bauhof abtransportiert oder anderweitig geschützt werden (Ausbau der Batterien); insbesondere aber verursacht die erforderliche Einarbeitungszeit bei Wiederinbetriebnahme nicht unerhebliche Anlaufkosten; vgl. hierzu Kießling, A., Winterbau steigert die Wirtschaftlichkeit, S.33, in: Das Baugewerbe, Heft $21,1973$.

62 vgl. Kosiol, E. u.a. (Hrsg.), Handwörterbuch des Rechnungswesens, Spalte 955-958.

63 Eine ähnliche Definition zur Kostenremanenz findet sich auch bei Mellerowicz:"... die immer wieder beobachtete Tatsache, daß bei absinkender Beschäftigung die Kosten in ihrem Absinken gegenüber dem Kostenanstieg zurückbleiben". vgl. Mellerowicz, K., Kosten und Kostenrechnung, Bd.1: Theorie der Kostenrechnung, S.310.

64 Zur Kostenremanenz und ihren Ursachen vgl. ausführlich Strube, E., Kostenremanenz und Beschäftigungsschwankungen, S.505ff. in: Zeitschrift für handelswissenschaftliche Forschung, 30.Jg., Heft 10, 1963 und auch Kosiol, E. u.a. (Hrsg.), Handwörterbuch des Rechnungswesens, Spalte 955-958.

65 vgl. ausführlich Biffar, M., Die Kosten der Fluktuation, S.293ff., in: Der Arbeitgeber, 11.Jg., Heft 10, 1959.

66 vgl. Ifo-Institut für Wirtschaftsforschung, Optimaler Winterbau, S.12. 
Die Aufstellung der Mehr- und Minderkosten erhebt keinen Anspruch auf Vollständigkeit. Sie zeigt aber bereits, wie zahlreich die Faktoren sind, die die betriebliche Kostensituation im Winter beeinflussen können. Ebenso zahlreich wie die Einflußfaktoren der betrieblichen Kostensituation sind auch die in der Literatur zu findenden unterschiedlichen Vorstellungen über die Höhe der anzusetzenden Winterbaumehrbzw. Winterbauminderkosten. ${ }^{67}$ Der hierdurch vermittelte Eindruck einer gewissen Intransparenz und Unsicherheit des Winterbau-Kosten-Erlösgefüges trägt nicht dazu bei, die unternehmerische Entscheidung für eine kontinuierliche Bautätigkeit - die in erster Linie von der Kenntnis des zu erwartenden quantitativen Nutzens der winterlichen Baumaßnahme abhängt - positiv zu beeinflussen.

Allerdings dürfen die betriebswirtschaftlichen Überlegungen zum Winterbau nicht von einer isolierten Betrachtung der einzelnen Winterbaumaßnahme ausgehen; sondern eine sinnvolle unternehmerische Entscheidung berücksichtigt auch mittel- und langfristige Kosten-Nutzen-Effekte. In diesem Zusammenhang ist vor allem die Tatsache von Bedeutung, daß sich durch eine gleichmäßigere ganzjährige Beschäftigung die fixen Kosten günstiger verteilen. ${ }^{68}$ Als fixe Kosten werden diejenigen Kostenarten bezeichnet, deren Höhe unabhängig vom jeweiligen Beschäftigungsgrad konstant bleibt, d.h. deren Reagibilitätsgrad gleich Null ist. ${ }^{69}$ Gelingt es nun, beispielsweise durch Winterbau den Beschäftigungsgrad zu erhöhen, d.h. die ansonsten stilliegende Kapazität zu nutzen, so verteilen sich die fixen Kosten auf eine größere Leistungsmenge; der Anteil der Fixkosten pro Leistungseinheit wird geringer, und damit sinken naturgemäß die Gesamtkosten dieser Einheit. ${ }^{70}$ Dieser als "Fixkostendegression" bezeichnete Effekt durch höhere Kapazitätsauslastung wird umso größer, je höher der Anteil der Fixkosten an den Gesamtkosten des Betriebes ist. Da der Fixkostenanteil

67 Zur ausführlichen Diskussion der Mehr- und Minderkosten des Winterbaues vgl. insbesondere Ebel, H. J., Der Winterbau. Betriebswirtschaftliche Grundlage, S.71ff. und Dressel, N./Dietel, V., Der betriebswirtschaftliche Nutzen des Winterbaues - Anleitung zur betrieblichen Berechnung, S.3ff., RG-Bau im RKW, Merkblatt 69.

68 vgl. Teschke, F., Kostenreduzierung durch Winterbau bei bereits gedeckten Fixkosten, S. 102ff., in: Bauwirtschaft, Heft 4, Januar 1980.

69 Als Reagibilitätsgrad bezeichnet Mellerowics das Verhältuis von prozentualer Änderung der Kostenart zur prozentualen Änderung des Beschäftigungsgrades, vgl. Mellerowicz, K., Kosten und Kostenrechnung, Bd.1: Theorie der Kostenrechnung, S.288.

$70 "$ "... beim Abbau von Leistungsspitzen im Sommer und Auffüllen von Leistungstälern im Winter sinkt der Fixkostenanteil absolut und damit die Kosten je Bauleistungseinheit", vgl. hierzu ausführlich Kießling, A., Winterbau steigert die Wirtschaftlichkeit, S.33, in: Das Baugewerbe, Heft 21, 1973. 
im Baugewerbe eine steigende Tendenz aufweist, ${ }^{71}$ gewinnt auch die ganzjährige Beschäftigung unter diesem wesentlichen quantitativen Kosten-Nutzen-Effekt zunehmend an Bedeutung

Faßt man die Ausführungen zusammen, so hat sich gezeigt, daß die Förderung der ganzjährigen Beschäftigung unter betriebswirtschaftichen Gesichtspunkten durchaus notwendig ist. Es bleibt daher abschließend zu klären, welche volkswirtschaftlichen Argumente für die Förderung der ganzjährigen Beschäftigung in der Bauwirtschaft sprechen.

\subsubsection{Die volkswirtschaftliche Sichtweise}

Ausgehend von dem Grundgedanken, daß Wirtschaftsordnungen - wie die soziale Marktwirtschaft - weder allein entstehen noch sich selbst erhalten, erfült die Wirtschaftspolitik in der Wirtschaftsordnung der sozialen Marktwirtschaft verschiedene Aufgaben. ${ }^{72}$ Sie soll einerseits die gewachsene Ordnung sichern, andererseits dort lenkend eingreifen, wo gesellschaftliche Ziele durch wirtschaftiche Entwicklungen gefährdet sind und schließlich initiativ werden, wenn die Wirtschaftsentwicklung Korrekturen und Ergänzungen des gesetzlichen Rahmens erforderlich macht. ${ }^{73}$

Dabei ist allerdings zu berücksichtigen, daß sich die wirtschaftspolitischen Ziele nur auf einen Teilbereich gesellschaftlichen Lebens beziehen, d.h. sie sind entweder nur Bestandteil viel umfassenderer gesellschaftlicher Grundwerte oder selbst ein Mittel, um diese Werte anzustreben. Die in diesem Zusammenhang wichtigsten gesellschaftspolitischen Grundwerte bzw. -ziele mit Bezug zu wirtschaftlichen Fragen sind wirtschaftliche Freiheit, wirtschaftliche Gerechtigkeit, sozialer Frieden, soziale Sicherheit, wirtschaftlicher Wohlstand und Fortschritt. $\mathrm{Da}$ in keiner Gesellschaft zu irgendeinem Zeitpunkt völlige Einigkeit über Inhalt und Rang dieser Werte besteht, können auch

71 Nach Betriebsvergleichen in Unternehmen des Baugewerbes verschiedener Größe ist der Fixkostenanteil von durchschnittlich $15 \%$ im Jahr 1960, auf etwa $20 \%$ bis 1970 angestiegen. Je nach Struktur und Eigenart der Baubetriebe schwankt der Fixkostenanteil beträchtlich und liegt 1980 bereits zwischen 20 und 35\%; vgl. Zentralverband des Deutschen Baugewerbes, Winterbau 73/74, Grundlage/Möglichkeiten/Kosten, S.17, und Teschke, F., Kostenreduzierung durch Winterbau bei bereits gedeckten Fixkosten, S. 103, in: Bauwirtschaft, Heft 4, Januar 1980.

72 vgl. Streit, M. E., Theorie der Wirtschaftspolitik, S.26-38 und Hensel, K. P., Grundformen der Wirtschaftsordnung, S.36ff.

73 vgl. von Beckerath, E. (Hrsg.), Art: "Wirtschaftspolitik", S.210-231, in: Handwörterbuch der Sozialwissenschaften, 1965. 
wirtschaftspolitische Ziele bestenfalls Ausdruck eines dauernden gesellschaftlichen Einigungsversuchs über wichtige Elemente der Grundwerte sein. Ihre inhaltliche Konkretisierung erfolgt dabei im Prozeß der politischen Willensbildung. ${ }^{74}$

Aufgrund der oben beschriebenen Aufgaben der Wirtschaftspolitik in der sozialen Marktwirtschaft können ordnungs-, ablauf- und verteilungspolitische Ziele unterschieden werden. Die folgende Aufstellung stellt die wesentlichen wirtschaftspolitischen Ziele anhand von Zielkomplexen dar, ohne sie dabei näher zu konkretisieren: ${ }^{75}$

- Bedarfsgerechter Einsatz der volkswirtschaftlichen Produktivkräfte

- Gerechte Einkommens- und Vermögensverteilung

- Stabilisierung des Wirtschaftsablaufs

- Freiheitliche Wirtschaftsordnung

Wie bereits erwähnt, stehen die wirtschaftspolitischen Ziele in engem Zusammenhang mit den gesellschaftspolitischen Grundwerten und sind aus diesen zu begründen. Die Vielfältigkeit dieser Beziehungen, ist beispielsweise bei den ablaufpolitischen Zielen festzustellen. Dabei werden die ablaufpolitischen Ziele häufig nach den Hauptzielen der Stabilitätspolitik unterschieden, d.h. Vollbeschäftigung der Produktionsfaktoren, Geldwertstabilität, außenwirtschaftliches Gleichgewicht und stetiges Wirtschaftswachstum. ${ }^{76}$ Vor diesem Hintergrund wird die Beziehung zwischen dem ablaufpolitischem Ziel Wirtschaftswachstum und verschiedenen gesellschaftlichen Grundwerten deutlich, wenn davon ausgegangen wird, daß ein entsprechendes Wirtschaftswachstum zu einer Erhöhung der allgemeinen materiellen Wohlfahrt führt und aus den gewonnenen verteilungspolitischen Spielräumen bestehende "Verteilungsungerechtigkeiten" beseitigt und somit die Versorgungsmöglichkeiten aller verbessert werden. Stetiges wirtschaftliches Wachstum fördert damit vor allem die gesellschaftlichen Grundwerte Wohlstand, Sicherheit, Gerechtigkeit und Fortschritt. ${ }^{77}$

74 vgl. Heinrichsmeyer, W./Gans, O./Evers, I., Einführung in die Volkswirtschaftslehre, S.40ff.

75 Zur ausführlichen Diskussion vgl. Preiser, E., Wirtschaftspolitik heute, S.23ff. und Streit, M. E., Theorie der Wirtschaftspolitik, S.130-138 und Heinrichsmeyer, W./Gans, O./Evers, I., Einführung in die Volkswirtschaftslehre, S.28ff.

76 vgl. Bombach, G., "Wirtschaftswachstum und Stabilität", in: Wachstum und Konjunktur, S.9.

77 vgl. Preiser, E., Wirtschaftspolitik heute, S.44 und Streit, M. E., Theorie der Wirtschaftspolitik, S.130-138. 
Von wirtschaftlichem Wachstum spricht man in der makroökonomischen Wachstumstheorie immer dann, wenn die Produktionskapazität einer Volkswirtschaft im langfristigen Zeitablauf erhöht wird, so daß mehr Sachgüter und Dienstleistungen für den Konsum und andere Zwecke zur Verfügung gestellt werden können. ${ }^{78}$ Während bei der Konjunkturanalyse die Schwankungen der ökonomischen Variablen um ihre trendmäßige Entwicklung im Vordergrund stehen, abstrahiert die Wachstumstheorie von den "...konjunkturellen Schwankungen und interessiert sich nur für das, was der Statistiker den Trend der Entwicklung nennt."79 Dabei versucht sie die Bestimmungsfaktoren für die Trendentwicklung der Produktionskapazität aufzuzeigen. Die folgenden Faktoren sind im wesentlichen für das Wachstum der Produktionskapaziät verantwortlich:80

- Wachstum des Produktionsfaktors Arbeit (personelle Kapazität): Der Arbeitskräfteeinsatz ist vor allem abhängig vom natürlichen Bevölkerungswachstum, dem Zustrom von Arbeitskräften sowie den Veränderungen der Erwerbstätigenquote und der Arbeitszeit pro Erwerbstätigen.

- Wachstum des Kapitalstocks (technische Kapazität): Abhängig von der Höhe der getätigten Investitionen bei Gebäuden, Maschinen und Infrastruktur.

- Technische und organisatorische Verbesserungen des Produktionsprozesses (technischer Fortschritt): Das Ausmaß des technischen Fortschrittes steht in engem Zusammenhang mit Investitionen im Bereich des Sachkapitals, der Ausbildung und der Forschung sowie der Anpassungsfähigkeit und Beweglichkeit der Produktionsfaktoren, die durch zahlreiche soziale, institutionelle und ökonomische Faktoren beeinflußt werden.

Vor dem Hintergrund des engen Zusammenhanges der wirtschaftspolitischen Ziele mit den gesellschaftspolitischen Grundwerten und der gesetzlichen Forderung nach Stabilität und Wachstum der Wirtschaft, ${ }^{81}$ geht es in den folgenden Ausführungen

78 vgl. Dürr, E., Wachstumspolitik, S.14ff. und Haberler, G., Wirtschaftswachstum und Stabilität, S.46-64.

79 vgl. Bombach, G., "Wirtschaftswachstum und Stabilität", in: Wachstum und Konjunktur, S.9.

$80 \mathrm{vgl}$. Heinrichsmeyer, W./Gans, O./Evers, I., Einführung in die Volkswirtschaftslehre, S.40ff.

81 Anmerkung: Nach §1 des Gesetzes zur Förderung der Stabilität und des Wachstums der Wirtschaft (StWG) sind im Rahmen der marktwirtschaftlichen Ordnung gleichzeitig Stabilität des Preisniveaus, ein hoher Beschäftigungsstand und außenwirtschaftliches Gleichgewicht bei stetigem und angemessenem Wirtschaftswachstum anzustreben. 
darum, darzulegen, welche positiven Effekte für die Volkswirtschaft von einer Förderung der ganzjährigen Beschäftigung in der Bauwirtschaft ausgehen.

Betrachtet man hierzu die drei oben genannten Bestimmungsfaktoren für das Wachstum der Produktionskapazität, so lassen sich durch den Rückgang der winterlichen Bautätigkeit bzw. den Anstieg der Saisonarbeitslosigkeit unmittelbare Auswirkungen auf die personelle und die technische Kapazität in der Bauwirtschaft erkennen. Wie stark der Auslastungsgrad der bauhauptgewerblichen Gesamtkapazität (personelle und technische Kapazität) während der Wintermonate absinkt, zeigt allein das Beispiel der personellen Kapazität, unter der in diesem Zusammenhang die Zahl der während der Sommermonate beschäftigten Bauarbeiter verstanden wird. Dividiert man die von diesen Arbeitern monatlich geleisteten Arbeitsstunden durch die personelle Kapazität, so erhält man die monatliche Arbeitszeit pro Arbeitnehmer. Diese Zeit schwankt im Laufe des Jahres erheblich. ${ }^{82}$ Parallel zu den Schwankungen des Auslastungsgrades der personellen Kapazität verändert sich auch der Auslastungsgrad der technischen Kapazität im Baugewerbe. ${ }^{83}$

Der primäre Wachstumseffekt der Realisierung der "Ganzjährigen Beschäftigung" bestünde nun darin, daß die jährliche Bauproduktion ohne Vergrößerung der personellen und technischen Kapazitäten - wenn man von der Anschaffung einiger Winterbaugeräte und Schutzvorrichtungen absieht - allein durch die Erhöhung des winterlichen Auslastungsgrades der vorhandenen Kapazitäten gesteigert wird. Dieser primäre Wachstumseffekt steht meist im Mittelpunkt volkswirtschaftlicher Überlegungen zur Förderung der ganzjährigen Beschäftigung in der Bauwirtschaft. Er ist jedoch nicht der einzige, denn die Winterbauförderung würde nicht nur sektoral das Wachstum des Baugewerbes und das Wachstum solcher Wirtschaftsgruppen, deren Beschäftigung aufgrund der wirtschaftlichen Interdependen $z^{84}$ von baugewerblichen Beschäftigungsschwankungen beeinträchtigt wird, stimulierend beeinflussen, sondern auch das gesamtwirtschaftliche Wachstum fördern. Der sekundäre Wachstumseffekt besteht da-

82 vgl. ausführlich Kap. 3.3.2.3. Wirkungen auf die Verstetigung der Bautätigkeit, S.159ff.

83 Der Gesetzgeber geht davon aus, daß eine verstärkte Bautätigkeit im Winter das Angebot an Bauleistungen erweitert und die Winterbaufördenungsmaßnahmen schließlich zur Preisstabilisierung auf dem Baumarkt beitragen würden; vgl. hierzu auch Schleicher, E., Kostenermittlung von Winterbauarbeiten, S.22ff., in: Schriftenreihe der Rationalisierungsgemeinschaft Bauwesen, Heft 1, 1972.

84 vgl. Kap. 2.1.1. Die Bauwirtschaft im Rahmen der Gesamtwirtschaft, S. $18 \mathrm{ff}$. 
her in einer durch die erhöhte baugewerbliche Kapazitätsausnutzung verursachten durchschnittlichen Erhöhung der gesamtwirtschaftlichen Kapazitätsauslastung. ${ }^{85}$

Ein weiterer wesentlicher volkswirtschaftlicher Aspekt zur Förderung der ganzjährigen Beschäftigung in der Bauwirtschaft liegt in der Gefährdung der ökonomischen Stabilität des bestehenden beitragsfinanzierten Sozialversicherungssystems. ${ }^{86}$ Denn bei der Finanzierung der Sozialleistungen läßt sich ein Gleichgewicht zwischen Einnahmen und Ausgaben ${ }^{87}$ nur dann garantieren, wenn sich beide Größen im Gleichschritt entwickeln. Steigen die Ausgaben stärker als die Einnahmen, entstehen in den eigenständigen Haushalten der Sozialversicherungsträger unmittelbar Finanzierungsdefizite, d.h. die Höhe des Leistungszuwachses übersteigt den Zuwachs der Beitragszahlung oder die Zahl der Leistungsempfänger nimmt stärker zu als die Zahl der Beitragszahler. Erhöhungen der Beitragssätze oder Leistungskürzungen werden erforderlich, um die Zahlungsfähigkeit zu sichern.

Das Verhältnis von Leistungsempfängern und Beitragszahlern verschiebt sich immer dann, wenn die sozialen Risiken und Tatbestände, die den Leistungsbezug erforderlich machen, zunehmen und/oder die Zahl der Beschäftigten sinkt. Diese negative Verschiebung des Verhältnisses von Beitragszahlern und Leistungsempfängern entsteht vor allem durch Arbeitslosigkeit. Der Einfluß der Arbeitslosigkeit auf die Finanzlage ist deswegen so gravierend, weil ein niedriger Beschäftigungsstand Ausgaben- und Einnahmenseite gleichermaßen negativ berührt. Dem steigenden Finanzbedarf auf der einen Seite, steht eine durch dieselben Ursachen verschlechterte Einnahmesituation auf der anderen Seite gegenüber. D.h. mit rückläufiger Beschäftigtenzahl sinken bei sonst gleichbleibenden Verhältnissen die Beitrags- und die Steuereinnahmen, während gleichzeitig - durch die hohe Zahl von Arbeitslosen - wachsende Ausgaben und damit gesamtwirtschaftliche Kosten verursacht werden. ${ }^{88}$

85 Laut eines Gutachtens des Ifo-Institut von 1976 entstehen durch Stillstandszeiten beim Bauhauptgewerbe jeden Winter volkswirtschaftliche Verluste in der Größenordnung von durchschnittlich 11 Mrd. DM; vgl. Rationalisierung aus der Sicht der Baubeteiligten, Gutachten des Ifo-Instituts für Wirtschaftsforschung, S.348, München, 1976.

86 vgl. Adamy/Steffen, Finanzierungsprobleme des Sozialstaates in der Beschäftigungskrise. Sozialpolitik zwischen solidarischer Sicherung und marktkonformer Funktionalität, S.81ff. und Bieback, K.-J., Die Sozialversicherung und ihre Finanzierung, S.34ff.

87 Die Einnahmen errechnen sich bei gegebenem Beitragssatz aus dem Produkt der Zahl der Beitragszahler und der Höhe der Arbeitseinkommen, die der Beitragszahlung zugrunde liegen. Die Ausgaben aus dem Produkt der Zahl der Leistungsempfänger und der Höhe der Leistungen.

88 vgl. Bieback, K.-J., Das Sozialleistungssystem in der Krise, in: Zeitschrift für Sozialreform 10$12 / 1985$. 
In gesamtfiskalischer Betrachtungsweise setzen sich die Kosten der Arbeitslosigkeit dabei im einzelnen aus den Mehrausgaben an Arbeitslosengeld bzw. Arbeitslosenhilfe, Renten- und Krankenversicherungsbeiträgen für Arbeitslose und den Sozialhilfe- und Wohngeldzahlungen zusammen. Bei den Mindereinnahmen sind insbesondere die geringeren Steuereinnahmen und die reduzierten Beiträge zu den Sozialversicherungen (Kranken- und Rentenversicherung) zu nennen.

Die durch ansteigende Arbeitslosigkeit bedingte gegenläufige Entwicklung, zwischen sinkenden Beitragseinnahmen und steigenden Leistungsausgaben, betriff daher zuerst die Finanzierung der Arbeitslosenversicherung. D.h. bereits nach kurzer Zeit werden die finanziellen Grenzen dieser Versicherung erreicht. ${ }^{89}$ Diese Tatsache zeigt, daß es sich bei Arbeitslosigkeit - anders als bei Krankheit, Alter oder Invalidität - um ein nicht versicherbares Risiko handelt. Aber auch Renten- und Krankenversicherung werden in dem Maße negativ beeinflußt, in dem Beitragszahler aus der solidarischen Risikofinanzierung herausfallen. So müssen beispielsweise die Renten entsprechend der Umlagefinanzierung von weniger Beitragszahlern finanziert werden, als dies ohne Arbeitslosigkeit der Fall gewesen wäre.

Es läßt sich daher festhalten, daß Arbeitslosigkeit - insbesondere die winterliche Massenarbeitslosigkeit der Bauwirtschaft - die gesamte Finanzierungsbasis der Sozialversicherung gefährdet. Dabei ist es im Prinzip unerheblich, ob die Sozialleistungen über das beitragsfinanzierte Sozialversicherungssystem oder über die steuerfinanzierten öffentlichen Haushalte abgewickelt werden, weil sinkende Beschäftigten- und steigende Arbeitslosenzahlen die Relation von Beitrags- und Steuerzahlern zu Leistungsempfängern immer im negativen Sinne verschieben. ${ }^{90}$ Nicht die Sozialpolitik ist daher zu teuer und gefährdet die ökonomische Stabilität, sondern die Arbeitslosigkeit ist zu teuer und gefährdet die Finanzierung der Sozialpolitik. Alle wirtschafts- und arbeitszeitpolitischen Maßnahmen zum Abbau der Arbeitslosigkeit tragen insofern dazu bei, die Finanzierungsgrundlage des Sozialleistungssystem zu sichern, d.h. die Beseitigung der Saisonarbeitslosigkeit und der Schlechtwetterausfallzeit in der Bauwirtschaft trägt wesentlich zur finanziellen Entlastung der Sozialversicherung bei.

89 vgl. Bieback, K.-J., Die Sozialversicherung und ihre Finanzierung, S.34ff. und Kieselbach/Wacker (Hrsg.), Individuelle und gesellschaftliche Kosten der Arbeitslosigkeit, S.85ff.

90 vgl. Bieback, K.-J., Die Sozialversicherung und ihre Finanzierung, Frankfurt, S.34ff. und Bäcker, G./Bispinck, R./Hofemann, K./Naegele, G., Sozialpolitik und soziale Lage in der Bundesrepublik Deutschland, Band 1: Arbeit, Einkommen, Qualifikation, S.28f. 
Aus diesem Grund und den bereits angefuhrten Wachstumseffekten, als Folge der Realisierung bzw. Förderung der ganzjährigen Beschäftigung in der Bauwirtschaft begründet sich auch die Notwendigkeit einer "Ganzjährigen Beschäftigung" aus volkswirtschaftlicher Sicht.

\subsection{Problemstellung}

Mit einem Zitat aus dem Jahr 1931, läßt sich die Problemstellung dieser Arbeit bzw. das Kernproblem der Bauwirtschaft - die saisonale Arbeitslosigkeit - treffend charakterisieren. In einem Vorwort zu einer Untersuchung über die Ursachen der Arbeitslosigkeit in Deutschland heißt es: "Kein sozialökonomisches Problem besitzt gegenwärtig eine so tragische Aktualität, wie das der Arbeitslosigkeit."91

Für die Bauwirtschaft hat dieses Zitat noch bis weit in die 50er Jahre hinein Gültigkeit, denn bis 1959 fiel die monatliche Produktion des Bauhauptgewerbes im Winter verglichen mit der im Sommer liegenden Saisonspitze ${ }^{92}$ - auf weniger als die Hälfte zurück. Meßkriterium hierfür ist die Zahl der geleisteten Arbeitsstunden, die sich um mehr als 50\% verringerte. ${ }^{93}$ Waren beispielsweise im Juli 1958 noch 242 Millionen Stunden geleistet worden, so sank die Zahl im Februar 1959 auf 112 Millionen Stunden. ${ }^{94}$ Die Folge davon war, daß auch auf dem Arbeitsmarkt die Zahl der männlichen Arbeitslosen aus dem Baugewerbe im Winter drastisch anstieg, d.h. zwischen dem Höhepunkt und Tiefpunkt der Bausaison um ein Vielfaches zunahm.

Dieses starke Absinken der Bauproduktion im Winter, verbunden mit einem erheblichen Anstieg der Saisonarbeitslosigkeit, insbesondere in den Monaten Januar und Februar jeden Jahres, gehörte zu den charakteristischen Merkmalen der Bauwirtschaft bis Ende der fünfziger Jahre. Daß sich dieser Zustand, trotz der volkswirtschaftlichen Bedeutung der Bauwirtschaft, nicht schon längst geändert hatte, lag in der Tatsache, daß die mit dem saisonalen Produktions- und Beschäftigungsrückgang einhergehenden Probleme zu Beginn der 50er Jahre noch als zweitrangig eingestuft wurden. Im

\footnotetext{
91 vgl. Fricke, R., Die Ursachen der Arbeitslosigkeit, S.8.

92 vgl. Ifo-Instituts für Wirtschaftsforschung e.V, Soziale und wirtschaftliche Auswirkungen der Winterbauförderung, Gutachten.

93 vgl. Kap. 3.3.2.1.1. Geleistete Arbeitsstunden, S.141ff.

94 vgl. Bundesanstalt für Arbeit, Bauen im Winter, Erfahrungsbericht, Nürnberg 1966.
} 
Vordergrund standen damals die Bemühungen, die anderen Arten der Arbeitslosigkeit, die einen unmittelbaren Massennotstand bildeten, $\mathrm{zu}$ beseitigen. ${ }^{95}$

Erst mit zunehmendem Beschäftigungsgrad Mitte der 50er Jahre wurde die besondere Problematik in der Bauwirtschaft wieder aufgegriffen. Diese nun ernsthaften Bemühungen führten schließlich 1959 zu konkreten Ergebnissen, als im Rahmen des Zweiten Änderungsgesetzes zum AVAVG die "Maßnahmen zur Förderung der ganzjährigen Beschäftigung in der Bauwirtschaft" eingeführt wurden.

Wenn auch heute noch - nach rund 30jähriger Winterbauförderung - im Winter wesentlich weniger Bauarbeiten ausgeführt werden als in der übrigen Zeit des Jahres, so nennen die Beteiligten dafür zahlreiche Gründe, von denen die meisten immer wieder auf einen gemeinsamen Ursprung zurückgeführt werden: Die Behinderung des Bauens durch die ungünstigen, zum Teil widrigen Witterungsverhältnisse während der Winterzeit. Neben diese, nicht zu ändernden Naturgegebenheiten, treten aber auch andere, oft traditionelle, Einflüsse und Einstellungen, sowie institutionelle Hinderungsgründe verschiedener Art, die dem Winterbau abträglich sind. ${ }^{96}$

Als weitere Ursachen für das Zurückgehen der Bauarbeiten während der Winterzeit, werden von den Betroffenen insbesondere noch die Auftragslage, die Finanzlage der Betriebe, die schwierige Kalkulation der Kosten des Winterbaues und die nicht abschätzbaren Kosten der durch Witterungsverhältnisse verursachten Arbeitspausen angeführt. ${ }^{97}$

Aufgrund dieser Feststellung liegt die Schlußfolgerung nahe, daß die im Verlauf der Jahre von 1959 bis heute eingesetzten gesetzlichen und tariflichen Förderungsmaßnahmen zur ganzjährigen Beschäftigung, von denen noch ausführlich die Rede sein wird, mehr oder weniger versagt hätten. Dabei übersieht man jedoch, daß die Bezeichnung "Ganzjährige Beschäftigung" ein komplexes Problem umreißt. ${ }^{98}$ Ein abschließendes Urteil über die Wirksamkeit der in der Bundesrepublik insgesamt getrof-

95 vgl. Bundesministerium für Arbeit, Abteilung Statistik (Hrsg.), Analyse der westdeutschen Arbeitslosigkeit, S.13, Bonn, September 1952.

96 vgl. hierzu ausführlich Kap. 2.2.2. Ursachen der Saisonschwankungen, S.53ff.

97 vgl. Schlieder, E., Den Bauunternehmern wird zuviel zugemutet - Noch kann vom wirtschaftlichen Erfolg des Winterbaus nicht die Rede sein, S.4.

98 vgl. Geerling, C., Winterbau und winterliche Arbeitslosigkeit, S.615, in: Der Bau und die Bauindustrie, 11. Jg., Nr.22, 1958. 
fenen Förderungsmaßnahmen läßt sich somit erst dann abgeben, wenn man alle Aspekte des zu behandelnden Problems dargestellt und die Effektivität der Maßnahmen in Bezug auf die jeweils betrachtete Teilproblematik untersucht hat. ${ }^{99}$

\subsection{Zielsetzung}

Ziel und Aufgabe der vorliegenden Arbeit ist es daher, die Bestrebungen und Maßnahmen zur Förderung der ganzjährigen Beschäftigung in der Bauwirtschaft, von ihren Anfängen in den 50er Jahren bis zum heutigen Zeitpunkt, zu analysieren. Dabei werden insbesondere diejenigen Maßnahmen untersucht und quantifiziert, die aufgrund ihres Förderungsumfanges der ganzjährigen Beschäftigung in der Bauwirtschaft dienen und zu einer Glättung des bauwirtschaftlichen Geschehens führen können.

Basis und Hintergrund der Untersuchung der vorliegenden Arbeit, bilden die im Verlauf der Zeit gesetzten Schwerpunkte durch die Veränderungen der gesetzlichen und tariflichen Rahmenbedingungen, zum Bauen im Winter. Aus diesen jeweils neuen Regelungen lassen sich eigenständige spezielle "Förderungszeiträume" ableiten, die unabhängig voneinander analysiert und vergleichend bewertet werden. Schließlich wird versucht, sinnvolle Alternativen zur Lösung der Beschäftigungsproblematik in der Bauwirtschaft aufzuzeigen.

Die Zielsetzung der vorliegenden Arbeit ist also eine zweifache:

- Sie soll einerseits darlegen, inwieweit es mit Hilfe des bislang eingesetzten wirtschafts- und sozialpolitischen Instrumentariums gelungen ist, unter Berücksichtigung eines zugrundeliegenden Zielsystems, den alljährlichen Produktions- und Beschäftigungsrückgang zu stoppen.

- Sie soll andererseits Möglichkeiten aufzeigen, wie man - möglichst unter Vermeidung von Zielkonflikten - die Förderungsmaßnahmen erweitern, verbessern und gegebenenfalls neu gestalten müßte, um eine höhere Effektivität zu erzielen.

99 Ähnliche Überlegungen finden sich in: Deutscher Bundestag, 4. Wahlperiode, Drucksache IV/643, Bericht der Bundesregienung über die Auswirkungen der Vorschriften zur Förderung der ganzjährigen Beschäftigung in der Bauwirtschaft nach Artikel VI des Zweiten Änderungsgesetzes zum AVAVG vom 7. Dezember 1959, 27. September 1962 (im folgenden zitiert als BTDrucks. IV/643). 
Eingebunden werden diese Analysen und Überlegungen in einen besonders aktuellen Rahmen zur Thematik der "Ganzjährigen Beschäftigung in der Bauwirtschaft". Einerseits werden, durch die gegenwärtig geführte Diskussion um die ersatzlose Streichung des seit dem Winter 1959/60 bestehenden Schlechtwettergeldes zum 1. Januar $1996^{100}$, die Tarifvertragsparteien unter einen gewissen Zeitdruck gesetzt. Andererseits sind sich die Tarifvertragsparteien des Baugewerbes darin einig, "...daß unmittelbar nach Beendigung der Einkommens-Tarifverhandlungen 1994 mit der Umsetzung der Vereinbarung vom 19. Mai 1992, begonnen wird. ${ }^{101}$ Aufgrund dieser Vereinbarung, werden die Tarifvertragsparteien in Verhandlungen über ein ganzjährig gesichertes Einkommen und die Möglichkeiten einer Verstetigung desselben, sowie über bauspezifische Lösungen der Wochen- und Jahresarbeitszeit, eintreten. Diese Verhandlungen werden sich auch mit der Lösung der Probleme befassen müssen, die sich aus dem vorgesehenen Wegfall der Schlechtwettergeldregelung ergeben. Die gefundenen tariflichen Regelungen sollen dann zum 1. Januar 1996 in Kraft treten."102

\subsection{Vorgehensweise und Abgrenzung}

Es gibt bereits eine Vielzahl von Veröffentlichungen über den Winterbau. Besonders die Fachzeitschriften des Baugewerbes greifen dieses Problem immer wieder auf. Doch beschränken sich diese Ausführungen durchweg auf die Behandlung von Teilbzw. Einzelfragen, und zwar in der Regel ohne sie in den Rahmen des Ganzen zu stellen. Veröffentlichungen, die sich eingehender mit der komplexen Winterbauproblematik auseinandersetzen sind großenteils älteren Datums, so daß die Auswirkungen der Förderungsmaßnahmen gar nicht oder nur zum Teil berücksichtigt werden konnten. ${ }^{103}$

100 Anmerkung: Überlegungen der Bundesregierung, das SWG betreffend, sind nicht neu. Schon 1984 wurden im Zuge der Haushaltsberatungen zur Konsolidierung der Staatsfinanzen Entlastungen auch im Bereich der Bundesanstalt für Arbeit beschlossen. Damals sollten durch Senkung der Leistungssätze beim Arbeitslosen-, Kurzarbeiter- und Schlechtwettergeld von 68 auf 63 v.H. für Leistungsempfänger ohne Kinder, 940 Mio. DM und durch die Verpflichtung des Arbeitgebers, die Kosten des Schlechtwettergeldbezuges für den ersten Tag im Monat zu übernehmen, weitere 100 Mio. DM, eingespart werden; vgl. hierzu Brocksiepe, G., Mehr Arbeitslose durch Verteuerung des Winterbaus, S.15.

101 Gemeinsame Erklärung der Tarifvertragsparteien vom 10. März 1994 in Leipzig.

102 Hinweis: Nach dem Abschluß der Lohnrunde 1992 haben sich die Tarifvertragsparteien in der Vereinbarung vom 19 Mai 1992 darüber verständigt, zu verhandeln, wie in der Baubranche eine ganzjährige Beschăftigung gesichert werden kann. $\mathrm{Zu}$ solchen Gesprächen, die damals noch 1995 in eine tarifvertragliche Regelung münden sollten, hatten sich beide Tarifparteien beim Tarifabschluß 1992 verpflichtet. 
In der vorliegenden Arbeit wird deshalb der Versuch unternommen, die Saisonproblematik der Bauwirtschaft in ihrer weit verzweigten Gesamtheit zu erfassen. Mit besonderer Gründlichkeit wird dabei die Entwicklung des eigentlichen Kernproblems - d.h. die Entwicklung der Produktionsausfälle im Bauhauptgewerbe während der Winterzeit und die dadurch ausgelöste Saisonarbeitslosigkeit in der Bauwirtschaft unter Berücksichtigung der jeweils getroffenen Förderungsmaßnahmen analysiert.

Die Vorgehensweise des Verfassers bei der nachfolgenden Untersuchung der Gesamtproblematik zur "Ganzjährigen Beschäftigung in der Bauwirtschaft", soll hier kurz skizziert werden:

Im Anschluß an dieses Kapitel wird zunächst ein Überblick über die Bauwirtschaft in Deutschland gegeben. Dieser Überblick beinhaltet die Darstellung der Bedeutung der Bauwirtschaft für die Gesamtwirtschaft, ihre betriebsstrukturelle Entwicklung sowie Besonderheiten des deutschen Baugewerbes und eine baukonjunkturelle Prognose.

Im weiteren Verlauf des zweiten Kapitels werden dann die Saisonschwankungen in der Bauwirtschaft und ihre Ursachen sowie Wirkungen dargelegt. Spätestens zu diesem Zeitpunkt werden die verschiedenartigen Gründe für eine Förderung der ganzjährigen Beschäftigung deutlich. Es schließen sich die Ausführungen über die bisherige Entwicklung (1959-1992) der unterschiedlichen gesetzlichen und tarifvertraglichen Förderungsmaßnahmen an, verbunden mit einer ausführlichen Diskussion der Zielvorstellungen der am Baugeschehen Beteiligten.

Im Rahmen des dritten Kapitels werden die Wirkungen der getroffenen Maßnahmen zur Förderung der ganzjährigen Beschäftigung in der Bauwirtschaft analysiert. $\mathrm{Da}$ die Untersuchung jedoch mit einigen Einschränkungen verbunden ist, werden diese zunächst aufgezeigt. So muß beispielsweise auf eine ausführliche Diskussion der technischen Gesichtspunkte des Winterbaues verzichtet werden, weil eine der-

103 Beispielhaft genannt seien hier vor allem Riester, F., Die Verhütung und Überwindung saisonaler Arbeitslosigkeit, insbesondere im Baugewerbe, als arbeitsmarktpolitische Aufgabe, Diss. Köln, 1959 und Krämer, K., Der Winterbau - Gesamt- und einzelwirtschaftliche sowie soziale Probleme seiner Förderung zur Ausschaltung der saisonalen Produktionsschwankungen im Baugewerbe Westdeutschlands, Diss. Essen, 1967 sowie Bellingen, K., Die Effektivität der wirtschafts- und sozialpolitischen Maßnahmen zur Förderung der ganzjăhrigen Beschäftigung in der Bauwirtschaft der Bundesrepublik Deutschland, Diss. Köln, 1975. 
artige Untersuchung über den Rahmen dieser Arbeit hinausginge. Ungeachtet dieser Tatsache, ist der Verfasser zu der Ansicht gelangt, daß die Winterbautechnik ohnehin so weit fortgeschritten ist, daß sie kein entscheidendes Hindernis für eine winterliche Bautätigkeit mehr darstellt. ${ }^{104}$ Auch die anderen Einschränkungen des Kapitel 3.1. spielen im Rahmen der Untersuchung nur eine untergeordnete Rolle, so daß der Versuch, die Saisonproblematik in ihrer Gesamtheit zu erfassen, nicht beeinträchtigt wird.

Nach der Formulierung der Untersuchungskriterien in Kapitel 3.2. werden dann die Auswirkungen der Förderungsmaßnahmen auf die ganzjährige Beschäftigung, vor allem quantitativ aber auch qualitativ, analysiert. Dies geschieht ausführlich im Rahmen der Wirkungsanalyse des Kapitel 3.3., bei der arbeitsmarkt-, wirtschaftsund sozialpolitische - d.h. insbesondere einkommenspolitische - Effekte im Mittelpunkt der Betrachtung stehen. In Kapitel 3.4. werden die gewonnenen Erkenntnisse bezüglich dieser einzelwirtschaftlichen Bewegungsgrößen zusammengefaßt.

Im Rahmen des vierten Kapitels wird eine abschließende Beurteilung der derzeit gültigen und im Zeitablauf getroffenen Förderungsmaßnahmen vorgenommen. Als Basis dieser Bewertung dienen einerseits die ermittelten Ergebnisse der Wirkungsanalyse und andererseits die geleisteten Zahlungen (SWG, Lohnausgleich, WG, MKZ, IKZ und WB-Umlage) sowie die geleisteten bzw. ausgefallenen Arbeitsstunden (SWG-Ausfallstunden, WG-Stunden, MKZ-Stunden) im Zusammenhang mit den Winterbauförderungsmaßnahmen. Mit der Analyse dieser Zahlungsund Leistungsströme ist eine relativ genaue Quantifizierung einzelner Effekte möglich.

In diesem Zusammenhang werden auch die alternativen Maßnahmen zur Förderung der ganzjährigen Beschäftigung in der Bauwirtschaft untersucht. Dabei werden sowohl mögliche Änderungen der gesetzlichen als auch der tariflichen Regelungen betrachtet. Unter möglichen Änderungen versteht der Verfasser dabei vor allem diejenigen Änderungen, die im Rahmen der aktuellen Diskussion der am Baugeschehen Beteiligten, d.h. insbesondere der Tarifpartner aber auch der Bundesregierung, eine Rolle spielen.

104 vgl. hierzu ausführlich Kap. 3.1.2. Technik des Winterbaues, S.97-98. 
Den Abschluß der Arbeit bildet daher ein in Ansätzen vorgestelltes Tarifmodell, bei dem die wesentlichen Rahmenbedingungen wie Arbeitszeit und Förderung aufgezeigt werden sollen.

Wie bereits erwähnt, werden die Analysen und Überlegungen zur Förderung der ganzjährigen Beschäftigung in der Bauwirtschaft in eine besonders aktuelle politische Diskussion eingebunden, die auch Handlungsbedarf bei den Tarifvertragsparteien erforderlich gemacht hat. Diese Tarifverhandlungen werden nach letztem Kenntnisstand des Verfassers im Spätherbst 1994 beginnen. 


\section{KAPITEL 2}

\section{Bauwirtschaft in Deutschland}

In Anbetracht der zentralen Bedeutung der Bauwirtschaft für die gesamte Volkswirtschaft ${ }^{105}$ ist eine Untersuchung des bauwirtschaftlichen Beitrages zum gesamtwirtschaftlichen Wachstum von großem Interesse. Denn nur durch eine nähere Analyse des Bausektors können die Auswirkungen der Winterbauförderungsmaßnahmen, vor allem auf Beschäftigung und Produktion in der Bauwirtschaft, "...sowie gesamtwirtschaftliche Multiplikatoreffekte in ihrer Größenordnung richtig eingeschätzt und quantifiziert werden." 106

\subsection{Strukturanalyse und Bedeutung der Bauwirtschaft}

Im Zusammenhang mit der Bauwirtschaft spricht man oft von der Schlüsselstellung dieses Wirtschaftszweiges für die Volkswirtschaft. ${ }^{107}$ Diese Tatsache wird deutlich, wenn man zu einer rein sektoralen Betrachtungsweise der Bauwirtschaft auch die von ihr ausgehenden Beziehungen und Verflechtungen zu anderen Wirtschaftszweigen der Volkswirtschaft analysiert. Kriterien hierfür sind ein Vergleich der im Baugewerbe Beschäftigten mit der Gesamtbeschäftigtenzahl, eine Übersicht über die Beiträge des Baugewerbes zum gesamten Inlandsprodukt, ein Vergleich der Bauinvestitionen mit den gesamten Anlageinvestitionen, sowie eine Gegenüberstellung von Bauvolumen und Bruttosozialprodukt und schließlich eine Darstellung der engen Verflechtung des Baugewerbes mit anderen Wirtschaftszweigen.

105 vgl. hierzu ausführlich Ifo-Institut für Wirtschaftsforschung, Volkswirtschaftliche Ausstrahlungen der Bauwirtschaft, Gutachten.

106 Hinweis: Versuche zur Quantifizierung des Multiplikators sind mehrfach angestellt worden; vgl. hierzu Bopp, E./Willeke, R, Konjunktursteuenung durch Bauwirtschaft?, S.8 und auch Pause, H., Argumente zur wirtschaftspolitischen Situation der Bauwirtschaft, S.13.

107 vgl. hierzu ausführlich Ifo-Institut für Wirtschaftsforschung, Volkswirtschaftliche Ausstrahlungen der Bauwirtschaft, Gutachten und Willeke, R., Möglichkeiten der Verstetigung der Baunachfrage durch Konjunkturprogramme, S.21ff. 


\subsubsection{Die Bauwirtschaft im Rahmen der Gesamtwirtschaft}

Nach wie vor gehört die bauausführende Wirtschaft, gemessen an der Beschäftigtenzahl, zu den größten Wirtschaftsbereichen der Volkswirtschaft. Allein 1990 waren 1,878 Millionen Menschen im Baugewerbe beschäftigt. Nicht mitgezählt sind in diesem Zusammenhang die Beschäftigten in den bauabhängigen Wirtschaftszweigen. ${ }^{108}$ Ein Vergleich der Beschäftigtenzahlen von Baugewerbe, Bauhauptgewerbe und Ausbaugewerbe mit der Gesamtwirtschaft zeigt, daß im Durchschnitt der Jahre 1960 bis 1990 in der Bauwirtschaft etwa 2 Millionen Menschen beschäftigt waren, das sind ca. 7,5\% aller Erwerbstätigen, wie aus Abbildung 2 ersichtlich wird.

Abbildung: 2

\begin{tabular}{|c|c|c|c|c|c|c|c|}
\hline \multicolumn{8}{|c|}{$\begin{array}{l}\text { Erwerbstätige } 109 \text { in } 1.000(\text { J) in der gesamten Wirtschaft } \\
\text { und in der Bauwirtschaft }\end{array}$} \\
\hline Jahr & Gesamt & $\begin{array}{l}\text { Bauge- } \\
\text { werbe }\end{array}$ & $\begin{array}{l}\text { In \% von } \\
\text { gesamt }\end{array}$ & $\begin{array}{l}\text { Bauhaupt- } \\
\text { gewerbe }\end{array}$ & $\begin{array}{l}\text { in \% von } \\
\text { Bauge- } \\
\text { werbe }\end{array}$ & $\begin{array}{l}\text { Ausbau- } \\
\text { gewerbe }\end{array}$ & $\begin{array}{l}\text { in \% von } \\
\text { Bauge- } \\
\text { werbe }\end{array}$ \\
\hline 1960 & 26.247 & 1.981 & 7,5 & 1.406 & 71,0 & 575 & 29,0 \\
\hline 1962 & 26.783 & 2.073 & 7,7 & 1.526 & 73,6 & 547 & 26,4 \\
\hline 1964 & 26.979 & 2.185 & 8,1 & 1.643 & 75,2 & 542 & 24,8 \\
\hline 1966 & 26.801 & 2.174 & 8,1 & 1.619 & 74,5 & 555 & 25,5 \\
\hline 1968 & 25.968 & 2.034 & 7,8 & 1.487 & 73,1 & 547 & 26,9 \\
\hline 1970 & 26.668 & 2.323 & 8,7 & 1.529 & 65,8 & 794 & 34,2 \\
\hline 1972 & 26.655 & 2.290 & 8,6 & 1.534 & 67,0 & 756 & 33,0 \\
\hline 1974 & 26.215 & 2.073 & 7,9 & 1.352 & 65,2 & 721 & 34,8 \\
\hline 1976 & 25.088 & 1.855 & 7,4 & 1.192 & 64,3 & 663 & 35,7 \\
\hline 1978 & 25.512 & 1.803 & 7,1 & 1.217 & 67,5 & 586 & 32,5 \\
\hline 1980 & 27.059 & 2.126 & 7,9 & 1.263 & 59,4 & 863 & 40,6 \\
\hline 1983 & 26.347 & 1.946 & 7,4 & 1.122 & 57,7 & 824 & 42,3 \\
\hline 1984 & 26.393 & 1.941 & 7,4 & 1.106 & 57,0 & 835 & 43,0 \\
\hline 1985 & 26.593 & 1.849 & 7,0 & 1.026 & 55,5 & 823 & 44,5 \\
\hline 1986 & 26.960 & 1.826 & 6,8 & 1.003 & 54,9 & 823 & 45,1 \\
\hline 1987 & 27.157 & 1.801 & 6,6 & 985 & 54,7 & 816 & 45,3 \\
\hline 1988 & 27.366 & 1.797 & 6,6 & 996 & 55,4 & 801 & 44,6 \\
\hline 1989 & 27.733 & 1.819 & 6,6 & 999 & 54,9 & 820 & 45,1 \\
\hline 1990 & 28.444 & 1.878 & 6,6 & 1.034 & 55,1 & 844 & 44,9 \\
\hline$\varnothing$ & 26.683 & 1.988 & 7,5 & 1.265 & 63,2 & 723 & 36,8 \\
\hline
\end{tabular}

Quelle: Hauptverband der Deutschen Bauindustrie (Hrsg.), Baustatistisches Jahrbuch 1978, S.55 und 1992, S.2; Zentralverband des Deutschen Baugewerbes, Baujahr 1992/Jahrbuch des Deutschen Baugewerbes, S.276 (Tabelle 18); Statistisches Bundesamt, Statistisches Jahrbuch 1992 für die Bundesrepublik Deutschland, S.110-113.

108 vgl. Die Deutsche Bauindustrie (Hrsg.), Bauwirtschaft im Zahlenbild 1993, Grafik 2.

109 Erwerbstätige: Alle Personen, die in einem Arbeitsverhältnis stehen (einschl. Soldaten und mithelfender Familienangehöriger) oder selbständig ein Gewerbe oder eine Landwirtschaft betreiben oder einen freien Beruf ausüben, vgl. Statistisches Bundesamt (Hrsg.), Statistisches Jahrbuch 1992, S.108. 
Neben der bauausführenden Wirtschaft gibt es noch zahlreiche andere, sogenannte bauabhängige Wirtschaftszweige, die als Vorlieferanten direkt an die Bauwirtschaft liefern, oder ihr nachgelagert sind. Die Beschäftigten dieser bauabhängigen Wirtschaftszweige zeigt Abbildung 3.

Abbildung: 3

\begin{tabular}{|c|c|}
\hline \multicolumn{2}{|c|}{ Beschäftigte in bauabhängigen Wirtschaftszweigen } \\
\hline Wirtschaftszweig & Beschäftigte \\
\hline Architektenbüros & 84.000 \\
\hline Bausparkassen & 21.000 \\
\hline Baumaschinengroßhandel und -vermietung & 19.000 \\
\hline Baustoffgroßhandel & 130.000 \\
\hline Herstellung von Bauelementen aus Holz & 91.000 \\
\hline Baumaschinenherstellung & 50.000 \\
\hline Stahlbau & 77.000 \\
\hline Grobkeramik und Fliesenherstellung & 40.000 \\
\hline Gewinnung und Verarbeitung von Steinen und Erden & 162.000 \\
\hline Landschaftsgärtnerei & 52.000 \\
\hline Wohnungswesen & 59.000 \\
\hline Grundstückswesen & 96.000 \\
\hline Vermessungsbüros & 7.000 \\
\hline Summe der Beschäftigten & 888.000 \\
\hline
\end{tabular}

Quelle: Hauptverband der Deutschen Bauindustrie (Hrsg.), Bauwirtschaft im Zahlenbild 1991, Grafik 17

Schätzungen gehen davon aus, daß die Zahl der Beschäftigten, die für die Bauwirtschaft in irgendeiner Form tätig sind, nahezu ebenso hoch ist, wie die Zahl der direkt im Baugewerbe Tätigen, d.h. nochmals rund 2 Millionen. Damit wäre etwa jeder 7. Erwerbstätige durch seine Tätigkeit mit dem "Bauen" verbunden. ${ }^{110}$

Zuverlässiger als anhand von Beschäftigtenziffern, läßt sich die Bedeutung eines Wirtschaftszweiges mit Hilfe der von ihm erbrachten Leistungen beurteilen, wie Abbildung 4 zeigt. Ein Maßstab für die Leistungen der Bauwirtschaft ist der Beitrag des Baugewerbes zur Bruttowertschöpfung. ${ }^{111}$ Dieser Anteil des Baugewerbes an der Bruttowertschöpfung in Westdeutschland lag bis 1970 bei etwa $8 \%$ und ist bis 1990 auf rund $5 \%$ zurückgegangen.

110 vgl. Ifo-Institut für Wirtschaftsforschung, Die konjunkturelle Schlüsselstellung der Bauwirtschaft, S.25.

111 vgl. auch Krämer, K., Der Winterbau, S.13. 
Die Produktion des Baugewerbes schlägt sich zum größten Teil in den Bauinvestitionen nieder, die ein weiteres Meßkriterium darstellen und im Gegensatz zur Bruttowertschöpfung auch die indirekten Steuern und die Vorleistungen anderer Wirtschaftszweige enthalten. ${ }^{112} \mathrm{Ihr}$ Anteil an den gesamten Anlageinvestitionen mit rund $50 \%$ im Jahr 1990 unterstreicht die große Bedeutung, die dem Baugewerbe, gerade auch im Hinblick der Ausstattung der Volkswirtschaft mit den für deren Wachstum unentbehrlichen Investitionen, zukommt. ${ }^{113}$

Zum Schluß sei das Bauvolumen ${ }^{114}$ genannt. Es enthält die gesamten Bauleistungen. Setzt man dessen absoluten Betrag ins Verhältnis zum Bruttosozialprodukt, so spiegelt sich die Stellung der Bauwirtschaft in noch stärkerem Maße wider, da neben den Bauinvestitionen auch die Instandsetzungsleistungen und die Militärbauten berücksichtigt werden. ${ }^{115}$ Der Unterschied zwischen Bauinvestitionen und Bauvolumen besteht also nur darin, daß das Bauvolumen um den Wert der Reparaturen und Verteidigungsbauten erhöht ist.

Abbildung 4 zeigt weiterhin, daß die Anteile des Bauvolumens am Sozialprodukt zwar seit 1970 rückläufig sind, aber heute immer noch einen Wert von etwa $13 \%$ erreichen.

112 vgl. Beckermann, T., Die Bauwirtschaft, S.14 (Schriftenreihe des Rheinisch-Westfalischen Instituts fuir Wirtschaftsforschung Essen, Heft 36, Berlin, 1976).

113 vgl. auch Krämer, K., Der Winterbau, Übersicht Nr.4: Anteil der Bauinvestitionen an den gesamten Anlageinvestitionen von 1950-1960, S.14.

114 Das Bauvolumen wird jährlich vom Deutschen Institut für Wirtschaftsforschung (DIW) errechnet und ist wie folgt definiert: Jener Teil der volkswirtschaftlichen Produktion, der der Errichtung, Verbesserung oder Reparatur von Anlagen dient, die unmittelbar mit Grund und Boden verbunden sind und nicht zur maschinellen Ausristung gehören. Das Bauvolumen setzt sich demnach zusammen aus allen im Inland erbrachten Bauleistungen (einschl. Fertigteilbau) ohne Rucksicht darauf, ob es sich um Neu-, Um-oder Erweiterungsbauten bzw. um werterhöhende Reparaturen handelt. Es rechnen ferner dazu alle in Bauwerke eingehenden Leistungen des Verarbeitenden Gewerbes; sie werden nach Ausbau und Montagebau unterschieden (z.B. Aufzugbau, Stahl- und Leichtmetallbauten, Holzkonstruktionen, auch Beitrage aus dem Bereich der Elektrotechnischen Industrie); ferner Dienstleistungen, wie insbesondere Architektenleistungen, amtliche Gebühren, Grundstücksubertragungskosten; außerdem die Eigenleistungen der Investoren, einschließlich derjenigen der privaten Haushalte beim Wohnungsbau (einschl. "Schwarzarbeit") wie auch die Regiearbeiten der offentlichen Hand. $\mathrm{Zu}$ den Bauleistungen rechnen auch die Außenanlagen der Bauwerke. Nicht erfaßt sind nicht werterhöhende Reparaturen, erbracht von "Nichtunternehmen".

115 vgl. hierzu auch Werner, K., Der Beitrag des Baugewerbes zum Sozialprodukt, S.1561ff. und Willeke, R., Möglichkeiten zur Verstetigung der Baunachfrage durch Konjunkturprogramme, S.17. 
Abbildung: 4

\begin{tabular}{|c|c|c|r|r|r|r|r|r|r|}
\hline \multicolumn{6}{|c|}{ Gesamtwirtschaftliche Bedeutung der Bauwirtschaft in Mrd. DM1) } \\
\hline Jahr & $\begin{array}{c}\text { Brutto- } \\
\text { wert- } \\
\text { schöpfung }\end{array}$ & $\begin{array}{c}\text { Anteil Bau- } \\
\text { gewerbe an } \\
\text { Bruttowert- } \\
\text { schöpfung }\end{array}$ & $\begin{array}{c}\text { Anteil in } \\
\%\end{array}$ & $\begin{array}{c}\text { Anlagein- } \\
\text { vestitionen } \\
\text { gesamt }\end{array}$ & $\begin{array}{c}\text { Bauin- } \\
\text { vestitionen }\end{array}$ & $\begin{array}{c}\text { Anteil } \\
\text { in\% }\end{array}$ & $\begin{array}{c}\text { Bau- } \\
\text { volumen }\end{array}$ & $\begin{array}{c}\text { Brutto- } \\
\text { sozial- } \\
\text { produkt }\end{array}$ & $\begin{array}{c}\text { Anteil in } \\
\%\end{array}$ \\
\hline 1960 & 302,3 & 23,3 & 7,7 & 73,6 & 46,4 & 63,0 & 50,5 & 303,0 & 16,7 \\
1970 & 645,9 & 51,5 & 8,0 & 172,0 & 106,2 & 61,7 & 119,7 & 675,7 & 17,7 \\
1980 & $1.415,9$ & 99,9 & 7,1 & 332,1 & 205,2 & 61,8 & 237,3 & $1.477,4$ & 16,1 \\
1982 & $1.545,7$ & 96,4 & 6,2 & 323,4 & 199,8 & 61,8 & 235,1 & $1.590,3$ & 14,8 \\
1983 & $1.624,4$ & 99,0 & 6,1 & 340,8 & 205,9 & 60,4 & 241,2 & $1.675,7$ & 14,4 \\
1984 & $1.702,6$ & 99,7 & 5,9 & 350,7 & 213,5 & 60,9 & 248,7 & $1.763,3$ & 14,1 \\
1985 & $1.774,3$ & 94,8 & 5,3 & 355,8 & 202,8 & 57,0 & 234,4 & $1.834,5$ & 12,8 \\
1986 & $1.874,1$ & 100,1 & 5,3 & 373,8 & 212,6 & 56,9 & 244,8 & $1.936,1$ & 12,6 \\
1987 & $1.928,5$ & 101,7 & 5,3 & 385,8 & 216,3 & 56,1 & 249,8 & $2.003,0$ & 12,5 \\
1988 & $2.031,5$ & 106,3 & 5,2 & 409,9 & 227,4 & 55,5 & 267,0 & $2.108,0$ & 12,7 \\
1989 & $2.151,9$ & 114,7 & 5,3 & 448,5 & 245,1 & 54,6 & 289,8 & $2.249,1$ & 12,9 \\
1990 & $2.335,2$ & 127,1 & 5,4 & 506,8 & 272,8 & 53,8 & 321,0 & $2.439,1$ & 13,2 \\
\hline
\end{tabular}

1) In jeweiligen Preisen.

Quelle: Statistisches Bundesamt Wiesbaden (Hrsg.), Volkswirtschaftliche Gesamtrechnungen Fachserie 18, Konten und Standardtabellen 1989, S.185; Statistisches Bundesamt, Statistisches Jahrbuch 1992, S.656-660; Hauptverband der Deutschen Bauindustrie (Hrsg.), Baustatistisches Jahrbuch 1992, S.57-59.

Bei dem hohen Anteil der im Baugewerbe Beschäftigten an den Gesamtbeschäftigten und dem großen Beitrag, den das Baugewerbe zum Bruttosozialprodukt bzw. Volkseinkommen liefert, sowie aufgrund der engen Verflechtung von Baugewerbe und Gesamtwirtschaft haben Produktions- und Beschäftigungsschwankungen im Baugewerbe weitgehende Auswirkungen auf das gesamtwirtschaftliche Geschehen. Daher gibt das Baugewerbe auch einen wirkungsvollen Ansatz für die staatliche Konjunkturpolitik. ${ }^{116}$

\subsubsection{Betriebsstrukturelle Entwicklung}

Die Betriebsstruktur und -größe, gemessen an der Zahl der Unternehmen und deren Beschäftigten sowie die Größe der einzelnen baugewerblichen Wirtschaftszweige bilden wichtige Merkmale, an deren Entwicklungen strukturelle Veränderungen in der Bauwirtschaft aufgezeigt werden können.

Betrachtet man die absolute Zahl der Betriebe des Bauhauptgewerbes, so verläuft deren Entwicklung mit der Baukonjunktur parallel. ${ }^{117}$ Hinter den Veränderungen der Gesamtzahl der Baubetriebe, die sich unter Berücksichtigung der Konkurse und Ver-

116 vgl. hierzu ausführlich Ifo-Institut für Wirtschaftsforschung, Volkswirtschaftliche Ausstrahlungen der Bauwirtschaft, Gutachten und Willeke, R., Möglichkeiten der Verstetigung der Baunachfrage durch Konjunkturprogramme, S.21ff.

117 vgl. Zentralverband des Deutschen Baugewerbes, Baujahr 1992/Jahrbuch des Deutschen Baugewerbes, S.2 und S.26 sowie Kap. 2.1.3. Baukonjunkturelle Entwicklung und Prognose, S.42ff. 
gleichsverfahren aus dem Saldo von Neugründungen und Betriebsauflösungen ergibt, verbirgt sich die Erscheinung, daß das Verhältnis von Neugründungen und Betriebsauflösungen pro Jahr einen Wert von rund einem Fünftel der Gesamtzahl der Betriebe ausmacht. Diese hohe Fluktuationsrate "...bestätigt sehr deutlich die These, daß der Baumarkt als Musterbeispiel für einen offenen Markt mit besonders ausgeprägtem Wettbewerb gelten kann". 118

Insgesamt, dies zeigt die Abbildung 5, ist das Bauhauptgewerbe durch eine kleinbetriebliche Struktur gekennzeichnet, die sich in den letzten 30 Jahren verfestigt hat. Im Jahr 1960 beschäftigte etwa drei Viertel aller Betriebe weniger als 20 Personen. Heute sind es sogar 83\%. Auch die Entwicklung der Anzahl der Beschäftigten in den Betrieben bestätigt diesen Trend. 1960 lag der Schwerpunkt der Beschäftigten mit $42 \%$ noch bei den Großbetrieben. 1990 sind die Anteile fast gleichmäßig verteilt.

Abbildung: 5

\begin{tabular}{|c|c|c|c|c|c|c|c|}
\hline \multicolumn{8}{|c|}{ BetriebsgröBenklassen in \% } \\
\hline \multirow[b]{2}{*}{ Jahr } & \multirow[b]{2}{*}{$\begin{array}{c}\text { Zahl der } \\
\text { Betriebe } \\
\text { insgesamt }\end{array}$} & \multicolumn{3}{|c|}{ Anteil der Betriebe mit } & \multicolumn{3}{|c|}{$\begin{array}{c}\text { Anteil der Beschäftigten in } \\
\text { Betrieben mit }\end{array}$} \\
\hline & & $\begin{array}{l}\text { 1-19 Be- } \\
\text { schäftigten }\end{array}$ & $\begin{array}{l}20-99 \mathrm{Be}- \\
\text { schäftigten }\end{array}$ & $\begin{array}{l}100 \text { und } \\
\text { mehr Be- } \\
\text { schäftigten }\end{array}$ & $\begin{array}{c}\text { 1-19 Be- } \\
\text { schăftigten }\end{array}$ & $\begin{array}{l}20-99 \mathrm{Be}- \\
\text { schăftigten }\end{array}$ & $\begin{array}{l}100 \text { und } \\
\text { mehr Be- } \\
\text { schäftigten }\end{array}$ \\
\hline 1960 & 60.902 & 73 & 22 & 5 & 20 & 38 & 42 \\
\hline 1970 & 64.399 & 73 & 23 & 5 & 21 & 38 & 41 \\
\hline 1978 & 59.589 & 76 & 20 & 3 & 26 & 40 & 34 \\
\hline 1979 & 60.666 & 76 & 20 & 3 & 26 & 39 & 35 \\
\hline 1980 & 60.294 & 76 & 21 & 3 & 26 & 39 & 35 \\
\hline 1981 & 62.511 & 77 & 19 & 3 & 27 & 39 & 34 \\
\hline 1982 & 63.411 & 79 & 18 & 3 & 29 & 39 & 33 \\
\hline 1983 & 59.644 & 78 & 19 & 3 & 30 & 39 & 32 \\
\hline 1984 & 60.255 & 79 & 18 & 3 & 30 & 38 & 32 \\
\hline 1985 & 59.478 & 81 & 17 & 3 & 32 & 38 & 31 \\
\hline 1986 & 59.132 & 81 & 16 & 2 & 32 & 37 & 31 \\
\hline 1987 & 59.030 & 82 & 16 & 2 & 32 & 37 & 31 \\
\hline 1988 & 59.677 & 83 & 15 & 2 & 33 & 36 & 31 \\
\hline 1989 & 63.298 & 84 & 14 & 2 & 34 & 36 & 30 \\
\hline 1990 & 64.369 & 83 & 15 & 2 & 33 & 36 & 31 \\
\hline
\end{tabular}

Quelle: Hauptverband der Deutschen Bauindustrie (Hrsg.), Baustatistisches Jahrbuch 1992, S.12 und S.14 sowie eigene Berechnungen.

Bei der Betrachtung der Bauzweige des Bauhauptgewerbes liegt der Schwerpunkt sowohl was die Zahl der Betriebe als auch die Beschäftigten angeht - eindeutig im Wirtschaftszweig 72 des Hoch- und Tiefbaues. In seiner Bedeutung hinzugewonnen hat der Spezialbau, bedingt durch immer höhere und komplexere Anforderungen an Bauleistungen und Technik. ${ }^{119}$ Im Wirtschaftszeig 75 des Zimmerei- und Dachdek-

118 vgl. Gluch, E./Söffner, F., Auswirkungen der Baunachfrage auf die Struktur der bauausfuihrenden Wirtschaft, S.51. 
kerhandwerkes läßt sich ein Trend zu mehr Großbetrieben erkennen. Die hier beschriebenen Entwicklungen zeigt die Abbildung 6.

Abbildung: 6

\begin{tabular}{|c|c|c|c|c|c|c|c|c|}
\hline \multicolumn{9}{|c|}{ Bauzweige des Bauhauptgewerbes in \% } \\
\hline \multirow[b]{2}{*}{ Jahr } & \multicolumn{4}{|c|}{ Zahl der Betriebe } & \multicolumn{4}{|c|}{ davon Beschăftigte in Betrieben } \\
\hline & \begin{tabular}{c|}
72 \\
Hoch- und \\
Tiefbau
\end{tabular} & $\begin{array}{c}73 \\
\text { Spezialbau } \\
\end{array}$ & $\begin{array}{l}74 \text { Stukka- } \\
\text { teurgewerbe, } \\
\text { Gipserei, } \\
\text { Verputzerei }\end{array}$ & $\begin{array}{c}75 \\
\text { Zimmerei, } \\
\text { Dach- } \\
\text { deckerei }\end{array}$ & $\begin{array}{c}72 \\
\text { Hoch- und } \\
\text { Tiefbau }\end{array}$ & $\begin{array}{c}73 \\
\text { Spezialbau } \\
\end{array}$ & \begin{tabular}{|c|}
74 Stukka- \\
teurgewerbe, \\
Gipserei, \\
Verputzerei \\
\end{tabular} & $\begin{array}{c}75 \\
\text { Zimmerei, } \\
\text { Dach- } \\
\text { deckerei }\end{array}$ \\
\hline 1960 & 61 & 1 & 9 & 29 & 87 & 1 & 4 & 7 \\
\hline 1970 & 60 & 3 & 11 & 26 & 87 & 2 & 4 & 7 \\
\hline 1980 & 60 & 6 & 11 & 23 & 83 & 4 & 4 & 9 \\
\hline 1981 & 59 & 7 & 12 & 23 & 82 & 4 & 4 & 10 \\
\hline 1982 & 58 & 8 & 12 & 22 & 81 & 4 & 4 & 10 \\
\hline 1983 & 58 & 7 & 11 & 23 & 80 & 4 & 5 & 11 \\
\hline 1984 & 58 & 8 & 11 & 23 & 80 & 4 & 5 & 11 \\
\hline 1985 & 58 & 8 & 11 & 23 & 79 & 5 & 5 & 12 \\
\hline 1986 & 57 & 9 & 11 & 23 & 79 & 5 & 4 & 12 \\
\hline 1987 & 56 & 9 & 11 & 23 & 78 & 5 & 5 & 12 \\
\hline 1988 & 56 & 10 & 11 & 23 & 78 & 5 & 5 & 12 \\
\hline 1989 & 55 & 11 & 11 & 23 & 77 & 6 & 5 & 12 \\
\hline 1990 & 55 & 12 & 11 & 22 & 77 & 6 & 5 & 12 \\
\hline
\end{tabular}

Quelle: Hauptverband der Deutschen Bauindustrie (Hrsg.), Baustatistisches Jahrbuch 1992, S. 13 und S.15 sowie eigene Berechnungen.

\subsubsection{Baukonjunkturelle Entwicklung und Prognose}

Ein Blick auf den Untersuchungszeitraum dieser Arbeit zeigt, daß die baukonjunkturelle Entwicklung einen sehr unterschiedlichen Verlauf genommen hat. Gemessen am Bauvolumen läßt sich ein Trend dahingehend charakterisieren, daß sich das Wachstum der Bautätigkeit von Jahrzehnt zu Jahrzehnt verlangsamt hat. ${ }^{120}$ Betrug der reale jahresdurchschnittliche Anstieg von 1951 bis 1960 8\%, so waren es in den 60er Jahren noch 3,7\% und in den 70er Jahren nur 1\%. Für den Durchschnitt der 80 er Jahre ist, trotz des kräftigen Wiederanstieges des Bauvolumens ab 1988, nur ein Zuwachs von $0,4 \%$ festzustellen. ${ }^{121}$

Die Zusammensetzung des Bauvolumens der letzten 40 Jahre zeigt Abbildung 8. Auf den ersten Blick läßt sich feststellen, daß der Wohnungsbau über den gesamten Zeit-

119 vgl. Hauptverband der Deutschen Bauindustrie (Hrsg.), Forschung und Entwicklung in der Bauwirtschaft - Beispiele moderner Spitzentechnik, S.14ff.

120 vgl. Die Deutsche Bauindustrie (Hrsg.), Bauwirtschaft im Zahlenbild 1993, Grafik 2.

121 vgl. Abbildung 7, letzte Zeile: Durchschnittliche reale Veränderung des Bauvolumens und des Bruttosozialproduktes in 10 Jahresschritten. 
Abbildung: 7

\begin{tabular}{|c|r|r|r|r|r|r|r|r|r|r|r|}
\hline \multicolumn{10}{|c|}{ Reale Veränderung von Bauvolumen und BSP zum Vorjahr in \% } \\
\hline Jahr & \multicolumn{1}{|c|}{$\begin{array}{c}\text { Bau- } \\
\text { volumen }\end{array}$} & BSP & Jahr & $\begin{array}{c}\text { Bau- } \\
\text { volumen }\end{array}$ & BSP & Jahr & $\begin{array}{c}\text { Bau- } \\
\text { volumen }\end{array}$ & BSP & Jahr & $\begin{array}{c}\text { Bau- } \\
\text { volumen }\end{array}$ & BSP \\
\hline 1951 & 5,3 & 9,4 & 1961 & 4,8 & 4,3 & 1971 & 7,8 & 3,0 & 1981 & $-4,7$ & 0,1 \\
1952 & 5,4 & 9,0 & 1962 & 4,8 & 4,6 & 1972 & 7,3 & 4,3 & 1982 & $-3,8$ & $-1,1$ \\
1953 & 17,6 & 8,4 & 1963 & 2,7 & 2,8 & 1973 & 0,6 & 4,8 & 1983 & 0,8 & 1,9 \\
1954 & 7,8 & 7,1 & 1964 & 12,7 & 6,6 & 1974 & $-8,5$ & 0,1 & 1984 & 0,8 & 3,1 \\
1955 & 13,5 & 11,8 & 1965 & 4,0 & 5,3 & 1975 & $-6,3$ & $-1,3$ & 1985 & $-6,6$ & 1,8 \\
1956 & 6,9 & 7,5 & 1966 & 3,4 & 2,9 & 1976 & 2,3 & 5,5 & 1986 & 2,7 & 2,2 \\
1957 & 1,7 & 5,9 & 1967 & $-4,7$ & $-0,2$ & 1977 & 0,7 & 2,6 & 1987 & 0,0 & 1,5 \\
1958 & 3,3 & 4,1 & 1968 & 1,1 & 5,7 & 1978 & 1,3 & 3,4 & 1988 & 4,7 & 3,7 \\
1959 & 12,6 & 7,5 & 1969 & 2,7 & 7,5 & 1979 & 2,9 & 4,0 & 1989 & 5,0 & 3,8 \\
1960 & 6,3 & 8,8 & 1970 & 5,9 & 5,0 & 1980 & 1,8 & 1,0 & 1990 & 5,2 & 4,5 \\
$51-60^{122}$ & $\mathbf{8 , 0}$ & $\mathbf{8 , 0}$ & $\mathbf{6 1 - 7 0}$ & $\mathbf{3 , 7}$ & $\mathbf{4 , 4}$ & $\mathbf{7 1 - 8 0}$ & $\mathbf{1 , 0}$ & $\mathbf{2 , 8}$ & $\mathbf{8 1}-\mathbf{9 0}$ & $\mathbf{0 , 4}$ & $\mathbf{2 , 2}$ \\
\hline
\end{tabular}

Quelle: Hauptverband der Deutschen Bauindustrie (Hrsg.), Bauwirtschaft im Zahlenbild 1993, Grafik 2; Deutsches Institut für Wirtschaftsforschung Berlin, Bauvolumensberechnung; Statistisches Bundesamt Wiesbaden (Hrsg.), Statistisches Jahrbuch 92, S.655 und Fachserie 18 Reihe 1.2, Konten und Standardtabellen 1993 sowie eigene Berechnungen.

raum einen gleichbleibenden Anteil von fast 50\% des Bauvolumens beanspruchte. Die restlichen $50 \%$ teilen sich, grob gerechnet, Wirtschaftsbau sowie Öffentlicher- und Verkehrsbau etwa zur Hälfte, d.h. jeweils 25\%. Bei genauerer Betrachtung zeigen sich jedoch bemerkenswerte Anteilsverschiebungenen, die im folgenden beschrieben werden.

Abbildung: 8

\begin{tabular}{|c|c|c|c|c|c|c|c|c|c|c|c|}
\hline \multicolumn{12}{|c|}{ Zusammensetzung des Bauvolumens in $\%$} \\
\hline Jahr & $\begin{array}{l}\text { Woth- } \\
\text { nunge. } \\
\text { beur }\end{array}$ & Wint & 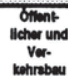 & Jahr & $\begin{array}{l}\text { Won- } \\
\text { nunger } \\
\text { beur }\end{array}$ & $\begin{array}{c}\text { Wirt } \\
\text { schathes } \\
\text { bew }\end{array}$ & 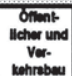 & Jahr & $\begin{array}{l}\text { Woh- } \\
\text { nunge } \\
\text { beut }\end{array}$ & $\begin{array}{c}\text { Writ } \\
\text { schathe } \\
\text { beut }\end{array}$ & 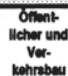 \\
\hline 1950 & 48,1 & 26,0 & 25,8 & 970 & 42,3 & 25,8 & 31,9 & $\overline{982}$ & 48,9 & 26,2 & 24,9 \\
\hline 1956 & 46,4 & 25,7 & 27,9 & 1971 & 45,0 & 26,1 & 28,9 & 1983 & 51,0 & 26,2 & 22,8 \\
\hline 1960 & 45,8 & 28,4 & 25,8 & 1972 & 48,9 & 25,1 & 26,0 & 1984 & 51,2 & 26,0 & 22,8 \\
\hline 1961 & 45,1 & 28,1 & 26,8 & 1973 & 50,2 & 24,8 & 25,0 & 1985 & 48,6 & 27,2 & 24,2 \\
\hline 1962 & 44,6 & 26,6 & 28,8 & 1974 & 47,5 & 24,4 & 28,1 & 1986 & 46,7 & 28,0 & 25,3 \\
\hline 1963 & 43,0 & 24,2 & 32,8 & 1975 & 46,6 & 24,6 & 28,9 & 1987 & 46,1 & 28,8 & 25,1 \\
\hline 1964 & 42,4 & 23,5 & 34,1 & 1976 & 48,3 & 24,9 & 26,8 & 1988 & 46,2 & 28,9 & 24,8 \\
\hline 1965 & 43,6 & 24,4 & 32,0 & 1977 & 49,4 & 25,0 & 25,6 & 1989 & 46,2 & 29,7 & 24,2 \\
\hline 1966 & 45,3 & 24,3 & 30,4 & 1978 & 49,5 & 24,4 & 26,1 & 1990 & 48,5 & 29,2 & 22,3 \\
\hline 1967 & 47,5 & 23,6 & 28,9 & 1979 & 49,7 & 24,5 & 25,8 & 1991 & 49,3 & 29,5 & 21,2 \\
\hline 1968 & 46,9 & 23,4 & 29,8 & 1980 & 49,4 & 24,9 & 25,7 & 1992 & 50,4 & 29,1 & 20,6 \\
\hline 1969 & 44,5 & 24,8 & 30,7 & 1981 & 49,2 & 25,4 & 25,5 & $x x x$ & $x x$ & $x x x$ & $x x x$ \\
\hline
\end{tabular}

Quelle: Deutsches Instituts für Wirtschaftsforschung (DIW) und eigene Berechnungen.

122 bis 1960 ohne Berlin (West) und das Saarland. 
Während sich in den 50er und 60er Jahren, dies zeigt die Abbildung 7, Bauvolumen und Bruttosozialprodukt noch parallel entwickelten ( $8 / 8=100 \%$ bzw. 3,7/4,4=84,1\%), blieb die Bautätigkeit seit Anfang der 70er Jahre hinter dem allgemeinen Wirtschaftswachstum zurück $(1 / 2,8=35,7 \%$ bzw. $0,4 / 2,2=18,2 \%)$. Begründet ist diese Tatsache vor allem durch den Nachholbedarf nach den Kriegsfolgen.

Die 50er Jahre, sogenannte Nachkriegsjahre, waren von einer enormen Aufbauleistung der durch den 2. Weltkrieg zerstörten Bausubstanz gekennzeichnet. So gab es beispielsweise auf dem Gebiet der alten Bundesrepublik Deutschland ${ }^{123}$ 2,3 Millionen zerstörte Wohnungen. Hinzu kamen 14 Millionen Flüchtlinge, die aufgenommen werden mußten. ${ }^{124}$ Daraus folgte, daß der Wohnungsneubau in dieser Zeit seinen Höhepunkt mit einem Anteil von fast $40 \%$ des Bauvolumens hatte, d.h. das Wohnungsbauvolumen bestand fast ausschließlich aus Neubauten. Dieser "Neubauanteil" hat im Laufe der Zeit zunehmend an Bedeutung verloren und betrug in den 80er Jahren nur noch $28 \%$, wie sich auch anhand der Gesamtzahl von 20 Millionen in Westdeutschland - Zeitraum 1950 bis 1992 - gebauten Wohnungen belegen läßt. Hieraus ergeben sich durchschnittlich 475.000 fertiggestellte Wohnungen pro Jahr. Seit dem Rekordergebnis von 1973 mit 714.000 fertiggestellten Wohnungen war der Trend, abgesehen von kurzen Unterbrechungen stark rückläufig und hatte 1988 mit 208.000 seinen Tiefstand. Auch die 375.000 Wohnungen von 1992 liegen noch unter dem langjährigen Durchschnitt. Dementsprechend angestiegen ist der Anteil der Altbauerneuerung, der Ende der 80 er Jahre fast $50 \%$ des Wohnungsbauvolumens ausmachte. ${ }^{125}$

In den 60er Jahren war das beherrschende Thema der baupolitischen Diskussion die angebliche "Überhitzung" der Baukonjunktur. Kennzeichnend dafür war die Verordnung zur Erteilung eines Baugenehmigungsstopps. ${ }^{126}$ Der Anteil der öffentlichen Hand am Bauvolumen stieg in dieser Zeit auf rund $34 \%{ }^{127}$ des Gesamtbauvolumens, da vor allem der Straßenbau, speziell der Autobahnbau, forciert betrieben wurde. Aber auch die erste Baurezession 1966/67 fiel in diesen Zeitraum. ${ }^{128}$

123 ohne Saarland und Berlin (West).

124 vgl. Hauptverband der Deutschen Bauindustrie (Hrsg.), Bauwirtschaft im Zahlenbild 1991, Grafik 2: Langfristige Entwicklung des Bauvolumens in Westdeutschland.

125 vgl. Hauptverband der Deutschen Bauindustrie (Hrsg.), Bauwirtschaft im Zahlenbild 1991, Grafik 4, Entwicklung des Bauvolumens 1950-1990, Zusammensetzung.

126 Gesetz vom 8. Juni 1962 zur Einschränkung der Bautătigkeit.

127 vgl. auch Abbildung 8: 1964.

128 vgl. auch Abbildung 7: Reale Veränderungen von Bauvolumen und BSP zum Vorjahr. 
Die 70er Jahre begannen mit einer Periode des "Bau-Booms", an die sich allerdings die zweite Baurezession (1973-75) nahtlos anfügte. Ein nachhaltiger Rückgang des öffentlichen Bauvolumens war aufgrund erschwerter Finanzierungsverhältnisse ebenfalls festzustellen. Die dritte und einschneidenste Baurezession folgte zu Beginn der 80er Jahre und setzte sich unter Einschluß einer Stagnationsphase bis 1987 fort. ${ }^{129}$ In dieser Zeit ging die Zahl der Beschäftigten im Baugewerbe von 2,126 Millionen 1980 auf 1,801 Millionen 1987 zurück. Erst gegen Ende der 80er Jahre, ausgelöst vor allem durch die Wiedervereinigung Deutschlands, kam es wieder zu einer spürbaren Belebung der Bautätigkeit. ${ }^{130}$

Für die zukünftige Entwicklung der Bauwirtschaft bezieht sich der Verfasser auf zwei umfangreiche wissenschaftliche Untersuchungen des Ifo-Instituts für Wirtschaftsforschung, die den Bedarf an Bauten aller Art in Deutschland prognostizieren. Die erste Studie "Baubedarf-Perspektive bis 2000", ${ }^{131}$ ausgehend vom Stand 1987, bezieht sich auf Westdeutschland. Aufgrund der getroffenen Annahmen wird ein Gesamtbaubedarf für den 13jährigen Untersuchungszeitraum ermittelt. Der sich daraus ergebende durchschnittliche jährliche Baubedarf von 286 Milliarden DM liegt rund 36\% über dem tatsächlichen Bauvolumen von 1987, was nicht mit einer jährlichen Steigerung um $36 \%$ verwechselt werden darf. ${ }^{132}$

Noch dramatischer als furr Westdeutschland ist das Ergebnis der zweiten Studie. Sie ermittelte nach den gleichen wissenschaftlichen Methoden den "Baubedarf in den neuen Bundesländern bis 2005", 133 und errechnete auf der Basis des Jahres 1990 einen aggregierten Baubedarf von 2,4 Billionen DM. Ausgehend von einem BauvolumenOst von rund 43 Mrd. DM im Jahr 1990, müßte die Bauproduktion Jahr für Jahr real $15 \%$ zunehmen, um den ermittelten Baubedarf bis zum Jahr 2005 zu realisieren. ${ }^{134}$

129 vgl. auch Abbildung 7: Reale Veränderungen von Bauvolumen und BSP zum Vorjahr.

130 vgl. auch Abbildungen 2 und 7.

131 vgl. Ifo-Institut für Wirtschaftsforschung, Baubedarf-Perspektive bis 2000, Gutachten im Auftrag des Hauptverbandes der Deutschen Bauindustrie von Karin Behring, München, 1989.

132 vgl. Ifo-Institut für Wirtschaftsforschung, Baubedarf-Perspektive bis 2000, Gutachten im Auftrag des Hauptverbandes der Deutschen Bauindustrie von Karin Behring, S.331-333, München, 1989.

133 vgl. Ifo-Institut für Wirtschaftsforschung, ifo studien zur bauwirtschaft 18, Baubedarf in den neuen Bundesländern bis 2005 von Erich Gluch, München, 1992.

134 vgl. Ifo-Institut für Wirtschaftsforschung, ifo studien zur bauwirtschaft 18, Baubedarf in den neuen Bundesländern bis 2005 von Erich Gluch, S.224-227, München, 1992. 
Provisorische Hochrechnungen erlauben eine Addition des Baubedarfs West und Ost, der in der folgenden Abbildung 9 dargestellt ist. Die sich daraus ergebende Summe von 8,3 Billionen DM bis zum Jahr 2005 ist fast das Dreifache des gesamten deutschen Bruttosozialproduktes von 1992. ${ }^{135}$

Abbildung: 9

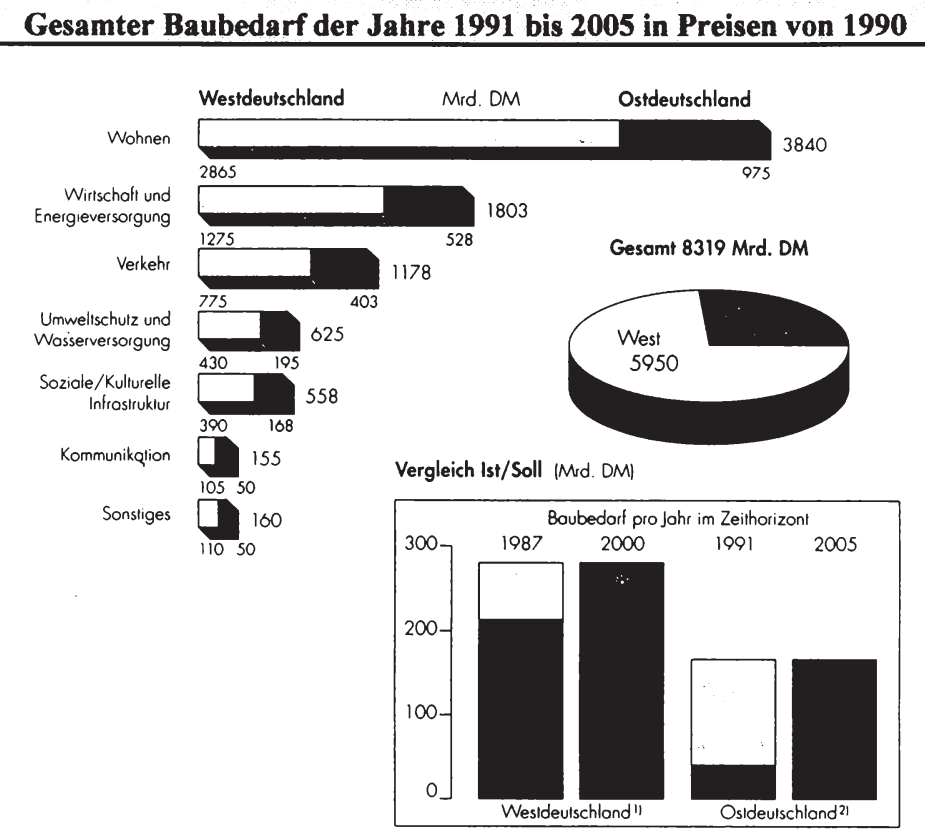

1) In Preisen von 1980 ohne Hochrechnung

2) In Preisen von 1990

Quelle: Für Westdeutschland: Ifo Baubedarfsstudie West für 1988 bis 2000, Hochgerechnet (BBIV) auf 1991 bis 2005 und für Ostdeutschland: Ifo Baubedarfsstudie Ost fur 1991 bis 2005, Informationsdienst des Bayerischen Bauindustrieverbandes e.V., Nr.7/92.

Reale Wachstumsraten von 15\% pro Jahr liegen jedoch deutlich über realistischen Erwartungen für das durchschnittliche Wachstum der Gesamtwirtschaft bzw. des Bausektors bis zum Jahr 2005. Der gesamte Baubedarf wird also innerhalb des analysierten Zeitraumes nicht gedeckt werden können. Vor diesem Hintergrund wird die For-

135 vgl. Hauptverband der Deutschen Bauindustrie (Hrsg.), Bauwirtschaft im Zahlenbild 1993, Grafik 6. 
derung nach ganzjähriger Beschäftigung besonders aktuell. Die Baubedarfsprognosen des Ifo-Instituts geben der Entwicklung der Bauwirtschaft eine gute Ausgangsposition und zeigen die Notwendigkeit auf, vorhandene Kapazitätsreserven stärker und gezielter nutzbar zu machen.

\subsubsection{Besonderheiten in der Bauwirtschaft}

Um die Wirkungen wirtschaftspolitischer Maßnahmen auf bauwirtschaftliche Aktivitäten abschätzen zu können, ist die Kenntnis einiger besonderer Gegebenheiten bei der Leistungserstellung der Bauwirtschaft erforderlich, da diese in gleicher Intensität in anderen Wirtschaftsbereichen nicht auftreten. ${ }^{136}$ Im Hinblick auf die ganzjährige Beschäftigung sind hier vor allem die Markt- und Produktionsbedingungen zu nennen, die das Baugeschehen maßgeblich beeinflussen.

Die Struktur des Baumarktes ist, wie bereits erwähnt, durch eine große Anzahl vorwiegend kleinerer und mittlerer Betriebe gekennzeichnet. Diesen Bauleistungsanbietern steht eine vielgestaltige Gruppe von Nachfragern gegenüber. Hierbei erscheint die öffentliche Hand, ${ }^{137}$ neben den privaten Bauherren, gemeinnützigen Wohnungsbauunternehmen und gewerblichen Unternehmen mit einem Viertel des Bauvolumens als der dominierende Nachfrager nach Bauleistungen. ${ }^{138}$ In einigen Bereichen, wie z.B. im Straßenbau, ist die öffentliche Hand praktisch der einzige Nachfrager. Dennoch deutet die Vielzahl der Anbieter und Nachfrager des gesamten Bausektors dem Anschein nach auf eine polypolistische Marktstruktur hin. ${ }^{139}$

Die Realität hingegen schränkt die Zahl der Marktteilnehmer, durch die außerordentliche Verschiedenartigkeit der einzelnen Bauleistungen und die sich daraus ergebenen Anforderungen an die personelle und maschinelle Ausstattung der Baubetriebe, sowie den räumlich eng begrenzten Aktionsradius der kleinbetrieblichen Bauunternehmen, verbunden mit der Standortgebundenheit der Bauvorhaben, erheblich ein. ${ }^{140}$ Daher

136 vgl. Kirner, W./Guicciardi, R./Menkhoff, H./Zinkhahn, W., Enquete über die Bauwirtschaft, S.727ff.

137 Anmerkung: Die Bauausgaben der öffentlichen Hand umfassen die Ausgaben von Bund, Ländern und Gemeinden sowie von Gemeinden- und Zweckverbänden (Gebietskörperschaften), ferner von Bahn, Post und Bundeswehr (einschließlich NATO) im gesamten Bundesgebiet.

138 vgl. auch Abbildung 8.

139 vgl. Schmidbauer, H., Allokation, technischer Fortschritt und Wettbewerbspolitik, S.127 und S.129. 
kann es den Baumarkt für die Gesamtheit der Bauleistungen oder auch nur einen regionalen Ausschnitt überhaupt nicht geben. Vielmehr ist er "...die Summe unzähliger einzelner Fälle von ad-hoc Marktbildungen, die durch Anfragen einzelner Interessenten für jeweils ein spezielles individuelles Objekt zustandekommen." 141

Die produktionsbedingten Besonderheiten der Bautätigkeit sind im Rahmen dieser Arbeit von großer Bedeutung. Kennzeichnend für die Unternehmen der bauausführenden Wirtschaft ist, daß sie lediglich als Anbieter von Bauleistungen fungieren und in der Regel das Produktionsprogramm nicht selbst bestimmen können. Der genaue Leistungsinhalt nach Art des herzustellenden Bauwerks, sämtliche Termine, wie z.B. Baubeginn und Baufertigstellung sowie die Baumethode werden normalerweise durch den Auftraggeber bestimmt ${ }^{142}$ Hierin liegt ein wesentlicher Unterschied zwischen der Bauwirtschaft und vielen anderen Industriezweigen, die ihre Erzeugnisse furr einen anonymen Markt produzieren. Man spricht daher auch von dem Absatzrisiko der übrigen Industriezweige und dem Auftragsrisiko in der Bauwirtschaft. ${ }^{143}$

Aufgrund der Tatsache, daß die Nachfrager nach Bauleistungen auf den gesamten Produktionsablauf einwirken können und die Bauwirtschaft in aller Regel nicht auf Lager produzieren kann, haben Nachfrageschwankungen im Bereich des Baugewerbes nahezu unmittelbare Auswirkungen auf die Bauproduktion, die sich nur durch ein noch vorhandenes Auftragspolster verzögern.

Diese ausgeprägte Abhängigkeit von der Nachfrage hat zur Folge, daß die bauausführende Wirtschaft für zu erwartende Auftragserteilungen gezwungen ist, bestimmte Geräte- und Arbeitskräftepotentiale vorzuhalten, was schließlich zu einer erhöhten Fixkostenbelastung bei den Baubetrieben führt. ${ }^{144} \mathrm{Da}$ wirtschaftliche Produktionsmethoden meistens mit hohen Investitionskosten verbunden sind, die eine kontinuierliche Auslastung voraussetzen, können sowohl Rationalisierungsbestrebungen als auch technische Weiterentwicklungen in den Betrieben beeinträchtigt werden. ${ }^{145}$ Eine

140 Hinweis: Die gemachten Aussagen erklären auch den Trend zu mehr spezialisierten Baubetrieben der Abbildung 6.

141 vgl. Brüggemann, H., Baumarkt - Enfant terrible der Marktwirtschaft?, S.16.

142 vgl. Gluch, E./Söffner, F., Auswirkungen der Baunachfrage auf die Struktur der bauausführenden Wirtschaft, S. 12.

143 vgl. Gluch, E./Söffner, F., Auswirkungen der Baunachfrage auf die Struktur der bauausführenden Wirtschaft, S. 17.

144 vgl. Fricke, W., Kosten und Kostenrechnung im Saisonbetrieb, S.22. 
kontinuierliche Produktion und Beschäftigung sind daher, bei wechselnden Anfall an Bauaufträgen und langen Zeiten der reinen Bereitstellung, kaum möglich.

Ein weiteres typisches Merkmal ist die Einzelfertigung. Zwar ist in geringem Umfang auch Serienfertigung - vor allem in einigen Bereichen des Hochbaus, z.B. Fertighäuser - zu beobachten, doch herrscht die für eine spezielle Funktionserfüllung ausgerichtete Einzelfertigung eindeutig vor.

Der wichtigste Unterschied der Bauwirtschaft zu anderen Wirtschaftszweigen liegt jedoch in der Witterungsabhängigkeit des Baugeschehens und den daraus resultierenden Schwierigkeiten für die Bauproduktion. Inwieweit diese Witterungsabhängigkeit das Baugeschehen tatsächlich beeinflußt, in dem sie Schwankungen in Bauproduktion und Beschäftigung bzw. Arbeitslosigkeit verursacht, soll im Rahmen der Wirkungsanalyse des dritten Kapitels untersucht und sofern möglich auch quantifiziert werden. In diesem Zusammenhang sind auch die im Verlauf der Jahre getroffenen Maßnahmen, zur Förderung der ganzjährigen Beschäftigung in der Bauwirtschaft ${ }^{146}$ und ihre Wirkungen zu überprüfen.

Bevor jedoch die einzelnen Förderungsmaßnahmen näher analysiert werden, zeigen die folgenden Abschnitte die verschiedenen Ursachen und Wirkungen der Saisonbewegungen, sowie grundsätzlich mögliche (Abschnitt 2.3.) und getroffene (Abschnitt 2.4.) Maßnahmen zur Förderung der ganzjährigen Beschäftigung in der Bauwirtschaft, auf.

145 vgl. Willeke, R., Möglichkeiten zur Verstetigung der Baunachfrage durch Konjunkturprogramme, S.16.

146 vgl. hierzu ausführlich Kap. 2.4. Zeitlicher Abriß der Förderungsmaßnahmen zur ganzjährigen Beschäftigung, S.64ff 


\subsection{Saisonbewegungen und deren Problematik für die Bauwirt- schaft}

Typische Wirtschaftsbewegungen, die auf verschiedene Einflüsse zurückzuführen sind, lassen sich in der Entwicklung einer jeden Volkswirtschaft bzw. eines jeden Wirtschaftszweiges erkennen. ${ }^{147}$ In der Bauwirtschaft bezeichnet man die besonders ausgeprägten Wirtschaftsbewegungen als Saisonschwankungen oder Saisonbewegungen und charakterisiert das Baugewerbe selbst häufig als Saisongewerbe. ${ }^{148}$

\subsubsection{Saisonschwankung}

An dieser Stelle ist darzulegen, was unter Saisonschwankung bzw. Saisonbewegung im einzelnen zu verstehen ist, und wie sie gegenüber anderen Einflüssen, denen die Volkswirtschaft im Zeitablauf unterliegt, abgegrenzt werden kann. Ausgangspunkt der Überlegung ist der Saisonbegriff. Auf die Diskussion der Meinungsverschiedenheiten über die Bedeutung und den damit verbundenen Auslegungsmöglichkeiten des Wortes Saison ${ }^{149}$ soll hier verzichtet werden. Statt dessen wird die in den Wirtschaftswissenschaften und der Statistik heute übliche Definition von Saison, als "...eine regelmäßig im Jahresablauf wiederkehrende Periode, die minimal einen Monat und maximal ein Jahr andauert ${ }^{150}$ und in der durch jahreszeitlich bedingte Einflüsse wirtschaftliche Vorgänge in relevanter Weise verändert werden", verwendet. ${ }^{151}$ In Anlehnung an die Definition bezeichnet Rösinger diese "...in gleichen Zeitabständen wiederkehrenden Bewegungen, die durch an bestimmte Termine und Jahreszeiten gebundene Wirtschaftsveränderungen entstehen", ${ }^{152}$ als Saisonschwankungen. Zusammenfassend ist also festzustellen: Die Saison beschreibt einen bestimmten Zeitraum

147 vgl. Schumpeter, J. A., Konjunkturzyklen, S. 184 und Fricke, W., Kosten und Kostenrechnung im Saisonbetrieb, S.4ff.

148 vgl. Krämer, K., Der Winterbau, S.27ff.

149 Das Wort "Saison" ist etwa im 17.Jahrhundert aus dem Französischen (la saison = die Jahreszeit) in die deutsche Sprache übernommen worden. Etymologisch ist es auf das lateinische Wort "satio" (=Saatzeit) zurückzufuihren, welches wiederum von "serere" säen abgeleitet ist. Im Laufe der Jahrhunderte hat sein Sinn verschiedene Ändenungen erfahren, die immer wieder Anlaß zu Meinungsverschiedenheiten gaben. Im deutschen Sprachgebrauch nahm "Saison" die Bedeutung von "Haupttätigkeit des Jahres" an; vgl. hierzu ausführlich Bibliographisches Institut (Hrsg.), Etymologie, S.305 sowie Schultz, K. H., Die Ökonomik des Saisonbetriebes, S.1.

150 vgl. Anliker, M., Unternehmung und Saisonschwankungen, S.11.

151 vgl. Schulz, K. H., Die Ökonomik des Saisonbetriebes, S.3.

152 vgl. Rösinger, F., Die Frage der Saisonschwankungen im Bauwesen, S.8. 
innerhalb eines Jahres und Saisonschwankungen sind Bewegungen einer Größe im Jahresverlauf. Dabei gilt die Einschränkung, daß dieser Begriff nicht, was vielfach üblich ist, auf alle Arten von rhythmischen Ausschlägen angewendet werden kann, sondern - entsprechend der Bezeichnung "Saison" - lediglich auf die jahreszeitlichen Schwankungen. ${ }^{153}$

Für eine nähere Charakterisierung der Saisonschwankungen ist es notwendig, zunächst eine Abgrenzung gegenüber anderen, insbesondere ähnlich gearteten Bewegungen im Wirtschaftsablauf vorzunehmen. Aufgrund der Vielfalt der möglichen Bewegungen kann hier nur eine verkürzte Darstellung gegeben werden, ${ }^{154}$ die sich auf die wesentlichen Bewegungsformen beschränkt. Man unterscheidet:

\section{Fortlaufende kontinuierliche Änderungen in gleichbleibender Richtung:}

Die genannte Bewegungsform beschreibt in der Regel die Tendenz einer langfristigen Entwicklung, wie die stetige Zunahme einer beobachteten Größe (z.B. das Wachstum einer Volkswirtschaft) und wird daher als Trend bezeichnet. ${ }^{155}$

\section{Fortlaufende kontinuierliche Änderungen mit wechselnder Richtung:}

Hier wird zwischen regelmäßig wiederkehrenden periodischen Schwankungen und unregelmäßigen, aperiodischen (sogenannten irregulären) Schwankungen unterschieden. Als irreguläre Schwankungen einer Zeitreihe werden gewöhnlich die Auswirkungen all jener Faktoren zusammengefaßt, die mit Trend, Konjunktur und Saison nicht in Beziehung gebracht werden können, sogenannte Störfaktoren. ${ }^{156}$ Dies sind z.B. Ereignisse wie Arbeitskämpfe, Naturkatastrophen oder auch die Wiedervereinigung Deutschlands. Die regelmäßig wiederkehrenden periodischen Schwankungen werden nach der Stärke der Schwankung und der Dauer der Zyklen charakterisiert. Nach der Zyklusdauer können kurz-, mittel- und langfristige Schwankungen unterschieden werden. ${ }^{157}$

153 vgl. Fürst, G./Spilker, H., Störungen der kurzfristigen Wirtschaftsbeobachtung durch jahreszeitliche und andere wiederkehrende Einflüsse, S.203.

154 vgl. hierzu ausfuihrlich Fricke, W., Kosten und Kostenrechnung im Saisonbetrieb, S.4ff.

155 vgl. Anderson, O., Trend, S.405-408.

156 vgl. Göppl, H./Kranz, O., Statistik, betriebliche, Sp.3713.

157 Anmerkung: Die langfristigen Schwankungen auch als "lange Wellen" oder "freie Schwingungen" bezeichnet werden durch ihre sehr langen und relativ unbestimmten Zyklen (Periodizităten von 50 bis 60 Jahre) charakterisiert. Sie haben im Rahmen dieser Arbeit nur untergeordnete Bedeutung; vgl. hierzu ausführlich Kondratieff, N. D., Die langen Wellen der Konjunktur, S.573-609. 
Zur Verdeutlichung der gemachten Ausführungen stellt die folgende Abbildung die soeben beschriebenen Komponenten einer Zeitreihe beispielhaft graphisch dar.

Abbildung: 10

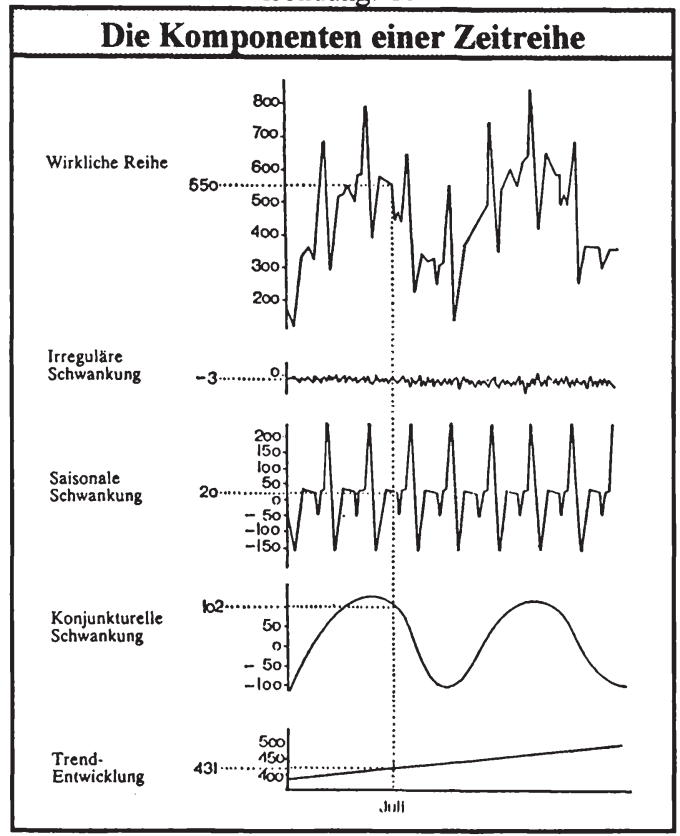

Quelle: Heribert Meffert, Marketing, 7. Aufl., Wiesbaden 1986, S.222. Nach: John C. G. Boot/Edwin B. Cox, Statistical Analysis for Managerial Decisions, 2. Aufl., New York u.a. 1974, S.446

$\mathrm{Zu}$ den kurzfristigen periodischen Schwankungen mit einer Periodenlänge von längstens einem Jahr gehören auch die Saisonschwankungen. ${ }^{158}$ Die mittelfristigen periodischen Schwankungen mit einer Zykluslänge von etwa vier bis sieben Jahren werden im allgemeinen als Konjunkturschwankungen bezeichnet. ${ }^{159}$ Sie unterscheiden sich von den Saisonschwankungen vor allem dadurch, daß sie neben einer längeren Zyklusdauer keinen so streng rhythmischen Verlauf aufweisen, d.h. ihr Auftreten unterliegt einer geringeren Regel- und Gleichmäßigkeit. Zudem erfassen sie meist die

158 vgl. Schäfer, E./Knoblich, H., Grundlagen der Marktforschung, S.218.

159 vgl. Vosgerau, H.-J., Konjunkturtheorie, S.478ff. 
gesamte Volkswirtschaft, während Saisonschwankungen meist nur Betriebe bestimmter Wirtschaftszweige betreffen. ${ }^{160}$

Die genannten Wirtschaftsbewegungen treten jedoch in der Regel nicht einzeln auf. Sie sind vielmehr gleichzeitig wirksam und überlagern sich. ${ }^{161}$ Darüber hinaus trifft man sie selten in ihrer eigentlichen, originären Form an. Dies ist u.a. darauf zurückzuführen, daß von verschiedenen Seiten versucht wird, ihren Verlauf zu beeinflussen. ${ }^{162}$ Insofern wird eine Abgrenzung zwischen Saisonschwankungen und anderen Bewegungskomponenten erschwert. Inwieweit eine exakte statistische Erfassung der "reinen" Saisonbewegung anhand einer ökonomischen Zeitreihe möglich ist und welche Schwierigkeiten dabei auftreten, soll im Rahmen der Wirkungsanalyse des dritten Kapitel analysiert werden. ${ }^{163}$

\subsubsection{Ursachen der Saisonschwankungen}

Nachdem die Saisonschwankung als diejenige kurzfristige Bewegungsform im Wirtschaftsablauf definiert wurde, die an bestimmte Zeitabschnitte des Jahres gebunden ist und von Jahr zu Jahr mit einer gewissen Gleichmäßigkeit wiederkehrende Auf- und Abwärtsbewegungen wirtschaftlicher Aktivitäten verzeichnet, ${ }^{164}$ stellt sich die Frage nach den Gründen, die zu einem derart ausgeprägtem Verlauf von wirtschaftlichen Bewegungsgrößen führen.

Obwohl bereits ausführlich - insbesondere auch zwischen den Tarifpartnern - über mögliche Ursachen der Saisonschwankungen in der Bauwirtschaft diskutiert und geschrieben worden ist, gibt es keine einheitliche Meinung unter den Beteiligten. ${ }^{165}$ Dies wird sich auch noch anhand der gesetzlichen Entwicklung zur "Förderung der ganz-

160 vgl. Pesch, H. J., Finanzplanung in Saisonindustrien, S.12ff.

161 vgl. Abbildung 10.

162 vgl. Schumpeter, J. A., Er bezeichnet den Wirtschaftsprozeß daher als eine in Wirklichkeit "unendlich komplexe Komposition vieler gleichzeitiger Wellen verschiedener Art". Für das Erkennen und die Ermittlung von Saisonschwankungen sind folglich Kenntnisse über alle möglichen Ursachen eingetretener Veränderungen einer beobachteten Größe von Bedeutung.

163 vgl. hierzu ausführlich Kap. 3.1.5. Zur Berechnung der Saisonschwankungen, S.107ff.

164 vgl. Graf Finck von Finckenstein, H.-W., Saisonschwankungen, S.84-85.

165 Anmerkung: Hier spielen sicherlich auch die unterschiedlichen Interessenslagen der Beteiligten eine Rolle. 
jährigen Beschäftigung in der Bauwirtschaft" zeigen, die immer wieder andere Schwerpunkte setzte und somit verschiedene Interessengruppen unterstützte. ${ }^{166}$

Der Verfasser möchte im folgenden versuchen, die nach seinem Dafürhalten wesentlichsten Ursachen der Saisonschwankungen aufzuzeigen. Er ist sich dabei der Tatsache bewußt, daß eine exakte quantitative und qualitative Auflösung des gesamten Ursachenkomplexes nicht möglich sein wird, da objektive Kriterien teilweise fehlen und die Ursachen sich überdecken. Dessen ungeachtet ist eine solche Untersuchung unerläßlich, weil nur die Kenntnis der Ursachen es ermöglicht, einerseits ein umfassendes Instrumentarium zur Förderung der kontinuierlichen Bautätigkeit zu erarbeiten und andererseits die bereits getroffenen "Maßnahmen zur Förderung der ganzjährigen Beschäftigung in der Bauwirtschaft" zu beurteilen.

Ausgangspunkt hierfür soll die in der Literatur gegebene Differenzierung in produktionsbedingte bzw. endogene und marktbedingte bzw. exogene Saisonschwankungen sein. ${ }^{167}$ Letztere lassen sich aufgrund unterschiedlicher Ursachen weiter in beschaffungs- und absatzbedingte Saisonschwankungen differenzieren. ${ }^{168}$

\subsubsection{Marktbedingte Saisonschwankungen}

In der Regel werden beschaffungsbedingte Saisonschwankungen durch Rohstoffe, die nur zu bestimmten Jahreszeiten beschaff werden können, verursacht. Dieses saisonal schwankende Angebot ist hauptsächlich bei natürlichen, organischen Stoffen festzustellen, deren Wachstumsprozeß vom Wetter abhängig ist. Folglich sind von beschaffungsbedingten Saisonschwankungen vor allem jene Wirtschaftszweige betroffen, die naturnahe Erzeugnisse verarbeiten. Für die Baubetriebe spielen daher beschaffungsbedingte Saisonschwankungen nur eine untergeordnete Rolle. ${ }^{169}$

Die absatzbedingten Saisonschwankungen werden allgemein auf saisonal schwankende Nachfragevolumen mit unterschiedlich starker Ausprägung zurückgeführt.

166 vgl. hierzu ausführlich Kap. 2.4. Zeitlicher Abriß der Förderungsmaßnahmen zur ganzjährigen Beschäftigung, S.64ff. und Kap. 2.5.1. Ziele des Gesetzgebers, S.79ff.

167 vgl. Weber, H. K., Industriebetriebslehre, S.106f.

168 vgl. Schäfer, E., Der Industriebetrieb, S.284 sowie Schultz, K. H., Die Ökonomik des Saisonbetriebes, S.14ff.

169 vgl. Pesch, H. J., Finanzplanung in Saisonindustrien, S.19 sowie Anliker, M., Unternehmung und Saisonschwankungen, S.12. 
Grundsätzlich wird zwischen einer im Jahresverlauf kontinuierlichen Nachfrage variierender Höhe und einer, auf eine bestimmte Jahreszeit beschränkte, diskontinuierlichen Nachfrage unterschieden. ${ }^{170}$ Verursacht werden sie einerseits durch die Natur, d.h. jahreszeitlich schwankende Witterungsverhältnisse, ${ }^{171}$ zum anderen aber auch durch bestimmte Verhaltensweisen der Bauherren, d.h. durch den Menschen selbst bzw. gesellschaftliche Institutionen ${ }^{172}$ und das trotz der Tatsache, daß die Nachfrage nach Bauleistungen an und furr sich von der Jahreszeit unabhängig ist, da Bauten im Winter nicht weniger dringend benötigt werden als im Sommer. ${ }^{173}$

Klimatisch bedingt sind sie dann, wenn sich der Bauvergabe seitens des Bauherrn witterungsbedingte Hindernisse ${ }^{174}$ in den Weg stellen, die eine Auftragserteilung bzw. einen Baubeginn verhindern oder verzögern. Betrachtet man die Verhaltensweisen der Nachfrager nach Bauleistungen, so sind die Gründe für nachfragebedingte Saisonschwankungen auch in der Person des Bauherrn zu suchen. An erster Stelle müssen hier die Winterbaumehrkosten genannt werden, die das Angebot des Bauunternehmers teurer als in den übrigen Jahreszeiten machen und daher Aufträge durch Bauherrn einschränken. Weitere wesentliche Punkte sind die Sorge vor Witterungsschäden und Qualitätsminderungen, die zahlreiche Bauherrn davon abhalten, Winterbauaufträge zu erteilen. ${ }^{175}$ So glauben sie, daß die Qualität eines im Winter erstellten Bauwerks schlechter sein muß, als die eines im Sommer errichteten. ${ }^{176}$ Neben dieser Risikoangst spielt auch die gewohnheitsmäßige Vergabe in der Hauptsaison ${ }^{177}$ und die ungleichmäßige Verteilung der öffentliche Finanzmittel über das Jahr eine gewisse

170 vgl. Fricke, W., Kosten und Kostenrechnung im Saisonbetrieb, S.17.

171 vgl. Brunner, M., Planung in Saisonunternehmen, S.2.

172 vgl. Pesch, H. J., Finanzplanung in Saisonindustrien, S.19 sowie Anliker, M., Unternehmung und Saisonschwankungen, S.12.

173 vgl. Ruckgaber, H., Probleme der sozialen Sicherheit im Baugewerbe unter besonderer Berücksichtigung der winterlichen Arbeitslosigkeit, S.32ff.

174 vgl. hierzu ausfuihrlich Kap. 3.1.4. Witterungsbedingungen, S.101ff.

175 vgl. Krämer, K., Der Winterbau, S.52 und Geerling, C.: "Bauen im Winter - sozialpolitisch gesehen", in: Der Bau und die Bauindustrie, Heft 18, 1955, S.546.

176 vgl. hierzu auch Schleicher, E., Der Winterbau und der Bauunternehmer, S.273: Er hingegen stellt zur Qualităt winterlicher Bauleistungen fest: "Jede Bauleistung läßt sich bei Anwendung geeigneter technischer Methoden mit einer Güte erreichen, die auch bei Normaltemperatur erzielt wird."

177 Vor allem bei Bauverwaltungen und Behörden hat sich ein Vergaberhythmus dahingehend eingespielt, daß der überwiegende Teil der Bauarbeiten im späten Frühjahr oder im Sommer zur Vergabe kommt, also zu einer Zeit, in der die Bituunternehmungen ohnehin in der Regel voll ausgelastet sind. Außerdem werden sehr kurze Bautermine gesetzt, um die Arbeiten mőglichst vor der witterungsungünstigen Jahreszeit zu beenden. 
Rolle. ${ }^{178}$ Daher muß den Verbänden der Bauwirtschaft zugestimmt werden, wenn sie darauf hinweisen, daß eine wichtige Voraussetzung für eine kontinuierliche Bautätigkeit die kontinuierliche Bauauftragsvergabe ist. ${ }^{179}$ Die Ausfuihrungen zeigen, daß in der Bauwirtschaft vorhandene absatzbedingte Saisonschwankungen unterschiedliche Ursachen haben können.

In der Literatur werden diese Ursachen noch weiter in "echte" und "unechte" bzw. "objektive" und "subjektive" Saisonschwankungen differenziert. ${ }^{180}$ Häufig werden jedoch gerade in der Bauwirtschaft die Ursachen der Schwankungen letztendlich auf die klimatischen Bedingungen zurückgeführt, wie das folgende Kapitel belegen wird. ${ }^{181}$

\subsubsection{Produktionsbedingte Saisonschwankungen}

Die produktionsbedingten Saisonschwankungen sind in der Regel auf einen witterungsabhängigen Produktionsprozeß zurückzuführen. Hierbei kann die Produktion aus technologischen Gründen nur unter bestimmten Witterungsbedingungen bzw. Schutzmaßnahmen aufrecht erhalten werden. ${ }^{182}$ Solche produktionsimmanenten Ursachen sind insbesondere bei der Produktion im Freien vorzufinden, ${ }^{183}$ also vor allem bei der äußeren Baustellenfertigung im Hoch- und Tiefbau. Deshalb lassen sich die von

178 vgl. Riester, F., Die Verhütung und Überwindung saisonaler Arbeitslosigkeit, insbesondere im Baugewerbe, als arbeitsmarktpolitische Aufgabe, S.91ff.

179 vgl. o.V., An der Schwelle des Winters 1961/62, S.1105.

180 Anmerkung: Auf die Diskussion der "unechten" bzw. "subjektiven" Saisonschwankungen soll im Rahmen dieser Arbeit ganz verzichtet werden, weil sie durch Ursachen hervorgerufen werden, die nach Ansicht des Verfassers schwer zu quantifizieren sind. Ähnlich äußern sich auch andere Autoren; vgl. Geerling, C., Winterbau und winterliche Arbeitslosigkeit, S.615: "Danach sind die psychologischen Momente die eigentlichen Gründe, warum es trotz aller Bemühungen mit dem Bauen im Winter nicht so recht weitergeht" und Vittali, W., Saisonschwankungen im Baugewerbe und ihre Auswirkungen auf die deutsche Volkswirtschaft, S.21: Er betrachtete die Technik des Winterbaus bereits 1931 als gelöst und vertrat die Ansicht, es werde mehr aus alter Gewohnheit als aus zwingender Notwendigkeit die Bautätigkeit im Winter wesentlich eingeschränkt.

181 Anmerkung: Dies kann muß aber nicht der Fall sein. Die Natur ist wohl als wichtigster, nicht aber als alleiniger Verursachungsfaktor für die Saisonbewegungen anzusehen ist. Sitten und Gebräuche können eine durchaus selbständige Rolle spielen und sind nicht notwendigerweise ein bloßer Ausfluß des Klimas, vgl. hierzu auch Fischer, M., Saisonarbeitslosigkeit und die Überwindung ihrer Folgen, S.26ff.

182 vgl. hierzu ausführlich Kap. 3.1.4. Witterungsbedingungen, S.101ff. und Kap. 3.1.3. Schutzmaßnahmen, S.98ff.

183 vgl. Weber, H. K., Industriebetriebslehre, S. 106ff. 
der Produktionsseite (d.h. durch den baubetrieblichen Prozeß, aber auch durch den Bauunternehmer oder Bauarbeiter) hervorgerufenen Saisonschwankungen in der Bauwirtschaft vorwiegend auf klimatische Einflüsse, insbesondere die den baubetrieblichen Produktionsprozeß behindernden Witterungsbedingungen wie Schnee, Kälte, Wind und Regen, zurückführen.

Man spricht daher auch von witterungsbedingten Saisonschwankungen, wobei sich die ungünstigen Wetterverhältnisse in zweifacher Hinsicht auswirken. Zum einen kann der Ablauf des technischen Produktionsvorganges unterbrochen werden, weil bestimmte Witterungsgrenzen eingetreten sind, die eine Fortfürung der Produktion unmöglich machen. ${ }^{184}$ Andererseits kann dem Bauarbeiter aufgrund seiner begrenzten physischen und psychischen Widerstandskraft lediglich ein bestimmtes Maß an Witterungsverhältnissen zugemutet werden. In diesem Zusammenhang ist es ungemein schwierig zu entscheiden, welche Witterungsbedingungen eine Weiterarbeit tatsächlich unmöglich machen und in welchen Fällen die klimatischen Verhältnisse nur als Vorwand benutzt werden, um die Arbeit niederlegen zu können. ${ }^{185}$

Zusammenfassend läßt sich feststellen, daß Saisonschwankungen unterschiedliche Herkünfte haben. Während die Ursachen der beschaffungs- sowie produktionsbedingten Saisonschwankungen noch recht homogen sind, lassen absatzbedingte Saisonschwankungen und insbesondere diejenigen, die auf Verhaltensweisen des Menschen zurückzuführen sind, diese Homogenität vermissen. ${ }^{186}$

In den nachfolgenden Ausführungen soll sich daher auf diejenigen Saisonschwankungen konzentriert werden, deren Ursachen weitgehend bestimmbar und deren Größe quantifizierbar ist. Wie schwierig allerdings die Quantifizierung der "reinen" Saisonbewegung ist, zeigt schon der Versuch, eine zahlenmäßige Aussage über den Verlauf der Saisonarbeitslosigkeit zu machen. Da sich "...erhebliche Abgrenzungsschwierigkeiten gegenüber den anderen Arten der Arbeitslosigkeit ergeben; vor allem konjunkturelle Einflüsse dürften sich kaum ausschließen lassen. Theoretisch müßten also im Einzelfall die Arbeitslosen befragt werden, aus welchem Grund sie ihren Arbeitsplatz

184 vgl. hierzu die entsprechenden Definitionen der Witterungsgrenzen des Deutschen Wetterdienstes in Kap. 3.1.4. Witterungsbedingungen, S.101ff.

185 Hinweis: Um subjektive Kriterien auszuschalten, verwendet der Verfasser die vom Deutschen Wetterdienst in Offenbach festgelegten Witterungsgrenzen nach denen die Fortführung der Bauarbeiten sehr erschwert werden, vgl. Kap. 3.1.4. Witterungsbedingungen, S. 102.

186 vgl. Fricke, W., Kosten und Kostenrechnung im Saisonbetrieb, S.19. 
verloren haben, was sich in der Praxis als undurchfürbar erweist. Zudem findet innerhalb der verschiedenen Arbeitslosigkeitsarten ein ständiger Wechsel statt, und schließlich ist zu berücksichtigen, daß auch die Beschäftigtenzahl auf den Umfang der Saisonbewegungen entscheidenden Einfluß ausübt." 187

Es versteht sich somit, daß die exakte statistische Erfassung unmöglich wird, da sie die Kenntnis sämtlicher übrigen Bewegungskomponenten einer Zeitreihe voraussetzt. ${ }^{188}$

\subsubsection{Wirkungen der Saisonschwankungen}

Die vorangegangenen Ausführungen haben Ursachen und Arten der für die Bauwirtschaft wesentlichen Saisonschwankungen beschrieben. An dieser Stelle soll der Versuch unternommen werden, mögliche Wirkungen der Saisonschwankungen auf wirtschaftliche Größen wie z.B Beschäftigung und Produktion aufzuzeigen, um deren Umfang später quantifizieren zu können.

Betrachtet man den witterungsabhängigen Produktionsprozeß in der Bauwirtschaft, so führt das Eintreten von Witterungsverhältnissen, die eine Produktion nicht zulassen, unmittelbar zu einer Produktionsunterbrechung und somit zu einer Produktionsmenge von Null. Dabei sind Beginn und Ende sowie die Häufigkeit dieses erzwungenen Produktionsstillstandes, wegen des direkten Einflusses der Natur auf den Produktionsprozeß, nicht genau terminiert. 189

Diese durch produktionsimmanente Saisonschwankungen verursachte saisonal schwankende Produktionsmenge hat unmittelbare Konsequenzen für die Auslastung der Fertigungskapazität, der grundsätzlich alle in der Fertigung eingesetzten Produktionsfaktoren ausgesetzt sind. In besonderem Maße trifft dies für die Betriebsmittel sowie die Arbeitskräfte zu. Aus der zeitweisen Nichtnutzung der betroffenen Kapazitäten resultieren Leerkosten, deren Höhe vor allem davon abhängt, ob und in welchem

187 vgl. Sartorius, R., Die arbeitspolitische Problematik des saisonabhängigen Berufes unter besonderer Berücksichtigung der Größenordnungen in Rheinland-Pfalz, Diss., Mainz 1954, S.59.

188 vgl. Donner, O., Die Saisonschwankungen als Problem der Konjunkturforschung, Vierteljahreshefte zur Konjunkturforschung, Hrsg. vom Institut für Konjunkturforschung, Sonderheft 6, Berlin 1928, S.10.

189 vgl. Fricke, W., Kosten und Kostenrechnung im Saisonbetrieb, S.22ff. 
Maße eine Anpassung des Einsatzes der Produktionsfaktoren an die jeweilige Beschäftigungslage möglich ist. Diese Anpassungsfähigkeit wird in der Literatur auch als Elastizität von Betrieben bezeichnet. ${ }^{190}$

Die Wirkungen von absatzbedingten Saisonschwankungen bzw. saisonal schwankenden Nachfragevolumen, können saisonal schwankende Absatzmengen und Preise sein. Diese können wiederum saisonale Beschäftigungsschwankungen für Arbeitskräfte und Betriebsmittel verursachen und schließlich zu Leerkosten führen. Aber auch saisonal schwankende Umsatzerlöse sind eine Folge von absatzbedingten Saisonschwankungen. Durch diesen schwankenden Kapitalrückfluß aus dem Umsatzprozeß entsteht ein saisonal schwankender Geldbedarf. ${ }^{191}$ So kann sich in der Nicht-Saison ein höherer Kreditbedarf ergeben, da in dieser Zeit weiterhin gewisse Kosten anfallen (wie z.B. Gehaltskosten und Fremdkapitalzinsen), denen aber geringere oder keine Umsatzerlöse gegenüberstehen. Insofern treten besondere Probleme im Finanzbereich auf. ${ }^{192}$

Die Ausführungen zeigen, daß Saisonschwankungen unabhängig von ihren Ursachen Auswirkungen auf die Beschaffung, die Produktion, den Absatz und die Finanzwirtschaft haben. So können ähnliche Wirkungen bei verschiedenen Ursachen auftreten. Das Ausmaß der Wirkungen von Saisonschwankungen ist überdies von der konkreten Ausprägung der jeweiligen Saisonschwankung, wie der Dauer, der Stärke und der Häufigkeit des Saisonausschlages, abhängig. Es bleibt daher Aufgabe - im Rahmen der Wirkungsanalyse des dritten Kapitels - zu klären, wie groß die Saisonschwankungen einzelner wirtschaftlicher Größen in der Bauwirtschaft tatsächlich sind und sofern möglich, den Anteil der verschiedenen Verursachungsarten an den Saisonschwankungen zu bestimmen.

Bevor allerdings damit begonnen wird, mögliche Ansätze zur Berechnung der Saisonschwankungen zu diskutieren und diese zu quantifizieren, sollen im folgenden $\mathrm{Ab}$ schnitt die konzeptionellen Möglichkeiten - getrennt nach gesetzlichen, tarifvertraglichen und sonstigen Maßnahmen - zur Realisierung der ganzjährigen Beschäftigung in der Bauwirtschaft kurz aufgezeigt werden. In Anlehnung an diese Unterteilung erfolgt dann in Abschnitt 2.4. ein Überblick über die tatsächliche Entwicklung der

190 vgl. Riebel, P., Die Elastizităt des Betriebes, S.87ff.

191 vgl. Mellerowicz, K., Kosten und Kostenrechnung, Verfahren, Teil 1: Allgemeine Fragen der Kostenrechnung und Betriebsabrechnung, S.430.

$192 \mathrm{Zu}$ den spezifischen Problemen der Finanzplanung in Saisonbetrieben siehe Pesch, H. J., Finanzplanung in Saisonindustrien, S.103ff. 
Förderungsmaßnahmen zur ganzjährigen Beschäftigung in der Bundesrepublik Deutschland. An diesen zeitlichen Abriß der Förderungsmaßnahmen schließt sich eine ausführliche Diskussion der Gründe an, die zu den entsprechenden gesetzlichen, tariflichen und sonstigen Förderungsmaßnahmen geführt haben.

Der Verfasser verspricht sich von dieser Vorgehensweise ein besseres Verständnis der Problematik zur "Ganzjährigen Beschäftigung", sowie die Aufdeckung eventueller Widersprüche oder Zielkonflikte in der Diskussion der Beteiligten und Ansatzpunkte zur Quantifizierung der Problematik.

\subsection{Die konzeptionellen Möglichkeiten zur Förderung der ganz- jährigen Beschäftigung in der Bauwirtschaft}

Bei den Ausführungen in diesem Kapitel geht es darum einmal aufzuzeigen, welche konzeptionellen Möglichkeiten zur Förderung bzw. Realisierung der ganzjährigen Beschäftigung in der Bauwirtschaft bestehen. Die folgende Aufzählung der konzeptionellen Möglichkeiten beschränkt sich zunächst auf die reine Darstellung möglicher Förderungsmaßnahmen, ohne die einzelnen Maßnahmen an dieser Stelle näher zu bewerten. Dabei werden auch Vorschläge berücksichtigt, die in der Diskussion der Beteiligten, d.h. der Tarifpartner und des Gesetzgebers, eine Rolle spielen bzw. gespielt haben. Entsprechend der Gliederung des Kapitels 2.4. wird zwischen gesetzlichen, tarifvertraglichen und sonstigen Maßnahmen unterschieden.

\section{Gesetzliche MaBnahmen:}

Eine Glättung des Baugeschehens läßt sich vor allem durch gesetzliche Restriktionen erreichen, die das Baugeschehen im Zeitablauf beeinflussen. $\mathrm{Zu}$ nennen sind hier beispielsweise sogenannte Baustoppgesetze, die die Bautätigkeit durch einen generellen oder partiellen Baustopp steuern. ${ }^{193}$ Aber auch die im Ausland zeitweise eingeführte Baubeginnsteuerung ${ }^{194}$ ermöglicht eine zeitlich gezielte Steuerung des Baugeschehens und kann schließlich eine kontinuierliche Bautätigkeit bewirken.

193 vgl. beispielsweise Gesetz zur Einschränkung der Bautătigkeit vom 8.6 .1962 bis zum 31.12.1973.

194 In Schweden wurde die Baubeginnsteuerung wieder aufgehoben, da sie nicht die gewünschten Erfolge gebracht hat und das Verfahren als zu schwerfallig angesehen wurde, vgl. Schriftenreihe des Bundesministers für Raumordnung, Bauwesen und Stădtebau: Bau- und Wohnforschung: Möglichkeiten zur Verstetigung der Baunachfrage durch Konjunkturprogramme, S.70. 
$\mathrm{Zu}$ den nicht derart restriktiven gesetzlichen Maßnahmen gehören die folgenden Vorschläge, die sich im Zeitablauf aus der Diskussion um die jeweils bestehenden gesetzlichen Förderungsmaßnahmen ergeben haben:

- Vorschlag des Ifo-Instituts aus dem Jahr 1967:195 Bei diesem Vorschlag des Ifo-Instituts sollen die Betriebe zwischen SWG und PWF wählen können. Entscheiden sie sich für die PWF erhalten sie Zuschüsse, die während des Winters gestaffelt sind und sich nach der Lohnsumme richten (November:10\%, Dezember:20\%, Januar:30\%, Februar:30\%, März:15\% der jeweiligen Lohnsumme). Finanziert werden sollen diese Zuschüsse über einen Fonds, der seine Mittel einerseits von der BA (in etwa der Höhe des SWG, das die BA durch die PWF einspart) und andererseits von den Bauherren (ca. $1 \%$ des Umsatzes aller Bauten) bezieht.

- Modifizierung der Produktiven Winterbauförderung: ${ }^{196}$ Die Vorschläge zur Änderung der PWF betreffen primär die Förderungssätze für WG, IKZ und MKZ. Durch eine Anhebung dieser Förderungssätze soll der Anreiz zum Winterbau insgesamt verstärkt werden. Die bisherige Regelung bei den IKZ197 bewirkt eine Konzentration und Begünstigung der Großunternehmen, daher sollen Kleinbetriebe mit einem deutlich höheren Prozentsatz bezuschußt werden, um so der mittelständischen Struktur der Baubranche gerecht zu werden.

- Modifizierung der SWG-Regelung: Die Änderungen der SWG-Regelung betreffen vor allem deren Höhe und Bezugsdauer. Bei der Höhe des SWG geht es primär darum, das Verhältnis von Arbeitslohn zum SWG bzw. Arbeitslosengeld neu zu überdenken. ${ }^{198}$ Bezüglich der Bezugsdauer gab es - unter Hinweis auf die Witterungsverhältnisse - Überlegungen, den Schlechwetterzeitraum auf die Zeit vom 15. Oktober bis zum 15. April auszudehnen. ${ }^{199}$

195 vgl. Ifo-Institut für Wirtschaftsforschung, Optimaler Winterbau, S.120ff.

196 vgl. Schriftenreihe des Bundesministers für Raumordnung, Bauwesen und Städtebau: Bau- und Wohnforschung: Saisonale Verstetigung der Bautătigkeit, S.33ff.

197 vgl. o.V., Mehrkostenzuschüsse für die kalten Monate, in: Handelsblatt vom 6.12.1984, S.23.

198 Hierzu erklärt das Ifo-Institut in einem Gutachten über den Winterbau: "...das beste Argument gegenüber den Arbeitern wäre der garantiert höhere Verdienst bei durchgehender Arbeit", vgl. Ifo-Institut für Wirtschaftsforschung, Optimaler Winterbau, S.75.

199 vgl. o.V., Drei Jahre Schlechtwetterregelung, in: Das Baugewerbe, 43. Jg., Nr.1, 1963, S.12ff. 


\section{Tarifvertragliche Maßnahmen:}

Ausgehend von dem Grundsatz, "...daß das, was die Beteiligten selber regeln können, nicht vom Staat durch ein Gesetz verlangt werden soll", ${ }^{200}$ beschreiben die folgenden Maßnahmen beispielhaft die Möglichkeiten, die die Tarifpartner durch Änderungen in ihren Tarifverträgen haben, um einen größeren Beitrag zur Förderung der ganzjährigen Beschäftigung in der Bauwirtschaft zu leisten. Diese tarifvertraglichen Maßnahmen zur Förderung der ganzjährigen Beschäftigung beinhalten vor allem verschiedene Arbeitszeitreglungen:

- Zweimonatige Arbeitsruhe im Winter:201 In den Monaten Januar und Februar wird nicht gearbeitet, da in diesen Monaten die höchsten Ausfalltagewerke zu verzeichnen sind. Die regelmäßige Arbeitszeit von März bis Dezember beträgt 48 Wochenstunden, d.h. die etwa 320 Ausfallstunden der Monate Januar und Februar würden lediglich "vorverlegt".

- Verlängerter Lohnausgleichszeitraum:202 Einführung einer über den Lohnausgleichszeitraum hinausgehenden "Ruhezeit" (z.B. um 6 Arbeitstage), die je nach Zahl der dazwischenliegenden Sonn- und Feiertage bis zum 12. Januar andauern könnte. Als Ausgleich dafür müßten die Arbeitnehmer auf eine weitere Verkürzung der wöchentlichen Arbeitszeit verzichten.

- Unterschiedliche Arbeitszeiten für Sommer und Winter: Eine diesbezügliche tarifvertragliche Regelung bestand bereits in den Jahren 1965 bis 1969. ${ }^{203}$ Damals betrug die regelmäßige wöchentliche Arbeitszeit in der Zeit vom 1. April bis 31 . Oktober 42 Stunden. In der Schlechtwetterzeit vom 1. November bis 31. März aber nur 40 Stunden. Seit 1. Oktober $1969^{204}$ galt einheitlich die 40 Stundenwoche (heute 39).

- Urlaubsregelung: Auslöser dieser zu diskutierenden Maßnahme ist die Tatsache, $\mathrm{da} ß$ in den baugünstigsten Monaten des Jahres (Juli, August) ein deutlicher Rück-

200 vgl. Deutscher Bundestag, 3. Wahlperiode, Stenographischer Bericht der 51. Sitzung vom 27. November 1958, S.2860.

201 vgl. Schlieder, E., Lösungsvorschlag zum Winterbauproblem: Winterpause am Bau - dafür längere Arbeitszeit im Sommer, in: Baumarkt, 69. Jg., Nr.46, 1970, S.2263ff.

202 vgl. Ifo-Institut für Wirtschaftsforschung, Soziale und wirtschaftliche Auswirkungen der Winterbauförderung, S.78.

203 vgl. §3 BRTV-Bau vom 31.März 1965.

204 vgl. Änderungstarifvertrag vom 20. August 1969. 
gang der Bautätigkeit durch die sommerliche Urlaubszeit zu verzeichnen ist. Durch eine entsprechende tarifvertragliche Vereinbarung könnte die Urlaubszeit ganz oder teilweise in die Schlechtwetterzeit gelegt werden und damit die kontinuierliche Bautätigkeit bzw. ganzjährige Beschäftigung gefördert werden.

\section{Sonstige Maßnahmen:}

Die ganzjährige Beschäftigung bzw. kontinuierliche Bautätigkeit wird grundsätzlich durch die staatlichen Ziele der Konjunkturpolitik - wonach im Rahmen der marktwirtschaftlichen Ordnung gleichzeitig Stabilität des Preisniveaus, ein hoher Beschäftigungsstand und außenwirtschaftliches Gleichgewicht bei stetigem und angemessenem Wirtschaftswachstum anzustreben sind ${ }^{205}$ - unterstützt. Um die ganzjährige Beschäftigung zu erreichen, liegt es daher nahe zu versuchen, durch gezielte antizyklische Veränderungen der öffentlichen Ausgaben und/oder Einnahmen, die Entwicklung in der Bauwirtschaft entsprechend zu beeinflussen und schließlich zu stabilisieren.

Hierunter sind diejenigen wirtschaftspolitischen Bemühungen zu verstehen, die auf eine Verstetigung der bauwirtschaftichen Nachfrage zielen. So kann beispielsweise die öffentliche Hand als Träger der Baupolitik die Nachfrage nach Bauleistungen, durch eine stärkere antizyklische Auftragsvergabe, gleichmäßiger auf das Jahr verteilen. Desweiteren können die Verhaltensweisen der privaten Bauherren durch gezielte steuerpolitische Maßnahmen indirekt beeinflußt werden. Daher können auch steuerpolitische Instrumente die winterliche Bautätigkeit und damit die ganzjährige $\mathrm{Be}-$ schäftigung positiv beeinflussen. ${ }^{206}$

Eine abschließende Beurteilung der konzeptionellen Möglichkeiten und die Diskussion der tatsächlich relevanten Maßnahmen zur Förderung der ganzjährigen Beschäftigung in der Bauwirtschaft erfolgt im Anschluß an die Ergebnisse der Wirkungsanalyse im Rahmen des vierten Kapitels.

\footnotetext{
205 vgl. §1 StWG.
}

206 vgl. Seewald, O., Beitrag zur Frage der Verstetigung offentlicher Bauinvestitionen, in: Schriftenreihe des Bundesminsiters für Raumordnung, Bauwesen und Städtebau, S.60, Hamburg, 1977. 


\subsection{Zeitlicher Abriß der Förderungsmaßnahmen zur ganzjährigen Beschäftigung}

Die folgenden Ausführungen befassen sich eingehend mit der geschichtlichen Entwicklung zur Förderung der ganzjährigen Beschäftigung in der Bauwirtschaft. Hierbei werden die diesbezüglich getroffenen Maßnahmen im Zeitablauf beschrieben und bestimmten Zeiträumen, die sich insbesondere durch die gesetzlichen Regelungen ergeben, zugeordnet. Diese charakteristischen Förderungszeiträume bilden schließlich die Basis zur Analyse der Wirkungen der getroffenen Förderungsmaßnahmen zur ganzjährigen Beschäftigung des dritten Kapitels.

Wie bereits in der Einführung erwähnt, läßt die Geschichte der Bestrebungen und Maßnahmen zur ganzjährigen Beschäftigung in der Bauwirtschaft erst in den 50er Jahren ernsthafte Bemühungen erkennen, die winterliche Arbeitspause zu überwinden. Während bis dahin eine fast ausschließlich repressive Folgebekämpfung der Saisonarbeitslosigkeit im Vordergrund gestanden hatte, trat nun an deren Stelle eine verstärkt präventive Bekämpfung. ${ }^{207}$

Erste Bemühungen gehen hier auf das Jahr 1950 zurück, als von der Bundesregierung ein ständiger "Interministerieller Arbeitsausschuß Bauwirtschaft"208 ins Leben gerufen wurde. Ihm gehörten die am Baugeschehen besonders interessierten Bundesministerien und der Bundesrechnungshof an. Dieser wurde u.a. mit der Aufgabe betraut, die Probleme der ganzjährigen Beschäftigung in der Bauwirtschaft bzw. des kontinuierlichen Bauens zu studieren, weil man sich zu diesem Zeitpunkt noch nicht im klaren war, inwieweit ein Bauen in der witterungsungünstigen Jahreszeit überhaupt möglich, geschweige denn zweckmäßig und erforderlich sei. Um diese Frage beantworten zu können, mußten ausfuhrliche Informationen beschafft werden, die dann die Ausgangsbasis für die zu treffenden Maßnahmen bilden sollten. ${ }^{209}$

207 vgl. Weddigen, W., Die Behandlung der saisonalen Arbeitslosigkeit im Rahmen des Versicherungsschutzes gegen Arbeitslosigkeit, S.11ff.

208 vgl. Schattenberg, H. H., Öffentlicher Bauherr und kontinuierliche Bautătigkeit, S.284f.

209 vgl. Kranz, G., Die Problematik der Winterarbeitslosigkeit in der Bauwirtschaft und die Bemühungen um die Lösung des Problems, S.23ff. 


\subsubsection{Gesetzliche Regelungen}

Bevor mit der Beschreibung der gesetzlichen Regelungen zur Förderung der ganzjährigen Beschäftigung in der Bauwirtschaft begonnen wird, soll der davor liegende Zeitraum ("Vorher" 1954-59) betrachtet werden. Er ist frei von gesetzlichen Förderungsmaßnahmen und liefert somit ein gutes Vergleichskriterium im Rahmen der Wirkungsanalyse.

\subsubsection{1954-59: Der Zeitraum "Vorher"}

Ab Mitte der 50er Jahre befaßten sich auch die BAVAV, das Rationalisierungskuratorium der Deutschen Wirtschaft, die IG Bau-Steine-Erden und die Arbeitgeberverbände der Bauwirtschaft mit der Problematik zur ganzjährigen Beschäftigung in der Bauwirtschaft. Neben zahlreichen Werbemaßnahmen für den Winterbau, ${ }^{210}$ Studienreisen von Vertretern der Tarifvertragsparteien, ${ }^{211}$ Erstellung von Gutachten durch die Bundesregierung ${ }^{212}$ und statistischen Sondererhebungen der BAVAV über Ausmaß und Verlauf der Saisonarbeitslosigkeit der Bauarbeiter, ${ }^{213}$ dienten die sogenannten Versuchs- und Vergleichsbauten als wichtiges Mittel zur Informationsbeschaffung. ${ }^{214}$ Für diese Bauten übernahm der Staat die Kosten, um zu gewährleisten, daß die gewonnenen Erkenntnisse laufend veröffentlicht und allen interessierten Stellen zugänglich gemacht wurden. ${ }^{215}$

210 In Broschüren und Zeitschriften sowie auf Vortragsveranstaltungen wurde für den Winterbau geworben. Außerdem gab es 1959 eine Wanderausstellung "Bauen im Winter", die in allen gröBeren Städten des Bundesgebietes umfassend über die Möglichkeit des Bauens im Winter unterrichtete.

211 vgl. hierzu vor allem Schleicher, E., Winterbau - Eine Tagung und eine Reise, und o.V., Der Winterbau in Schweden, S.3.

212 Beispielhaft zu erwähnen ist hier das Gutachten über "Die Ursachen des hohen Ausschlags der Arbeitslosigkeit im Winter", das im Auftrag des Bundeswirtschaftsministeriums im Dezember 1955 vom Ifo-Institut erstellt wurde. Es ging allerdings auf die eigentlichen Ursachen noch zu wenig ein und bot daher keine Ansatzpunkte für eine Lösung des Problems der kontinuierlichen Bautätigkeit. Weitere Gutachten sind das von Weddigen über "Die Behandlung der saisonalen Arbeitslosigkeit im Rahmen des Versicherungsschutzes gegen Arbeitslosigkeit" und die "Rothenfelser Denkschrift", die sich primär mit einer Neuordnung der sozialen Leistungen befaßte.

213 vgl. auch das Bulletin des Presse- und Informationsamtes der Bundesregierung: Die wirkliche Größe der Saisonarbeitslosigkeit festgestellt, S.1586f. und Die Winterarbeitslosigkeit im Baugewerbe, S. 1793f.

214 vgl. Schepsky, J., Erfahrungen aus den Winterbauten der Jahre 1955/59, S.190ff.

215 Anmerkung: Eine Publizierung irgendwelcher technischer oder wirtschaftlicher Erfahrungen von Seiten der Privatfirmen wäre nicht zu erwarten gewesen. 
Zur Erforschung der speziellen Winterbauprobleme - insbesondere der technischen, wirtschaftlichen und sozialen Fragen - wurde schließlich im April des Jahres 1955 beim Bundesministerium für Wohnungsbau die Einsetzung eines Ausschusses für das "Bauen im Winter" beschlossen. ${ }^{216}$ Auf Initiative dieses Ausschusses wurden in den Wintermonaten im Auftrag des Bundesministeriums für Wohnungsbau die oben genannten Versuchs- und Vergleichsbauten errichtet, die vornehmlich zwei Aufgaben hatten. Einerseits galt es zu erkunden, welche technischen Hilfsmittel und Organisationsmöglichkeiten bei welchen Temperaturen am vorteilhaftesten einzusetzen waren. Andererseits sollte geklärt werden, welche wirtschafts- und sozialpolitischen Folgerungen - insbesondere in gesetzlicher Hinsicht - sich mit Hilfe der an diesen Baustellen gewonnenen Erfahrungen ziehen ließen. Der Beweis, daß es technisch möglich ist, auch während der Wintermonate zu bauen, wurde schon bald erbracht. ${ }^{217}$

Die lebhaften, vielfach kontrovers geführten Diskussionen dieser Jahre, an denen sich Sozialpolitiker, Arbeitgeber, Gewerkschaften, Wissenschaftler und Fachleute der Arbeitsverwaltung gleichermaßen beteiligten, kamen zu dem Ergebnis, daß das Bauen im Winter volkswirtschaftlich notwendig sei und eine "Schlechtwetterregelung" gefunden werden müßte. ${ }^{218}$ Dennoch mißlang der Versuch, eine brauchbare Regelung für das Bundesgebiet, im Rahmen der großen Novelle von 1956 zum Gesetz über Arbeitsvermittlung und Arbeitslosenversicherung (AVAVG), zu schaffen.

Erfolgversprechender war die im November 1958 vom Bundesministerium für Wohnungsbau veröffentlichte Diskussionsvorschrift "Erwägungen zum Winterbau", 219 die wesentliche mit der winterlichen Bautätigkeit zusammenhängende Probleme untersuchte und Lösungsvorschläge lieferte, die großenteils in den später getroffenen gesetzlichen Regelungen Berücksichtigung fanden. Die Ergebnisse der Untersuchungen haben nach Ansicht von Kranz "...wesentlich zur Klärung der Sachlage und gewisser Voraussetzungen, die bei künftigen administrativen, gesetzgeberischen und tarifvertraglichen Maßnahmen zu beobachten waren, beigetragen und erreicht, daß

216 vgl. Steinbiss, M., Untersuchungen über Winterarbeiten im Hochbau und Ergebnisse der vergleichenden Bauforschung, S.38ff.

217 Anmerkung: Durch Anwendung der verschiedenen Schutzvorkehrungen lassen sich die Arbeiten im Winter in der Regel bereits mit verhältnismäßig einfachen Mitteln weiterführen, vgl. hierzu BT-Drucks. IV/643, S.6 und Kap. 3.1.3. Schutzmaßnahmen, S.98ff.

218 vgl. Kranz, G., Der Weg zum Gesetzentwurf über die Förderung der ganzjährigen Beschäftigung in der Bauwirtschaft, S.23ff.

219 Hauptausschuß "Bauen im Winter", Erwägungen zum Winterbau, Diskussionsvorschrift. 
sich die verantwortlichen Stellen nunmehr zur Änderung der von allen Seiten als unerwünscht bezeichneten Situation auf die noch nicht geklärten weiteren Fragen konzentrieren konnten." 220

Die bislang aufgezählten Aktivitäten der Beteiligten zur ganzjährigen Beschäftigung in der Bauwirtschaft belegen deutlich, daß man es sich mit der Schaffung gesetzlicher Rahmenbedingungen und Förderungsmaßnahmen nicht leicht gemacht hat. Mittlerweile herrschte, wie wenig später im Bericht der Bundesregierung zum Ausdruck kam, "...Übereinstimmung darüber, daß die Abkehr vom traditionellen bauwirtschaftlichen Produktionsrhythmus nicht über eine marktwirtschaftliche Automatik (z.B. winterliche Fixkostenbelastung, niedrigere Winterpreise) erreicht werden kann, sondern daß mindestens als Übergangslösung materielle Anreize für alle Beteiligten, also befristete Winterbauförderungsmaßnahmen, wirtschaftspolitisch gutzuheißen sind."221

\subsubsection{1960-68: Das zweite Änderungsgesetz zum AVAVG}

Ausgangspunkt für die Behandlung des Winterbauproblems im Bundestag war die Anfrage der SPD-Fraktion vom 30. Juni 1958. Hierin wurde die Bundesregierung nach ihren Maßnahmen befragt, "...um den Schwankungen in der Beschäftigung der Bauwirtschaft mit dem Ziel entgegenzuwirken, eine ausgeglichene ganzjährige Vollbeschäftigung der Bauwirtschaft zu erreichen". 222 Am 27. November 1958 faßte der Bundestag einen einstimmig angenommenen Antrag aller Fraktionen, in dem die Bundesregierung aufgefordert wurde, bis zum 31. Mai 1959 ein Gesamtprogramm aller möglicherweise geeigneten Maßnahmen zur Förderung der kontinuierlichen Bautätigkeit vorzulegen. ${ }^{223}$ Dieser Aufforderung kam die Bundesregierung mit ihrem Bericht über die "Verbesserung der Verhältnisse in der Bauwirtschaft"224 vom 29. Juni 1959 nach.

Ein Gesetzentwurf über Maßnahmen zur Förderung der ganzjährigen Beschäftigung in der Bauwirtschaft wurde schließlich am 29. August 1959 dem Bundestag vorge-

220 Kranz, G., Winterbau. Förderung der ganzjährigen Beschăftigung in der Bauwirtschaft, S.6.

221 BT-Drucks. IV/643, S.8.

222 BT-Drucks. III/495.

223 Deutscher Bundestag, 3.Wahlperiode, Stenographischer Bericht der 51. Sitzung vom 27. November 1958, S.2823ff. und o.V., Die Bundestagsdebatte, in: Die Bauwirtschaft, S.1100ff.

224 BT-Drucks. III/1240. 
legt. Erst mit diesem Zweiten Änderungsgesetz zum Gesetz über Arbeitsvermittlung und Arbeitslosenversicherung, ${ }^{225}$ das nach seiner Verkündung am 7. Dezember 1959 rückwirkend zum 1. Dezember 1959 in Kraft trat, gelang der Versuch des Deutschen Bundestages, das Winterbauproblem mit gesetzgeberischen Maßnahmen in den Griff zu bekommen. Hierbei ist anzumerken, daß das Zustandekommen des Gesetzes erst durch die im Herbst 1959 abgeschlossenen Tarifverträge in der Bauwirtschaft möglich geworden war. ${ }^{226}$

Unter der Bezeichnung "Förderung der ganzjährigen Beschäftigung in der Bauwirtschaft" wurden erstmals besondere, auf den Winterbau bezogene Vorschriften in das AVAVG eingefügt. ${ }^{227}$ Sie sahen vor, daß Bauherren, Bauunternehmen und Bauarbeitern Leistungen aus Mitteln der BAVAV gewährt werden konnten. Damit sollten Anreize gegeben werden, die Bauarbeiten auch während der witterungsungünstigen Wintermonate aufzunehmen oder fortzusetzen. Im Vordergrund dieser Förderungsmaßnahmen stand dabei die Gewährung des sogenannten Schlechtwettergeldes (SWG), das für Tage, an denen aus zwingenden Witterungsgründen die Arbeiten auf dem Bau nicht fortgesetzt werden konnten, die Lohnausfälle der Bauarbeiter teilweise ausgeglichen wurden.

Die Einführung entsprechender Vorschriften erwies sich als erforderlich, weil nach dem bis dahin geltenden Recht die Bestimmungen über Lohnausfallvergütung - vornehmlich Kurzarbeitergeld - auf die Winterarbeitslosigkeit in der Bauwirtschaft nicht anwendbar waren, und Arbeitslosengeld nur an Arbeitslose, also von ihrem Betrieb entlassene Arbeitnehmer, bezahlt wurde. Durch das Schlechtwettergeld, das nur während der Schlechtwetterzeit vom 1. November bis 31. März gewährt wird, erhielten die Arbeitnehmer des Baugewerbes nun einen Rechtsanspruch gegen die BAVAV auch für solche Fälle, in denen das Arbeitsverhältnis zwar fortbesteht, aber aus Witterungsgründen Lohnausfälle eintreten. Für die Bauarbeiter war diese Regelung insbesondere deshalb von Bedeutung, weil sie auch nach den tariflichen Bestimmungen bisher keinen Lohnanspruch hatten, wenn die Arbeit infolge ungünstiger Witterung unmöglich geworden war. Man spricht daher auch von der Lohnersatzfunktion des Schlechtwettergeldes. ${ }^{228}$

225 AVAVG vom 7.Dezember 1959, BGB1.1 S.705.

226 vgl. auch Kap. 2.4.2. Tarivertragliche Leistungen und Regelungen, S.74ff.

227 vgl. Unterabschnitt C des 4. Abschnittes des AVAVG ( $\$ 1143 a$ bis 143n) und zur ausfuihrlichen Erläuterung auch Anhang I, S.243.

228 vgl. Heberer, O./Kuhn, A./Wagner, H.-G., Kurzarbeitergeld/Winterbauförderung, S.85. 
Die Regelungen, des am 1. Dezember 1959 in Kraft getretenen Gesetzes, über die Förderung der ganzjährigen Beschäftigung in der Bauwirtschaft, wurden in einigen Punkten bis zur Ablösung des AVAVG durch das Arbeitsförderungsgesetz (AFG) verbessert und vereinfacht, ohne das grundlegende Neuerungen eingeführt wurden. An dieser Stelle sollen daher nur einige Änderungen erwähnt werden. Zu nennen ist das Dritte Änderungsgesetz zum AVAVG, ${ }^{229}$ das am 1. November 1960 in Kraft trat und eine Reihe von Verbesserungen bezüglich der SWG-Regelung enthielt. ${ }^{230}$ So war beispielsweise die Gewährung von SWG nun nicht mehr abhängig vom Ausfall eines vollen Arbeitstages ${ }^{231}$, und die Höhe des SWG lag etwas über der des Arbeitslosengeldes. ${ }^{232}$ Im Fünften Änderungsgesetz zum AVAVG vom 15. November 1963233 wurde insbesondere die Berechnung des SWG vereinfacht, und im Siebten Änderungsgesetz zum AVAVG vom 10. März $1967^{234}$ wurden schließlich Arbeitslosen-, Kurzarbeiter- und Schlechtwettergeld gleichgesetzt. ${ }^{235}$

Die in diesem Zeitraum angeführten zahlreichen Änderungen, denen die gesetzlichen und administrativen Regelungen zur Förderung der ganzjährigen Beschäftigung in der Bauwirtschaft unterworfen waren, machen deutlich, daß sich die Beteiligten noch mehr oder weniger in einem Versuchsstadium befanden und auf weiteres Informationsmaterial angewiesen waren. Daher wurden die Versuchs- und Vergleichsbauten fortgefuhrt und zusätzliche Gutachten bzw. Stellungnahmen der Bauverbände eingeholt. Größere Bedeutung für die weitere Entwicklung der gesetzlichen Bestimmungen erlangten dabei zum einen die Veröffentlichungen des Ifo-Instituts für Wirtschafts-

229 BGBl.1, S.833f

230 vgl. hierzu ausführlich Unkelbach, L., Gesetzliche Schlechtwettergeldregelung, S.1074ff. und siehe auch Kranz, G., Die jüngsten Bemühungen um ein kontinuierliches ganzjähriges Bauen, S.97ff.

231 Anmerkung: Der §143e AVAVG wurde dahingehend geändert, daß ein Arbeitstag auch dann noch als voll ausgefallen galt, wenn die Arbeit spätestens drei Stunden nach Beginn aus witterungsbedingten Gründen abgebrochen werden mußte.

232 Anmerkung: Um die Bezieher von SWG finanziell nicht schlechter zu stellen, als die Bezieher von Arbeitslosengeld, was aufgrund der bisherigen Berechnungsmethode (nur ganze Ausfalltage zählen) durchaus vorkommen konnte, wurde §143 AVAVG entsprechend geändert.

233 BGBl.1, S.789ff.

234 BGBl.1, S.266ff.

235 Anmerkung: Trotz Gleichstellung von Arbeitslosen-, Kurzarbeiter- und Schlechtwettergeld gab es vom 1. Januar 1968 bis zum Inkrafttreten des Haushaltsstrukturgesetzes zusätzlich zum SWG für jede Ausfallstunde noch einen Zuschlag von 0,30 DM, um den Mehraufwand (Fahrtkosten, ständige Arbeitsbereitschaft) der Bauarbeiter auszugleichen. 
forschung ${ }^{236}$ und zum anderen die der RG "Bauwesen" im RKW, ${ }^{237}$ deren Vorschläge in den neuen Winterbauförderungsmaßnahmen berücksichtigt wurden.

\subsubsection{1969-71: Das Arbeitsförderungsgesetz}

Auslöser dieses Gesetzes war der Beschluß des Bundestages vom 29. Juni 1966, worin die Bundesregierung aufgefordert wurde, das vielfach novellierte AVAVG vom 16. Juli 1927 erneut an die wirtschaftliche Entwicklung und den technischen Fortschritt anzupassen. ${ }^{238}$ Doch statt einer Novelle legte die Bundesregierung einen neuen Gesetzesentwurf vor, das sogenannte Arbeitsforderungsgesetz (AFG), das das alte AVAVG ablösen sollte. ${ }^{239}$ Dieses neue Gesetz übernahm einerseits eine Reihe von Vorschriften aus dem AVAVG und zwar diejenigen, von denen man annahm, daß sie sich bewährt hätten. Andererseits enthielt es aber auch viele Neuerungen, wie schon die Dreiteilung des Zweiten Unterabschnitt des dritten Abschnitts des AFG über die "Förderung der ganzjährigen Beschäftigung in der Bauwirtschaft" (§§74-90) in SWGRegelung, Produktive Winterbauförderung (PWF) und Sonstige Leistungen, belegt. ${ }^{240}$

Zusammenfassend läßt sich feststellen, daß das am 1. Juli 1969 in Kraft getretene $\mathrm{AFG}^{241}$ mit der sogenannten Produktiven Winterbauförderung (PWF) eine grundsätzlich neuartige Form der Bezuschussung von Bauten während der Winterperiode brachte. Statt der bisherigen Bauherrenförderung ${ }^{242}$ wurden nun als besondere Anreize zur Fortsetzung der Bautätigkeit in der witterungsungünstigen Jahreszeit, zusätzlich zum Schlechtwettergeld, Zuschüsse an Bauunternehmer zu den Mehrkosten des Bauens in der Schlechtwetterzeit eingeführt.

236 Es handelt sich dabei um folgende Veröffentlichungen des Ifo-Instituts für Wirtschaftsforschung: Soziale und wirtschaftliche Auswirkungen der Winterbauförderung, Gutachten im Auftrag des Bundesministers für Arbeit und Sozialordnung, Bonn 1964 und Optimaler Winterbau, Gutachten im Auftrag des Bundesministeriums für Wohnungswesen und Städtebau, hrsg. von der Rationalisierungs-Gemeinschaft Bauwesen im RKW, Frankfurt/Main 1967.

237 vgl. o.V., Produktive Winterbauförderung statt Schlechtwettergeld, S.1579ff. und Walper, K. H., Bauen im Winter, S.45ff.

238 vgl. Deutscher Bundestag, 5. Wahlperiode, Stenographischer Bericht der 52. Sitzung vom 29. Juni 1966, S. 2477-2531.

239 BT-Drucks. V/2291.

240 vgl. zur ausführlichen Erläuterung Anhang II, S.245-246.

241 BGBl.I, S.582ff.

242 vgl. §143a AVAVG. 
Dieser sogenannte Mehrkostenzuschuß (MKZ), der die Förderungsleistungen an Bauherren ersetzte, war im Gegensatz zu den lediglich konsumorientierten Leistungen des Arbeitslosen- und Schlechtwettergeldes produktionsorientiert. Mit ihm wurde der Zweck verfolgt, die Unternehmen des Baugewerbes zu veranlassen, bessere Schutzvorkehrungen gegen Witterungseinflüsse zu schaffen und überhaupt einen Anreiz zu geben, kontinuierlicher zu bauen. Die pauschalierten Zuschüsse je geleisteter Arbeitsstunde sollten die durch das Bauen im Winter verursachten Kosten teilweise ausgleichen. So schwankte der Förderungssatz je geleisteter Arbeitsstunde und Art der durchzuführenden Bauarbeiten zwischen 0,60 DM für den Ausbau im Hochbau und 2,70 DM für die Herstellung von Versorgungsleitungen im Tiefbau. ${ }^{243}$

Faßt man an dieser Stelle die bisherige Entwicklung der Winterbauförderung kurz zusammen, so läßt sich der Zeitraum 1960-68 als eine erste Versuchsphase charakterisieren, deren Ziel es war, wertvolle Informationenen über Möglichkeiten und Grenzen des Winterbaues zu sammeln. In der dann folgenden zweiten Phase - im Zeitraum 1969-71 - setzte sich die Erkenntnis durch, daß die Winterbauförderung neben den rein konsumtiven Leistungen auch produktionsorientierte Aspekte enthalten müßte.

Die Tatsache, daß die Bundesregierung nur drei Jahre nach Inkrafttreten des Arbeitsförderungsgesetzes erneut einen Gesetzesentwurf zum Thema "Ganzjährige Beschäftigung" vorlegte, ${ }^{244}$ macht deutlich, daß die Regelungen des AFG von 1969 offenbar immer noch nicht ausreichten, dem Winterbau zum Durchbruch zu verhelfen. In konsequenter Verfolgung der produktionsorientierten Zielsetzung wurde daher die in den folgenden Ausführungen beschriebene dritte Phase (1972-85) der Winterbauförderung, mit dem "Zweiten Gesetz zur Änderung und Ergänzung des Arbeitsförderungsgesetzes" vom 19. Mai $1972^{245}$, geschaffen.

\subsubsection{1972-85: Die Winterbaunovelle}

Der Schwerpunkt dieser sogenannten Winterbaunovelle lag in der Verbesserung der produktionsorientierten Förderungsleistungen. Auslöser dafür waren wissenschaftliche Untersuchungen, die ergeben hatten, daß von den 380 Millionen angezeigten

243 vgl. hierzu ausführlich Krebs, H., Arbeitsforderungsgesetz (AFG), Kommentar zu $\$ 82-87$ und Hennig, W./Kühl, H./Heuer, E., Arbeitsforderungsgesetz (AFG), Kommentar, S.116ff.

244 BT-Drucks. VI/2689.

245 BGB1.I, S.791ff. 
witterungsbedingten Arbeitsausfällen in der Zeit von 1959 bis 1971 etwa 2/3 beim Einsatz von Witterungsschutzvorkehrungen produktiv nutzbar gewesen wären. ${ }^{246}$

Der Kernpunkt der Gesetzesänderung, die sich in enger Abstimmung mit Sachverständigen aus der Bauwirtschaft ergab, lag in der Einführung eines Wintergeldes (WG) für Bauarbeiter in Höhe von 2,- DM für jede in der Förderungszeit geleistete Arbeitsstunde. ${ }^{247}$ Außerdem wurden Rechtsansprüche auf Förderungsleistungen sowohl für die Arbeitgeber (Investitions- und Mehrkostenzuschüsse) als auch für die Arbeitnehmer (Wintergeld) durch Rechtsverordnungen (Baubetriebe-Verordnung ${ }^{248}$, Winterbau-Umlageverordnung ${ }^{249}$, Winterbau-Anordnung ${ }^{250}$ und Arbeitsschutz-Verordnung für Winterbaustellen ${ }^{251}$ ) geschaffen.

Auffallend ist auch - dies zeigt schon die Unterteilung im AFG, die von der alten Fassung stark abweicht - daß der Gesetzgeber die Vorschriften über die PWF vor die Regelungen über das SWG stellt, ${ }^{252}$ um zu dokumentieren, "...daß der Schwerpunkt nun auf der Produktivität und nicht auf dem unproduktiven Schlechtwettergeld liegt." 253 Die neue gesetzliche Gliederung der Maßnahmen zur "Förderung der ganzjährigen Beschäftigung in der Bauwirtschaft" ist daher: Allgemeine Vorschriften (§§74-76), PWF (§§77-82) und SWG (§§83-89). ${ }^{254}$

246 BR-Drucks. 435/71, S.9.

247 vgl. $\$ 80$ Abs. 1 AFG.

248 §76 Abs.2 AFG:"Verordnung über die Betriebe des Baugewerbes, in denen die ganzjährige Beschäftigung zu fördern ist (Baubetriebe-Verordnung)" vom 19. Juli 1972 (BGBl. I, S. 1257ff.) i.d.F. der ersten Verordnung zur Änderung der Baubetriebe-VO vom 30. April 1975 (BGBl. I, S.1056).

249 \$186a Abs. 3 AFG:"Verordnung über die Umlage zur Aufbringung der Mittel für die Produktive Winterbauförderung (Winterbau-Umlageverordnung)" vom 13. Juli 1972 (BGBl. I, S.1102) i.d.F. der Verordnung zur Änderung der Winterbau-Umlage-VO vom 30. April 1975 (BGBl. I, S.1102).

$250 \S \S 82$ und 89 i.V.m. $\$ 191$ Abs.3 AFG:"Anordnung des Verwaltungsrates der Bundesanstalt für Arbeit über die Förderung der ganzjährigen Beschäftigung in der Bauwirtschaft (WinterbauAnordnung)" vom 4. Juli 1972 (ANBA, 20. Jg., Nr.9, 1972, S.511ff.) i.d.F. der 1. ÄndenungsAO vom 18. Dezember 1975 (Rd.Erl. der BA 61/76, S.338) und der 2.Änderungs-AO vom 15. Juni 1976 (ANBA, 24. Jg., Nr.9, 1976, S.869).

251 "Verordnung über besondere Arbeitsschutzanforderungen bei Arbeiten im Freien in der Zeit vom 1. November bis 31. Mărz (Arbeitsschutz-Verordnung für Winterbaustellen) vom 1. August 1968 (BGBl. I, S.901 f.) i.d.F. der "Ersten Verordnung zur Änderung der Verordnung über besondere Arbeitsschutzanforderungen bei Bauarbeiten in der Zeit vom 1. November bis 31 . März" vom 23. Juli 1974 (BGBl. I, S.1569) und der Arbeitsstăttenverordnung (ArbStăttV) vom 20. März 1975 (BGBl. I, S.729ff.)

252 vgl. "alte" Reihenfolge im AFG von 1969: SWG-Regelung, PWF und Sonstige Leistungen.

253 vgl. Röthig, H., Winterbau auf neuen Wegen, S.20ff. und BT-Drucks. VI/2689, S.9. 


\subsubsection{1986-92: Aussetzung der Förderung von IKZ und MKZ}

"Das kontinuierliche Bauen, das Bauen auch im Winter, hat einen Rückschlag erlitten."255 Mit diesen Worten kommentierten diejenigen Baubetriebe, die die Förderung in Anspruch genommen hatten, den hier zu beschreibenden Zeitraum. Denn der Deutsche Bundestag hatte am 26. Juli 1986 das "Gesetz zur Änderung wirtschafts- und verbraucherrechtlicher sowie arbeits- und sozialrechtlicher Vorschriften" beschlossen. ${ }^{256}$ In diesem Gesetz bezieht sich der Artikel 12 auf arbeitsrechtliche Vorschriften, denn er ändert, allerdings nur auf Zeit, das AFG durch Einfügen des §238. Dieser lautet: "Die Leistungen der Produktiven Winterbau-Förderung nach $\S \S 77$ bis 79 werden vom 1. Juli 1986 bis zum 31. März 1989 nicht gewährt, es sei denn, daß die Anerkennung einer Förderung vor dem 1. Juli 1986 beantragt worden ist. "257

Der Gesetzgeber sah diese Regelung zur Flankierung einer notwendigen Strukturbereinigung im Baugewerbe als erforderlich an. ${ }^{258}$ Das Aussetzen der Förderung führte zu einer Minderung des Prozentsatzes der Winterbau-Umlage, von 3 auf $2 \%$ der Bruttolohnsumme 259 und damit zur Senkung der Lohnnebenkosten der Baubetriebe.

Durch das Gesetz vom 20. Dezember $1988^{260}$ hat der Gesetzgeber den Aussetzungszeitraum bis zum 31.März 1992 verlängert. ${ }^{261}$ Diejenigen, die noch 1986 argumentierten, daß "mit Sicherheit nach Ablauf der Sperrfrist, nach dem 31. März 1989, die Produktive Winterbauförderung weitergeführt werden würde, um auch im Winter kontinuierlich zu bauen"262, wurden eines Besseren belehrt. Mittlerweile wurde in Absprache mit den Verbänden der Bauwirtschaft eine weitere Verlängerung der "Förderpause" bis zum 31.Dezember 1994 beschlossen. ${ }^{263}$ Die vorübergehende Entlastung der Baubetriebe von Lohnnebenkosten erschien dem Gesetzgeber nach wie vor dring-

254 vgl. zur ausführlichen Erläuterung Anhang III, S.247ff.

255 vgl. Röthig, H., Baurationalisierung: Frostige Zeiten für den Winterbau, S.634.

256 vgl. BGB1.I, S. 1169.

257 BGBl.I, S.1169, Gesetz vom 25.7.1986.

258 vgl. BT-Drs. 10/5771, S.26 zu Art. 12.

259 vgl. VO vom 3.November 1986, BGB1.I, S. 1728.

260 BGB1. I, S.2343.

261 vgl. BT-Drs. 11/2990, S.23, zu Nr.28.

262 vgl. Röthig, H., Baurationalisierung: Frostige Zeiten für den Winterbau, S.634.

263 Ändenungsgesetz zum AFG, BT-Drs. 12/3211. 
licher, als die Erhaltung der stabilisierenden Wirkung der Winterbauförderung, die jetzt nach der Einführung des $\S 238$ Arbeitsförderungsgesetz (AFG) noch die Leistungen Wintergeld (WG), Schlechtwettergeld (SWG) und Beitragszuschüsse zur Rentenversicherung der SWG-Bezieher (RV-Beitragszuschüsse) umfaßt. Investitionskostenzuschuß (IKZ) und Mehrkostenzuschuß (MKZ) werden, wie bereits erwähnt, aufgrund dieser Rechtsvorschrift nicht mehr gewährt.

Faßt man die Beschreibung der geschichtlichen Entwicklung der Winterbauförderung im Verlauf der Jahrzehnte zusammen, so lassen sich unterschiedliche Schwerpunkte erkennen. In den 50er Jahren, als wegen des Fehlens spezieller gesetzlicher und tariflicher Regelungen jeden Winter mehrere hunderttausend Bauarbeiter arbeitslos wurden, begann die Diskussion um dieses folgenreiche Problem der Bauwirtschaft. Die Förderungsmaßnahmen der 60er und 70er Jahre sollten insbesondere durch die Schlechtwettergeldregelung das Problem der Winterarbeitslosigkeit weitgehend überwinden. Seit Anfang der 80er Jahre traten Überlegungen in den Vordergrund des Interesses, wie angesichts eines verringerten Baunachfragevolumens die Überkapazitäten am Bau abgebaut werden könnten. Schließlich mündete die geführte Diskussion in den geplanten Wegfall des Schlechtwettergeldes.

\subsubsection{Tarifvertragliche Leistungen und Regelungen}

Die oben beschriebenen gesetzlichen Regelungen zur Förderung der ganzjährigen Beschäftigung in der Bauwirtschaft und die hier zu behandelnden tariflichen Regelungen dieser Branche sind eng verzahnt. Dies wird durch die gesetzliche Forderung deutlich, wonach Arbeitnehmern in Betrieben des Baugewerbes bei witterungsbedingtem Arbeitsausfall in der Schlechtwetterzeit nur dann SWG gewährt werden darf, wenn

- das Arbeitsverhältnis in dieser Zeit aus Witterungsgründen nicht gekündigt werden kann und

- bei Arbeitsausfall unbeschadet des Anspruchs auf Urlaub eine Anwartschaft auf Lohnausgleich für einen zusammenhängenden Ausgleichszeitraum, der mindestens die Zeit vom 25. Dezember bis 1. Januar umfaßt, gewährleistet ist. ${ }^{264}$

264 vgl. §83 AFG. 
Die Reaktionen der Tarifpartner der Bauwirtschaft auf diese Forderungen des Gesetzgebers zeigten sich in den im Herbst 1959 getroffenen Tarifabschlüssen, in denen die Voraussetzungen für das Zweite Änderungsgesetz über Arbeitsvermittlung und Arbeitslosenversicherung geschaffen wurden. Dies sind im einzelnen:

\section{Bundesrahmentarifvertrag (BRTV):}

Der Bundesrahmentarifvertrag (BRTV) für das Baugewerbe vom 20. August 1959 legte fest, daß eine witterungsbedingte Kündigung des Arbeitsverhältnisses während der gesetzlichen Schlechtwetterzeit (1. November bis 31. März) mit sofortiger Wirkung nicht mehr zulässig sein sollte. ${ }^{265}$ Damit wurde der ersten gesetzlichen Forderung für die Voraussetzung des Bezuges von SWG entsprochen. Im Verlauf der Zeit wurden die tarifvertraglichen Regelungen zwar des öfteren geändert, blieben aber dem Sinn nach stets gleich.

\section{TV Lohnausgleich:}

Die zweite Voraussetzung des Gesetzgebers für den SWG-Bezug, nämlich einen Ausgleich furr den Lohnausfall im Zeitraum 25. Dezember bis 1. Januar zu schaffen, ${ }^{266}$ wurde durch den "Tarifvertrag zur Förderung der Aufrechterhaltung der Beschäftigungsverhältnisse im Baugewerbe während der Winterperiode (TV Lohnausgleich)" vom 20. August 1959 garantiert. Hiermit wurde anstelle der bislang geleisteten finanziellen Beihilfen, nunmehr für die Weihnachtswoche einschließlich des Neujahrstages (sog. Ausgleichszeitraum), ein Lohnausgleich gezahlt. ${ }^{267}$ Damit war auch die zweite Forderung des Gesetzgebers erfült.

Diesen Lohnausgleich, wie auch die anderen tarifvertraglich festgelegten Leistungen an Urlaub, Winterausgleichszahlung, Berufsbildungskostenerstattung und Zusatzversorgung erbringen die Sozialkassen des Baugewerbes ${ }^{268}$ als gemeinsame Einrichtung der Tarifvertragsparteien in der Bauwirtschaft (Tarifvertrag über das Sozialkassenverfahren im Baugewerbe und TV Lohnausgleich). Anspruch auf Lohnausgleich hat jeder Arbeitnehmer in Betrieben des Baugewerbes, wenn er so-

265 vgl. §12. Nr. 2 BRTV: Kündigungsausschluß.

266 Durch den Änderungs-TV vom 27. Januar 1975 wurde der Ausgleichszeitraum um einen Tag erweitert und beginnt ab der Leistungsperiode 1975/76 schon am 24. Dezember.

267 vgl. Geerling, C., Der neue Tarifvertrag zur Förderung der Aufrechterhaltung der Arbeitsverhăltnisse im Winter, S.855ff.

268 Dies sind die Urlaubs- und Lohnausgleichskasse der Bauwirtschaft (ULAK), die Gemeinnützige Urlaubskasse des Bayerischen Baugewerbes e.V. (UKB) und die Zusatzversorgungskasse des Baugewerbes (ZVK-Bau). 
wohl zu Beginn als auch am Ende des Ausgleichszeitraumes in einem Arbeitsverhältnis steht und im laufenden Kalenderjahr mehr als 13 Wochen gearbeitet hat. ${ }^{269}$ Schachtmeister und Poliere haben ebenso wie kaufmännische Angestellte und Lehrlinge keinen Anspruch auf Leistungen der Lohnausgleichskasse.

Die Höhe des Lohnausgleichs ergibt sich aus der dem TV Lohnausgleich anliegenden Lohnausgleich-Tabelle. Sie ist von der Höhe des durchschnittlichen Bruttostundenverdienstes abhängig und zwar von dem Bruttostundenverdienst den der Arbeitnehmer während des vor dem Ausgleichszeitraum liegenden letzten Lohnabrechnungszeitraumes, der mindestens 4 Wochen umfassen muß, erzielt hat. Im Gegensatz zum SWG und WG ist die Lohnausgleichspauschale als laufender Arbeitslohn zu behandeln und demzufolge lohnsteuerpflichtig.

Die Sozialkassenbeiträge werden von den Arbeitgebern mit einem monatlich abzuführenden Gesamtbetrag in Prozent von der Bruttolohnsumme der gewerblichen Arbeitnehmer des jeweiligen Betriebes (in den alten Bundesländern: 20\%, im Beitrittsgebiet: 14,9\% der Bruttolohnsumme, $\S \S 24,48$ VTV) getragen.

\subsubsection{Sonstige Maßnahmen}

Um der Vollständigkeit zu genügen, sollen noch auszugsweise einige Maßnahmen, ohne sie im Detail zu beschreiben, zur Förderung der ganzjährigen Beschäftigung in der Bauwirtschaft skizziert werden, die weder in die Kategorie der gesetzlichen noch in die der tariflichen Regelungen fallen. $\mathrm{Zu}$ nennen sind insbesondere einige Ausschüsse, die sich vor allem in den Jahren vor und kurz nach der Einführung des Zweiten Änderungsgesetzes zum AVAVG gebildet haben und sich mit der Winterbauproblematik befaßten. Im einzelnen sind dies: ${ }^{270}$

- Interministerieller Arbeitsausschuß Bauwirtschaft (IAB)

- Hauptausschuß "Bauen im Winter"

- Ausschuß "Kontinuierliches Bauen - Bauen im Winter"

- Baukoordinierungsausschüsse resp. Winterbauausschüsse

269 gemäß $\$ 3$ Nr. 2 TV-Lohnausgleich.

270 vgl. Bundesbaublatt, 4.Jg., Heft 11, 1955, S.546ff. und Bundesbaublatt, 8.Jg., Heft 9, 1959, S. 475ff. 
Obwohl diese Ausschüsse unterschiedliche Themenkomplexe untersuchten, so war doch ihre Zielsetzung, nämlich den gesetzgebenden Organen Informationsmaterial für die gesetzgeberische Arbeit zu liefern, meistens gleich. Eine weitere Gemeinsamkeit der Ausschüsse bestand in der Einbeziehung aller am Winterbau Beteiligten (wie z.B. Tarifvertragsparteien, Bundesressorts, Forschungsinstitute und Wohnungsbauverbände). Dadurch wurde gewährleistet, daß die Themen nicht einseitig, sondern aus verschiedenen Perspektiven betrachtet werden konnten.

Als eine entscheidende Aufgabe der Ausschüsse wurde die Verlagerung von Bauaufträgen in die witterungsungünstige Jahreszeit angesehen. ${ }^{271} \mathrm{Im}$ Zusammenhang damit trat ein weiteres Problem, nämlich das der gleichmäßigen Vergabe der Bauaufträge während des Kalenderjahres, hervor. Zur Bekämpfung von Überhitzungserscheinungen standen den Ausschüssen jedoch keine exekutiven Befugnisse zu, so daß sie auf den guten Willen und die freiwillige Mitarbeit der Beteiligten angewiesen waren. Dies hatte zur Folge, daß die Verbesserung der Auftragsvergabe bereits in der Winterbaudebatte des Deutschen Bundestages vom 27. November $1958 \mathrm{zu}$ einem einstimmigen Entschluß aller Fraktionen führte, in dem der Bundestag die Bundesregierung ersuchte, "auf Länder und Gemeinden dahingehend einzuwirken, daß entsprechend der Praxis im öffentlich geförderten Wohnungsbau auch die von Ländern und Gemeinden zum Einsatz gelangenden Mittel im Hoch- und Tiefbau so rechtzeitig bereitgestellt werden, daß eine kontinuierliche Planung und Bautätigkeit gefördert wird." 272 Bezugnehmend auf dieses Ersuchen des Bundestages legte die Bundesregierung in ihrem am 29. Juni 1959 veröffentlichten Bericht ein Aktionsprogramm vor, das im wesentlichen aus den folgenden Punkten bestand:273

\section{- Zusammenlegung von Haushalts- und Kalenderjahr ${ }^{274}$}

Diese immer wieder gestellte Forderung der Tarifvertragsparteien wurde von der Bundesregierung erstmals für das Jahr 1961 beschlossen. Auf diese Weise sollte die Voraussetzung für eine frühzeitige Vergabe der Baugelder und damit zugleich für eine geordnete Bauplanung geschaffen werden. ${ }^{275}$

\footnotetext{
271 vgl. insbesondere die sog. Koordinierungsausschüsse.

272 Deutscher Bundestag, 3. Wahlperiode, Stenographischer Bericht der 51. Sitzung vom 27. November 1958, Anlage 3 (Umdruck 189), S.2877.

273 vgl. BT-Drucks. III/1211, S.7f.

274 Anmerkung: Ursprünglich begann das Haushaltsjahr am 1. April und endete mit dem 31. Mărz.
} 


\section{- Antizyklische Auftragsvergabe der öffentlichen Bautätigkeit}

Noch vor Inkraftreten des Zweiten Änderungsgesetzes zum AVAVG wurden die Vertreter aller öffentlichen Bauträger im Oktober 1959 zu einer Aussprache über das Thema Winterbau nach Bonn eingeladen. Das Ergebnis dieser Diskussion - verbunden mit dem Kabinettsbeschluß vom 9. März 1960 - waren die Forderungen, einerseits Bauauftäge antizyklisch zu vergeben und andererseits öffentliche Haushaltsmittel so einzusetzen, daß $30 \%$ der öffentlichen Bauausführung in den Monaten November bis März erfolgte. ${ }^{276}$

\section{- MaBnahmen zur Verbesserung der Verhältnisse auf dem Baumarkt}

Dieser Beschluß vom 8. November 1962, der am 24. April 1963 neugefaßt und ergänzt wurde, befaßte sich großenteils mit der Förderung der kontinuierlichen Bautätigkeit. Voraussetzung sollte die Aufstellung mehrjähriger öffentlicher Bauprogramme sein, die von den jeweiligen Bundesressorts für ihre Bereiche für die folgenden beiden Jahre aufgestellt und bei den Haushaltsvoranschlägen berücksichtigt werden sollten.

Der Verwirklichung dieser Programmpunkte kommt insofern eine erhebliche Bedeutung zu, weil die öffentliche Hand am gesamten Bauvolumen maßgeblich beteiligt ist. ${ }^{277}$ Aus dieser Tatsache läßt sich ableiten, daß eine Realisierung der oben beschriebenen Punkte die kontinuierliche Bautätigkeit entscheidend fördern könnte. $\mathrm{Zu}$ den Bemühungen, das Problem der Förderung der ganzjährigen Beschäftigung in der Bauwirtschaft auf internationaler Ebene zu lösen, läßt sich feststellen, daß schon frühzeitig eine Reihe von Initiativen ergriffen wurden. Hierbei handelte es sich primär um die Erarbeitung und Veröffentlichung von allgemeinen Richtlinien zum Winterbau. ${ }^{278} \mathrm{Da}$ die Aktivitäten all dieser Gremien aber über unverbindliche Vorschläge nicht hinausgingen, soll eine ausführliche Darstellung hier unterbleiben.

275 vgl. Gesetz zur Anpassung des Rechnungsjahres an das Kalenderjahr vom 29. Dezember 1959, BGBl. I, S.832.

276 vgl. BT-Drucks. IV/643, S.8.

277 vgl. Ifo-Institut für Wirtschaftsforschung, Bauwirtschaft und öffentliche Hand - Partner am Baumarkt, S.29 und von Monschaw, B., Perspektiven für das deutsche Baugewerbe, Teil 1 : Bauwirtschaft im Rahmen der Gesamtwirtschaft, S.35 und auch Abbildung 8, S.43.

278 vgl. Internationale Arbeitsorganisation, Entschließung Nr. 26 über die Verringerung der jahreszeitlich bedingten Arbeitslosigkeit im Baugewerbe. 
Die vielfachen psychologischen Hemmnisse bei Unternehmern, Arbeitnehmern und Bauherren, die einer Ausdehnung der Bautätigkeit im Winter entgegenstehen, wurden bereits erwähnt. ${ }^{279}$ Im Rahmen dieser Arbeit soll jedoch der Schwerpunkt auf der Bewertung der dargestellten gesetzlichen und tariflichen Regelungen liegen, weil diese größtenteils objektiv quantifizierbar und somit hinsichtlich wirtschafts- und sozialpolitischer Wirksamkeit analysierbar sind.

\subsection{Vorstellungen der Beteiligten von den Förderungsmaßnahmen zur ganzjährigen Beschäftigung}

Nach der aufgezeigten geschichtlichen Entwicklung ist es die Aufgabe dieses Kapitels, die Zielvorstellungen der Beteiligten ${ }^{280}$ von einer "Ganzjährigen Beschäftigung in der Bauwirtschaft" darzustellen. Aufgrund unterschiedlicher Interessenvertretungen - insbesondere bei den Tarifpartnern - kann es nicht verwundern, daß die Vorstellungen bezüglich notwendiger Förderungsmaßnahmen teilweise stark differieren. Welche Zielvorstellungen im einzelnen von den Beteiligten wann und mit welchen Begründungen verfolgt wurden, versuchen die folgenden Ausführungen zu verdeutlichen. Hierbei kommt es dem Verfasser vor allem darauf an, die im Zeitablauf gesetzten Schwerpunkte in der Förderung aufzuzeigen, um die getroffenen Maßnahmen im Rahmen der Wirkungsanalyse entsprechend beurteilen zu können.

\subsubsection{Ziele des Gesetzgebers}

$\mathrm{Zu}$ Anfang werden die Zielvorstellungen des Gesetzgebers aufgezeigt, die den weitaus größten Teil der in Kapitel 2.3. beschriebenen Förderungsmaßnahmen für sich beanspruchen. Die Vermutung, daß sich in den jetzt rund 30 Jahren, in denen die ganzjährige Beschäftigung in der Bauwirtschaft auf gesetzlicher Grundlage gefördert wurde, die Förderungsprioritäten durchaus gewandelt haben und neue hinzugetreten sind, wird insbesondere durch die im zeitlichen Abriß beschriebenen Gesetzesänderungen bekräftigt. Daher ist aufzuzeigen, von welchen Zielvorstellungen man bei Einführung des AVAVG ausging; warum das AVAVG durch das AFG ersetzt wurde, dem schon

279 vgl. hierzu Kap. 1.3. Problemstellung, S.30 und Kap. 2.2.2.1. Marktbedingte Saisonschwankungen, S.54-56.

280 Hinweis: Beteiligte sind hier die Tarifvertragsparteien, d.h. die Arbeitgeberverbände des Baugewerbes und die IG Bau-Steine-Erden, sowie der Gesetzgeber (Bundesregierung). 
bald die Winterbaunovelle folgte und welche Gründe schließlich zur Aussetzung der Förderung von IKZ und MKZ führten.

\subsubsection{AVAVG}

Insbesondere die Arbeitslosenversicherung im Baugewerbe ${ }^{281}$ war immer wieder Gegenstand kritischer Diskussionen. So forderte der damalige Bundesminister für Arbeit, Anton Storch, diesbezüglich eine Neuregelung mit folgenden Zielen:282

- Sozialpolitisch: Stabilisierung der Beschäftigung und wirtschaftliche Absicherung der Bauarbeiter bei Arbeitsausfall.

- Arbeitsmarktpolitisch: Eindämmung der Abwanderungstendenzen und damit Sicherung des Arbeitskräftebedarfs in der Bauwirtschaft sowie Eindämmung der Abneigung gegen die Bauberufe beim Nachwuchs durch stabilere Beschäftigung und regelmäßigeres Einkommen.

- Wirtschaftspolitisch: Steigerung der Baukapazität und gleichmäßigere Beschäftigung bei den Baustoff- und Zulieferungsindustrien durch bessere Ausnutzung der technisch möglichen Bauzeit.

Wie die Ausführungen des Bundesministers für Arbeit zeigen, sollte eine Änderung bzw. Ergänzung des AVAVG nicht etwa nur auf eine Beseitigung der saisonalen Arbeitslosigkeit ausgerichtet sein. ${ }^{283}$ Diese Ansichten spiegeln sich auch im Bericht der

281 Hinweis: Wie bereits erwähnt, hatten die Arbeitnehmer des Baugewerbes vor Inkraftureten des AVAVG keinen Lohnanspruch, wenn die Arbeit infolge ungünstiger Witterung ausfiel und das Arbeitsverhältnis fortbestand, vgl. hierzu auch Kap. 2.4.1.2. Das zweite Änderungsgesetz zum AVAVG, S.67ff.

282 vgl. auch Weddigen, W., Die Behandlung der saisonalen Arbeitslosigkeit im Rahmen des Versicherungsschutzes gegen Arbeitslosigkeit, Sozialpolitische Schriften, Heft 8, Berlin 1957, S.82.

283 Anmerkung: Obwohl der 4.Abschnitt des AVAVG, der die Winterbauförderungsmaßnahmen beinhaltet (§§143a-n), mit "Maßnahmen zur Verhütung und Beendigung der Arbeitslosigkeit" überschrieben ist, darf hier nicht - wie verschiedene Autoren dies tun - darauf geschlossen werden, daß es dem Gesetzgeber lediglich auf die Vermeidung von Saisonarbeitslosigkeit ankam und er alle anderen Aspekte außer acht ließ, vgl. hierzu beispielsweise Gerland, E., Die sozialen, volkswirtschaftlichen und betriebswirtschaftlichen Auswirkungen der gesetzlichen Schlechtwetter-Regelung im Baugewerbe, Diss. Frankfurt,Main, S.13. 
Bundesregierung über die Möglichkeiten zur Verbesserung der Verhältnisse in der Bauwirtschaft wieder, in dem es heißt: ${ }^{284}$

"Die Bundesregierung bekennt sich aus volkswirtschaftichen und sozialpolitischen Gründen zum Gedanken der kontinuierlichen Beschäftigung in der Bauwirtschaft und ist gewillt, alle ihr zu Gebote stehenden Möglichkeiten zur Verwirklichung dieses Gedankens zu nutzen. Ganzjahresbau und Winterbau bedeuten eine Abkehr von der bisherigen Übung im Bauwesen. Die Bemühungen der Bundesregierung sind darauf gerichtet, sofort einen nachhaltigen Einbruch in die bisherigen Gewohnheiten zu erzielen und eine kontinuierliche Bautätigkeit zu verwirklichen." 285

Inwieweit der Gesetzgeber aber tatsächlich volkswirtschaftliche Zielsetzungen hatte, läßt sich insbesondere durch die folgenden Aussagen in Zweifel stellen:

- "...zu keiner Zeit der Bemühungen um die ganzjährige Beschäftigung in der Bauwirtschaft war daran gedacht, daß Jahresbauvolumen auszuweiten. "286

- "...man könnte mit der vorhandenen Kapazität, die auf die Jahresspitze im Sommer abgestellt ist, bei Beschäftigung durch das ganze Jahr hindurch ein wesentlich höheres Bauvolumen bewältigen. "287

- "...das Bauvolumen könnte bei gleichmäßigerer Verteilung der Bauarbeiten über das Jahr mit einer wesentlich geringeren Kapazität bewältigt werden. "288

- "..winterliche Bautätigkeit als Möglichkeit zur Steigerung des Sozialproduktes"289

- "...Steigerung des Bauvolumens ist konjunkturpolitisch von großer Bedeutung. "290

284 vgl. BT-Drucks. III/1211, S.2.

285 Anmerkung: Dieses Zitat unterstützt die These, daß der Gesetzgeber den Beschäftigungsbegriff nicht nur sozialpolitisch verstand, sondern die Produktionsseite durchaus mit einbeziehen wollte, vgl. auch Kap. 1.1.1. Ganzjährige Beschäftigung, S.3ff.

286 Äußerung des Referenten für Winterbaufragen im Bundesministerium für Arbeit und Sozialordnung, Kranz, G., Die Auswirkungen der Maßnahmen zur Förderung des Winterbaues, in: Bundesarbeitsblatt, 11.Jg., Nr.8, 1960, S.276ff.

287 Begründung Georg Lebers (SPD) zur Verbesserung der Verhältnisse in der Bauwirtschaft; vgl. Deutscher Bundestag, 3. Wahlperiode, Stenographischer Bericht der 51. Sitzung vom 27. November 1958, S.2838.

288 Aussage Georg Lebers (SPD); vgl. Deutscher Bundestag, 3. Wahlperiode, Stenographischer Bericht der 51. Sitzung vom 27. November 1958, S.2838.

289 Auffasung des Abgeordneten Weimer (CDU/CSU); vgl. Deutscher Bundestag, 3. Wahlperiode, Stenographischer Bericht der 51. Sitzung vom 27. November 1958, S.2862.

290 Auffasung des Abgeordneten Deist (SPD); vgl. Deutscher Bundestag, 3. Wahlperiode, Stenographischer Bericht der 51. Sitzung vom 27. November 1958, S.2858. 
Die hier aufgefuhrten Zitate belegen die Meinungsvielfalt sowohl bei Vertretern der Regierung als auch bei denen der Opposition. Unbestritten ist allerdings die Tatsache, daß die Ausweitung des Jahresbauvolumens zum damaligen Zeitpunkt kein Hauptzweck des Winterbaues darstellen sollte. Vielmehr ging es im wesentlichen darum, die "...anomale Situation auf dem Baumarkt - mit Überzeitarbeit im Sommer und Arbeitsruhe im Winter - zu beseitigen und durch eine gleichmäßige Bautätigkeit zu ersetzen." 291

Diese Aussage findet sich auch in ähnlicher Form im Bericht des Ausschusses für Arbeit zum Gesetzentwurf über Maßnahmen zur Förderung der ganzjährigen Beschäftigung in der Bauwirtschaft. Dort heißt es: "Das Kernstück dieses Gesetzentwurfs ist darauf gerichtet, den Saisoncharakter des Baugewerbes zu überwinden und wichtige Voraussetzungen zu schaffen, die geeignet sind, eine ganzjährige, ausgeglichene Vollbeschäftigung der Bauwirtschaft zu erreichen."292 Mit den Worten der Präsidenten der BAVAV, Anton Sabel, ergeben sich die folgenden Zielvorstellungen:293

- Verstärkung der winterlichen Bautätigkeit, um Überhitzungserscheinungen auf dem Baumarkt während der Sommermonate zu vermeiden.

- Stabilisierung der Arbeitsverhältnisse im Baugewerbe bei gleichzeitiger Verringerung der Fluktuation der Arbeitskräfte.

- Verbesserung der Relation zwischen den Beitragszahlungen der Bauwirtschaft an die Bundesanstalt und deren Leistungen. ${ }^{294}$

Bezüglich der Rangfolge läßt sich nach Aussage des damaligen Bundesarbeitsministers Katzer feststellen, daß die in das Gesetz über Arbeitsvermittlung und Arbeitslosenversicherung eingefügten Vorschriften, über die Förderung der ganzjährigen Be-

291 vgl. hierzu BT-Drucks. III/1211, S.3 und BT-Drucks. IIU/1240, S. 10: "Die Bundesregierung hat mehrmals darauf hingewiesen, daß die in der Bauwirtschaft in besonderem Maße festzustellende Ableistung von Überzeitarbeit in den Sommermonaten wegen der schädlichen Auswirkungen für den einzelnen Bauarbeiter selbst wie aber auch für die Gesamtlage der Bauwirtschaft eingeschränkt werden muß."

292 vgl. Deutscher Bundestag, 3. Wahlperiode, Drucksache 1294. Schriftlicher Bericht des Ausschusses für Arbeit über den von der Bundesregierung eingebrachten Entwurf eines Gesetzes über Maßnahmen zur Förderung der ganzjährigen Beschäftigung in der Bauwirtschaft und Zweites Ändenungsgesetz zum AVAVG, vom 16. Oktober 1959, S.1.

293 vgl. Sabel, A., Reformwünsche zur Arbeitslosenversicherung, in: Arbeit und Sozialpolitik, 18. Jg., Nr.3, 1964, S.67ff. und BT-Drucks. IIV/1240, S.10.

294 vgl. Bulletin des Presse- und Informationsamtes der Bundesregierung, Schlechtwettergeld, Bonn, den 23. Juni 1959, Nr.109, S.1103. 
schäftigung in der Bauwirtschaft, in erster Linie sozial- und arbeitsmarktpolitische Zwecke verfolgten. ${ }^{295}$

\subsubsection{AFG}

In der regierungsamtlichen Begründung zum Entwurf des AFG wird die Forderung erhoben, daß "...die Bundesanstalt in Zukunft erheblich stärker als bisher zu Vollbeschäftigung und wirtschaftlichem Wachstum beitragen kann."296 Vor diesem Hintergrund, ist insbesondere §1 AFG zu sehen, der ausdrücklich drei Ziele nennt, die mit Hilfe dieses Gesetzes erreicht werden sollen:

- Erreichung und Aufrechterhaltung eines hohen Beschäftigungsstandes

- Verbesserung der Beschäftigtenstruktur

- Förderung des Wirtschaftswachstums

Ähnlich äußert sich auch Erwin Schönfelder, der in einem Vergleich von AFG zu AVAVG feststellt, daß der "... 1 AFG in seiner Auswirkung weit über den bisherigen $\S 38$ AVAVG hinausgeht. Er beinhaltet den Übergang von bloßer Arbeitsmarktpolitik $\mathrm{zu}$ umfassender Beschäftigungspolitik mit weit gesteckten wirtschafts-, berufs- und gesellschaftspolitischen Zielen." 297

Welche neue Zielsetzung bezüglich der Winterbauförderung mit Einführung des Arbeitsförderungsgesetzes verfolgt wurde, zeigt u.a. ein Aufsatz des damaligen Fachreferenten für Winterbaufragen im Bundesministerium für Arbeit und Sozialordnung Günter Kranz. Er forderte eine wertschaffende Winterbauförderung mit der Begründung, daß in jedem Winter durchschnittlich 30 Millionen Tagewerke ausfielen, die es zusätzlich zum normalen Produktionsvolumen mit Arbeit auszufüllen gelte. ${ }^{298}$ In diesem Zusammenhang, ist das o.g. Ziel des §1 AFG "Förderung des Wirtschaftswachstums" - soweit es sich auf die Winterbauforderung bezieht - zu .interpretieren, als

295 vgl. hierzu Deutscher Bundestag, 5. Wahlperiode, Stenographischer Bericht der 14. Sitzung vom 13. Januar 1966, S.529ff.

296 vgl. BT-Drucks. V/2291, S.53.

297 vgl. Schönfelder, E., Das Arbeitsforderungsgesetz - Instrument der Beschăftigungspolitik, in: Arbeit, Beruf und Arbeitslosenhilfe, 20.Jg., Heft 6, 1969, S.157ff.

298 vgl. Kranz, G., Der Winterbau im Widerstreit der Meinungen, in: Arbeit, Beruf und Arbeitslosenhilfe, 15.Jg., Heft 12, 1964, S.281ff. 
"Steigerung des Sozialproduktes mittels Ausweitung des Jahresbauvolumens. Neben diesem wirtschaftspolitischen Ziel steht die sozialpolitische Zielsetzung, Arbeitslosigkeit zu vermeiden." 299

Ihre eindeutige Fixierung findet diese wirtschaftspolitische Zielsetzung schließlich in der sogenannten Produktiven Winterbauförderung (PWF) der $§ \S 82-87$ AFG, die schon durch ihren Titel keinen Zweifel am Förderungsschwerpunkt aufkommen läßt. Im Vergleich zum AVAVG haben insbesondere der Förderungsumfang und -ansatz eine grundsätzlich neuartige Form. ${ }^{300}$ In der Bundestagsdrucksache V/2291 heißt es sogar, die PWF sei "ausschließlich produktionsorientiert". 301

Ein weiterer Unterschied in der Zielsetzung beider Gesetze zeigt sich darin, daß der Gedanke, präventiv tätig zu werden, im AFG stärker in den Vordergrund tritt. ${ }^{302}$ Dieser Gedanke wird auch durch die Änderungen der eher passiven Bezeichnungen von "Gesetz über Arbeitsvermittlung und Arbeitslosenversicherung" und "Bundesanstalt für Arbeitsvermittlung und Arbeitslosenversicherung" in die aktiveren Titel "Arbeitsförderungsgesetz" bzw. "Bundesanstalt für Arbeit" vermittelt. ${ }^{303}$ Zusammenfassend läßt sich daher festhalten, daß das AFG - im Gegensatz zum sozialpolitischen Charakter des AVAVG - wie die Ausführungen gezeigt haben, den wirtschaftspolitischen Zielsetzungen Vorrang einräumt.

\subsubsection{Winterbaunovelle}

Das AFG von 1969 änderte zwar einiges an den Vorschriften über die Förderung der ganzjährigen Beschäftigung in der Bauwirtschaft, behielt aber im wesentlichen das konsumtiv orientierte, versicherungsrechtliche System des alten AVAVG bei. Die

299 vgl. Schmidt, R., Neue Vorschriften über die Winterbauförderung, in: Bundesarbeitsblatt, 20.Jg., Nr.6, 1969, S.346ff.

300 Hinweis: Bezüglich des Förderungsumfanges werden im AFG alle Bauten und nicht mehr nur der öffentlich soziale Wohnungsbau gefördert. Bezüglich des Förderungsansatzes werden jetzt durch Mehrkostenzuschüsse (MKZ) erstmalig produktionsorientierte Anreize gegeben, vgl. auch Kap. 2.4.1.3. 1969.71: Das Arbeitsförderungsgesetz, S.70ff.

301 vgl. BT-Drucks. V/2291, S.60.

302 vgl. o.V., Vollbeschäftigung durch Arbeitsförderung sichern helfen, in: Sozialpolitische Information, 1.Jg., Nr.5, 1967, S.1ff.:"Arbeitslosigkeit verhindern helfen und nicht erst tătig zu werden, wenn die Arbeitslosigkeit bereits eingetreten ist."

303 vgl. Schmidt, F., Wandlung der deutschen Arbeitslosenversicherung?, in: Arbeit, Beruf und Arbeitslosenhilfe, 19.Jg., Heft 2, 1968, S.37ff. 
hohe Anzahl witterungsbedingter Arbeitsausfalle in den folgenden Wintern (1969/70: 51,7 Mio. angezeigte Ausfalltagewerke und 1970/71: 31,8 Mio. angezeigte Ausfalltagewerke) sowie die über die Milliardengrenze hochschnellenden Ausgaben der BA für das Schlechtwettergeld ${ }^{304}$ - das nur der Bauwirtschaft zugute kommt, aber von allen Beitragspflichtigen aufgebracht wird - gaben schließlich die Impulse für ein erneutes Umdenken in der Förderung. ${ }^{305}$

Nach nur drei Jahren kündigte sich mit dem Gesetzesentwurf über "Maßnahmen zur Verbesserung des Mietrechts und der Begrenzung des Mietanstiegs" die sogenannte Winterbaunovelle an, mit der die folgenden Ziele verwirklicht werden sollten: ${ }^{306}$

- Steigerung der winterlichen Bauproduktion und dadurch gleichmäßigere Verteilung der Bautätigkeit.

- Preisdämpfende Wirkungen auf dem Baumarkt durch Ausweitung des Angebots an Bauleistungen.

- Sicherung des vollen Jahreslohns für die Arbeitnehmer des Baugewerbes.

- Sicherung der vollen Ausnutzung der Investitionsgüter für die Arbeitgeber des Baugewerbes.

Diese bereits bekannten wirtschafts- und sozialpolitischen sowie betriebswirtschaftlichen Zielsetzungen, finden sich auch in einigen Bundestagsdrucksachen - wenn auch in abgeschwächter Form ${ }^{307}$ - zur Novellierung des AFG. Dort heißt es beispielsweise:

- "...die Attraktivität der Bauberufe muß angehoben werden, um Abwanderungen und Nachwuchsmangel zu vermeiden." ${ }^{308}$

- "...eine Steigerung der Bauproduktion im Winter, eine gleichmäßigere Verteilung der Bautätigkeit auf das ganze Jahr, eine stärkere Ausnutzung der Baukapazitäten

304 Insgeamt mehr als 2 Mrd. DM (1969/70: 1,229 Mrd. DM und 1970/71: 817,7 Mio. DM) für die Schlechtwetterzeiten 1969/70 und 1970/71.

305 vgl. "Bericht über die Förderung der ganzjährigen Beschäftigung in der Bauwirtschaft (Winterbauförderung) nach dem Arbeitsförderungsgesetz, in: Schreiben des Bundesministers fuir Arbeit und Sozialordnung, Dr. Norbert Blüm, an den Vorsitzenden des Bundestags-Ausschusses für Raumordnung, Bauwesen und Städtebau, Werner Dörflinger, vom 12.Juni 1992, S.2.

306 vgl. Deutscher Bundestag, 6. Wahlperiode, Drucksache VI/1549, Entwurf eines Gesetzes über Maßnahmen zur Verbesserung des Mietrechts und der Begrenzung des Mietanstiegs, vom 4. Dezember 1970.

307 Anmerkung: So wird beispielsweise auf die absolute Formulierung "voll" verzichtet.

308 vgl. BT-Drucks. VI/2689, S.9. 
in den Wintermonaten und zugleich eine Verbesserung der arbeits- und sozialrechtlichen Lage der Bauarbeiter." ${ }^{309}$

- "...aus finanzpolitischer Sicht ist ein Zuwachs an Steuern und Beiträgen für die Träger der Sozialversicherung sowie Einsparungen an Arbeitslosen- und Schlechtwettergeld zu erwarten." 310

- "...in erster Linie wird auf die Erhaltung der witterungsabhängigen Arbeitsplätze der Bauarbeiter im Winter abgezielt. Die Förderung soll mit marktkonformen Mitteln dahin wirken, daß Bauarbeiter und Baustellen vor den nachteiligen Folgen des Winterwetters ausreichend geschützt werden, um die Bauarbeiten bei zumutbaren Bedingungen ohne nennenswerte Unterbrechungen fortführen zu können." 311

Hier stellt sich die Frage, was den Gesetzgeber letztendlich veranlaßt hat, nach nur drei Jahren Produktiver Winterbauförderung des AFG, diese durch die neue Winterbaunovelle zu ersetzen. Die Vermutung liegt nahe, daß insbesondere die bereits erwähnte hohe Zahl witterungsbedingter Arbeitsausfalle in den Wintern 1969/70 und 1970/71, verbunden mit den entsprechenden Ausgaben der BA für das SWG, Zweifel in der Effizienz der Förderung aufkommen ließen. ${ }^{312}$ Ähnlich äußert sich auch Horst Röthig, der den Schwerpunkt der Förderung in der Produktivität und nicht im unproduktiven SWG sieht. ${ }^{313}$ Diese Auffassung wird durch die gesetzlichen Vorschriften der "Winterbaunovelle" unterstützt. So sind beispielsweise die Paragraphen der Produktiven Winterbauförderung ( $§ \S 77-82$ ) nun vor die der SWG-Regelung ( $\S \S 83-89$ ) gerückt und der produktive Förderungsumfang wurde, insbesondere durch die Förderung von geleisteten Arbeitstunden, nochmalig wesentlich erweitert. ${ }^{314}$ Daher soll diese Gesetzesänderung als Weiterentwicklung der wirtschaftspolitischen Zielsetzung des AFG verstanden werden.

309 vgl. BT-Drucks. VI/3261, S.2, eine entsprechende "Kurzfassung" der Zielsetzung findet sich in $\$ 74$ Abs. 1 AFG.

310 vgl. Deutscher Bundestag, 6.Wahlperiode, Stenographischer Bericht der 180. Sitzung vom 12. April 1972, S.10456ff.

311 vgl. BT-Drucks. 7/1623, S.1.

312 vgl. Schmidt, R., Die Förderung der ganzjährigen Beschäftigung in der Bauwirtschaft - eine Hilfe der Arbeitsförderung für Bauarbeiter, S.305.

313 vgl. Röthig, H., Winterbau auf neuen Wegen, S.20ff.

314 Einfuihrung des Wintergeldes von 2,- DM für jede in der Förderungszeit geleistete Arbeitsstunde, vgl. auch Kap. 2.4.1.4. 1972-85: Die Winteraunovelle, S.71ff. 


\subsubsection{IKZ und MKZ}

Ausgangspunkt dieser neuerlichen Gesetzesänderung war die dramatische Baurezession Anfang der 80er Jahre, die mit ihrer katastrophalen Auftragslage zwangsläufig zu einer Beschäftigungskrise führte. ${ }^{315}$ Die schlagartig sichtbar gemachten Überkapazitäten hatten einen Verlust von 330.000 Arbeitsplätzen in der bauausführenden Wirtschaft zur Folge. ${ }^{316}$ In dieser Phase wurde jegliche staatliche oder kollektive Förderung des Winterbaues kritischer betrachtet als früher. Die ganzjährige Auslastung der Baukapazitäten schien nicht mehr so wichtig zu sein, wie dies noch in den 70er Jahren der Fall war. ${ }^{317}$ So heißt es beispielweise in einem Artikel in der "Bauwirtschaft": "Nicht mehr die Winterbauförderung ist das Ziel, sondern wirtschaftliche Fragen ..... an erster Stelle muß das genaue Kalkulieren von Mehr- und Minderkosten stehen, die bei der Durchführung von Baumaßnahmen im Winter entstehen." ${ }^{318}$

Initiator dieser Gesetzesänderung waren die Verbände der Bauwirtschaft, die die Folgen des tiefgreifenden strukturellen Anpassungsprozesses ihres Wirtschaftszweiges vermindern wollten und zumindest für eine befristete Zeit finanzielle Entlastungen suchten. Hierbei sollte der sozial- und gesellschaftspolitische Status des Bauarbeiters, d.h. der Lohnkostensektor, möglichst nicht verändert werden. Aufgrund der Tatsache, $\mathrm{da} ß$ insbesondere die Lohnnebenkosten in den vergangenen Jahren ständig gestiegen waren, wurden deren Einzelkosten näher analysiert. Die Berechnungen der Bauverbände kamen schließlich zu dem Ergebnis, daß das Aussetzen von Teilen der Produktiven Winterbauförderung, nämlich des IKZ und des MKZ für eine gewisse Zeit, zur Senkung der Winterbau-Umlage von 3,0\% um 0,9\% auf 2,1\% der Bruttolohnsumme und damit zur Minderung der Lohnnebenkosten der Baubetriebe führen würde. Dadurch wäre es möglich, den Betrieben des Bauhauptgewerbes eine jährliche Entlastung von über 200 Mio. DM zu verschaffen. ${ }^{319}$

315 vgl. o.V., Winterbau - eine Frage der Wirtschaftlichkeit, S.1323, in: Bauwirtschaft, Heft 37, 11. September 1986.

316 vgl. auch Abbildung 2, S.18.

317 vgl. auch Kap. 2.5.1.3. Winterbaunovelle, S.84ff.

318 vgl. o.V., Winterbau - eine Frage der Wirtschaftlichkeit, S.1323, in: Bauwirtschaft, Heft 37, 11. September 1986.

319 vgl. Röthig, H., Frostige Zeiten für den Winterbau, in: Baumarkt, Heft 12, 1986, S.634. 
Auch die Bundesregierung sah die Notwendigkeit, die Bauwirtschaft zumindest für einen gewissen Zeitraum finanziell zu entlasten, daher wurde der Gedanke der zeitweiligen und partiellen Unterbrechung der Produktiven Winterbauförderung aufgegriffen und der $\S 238$ in das AFG eingefuigt. ${ }^{320}$

Die Verlängerungen der "Förderungspause" erfolgten zum einen mit Rücksicht auf die Lage der Baubetriebe in den neuen Bundesländern, ${ }^{321}$ zum anderen soll sie den Verbänden der Bauwirtschaft Gelegenheit geben, tarifvertraglich ein Arbeitsentgelt (Winterlohn) für witterungsbedingte Ausfallstunden zu vereinbaren. Hierdurch würde das Witterungsrisiko gemäß $§ 616$ BGB arbeitsrechtlich den Arbeitgebern zugeordnet und ein ganzjährig gesichertes Einkommen der Bauarbeiter erzielt werden. ${ }^{322}$ Es bleibt festzuhalten, daß im Vordergrund der Aussetzung von IKZ und MKZ eindeutig wirtschaftliche Kriterien eine Rolle gespielt haben.

\subsubsection{Ziele der Arbeitgeber}

Die Vorstellungen der Arbeitgeberverbände der Bauwirtschaft, ${ }^{323}$ bezüglich der Förderung der ganzjährigen Beschäftigung, haben schwerpunktmäßig wirtschaftspolitische und betriebswirtschaftliche Zielsetzungen zum Inhalt. Insbesondere sollen die winterlichen Kapazitätsreserven mobilisiert werden, ${ }^{324}$ "...denn das Ziel des Winterbaues sei die Produktion." 325 Darüber hinaus erhofft man sich vor allem Auswirkungen betrieblicher Art, wie eine Stellungnahme des Haupverbandes der Deutschen Bauindustrie aus dem Jahr 1961 zeigt: $^{326}$

320 Der Gesetzgeber sah diese Regelung zur Flankierung einer notwendigen Strukturbereinigung im Baugewerbe als erforderlich an, vgl. BT-Drs.10/5771, S.26 zu Art.12.

321 Anmerkung: Der Umlagesatz müßte andernfalls auf über 3\% der Bruttolohnsumme heraufgesetzt werden.

322 vgl. Schmidt, R., Die Förderung der ganzjährigen Beschăftigung in der Bauwirtschaft - eine Hilfe der Arbeitsförderung für Bauarbeiter, S.307.

323 Hauptverband der Deutschen Bauindustrie und Zentralverband des Deutschen Baugewerbes.

324 vgl. Schleicher, E., Der Winterbau und der Bauunternehmer, in: Das Baugewerbe, 45.Jg., Nr.5, 1965, S.272.

325 Stellungnahme des Hauptverbandes der Deutschen Bauindustrie, Winterbau-Vorsorge im Für und Wider, in: Bau und Bauindustrie, 17.Jg., Nr.2, 1964, S.36.

326 Hauptverband der Deutschen Bauindustrie (Hrsg.), Zur marktkonformen Gestaltung des Baumarktes. 32 Vorschläge der Bauindustrie, Frankfurt/Main 1961, S.20. 
- gleichmäßige Auslastung der Produktionsmittel und Abbau der fixen Kosten.

- Verringerung der Personalkosten, denn auch in bauschwachen Monaten können es sich die Unternehmen nicht leisten, hochwertige Spezialisten zu entlassen.

- Steigerung des Umsatzes und Gewinns als Resultat der genannten Ziele.

Die weitere Entwicklung der Zielvorstellungen der Arbeitgeber zeigen einige, im Zeitablauf chronologisch aufgefürte Zitate, die die oben gemachte Aussage im wesentlichen unterstützen:

- "...der Erfolg im Hinblick auf eine kontinuierliche Beschäftigung auch in den Wintermonaten ist sehr gering geblieben. Von einem wirtschaftlichen Erfolg, also von einer gegenüber den früheren Jahren im Winter erzielten Mehrleistung an Bauarbeiten, kann kaum die Rede sein. Dabei ist die technische Seite praktisch gelöst." 327

- "...Gewinnung qualifizierten Nachwuchses (schwankende Arbeits- und Einkommensverhältnisse halten viele davon $a b$, den Bauberuf zu wählen) und die Verhinderung von Abwanderungen der Bauarbeiter in stationäre Wirtschaftszweige durch Verbesserung der Attraktivität der Bauberufe." 328

- "...bei der Überlegung: Winterbau oder nicht, ist die Kostenfrage meist bestimmend für die Entscheidung. Sie fällt heute noch überwiegend gegen den Ganzjahresbau aus." 329

- "...erweist sich für viele Betriebe der Bauwirtschaft als besonders negativ, daß sie die gesamte vorgehaltene Betriebsbereitschaft nicht kontinuierlich auslasten können. Diese Betriebsbereitschaft besteht aus dem Anlagevermögen ein-

327 vgl. Schlieder, E., Den Bauunternehmern wird zuviel zugemutet, in bau-Zentralblatt, Nr.11, November 1968.

328 Dieses Ziel hatte angesichts der immer stärker werdenden Personalknappheit insbesondere zu Anfang der 70er Jahre an Bedeutung gewonnen, vgl. hierzu Brunner, H., Präsident des Hauptverbandes der Deutschen Bauindustrie, Wirtschaftspolitische Fordenungen der Deutschen Bauindustrie, in: Architekt und Ingenieur, 21.Jg., Nr.7, 1970 und Knechtel, E., Das sozialpolitische Rahmenprogramm der Bauindustrie, in: Die Bauwirtschaft, 24.Jg., Heft 23, 1970, S.709ff.

329 vgl. Kießling, A., Untersuchung der Wirtschaftlichkeit von Bauunternehmungen beim Bauen mit und ohne Winterpause, S.27, in: rationeller bauen, September 1972. 
schließlich der Maschinen, Baugeräte, Materialvorräte usw. In erster Linie besteht sie aber aus dem Personal in der Verwaltung und im produzierenden Bereich." 330

\subsubsection{Ziele der IG Bau-Steine-Erden}

Als Interessenvertretung der Arbeitnehmer, stellt die Gewerkschaft naturgemäß die materielle und soziale Sicherung der Arbeitnehmer in den Vordergrund. So wurde schon im "Grundstein" 1959 die Schaffung von zumutbaren Arbeitsbedingungen während der Schlechtwetterzeit gefordert. Hierzu heißt es: "...Die Schaffung und die Bereitstellung von Arbeitsmitteln und Baustelleneinrichtungen, die eine Fortsetzung der Arbeit unter schlechten Witterungsverhältnissen für den Menschen auf der Baustelle erträglich machen, sind eine wichtige und unerläßliche Voraussetzung für das Gelingen. Angefangen bei einer ordentlichen Beheizung, guten Aufenthaltsräumen und Unterkünften, bis zu einer möglichen Abschirmung des Arbeitsplatzes gegen die Witterung, zweckmäßige Arbeitskleidung und Arbeitsgeräte, entsprechende Vorsorge gegen Unfälle aller Art, sind viel mehr Dinge als bisher auf den Baustellen erforderlich, ehe wir die Zumutbarkeit im Winter bejahen können." ${ }^{\text {331 }}$

Auch der damalige 1.Vorsitzende der IG Bau-Steine-Erden, Georg Leber, sah den Hauptakzent in der sozialpolitischen Zielrichtung. ${ }^{332}$ So galt es insbesondere Arbeitslosigkeit zu vermeiden, d.h., daß der Arbeitnehmer nicht willkürlich aus Witterungsgründen entlassen werden konnte und auch im Falle der Nichtarbeit ein möglichst hohes Einkommen erhielt. Wenn der arbeitswillige und arbeitsfähige Arbeitnehmer infolge Witterungseinflusses keine Möglichkeit hat zu arbeiten, darf dies nach Gewerkschaftsmeinung nicht zu einer Schmälerung seines Lebensstandards führen. ${ }^{333}$ Weitere Forderungen sind:

330 vgl. Nolte, R., Winterbau verbessert Rentabilität und Wirtschaftlichkeit - Eine Chance zum Überleben, S.1409, in: Bauwirtschaft, Heft 41, 11.Oktober 1984.

331 vgl. o.V., Das erreichte Deine Gewerkschaft für Dich. Zumutbarkeit in der Winterperiode, in: Der Grundstein, 10.Jg., Nr.24,29.November 1959, S.4ff.

332 vgl. Leber, G., Ganzjałhriges Bauen aus sozialer Sicht, in: Der Grundstein, 10.Jg., Nr.13, 28. Juni 1959, S.3.

333 vgl. auch "Tarifvertrag zur Durchführung der Vereinbarung vom 2. März 1972 über eine pauschale Abgeltung witterungsbedingter Lohnausfäle während der Zeit vom 1.April bis 31. Oktober" vom 17.Juli 1973. Danach erhalten alle Arbeitnehmer des Baugewerbes (ausgenommen Auszubildende), soweit sie unter den Geltungsbereich des BRTV-Bau fallen, für die in der Zeit 
- "...Dreh- und Angelpunkt dieser Tarifpolitik ist das ganzjährig gesicherte Einkommen. Die IG Bau fordert daher: Ein ganzjährig gesichertes Einkommen, gesicherte Arbeitsplätze und ganzjährige Beschäftigung." 334

- "...unter dem ganzjährig gesicherten Einkommen verstehen wir eine Regelung, die unter dem Strich dazu führt, daß Bauarbeitnehmer mindestens ein durchschnittliches Jahresbruttoeinkommen erzielen können, wie es im Industriedurchschnitt erreicht wird." 335

- "...insbesondere die öffentliche Hand hat bei ihren Bauvorhaben gesamtwirtschaftliche Aspekte zu berücksichtigen. Die IG Bau fordert deshalb eine verstärkte öffentliche Bautätigkeit im Winter." ${ }^{336}$

- "...eine auf hohem Niveau verstetigte Bautätigkeit durch politische Entscheidungen und wirtschaftliche Anreize systematisch zu fördern." 337

- "...die Schaffung neuer Anreize für das ganzjährige Bauen sind sowohl volkswirtschaftlich als auch betriebswirtschaftlich sinnvoll. So begründet der IG Bau Vorsitzende Bruno Köbele eine Initiative seiner Gewerkschaft, die er in den $\mathrm{Zu}$ sammenhang mit einem Gesamtkonzept "Bauberufe 2000" stellte. Daher läge eine ganzjährige Bauproduktion im Verbund mit einem systematischen Winterbau im gemeinsamen Interesse von Staat, Bau-Arbeitgebern und Bau-Arbeitnehmern." 338

- "...die Kosten des winterbedingten Arbeitsausfalles betragen mindestens 2 Milliarden DM in der westdeutschen Bauwirtschaft. Diese setzen sich zusammen aus

vom 1.April bis 31.Oktober infolge ungünstiger Witterung eingetretenen Lohnausfalle einen jahrlichen Abgeltungsbetrag von damals 190,- DM.

334 vgl. o.V., Bauarbeit muß sich immer lohnen - im Sommer und im Winter, in : Der Grundstein, Ausgabe 2/89, S.2 und Rudolf Sperner, IG Bau fordert gesichertes Jahreseinkommen, in: BauMarkt, 70.Jg., Nr.3, 1971, S.63ff.

335 IG Bau-Steine-Erden, Rahmenkonzept zur Durchsetzung eines "Ganzjährig gesicherten Einkommens" für Bauarbeiter, Abteilung Tarifpolitik, Frankfurt, 13. Juni 1989

336 vgl. IG Bau-Steine-Erden, Verstärkte Winterbautatigkeit bei öffentlichen Bauvorhaben, Frankfurt/Main, 12.Februar 1991.

337 vgl. IG Bau-Steine-Erden, Abteilung Bundesvorsitzender, Rundschreiben Nr.22/1992, Konzeption zur Überwindung der Engpässe im Wohnungsbau durch ganzjăhrige Bautătigkeit/Winterbau, S.3.

338 vgl. Abteilung Bundesvorsitzender Nr.49/92, BSE-Extern, Verstetigte Bautătigkeit, 3. August 1992. 
dem SWG (1990/91: rund 870 Millionen), winterbedingter Arbeitslosigkeit, Kurzarbeit und Steuerausfällen sowie Ausfällen an Sozialversicherungsbeiträgen, die auch durch die hohe Überstundenzahl im Sommer nicht ausgeglichen werden." 339

Die Ausführungen haben den Umfang vorhandener Zielvorstellungen der Beteiligten bezüglich der ganzjährigen Beschäftigung in der Bauwirtschaft aufgezeigt. Vor allem aus den unterschiedlichen Interessen der Beteiligten läßt sich erklären, daß sowohl sozial- und wirtschaftspolitische als auch betriebswirtschaftliche Zielsetzungen verfolgt wurden.

Es bleibt dennoch festzuhalten, daß trotz des umfassenden Zielkataloges mit seinen unterschiedlichen Schwerpunkten die jeweils beschlossenen Förderungsmaßnahmen als das Werk aller Beteiligten angesehen werden müssen. Wie eng die Zusammenarbeit zwischen den Beteiligten gewesen ist, belegt beispielsweise die gesetzliche Forderung nach Einführung eines witterungsbedingten Kündigungsschutzes und Lohnausgleiches als Voraussetzung des Zweiten Änderungsgesetzes zum AVAVG, der die Tarifpartner mit entsprechenden Tarifabschlüssen im Herbst 1959 Folge leisteten. ${ }^{340}$

Aber auch der umgekehrte Fall, d.h. der Einfluß der Tarifpartner auf den Gesetzgeber, darf nicht unterschätzt werden. Dies zeigt sich insbesondere in der aktuellen Diskussion um die Streichung des SWG. So wurde bereits Beschlossenes - auf Druck der Organisationen - stufenweise wieder rückgängig gemacht.

Insgesamt läßt sich die Diskussion um die Ziele zur ganzjährigen Beschäftigung mit einem Zitat von Georg Leber am besten charakterisieren: "Durch eine erfreuliche, sachliche Zusammenarbeit zwischen der Bundesregierung, den Arbeitgeberverbänden und der Industriegewerkschaft Bau-Steine-Erden ist es gelungen, tarifvertragliche, gesetzliche und wirtschaftspolitische Voraussetzungen für eine Überwindung des althergebrachten Saisoncharakters der Bautätigkeit zu schaffen...".341

339 vgl. IG Bau-Steine-Erden für Verstärkte Winterbautătigkeit, Frankfurt/Main, 26. August 1992.

340 BRTV und TV Lohnausgleich vom 20. August 1959, vgl. hierzu Kap. 2.4.2. Tarifvertragliche Leistungen und Regelungen, S.75.

341 vgl. Leber, G., 1.Vorsitzender der IG Bau-Steine-Erden, Bauen ohne Winterpause, S.2, in: Der Querschnitt, 1959. 
Aufgrund der Tatsache, daß die jeweiligen Förderungsmaßnahmen nicht als das Werk eines einzelnen angesehen werden können, hat das Zitat von Georg Leber aus dem Jahr 1959 - d.h. zu Beginn der Maßnahmen zur Förderung der ganzjährigen Beschäftigung in der Bauwirtschaft - seine Gültigkeit auch für alle weiteren getroffenen Förderungsmaßnahmen.

Faßt man das zweite Kapitel an dieser Stelle zusammen, so haben insbesondere die ausführliche Darstellung der gesetzlichen Förderungsmaßnahmen in Abschnitt 2.4. und die Diskussion der Zielvorstellungen der Beteiligten in Abschnitt 2.5. verdeutlicht, daß die Saisonbewegungen und deren Problematik für die Bauwirtschaft in Deutschland von großer Bedeutung sein müssen. 


\section{KAPITEL 3}

\section{Wirkungsanalyse}

Im Rahmen der nun folgenden Wirkungsanalyse soll einerseits der Umfang der Saisonschwankungen wirtschaftlicher Bewegungsgrößen aufgezeigt und andererseits die Wirkungen der Förderungsmaßnahmen zur ganzjährigen Beschäftigung auf die Saisonschwankungen analysiert werden. Aufgrund der im Zeitablauf getroffenen gesetzlichen Förderungsmaßnahmen werden sogenannte charakteristische Förderungszeiträume gebildet, die getrennt untersucht und vergleichend bewertet werden können. Dies sind die Zeiträume:

- 1954-59

- 1960-68

- 1969-71

- 1972-85

$-1986-92$

Zunächst werden jedoch, in den folgenden Abschnitten 3.1. und 3.2., die mit der Untersuchung verbundenen Einschränkungen bzw. die für die Analyse notwendigen Untersuchungskriterien aufgezeigt.

Ziel und Aufgabe der Wirkungsanalyse ist es, die genannten Maßnahmen zur Förderung der ganzjährigen Beschäftigung in der Bauwirtschaft auf ihre Effektivität hin zu untersuchen. Wie der zeitliche Abriß und die Zielvorstellungen der Beteiligten von den Förderungsmaßnahmen gezeigt haben, muß das Problem unter verschiedenen Aspekten betrachtet werden. Im Rahmen der Wirkungsanalyse müssen deshalb sozialpolitische, volks- und betriebswirtschaftliche sowie finanzpolitische Kriterien berücksichtigt werden. Dieser Kriterienkatalog, der als Maßstab für die Beurteilung der Förderungsmaßnahmen dienen soll, wird im Anschluß an den folgenden Abschnitt "Einschränkungen in der Untersuchung" definiert. 


\subsection{Einschränkungen in der Untersuchung}

Bevor damit begonnen werden kann, die Wirkungen einzelner Maßnahmen auf die ganzjährige Beschäftigung in der Bauwirtschaft zu analysieren, müssen die mit der Untersuchung verbundenen Einschränkungen aufgezeigt und deren Bedeutungsumfang für die Analyse festgestellt werden. Hierbei handelt es sich um die folgenden Punkte:

- Statistik

- Technik des Winterbaues

- Schutzmaßnahmen

- Witterungsbedingungen

- Berechnungsmethode

- Sonstige

\subsubsection{Statistik}

Dem zur Verfugung stehenden statistischen Zahlenmaterial kommt für die Beurteilung der Förderungsmaßnahmen eine wichtige Rolle zu. In der Bauwirtschaft sind dies vor allem die Erhebungen im Bauhaupt- und Ausbaugewerbe. ${ }^{342}$ Sie dienen im wesentlichen der Beurteilung der Betriebs- und Beschäftigtenstruktur dieser Wirtschaftsbereiche und werden jeweils zur Jahresmitte durchgeführt. ${ }^{343}$ Die Erhebungen im einzelnen:

Totalerhebung im Bauhauptgewerbe: Sie wird seit mehr als drei Jahrzehnten im früheren Bundesgebiet ${ }^{344}$ durchgeführt. Ab dem Berichtsjahr 1991 sind in diese Erhebung auch die Betriebe der fün neuen Bundesländer und von Berlin-Ost einbezogen. Sie erfaßt alle bauhauptgewerblichen Betriebe ${ }^{345}$ von Unternehmen

342 Ab Berichtsjahr 1976 liegt den Erhebungen im Bauhaupt- und Ausbaugewerbe die Systematik der Wirtschaftszweige in der Fassung fuir die Statistik im Produzierenden Gewerbe (SYPRO) zugrunde. Die Zuordnung der Erhebungseinheiten zu den einzelnen Wirtschaftszweigen des Baugewerbes erfolgt nach dem Schwerpunkt der baugewerblichen Tătigkeit.

343 vgl. Statistisches Bundesamt (Hrsg.); Beschäftigung, Umsatz und Gerătebestand der Betriebe im Baugewerbe 1992, in: Fachserie 4 Produzierendes Gewerbe, Reihe 5.1.

344 Gebietsstand der Bundesrepublik Deutschland bis zum 3.10.1990 einschließlich Berlin-West.

345 Anmerkung: Zur Erhebungseinheit "Betrieb" zăhlen hier die örtlichen Einheiten mit eigenem Bau- bzw. Lohnbüro (in der Regel nicht die Baustellen), die nach dem Schwerpunkt ihrer wirtschaftlichen Tătigkeit Bauleistungen für den Markt erbringen, unabhängig davon, ob es sich um 
des Bauhauptgewerbes, des übrigen produzierenden Gewerbes, anderer Wirtschaftsbereiche sowie die Arbeitsgemeinschaften des Bauhauptgewerbes, soweit sich die Tätigkeit auf das Inland bezieht. Totalergebnisse für das frühere Bundesgebiet liegen seit 1960 vor.

Jährliche Erhebung im Ausbaugewerbe: Sie wurde im Zuge der Neuordnung der Statistik im produzierenden Gewerbe ${ }^{346}$ im früheren Bundesgebiet einschließlich Berlin-West neu eingeführt. Ab dem Berichtsjahr 1991 sind in diese Erhebung auch die Betriebe der fünf neuen Bundesländer und von Berlin-Ost einbezogen. Sie erfaßt alle handwerklichen und nichthandwerklichen Betriebe von Unternehmen des Ausbaugewerbes und des übrigen produzierenden Gewerbes mit 10 Beschäftigten und mehr. Hinzu kommen die Arbeitsgemeinschaften sowie auch Betriebe mit Schwerpunkt im Ausbaugewerbe, die mindestens 10 Personen beschäftigen, jedoch zu Unternehmen außerhalb des produzierenden Gewerbes gehören. Ergebnisse der jährlichen Erhebung im Ausbaugewerbe wurden für das frühere Bundesgebiet einschließlich Berlin (West) erstmalig für 1978 veröffentlicht.

Die vorliegende Wirkungsanalyse beschränkt sich im wesentlichen auf das Bauhauptgewerbe, da für das Ausbaugewerbe, wie beschrieben, die entsprechenden Statistiken nicht vollständig zur Verfügung stehen. Diese Einschränkung spielt aus zweierlei Gründen aber nur eine untergeordnete Rolle und ist daher durchaus legitim. Einerseits umfaßt das Bauhauptgewerbe ohnehin den größten Teil der Beschäftigten und des baugewerblichen Produktionsvolumens, ${ }^{347}$ andererseits sind die Wirtschaftszweige des Ausbaugewerbes nicht ursächlich verantwortlich für die Saisonbewegungen in der Bauwirtschaft. Es handelt sich hierbei fast ausschließlich um nachgelagerte Tätigkeitsbereiche des Bauhauptgewerbes, deren Einsatz erst ab einem gewissen Baufortschritt - je nach Wirtschaftszweig - erforderlich bzw. möglich wird. ${ }^{348}$

handwerkliche oder nichthandwerkliche Einheiten handelt. Infolge seiner kleingewerblichen Struktur wird ein Teil der Betriebe im Ausbaugewerbe nicht erfaßt. Angaben über die Gesamtzahl der Betriebe im Ausbaugewerbe, wie sie im früheren Bundesgebiet durch die Arbeitsstättenzăhlung 1987 erfaßt worden sind, liegen für die neuen Lănder nicht vor.

346 Ab Berichtsjahr 1976.

347 vgl. Abbildung 2 und Hauptverband der Deutschen Bauindustrie (Hrsg.), Baustatistisches Jahrbuch 1992, S.60.

348 Hinweis: z.B. Maler- und Lackierergewerbe, Tapetenkleberei, Pakett- und Fliesenlegerei und andere, vgl hierzu auch Abbildung 1: Wirtschaftszweige des Ausbaugewerbes. 


\subsubsection{Technik des Winterbaues}

An dieser Stelle ist zu klären, inwieweit der Winterbau überhaupt technisch durchführbar ist und wenn ja, mit welchen Schutzmaßnahmen bzw. bis zu welchen Witterungsbedingungen.

Der Winterbau ist technisch längst kein Problem mehr. ${ }^{349} \mathrm{Zu}$ diesem Ergebnis kommt eine Studie des Instituts für Arbeits- und Baubetriebswissenschaft Leonberg aus dem Jahr 1978, die mögliche Winterbau- und Schutzmaßnahmen bei verschiedenen Witterungsbedingungen gegenüberstellt und bewertet. ${ }^{350}$

Auch andere Autoren betrachten die Frage nach der Technik des Winterbaues bereits als gelöst. ${ }^{351}$ Das heißt, über die Technik des Winterbaues ist bereits so viel bekannt, daß "...jedes Bauvorhaben, dessen kontinuierliche Baudurchfürung als sinnvoll anzusehen ist, mit Hilfe von Winterbauschutzmaßnahmen auch durchgeführt werden kann. Eine langjährige Erfahrung steht hier zur Verfügung."352 Ähnlich argumentiert auch Hampe, der den Nachweis, daß das Bauen im Winter technisch möglich ist, bereits durch eine größere Anzahl von Demonstrativbaumaßnahmen in den 50er und 70er Jahren als erbracht ansieht. Heute erlaubt die Technik die Errichtung von Bauwerken aller Art bei fast jeder Witterung und der sogenannte Winterbau ist nur ein technisches Hilfsmittel, um den Bauvorgang kontinuierlich betreiben zu können. ${ }^{353} \mathrm{Nach}$ der Art, wie Baustellen wetterunabhänig eingerichtet werden, unterscheidet man zwischen Schlechtwetterbau und Frostbau:

Schlechtwetterbau: Hierunter versteht man die Ausführung von Bauleistungen in der winterlichen Jahreszeit unter Witterungsbedingungen, die nur Maßnahmen geringeren Umfanges zum Schutz der Arbeiten gegen die Einwirkung von Kälte, Nässe und Schnee erfordern.

349 Ausnahme: Bezüglich der technischen Möglichkeiten für den Winterbau ist der reine Straßenbau, bei dem der Winterbau technisch nicht sinnvoll wăre, auszuklammern; vgl. hierzu Röthig, H., Das kontinuierliche Bauen mit Hilfe von Winterbau-Schutzmaßnahmen, S.1516.

350 vgl. Schönberg, G./Dobler, M./Werthwein, R., Untersuchungen über Winterbauschutzmaßnahmen; Die Wirtschaftlichkeit wird positiv beeinflußt, S.13.

351 vgl. o.V., Wer rechnet baut auch im Winter. Bessere Kapazitätsauslastung durch Kontinuität, S.2152; Frank, P., Winterbau - Anforderungen und Bewertungskriterien, S.42 und Pause, H., Die Folgen winterbedingter Produktionsausfäle im Bauhauptgewerbe, S.2.

352 vgl. Röthig, H., Interessante Daten aus dem Winterbau-Bereich/Ergebnisse einer umfangreichen Untersuchung, S.33.

353 vgl. Hampe, K.-H., Winterbau-Technik, S.7. 
Frostbau: Ausführungen von Bauleistungen unter Witterungsbedingungen, bei denen die Weiterführung der Arbeiten zusätzliche Maßnahmen, insbesondere gegen die Einwirkungen des Frostes erfordert.

Bei beiden Ausführungsformen werden Schutzvorkehrungen und Sicherungsmaßnahmen zur Winterfestmachung der Baustellen und Ausführung der Bauarbeiten während der Winter- und Schlechtwetterperiode getroffen. ${ }^{354}$ Welche Maßnahmen im einzelnen getroffen werden können und wie sie sich voneinander unterscheiden, zeigt das folgende Kapitel.

\subsubsection{Schutzmaßnahmen}

Die Vielzahl von technischen Hilfsmitteln, die zur Verfügung stehen - sogenannte Winterbauschutzmaßnahmen - haben die Grenzen des auf technische Ursachen zurückzuführenden Produktionsstopps sehr weit hinausgeschoben. Hierbei handelt es sich um Maßnahmen, die winterliche Bauarbeiten ermöglichen, weil sie Arbeitsplätze, Arbeitsvorgänge, Baustoffe und Bauteile vor den Witterungseinflüssen schützen. Nach Schutzart und Schutzumfang werden heute Einzel-, Teil-, Voll- und kombinierter Schutz unterschieden, die Hampe wie folgt beschreibt: ${ }^{355}$

Einzelschutz: Winterbauschutzmaßnahme kleineren Umfanges, durch welche Arbeitsplätze, Materiallager, Aufbereitungs- und andere Anlagen so geschützt werden, daß die Arbeiten fortgeführt werden können (z.B. Schutz der Betonmischanlage, Aufheizen des Wassers, beheizbare Materiallager und Kiesboxen, Schutz von frisch betonierten Bauteilen, Schutz vor Wasserhaltungsanlagen, Windschutzwände, Schweißzelte etc.).

Teilschutz: Winterbauschutzmaßnahme die erreicht wird, wenn

- die Außenwandöffnungen des Rohbaues abgedichtet werden, und das Dach bzw. die oberste Geschoßdecke abgedeckt sind. Die Innenräume des Rohbaues sind durch eine mobile Beheizungsanlage oder durch die zum Bauobjekt gehöri-

354 vgl. Eyerich, J./Lenz, J./Witschel, K., Einsparungen beim Bauen im Winter, S.44-45.

355 vgl. Hampe, K.-H., Winterbau-Technologie, Planung/Vergabe/Ausfuihrung, S.48ff. 
ge endgültige Heizung so zu beheizen, daß sämtliche Innenausbauarbeiten in der Winterzeit ausgeführt werden können.

- Teile der Bauleistung (z.B. Fertigung von Bauwerkseinzelteilen, Vorrichtungen von Schalungselementen, Bewehrungs- oder Stahlteilen, Spannbetongliedern usw.) getrennt vom Bauwerk oder außerhalb der Baustelle unter Bedingungen des Voll- oder Teilschutzes hergestellt werden können.

Vollschutz: Winterbauschutzmaßnahme, die das Bauwerk oder Teile des Bauwerkes vollständig umhüllt. Die Umhüllung (Winterbauschutzhalle, Zelte oder ähnliches) ist so gestaltet, daß die für die Winterbauzeit vorgesehenen Bauleistungen kontinuierlich fortgefuihrt werden können. Der Innenraum muß beheizbar sein. Bei Bauten oder Teilen von Bauten, die ganz oder teilweise in offener Baugrube ausgeführt werden, ist der Vollschutz auch dann gegeben, wenn durch eine obere Abdeckung und durch Querschürzen in der Baugrube ein beheizbarer Arbeitsraum geschaffen wird (z.B. U-Bahn-Bau, Kanalisationsbau, Kellerbauteile). Bei Winterbauschutzhallen, Zelten oder Umhüllungen müssen Teile der Außenhaut lichtdurchlässig sein. Zur Winterbauschutzhalle gehört eine der Raumgröße und der Außenhaut entsprechend dimensionierte Beheizungsanlage.

Kombinierter Schutz: Winterbauschutzmaßnahme, die aus Elementen des Teilund Vollschutzes besteht. Beim kombinierten Schutz wird nur ein Teil des zu erstellenden Bauwerks geschützt. Ist das Wetter ungünstig, wird insgesamt in dem geschütztem Teil gearbeitet. Bei günstigem Wetter hingegen wird im ungeschützten Bereich gearbeitet.

Von den hier beschriebenen Schutzmaßnahmen werden die verschiedenen Elemente des Einzelschutzes am häufigsten auf den Baustellen angewendet. ${ }^{356}$ Bei der Entscheidung, ob Bauleistungen im Winter unter Einzel-, Teil-, Vollschutz oder kombiniertem Schutz durchgefuhrt werden sollen, spielt neben den Witterungsbedingungen sicherlich auch die Investitionsbereitschaft des Betriebes eine Rolle. Unabhängig davon ist die Kenntnis der mit den verschiedenen Schutzmaßnahmen verbundenen Vorund Nachteile unerläßlich, um eine optimale Auswahl für das einzelne Bauobjekt zu treffen. Auf die entsprechende Diskussion kann hier verzichtet werden, weil sie letztendlich zu dem zu erwartenden Ergebnis führen würde, daß Teil- und Einzelschutz-

356 vgl. Hampe, K.-H., Winterbau-Technologie, Planung/Vergabe/Ausführung, S.50. 
maßnahmen gegenüber Vollschutzmaßnahmen zwar geringere Kosten aufweisen, aber eine Unterbrechung der Bauarbeiten nicht ausschließen können. ${ }^{357}$

Die Unterbrechung der Bauarbeiten wird nach Aussage des Bauforschungs- und Beratungsinstituts Beidatsch durch die Anwendung von Vollschutzmaßnahmen vermieden. Auf diese Weise entstehen auch keine Ausfalltage und kein SWG. ${ }^{358} \mathrm{Zu}$ einem ähnlichen Ergebnis kommt auch das Institut für Arbeits- und Baubetriebswissenschaft, $\mathrm{da} ß$ in seinem Forschungsvorhaben füf Winterbaustellen mit unterschiedlichen Schutzmaßnahmen vergleichend untersuchte. ${ }^{359}$ Wie die entsprechenden Fallbeispiele der Untersuchung zeigen, hat es bei den Ausbauarbeiten - trotz nur geringfügiger Schutzmaßnahmen - keinen Arbeitsausfall in der Förderungszeit gegeben, ${ }^{360}$ weil "...ein fertiger Rohbau ${ }^{361}$ für eine kontinuierliche Weiterführung der Bauarbeiten in der Schlechtwetterzeit die billigste Wetterschutzhalle darstellt." ${ }^{\text {362 }}$ Bei den Rohbauarbeiten hingegen hängt der Arbeitsausfall eindeutig vom Umfang der gewählten Schutzmaßnahmen ab, daß heißt, eine kontinuierliche Weiterfuhrung der Rohbauarbeiten bei jedem Wetter ist nur durch den Einsatz von Winterschutzhallen (Vollschutz) gewährleistet. ${ }^{363}$

Diese Erkenntnis, daß der Vollschutz - im Gegensatz zum Teilschutz - die Ausfalltage auf ein Minimum reduziert, führt zu der Schlußfolgerung, daß die technische

357 vgl. hierzu ausführlich Schriftenreihe des Bundesministers für Raumordnung, Bauwesen und Städtebau, Bau und Wohnforschung, Winterbau-Schutzmaßnahmen bei verschiedenen Witterungsbedingungen, Heft 04.043, Bonn, 1978, S.99.

358 vgl. Bauforschungs- und Beratungsinstitut Beidatsch, Der Einfluß des Winterwetters auf die Bautătigkeit im Wohnungsbau und die kostenmäBigen Auswirkungen für die Bauwirtschaft Winter 1967/1968, S.614.

359 vgl. Schönberg, G./Dobler, M./Werthwein, R., Untersuchungen über Winterbauschutzmaßnahmen; Die Wirtschaftlichkeit wird positiv beeinflußt, S.13ff.

360 Anmerkung: Diese Tatsache unterstützt die These des Verfassers, daß das Ausbaugewerbe in einem wesentlich geringeren Maße von Witterungseinflüssen betroffen ist, als das die Rohbauarbeiten durchführende Bauhauptgewerbe.

361 Hinweis: Nach Fertigstellung des Rohbaues wird mit dem Ausbau begonnen.

362 Ergebnis einer Repräsentativuntersuchung des Bauforschungs- und Beratungsinstituts Beidatsch über den Einfluß des Winterwetters auf die Bautătigkeit im Wohnungsbau und die kostenmäßigen Auswirkungen für die Bauwirtschaft Winter 1967/1968, S.614.

363 So sind beispielsweise beim Bau der Lagerhalle in Tailfingen (Süddeutschland) unter Teilschutz 33 Arbeitstage in der Fördenungszeit ausgefallen, während der Bau des Wohnblocks in München unter Vollschutz keine Ausfalltage in der Förderungszeit zu verzeichnen hatte; vgl. hierzu Schönberg, G./Dobler, M./Werthwein, R., Untersuchungen über Winterbauschutzmaßnahmen; Die Wirtschaftlichkeit wird positiv beeinflußt, S.13ff, und Bauforschungs- und Beratungsinstitut Beidatsch, Der Einfluß des Winterwetters auf die Bautătigkeit im Wohnungsbau und die kostenmäßigen Auswirkungen für die Bauwirtschaft Winter 1967/1968, S.614. 
Seite des Winterbaues nur mittels Vollschutzmaßnahmen zufriedenstellend gelöst wird und eine kontinuierliche Bautätigkeit auf diese Weise am ehesten gewährleistet werden kann. Inwieweit nun Witterungsbedingungen die winterliche Bautätigkeit tatsächlich beeinflussen, d.h. an wieviel Tagen im Jahr Vollschutzmaßnahmen getroffen werden müßten, soll das folgende Kapitel klären.

\subsubsection{Witterungsbedingungen}

Die klimatischen Bedingungen, die dazu zwingen die Arbeit einzustellen, beschreibt Hampe mit drei unterschiedliche Grenzen, die er wie folgt definiert: ${ }^{364}$

Technische Grenze: Sie folgt aus den technischen Vorschriften mit den Grenzwerten allgemeiner Witterungskriterien. Bis auf wenige Ausnahmen wird hier die Luftemperatur von $+5^{\circ} \mathrm{C}$ als Limit zugrunde gelegt. Das heißt, daß eine ordnungsgemäße Bauausführung unter diesem Limit nur dann gewährleistet ist, wenn bestimmte Schutzmaßnahmen ergriffen werden.

Witterungsgrenze: Sie gibt an, bis zu welchen Wetterdaten die Arbeiten auf der Baustelle unter entsprechenden Schutzmaßnahmen und Vorkehrungen durchgeführt werden können. Sie resultiert aus den objektspezifischen Faktoren des Bauvorhabens (Standort, Art und Konstruktion des Bauwerkes, Bauverfahren und Bauablauf) und der Möglichkeit, die erforderlichen Winterbau-Schutzmaßnahmen anzuwenden. Dabei ist immer ein ausreichender Witterungsschutz des Bauarbeiters sicherzustellen.

Absolute Grenze: Sie ist gegeben, wenn Witterungsbedingungen herrschen, unter denen das Bauen mit Schutzmaßnahmen weder technisch sinnvoll, noch wirtschaftlich möglich, noch den Bauarbeitern zumutbar ist.

Diese hier beschriebenen Grenzen sind wie die Definition gezeigt hat, für das einzelne Bauvorhaben jeweils neu zu bestimmen und daher für eine Verallgemeinerung ungeeignet. ${ }^{365}$ Einen wesentlich besseren Ansatz meßbarer Kriterien liefert der Deutsche

364 vgl. Hampe, K.-H., Winterbau-Technologie, Planung/Vergabe/Ausfuihrung, S.7.

365 Anmerkung: Die definierten Grenzen basieren auf rein subjektiven Kriterien, wie die Projektleitung (Karl-Heinz Hampe) des Arbeitskreises Winterbau-Technologie dem Verfasser mitteilte. Das heißt, die Schutzmaßnahmen werden für jedes einzelne Bauvorhaben von den Beteiligten 
Wetterdienst in Offenbach. Er trifft aufgrund der maximalen und minimalen Tagestemperatur, der Niederschlagsmenge, der Niederschlagsdauer und der Schneedeckenhöhe eine eigene Einteilung für "...Tage mit Witterungserscheinungen, die die Fortführung der Bauarbeiten sehr erschweren..."366 Diese Einteilung gilt für Tage, an denen eine der folgenden Bedingungen erfüllt ist:

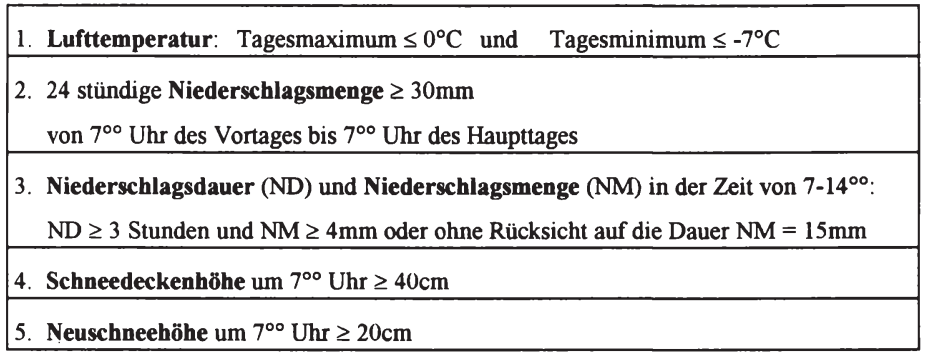

Hinweis: Auf die Verwendung des statistischen Zahlenmaterials über die Kältesummen und Eis- bzw. Frosttage einzelner Regionen (Tage, an denen die Tageshöchsttemperaturen die Nullgradgrenze nicht überschritten haben) kann hier verzichtet werden, weil sie einerseits zum Teil in der o.g. 1.Bedingung des Deutschen Wetterdienstes enthalten sind und andererseits kein hinreichendes Kriterium für eine erschwerte Bauarbeit darstellen. Dies gilt beispielsweise für alle Tage mit einer Tagestemperatur zwischen $0^{\circ} \mathrm{C}$ und $-7^{\circ} \mathrm{C}$, die zwar Eis- bzw. Frosttage sind - vorausgesetzt sie überschreiten die Nullgradgrenze nicht - aber die o.g. 1.Bedingung nicht erfullen.

Ein großer Vorteil dieser getroffenen Einteilung liegt in der Tatsache, daß sowohl Temperaturen als auch Niederschläge berücksichtigt werden, denn die winterliche Bautätigkeit wird "...nicht allein durch die Temperatur, sondern in fast noch stärkerem Maße auch durch starke Niederschläge..." erheblich beeinflußt. ${ }^{367}$

Die folgenden Abbildungen 11 bis 14 zeigen die Tage mit Witterungserscheinungen, die die Fortfuhrung der Bauarbeiten sehr erschweren. Entsprechend der Entwicklung zur Förderung der ganzjährigen Beschäftigung in der Bauwirtschaft, werden die Witterungserscheinungen nach Förderungszeiträumen getrennt betrachtet. ${ }^{368}$ Begrenzt

auf ihre Notwendigkeit, Möglichkeit (beispielsweise kann der winterliche Starßenbau nicht mit einer Winterbauhalle geschützt werden $=>$ Unmöglichkeit des Vollschutzes) und Wirtschaftlichkeit hin untersucht.

366 Hinweis: Auch "Zahl der Schlechtwettertage nach der Kategorie A"; vgl. hierzu Bundesanstalt für Arbeit, Winterbauförderung, Erfahrungsberichte.

367 vgl. Pause, H., Die Folgen winterbedingter Produktionsausfälle im Bauhauptgewerbe, S.2 und auch Bundesanstalt für Arbeit, Winterbauförderung, Winterbau-Information 1989/90, S.7.

368 vgl. Kap. 2.4. Zeitlicher Abriß der Förderungsmaßnahmen zur ganzjährigen Beschäftigung, S.64ff. 
wird dieser klimatische Vergleich auf sieben ausgewählte Städte, die sich allerdings über das gesamte ehemalige Bundesgebiet verteilen. ${ }^{369}$ Auf diese Weise werden einerseits gewisse Unterschiede - wie z.B. die der jährlichen Niederschlagsmengen im Norddeutschen Tiefland, in den Mittelgebirgen und den Alpen - im Klima der Bundesrepublik Deutschland berücksichtigt. ${ }^{370}$ Andererseits sind aufgrund eines allmählichen Überganges vom mehr ozeanischem zu mehr kontinentalem Klima von Nordwesten nach Südosten sowohl die Tagesschwankungen als auch jahreszeitliche Temperaturunterschiede zwischen den sieben Städten nicht sehr extrem. ${ }^{371}$ Insofern ist eine Vernachlässigung örtlicher oder regional auftretender extremer Witterungserscheinungen im Rahmen dieser Arbeit von untergeordneter Bedeutung. ${ }^{372}$

Der Zeitraum 1960-68 hat mit durchschnittlich 15 "Schlechtwettertagen"373 pro Jahr und Stadt, den insgesamt ungünstigsten Witterungsverlauf aller untersuchten Zeiträume zu verzeichnen. Verantwortlich dafür ist vor allem die Schlechtwetterzeit 1962/63, die mit insgesamt 243 und durchschnittlich 35 Schlechtwettertagen in allen Städten den mit Abstand bauungünstigsten Witterungsverlauf seit Einführung des SWG 1959/60 aufweist. Von den sieben ausgewählten Städten sind nennenswerte Abweichungen vom Durchschnitt (15), einerseits bei Nürnberg (18) und München (22) sowie andererseits bei Stuttgart (11) und Essen (11), zu verzeichnen. Die beschriebenen Ergebnisse zeigt die folgende Abbildung:

369 vgl. Bundesanstalt für Arbeit, Winterbauförderung, Erfahrungsberichte.

370 vgl. Statistisches Bundesamt, Statistisches Jahrbuch 1992 für die Bundesrepublik Deutschland, S.11.

371 vgl. Statistisches Bundesamt, Statistisches Jahrbuch 1992 für die Bundesrepublik Deutschland, S.11.

372 Anmerkung: Es besteht auch die Möglichkeit, statistische Werte der Witterungsbedingungen vom jeweiligen Standort der Baustelle zu erhalten. Der Deutsche Wetterdienst in Offenbach bietet dafür langjährig erfaßte Daten an, die je nach Wunsch gegen Kostenerstattung zusammengestellt werden können. Diese statistischen Witterungsdaten sind Mittel- bzw. Durchschnittswerte aus langjăhrigen Messungen der Wetterämter. Aufgrund ihrer genauen Ortsbezogenheit und ihres Datenumfanges (z.B. zusätzliche Angaben über mittlere und maximale Windgeschwindigkeiten) sind sie im Vergleich zu den Daten der Abbildungen 11 bis 15, die nur die Witterungserscheinungen von sieben ausgewählten Städten betrachten und diese auch nicht năher spezifizieren, wesentlich besser geeignet, die Art und den Umfang von Winterbauschutzmaßnahmen zu bestimmen. Eine derartige Betrachtungsweise, die die Witterung an einzelnen Baustellen berücksichtigt, ist im Rahmen dieser Arbeit aber nicht durchführbar. Daher wird die gemachte Einschränkung auf sieben ausgewăhlte Städte in Kauf genommen.

373 Dieser Begriff entspricht den "...Tagen mit Witterungserscheinungen, die die Fortfuihrung der Bauarbeiten sehr erschweren...", vgl. auch Bundesanstalt für Arbeit, Winterbauforderung, Erfahrungsberichte. 
Abbildung: 11

1960-68: Tage mit Witterungserscheinungen, die die Fortfuhrung der Bauarbeiten sehr erschweren

\begin{tabular}{|c|r|r|r|r|r|r|r|r|r|}
\hline $\begin{array}{c}\text { Schlecht } \\
\text { wetterzeit }\end{array}$ & Nürmberg & Sturtgart & Múnchen & Hamburg & Frankturt & Hannover & Eseen & Surmme & \multicolumn{1}{c|}{$\varnothing$} \\
\hline $1959 / 60$ & 12 & 8 & 18 & 13 & 8 & 9 & 6 & 74 & 11 \\
$1960 / 61$ & 14 & 4 & 11 & 9 & 8 & 10 & 4 & 60 & 9 \\
$1961 / 62$ & 15 & 8 & 26 & 20 & 11 & 14 & 10 & 104 & 15 \\
$1962 / 63$ & 40 & 28 & 48 & 31 & 29 & 38 & 29 & 243 & 35 \\
$1963 / 64$ & 21 & 16 & 31 & 14 & 18 & 16 & 7 & 123 & 18 \\
$1964 / 65$ & 17 & 8 & 26 & 10 & 14 & 8 & 9 & 92 & 13 \\
$1965 / 66$ & 17 & 12 & 21 & 19 & 16 & 21 & 14 & 120 & 17 \\
$1966 / 67$ & 9 & 8 & 12 & 9 & 7 & 5 & 10 & 60 & 9 \\
$1967 / 68$ & 15 & 9 & 17 & 9 & 11 & 13 & 11 & 85 & 12 \\
$1968 / 69$ & 18 & 7 & 13 & 12 & 11 & 14 & 7 & 82 & 12 \\
\hline Summe & 178 & 108 & 223 & 146 & 133 & 148 & 107 & 1043 & 149 \\
$\varnothing$ & 18 & 11 & 22 & 15 & 13 & 15 & 11 & 105 & 15 \\
\hline
\end{tabular}

Quelle: Bundesanstalt für Arbeit: Winterbauförderung; Erfahrungsbericht für den Winter 1984/85, Anlage 4, Bericht zu den RdErl. vom 23.2.1976 und 24.5.1985 -IIIa5 - 7238, eigene Berechnungen

Der Witterungsverlauf der Jahre 1969-71 zeigt sich mit durchschnittlich 14 Schlechtwettertagen insgesamt etwas günstiger ${ }^{374}$ Interessant ist die Feststellung, daß auch hier die Städte Nürnberg (18) und München (20) deutlich mehr Schlechtwettertage aufweisen als der Durchschnitt (13). Dagegen sind Stuttgart (8) und Essen (9) wiederum von der Witterung begünstigt worden.

Abbildung: 12

\begin{tabular}{|l|r|r|r|r|r|r|r|r|r|}
\hline 1969-71: Tage mit Witterungserscheinungen, die die Fortithrung der \\
\hline
\end{tabular}

Quelle: Bundesanstalt für Arbeit: Winterbauförderung; Erfahrungsbericht für den Winter 1984/85, Anlage 4, Bericht zu den RdErl. vom 23.2.1976 und 24.5.1985 -IIIa5 - 7238, eigene Berechnungen

Der Zeitraum 1972-85 bildet mit 15 Vergleichswerten die längste Beobachtungsdauer. Sein Witterungsverlauf ist bis einschließlich der Schlechtwetterzeit 1977/78 deutlich günstiger als der Durchschnitt mit 14 Schlechtwettertagen. In diesen witterungsgünstigen Zeitabschnitt fält auch der mildeste Winter (1974/75) seit Beginn 
meteorologischer Messungen in unserem Klimagebiet. ${ }^{375}$ Ganz anders hingegen verlief die Entwicklung zum Ende des Beobachtungszeitraumes. Hier ist eine deutliche Verschlechterung des Witterungsverlaufes festzustellen, wodurch die Bauarbeiten erheblich erschwert wurden. ${ }^{376}$ Insbesondere die letzten zwei Jahre mit 28 und 26 Schlechtwettertagen zeigen diese Entwicklung. So ist beispielsweise der Witterungsverlauf in der Schlechtwetterzeit 1984/85 der weitaus bauungünstigste seit Einfürung der neuen Winterbauförderung im Jahr 1972 und die Gesamtsumme der Schlechtwettertage ist mit 193 Tagen entsprechend die höchste seit mehr als 20 Jahren. Sie wurde nur einmal in der Schlechtwetterzeit 1962/63 mit 243 Tagen übertroffen. ${ }^{377}$

Abbildung: 13

\begin{tabular}{|c|c|c|c|c|c|c|c|c|c|}
\hline $\begin{array}{l}\text { Schlecht } \\
\text { wetterzeit }\end{array}$ & Nûrnberg & Stuttgart & Múnchen & Hamburg & Frankturt & Hannover & Eesen & summe & $\varnothing$ \\
\hline $1971 / 72$ & 7 & 6 & 10 & 8 & 5 & 6 & 7 & 49 & 7 \\
\hline $1972 / 73$ & 9 & 3 & 20 & 8 & 6 & 1 & 6 & 53 & 8 \\
\hline $1973 / 74$ & 9 & 5 & 13 & 7 & 3 & 5 & 7 & 49 & 7 \\
\hline $1974 / 75$ & 5 & 3 & 6 & 3 & 6 & 4 & 8 & 35 & 5 \\
\hline $1975 / 76$ & 11 & 7 & 17 & 14 & 8 & 9 & 11 & $\pi$ & 11 \\
\hline $1976 / 77$ & 13 & 14 & 21 & 8 & 13 & 6 & 4 & 79 & 11 \\
\hline $1977 / 78$ & 11 & 8 & 29 & 10 & 6 & 10 & 8 & 82 & 12 \\
\hline $1978 / 79$ & 18 & 19 & 18 & 19 & 16 & 27 & 24 & 141 & 20 \\
\hline 1979/80 & 15 & 8 & 18 & 21 & 21 & 10 & 8 & 101 & 14 \\
\hline $1980 / 81$ & 18 & 12 & 27 & 14 & 9 & 15 & 10 & 105 & 15 \\
\hline $1981 / 82$ & 24 & 15 & 27 & 24 & 17 & 19 & 18 & 144 & 21 \\
\hline $1982 / 83$ & 9 & 7 & 14 & 3 & 4 & 7 & 7 & 51 & 7 \\
\hline $1983 / 84$ & 17 & 13 & 24 & 11 & 11 & 8 & 10 & 94 & 13 \\
\hline $1984 / 85$ & 28 & 29 & 31 & 30 & 25 & 27 & 23 & 193 & 28 \\
\hline $1985 / 86$ & 25 & 26 & 33 & 26 & 17 & 29 & 24 & 180 & 26 \\
\hline Summe & 219 & 175 & 308 & 206 & 167 & 183 & 175 & 1.433 & 205 \\
\hline$\varnothing$ & 15 & 12 & 21 & 14 & 11 & 12 & 12 & 97 & 14 \\
\hline
\end{tabular}

Quelle: Bundesanstalt für Arbeit: Winterbau-Information; Erfahrungsbericht für den Winter 1992/93, Anlage 4, Bericht zu den RdErl. vom 23.2.1976 und 24.6.1991 -IIIa5 7238 , eigene Berechnungen

Der letzte Beobachtungszeitraum von 1986-92 ist durch einen besonders günstigen Witterungsverlauf geprägt. So fällt in diesen Zeitraum der Winter 1987/88, der zu den fünf mildesten Wintern des 20. Jahrhunderts in Deutschland zählt und die Bauarbeiten insgesamt nur geringfügig beeinflußte. ${ }^{378}$ Desweiteren verlief die Witterung des Win-

375 vgl. Zentralamt des Deutschen Wetterdienstes, Offenbach.

$376 \mathrm{vgl}$. hierzu Ifo-Institut für Wirtschaftsforschung, München, in ifo-Schnelldienst 18/87, S.12:"...das Baugewerbe hat nicht nur unter den Witterungseinflüssen zu leiden, sondern ist weiterhin auch konjunkturellen Wechselbädern ausgesetzt."

377 vgl. Schmidt, R., Der Winterbau lebt, Winterbaubericht 1984/85, S.11. 
ters 1988/89 ebenfalls außerordentlich günstig, so daß im Durchschnitt dieses Winters nur 5 Schlechtwettertage anfielen. Dies ist der niedrigste Stand seit Einfuhrung der SWG-Regelung 1959-60. ${ }^{379}$ Aufgrund der geschilderten Witterungsverläufe läßt sich auch die relativ niedrige Durchschnittszahl der Schlechtwettertage (13) erklären. Bezüglich der augewählten Städte, setzt sich der Trend zu geringeren Schwankungsbreiten - München (18), Frankfurt (11), Durchschnitt (13) - fort. Diese Entwicklung war auch schon im Zeitraum 1972-86 zu beobachten.

Abbildung: 14

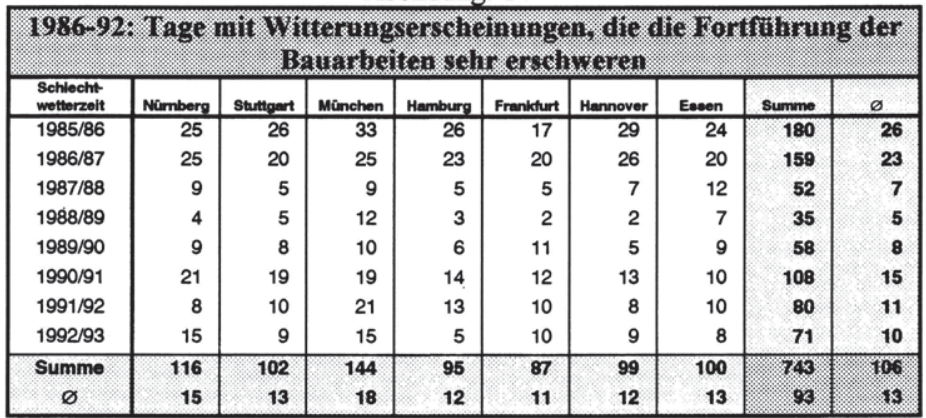

Quelle: Bundesanstalt für Arbeit: Winterbau-Information; Erfahrungsbericht für den Winter 1992/93, Anlage 4, Bericht zu den RdErl. vom 23.2.1976 und 24.6.1991 -IIla5 7238, eigene Berechnungen

Zusammenfassend läßt sich feststellen, daß ein Vergleich der durchschnittlichen Schlechtwettertage der einzelnen Zeiträume nur geringfügige Unterschiede aufweist. Eine Betrachtung der einzelnen Städte läßt zwar einerseits gewisse Abweichungen erkennen - hier liegen Nürnberg und München immer über dem Durchschnitt - aber andererseits auch eine Entwicklung zu geringeren Schwankungen. Die Ergebnisse im einzelnen zeigt die folgende Tabelle.

Abbildung: 15

\begin{tabular}{|c|c|c|c|c|c|r|r|r|}
\hline \multicolumn{10}{|c|}{ Vergleich der Witterungserscheinungen in Zeiträumen } \\
\hline Zoitraum & Nümberg & Sturtgart & München & Hamburg & Frankturt & Hannover & Eaeen & \multicolumn{1}{|c|}{} \\
\hline $1960-68$ & 18 & 11 & 22 & 15 & 13 & 15 & 11 & 15 \\
$1969-71$ & 18 & 8 & 20 & 14 & 14 & 17 & 9 & 14 \\
$1972-85$ & 15 & 12 & 21 & 14 & 11 & 12 & 12 & 14 \\
$1986-92$ & 15 & 13 & 18 & 12 & 11 & 12 & 13 & 13 \\
\hline $1959-93$ & 16 & 11 & 21 & 13 & 12 & 13 & 11 & 14 \\
\hline
\end{tabular}

Quelle: Eigene Berechnungen

378 vgl. Schmidt, R., Geringfügig behindert, Winterbau 1987/88, S.9.

379 vgl. Schmidt, R., Im konjunkturellen Aufwind, Winterbau 1988/89, S.7. 


\subsubsection{Zur Berechnung der Saisonschwankungen}

Die Probleme in der Bauwirtschaft - d.h. insbesondere diejenigen bezüglich ausgeglichener Beschäftigung und kontinuierlicher Produktion - sind wie bereits dargelegt, auf ausgeprägte Wirtschaftsbewegungen, die sogenannten Saisonschwankungen, zurückzuführen. ${ }^{380}$ Diese gilt es nun zu quantifizieren. Daher soll an dieser Stelle ein Verfahren ausgewählt werden, mit dem eine möglichst exakte statistische Erfassung der "reinen" Saisonbewegung einer ökonomischen Zeitreihe ermöglicht wird.

Die folgende kurze Abhandlung über die Zeitreihenanalyse verfolgt dabei nicht das Ziel, die methodischen Grundlagen und Konzepte bzw. numerische Unterschiede verschiedener Verfahren zur Saisonbereinigung vergleichend zu analysieren; oder herauszufinden, welches Verfahren wohl die "wahre" Saisonkomponente am "besten" schätzt. Selbst Institutionen wie Wirtschaftsforschungsinstitute, Statistisches Bundesamt usw. arbeiten immer noch mit unterschiedlichen Verfahren, die u.U. zu erheblich divergierenden Schlüssen kommen. ${ }^{381}$ Vielmehr soll hier nur die Grundproblematik der Saisonbereinigung aufgezeigt werden, um zu verdeutlichen, daß mit einer derartigen Analyse unweigerlich gewisse Einschränkungen verbunden sind. ${ }^{382}$

\subsubsection{Exkurs: Zeitreihenanalyse}

Insbesondere bei ökonomischen Zeitreihen findet man langfristige Veränderungen oder eine sich jährlich wiederholende Saisonfigur. ${ }^{383}$ Für diese ökonomischen Zeitreihen wurden daher Modelle entwickelt, die versuchen sollen die einzelnen Gegebenhei-

380 vgl. hierzu ausfuhrlich Kap. 2.2. Saisonbewegungen und deren Problematik für die Bauwirtschaft, S.50ff.

381 Anmerkung: Diese Tatsache unterstützt das weit verbreitete Vorurteil, daß man mit Statistik schließlich alles beweisen kann, vgl. hierzu auch Stier, W., Konstruktion und Einsatz von Digitalfiltern zur Analyse und Prognose ökonomischer Zeitreihen, Forschungsbericht Nr. 2760 des Landes Nordrhein-Westfalen, Bochum, 1978.

382 vgl. hierzu auch Birkenfeld, W., Methoden zur Analyse von kurzen Zeitreihen, S.7: Er sieht eine gravierende Schwäche vor allem in dem Mangel an "nicht-asymptotischen Aussagen" über die verwendeten Schătzfunktionen, Basel/Stuttgart, 1977.

383 So ist beispielsweise die Zahl der Arbeitslosen im Winter regelmaßßig großßer als im Sommer, ebenso hängt der Stromverbrauch von der Jahreszeit ab. 
ten zu berücksichtigen. Sie gehen dabei - wie bereits erwähnt ${ }^{384}$ - von den folgenden vier Komponenten aus: ${ }^{385}$

- Der Trend, das ist eine langfristige systematische Veränderung des mittleren Niveaus der Zeitreihe.

- Die Konjunkturkomponente, die eine mehrjährige, nicht notwendig regelmäBige Schwankung darstellt.

- Die Saison, das ist eine jahreszeitlich bedingte Schwankungskomponente, die sich relativ unverändert jedes Jahr wiederholt.

- Die Restkomponente, die die nicht zu klärenden Einflüsse oder Störungen zusammenfaßt.

Entscheidend für die statistische Analyse einer ökonomischen Zeitreihe ist es nun, inwieweit es gelingen kann, die Saisonschwankungen zu isolieren. Dafür müßte man die Zeitreihe zunächst in ihre Bewegungskomponenten zerlegen und die unerwünschten Einflußgrößen, d.h. die Trendkomponente, die Konjunkturkomponente und die Restkomponente, eliminieren. ${ }^{386}$ Dies setzt allerdings die Kenntnis des jeweiligen Einflusses sämtlicher Bewegungskomponenten voraus, um den tatsächlichen Saisoneinfluß als Residuum zu erhalten, was wiederum aufgrund des Ineinandergreifens und sich gegenseitig Beeinflussens der einzelnen Komponenten unmöglich wird. ${ }^{387}$

Die Vielzahl von Verfahren zur Saisonbereinigung, die dafür zur Verfügung stehen, stützten sich häufig auf Computerprogramme, die dem Benutzer ein Sortiment diverser Varianten offerieren. ${ }^{388}$ Hierdurch werden einerseits flexible Approximationen an

384 vgl. hierzu ausführlich Kap. 2.2.1. Saisonschwankung, S.50-53.

385 vgl. Schlittgen, R./Streitberg, B., Zeitreihenanalyse, S.9, München, 1991.

386 vgl. Leiner, B., Einführung in die Zeitreihenanalyse, S.6.

387 Hierin liegt ein zentraler Kritikpunkt an den "Komponentenmodellen" als Basis für Saisonbereinigungsverfahren, da sie bei der Auswahl von Funktionen bzw. Filtern zur Eliminierung der Komponenten willkürlich vorgehen, vgl. hierzu Schlittgen, R./Streitberg, B., Zeitreihenanalyse, S.68, München, 1991.

$388 \mathrm{Zu}$ nennen sind insbesondere das Census X11-, das ASA-II- und das Berliner Verfahren, die eine Mischung aus lokalen und globalen Modellansătzen darstellen und im allgemeinen zahlreiche kaum durchschaubare Iterationszyklen durchlaufen, vgl. hierzu insbesondere Schlittgen, R./Streitberg, B., Zeitreihenanalyse, S.68, München, 1991. 
die jeweiligen zu betrachtenden Zeitreihen ermöglicht, doch andererseits geht in der Fülle der Varianten der modellmäßige Überblick verloren. ${ }^{389}$

Alle entwickelten und praktizierten Saisonbereinigungsverfahren werden auch nach wie vor, insbesondere bezüglich ihrer methodischen Grundlagen, kritischen Analysen unterworfen. Außerdem ist man sich in der Notwendigkeit derartiger Bereinigungen für die Lösung konkreter Probleme der Wirtschaftsforschung und -politik durchaus einig, dennoch gehen die Meinungen darüber, wie die jeweiligen Vor- und Nachteile einzelner Verfahren zu bewerten bzw. ob sie als solche überhaupt zu erkennen sind, teilweise erheblich auseinander. ${ }^{390}$

Die unterschiedlichen statistischen Methoden mit denen die einzelnen Komponenten gegeneinander abgegrenzt und isoliert analysiert werden, dürfen aber nicht über die Tatsache hinwegtäuschen, daß die Verfahren alle der Gemeinsamkeit unterworfen sind, zur Berechnung von Saisonschwankungen die Monatswerte einer Reihe aufeinanderfolgender Jahre zu benötigen; denn "...nur dadurch gleichen sich Sonderbewegungen und einmalige sowie zufällige Einflüsse einigermaßen aus. "391

Die Ausführungen haben gezeigt, daß jede als Saisonschwankung bezeichnete Wirtschaftsbewegung mit einer gewissen Ungenauigkeit behaftet ist und eine exakte statistische Erfassung der "reinen" Saisonbewegung unmöglich ist. Dennoch will der Verfasser das im nächsten Kapitel beschriebene Phasendurchschnittsverfahren als Berechnungsgrundlage für die Wirkungsanalyse verwenden, da sich durchaus Rückschlüsse über die Struktur und die Intensität - d.h. einerseits über die Verteilung der saisonmäßigen Hoch- und Tiefpunkte und andererseits über die Ausschlagsweite der Saisonschwankungen ziehen lassen.

389 vgl. Leiner, B., Einführung in die Zeitreihenanalyse, S.54, München, 1991.

390 vgl. Stier, W., Konstruktion und Einsatz von Digitalfiltern zur Analyse und Prognose ökonomischer Zeitreihen, S.38ff.

391 vgl. Kellerer, H., Statistik im modernen Wirtschafts- und Sozialleben, S.100. 


\subsubsection{Das Phasendurchschnittsverfahren}

Das Vorgehen beim Phasendurchschnittsverfahren ${ }^{392}$ läßt sich im wesentlichen in die folgenden Schritte unterteilen. In einem ersten Schritt werden furr alle Monatswerte ${ }^{393}$ sogenannte Phasendurchschnitte (MD) gebildet, die sich aus dem arithmetischen Mittel aller Beobachtungen (B) gleichen Monats ergeben. Man bildet also z.B. für den Phasendurchschnitt des Monats Januar die Summe aller Januarwerte und dividiert diese durch ihre Anzahl. Bei einer Zeitreihe, in der für eine bestimmte Anzahl von Jahren $(\mathrm{J})$ die Beobachtungen für alle Monate $(\mathrm{M})$ vorliegen, stehen daher, entsprechend der Anzahl von Jahren multipliziert mit den Monaten, Daten zur Verfügung.

Im zweiten Schritt berechnet man den Gesamtdurchschnitt aller Beobachtungswerte, d.h. man summiert die Phasendurchschnitte der Monate und dividiert diese anschließend durch ihre Anzahl. Im Anschluß daran werden dann die Phasendurchschnitte in bezug auf den Gesamtdurchschnitt - durch die Bildung von sogenannten Saisonfaktoren (SF) oder auch Saisonindexziffern - relativiert. Man dividiert dabei z.B. den Januardurchschnitt durch den Gesamtdurchschnitt und verfährt entsprechend mit den anderen Monatsdurchschnitten. Durch diese Relativierung erhält man die Saisonfaktoren (SF), die je nach Ausgangswerten vom Durchschnittswert 1 mehr oder weniger stark abweichen können. Sind die Januarwerte beispielsweise überdurchschnittlich groß, so ist der entsprechende Saisonfaktor $>1$. Sind sie überdurchschnittlich klein, so ist er $<1$. Schließlich können noch in einem weiteren Schritt die Beobachtungen durch die zugehörige Saisonindexziffer dividiert werden, um somit den saisonbereinigten Wert zu erhalten.

Im Rahmen der Analyse der Förderungsmaßnahmen zur ganzjährigen Beschäftigung in der Bauwirtschaft werden die folgenden Berechnungsschritte des Phasendurchschnittsverfahrens durchgefürt:

1. Summe für einen Monat aus den Beobachtungen aller Jahre bilden.

2. Summe durch die Anzahl der Jahre teilen $\Rightarrow$ Phasendurchschnitt (MD).

3. Summierung der Phasendurchschnitte für alle Monate.

392 vgl. hierzu ausführlich Leiner, B., Einfuihrung in die Zeitreihenanalyse, S.54ff.

393 Anmerkung: Dies gilt entsprechend auch für Quartalsdaten. 
4. Phasensummendurchschnitt durch die Anzahl der Monate teilen $\Rightarrow$ Gesamtdurchschnitt (JD).

5. Bildung der Verhätnisse von Phasendurchschnitt zu Gesamtdurchschnitt $\Rightarrow$ Saisonfaktor (SF).

Die auf diese Weise gewonnenen Saisonfaktoren stellen natürlich keinesfalls die "reine" Saisonschwankung dar, die zu eliminieren unmöglich ist. ${ }^{394}$ Aber auch andere Saisonbereinigungsverfahren sind mit Einschränkungen verbunden und bieten keinen Ansatz, die nicht saisonbedingten Einflüsse gänzlich auszuschalten. Aufgrund der Regelmäßigkeit des baugewerblichen Produktionsablaufes, insbesondere des Beschäftigungsverlaufes, bei dem sich zyklische und außergewöhnliche Ursachen in verhältnismäßig engen Grenzen halten, erscheint das Phasendurchschnittsverfahren für die Wirkungsanalyse dieser Arbeit durchaus geeignet. ${ }^{395}$

\subsubsection{Sonstige Einschränkungen}

Eine weitere Einschränkung, die mit der Analyse der Förderungsmaßnahmen zur ganzjährigen Beschäftigung in der Bauwirtschaft verbunden ist, liegt in der Tatsache, daß sich die Ergebnisse der Wirkungsanalyse nur auf das frühere Bundesgebiet beziehen, weil die entsprechenden Statistiken erstmals für das Jahr 1991 gesamtdeutsche Ergebnisse mit der Unterteilung früheres Bundesgebiet, neue Bundesländer und Berlin-Ost liefern. ${ }^{396}$ Diese Einschränkung gilt allerdings nur für die im dritten Kapitel durchgeführte ex-post-Analyse der getroffenen Förderungsmaßnahmen. Im Rahmen der Diskussion alternativer Maßnahmen zur ganzjährigen Beschäftigung des vierten Kapitels werden die neuen Bundesländer mit einbezogen. Dies gilt insbesondere für den Ansatz eines Tarifmodells in Kapitel 4.4.

Im Zusammenhang mit den bereits erwähnten Bemühungen das Problem der ganzjährigen Beschäftigung in der Bauwirtschaft auf internationaler Ebene zu lösen, ${ }^{397}$ wird

\footnotetext{
394 vgl. hierzu ausführlich Kap. 2.2.1. Saisonschwankung, S.50ff.

395 Diese Auffassung vertritt auch Donner, weil die Genauigkeit des Phasendurchschnittsverfahrens (=Monatsdurchschnittsverfahren) den anderen Methoden in nichts nachstehe und zudem den Vorteil besitze, besonders anschaulich und rechentechnisch einfach zu sein, vgl. Donner, O., Die Saisonschwankungen als Problem der Konjunkturforschung, S.30ff.

396 vgl. Statistisches Bundesamt (Hrsg.), Statistisches Jahrbuch 1992, Vorwort.

397 vgl. Kap. 2.4.3. Sonstige Maßnahmen, S.76ff.
} 
immer wieder das Vorbild Schweden angeführt. ${ }^{398}$ Der Verfasser vertritt allerdings die Ansicht, daß ein sinnvoller Vergleich der ganzjährigen Beschäftigung in der Bauwirtschaft zwischen Deutschland und anderen Ländern - beispielsweise Schweden nur dann möglich wäre, wenn die entsprechenden Bauwirtschaften dieser Länder einschließlich ihrer Winterbauförderung - sofern vorhanden - und sonstiger Rahmenbedingungen, wie z.B. Witterungsverhältnisse, genauso umfangreich analysiert würden, wie das im Rahmen dieser Arbeit für die Bundesrepublik Deutschland geschieht. Eine bloße Analyse der veröffentlichten Literatur ist hierfür nicht ausreichend, zumal die dort aufgefürten Maßnahmen auch in Deutschland bereits bekannt bzw. schon getroffen worden sind. ${ }^{399}$ Daher muß ein internationaler Vergleich zur ganzjährigen Beschäftigung in der Bauwirtschaft im Rahmen dieser Arbeit unterbleiben.

\subsubsection{Zusammenfassung der Einschränkungen}

Faßt man an dieser Stelle alle beschriebenen Einschränkungen stichpunktartig zusammen, so ergeben sich die folgenden Punkte:

- Die Analysen des statistischen Zahlenmaterials beziehen sich hauptsächlich auf das Bauhauptgewerbe. Bei Abweichungen wird entsprechend darauf hingewiesen.

- Die Analyse der Auswirkungen von witterungsbedingten Einflüssen auf die ganzjährige Beschäftigung bzw. kontinuierliche Bautätigkeit beschränkt sich auf Witterungsdaten von sieben Städten. Diese verteilen sich jedoch geographisch auf die gesamten alten Bundesländer.

- Die Technik des Winterbaues gilt als gelöst, d.h. insbesondere bei der Anwendung von Vollschutzmaßnahmen steht einer kontinuierlichen Bauausführung von der technischen Seite her nichts im Wege.

398 vgl. o.V., Auch in Deutschland soll rund ums Jahr gebaut werden, in: FAZ, vom 16. Februar 1993 und Brännström, A., Neue Chancen für den Winterbau, S.20ff, in: Baugewerbe, Heft 24, 1990.

399 vgl. beispielsweise FAZ vom 16.02.93, Winterbau in Schweden ist selbstverstăndlich und Brännström, A., Neue Chancen für den Winterbau, S.20ff. in: Baugewerbe, Heft 24, 1990. 
- Auf einen Vergleich der Winterbauförderungsmaßnahmen mit anderen Ländern wird im Rahmen dieser Arbeit verzichtet.

- Die neuen Bundesländer können im Rahmen der Wirkungsanalyse des dritten Kapitels noch nicht berücksichtigt werden. In die Diskussion über künftige Maßnahmen zur Förderung der ganzjährigen Beschäftigung im vierten Kapitel, werden sie jedoch mit einbezogen.

Das folgende Kapitel definiert die Kriterien, anhand derer die Maßnahmen zur Förderung der ganzjährigen Beschäftigung in der Bauwirtschaft beurteilt werden sollen.

\subsection{Formulierung der Untersuchungskriterien aus den Zielvorstel- lungen}

Die Diskussion über die Zielvorstellungen der Beteiligten von den Förderungsmaßnahmen zur ganzjährigen Beschäftigung in der Bauwirtschaft ${ }^{400}$ hat gezeigt, daß diese Zielvorstellungen sehr unterschiedlicher Natur sind. So haben sich die Ziele in den rund 30 Jahren seit Einfuhrung erster gesetzlicher Regelungen mit dem Zweiten Änderungsgesetz zum AVAVG von 1959 bis heute nicht nur geändert, sondern neue Ziele sind hinzugetreten oder die Rangfolge hat gewechselt.

Es wäre demnach unzulässig, die Auswirkungen der Förderungsmaßnahmen von 1959 bis 1992 an einem Zielsystem zu messen, das auf den aktuellen Zielvorstellungen der Beteiligten basiert. Andererseits erscheint es nicht sinnvoll, für jeden charakteristischen Förderungszeitraum eigene Untersuchungskriterien aufzustellen, denn hierdurch würde die Vergleichbarkeit der Förderungszeiträume erheblich eingeschränkt werden.

Diese Auffassung wird nach Ansicht des Verfassers auch dadurch bestätigt, daß trotz der ausführlichen Diskussion der Zielvorstellungen in Abschnitt 2.5. sich keine exakten Abgrenzungen der Ziele zwischen den Zeiträumen definieren lassen und die angestrebten Ziele der Beteiligten in einzelnen Förderungszeiträumen teilweise widersprüchlich waren. So forderte man beispielsweise im Rahmen der Förderungsmaßnahmen von 1959 sowohl die Steigerung des Bauvolumens als auch dessen Begrenzung. Desweiteren sollte die kontinuierliche Bautätigkeit mit allen Mitteln verwirk-

400 vgl. hierzu ausführlich Kap. 2.5. Vorstellungen der Beteiligten von den Förderungsmaßnahmen zur ganzjährigen Beschäftigung, S.79ff. 
licht werden, ${ }^{401}$ dennoch schuf man die SWG-Regelung in Verbindung mit der Einführung des tariflichen Lohnausgleichszeitraumes. ${ }^{402}$

Aufgrund der Tatsache, daß schon bei der Einführung der Förderungsmaßnahmen auch produktive Zielvorstellungen eine Rolle gespielt haben und der genannten Schwierigkeiten bezüglich der Zuordnung der Zielvorstellungen auf die einzelnen Förderungszeiträume, möchte der Verfasser einen möglichst umfassenden Kriterienkatalog erstellen. Anhand dieses Kriterienkataloges werden dann alle Förderungszeiträume gleichermaßen untersucht, um einerseits die Vergleichbarkeit nicht einzuschränken und andererseits aber auch unbeabsichtigte Auswirkungen auf die wirtschaftlichen Bewegungsgrößen erkennen zu können.

Der Verfasser unterscheidet dabei zwischen quantitativen und qualitativen Zielvorstellungen der Beteiligten, wobei erstere unter den Primärkriterien und letztere unter den Sekundärkriterien zusammengefaßt werden.

\subsubsection{Primärkriterien}

Anhand der hier aufgeführten Primärkriterien sollen die Wirkungen der getroffenen Maßnahmen zur Förderung der ganzjährigen Beschäftigung in der Bauwirtschaft auf die einzelnen Zeiträume untersucht und auch quantifiziert werden. Für die Quantifizierung ist es erforderlich, auf monatlich erhobene Daten zurückgreifen zu können. ${ }^{403}$ Daher werden folgende Untersuchungskriterien bestimmt:

\section{Arbeitsmarktpolitische Kriterien:}

- Beseitigung der Saisonarbeitslosigkeit

- Stabilisierung der Beschäftigung, d.h. gleichmäßigere Beschäftigung auf hohem Niveau

Wirtschaftspolitische Kriterien:

- Verstärkung der winterlichen Bautätigkeit

- Erhöhung des Jahresbauvolumens insgesamt

401 vgl. BT.-Drucks. IIV1211, S.2.

402 vgl. hierzu ausführlich Kap. 2.5.1.1. AVAVG, S.80-83.

403 vgl. Kap. 3.3. Ergebnisse der Wirkungsanalyse, S.116. 
- Verwirklichung der kontinuierlichen Bautätigkeit, d.h. Verringerung der bauwirtschaftlichen Produktionsschwankungen

\section{Einkommenspolitische Kriterien:}

- Verstetigung des Bauarbeitereinkommens

- Erhöhung des Bauarbeitereinkommens

Die Wirkungen der Förderungsmaßnahmen in finanzpolitischer Hinsicht - insbesondere die geforderte Verbesserung der Relation zwischen Beitragszahlungen der Bauwirtschaft an die Bundesanstalt für Arbeit und deren Leistungen sowie die Erhöhung des Steueraufkommens - stehen zwar in ihrer Bedeutung hinter den sozial- und wirtschaftspolitischen Zielsetzungen zurück; sie dürfen jedoch nicht vernachlässigt werden. Daher werden die fiskalischen Effekte der Förderungsmaßnahmen, die sich erst im Anschluß an die Ergebnisse der Wirkungsanalyse quantifizieren lassen, im vierten Kapitel untersucht.

\subsubsection{Sekundärkriterien}

Unter den Sekundärkriterien werden diè qualitativen Effekte der Förderungsmaßnahmen zusammengefaßt. Diese sind größtenteils als Folgeerscheinungen, der Auswirkungen von Förderungsmaßnahmen auf die Primärkriterien, anzusehen. Aufgrund der Zielvorstellungen des Abschnitts 2.5. ergeben sich die folgenden Sekundärkriterien:

- Image- und Attraktivitätsverbesserung des Bauarbeiterberufes

- Verbesserung des sozialen Status der Bauarbeiter

- Verbesserung der Arbeitsbedingungen im Baugewerbe

- Beseitigung des Nachwuchsmangels an Lehrlingen

Anhand der genannten Primär- und Sekundärkriterien, die sich vor allem aus den Zielvorstellungen der Beteiligten ergeben haben, wird die Tragweite des Problems der "Ganzjährigen Beschäftigung in der Bauwirtschaft" deutlich. Im Abschnitt 3.3. werden nun die Wirkungen der getroffenen Förderungsmaßnahmen auf einzelne Primärkriterien analysiert. 


\subsection{Ergebnisse der Wirkungsanalyse}

Um das Ausmaß der Saisonschwankungen in der Bauwirtschaft - unter Berücksichtigung der entsprechenden Einschränkungen - zu ermitteln, wird das verfügbare statistische Zahlenmaterial analysiert. Hierbei dient insbesondere die sogenannte Bauberichterstattung der Analyse, die in selbständigen Erhebungen die Bereiche Bauhauptund Ausbaugewerbe in der Abgrenzung der Systematik der Wirtschaftszweige (SYPRO) erfaßt. Zu diesen monatlichen im Bauhaupt- und Ausbaugewerbe erhobenen Berichten melden die Baubetriebe mit 20 und mehr Beschäftigten sowie alle Arbeitsgemeinschaften die erforderlichen Daten. Diese Daten werden dann im Bauhauptgewerbe - mit Ausnahme der gemeldeten Auftragseingänge und Auftragsbestände - auf Ergebnisse für alle Betriebe aufgeschätzt. Grundlage hierfür sind die Ergebnisse der jährlichen Totalerhebung im Bauhauptgewerbe. Eine entsprechende Aufschätzung der im Ausbaugewerbe erhobenen Daten erfolgt nicht. ${ }^{404}$ Dadurch erklärt sich auch die gemachte Einschränkung auf das Bauhauptgewerbe in der Analyse des statistischen Zahlenmaterials. ${ }^{405}$

Für die Analyse der quantitativen Effekte der Maßnahmen zur Förderung der ganzjährigen Beschäftigung in der Bauwirtschaft, bezüglich der getroffenen Primär- und Sekundärkriterien ist es wichtig, auf monatlich erhobene Daten zurückgreifen zu können. Hierfür stehen folgende statistische Erhebungen zur Verfügung:

- Arbeitslose in den Bauberufen

- Beschäftigte im Bauhauptgewerbe

- Geleistete Arbeitsstunden im Bauhauptgewerbe

- Index der Nettoproduktion im Bauhauptgewerbe

- Bruttolohnsummen im Bauhauptgewerbe

In der Vorgehensweise zur Ermittlung der quantitativen Effekte werden die statistischen Daten entsprechend den gewählten "charakteristischen Förderungszeiträumen" zusammengefaßt und nacheinander - mit Hilfe des Phasendurchschnittsverfahrens im Zeitablauf analysiert. ${ }^{406}$

$\overline{404}$ vgl. Statistisches Bundesamt (Hrsg.); Ausgewählte Zahlen für die Bauwirtschaft, August 1992, in: Fachserie 4 Produzierendes Gewerbe, Einzelveröffentlichungen.

405 vgl. auch Kap. 3.1. Einschränkungen in der Untersuchung, S.95ff.

406 vgl. Kap. 2.4. Zeitlicher Abriß der Förderungsmaßnahmen zur ganzjăhrigen Beschäftigung, S.64ff. 


\subsubsection{Arbeitsmarktpolitische Effekte der getroffenen Förderungs- maßnahmen}

Als geeignete Zeitreihen für die Erfassung der Saisonschwankungen auf dem Arbeitsmarkt im Baugewerbe bieten sich die Statistiken der Arbeitslosen und die der Beschäftigten an. ${ }^{407}$ Hierbei ist zu berücksichtigen, daß der Spitzenbedarf an Bauarbeitern in den Sommermonaten zum Teil durch berufsfremde Kräfte, die nur während dieser Zeit im Baugewerbe tätig sind, sowie insbesondere durch ausländische Arbeitnehmer, die im Winter größtenteils in ihre Heimatländer zurückkehren, gedeckt wird. Außerdem ist die Fluktuation in diesem Wirtschaftszweig sehr groß, da ein nicht unbeträchtlicher Teil der Bauarbeiter in den Wintermonaten in andere Industriegruppen überwechselt. Aus diesen Gründen würden direkte Vergleiche zwischen den Schwankungen der Arbeitslosenzahlen und denen der Beschäftigtenzahlen, insbesondere durch einfache Umkehrung, zu fehlerhaften Ergebnissen führen. ${ }^{408}$

\subsubsection{Wirkungen auf die Arbeitslosenzahlen}

Zuerst sollen die Schwankungen der Arbeitslosen so dargestellt werden, wie sie vor dem Einsetzen der wirtschafts- und sozialpolitischen Maßnahmen zur Förderung der ganzjährigen Beschäftigung bestanden haben. Dadurch werden einerseits die Schwankungen in ihrem vollem Umfang nachgewiesen und andererseits bilden sie eine förderungsfreie Vergleichsbasis, an der der Erfolg der getroffenen Maßnahmen gemessen werden kann. ${ }^{409}$ Die folgende Abbildung zeigt den Verlauf der Arbeitslosen für die Jahre 1954 bis 1959.410

407 Anmerkung: Die Tabellen über den Verlauf der Arbeitslosen berücksichtigen das gesamte Baugewerbe (d.h. Bauhaupt- und Ausbaugewerbe), die über den Verlauf der Beschäftigten hingegen nur das Bauhauptgewerbe. Diese Tatsache ist bei etwaigen Vergleichen zwischen beiden Statistiken zu berücksichtigen.

408 vgl. auch van Gries, H.-A., Die Auswirkungen der Saisonschwankungen im Wohnungsbau auf die Gesamtwirtschaft. Eine Multiplikatoranalyse, S.19.

409 Anmerkung: Dies gilt entsprechend für alle weiteren Abschnitte zur Ermittlung der quantitativen Effekte der Förderungsmaßnahmen.

410 Anmerkung: Die amtliche Statistik liefert erst ab 1954 brauchbare Werte. Bis zu diesem Zeitpunkt wurden nur Betriebe mit 20 und mehr Beschäftigten erfaßt, wobei der Firmenkreis zudem im Oktober eines jeden Jahres neu festgesetzt wurde. 
Abbildung: 16

\begin{tabular}{|c|c|c|c|c|c|c|c|c|c|c|c|c|c|}
\hline \multicolumn{14}{|c|}{ Arbeitslose in den Bauberufent) 1954 - 195927} \\
\hline Jahr & (Januar') & Februar & März & April & Mal & Juni & Jull & August & September & Olctober & November & Desember & JD \\
\hline 1954 & 27.476 & 642.959 & 265.818 & 185.289 & 125.419 & 100.749 & 84.381 & 69.928 & 57.152 & 57.410 & 121.453 & 285.214 & 218.604 \\
\hline 1955 & 609.631 & 636.329 & 348.302 & 89.622 & 47.535 & 34.867 & 25.843 & 20.403 & 18.313 & 22.093 & 57.538 & 308.261 & 184.896 \\
\hline 1956 & 433.531 & 807.822 & 252.590 & 56.754 & 34.560 & 24.948 & 23.235 & 20.816 & 20.032 & 24.878 & 148.914 & 417.769 & 188.821 \\
\hline 1957 & 657.746 & 374.770 & 130.010 & 85.975 & 59.226 & 55.052 & 38.685 & 31.507 & 30.751 & 27.543 & 65.134 & 545.036 & 76.120 \\
\hline 1958 & 667.254 & 589.029 & 436.272 & 87.254 & 43.777 & 28.346 & 21.558 & 16.948 & 15.239 & 19.762 & 40.905 & 335.873 & 191.851 \\
\hline 1959 & 600.476 & 437.231 & 113.705 & 37.228 & 25.500 & 16.443 & 12.275 & 9.360 & 8.979 & 10.545 & 22.657 & $\left(130.196^{4)}\right.$ & 118.716 \\
\hline MD & 590.352 & 581.357 & 257.783 & 90.364 & 56.003 & 43.401 & 34.330 & 28.160 & 25.078 & 27.039 & 76.100 & 337.058 & 178668 \\
\hline SF & 3,34 & 3,24 & 1,43 & 0,50 & 0,31 & 0,24 & 0,19 & 0,16 & 0,14 & 0,16 & 0,42 & 1,88 & 18,00 \\
\hline
\end{tabular}

1) Die Berufsgruppe Bauberufe (24) beinhaltet: Maurer (2411), Maurerhelfer (2414), Zimmerer (2431), Dachdecker (2433), Straßen- und Tiefbauer (2444/45), Maler und Lackierer (2478), Baustätten- und Erdbewegungsarbeiter (2480)

2) Bundesgebiet ohne Saarland und Berlin

3) Arbeitslose jeweils am Ende des Monats

4) Beeinflußt durch den Beginn der gesetzlichen Regelungen zur Förderung der ganzjährigen Beschäftigung in der Bauwirtschaft

Quelle: Bundesanstalt für Arbeit, ANBA, Ergebnisse der Arbeitsstatistik: Die Arbeitslosen im Bundesgebiet nach Berufsgruppen, $1955 \mathrm{ff}$.

Wie sich anhand der Zahlen des obigen Zeitraumes ablesen läßt, haben die Schwankungen der Arbeitslosen in den Bauberufen stets die gleiche Struktur. Mit Beginn des Herbstes, im Oktober, steigt die Arbeitslosigkeit erstmals an und nimmt dann kontinuierlich bis zum Februar zu. Charakteristisch dabei ist, daß in jedem Jahr ein besonders steiler Anstieg im Dezember zu verzeichnen ist und das Maximum der Arbeitslosigkeit immer im Januar oder Februar liegt. Von da an verringert sie sich kontinuierlich bis zum September, wobei eine besonders starke Abnahme der Arbeitslosigkeit jedes Jahr im April zu beobachten ist. Faßt man diese Entwicklung zusammen, so herrscht während der einen Hälfte des Jahres - November bis April - mehr oder weniger "Unterbeschäftigung" und in der anderen Hälfte - Juni bis September - eine so große Nachfrage nach Bauarbeitern, daß hier durchaus von "Überbeschäftigung" gesprochen werden kann. ${ }^{411}$

Die erhebliche Diskrepanz zwischen Sommer- und Wintermonaten zeigt sich besonders deutlich, wenn als weitere quantitative Größe der sogenannte Saisonausschlag ${ }^{412}$

411 vgl. hierzu ausführlich Sabel, A., Winterarbeit in der Bauwirtschaft, S.1689f., in: Bau-Markt, 57.Jg., Nr.48, 1958. Er charakterisiert den Zustand auf dem Arbeitsmarkt der Bauwirtschaft mit 4 Monate Normalbeschäftigung, 4 Monate Überbeschäftigung und 4 Monate Unterbeschäftigung.

412 Anmerkung: Auch Schwankungsdifferenz oder Variationsbreite genannt, vgl. hierzu Fricke, W., Kosten und Kostenrechnung im Saisonbetrieb, S.19. 
ermittelt wird. Er berechnet sich aus der Differenz zwischen dem jahreszeitlich höchstem und niedrigstem Wert in der Arbeitslosigkeit.

Abbildung: 17

\begin{tabular}{|c|c|c|c|}
\hline \multicolumn{3}{|c|}{ Saisonausschlag der Arbeitslosigkeit 1954 - 1959} \\
\hline Jahr & Maximum & Minimum & \multicolumn{1}{c|}{ Differenz } \\
\hline 1954 & 642.959 & 57.152 & $\mathbf{5 8 5 . 8 0 7}$ \\
1955 & 636.329 & 18.313 & $\mathbf{6 1 8 . 0 1 6}$ \\
1956 & 807.822 & 20.032 & $\mathbf{7 8 7 . 7 9 0}$ \\
1957 & 657.746 & 30.751 & $\mathbf{6 2 6 . 9 9 5}$ \\
1958 & 667.254 & 15.239 & $\mathbf{6 5 2 . 0 1 5}$ \\
1959 & 600.746 & 8.979 & $\mathbf{5 9 1 . 7 6 7}$ \\
\hline Durchschnitt & $\mathbf{6 6 8 . 8 0 9}$ & $\mathbf{2 5 . 0 7 8}$ & 643.782 \\
\hline
\end{tabular}

Quelle: Eigene Berechnungen aus Abbildung 16.

Wie die Abbildung 17 zeigt, liegt diese Differenz in der Zeit vor Einführung der gesetzlichen Maßnahmen zur Förderung der ganzjährigen Beschäftigung in der Bauwirtschaft bei einem Jahresdurchschnitt von etwa 650.000 Arbeitslosen. Die Bedeutung dieser Schwankungen für die gesamte Volkswirtschaft der Bundesrepublik tritt noch eindringlicher hervor, wenn die Zahl der Arbeitslosen in den Bauberufen zur Gesamtzahl der Arbeitslosen in Beziehung gesetzt wird. Diesen Vergleich zeigt die folgende Abbildung.

Abbildung: 18

\begin{tabular}{|c|c|c|c|}
\hline \multicolumn{4}{|c|}{$\begin{array}{l}\text { Antell der Arbeitslosigheit in den Bauberimen an ier } \\
\text { (Gesambarbeitslosigketh) }\end{array}$} \\
\hline Jahr & Insgesamt & Bauberufe & $\%$ von Insgesamt \\
\hline 1954 & 1.220 .607 & 218.604 & 17,91 \\
\hline 1955 & 928.306 & 184.895 & 19,92 \\
\hline 1956 & 761.413 & 188.821 & 24,80 \\
\hline 1957 & 662.334 & 175.120 & 26,44 \\
\hline 1958 & 683.117 & 191.851 & 28,08 \\
\hline 1959 & 479.924 & $118.716^{2)}$ & $\left.24,74^{2}\right)$ \\
\hline Durchschnitt & 789.284 & 179.668 & 22,76 \\
\hline
\end{tabular}

1) Jahresdurchschnittswerte: Insgesamt und Bauberufe

2) Beeinflußt durch den Beginn der gesetzlichen Regelungen zur Förderung der ganzjăhrigen Beschäftigung in der Bauwirtschaft

Quelle: Eigene Berechnungen aus Abbildung 16 und Hauptergebnisse der Arbeits- und Sozialstatistik, 1955-1959. 
Der Anteil der arbeitslosen Bauarbeiter - der sich von Jahr zu Jahr erhöhte - beträgt mit durchschnittlich knapp 23\% fast ein Viertel der Gesamtarbeitslosigkeit. ${ }^{413}$ Interessant ist dabei die Feststellung, daß die Arbeitslosigkeit insgesamt kontinuierlich zurückging, während die Saisonarbeitslosigkeit im Baugewerbe in vollem Umfang bestehen blieb.

Spätestens an dieser Stelle wird klar, daß eine solche Entwicklung der Saisonarbeitslosigkeit, im Zeichen einer allgemein fortschreitenden Beschäftigung, für die Beteiligten und hier insbesondere für die Arbeitnehmer des Baugewerbes, sowie für die gesamte Volkswirtschaft, schwerwiegende Folgen haben muß. Inwieweit diese Entwicklung mit Hilfe der getroffenen Förderungsmaßnahmen gestoppt werden konnte, sollen die folgenden Abbildungen (19 bis 23) über die Arbeitslosen in den Bauberufen, getrennt nach Förderungszeiträumen, aufzeigen.

Abbildung: 19

\begin{tabular}{|c|c|c|c|c|c|c|c|c|c|c|c|c|c|}
\hline \multicolumn{14}{|c|}{ Arbeitslase in ben Bauberufent $1960-1968$} \\
\hline Jahr & Januar $^{2}$ ) & Februar & Mărz & Aprill & Mal & Junl & Jull & August & September & Oktober & November & Dezember & ID \\
\hline 1960 & 238.522 & 191.224 & 40.711 & 16.201 & 10.043 & 8.055 & 6.623 & 5.615 & 5.482 & 6.138 & 10.257 & 65.422 & 60.358 \\
\hline 1961 & 130.033 & 77.981 & 18.936 & 8.602 & 6.205 & 4.843 & 4.401 & 4.433 & 4.181 & 4.486 & 8.579 & 50.067 & 26.896 \\
\hline 1962 & 50.864 & 43.022 & 23.718 & 6.701 & 3.655 & 3.021 & 2.505 & 2.268 & 2.250 & 2.550 & 6.789 & 49.907 & 16.438 \\
\hline $1963^{3)}$ & 107.516 & 109.457 & 39.183 & 9.813 & 5.831 & 4.755 & 4.196 & 4.125 & 3.882 & 4.450 & 7.896 & 51.922 & 29.419 \\
\hline 1964 & 86.609 & 73.130 & 45.931 & 11.150 & 7.478 & 5.839 & 4.902 & 4.755 & 4.596 & 5.490 & 9.614 & 39.428 & 24.910 \\
\hline 1965 & 77.950 & 78.510 & 47.665 & 13.675 & 7.752 & 5.866 & 4.734 & 4.250 & 3.840 & 4.212 & 12.470 & 34.723 & 24.637 \\
\hline 1966 & 70.871 & 58.915 & 20.209 & 11.810 & 7.940 & 6.616 & 6.394 & 6.648 & 7.285 & 11.191 & 30.624 & 88.203 & 27.226 \\
\hline 1967 & 194.093 & 210.842 & 154.633 & 98.730 & 77.230 & 55.230 & 43.814 & 35.392 & 30.603 & 30.354 & 41.701 & 101.028 & 89.471 \\
\hline 1968 & 179.948 & 157.985 & 100.795 & 42.029 & 23.195 & 16.175 & 11.815 & 9.726 & 8.397 & 8.757 & 15.707 & 51.083 & 62.134 \\
\hline MD & 126.267 & 111.230 & 54.642 & 24.301 & 16.592 & 12.267 & 9.832 & 8.579 & 7.835 & 8.625 & 16.960 & 59.087 & 37.049 \\
\hline SF & 3,33 & 2,93 & 1,44 & 0,64 & 0,44 & 0,32 & 0,26 & 0,23 & 0,21 & 0,23 & 0,42 & 1,56 & 1,00 \\
\hline
\end{tabular}

1) Die Berufsgruppe Bauberufe (24) beinhaltet: Maurer (241), Betonbauer (242), Zimmerer/Dachdecker/Gerüstbauer (243), Straßenbauer (244), Tiefbauer (245), Bauausstatter (247), Bauhandlanger/Baustätten- und Erdbewegungsarbeiter (3911)

2) Arbeitslose am Ende des Monats

3) Ab 1963 einschließlich Berlin (West)

Quelle: Bundesanstalt für Arbeit, ANBA, Ergebnisse der Arbeitsstatistik: Die Arbeitslosen im Bundesgebiet einschlieBlich Berlin (West) nach Berufsgruppen, 1959ff.

413 Anmerkung: Hierbei ist zu berücksichtigen, daß der Durchschnittswert der Arbeitslosen in den Bauberufen im Jahr 1959 ohne den Einfluß der begonnenen gesetzlichen Förderung (Dezember 1959) erheblich höher ausgefallen wäre und damit auch der Anteil an der Gesamtarbeitslosigkeit, so daß ein durschnittlicher Anteil von 25\% oder mehr, durchaus realistisch gewesen wäre; vgl. Abbildung 16, Arbeitsiose in den Bauberufen 1954-1959, S109. 
Für den folgenden Untersuchungszeitraum 1969-1971 ist darauf hinzuweisen, daß in der Aussagefahigkeit der Ergebnisse sicherlich gewisse Einschränkungen in Kauf genommen werden müssen, da sich insbesondere hier die Frage stellt, ob ein Zeitraum von 3 Jahren überhaupt ausreicht, um eine Aussage über den typischen Verlauf einer Saisonbewegung zu ermöglichen. ${ }^{414}$ Aufgrund der eigenen gesetzlichen Bestimmungen, in der Zeit von 1969-1971, ${ }^{415}$ möchte der Verfasser diesen Zeitraum dennoch gesondert darstellen und ihn nicht dem vorherigen oder nachfolgenden zuordnen, weil eine derartige Vorgehensweise die Ergebnisse der anderen Zeiträume verfälschen würde.

Abbildung: 20

\begin{tabular}{|c|c|c|c|c|c|c|c|c|c|c|c|c|c|}
\hline \multicolumn{14}{|c|}{ Arbeissose in ien Bauberufen $1969 \cdot 1971$} \\
\hline Jahr & Januar $\left.{ }^{2}\right)$ & Februar & März & April & Mal & Junl & Jull & August & September & Oktober & November & Dezember & JD \\
\hline 1960 & 101.915 & 97.513 & 46.221 & 11.943 & 5.660 & 4.229 & 3.618 & 3.367 & 3.124 & 3.396 & 5.631 & 33.502 & 26.677 \\
\hline $1970^{3)}$ & 72.649 & 62.554 & 38.554 & 7.657 & 3.895 & 3.004 & 2.822 & 2.802 & 2.749 & 3.215 & 5.909 & 20.259 & 18.838 \\
\hline 1971 & 60.869 & 47.810 & 29.794 & 9.701 & 5.851 & 4.784 & 4.457 & 4.588 & 4.853 & 6.571 & 14.072 & 34.379 & 18.977 \\
\hline MD & 78.478 & 69.292 & 38.190 & 9.767 & 6.135 & 4.006 & 3.632 & 3.686 & 3.675 & 4.394 & 8.537 & 29.380 & 212408 \\
\hline SF & 3,66 & 3,22 & 1,78 & 0,46 & 0,24 & 0,19 & 0,17 & 0,17 & 0,17 & 0,20 & 0,40 & 1,37 & $1: 00$ \\
\hline
\end{tabular}

1) Die Berufsgruppe Bauberufe (24) beinhaltet: Maurer (241), Betonbauer (242), Zimmerer/Dachdecker/Gerüstbauer (243), Straßenbauer (244), Tiefbauer (245), Bauausstatter (247), Bauhandlanger/Baustätten- und Erdbewegungsarbeiter (3911)

2) Arbeitslose am Ende des Monats

3) Einführung einer neuen Klassifizierung der Bauberufe. Berufsgruppe 44-47 (Bauberufe), 48-49 (Bau- und Raumausstatter, Polsterer) und 51 (Maler, Lackierer und verwandte Berufe)

Quelle: Bundesanstalt für Arbeit, ANBA, Ergebnisse der Arbeitsstatistik: Die Arbeitslosen aus den Bauberufen, 1969ff.

Der Zeitraum 1972-1985 ist, was die Statistik der Arbeitslosen in den Bauberufen betriff, zweigeteilt. Die Ursache dafür liegt in einer Änderung des Umfanges der erhobenen Daten. So wurden die Arbeitslosen von 1972-1981 - mit Ausnahme der Jahre 1976 und 1977, die aus der Berechnung ausgeklammert werden - noch monatlich, ab 1982 aber nur noch Quartalsweise gemeldet. Diese Tatsache wird daher bei der Berechnung der Monats- bzw. Jahresdurchschnitte und der Saisonfaktoren berücksichtigt, d.h. auf eine Interpretation der Ergebnisse seit $1982 \mathrm{muß}$ aufgrund der geänderten Datenerfassung verzichtet werden. ${ }^{416}$

414 Diese Bedenken äußern auch andere Autoren, vgl. beispielsweise Goldack, G., Die Saisonnormale, in: Jahrbuch der Absatz- und Verbrauchsforschung, 3. Jg., Heft 2, 1957, S.173ff: Nach Goldack sollte die Beobachtungsdauer mindestens 5, besser 10 Jahre betragen,.

415 vgl. hierzu Kap. 2.4.1.3. 1969-71: Das Arbeitsförderungsgesetz, S.70ff.

416 Hinweis: Bei den Beschäftigtenzahlen dagegen kann auf alle monatlichen Daten von 1954 bis 1992 zurückgegriffen werden. 
Abbildung: 21

\begin{tabular}{|c|c|c|c|c|c|c|c|c|c|c|c|c|c|}
\hline \multicolumn{14}{|c|}{ Arbeitslose in den Bauberufent) 1972,1981} \\
\hline Jahr & Januar $\left.{ }^{2}\right)$ & Februar & März & April & Mal & Junt & Jull & August & September & Oktober & November & Dezember & JD \\
\hline 1972 & 72.914 & 66.658 & 28.478 & 14.990 & 10.595 & 8.284 & 7.266 & 6.761 & 6.694 & 7.448 & 11.402 & 27.228 & 2. \\
\hline 1973 & 57.833 & 52.090 & 32.624 & 15.767 & 8.700 & 7.196 & 7.653 & 6.081 & 8.076 & 10.768 & 23.597 & 76.284 & 5. \\
\hline 1974 & 117.827 & 114.136 & 91.333 & 60.019 & 47.422 & 42.410 & 29.058 & 28.541 & 41.039 & 42.546 & 68.597 & 136.954 & 8.3 \\
\hline 1975 & 206.213 & 211.716 & 182.007 & 128.420 & 106.600 & 97.983 & 72.355 & 60.572 & 65.215 & 68.320 & 80.219 & 126.397 & 117. \\
\hline 1976 & 172.937 & 178.789 & 126.458 & & & 47.047 & & & 36.114 & & & 92.732 & 28. \\
\hline 1977 & 151.082 & 145.875 & 93.860 & & & 46.933 & & & 37.350 & & & 90.505 & 94 \\
\hline 1978 & 134.974 & 142.259 & 101.974 & 2.320 & 46.523 & 6.009 & 1.136 & 30.428 & 30.729 & 30.508 & 36.753 & 69.667 & 61.94 \\
\hline 1979 & 128.740 & 125.646 & 69.004 & 37.430 & 24.896 & 23.559 & 21.158 & 21.356 & 21.481 & 22.235 & 32.091 & 54.837 & 48.536 \\
\hline 1980 & 113.322 & 102.470 & 62.440 & 38.224 & 31.217 & 31.302 & 29.770 & 30.676 & 32.803 & 36.449 & 54.226 & 99.433 & 55.194 \\
\hline 1981 & 158.795 & 157.643 & 119.403 & 74.941 & 63.516 & 66.143 & 62.077 & 65.766 & 75.360 & 84.045 & 117.992 & 192.641 & 103. \\
\hline MD & 123.827 & 121.577 & 85.908 & 52.764 & 42.434 & 39.111 & 32.659 & 31.273 & 35.175 & 37.790 & 53.110 & 97.930 & 62.78 \\
\hline SF & 1,97 & 1,94 & 1,37 & 0,84 & 0,68 & 0,62 & 0,52 & 0,50 & 0,56 & 0,60 & 0,85 & 1,56 & \\
\hline
\end{tabular}

1) Klassifizierung der Berufsgruppe Bauberufe: 44 (Maurer, Betonbauer), 45 (Zimmerer, Dachdecker, Gerüstbauer), 46 (Straßen- und Tiefbauer), 47 (Bauhilfsarbeiter), 48/49 (Bau- und Raumausstatter, Polsterer) und 51 (Maler, Lackierer und verwandte Berufe).

2) Arbeitslose am Ende des Monats

Quelle: Bundesanstalt für Arbeit, ANBA, Ergebnisse der Arbeitsstatistik: Die Arbeitslosen aus den Bauberufen, 1971ff.

Abbildung: 22

\begin{tabular}{|c|c|c|c|c|c|}
\hline \multicolumn{6}{|c|}{ Arbeitslose in den Babberufenl) 1982 - 1985} \\
\hline Jahr & März²) & Juni & September & Dezember & $\mathrm{JD}^{3)}$ \\
\hline 1982 & 234.101 & 148.977 & 150.034 & 256.114 & 189.372 \\
\hline 1983 & 303.197 & 176.594 & 151.735 & 247.837 & 220.875 \\
\hline 1984 & 293.666 & 183.810 & 174.735 & 263.754 & 227.002 \\
\hline 1985 & 362.608 & 217.244 & 185.283 & 268.057 & 257.760 \\
\hline MD & 298.393 & 181.656 & 165.447 & 258.941 & 223.752 \\
\hline SF & 1,33 & 0,81 & 0,74 & 1,16 & 1,00 \\
\hline
\end{tabular}

1) Klassifizierung der Berufsgruppe Bauberufe: 44 (Maurer, Betonbauer), 45 (Zimmerer, Dachdecker, Gerüstbauer), 46 (Straßen- und Tiefbauer), 47 (Bauhilfsarbeiter), 48/49 (Bau- und Raumausstatter, Polsterer) und 51 (Maler, Lackierer und verwandte Berufe).

2) Arbeitslose am Ende des Monats

3) Berechnung des Jahresdurchschnittes: $1 / 4 \mathrm{x}$ (Dezember des Vorjahres/2 + März + Juni + September + Dezember des Berichtjahres/2)

Quelle: Bundesanstalt für Arbeit, ANBA, Ergebnisse der Arbeitsstatistik: Die Arbeitslosen aus den Bauberufen, 1971ff. 
Abbildung: 23

\begin{tabular}{|c|c|c|c|c|c|}
\hline \multicolumn{7}{|c|}{ Arbeitslose in den Bauberufen 1 1986-1992 } \\
\hline Jahr & März & \multicolumn{1}{c|}{ Juni } & September & Dezember & \multicolumn{1}{c|}{ JD $^{2)}$} \\
\hline 1986 & 345.515 & 179.278 & 151.866 & 227.672 & $\mathbf{2 3 1 . 1 3 1}$ \\
1987 & 334.791 & 169.274 & 147.512 & 225.414 & $\mathbf{2 1 9 . 5 3 0}$ \\
1988 & 296.692 & 156.277 & 138.098 & 195.691 & $\mathbf{2 0 0 . 4 0 5}$ \\
1989 & 217.452 & 127.731 & 113.555 & 157.194 & $\mathbf{1 5 8 . 7 9 5}$ \\
1990 & 156.399 & 102.300 & 93.506 & 127.393 & $\mathbf{1 2 3 . 6 2 5}$ \\
1991 & 137.848 & 90.224 & 86.225 & 124.064 & $\mathbf{1 1 0 . 0 0 6}$ \\
1992 & 132.066 & 98.354 & 98.480 & 136.261 & $\mathbf{1 1 4 . 7 6 6}$ \\
\hline MD & $\mathbf{2 3 1 . 5 3 8}$ & $\mathbf{1 3 1 . 9 2 0}$ & $\mathbf{1 1 8 . 4 6 3}$ & $\mathbf{1 7 0 . 5 2 7}$ & $\mathbf{1 6 5 . 4 6 5}$ \\
\hline SF & $\mathbf{1 , 4 0}$ & $\mathbf{0 , 8 0}$ & $\mathbf{0 , 7 2}$ & $\mathbf{1 , 0 3}$ & $\mathbf{1 . 0 0}$ \\
\hline
\end{tabular}

1) Klassifizierung der Berufsgruppe Bauberufe: 44 (Maurer, Betonbauer), 45 (Zimmerer, Dachdecker, Gerüstbauer), 46 (Straßen- und Tiefbauer), 47 (Bauhilfsarbeiter), 48/49 (Bau- und Raumausstatter, Polsterer) und 51 (Maler, Lackierer und verwandte Berufe).

2) Berechnung des Jahresdurchschnittes: $1 / 4 \times$ (Dezember des Vorjahres/2 + Mărz + Juni + September + Dezember des Berichtjahres/2)

Quelle: Hauptverband der Deutschen Bauindustrie (Hrsg.), Baustatistisches Jahrbuch 1992, S.43 und Bundesanstalt für Arbeit, ANBA, Ergebnisse der Arbeitsstatistik, 1986ff.

Ein Vergleich der Arbeitslosenzahlen in den Bauberufen - getrennt nach Förderungszeiträumen - läßt unschwer erkennen, daß mit dem Inkraftreten gesetzlicher Winterbauförderungsmaßnahmen die negative Entwicklung der Saisonarbeitslosigkeit nicht nur gestoppt werden konnte, sondern sogar ein deutlicher Rückgang in der Arbeitslosenzahl der Bauarbeiter zu beobachten ist. So erreicht die Arbeitslosigkeit bereits im Dezember 1959, also dem Monat, in dem die Förderungsmaßnahmen erstmals wirksam wurden, mit nur 130.196 Arbeitslosen einen bislang für diesen Monat nie dagewesenen Tiefstand;417 und das, obwohl die Maßnahmen gar nicht mehr voll zur Geltung kommen konnten, da sie erst am 7. Dezember 1959 veröffentlicht wurden.

Dieser Trend in der Abnahme der Arbeitslosigkeit spiegelt sich zunächst auch in den jährlichen Durchschnittswerten wieder. Für den Zeitraum 1954-1959 liegt dieser Wert noch bei 179.668 Arbeitslosen und sinkt dann in 1960-1968 auf durchschnittlich 37.943 Arbeitslose. ${ }^{418}$ Dies ist eine Abnahme um fast $80 \%$ bzw. auf ein Fünftel des ursprünglichen Durchschnittswertes. Auch der Zeitraum 1969-1971 setzt diese be-

417 vgl. hierzu auch Abbildung 16, der bis dahin niedrigste Stand lag bei 285.214 Arbeitslosen im Jahr 1954.

418 vgl. Abbildung 16 und 19. 
gonnene Entwicklung fort und erreicht mit durchschnittlich 21.498 Arbeitslosen das Minimum aller untersuchten Zeiträume. Ab 1972 kehrt sich diese positive Entwicklung allerdings wieder um und die Arbeitslosenzahlen steigen von 62.788 (1972-81 $)^{419}$ über 223.752 (1982-85) auf 165.456 (1986-92) durchschnittliche Arbeitslose in den Bauberufen an. ${ }^{420}$ Parallel dazu erhöht sich auch die Gesamtarbeitslosigkeit wieder deutlich und zwar insbesondere in der Zeit von 1980 bis 1985, wo sie von knapp 900.000 auf 2,3 Millionen Arbeitslose ansteigt. ${ }^{421}$ Insofern liegt die Vermutung nahe, daß während dieser Zeit konjunkturelle Einflüsse erheblich zur Entwicklung der Arbeitslosigkeit in den Bauberufen beigetragen haben.

Die Wirkungen auf die Verminderung der saisonalen Arbeitslosigkeit lassen sich anhand der Durchschnittszahlen für die Zeit nach 1972 nur schwer erkennen. Diese wird erst sichtbar, wenn die Entwicklung der Saisonausschläge der Arbeitslosen in den Bauberufen nach Förderungszeiträumen vergleichend gegenübergestellt wird, wie die Abbildungen 24 bis 27 belegen.

Schon der erste Zeitraum von 1960-1968 nach Einführung der gesetzlichen Regelungen zeigt eine Verringerung des Saisonausschlages um $81 \%$ gegenüber des Zeitraumes 1954-1959 auf 122.624. ${ }^{422}$ Dabei ist zu berücksichtigen, daß die Ergebnisse der Jahre 1960 und 1961 noch durch gewisse Anpassungseffekte beeinflußt wurden und sich die Verhältnisse erst von 1962 an stabilisierten. Gegen Ende des "Förderungszeitraumes" änderte sich allerdings diese positive Entwicklung mit dem Beginn der ersten Baurezession, die sich schon im Jahr 1966 bemerkbar machte und etwa bis Mitte 1968 anhielt. ${ }^{423}$

419 Hinweis: Für die Jahre 1976 und 1977 wurden die Arbeitslosen nur in den Monaten Dezember bis März, sowie Juni und September erhoben. Daher werden diese beiden Jahre in den Berechnungen nicht berücksichtigt; vgl. Abbildung 21, S.122.

420 Anmerkung: Bezüglich der Vergleichbarkeit der Arbeitslosenzahlen muß an dieser Stelle erwähnt werden, daß die Arbeitslosen in den Bauberufen seit 1982 nur noch Quartalsweise erhoben werden und daher nur noch 4 statt der bis dahin 12 Werte für die Analyse zur Verfügung stehen.

421 vgl. Statistisches Bundesamt (Hrsg.), Statistisches Jahrbuch 1992 für die Bundesrepublik Deutschland, S.127.

422 vgl. Abbildungen 17 und 24.

423 Anmerkung: Hier zeigt sich der Einfluß von Konjunkturschwankungen auf den Verlauf der Saisonbewegungen, vgl. auch Kap. 2.1.3. Baukonjunkturelle Entwicklung und Prognose, S.42ff. 
Abbildung: 24

\begin{tabular}{|c|r|r|r|}
\hline \multicolumn{3}{|c|}{ Saisonausschlag der Arbeitslosigkelt 1960-1968 } \\
\hline Jahr & Maximum & \multicolumn{1}{|c|}{ Minimum } & \multicolumn{1}{c|}{ Differenz } \\
\hline 1960 & 238.522 & 5.482 & 233.040 \\
1961 & 130.033 & 4.181 & 125.852 \\
1962 & 50.864 & 2.250 & 48.614 \\
1963 & 109.457 & 3.882 & 105.575 \\
1964 & 86.609 & 4.596 & 82.013 \\
1965 & 78.510 & 3.840 & 74.670 \\
1966 & 88.203 & 6.394 & 81.809 \\
1967 & 210.842 & 30.354 & 180.488 \\
1968 & 179.948 & 8.397 & 171.551 \\
\hline Durchschnitt & $\mathbf{1 3 0 . 3 3 2}$ & $\mathbf{7 . 7 0 8}$ & $\mathbf{1 2 2 . 6 2 4}$ \\
\hline
\end{tabular}

Quelle: Eigene Berechnungen aus Abbildung 19.

Abbildung: 25

\begin{tabular}{|c|r|c|c|}
\hline Saisonausschlag der Arbeitslosigkeit & 1969-1971 \\
\hline Jahr & Maximum & Minimum & Differenz \\
\hline 1969 & 101.915 & 3.124 & 98.791 \\
1970 & 72.649 & 2.749 & 69.900 \\
1971 & 60.869 & 4.457 & 56.412 \\
\hline Durchschnitt & $\mathbf{7 8 . 4 7 8}$ & $\mathbf{3 . 4 4 3}$ & $\mathbf{7 5 . 0 3 4}$ \\
\hline
\end{tabular}

Quelle: Eigene Berechnungen aus Abbildung 20.

Abbildung: 26

\begin{tabular}{|c|r|r|r|}
\hline Saisonausschlag der Arbeitslosigkeit 1972.1985 \\
\hline Jahr & \multicolumn{1}{|c|}{ Maximum } & \multicolumn{1}{|c|}{ Minimum } & \multicolumn{1}{c|}{ Diftorenz } \\
\hline 1972 & 72.914 & 6.761 & 66.153 \\
1973 & 76.284 & 6.081 & 70.203 \\
1974 & 136.954 & 28.541 & 108.413 \\
1975 & 211.716 & 60.572 & 151.144 \\
1976 & 178.789 & 36.114 & 142.675 \\
1977 & 151.082 & 37.350 & 113.732 \\
1978 & 142.259 & 30.428 & 111.831 \\
1979 & 128.740 & 21.158 & 107.582 \\
1980 & 113.322 & 29.770 & 83.552 \\
1981 & 192.641 & 62.077 & 130.564 \\
1982 & 256.114 & 148.977 & 107.137 \\
1983 & 303.197 & 151.735 & 151.462 \\
1984 & 293.666 & 174.735 & 118.931 \\
1985 & 362.608 & 185.283 & 177.325 \\
\hline Durchschnit & $\mathbf{1 8 7 . 1 6 3}$ & $\mathbf{6 9 . 9 7 0}$ & $\mathbf{1 1 7 . 1 9 3}$ \\
\hline
\end{tabular}

Quelle: Eigene Berechnungen aus Abbildungen 21 und 22. 
Nach Beendigung der Rezessionsphase 1969 ergeben sich dann wieder Werte, die innerhalb der Differenzen liegen, wie sie für die Zeit zwischen 1962 und 1965 angeführt wurden. Diese Trendwende, zu einer erneut positiven Entwicklung, wird unterstützt durch eine Periode des "Bau-Booms" zu Beginn der 70er Jahre, wie auch die Ergebnisse der Saisonausschläge von 1972 und 1973 bestätigen. ${ }^{424}$

Die zweite Baurezession (1973-1975) verlief dann parallel mit der bislang schärfsten Wirtschaftskrise in der Geschichte der Bundesrepublik Deutschland und ließ die Arbeitslosenzahlen wieder stark ansteigen. Begleitet von einem nachhaltigen Rückgang des öffentlichen Bauvolumens, folgte schließlich zu Beginn der 80er Jahre die dritte und einschneidendste Baurezession, die sich unter Einschluß einer Stagnationsphase bis 1987 fortsetzte. ${ }^{425}$ Auch wenn einzelne Saisonausschläge diese konjunkturellen Einflüsse teilweise widerspiegeln, so liegen die Werte insgesamt noch erheblich unter dem Höchststand der Arbeitslosigkeit vor Inkrafttreten der Winterbauförderung. ${ }^{426}$

Abbildung: 27

\begin{tabular}{|c|c|c|c|}
\hline \multicolumn{4}{|c|}{ Saisonausschlag der Arbeitslosigkeit 1986-1992 } \\
\hline Jahr & Maximum & Minimum & \multicolumn{1}{c|}{ Differenz } \\
\hline 1986 & 345.515 & 151.866 & 193.649 \\
1987 & 334.791 & 147.512 & 187.279 \\
1988 & 296.692 & 138.098 & 158.594 \\
1989 & 217.452 & 113.555 & 103.897 \\
1990 & 156.399 & 93.506 & 62.893 \\
1991 & 137.848 & 86.225 & 51.623 \\
1992 & 132.066 & 98.354 & 33.712 \\
\hline Durchschnitt & $\mathbf{2 3 1 . 5 3 8}$ & $\mathbf{1 1 8 . 4 4 5}$ & $\mathbf{1 1 3 . 0 9 2}$ \\
\hline
\end{tabular}

Quelle: Eigene Berechnungen aus Abbildung 23.

Aufgrund der gemachten Feststellungen, erscheint eine Analyse des statistischen Zahlenmaterials der Jahre, die durch starke konjunkturelle Einflüsse ${ }^{427}$ beeinflußt sind nicht unbedingt sinnvoll, weil hier die Konjunkturschwankungen die Saisonschwankungen zu sehr überlagern. Zwar läßt sich, wie bereits dargelegt wurde, die "reine" Saisonbewegung ohnehin nicht eliminieren; ${ }^{428}$ daß heißt aber keineswegs, daß die

424 vgl. auch Kap. 2.1.3. Baukonjunkturelle Entwicklung und Prognose, S.42ff.

425 vgl. auch Abbildung 7: Reale Veränderungen von Bauvolumen und BSP zum Vorjahr in \%, S.43.

426 vgl. Abbildung 17.

427 Insbesondere die genannten Rezessions- und Boomphasen, vgl. auch Kap. 3.3.1.3. Erklärungsmöglichkeiten, S.132ff.

428 vgl. Kap. 3.1.5.1. Exkurs: Zeitreihenanalyse, S.107ff. 
Jahre, in denen die Saisonkomponente einen im Vergleich zum sonstigen Beobachtungszeitraum geringeren Einfluß auf die Zeitreihe ausübt, bei der Analyse gänzlich unberücksichtigt bleiben dürfen.

Die folgende Abbildung der Saisonfaktoren der Arbeitslosen in den Bauberufen faßt die gewonnenen Erkenntnisse - getrennt nach Förderungszeiträumen - noch einmal zusammen.

Abbildung: 28

\begin{tabular}{|c|c|c|c|cc|c|}
\hline \multicolumn{6}{|c|}{ Saisonfaktoren der Arbeitslosen in ien Bauberufen } \\
\hline Zeitraum & $\mathbf{1 9 5 4 - 1 9 5 9}$ & $\mathbf{1 9 6 0 - 1 9 6 8}$ & $\mathbf{1 9 6 9 - 1 9 7 1}$ & $\mathbf{1 9 7 2 - 1 9 8 1}$ & $\mathbf{1 9 8 2 - 1 9 8 5}$ & $\mathbf{1 9 8 6 - 1 9 9 2}$ \\
\hline Januar & 3,34 & 3,33 & 3,65 & 1,97 & & \\
Februar & 3,24 & 2,93 & 3,22 & 1,94 & & \\
März & 1,43 & 1,44 & 1,78 & 1,37 & 1,16 & 1,40 \\
April & 0,50 & 0,64 & 0,45 & 0,84 & & \\
Mai & 0,31 & 0,44 & 0,24 & 0,68 & & \\
Juni & 0,24 & 0,32 & 0,19 & 0,62 & 0,74 & 0,80 \\
Juli & 0,19 & 0,26 & 0,17 & 0,52 & & \\
August & 0,16 & 0,23 & 0,17 & 0,50 & & \\
September & 0,14 & 0,21 & 0,17 & 0,56 & 0,81 & 0,72 \\
Oktober & 0,15 & 0,23 & 0,20 & 0,60 & & \\
November & 0,42 & 0,42 & 0,40 & 0,85 & & \\
Dezember & 1,88 & 1,56 & 1,37 & 1,56 & 1,33 & 1,03 \\
\hline JD & 1,00 & 1,00 & 1,00 & 1,00 & 1,00 & 1,00 \\
\hline SA & 3,20 & 3,12 & 3,48 & 1,47 & $(0,59)$ & $(0,68)$ \\
\hline
\end{tabular}

Quelle: Abbildungen 16, 19 bis 23.

Läßt man hier den Zeitraum 1969-1971 außer acht, ${ }^{429}$ so ist festzustellen, daß sich die Saisonfaktoren aller Monate von Zeitraum zu Zeitraum mehr und mehr dem Idealwert von 1,00 nähern. Diese Entwicklung spiegeln auch die Saisonausschläge wider, die sich kontinuierlich und ganz besonders mit Einführung der Winterbaunovelle, von 3,20 über 3,12 auf 1,47 verringert haben, was einen Rückgang von insgesamt 55\% bedeutet. ${ }^{430}$ Hierbei ist zusätzlich zu berücksichtigen, daß die sich hinter dem Saisonausschlag verbergende absolute Zahl der Arbeitslosigkeit, von durchschnittlich 650.000 Arbeitslosen im Zeitraum 1954-1959, auf durchschnittlich etwa $120.000 \mathrm{Ar}$ beitslose in den Zeiträumen nach Einführung der Förderungsmaßnahmen zurückgegangen ist.

429 Anmerkung: Auf die Schwierigkeiten bei der Analyse dieses Zeitraumes wurde bereits mehrfach hingewiesen (z.B. 3 Jahre, relativ ungünstige Witterungsverhältnisse).

430 Anmerkung: Aufgrund der fehlenden monatlichen Erhebungen lassen sich die Saisonausschläge ab 1982 nur noch Quartalsweise bilden und können daher nicht mit den vorherigen Ergebnissen verglichen werden. Dennoch bestätigen die vorhandenen Monatsdaten den beschriebenen Trend. 
Es bleibt daher abschließend festzuhalten, daß die Hoffnungen, die der Gesetzgeber und die Sozialpartner des Baugewerbes in die Maßnahmen zur Förderung der ganzjährigen Beschäftigung in der Bauwirtschaft setzten - soweit es die Saisonarbeitslosigkeit betrifft - sich weitgehend erfüllt haben. ${ }^{431}$

\subsubsection{Wirkungen auf die Beschäftigtenzahlen}

Um die Wirkungen der Förderungsmaßnahmen auf die Beschäftigtenzahlen zu ermitteln, wird die Entwicklung der Beschäftigung im Bauhauptgewerbe in den folgenden Abbildungen dargestellt.

Abbildung: 29

\begin{tabular}{|c|c|c|c|c|c|c|c|c|c|c|c|c|c|}
\hline \multicolumn{14}{|c|}{ Beschäftigtel) im Bauhauptgewerbe $1954-1959$} \\
\hline Jahr & Januar & Februar & März & April & Mal & Junl & $\left.\mathrm{Jull}^{2}\right)$ & August & September & Oktober & November & Dezember & JD \\
\hline 1954 & 521.636 & 513.902 & 884.381 & 975.882 & 1.036 .937 & 1.083 .517 & 1.118.977 & 1.142 .884 & 1.157 .988 & 1.152 .068 & 1.107 .523 & 948.479 & 970.348 \\
\hline 1955 & 657.152 & 600.689 & 902.491 & 1.136 .101 & 1.200 .695 & 1.230 .882 & 1.256.067 & 1.262.122 & 1.253 .568 & 1.239 .723 & 1.197.381 & 1.016.910 & 1.079 .482 \\
\hline 1956 & 834.621 & 440.128 & 997.479 & 1.194 .712 & 1.250 .548 & 1.263 .371 & 1.271 .706 & 1.257 .989 & 1.237 .049 & 1.216.267 & 1.139.188 & 898.283 & 1.083 .445 \\
\hline 1957 & 708.396 & 892.889 & 1.072 .807 & 1.129 .733 & 1.159 .305 & 1.149.980 & 1.178 .753 & 1.181 .325 & 1.167 .941 & 1.171 .804 & 1.144 .460 & 833.134 & 1.066 .877 \\
\hline 1958 & 668.013 & 708.545 & 864.058 & 1.110 .545 & 1.171 .016 & 1.196 .410 & 1.231 .482 & 1.228 .799 & 1.230 .690 & 1.223 .488 & 1.198 .042 & 1.010 .889 & 1.070 .166 \\
\hline $1959^{3)}$ & 786.823 & 861.053 & 1.147 .442 & 1.245 .563 & 1.262 .949 & 1.285 .569 & 1.300 .986 & 1.292 .329 & 1.287 .314 & 1.273 .462 & 1.242 .958 & 1.171.198 & 1.179 .804 \\
\hline MD & 696.107 & 669.634 & 978.110 & 1.132 .000 & 1.120 .242 & 1.201 .622 & 1.226 .329 & 1.227 .678 & 1.222 .425 & 1.212 .002 & 1.171 .692 & 979.816 & 1.074 .853 \\
\hline SF & 0,65 & 0,62 & 0,91 & 1,05 & 1,10 & 1,12 & 1,14 & 1,14 & 1,14 & 1,13 & 1,09 & 0,91 & 1,00 \\
\hline
\end{tabular}

1) Beschäftigte sind hier alle am Monatsende im Betrieb Tătigen Facharbeiter einschließlich Poliere und Meister, Fachwerker und Werker, Helfer und Hilfsarbeiter sowie gewerblich Auszubildende

2) Ab Juli 1959 einschließlich Saarland

3) Dezember 1959: Beeinflußt durch den Beginn der gesetzlichen Regelungen zur Förderung der ganzjährigen Beschäftigung in der Bauwirtschaft

Quelle: Statistisches Bundesamt (Hrsg.), Zahlen aus der Bauwirtschaft, Ergebnisse der monatlichen Bauberichterstattung für Betriebe, 1955-1960

Ähnlich der Entwicklung bei den Arbeitslosenzahlen unterliegen auch die Beschäftigtenzahlen im Bauhauptgewerbe - wie ein Blick auf die Abbildung 29 zeigt - Jahr für Jahr nahezu gleichen Schwankungen. Nach dem Tiefstand im Januar/Februar steigt die Beschäftigung mit Beginn des Frühjahres (März/April) steil an und erreicht ihren Höhepunkt in der Zeit von Juli bis September. Danach fällt sie zunächst langsam ab (Oktober/November), bis im Dezember der erste starke Einbruch erfolgt. Die Intensi-

431 vgl. auch BT-Drucks. IV/643, S.9 und Krämer, K., Der Winterbau, S.140f. 
tät der Schwankungen wird durch die Tatsache verdeutlicht, daß die Zahl der Beschäftigten dieses förderungsfreien Zeitraumes um etwa $45 \%$ zwischen dem Minimum zu Beginn des Jahres und dem Maximum der Monate Juli bis September differiert.

Abbildung: 30

\begin{tabular}{|c|c|c|c|c|c|c|c|c|c|c|c|c|c|}
\hline \multicolumn{14}{|c|}{ Beschâfígtel) im Bauhauptgewerbe $1960-196843$} \\
\hline Jahr & Januar & Februar & März & pril & Mai & Juni & Jull & August & September & Oktober & November & Dezember & JD \\
\hline 1960 & 1.059 .182 & 1.060 .668 & 1.193 .569 & 1.237 .559 & 1.263 .701 & 1.268 .436 & 1.292.273 & 1.281 .809 & 1.261 .961 & 1.239 .429 & 1.227 .720 & 1.178.102 & 1.213. \\
\hline 1961 & 1.100 .525 & 1.152 .675 & 1.223 .869 & 1.254 .333 & 1.267 .879 & 1.290 .351 & 1.315 .186 & 1.308 .173 & 1.291 .749 & 1.284 .526 & 1.268 .609 & 1.224 .790 & 1.248 \\
\hline 1962 & 1.190 .939 & 1.203 .131 & 1.262 .381 & 1.319 .454 & 1.350 .966 & 1.363 .922 & 1.398 .332 & 1.389 .042 & 1.374 .508 & 1.368 .164 & 1.343 .948 & 1.287 .543 & 1.321 .028 \\
\hline $1963^{2)}$ & 1.235 .338 & 1.221 .289 & 1.361 .489 & 1.448 .845 & 1.489 .609 & 1.501 .768 & 1.515 .282 & 1.507 .018 & 1.488 .412 & 1.473 .815 & 1.448 .640 & 1.394.128 & 1.423. \\
\hline 1964 & 1.321 .202 & 1.339 .364 & 1.409 .783 & 1.486 .918 & 1.502 .677 & 1.520 .535 & 1.525 .312 & 1.515 .615 & 1.504 .346 & 1.480 .876 & 1.451.363 & 1.392.462 & 1.464 .20 \\
\hline 1965 & 1.323 .686 & 1.312 .774 & 1.414 .280 & 1.478 .206 & 1.494.261 & 1.505 .795 & 1.512 .952 & 1.513 .761 & 1.502 .803 & 1.482 .409 & 1.447 .095 & 1.383 .360 & 1.447 .6 \\
\hline 1966 & 1.317 .655 & 1.360 .494 & 1.443 .749 & 1.473 .538 & 1.480 .031 & 1.484 .717 & 1.475 .110 & 1.468 .629 & 1.451 .144 & 1.421 .795 & 1.370 .837 & 1.285.915 & 419 \\
\hline 1967 & 1.165 .751 & 1.140 .278 & 1.219 .592 & 1.260 .063 & 1.282.166 & 1.298 .764 & 1.312 .183 & 1.329 .631 & 1.328 .085 & 1.329 .145 & 1.313 .658 & 1.260.212 & 1 \\
\hline 1968 & 1.183 .110 & 1.186 .685 & 1.238 .629 & 1.287 .798 & 1.306 .533 & 1.315 .641 & 1.333.984 & 1.340 .248 & 1.334 .308 & 1.334 .663 & 1.316 .912 & 1.274 .734 & 1.287 .770 \\
\hline MD & 1.210 .821 & 1.219 .706 & 1.307 .482 & 1.360 .746 & 1.381 .980 & 1.394 .437 & 1.408 .967 & 1.406.992 & 1.393 .036 & 1.379 .426 & 1.364 .309 & 1.297.916 & 1.342 \\
\hline SF & 0,90 & 0,91 & 0,97 & 1,01 & 1,03 & 1,04 & 1,05 & 1,05 & 1,04 & 1,03 & 1,01 & 0,97 & \\
\hline
\end{tabular}

1) Beschäftigte sind hier alle am Monatsende im Betrieb Tätigen Facharbeiter einschließlich Poliere und Meister, Fachwerker und Werker, Helfer und Hilfsarbeiter sowie gewerblich Auszubildende

2) Ab 1963 einschließlich Berlin (West)

Quelle: Statistisches Bundesamt (Hrsg.), Fachserie 4: Produzierendes Gewerbe: Ausgewählte Zahlen für die Bauwirtschaft, Ergebnisse der monatlichen Bauberichterstattung für Betriebe, Dezember und Jahr 1963-1970.

Wie ein Vergleich der Abbildungen 29 und 30 zeigt, haben sich die Beschäftigtenzahlen im Bauhauptgewerbe bereits unmittelbar nach Inkraftreten der gesetzlichen Förderungsmaßnahmen weitgehend stabilisiert. Dies verdeutlicht die Schwankungsbreite der Saisonfaktoren, die auf 0,15 zurückgegangen ist; ${ }^{434} \mathrm{~d} . \mathrm{h}$. die Schwankungen in den Beschäftigtenzahlen betragen nur noch etwa $14 \%$ während des ganzen Jahres. Ob dieser Trend weiter fortgesetzt werden konnte, zeigen die folgenden Abbildungen 31 bis 33 .

432 Berechnet aus dem Verhältnis der Saisonfaktoren (SF) 0,62 bzw. 0,65 zu 1,14.

433 Hinweis: Eine im Jahr 1961 durchgeführte Arbeitsstättenzählung brachte das Ergebnis, daß die Beschäftigtenzahl für das Bauhauptgewerbe um etwa $2 \%$ zu niedrig angesetzt war. Daher ist die Vergleichbarkeit des Zahlenmaterials von 1962 an mit den Zahlen der Vorjahre eingeschränkt; vgl. auch Wirtschaft und Statistik, 2/1963, S.102ff.

434 vgl. auch Abbildung 34, S.131. 
Abbildung: 31

\begin{tabular}{|c|c|c|c|c|c|c|c|c|c|c|c|c|c|}
\hline \multicolumn{14}{|c|}{ Beschätígtel im Banhauptgewerbe $1969-1971$} \\
\hline Jahr & Januar & Februar & März & April & Mal & Juni & Jull & August & Septenber & Oktober & November & Dezember & JD \\
\hline 1969 & 1.215 .761 & 1.201 .040 & 1.257 .125 & 1.311 .570 & 1.330 .246 & 1.341 .650 & 1.353 .689 & 1.351 .209 & 1.344 .636 & 1.329 .083 & 1.308 .092 & 1.266 .778 & 1.300 .907 \\
\hline 1970 & 1.206 .823 & 1.199 .884 & 1.262 .450 & 1.322 .688 & 1.342 .984 & 1.362 .467 & 1.379 .447 & 1.380 .621 & 1.378 .046 & 1.359 .623 & 1.338 .498 & 1.302 .923 & 1.319 .706 \\
\hline 1971 & 1.238 .710 & 1.233 .524 & 1.308 .307 & 1.350 .299 & 1.360 .666 & 1.367 .078 & 1.373 .301 & 1.378 .276 & 1.371 .907 & 1.355 .003 & 1.327 .580 & 1.283 .175 & 1.328.986 \\
\hline MD & 1.220 .431 & 1.211 .403 & 1.276 .961 & 1.328 .126 & 1.344 .632 & 1.367 .065 & 1.368 .812 & 1.370 .036 & 1.364 .863 & 1.347 .903 & 1.324 .723 & 1.284 .292 & 1.316 .632 \\
\hline SF & 0,93 & 0,92 & 0,97 & 1,01 & 1,02 & 1,03 & 1,04 & 1,04 & 1,04 & 1,02 & 1,01 & 0,98 & 1,00 \\
\hline
\end{tabular}

1) Beschäftigte sind hier Facharbeiter, Fachwerker und Werker sowie Gewerblich Auszubildende

Quelle: Statistisches Bundesamt (Hrsg.), Fachserie 4: Produzierendes Gewerbe: Ausgewăhlte Zahlen für die Bauwirtschaft, Ergebnisse der monatlichen Bauberichterstattung für Betriebe, Dezember und Jahr 1970-1974.

Abbildung: 32

\begin{tabular}{|c|c|c|c|c|c|c|c|c|c|c|c|c|c|}
\hline \multicolumn{14}{|c|}{ Beschäftigtel) im Bauhaumtgewerbe $1972-1985$} \\
\hline Jahr & Januar & Februar & Mărz & April & Mal & Juni & Jull & August & September & Oktober & November & Dezember & JD \\
\hline 1972 & 1.190 .187 & 1.212 .356 & 1.305 .503 & 1.332 .432 & 1.343 .069 & 1.352 .197 & 1.354 .184 & 1.360 .243 & 1.351 .151 & 1.336 .505 & 1.322 .231 & 1.287.853 & 1.312 .326 \\
\hline 1973 & 1.221 .669 & 1.212 .595 & 1.277 .054 & 1.307 .267 & 1.321 .049 & 1.323 .882 & 1.328 .346 & 1.321 .161 & 1.307 .504 & 1.286 .229 & 1.254 .549 & 1.202.205 & 1.280 .283 \\
\hline 1974 & 1.137 .737 & 1.115 .230 & 1.150 .239 & 1.162 .583 & 1.160 .262 & 1.154 .237 & 1.155 .687 & 1.148 .228 & 1.137 .311 & 1.119 .387 & 1.086.992 & 1.045 .764 & 1.131. \\
\hline 1975 & 976.503 & 943.994 & 976.363 & 1.002 .772 & 1.009 .787 & 1.019 .164 & 1.032 .992 & 1.038 .607 & 1.043 .061 & 1.027 .152 & 1.010 .690 & 984.290 & 1.005 .448 \\
\hline 1976 & 932.737 & 913.056 & 967.695 & 995.386 & 1.007 .396 & 1.016 .046 & 1.019 .888 & 1.031 .288 & 1.029 .584 & 1.023 .066 & 1.009 .228 & 983.038 & 994.034 \\
\hline 1977 & 893.572 & 885.252 & 937.977 & 947.414 & 950.613 & 962.630 & 954.613 & 970.588 & 973.500 & 959.331 & 946.369 & 926.140 & 942.333 \\
\hline 1978 & 898.979 & 894.875 & 949.054 & 975.794 & 985.972 & 1.008 .828 & 1.001 .404 & 1.020 .069 & 1.025 .290 & 1.018 .790 & 1.011 .583 & 995.274 & 982.169 \\
\hline 1979 & 949.513 & 941.754 & 1.005 .490 & 1.023 .800 & 1.034 .462 & 1.046 .008 & 1.047 .242 & 1.061 .448 & 1.063 .522 & 1.060 .200 & 1.047 .845 & 1.034 .708 & 1.026 .323 \\
\hline 1980 & 994.062 & 995.299 & 1.042 .252 & 1.053 .606 & 1.055 .789 & 1.062 .648 & 1.059 .371 & 1.068 .781 & 1.073 .200 & 1.059 .024 & 1.045 .664 & 1.023 .430 & 1.044 .427 \\
\hline 1981 & 975.933 & 958.066 & 1.010 .480 & 1.025.947 & 1.027 .159 & 1.032 .588 & 1.028 .091 & 1.034 .887 & 1.031 .417 & 1.009 .409 & 987.217 & 955.153 & 1.006 .362 \\
\hline 1982 & 879.667 & 857.815 & 915.719 & 943.581 & 950.821 & 963.518 & 963.444 & 974.726 & 972.525 & 954.436 & 934.710 & 904.356 & 934.610 \\
\hline 1983 & 820.313 & 800.509 & 854.480 & 903.420 & 921.928 & 938.587 & 945.508 & 966.473 & 973.416 & 958.353 & 944.685 & 918.466 & 912.178 \\
\hline 1984 & 834.094 & 819.256 & 877.638 & 906.232 & 920.396 & 924.340 & 931.350 & 942.350 & 939.737 & 920.085 & 901.821 & 874.157 & 99.288 \\
\hline 1985 & 781.255 & 739.403 & 778.914 & 823.218 & 837.256 & 847.274 & 856.542 & 866.794 & 870.808 & 859.990 & 844.266 & 816.456 & 826.848 \\
\hline MD & 963.302 & 949.247 & 1.003 .490 & 1.022 .818 & 1.037 .669 & 1.046 .668 & 1.048 .476 & 1.067 .546 & 1.056 .673 & 1.042 .283 & 1.024 .846 & 996.621 & 1.021 .270 \\
\hline SF & 0,94 & 0,93 & 0,98 & 1,01 & 1,02 & 1,02 & 1,03 & 1,04 & 1,03 & 1,02 & 1,00 & 0,98 & 1,00 \\
\hline
\end{tabular}

1) Beschäftigte sind hier Facharbeiter, Fachwerker und Werker sowie Gewerblich Auszubildende

Quelle: Statistisches Bundesamt (Hrsg.), Fachserie 4: Produzierendes Gewerbe: Ausgewählte Zahlen für die Bauwirtschaft, Ergebnisse der monatlichen Bauberichterstattung für Betriebe, Dezember und Jahr 1973-1987. 
Abbildung: 33

\begin{tabular}{|c|c|c|c|c|c|c|c|c|c|c|c|c|c|}
\hline \multicolumn{14}{|c|}{ Beschätigtel') im Bamhauptgewerbe $1986=1992$} \\
\hline Jahr & Januar & Februar & März & pral & Mal & Juni & Jull & August & September & Oktober & November & Dezember & JD \\
\hline 1886 & 745.431 & 714.768 & 743.353 & 805.511 & 821.222 & 833.929 & 43.907 & 853.167 & 856.943 & 844.988 & 832.108 & 809.964 & 808.774 \\
\hline 1987 & 732.445 & 699.288 & 740.525 & 794.525 & 809.908 & 6.841 & 824.516 & 832.377 & 832.806 & 820.949 & 811.692 & 791.976 & 792.321 \\
\hline $1988^{2)}$ & 723.930 & 703.694 & 725.957 & 778.816 & 793.216 & 800.269 & 804.826 & 813.436 & 813.146 & 803.060 & 796.433 & 779.434 & 778.018 \\
\hline 1969 & 752.830 & 745.232 & 771.528 & 791.982 & 800.616 & 806.722 & 812.047 & 821.046 & 821.461 & 815.958 & 815.146 & 804.358 & 796.577 \\
\hline 1990 & 771.836 & 768.083 & 807.329 & 820.558 & 828.698 & 833.637 & 841.532 & 850.334 & 851.297 & 847.919 & 843.573 & 833.248 & 8 \\
\hline 1991 & 802.155 & 785.988 & 822.828 & 844.490 & 849.362 & 853.826 & 863.969 & 869.780 & 872.802 & 865.445 & 861.128 & 849.532 & 845.100 \\
\hline 1992 & 816.712 & 803.827 & 842.918 & 854.007 & 859.854 & 864.719 & 869.428 & 875.035 & 878.204 & 870.026 & 863.200 & 851.363 & 854.108 \\
\hline MD & 763.620 & 745.840 & 778.206 & 812.841 & 823.268 & 829.992 & 837.175 & 845.026 & 846.666 & 838.335 & 831.897 & 817.125 & 14240 \\
\hline SF & 0,94 & 0,92 & 0,96 & 1,00 & 1,01 & 1,02 & 1,03 & 1,04 & 1,04 & 1,03 & 1,02 & 1,00 & 1,00 \\
\hline
\end{tabular}

1) Beschäftigte sind hier Facharbeiter, Fachwerker und Werker sowie Gewerblich Auszubildende

2) Ab 1988 Berücksichtigung der Ergebnisse der Arbeitsstättenzählung von 1987

Quelle: Statistisches Bundesamt (Hrsg.), Fachserie 4: Produzierendes Gewerbe: Ausgewählte Zahlen für die Bauwirtschaft, Ergebnisse der monatlichen Bauberichterstattung für Betriebe, Dezember und Jahr 1987-1992.

Um die erreichten Ergebnisse zu verdeutlichen, zeigt die folgende Abbildung die Gegenüberstellung der Saisonfaktoren der Beschäftigten im Bauhauptgewerbe nach Förderungszeiträumen.

Abbildung: 34

\begin{tabular}{|c|c|c|c|c|c|}
\hline \multicolumn{6}{|c|}{ Sqisonfaktoren der Beschaftigen im Bauhauptgeveroe } \\
\hline Zeitraum & $1954-1959$ & $1960-1968$ & $1969-1971$ & $1972-1985$ & $1986-1992$ \\
\hline Januar & 0,65 & 0,90 & 0,93 & 0,94 & 0,94 \\
Februar & 0,62 & 0,91 & 0,92 & 0,93 & 0,92 \\
März & 0,91 & 0,97 & 0,97 & 0,98 & 0,96 \\
April & 1,05 & 1,02 & 1,01 & 1,01 & 1,00 \\
Mai & 1,10 & 1,03 & 1,02 & 1,02 & 1,01 \\
Juni & 1,12 & 1,04 & 1,03 & 1,02 & 1,02 \\
Juli & 1,14 & 1,05 & 1,04 & 1,03 & 1,03 \\
August & 1,14 & 1,05 & 1,04 & 1,04 & 1,04 \\
September & 1,14 & 1,04 & 1,04 & 1,03 & 1,04 \\
Oktober & 1,13 & 1,03 & 1,02 & 1,02 & 1,03 \\
November & 1,09 & 1,01 & 1,01 & 1,00 & 1,02 \\
Dezember & 0,91 & 0,97 & 0,98 & 0,98 & 1,00 \\
\hline JD & 1,00 & 1,00 & 1,00 & 1,00 & 1,00 \\
\hline SA & 0,52 & 0,15 & 0,12 & 0,11 & 0,12 \\
\hline
\end{tabular}

Quelle: Abbildungen 29 bis 33.

Es zeigt sich, wie bereits erwähnt, daß das Ausmaß der Schwankungsbreite zwischen höchstem und niedrigstem Beschäftigtenstand, schon mit Einführung der ersten Förderungsmaßnahmen zur ganzjährigen Beschäftigung in der Bauwirtschaft, entschei- 
dend verringert werden konnte. Betrug der Saisonausschlag in der "förderungsfreien" Zeit noch 0,52, so ist er mit der Einfuhrung des SWG um über 70\% auf 0,15 gefallen. Dieses Ergebnis ist um so höher zu bewerten, weil der Anteil der ausländischen Arbeitnehmer - die bekanntlich im Winter häufig in ihre Heimatländer zurückkehren und damit die Beschäftigtenzahlen während dieser Zeit negativ beeinflussen - an den Gesamtbeschäftigten im Baugewerbe in den 60er und zu Beginn der 70er Jahre, stark angestiegen ist. ${ }^{435}$

Mit Einführung der Winterbaunovelle konnte der Saisonausschlag nochmals um fast $30 \%$ reduziert werden, so daß die Beschäftigtenzahlen im gesamten Jahresverlauf nur noch minimale Schwankungen $(0,11)$ aufweisen. Welche der Maßnahmen für diesen Erfolg verantwortlich sind, versucht das folgende Kapitel zu klären.

\subsubsection{Erklärungsmöglichkeiten}

In den beiden vorangegangenen Abschnitten wurden anhand der Entwicklung der Arbeitslosen- und der Beschäftigtenzahlen aufgezeigt, daß die arbeitsmarktpolitischen Effekte insgesamt als sehr positiv zu bezeichnen sind. Es stellt sich daher nun die Frage, ob die Arbeitsmarktsituation in der Bauwirtschaft durch die getroffenen Förderungsmaßnahmen entscheidend beeinflußt wurde, oder ob auch andere Einflüsse eine wichtige Rolle gespielt haben.

Betrachtet man zuerst die Arbeitslosenzahlen der Zeiträume 1954-1959 und 19601968 (Abbildung 16 und 19), so fällt bei der näheren Analyse auf, daß sich die Arbeitslosigkeit nicht nur in den Förderungsmonaten (November bis März), sondern auch während der übrigen Zeit (April bis Oktober) von Jahr zu Jahr kontinuierlich verringert hat. ${ }^{436} \mathrm{Im}$ September beispielsweise, der im allgemeinen durch den niedrigsten Arbeitslosenstand innerhalb des Jahres gekennzeichnet ist, sank die Arbeitslosenzahl von 8.979 (1959) auf 5.482 (1960) im ersten "Förderungsjahr". Obwohl der September - wie bereits erwähnt ${ }^{437}$ - kein Förderungsmonat ist, setzte sich die Ab-

435 Der Anteil der ausländischen Arbeitnehmer an den Beschäftigten im Baugewerbe ist kontinuierlich von 3,6\% (1960) auf ein Maximum von 19,6\% (1972) gestiegen; vgl. Hauptverband der Deutschen Bauindustrie (Hrsg.), Baustatistisches Jahrbuch 1976, S.55-56.

436 Anmerkung: Dies gilt nur für die Zeiten, in denen die Saisonschwankungen nicht durch besonders starke Konjunkturschwankungen überlagert werden, d.h. die Zeiten der Rezession bleiben unberücksichtigt, vgl. auch 2.1.3. Baukonjunkturelle Entwicklung und Prognose, S.42ff.

437 vgl. Anhang II, S.245 und Anhang III, S.247. 
nahme der Arbeitslosenzahl, bis auf ein Minimum von 2.749 im Jahr 1970, fort. ${ }^{438}$ Diese Entwicklung läßt sich auch in den anderen förderungsfreien Monaten verfolgen.

Für die Beschäftigtenzahlen dieser beiden Zeiträume gilt das Gleiche, wie für die Arbeitslosenzahlen, nur in umgekehrter Weise. Das heißt, dem Beschäftigungsminimum im Januar steht ein Maximum an Arbeitslosigkeit bzw. dem Beschäftigungsmaximum - abgesehen von kleinen Abweichungen - das Minimum der Arbeitslosigkeit gegenüber. Ansonsten verläuft die Entwicklung hier ähnlich wie bei den Arbeitslosenzahlen, nur mit dem Unterschied, daß die Beschäftigtenzahlen - im Gegensatz zur Arbeitslosigkeit - ansteigen.

Das eine derartige Entwicklung nicht allein mit Saisoneinflüssen zu erklären ist, macht ein Vergleich zwischen den Jahren 1954 und 1962 besonders deutlich, denn im Jahr 1954 gab es den geringsten Arbeitslosenstand im September mit 57.152 Arbeitslosen. Das ist mehr, als der maximale Arbeitslosenstand des Jahres 1962 mit 50.864 Arbeitslosen im Januar.

Aufgrund der hier beschriebenen Entwicklung ist zu vermuten, daß starke konjunkturelle Einflüsse in den Zeiträumen 1954-1959 und 1960-1968 einen nicht unerheblichen Anteil an den positiven Effekten auf dem Arbeitsmarkt gehabt haben. ${ }^{439}$ Eine Verbesserung der allgemeinen Konjunkturlage und der damit verbundenen stärkeren Nachfrage auf dem Arbeitsmarkt, läßt sich dabei am deutlichsten anhand des Rückganges der Arbeitslosenquote im Jahresdurchschnitt beweisen. Diese ist zwischen 1954 und 1970 von $7,6 \%$ auf $0,7 \%$ gesunken. ${ }^{440}$ Legt man nun, um Saisonschwankungen auszuschalten, nicht die Arbeitslosenquote des Jahresdurchschnittes, sondern die Monatsquote für September zugrunde, so zeigt sich auch hier ein deutlicher Rückgang in der Arbeitslosenquote von 5,3\% im Jahr 1954 auf 1,6\% im Jahr 1957.441 Aufgrund dieser Entwicklung spricht man bereits 1957 von einem Zustand der Vollbeschäftigung. ${ }^{442}$

438 Ausnahme: Rezession von 1966-1968.

439 vgl. auch Kap. 2.1.3. Baukonjunkturelle Entwicklung und Prognose, S.42ff.

440 Die Arbeitslosenquote ist hier definiert als der Anteil der Arbeitslosen in \% der abhăngigen Erwerbspersonen, vgl. Bundesanstalt für Arbeit (Hrsg.), ANBA, Sondernummer: Arbeitsstatistik 1971 - Jahreszahlen, 20.Jg., 1972, S.84f.

441 vgl. Bundesanstalt für Arbeit (Hrsg.), ANBA, Sondernummer: Arbeitsstatistik 1971 - Jahreszahlen, 20.Jg., 1972, S.84f.

442 vgl. Bulletin des Presse- und Informationsamtes der Bundesregierung, Arbeitslosenquote: 1,9\% - Vollbeschăftigung, Bonn, 5. November 1957, Nr.205, S.1888ff. 
Für die verbleibenden Zeiträume (1969-1971, 1972-1985, und 1985-1992) lassen sich die gleichen konjunkturellen Begleiterscheinungen in den Schwankungen der Arbeitslosen- und Beschäftigtenzahlen der Bauwirtschaft feststellen, wie für die bereits betrachteten. So sinken die jahresdurchschnittlichen Arbeitslosenzahlen nach Beendigung der Rezessionsphase 1968 stetig, von 52.134 auf 22.393 im Jahr 1972. ${ }^{443}$ Entsprechend steigen die Beschäftigtenzahlen in der gleichen Zeitspanne um durchschnittlich etwa 30.000 an. Mit dem Auslaufen der Boomphase zu Beginn der 70er Jahre fallen sie dann während der Rezession 1973-1975 um durchschnittlich 300.000.444 Auch die Arbeitslosigkeit steigt in diesen drei Jahren auf jahresdurchschnittliche 117.168 an. ${ }^{445}$ Dieser Wert ist fast funfmal so hoch wie der von 1973. In der zweiten Hälfte der 70er Jahre sinken die Arbeitslosenzahlen erneut und erreichen 1979 mit 48.536 ein weiteres Minimum.

Bei den Beschäftigtenzahlen sind in dieser Zeit keine spürbaren Veränderungen festzustellen. Sie schwanken nur leicht um den Wert von einer Millionen. Erst mit der einschneidenden Rezession zu Beginn der 80er Jahre, die sich unter Einschluß einer Stagnation bis 1987 fortsetzt, verringern sich die Beschäftigten um insgesamt 200.000 auf etwa 800.000. ${ }^{446}$ Parallel dazu stiegen die Arbeitslosenzahlen auf Jahresdurchschnittswerte, wie sie vor Einführung der Förderungsmaßnahmen erreicht wurden. ${ }^{447}$ Seit der Wiedervereinigung 1989, die mit einem spürbaren Aufschwung in der Baukonjunktur verbunden ist, haben sich die Verhältnisse sowohl bei den Arbeitslosen als auch bei den Beschäftigten verbessert.

$\mathrm{Faßt}$ man die beschriebenen Entwicklungen unter Berücksichtigung der konjunkturellen Einflüsse zusammen, so läßt sich festhalten:

- Obwohl sich die Gesamtzahl der Arbeitslosen in Deutschland im Zeitraum von 1954 bis 1959 um etwa 60\% reduzierte (1954 gab es 1.220 .607 Arbeitslose, 1959 nur 479.924), blieb die Zahl der Arbeitslosen in den Bauberufen mit Schwankungen zwischen 180.000 und 200.000 nahezu konstant. Auch der Sai-

\footnotetext{
443 vgl. Abbildung 19, 20 und 21.

$444 \mathrm{vgl}$. Abbildung 30, 31 und 32.

445 vgl. Abbildung 21.

446 vgl. Abbildung 32 und 33

447 Anmerkung: Die Vergleichbarkeit ist hier aufgrund der nur noch quartalsweise erfolgenden Erhebung der Arbeitslosenzahlen eingeschränkt.
} 
sonausschlag verringerte sich während dieser Zeit nicht, sondern nahm im Gegenteil noch $\mathrm{zu} .{ }^{448}$

- Unmittelbar nach Inkraftreten der gesetzlichen Winterbauförderungsmaßnahmen im Dezember 1959 sank die Zahl der jahresdurchschnittlichen Arbeitslosen von $191.851(1958)^{449}$ auf $50.358 \mathrm{im}$ Jahr 1960. Betrachtet man fur diesen Vergleich die Jahre 1961-1966 - da im Jahr 1960 noch gewisse Anpassungseffekte eine Rolle spielten, was die außergewöhnlich hohen Arbeitslosenzahlen für Januar und Februar bestätigen ${ }^{450}$ - so fällt der Rückgang auf etwa 25.000 Arbeitslose im Jahresdurchschnitt noch stärker aus. ${ }^{451}$

- Bezüglich des Saisonausschlages ist festzustellen, daß dieser gerade im Zeitraum 1960-1968 nach Einführung der Förderungsmaßnahmen derart stark zurückging, daß hierfür kaum konjunkturelle Einflüsse maßgeblich verantwortlich sein können. Zumal sich derartige Änderungen sowohl bei den Arbeitslosen als auch bei den Beschäftigtenzahlen im weiteren Zeitablauf nicht wiederholt haben. Insgesamt verringerte sich der Saisonausschlag bei den Arbeitslosen von ca. 650.000 auf etwa 120.000. Dieser Stand wurde auch in den weiteren Förderungszeiträumen beibehalten. Der Saisonausschlag der Beschäftigtenzahlen betrug nach Einführung der Förderungsmaßnahmen nur noch $\pm 5 \%$ (vorher waren es noch $-40 \%$ und $+10 \%$ ).

Aufgrund der Tatsache, daß die besonders ausgeprägten positiven Effekte auf dem Arbeitsmarkt unmittelbar mit der Einführung der ersten Maßnahmen zur Förderung der ganzjährigen Beschäftigung in der Bauwirtschaft zusammenhängen, liegt die Vemutung nahe, daß die SWG-Regelung innerhalb des Maßnahmenbündels von 1959 einen erheblichen Anteil am erzielten Erfolg zur Beseitigung der Saisonarbeitslosigkeit besitzen dürfte.

448 Anstieg von 585.807 bis auf 652.015, vgl. Abbildung 17, S.119.

449 Das Jahr 1959 ist für diesen Vergleich ungeeignet, da die Arbeitslosenzahl des Dezembers 1959 schon durch den Förderungsbeginn beeinflußt wurde und somit den Jahresdurchschnitt verfalscht, vgl. Abbildung 16, S.118.

450 Die Werte für Januar und Februar liegen deutlich oberhalb der Durchschnittswerte dieser Monate für den Zeitraum 1960-1968, vgl. Abbildung 19, S.120.

451 vgl. Abbildung 19 
Wie bereits erwähnt, sollte die "Lohnersatzfunktion" des SWG 452 - das an die Stelle des Arbeitslosengeldes trat - den Arbeitslosen durch den Schlechtwettergeldbezieher ersetzen, der im Gegensatz zum Arbeitslosen zwar in seinem Beschäftigungsverhältnis verbleibt, aber ebensowenig wie dieser produktiv tätig ist. Als logische Folgerung ergibt sich, daß auch ohne eine Steigerung der winterlichen Bauproduktion die statistisch ausgewiesene Arbeitslosigkeit stark zurückgehen müßte. Diese Aussage konnte, was die Arbeitslosigkeit betriff, durch das statistische Zahlenmaterial bereits bestätigt werden. ${ }^{453}$ Bewiesen wird der Zusammenhang zwischen der Beseitigung der Saisonarbeitslosigkeit und der Einführung des SWG durch die folgende Abbildung 35, die die Ausgaben der BA an Arbeitslosengeld und SWG gegenüberstellt. ${ }^{454}$

Abbildung: 35

\begin{tabular}{|c|c|c|c|}
\hline \multicolumn{4}{|c|}{$\begin{array}{l}\text { A asgaben der BA für die Bauwirtschaft an } \\
\text { A rbeitslosengeld und SWC m MHo. DM }\end{array}$} \\
\hline $\begin{array}{c}\text { Berichtszeit } \\
\text { 1.7.-30.6. }\end{array}$ & $\begin{array}{l}\text { Arbeits- } \\
\text { losengeld }\end{array}$ & SWG & Summe \\
\hline $1955 / 56$ & 367 & 0 & 367 \\
\hline $1956 / 57$ & 341 & 0 & 341 \\
\hline $1957 / 58$ & 538 & 0 & 538 \\
\hline $1958 / 59$ & 431 & 0 & 431 \\
\hline $1959 / 60$ & 169 & 120 & 289 \\
\hline $1960 / 61$ & 88 & 136 & 224 \\
\hline $1961 / 62$ & 80 & 384 & 464 \\
\hline $1962 / 63$ & 105 & 859 & 964 \\
\hline $1963 / 64$ & 95 & 536 & 631 \\
\hline $1964 / 65$ & 102 & 492 & 594 \\
\hline $1965 / 66$ & 79 & 472 & 551 \\
\hline $1966 / 67$ & 339 & 281 & 620 \\
\hline $1967 / 68$ & 409 & 678 & 1.087 \\
\hline $1968 / 69$ & 209 & 813 & 1.022 \\
\hline $1969 / 70$ & 163 & 1.230 & 1.393 \\
\hline $1970 / 71$ & 148 & 813 & 961 \\
\hline $1971 / 72$ & 219 & 656 & 875 \\
\hline $1972 / 73$ & 199 & 482 & 681 \\
\hline
\end{tabular}

Quelle: Bundesanstalt für Arbeit (Hrsg.), ANBA, Sondernummer: Arbeitsstatistik 1970 - Jahreszahlen, 19. Jg., 1971, S.263; Schreiben des Präsidenten der Bundesanstalt für Arbeit vom 15. November 1976 (Az.: 1lla5-7238), An die Landesarbeitsämter und Arbeitsämter, Betr.: Winterbauförderung; hier Erfahrungsbericht für den Winter 1975/76, Anlage 7 und 8.

452 vgl. Kap. 2.4.1.2. 1960-1968: Das zweite Änderungsgesetz zum AVAVG, S.68.

$453 \mathrm{Zu}$ den Wirkungen der Förderungsmaßnahmen auf die Bauproduktion, vgl. ausführlich Kap. 3.3.2. Wirtschaftspolitische Effekte der getroffenen Förderungsmaßnahmen, S.138.

454 Hinweis: Die Gegenüberstellung von Arbeitslosengeld und SWG in den Bauberufen läßt sich aufgrund fehlender statistischer Erhebungen, nur für den besagten Zeitraum 1955/56 bis $1972 / 73$ machen. 
Es zeigt sich, daß im gleichen Augenblick, in dem die SWG-Regelung in Kraft tritt, nämlich im Winter 1959/60 - die Zahlung des Arbeitslosengeldes stark zurückgeht und statt dessen SWG gezahlt wird. Dabei sind die Zahlungen in den ersten beiden Jahren nach Einführung der gesetzlichen Regelungen für das SWG noch verhältnismäßig niedrig, was mit gewissen Anlaufschwierigkeiten begründet werden kann. ${ }^{455}$ In der Folgezeit hingegen übersteigt das SWG das Arbeitslosengeld erheblich. Erst in den Rezessionsjahren 1966/67 und 1967/68 erreichen Arbeitslosen- und Schlechtwettergeld wieder ähnliche Größenordnungen, so daß die Bedeutung des Arbeitslosengeldes in rezessiven Phasen wieder vor die des SWG tritt.

Mit Hilfe dieser Interpretation des statistischen Materials kommt der Verfasser zu der Ansicht, daß zwar der allgemeine Wirtschaftsaufschwung der 60er Jahre und die hierdurch hervorgerufene angespannte Arbeitsmarktlage auf die Verminderung der Saisonarbeitslosigkeit einen gewissen Einfluß ausgeübt haben muß. Denn auch der Unternehmer ist in Zeiten des Arbeitskräftemangels eher bereit, Arbeitnehmer nicht zu entlassen, selbst wenn objektiv keine Beschäftigungsmöglichkeit besteht. Wobei sich eine solche Verhaltensweise, wie Rocholl zu diesem Problemkreis richtig bemerkt, zahlenmäßig natürlich nicht nachweisen läßt. ${ }^{456}$

Andererseits sollte dieser Einfluß nicht überschätzt werden, da es sich kein Betrieb leisten könnte, seine Belegschaft oder auch nur einen Teil davon während mehrerer Monate des Jahres ohne Arbeit in ihrer Stellung zu behalten und ohne Gegenleistung zu entlohnen. Vielmehr würden von einer Verbesserung der allgemeinen Konjunkturlage die Facharbeiter und sonstige qualifizierte Stammkräfte profitieren, nicht aber die Masse der Hilfsarbeiter, die aus Wirtschaftlichkeitsüberlegungen heraus auch weiterhin entlassen werden müßten.

Es bleibt daher festzuhalten, daß eine derart plötzliche Verringerung der Saisonarbeitslosigkeit im Baugewerbe zu Beginn der 60er Jahre, wie aus den obigen Berechnungen hervorgegangen ist, zum weitaus größten Teil auf das Inkrafttreten der gesetzlichen Förderungsmaßnahmen und hier insbesondere auf die SWG-Regelung zurückzuführen ist. ${ }^{457}$

455 vgl. Gudat, W., Bauwirtschaftliche Erfahrungen mit dem Schlechtwettergeldgesetz, in: Die Bauwirtschaft, 14. Jg., Heft 6, 1960, S.106ff.

456 vgl. Rocholl, E., Im Blickfeld der Bauwirtschaft, in: Das Baugewerbe, 45.Jg., Nr.2, 1965, S.53f. 457 vgl. auch BT-Drucks. IV/643, S. 10. 


\subsubsection{Wirtschaftspolitische Effekte der getroffenen Förderungs- maßnahmen}

Die Diskussion der Zielvorstellungen der Beteiligten von einer "Ganzjährigen Beschäftigung in der Bauwirtschft" hat gezeigt, daß sich die Ziele im Zeitablauf sowohl geändert als auch ergänzt haben. ${ }^{458}$ So wurden wirtschaftspolitische Zielsetzungen erst seit Inkrafttreten des AFG und der Winterbaunovelle besonders beachtet. Inwieweit es gelungen ist, mit den gerade in diesen beiden Gesetzeswerken eingeführten produktionsorientierten Förderungsmaßnahmen die Überwindung des Saisoncharakters der Bauwirtschaft herbeizuführen, soll die nachfolgende Analyse aufzeigen.

Ungeachtet der Tatsache, daß wirtschaftspolitische Zielsetzungen in besonderem Maße erst mit Einführung des AFG verfolgt wurden, sollen hier alle Förderungszeiträume auf wirtschaftspolitische Effekte analysiert werden. Denn selbst, wenn wirtschaftspolitische Auswirkungen mit der Einführung der Förderungsmaßnahmen ursprünglich noch nicht angestrebt waren, sind sie volkswirtschaftlich zu bedeutsam, als daß sie übergangen werden dürften.

\subsubsection{Wirkungen auf die Produktionsschwankungen}

Inwieweit die maßgeblichen wirtschaftspolitischen Zielsetzungen der Maßnahmen zur Förderung der ganzjährigen Beschäftigung in der Bauwirtschaft - wie Verringerung der Produktionsschwankungen, Abbau der sommerlichen Beschäftigungsspitzen und Steigerung des Wirtschaftswachstums durch Erhöhung des Jahresbauvolumens - erreicht werden konnten, soll nun mit Hilfe geeigneter Zeitreihen, die die monatlichen Schwankungen in der Bauproduktion beschreiben, aufgezeigt werden.

Für die Erfassung der Produktionsschwankungen in der Bauwirtschaft stehen aufgrund der entsprechenden statistischen Erhebungen im wesentlichen die folgenden monatlichen Zeitreihen zur Verfügung:

- Indizes der Nettoproduktion für das Produzierende Gewerbe

- Geleistete Arbeitsstunden für das Bauhauptgewerbe

- Umsatzzahlen des Bauhaupt- und Ausbaugewerbes

458 vgl. Kap. 2.5. Vorstellungen der Beteiligten von den Förderungsmaßnahmen zur ganzjährigen Beschäftigung, S.79ff. 
Bezüglich der monatlichen Umsatzzahlen des Bauhaupt- und Ausbaugewerbes ist jedoch festzustellen, daß diese für die Messung der Produktionsschwankungen eher ungeeignet sind, da sie im Grunde nur eine Aussage über die Rechnungslegung in dem betreffenden Monat machen und somit nicht die tatsächliche wirtschaftliche Leistung dieses Wirtschaftszweiges widerspiegeln. Dies zeigt sich auch darin, daß im Gegensatz zur sonstigen Entwicklung in der Bauwirtschaft die Umsätze im Dezember - obwohl die Bautätigkeit hier bereits stark zurückgeht - infolge des Jahresabschlusses besonders hoch liegen. ${ }^{459}$ Aus diesen Gründen werden die monatlichen Umsatzzahlen nicht in die Analyse einbezogen und der Verfasser beschränkt sich auf die beiden erstgenannten Zeitreihen.

Die Aufgabe des Index der Nettoproduktion, der zu den wichtigsten Indikatoren der kurzfristigen Konjunkturbeobachtung gehört, ist es, laufend unter Ausschaltung der Preisveränderungen die Entwicklung der Nettoleistung der einzelnen Wirtschaftszweige und ihrer verschiedenen Gruppierungen und Zusammenfassungen, bis hin zum Produzierenden Gewerbe insgesamt, darzustellen. 460 Die preisbereinigte Nettoproduktion gilt dabei als Maß für die eigene Leistung des Wirtschaftsbereichs, sie entspricht also der preisbereinigten Bruttowertschöpfung zu Marktpreisen in den Volkswirtschaftlichen Gesamtrechnungen. Als Ausgangsmasse werden die Nettoproduktionswerte des Basisjahres verwendet, die mittels geeigneter Meßreihen monatlich fortzuschreiben sind. Beim Bau-Produktionsindex erfolgt die monatliche Fortschreibung des Nettoproduktionswertes mit Hilfe der geleisteten Arbeitsstunden unter Anwendung eines Produktivitätsfaktors, ${ }^{461}$ der aus den Daten der Bauberichterstattung ermittelt wird.

Leider sind derartige Indexzahlen bezüglich der Interpretation ihrer Ergebnisse mit gewissen Mängeln behaftet. So ist beispielsweise das Problem der Kalenderbereinigung der Produktionsindizes noch nicht ganz zufriedenstellend gelöst. Zwar wurden die Einflüsse der Kalenderunregelmäßigkeiten ${ }^{462}$ - insbesondere mit der Umstellung

459 vgl. Bihn, W. R., Kurzfristige Indexziffern der Bauproduktion, Diss. Heidelberg, 1961, S. 107.

460 "Die wirtschaftliche Leistung eines Wirtschaftszweiges wird beschrieben durch die indexmäßige Darstellung der Entwicklung der Produktion", vgl. hierzu Herbel, N., Erfahrungen mit dem neuen System der Produktionsindizes, in: Wirtschaft und Statistik, 5/1986, S.374.

461 Hinweis: Produktivität ist hier definiert als "preisbereinigter Umsatz je geleisteter Arbeitsstunde".

462 Anmerkung: Völlig unabhängig vom Kalendereinfluß sind - ex definitione - alle Bestandsdaten, also Ergebnisse, bei denen der Bestand an bestimmten Stichtagen festgestellt wird, wie etwa Bestände an Waren, Gebäuden usw. Aber auch die Ergebnisse von sog. Bewegungsmassen können völlig unbeeinflußt vom Kalender sein. Dies gilt beispielsweise für die noch zu behan- 
des Produktionsindizes auf das nächste Basisjahr ${ }^{463}$ - laufend verringert, dennoch wird nach wie vor an einer "...Verbesserung des Verfahrens gearbeitet."464

Weitere Probleme ergeben sich in der Art der Fortschreibung sowie auch in Fehlermöglichkeiten bei der Erhebung und Aufbereitung. ${ }^{465}$ Dennoch bleibt der Produktionsindex - trotz der zu machenden Einschränkungen, die sich allerdings durch die Weiterentwicklung der Erhebungs- und Aufbereitungsverfahren spürbar vermindern für die Wirtschaftsanalyse und -politik unverzichtbar. ${ }^{466}$ Aufgrund des Mangels geeigneteren Zahlenmaterials, wird er daher auch im Rahmen dieser Untersuchung verwendet.

Entsprechendes gilt für die monatlich geleisteten Arbeitsstunden im Bauhauptgewerbe. Diese absoluten Zahlen bieten sich auf den ersten Blick zwar an, weisen aber ebenfalls einige Unzulänglichkeiten auf. So lassen sie beispielsweise den allgemeinen Produktivitätsfortschritt außer acht, ${ }^{467}$ was allerdings im Rahmen dieser Untersuchung nicht unbedingt entscheidend ist, da es ausreichen dürfte, zu zeigen wie sich die Arbeitsstunden im Zeitablauf entwickeln.

Andererseits können die geleisteten Arbeitsstunden jedoch nicht als exakte Berechnungsgrundlage für die Schwankungen der Bauproduktion herangezogen werden; da angenommen werden darf, daß die Produktivität der im Winter geleisteten Arbeitsstunden infolge zahlreicher Nebenarbeiten, wie Aufbau und Unterhaltung von Schutz

delnden Bruttolohnsummen, die in Monaten mit 31 Tagen nicht höher ausfallen als in Monaten mit 30, 29 oder 28 Tagen.

463 Auf die vielfăltigen Interpretationsmöglichkeiten, die die "reformierten" Produktionsindizes jeweils bieten, soll hier nicht näher eingegangen werden, vgl hierzu ausführlich Herbel, N., Erfahrungen mit dem neuen System der Produktionsindizes, in: Wirtschaft und Statistik, $5 / 1986$, S.374ff.

464 Mittlerweile ist die 4. Version des sog. "Berliner Verfahrens" eingeführt mit dem eine gesonderte Darstellung kalenderbereinigter Ergebnisse möglich ist; vgl. Strohm, W., Zur Frage der Kalenderbereinigung von Zeitreihen, in: Wirtschaft und Statistik, 6/1986, S.421ff.

465 vgl. hierzu ausführlich Strohm, W., Zur Aussage der Indizes der Nettoproduktion für das Produzierende Gewerbe - Möglichkeiten und Grenzen, in: Wirtschaft und Statistik, 1/1985, S.2lff.

466 vgl. Angermann, O., Zur Neuberechnung der Produktions- und Produktivitätsindizes im Produzierenden Gewerbe auf Basis 1985, in: Wirtschaft und Statistik, 3/1988, S.182ff.

467 vgl. Bihn, W. R., Kurzfristige Indexziffern der Bauproduktion, Diss. Heidelberg, 1961, S.92ff. Besonders zu beachten sind die dort ermittelten nicht unerheblichen Divergenzen zwischen dem Index der industriellen Nettoproduktion und dem der geleisteten Arbeitsstunden im Bauhauptgewerbe. 
vorrichtungen, Schneeschaufeln, Beheizung usw. geringer ist als in der übrigen Jahreszeit. ${ }^{468}$ Daraus ist zu schließen, daß die tatsächlichen Produktionsschwankungen noch größer sind als die sich aus den folgenden Berechnungen anhand der Zahl der geleisteten Arbeitsstunden ergebenden Bewegungen.

\subsection{Geleistete Arbeitsstunden}

Als Ausgangspunkt für die Ermittlung der Produktionsschwankungen werden die geleisteten Arbeitsstunden im Bauhauptgewerbe herangezogen. ${ }^{469}$ Deren Verlauf für den Zeitraum 1954-1959 zeigt die folgende Abbildung.

Abbildung: 36

\begin{tabular}{|c|c|c|c|c|c|c|c|c|c|c|c|c|c|}
\hline Jahr & Januar & Februar & März & Aprll & Mal & Junl & Jull $1^{1)}$ & August & September & Oktober & November & Dezember & JD \\
\hline 1954 & 84.184 & 65.153 & 157.819 & 188.125 & 206.791 & 217.905 & 229.227 & 232.831 & 237.022 & 230.252 & 220.527 & $\mid 191.847$ & 188.474 \\
\hline 1955 & 102.801 & 98.194 & 127.896 & 210.839 & 241.694 & 249.719 & 254.767 & 264.250 & 256.414 & 249.314 & 240.305 & 201.401 & 208.133 \\
\hline 1956 & 159.846 & 64.658 & 167.242 & 225.571 & 256.076 & 258.722 & 257.819 & 260.978 & 243.056 & 250.592 & 223.926 & 181.972 & 212.538 \\
\hline 1957 & 120.958 & 144.081 & 195.201 & 215.989 & 228.519 & 211.534 & 229.030 & 225.650 & 213.971 & 223.116 & 211.276 & $\mid 159.811$ & 198.261 \\
\hline 1958 & 113.090 & 110.137 & 130.226 & 195.837 & 219.336 & 221.692 & 242.164 & 228.923 & 234.336 & 237.499 & 215.829 & $\mid 190.517$ & 194.966 \\
\hline 1959 & 116.927 & 112.162 & 197.786 & 231.872 & 226.980 & 240.029 & 252.386 & 239.854 & 249.726 & 242.173 & 224.899 & $191.521^{2)}$ & 210.526 \\
\hline MD & 116.301 & 99.064 & 162.695 & 211.372 & 229.899 & 233.267 & 244.232 & 242.081 & 239.088 & 238.824 & 222.794 & 186.178 & $202: 180$ \\
\hline SF & 0,68 & 0,49 & 0,80 & 1,06 & 1,14 & 1,16 & 1,21 & 1,20 & 1,18 & 1,18 & 1,10 & 0,92 & 1,00 \\
\hline
\end{tabular}

1) Ab Juli 1959 einschließlich Saarland

2) Beeinflußt durch den Beginn der gesetzlichen Regelungen zur Förderung der ganzjährigen Beschăftigung in der Bauwirtschaft

Quelle: Statistisches Bundesamt (Hrsg.), Zahlen aus der Bauwirtschaft, Ergebnisse der monatlichen Bauberichterstattung für Betriebe, 1955-1960.

Dabei läßt sich bereits auf den ersten Blick das erhebliche Gefälle in der Zahl der geleisteten Arbeitsstunden zwischen Sommer- und Wintermonaten erkennen. Noch

468 Eine Aussage über den Umfang dieser Produktivitătsverluste ist mit großen Unsicherheitsfaktoren behaftet; zum Versuch einer solchen Quantifizierung vgl. RG-Bau Mekblatt 69, Der betriebswirtschaftliche Nutzen des Winterbaues, S.5ff.

469 Zur Definition der "Geleisteten Arbeitsstunden": Alle auf den Baustellen und Bauhöfen tatsächlich geleisteten (nicht etwa die bezahlten) Arbeitsstunden; gleichgültig, ob sie von Arbeitern, Polieren, Schachtmeister und Meister, Inhabern, Familienangehörigen oder Auszubildenden geleistet wurden. Einbezogen sind auch die geleisteten Über- und Feiertagsstunden. Nicht einbezogen sind die für Bürotătigkeiten geleisteten Arbeitsstunden. 
deutlicher werden die Abweichungen bei der Betrachtung der Saisonfaktoren dieses Zeitraumes. ${ }^{470}$

Wie schon bei den Arbeitslosen- und Beschäftigtenzahlen festzustellen war, so unterliegt auch die Zahl der geleisteten Arbeitsstunden im Bauhauptgewerbe einer im Jahresverlauf gleichmäßigen Schwankung. Parallel zum Maximum der Arbeitslosigkeit in den Bauberufen ${ }^{471}$ und dem Minimum in den Beschäftigtenzahlen ${ }^{472}$ liegt das Minimum der geleisteten Arbeitsstunden in den Monaten Januar und Februar eines jeden Jahres.

Betrachtet man die Saisonfaktoren des Zeitraumes 1954-1959 so ist festzustellen, daß dieses Minimum der geleisteten Arbeitsstunden oftmals um mehr als die Hälfte niedriger liegt als in den Sommermonaten. Auf der anderen Seite steht diesem Minimum eine um etwa $20 \%$ über dem Durchschnitt liegende Arbeitsstundenzahl in den Monaten Juli bis Oktober gegenüber, ${ }^{473}$ die auf zahlreiche Überstunden schließen läßt. Selbst wenn man berücksichtigt, daß die Abbildung 36 hinsichtlich der Zahl der Arbeitstage nicht gewichtet ist ${ }^{474}$ und in den Wintermonaten infolge des früheren Einsetzens der Dunkelheit ohnehin weniger Stunden geleistet werden können, bleibt doch die Tatsache bestehen, daß hier - in bezug auf eine Erhöhung des Arbeitskräftepotentials - einerseits viele Reserven stecken und andererseits eine Überlastung vorherrscht.

Inwieweit dieser Zustand mit Hilfe der eingeführten Förderungsmaßnahmen zur ganzjährigen Beschäftigung in der Bauwirtschaft beseitigt und die angestrebte kontinuierlichere Bautätigkeit herbeigefuhrt werden konnte, sollen die folgenden Abbildungen 37 bis 40 verdeutlichen.

470 Die Indizes der Saisonfaktoren wurden mit Hilfe des Phasendurchschnittsverfahrens errechnet. Der niedrigste Wert liegt im Februar $(0,49)$, der höchste im Juli $(1,21)$. Daraus resultiert eine Schwankungsbreite von 0,72, vgl. auch Kap. 3.1.5.2. Das Phasendurchschnittsverfahren, S.110ff.

471 vgl. Kap. 3.3.1.1. Wirkungen auf die Arbeitslosenzahlen, S.117ff.

472 vgl. Kap. 3.3.1.2. Wirkungen auf die Beschäfigtenzahlen, S.128ff.

473 Siehe Saisonfaktoren Juli bis Oktober: 1,$21 ; 1.20 ; 1,18 ; 1,18$.

474 Anmerkung: Das heißt bezüglich der Arbeitstage in den einzelnen Monaten werden keine Unterschiede zwischen "langen" (31 Tage) und "kurzen" (Februar) Monaten gemacht. 
Abbildung: 37

Geleistete Arbeitsstunden in 1.000 Stunden in Bauhauptgewerbe 1960 - 1968475

\begin{tabular}{|c|c|c|c|c|c|c|c|c|c|c|c|c|c|}
\hline Jahr & Januar & Februar & März & April & Mal & Junl & Jull & Augurt & September & Olktober & November & Dezember & JD \\
\hline 1960 & 130.493 & 138.697 & 212.729 & 223.445 & 238.336 & 237.420 & 237.305 & 240.188 & 235.332 & 223.270 & 224.885 & 180.825 & 210.244 \\
\hline 1961 & 143.602 & 168.825 & 227.941 & 223.663 & 243.927 & 241.556 & 239.076 & 246.224 & 236.341 & 238.984 & 226.902 & 158.596 & 216.303 \\
\hline 1962 & 159.835 & 144.064 & 172.840 & 231.145 & 261.301 & 252.500 & 259.894 & 259.555 & 246.262 & 265.241 & 236.441 & 151.631 & 220.059 \\
\hline $1963^{1)}$ & 71.171 & 59.259 & 178.213 & 261.820 & 285.284 & 263.470 & 292.453 & 270.083 & 270.171 & 283.434 & 256.297 & 167.872 & 221.627 \\
\hline 1964 & 139.732 & 167.178 & 203.500 & 274.370 & 267.162 & 283.516 & 288.592 & 260.792 & 285.465 & 277.025 & 254.463 & 205.999 & 242.316 \\
\hline 1965 & 167.882 & 132.023 & 190.262 & 259.642 & 267.737 & 276.178 & 275.746 & 265.029 & 277.684 & 270.283 & 226.747 & 191.511 & 233.310 \\
\hline 1966 & 126.412 & 176.386 & 243.644 & 252.295 & 268.567 & 269.676 & 257.868 & 259.961 & 266.536 & 255.269 & 237.206 & 179.445 & 232.772 \\
\hline 1967 & 151.220 & 144.796 & 200.902 & 210.723 & 225.174 & 235.533 & 230.198 & 231.056 & 233.323 & 240.498 & 226.422 & 144.888 & 206.228 \\
\hline 1968 & 126.921 & 151.761 & 176.736 & 219.753 & 238.586 & 218.433 & 239.871 & 229.786 & 232.184 & 252.564 & 226.806 & 158.272 & 205.973 \\
\hline MD & 136.252 & 142.654 & 200.752 & 239.651 & 256.119 & 253,031 & 267.889 & 261.408 & 253.700 & 256.285 & 236,130 & 171.004 & 2209083 \\
\hline sf & 0,61 & 0,65 & 0,91 & 1,08 & 1,15 & 1,15 & 1,17 & 1,14 & 1,16 & 1,16 & 1,06 & 0,77 & 1,00 \\
\hline
\end{tabular}

1) Ab 1963 einschließlich Berlin (West)

Quelle: Statistisches Bundesamt (Hrsg.), Fachserie 4: Produzierendes Gewerbe: Ausgewählte Zahlen für die Bauwirtschaft, Ergebnisse der monatlichen Bauberichterstattung für Betriebe, Dezember und Jahr 1961-1970.

Abbildung: 38

\section{Geleistete Arbeitsstunden in 1.000 Stunden in Bauhauptgewerbe 1969 . 1971}

\begin{tabular}{|c|c|c|c|c|c|c|c|c|c|c|c|c|c|}
\hline Jahr & Januar & Februar & Mărz & April & Mal & Junl & Jull & August & September & Oktober & November & Dezember & JD \\
\hline 1969 & 147.580 & 105.947 & 165.692 & 224.398 & 234.449 & 233.696 & 248.622 & 227.140 & 247.489 & 255.130 & 216.986 & 133.275 & 203.367 \\
\hline 1970 & 105.114 & 108.796 & 161.069 & 235.398 & 231.363 & 256.322 & 259.687 & 236.395 & 258.176 & 252.149 & 231.037 & 190.066 & 210.464 \\
\hline 1971 & 131.900 & 167.712 & 177.812 & 231.175 & 234.827 & 243.237 & 242.266 & 231.428 & 252.933 & 243.151 & 220.788 & 186.705 & 212.828 \\
\hline MD & 128.198 & 124.152 & 168.191 & 230.324 & 233.646 & 244.418 & 250.192 & 231.654 & 252,866 & 250.143 & 222.937 & 170.015 & $208: 886$ \\
\hline sf & 0,61 & 0,50 & 0,81 & 1,10 & 1,12 & 1,17 & 1,20 & 1,11 & 1,21 & 1,20 & 1,07 & 0,81 & 1,00 \\
\hline
\end{tabular}

Quelle: Statistisches Bundesamt (Hrsg.), Fachserie 4: Produzierendes Gewerbe: Ausgewählte Zahlen für die Bauwirtschaft, Ergebnisse der monatlichen Bauberichterstattung für Betriebe, Dezember und Jahr 1970-1972.

475 Hinweis: Eine im Jahr 1961 durchgeführte Arbeitsstättenzählung brachte das Ergebnis, daß die Beschäftigtenzahl für das Bauhauptgewerbe um etwa $2 \%$ zu niedrig angesetzt war. Daher ist die Vergleichbarkeit des Zahlenmaterials von 1962 an mit den Zahlen der Vorjahre eingeschränkt; vgl. auch Wirtschaft und Statistik, 2/1963, S.102ff. 
Abbildung: 39

\section{Geleistete Arbeitsstunden in 1.000 Stunden im Bauhauptgewerbe 1972 - 1985}

\begin{tabular}{|c|c|c|c|c|c|c|c|c|c|c|c|c|c|}
\hline Jahr & Januar & Februar & März & April & Mai & Juni & Juli & August & September & Oktober & November & Dezember & JD \\
\hline 1972 & 131.378 & 155.913 & 217.238 & 218.621 & 236.496 & 239.648 & 223.479 & 224.619 & 232.725 & 242.337 & 224.476 & 177.331 & 210.355 \\
\hline 1973 & 157.555 & 153.533 & 190.024 & 203.231 & 232.462 & 219.349 & 209.994 & 212.034 & 212.969 & 231.984 & 200.191 & 128.283 & 195.967 \\
\hline 1974 & 148.399 & 149.113 & 171.616 & 188.604 & 196.480 & 175.374 & 183.313 & 170.997 & 183.340 & 198.241 & 173.734 & 130.820 & 172.603 \\
\hline 1975 & 131.869 & 123.050 & 134.007 & 164.104 & 155.689 & 165.210 & 162.235 & 153.499 & 176.868 & 183.986 & 156.852 & 122.979 & 152.520 \\
\hline $1976^{1)}$ & 101.758 & 97.688 & 142.739 & 160.364 & 164.311 & 166.554 & 153.856 & 157.310 & 176.118 & 173.076 & 165.464 & 124.042 & 148.607 \\
\hline 1977 & 97.110 & 108.971 & 154.287 & 145.295 & 154.603 & 155.585 & 133.827 & 144.578 & 162.191 & 157.320 & 141.015 & 109.830 & 138.718 \\
\hline 1978 & 108.221 & 74.499 & 141.346 & 155.152 & 152.475 & 170.632 & 141.872 & 152.731 & 162.200 & 172.938 & 160.289 & 99.649 & 141.000 \\
\hline 1979 & 60.111 & 78.876 & 146.505 & 157.134 & 176.200 & 163.091 & 158.836 & 153.273 & 164.959 & 187.499 & 161.831 & 115.926 & 3.687 \\
\hline 1980 & 91.748 & 126.028 & 156.909 & 165.204 & 158.674 & 158.660 & 157.113 & 137.702 & 175.552 & 181.691 & 144.505 & 91.171 & 145.413 \\
\hline 1981 & 73.582 & 91.089 & 140.598 & 160.749 & 153.703 & 153.829 & 150.824 & 136.761 & 167.750 & 162.816 & 140.707 & 81.547 & 134.496 \\
\hline 1982 & 56.279 & 85.339 & 136.054 & 142.889 & 139.132 & 144.827 & 133.826 & 134.565 & 157.589 & 148.242 & 140.902 & 103.026 & 126.889 \\
\hline 1983 & 82.955 & 63.044 & 121.814 & 126.983 & 136.432 & 144.967 & 131.129 & 137.335 & 156.023 & 148.821 & 140.364 & 90.464 & 123.361 \\
\hline 1984 & 81.672 & 84.427 & 118.200 & 123.830 & 144.883 & 131.341 & 139.399 & 129.697 & 134.859 & 151.301 & 129.606 & 91.528 & 121.729 \\
\hline 1985 & 47.547 & 52.842 & 94.554 & 117.871 & 123.637 & 117.210 & 134.105 & 115.986 & 132.385 & 143.803 & 104.634 & 84.879 & 105.788 \\
\hline MD & 97.870 & 103.172 & 147.664 & 159.288 & 166.084 & 164.734 & 158.129 & 154.363 & 171.109 & 177.433 & 166.041 & 110.820 & 147,217 \\
\hline SF & 0,66 & 0,70 & 1,00 & 1,08 & 1,13 & 1,12 & 1,07 & 1,05 & 1,16 & 1,21 & 1,06 & 0,75 & 1,00 \\
\hline
\end{tabular}

1) $\mathrm{Ab} 1976$ neue Berichtskreisabgrenzung nach der Systematik der Wirtschaftszweige (SYPRO) ${ }^{476}$

Quelle: Statistisches Bundesamt (Hrsg.), Fachserie 4: Produzierendes Gewerbe: Ausgewählte Zahlen für die Bauwirtschaft, Ergebnisse der monatlichen Bauberichterstattung für Betriebe, Dezember und Jahr 1973-1986.

Abbildung: 40

Geleistete Arbeitsstunden in 1.000 Stunden im Bauhauptgewerbe 1986 - 1992

\begin{tabular}{|c|c|c|c|c|c|c|c|c|c|c|c|c|c|}
\hline Jahr & Januar & Februar & März & April & Mal & Junl & Jull & August & September & Oktober & November & Dezember & JD \\
\hline 1986 & 65.312 & 46.390 & 80.065 & 125.107 & 111.802 & 124.791 & 131.828 & 111.716 & 135.242 & 139.629 & 117.599 & 89.801 & 106.607 \\
\hline 1987 & 42.540 & 55.645 & 73.551 & 116.727 & 116.623 & 119.873 & 127.708 & 114.095 & 133.900 & 132.134 & 118.120 & 85.637 & 103.046 \\
\hline $1988^{1)}$ & 72.375 & 72.891 & 88.211 & 108.187 & 118.245 & 120.745 & 111.986 & 118.144 & 127.409 & 122.428 & 110.802 & 85.843 & 104.772 \\
\hline 1989 & 88.487 & 85.198 & 103.848 & 113.383 & 110.409 & 129.071 & 111.838 & 118.072 & 122.164 & 129.742 & 117.821 & 83.030 & 109.422 \\
\hline 1990 & 87.684 & 87.737 & 117.777 & 113.437 & 128.408 & 117.000 & 122.825 & 118.351 & 121.091 & 135.190 & 118.453 & 78.635 & 112.216 \\
\hline 1991 & 89.459 & 61.345 & 111.010 & 127.990 & 116.724 & 123.166 & 128.658 & 113.026 & 128.130 & 134.202 & 115.916 & 80.971 & 110.883 \\
\hline 1992 & 84.128 & 89.606 & 116.279 & 123.274 & 119.651 & 125.723 & 126.105 & 111.571 & 134.821 & 132.580 & 117.603 & 94.743 & 114.674 \\
\hline MD & 76.712 & 71.259 & 98.677 & 118.301 & 117.409 & 122.910 & 122.993 & 114.996 & 128.965 & 132.272 & 116.616 & 85.523 & 108.800 \\
\hline SF & 0,70 & 0,65 & 0,91 & 1,09 & 1,08 & 1,13 & 1,13 & 1,06 & 1,19 & 1,22 & 1,07 & 0,79 & 1,00 \\
\hline
\end{tabular}

1) Ab 1988 Berücksichtigung der Ergebnisse der Arbeitsstättenzählung von 1987

Quelle: Statistisches Bundesamt (Hrsg.), Fachserie 4: Produzierendes Gewerbe: Ausgewählte Zahlen für die Bauwirtschaft, Ergebnisse der monatlichen Bauberichterstattung für Betriebe, Dezember und Jahr 1987-1993.

476 vgl. Kap. 1.1.3. Bauhaupt- und Ausbaugewerbe, S.8ff. 
Wie bereits angedeutet, verläuft die Entwicklung der Zahl der geleisteten Arbeitsstunden im Bauhauptgewerbe etwa umgekehrt proportional zur Entwicklung der Arbeitslosigkeit und zwar mit einem Jahr für Jahr gleichartigen charakteristischen Verlauf. Das heißt mit Beginn des Herbstes, gehen die geleisteten Arbeitsstunden drastisch zurück und erreichen ihr Minimum im Januar/Februar. Von da an steigen sie kontinuierlich, bis zum Maximum ungefähr im Juli. 477 Der darauf folgende kurze Abfall im August muß mit der sommerlichen Urlaubszeit erklärt werden. Ansonsten behält die Kurve ihr Maximum bis etwa Oktober bei.

Abgesehen von dieser Besonderheit ähnelt der Verlauf der geleisteten Arbeitsstunden, damit dem Verlauf der Beschäftigtenzahlen. Jedoch treten die Schwankungen bei den Arbeitsstunden noch intensiver hervor, ${ }^{478}$ da nicht nur der Ausfall der bei den Arbeitsämtern als arbeitslos gemeldeten Personen erfaßt wird, sondern auch der der sogenannten "Stammarbeiter", die ohne produktiv tätig zu sein von den Bauunternehmen auch während der Winterzeit nicht entlassen werden, um sie nicht an andere Betriebe zu verlieren.

Abbildung: 41

\begin{tabular}{|c|c|c|c|c|c|}
\hline \multicolumn{7}{|c|}{ Saisonfaktoren der Arbeitsstunden im Bahluauntgewerbe } \\
\hline Zeitraum & $1954-1959$ & $1960-1968$ & $1969-1971$ & $1972-1985$ & $1986-1992$ \\
\hline Januar & 0,58 & 0,61 & 0,61 & 0,66 & 0,70 \\
Februar & 0,49 & 0,65 & 0,59 & 0,70 & 0,65 \\
Mär & 0,80 & 0,91 & 0,81 & 1,00 & 0,91 \\
April & 1,05 & 1,08 & 1,10 & 1,08 & 1,09 \\
Mai & 1,14 & 1,15 & 1,12 & 1,13 & 1,08 \\
Juni & 1,15 & 1,15 & 1,17 & 1,12 & 1,13 \\
Juli & 1,21 & 1,17 & 1,20 & 1,07 & 1,13 \\
August & 1,20 & 1,14 & 1,11 & 1,05 & 1,06 \\
September & 1,18 & 1,15 & 1,21 & 1,16 & 1,19 \\
Oltober & 1,18 & 1,16 & 1,20 & 1,21 & 1,22 \\
November & 1,10 & 1,06 & 1,07 & 1,06 & 1,07 \\
Dezember & 0,92 & 0,77 & 0,81 & 0,75 & 0,79 \\
\hline JD & 1,00 & 1,00 & 1,00 & 1,00 & 1,00 \\
\hline SA & 0,72 & 0,56 & 0,62 & 0,55 & 0,57 \\
\hline
\end{tabular}

Quelle: Abbildungen 36 bis 40 .

Aus dem Vergleich der Förderungszeiträume ergibt sich also, daß die Schwankungsbreite mit Inkrafttreten der Winterbauförderungsmaßnahmen zwar um einiges abgenommen hat, allerdings nicht in dem Ausmaß, wie das die Verringerung der Schwan-

477 Im Gegensatz zur Entwicklung der Beschäftigtenzahlen, die ihren höchsten Stand ja im August/September aufweisen, vgl. Abbildungen 29 bis 33 und 34 .

478 Dies zeigt der Vergleich der geänderten Saisonausschlăge, vgl. Abbildungen 34 und 41. 
kungen der Beschäftigtenzahlen hätte vermuten lassen können. ${ }^{479}$ Dies zeigt auch die Gegenüberstellung der Saisonfaktoren in Abbildung 41.

\subsection{Nettoproduktion für das Bauhauptgewerbe}

Bevor die Ergebnisse der geleisteten Arbeitsstunden näher analysiert werden, wird der auf der Grundlage der Zahl der geleisteten Arbeitsstunden errechnete Index der Nettoproduktion furr das Bauhauptgewerbe herangezogen. Dieser ist in den folgenden Abbildungen 42 bis 51 in absoluten Zahlen und in Saisonfaktoren dargestellt.

Abbildung: 42

\begin{tabular}{|c|c|c|c|c|c|c|c|c|c|c|c|c|c|}
\hline \multicolumn{14}{|c|}{ Index't der Nettoproduktion fïr das Bauhauptgewerbe 1954 - 19592 f } \\
\hline Jahr & Januar & Februar & März & April & Mal & Junl & Jull & August & September & Oktober & November & Dezember & JD \\
\hline 1954 & 68 & 55 & 119 & 161 & 177 & 186 & 174 & 184 & 188 & 183 & 185 & 152 & 153 \\
\hline 1955 & 87 & 85 & 99 & 183 & 211 & 216 & 205 & 207 & 207 & 201 & 206 & 163 & 173 \\
\hline 1956 & 131 & 55 & 136 & 199 & 235 & 213 & 213 & 210 & 211 & 202 & 200 & 166 & 181 \\
\hline 1957 & 102 & 133 & 167 & 200 & 204 & 214 & 191 & 190 & 194 & 188 & 197 & 153 & 178 \\
\hline 1958 & 101 & 106 & 116 & 190 & 213 & 224 & 211 & 209 & 213 & 209 & 219 & 183 & 183 \\
\hline 1959 & 110 & 113 & 201 & 220 & 256 & 244 & 235 & 238 & 249 & 235 & 245 & 204 & 213 \\
\hline
\end{tabular}

1) Basisjahr $1950=100$, arbeitstäglich

2) Bundesgebiet ohne Saarland und Berlin

Quelle: Statistisches Bundesamt (Hrsg.): Fachserie D, Reihe 2: Produktion ausgewählter industrieller Erzeugnisse, Index der industriellen Produktion sowie Wirtschaft und Statistik, 1956 bis 1960.

Abbildung: 43

\begin{tabular}{|c|c|c|c|c|c|c|c|c|c|c|c|c|c|}
\hline \multicolumn{14}{|c|}{ Saisonfaktoren der Nettoproduktion fur das Banhauptgewerbe 1954 - 1959} \\
\hline Jahr & Januar & Februar & Mărz & April & Mai & Junl & Jull & Augurt & September & Oktober & November & Dezember & JD \\
\hline 1954 & 44,5 & 36,0 & 77,9 & 105,5 & 115,9 & 121,8 & 114,0 & 120,5 & 123,1 & 119,9 & 121,2 & 99,6 & 100,0 \\
\hline 1955 & 50,4 & 49,3 & 57,4 & 106,1 & 122,3 & 125,2 & 118,8 & 120,0 & 120,0 & 116,5 & 119,4 & 94,5 & 100,0 \\
\hline 1956 & 72,4 & 30,4 & 75,2 & 110,0 & 129,9 & 117,7 & 117,7 & 116,1 & 116,6 & 111,7 & 110,5 & 91,8 & 100,0 \\
\hline 1957 & 57,4 & 74,8 & 94,0 & 112,5 & 114,8 & 120,4 & 107,5 & 106,9 & 109,1 & 105,8 & 110,8 & 86,1 & 100,0 \\
\hline 1958 & 55,2 & 58,0 & 63,4 & 103,9 & 116,5 & 122,5 & 115,4 & 114,3 & 116,5 & 114,3 & 119,8 & 100,1 & 100,0 \\
\hline 1959 & 51,8 & 53,2 & 94,6 & 103,5 & 120,5 & 114,8 & 110,6 & 112,0 & 117,2 & 110,6 & 115,3 & 96,0 & 100,0 \\
\hline SF & 0,55 & 0,50 & 0,77 & 1,07 & 1,20 & 1,20 & 1,14 & 1,15 & 1,17 & 1,13 & 1,16 & 0,95 & 1,00 \\
\hline
\end{tabular}

Quelle: Eigene Berechnungen aus Abbildung 42.

479 vgl. Abbildung 34, S.131. 
Betrachtet man an dieser Stelle zunächst den förderungsfreien Zeitraum 1954-1959, so ist es nicht verwunderlich festzustellen, daß die Nettoproduktion analog zu den Ergebnissen der "geleisteten Arbeitsstunden" dieses Zeitraumes verläuft, da der Nettoproduktionswert unter Berücksichtigung der geleisteten Arbeitsstunden ermittelt wird. ${ }^{480}$ So erreicht die monatliche Bauproduktion etwa im Juni ihr Maximum mit ca. $20 \%$ über dem jährlichen Durchschnittswert. Dieses behält sie unter geringen Schwankungen - bedingt durch die Urlaubszeit - bis einschließlich November bei. Ihr Minimum liegt dann analog der Entwicklung der geleisteten Arbeitsstunden und Beschäftigtenzahlen im Januar/Februar. Im Zeitraum 1954-1959 beträgt der Saisonfaktor dieser beiden Monate nur 0,55 bzw. 0,50 des Jahresdurchschnitts. Im Vergleich zur Saisonspitze sinkt die Bauproduktion sogar um etwa $60 \%(0,50 / 1,20)$. Die folgenden Abbildungen 44 bis 51 zeigen die Entwicklung der Bauproduktion unter Einfluß der Förderungsmaßnahmen.

Abbildung: 44

\begin{tabular}{|c|c|c|c|c|c|c|c|c|c|c|c|c|c|}
\hline \multicolumn{14}{|c|}{ Index') der Nettoproduktion fir das Bauhauptgererbe $1960=1968481$} \\
\hline Jahr & Januar & Februar & März & April & Mal & Junl & Jull & August & September & Oktober & November & Dezember & JD \\
\hline 1960 & 139 & 147 & 209 & 247 & 254 & 273 & 244 & 240 & 243 & 231 & 248 & 189 & $222^{2)}$ \\
\hline 1961 & 151 & 192 & 237 & 267 & 281 & 266 & 262 & 253 & 261 & 256 & 262 & 195 & 240 \\
\hline 1962 & 174 & 172 & 187 & 292 & 302 & 317 & 291 & 282 & 303 & 290 & 291 & 208 & 259 \\
\hline 1963 & 79 & 73 & 208 & 326 & 340 & 378 & 321 & 311 & 326 & 315 & 332 & 221 & 269 \\
\hline 1964 & 86 & 111 & 137 & 170 & 207 & 184 & 172 & 169 & 179 & 172 & 175 & 135 & $158^{3)}$ \\
\hline 1965 & 116 & 91 & 116 & 184 & 191 & 198 & 182 & 177 & 186 & 189 & 164 & 129 & 160 \\
\hline 1966 & 89 & 130 & 157 & 193 & 198 & 197 & 180 & 169 & 180 & 178 & 171 & 154 & 166 \\
\hline 1967 & 103 & 107 & 138 & 151 & 169 & 157 & 158 & 148 & 160 & 164 & 166 & 133 & 146 \\
\hline $1968^{5)}$ & 67 & 85 & 99 & 131 & 136 & 152 & 126 & 128 & 134 & 134 & 143 & 102 & $\left.120^{4}\right)$ \\
\hline
\end{tabular}

1) von Kalenderunregelmäßigkeiten bereinigt.

2) 1960 bis 1963: Basisjahr $1950=100$, Bundesgebiet ohne Saarland und Berlin.

3) 1964 bis 1967: Basisjahr $1958=100$.

4) 1968: Basisjahr $1962=100$.

5) Aufgrund der Einführung der Mehrwertsteuer ab Januar 1968 mußte die bis zu diesem Zeitpunkt praktizierte Produktivitätsmessung zwangslăufig aufgegeben werden, da zwischen Arbeitsstunden und Umsätzen neuer Art kein zeitlicher Zusammenhang mehr bestand.

Quelle: Statistisches Bundesamt (Hrsg.), Fachserie 4: Produzierendes Gewerbe: Ausgewählte Zahlen für die Bauwirtschaft, Ergebnisse der monatlichen Bauberichterstattung für Betriebe, Dezember und Jahr 61-70.

480 vgl. Kap. 3.3.2.1. Wirkungen auf die Produktionsschwankungen, S.138ff.

481 Hinweis: Eine im Jahr 1961 durchgeführte Arbeitsstättenzählung brachte das Ergebnis, daß die Beschäftigtenzahl für das Bauhauptgewerbe um etwa $2 \%$ zu niedrig angesetzt war. Daher ist die Vergleichbarkeit des Zahlenmaterials von 1962 an mit den Zahlen der Vorjahre eingeschränkt; vgl. auch Wirtschaft und Statistik, 2/1963, S.102ff. 
Abbildung: 45

\begin{tabular}{|c|c|c|c|c|c|c|c|c|c|c|c|c|c|}
\hline $\mathrm{hr}$ & nuar & bruar & März & Apru & Mat & Junt & Jull & August & September & Oktober & November & Dezember & JD \\
\hline & 62,6 & 66,2 & b.1 & 111,3 & 4,4 & 123,0 & 9,9 & 8,1 & 9,5 & 04,1 & 111,7 & 85,1 & 100,0 \\
\hline & 62,9 & 79 & 3,6 & 1 & 117,0 & 110,7 & 09,1 & 105,3 & 08,6 & 06,6 & 109,1 & 81,2 & 100,0 \\
\hline & 67,2 & 66,4 & 72,2 & 112,7 & 116,6 & 122,4 & 112,3 & 108,8 & 117,0 & 111,9 & 112,3 & 80,3 & 100,0 \\
\hline & 29,3 & 27,1 & 77,3 & 121,1 & 126,3 & 140,4 & 119,3 & 115,5 & 121,1 & 117,0 & 123,3 & 82,1 & 100,0 \\
\hline 54 & 54,4 & 70,2 & 86,7 & 107,5 & 130,9 & 116,4 & 108,8 & 106,9 & 113,2 & 108,8 & 110,7 & 85,4 & 100,0 \\
\hline 55 & 72,4 & 56,8 & 2,4 & 14,8 & 119,2 & 23,6 & 113,6 & 110,5 & 16, & 9 & 102,3 & 80,5 & 100,0 \\
\hline & 53,5 & & $5 x, 4$ & 116,0 & 119,0 & 118,4 & 108,2 & 101,6 & 108,2 & 107,0 & 102,8 & 92,6 & 100,0 \\
\hline & 70,5 & 73 & 4,4 & 103,3 & 11 & 10 & 108,1 & 101,3 & 109,5 & 112,2 & 113,6 & 91,0 & 100,0 \\
\hline 68 & 55,9 & 71,0 & 82,7 & 109,4 & 113,6 & 126,9 & 105,2 & 106,9 & 111,9 & 111,9 & 119,4 & 85,2 & 100,0 \\
\hline & 0,59 & 0,65 & 86 & 1,12 & 1, & 1 & 1,11 & 1,07 & 1,1 & 1,1 & 1,12 & 0,85 & 1,00 \\
\hline
\end{tabular}

Quelle: Eigene Berechnungen aus Abbildung 44.

Abbildung: 46

\begin{tabular}{|c|c|c|c|c|c|c|c|c|c|c|c|c|c|}
\hline \multicolumn{14}{|c|}{ Index" der Nettoproduktion fir das Bauhauptgewerbe 1969 - 1971} \\
\hline Jahr & Januar & Februar & Mârz & April & Mal & Junt & Jull & August & September & Oktober & November & Desember & JD \\
\hline 1969 & 82 & 64 & 97 & 139 & 154 & 153 & 137 & 139 & 144 & 142 & 146 & 86 & $124^{2)}$ \\
\hline 1970 & 64 & 69 & 103 & 139 & 176 & 161 & 150 & 151 & 157 & 154 & 154 & 121 & 33 \\
\hline 1971 & 88 & 104 & 103 & 156 & 167 & 163 & 151 & 144 & 158 & 159 & 148 & 116 & 138 \\
\hline
\end{tabular}

1) von Kalenderunregelmäßigkeiten bereinigt.

2) 1969 bis 1971: Basisjahr $1962=100$.

Quelle: Statistisches Bundesamt (Hrsg.), Fachserie 4: Produzierendes Gewerbe, Ausgewählte Zahlen für die Bauwirtschaft, Dezember und Jahr 1970-1972.

Abbildung: 47

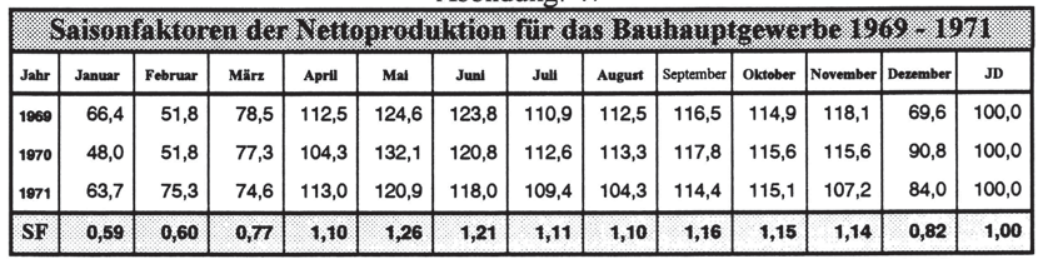

Quelle: Eigene Berechnugen aus Abbildung 46. 
Abbildung: 48

\begin{tabular}{|c|c|c|c|c|c|c|c|c|c|c|c|c|c|}
\hline \multicolumn{14}{|c|}{ Index I) der Nettoproduktion III das Bauhauptgewerbe 1972 . 1985} \\
\hline Jahr & Januar & Februar & März & April & Mal & Junt & Jull & August & September & Olctober & November & Dezember & JD \\
\hline 1972 & 89 & 104 & 140 & 165 & 170 & 163 & 155 & 144 & 162 & 162 & 161 & 137 & $\left.146^{2}\right)$ \\
\hline 1973 & 105 & 113 & 128 & 160 & 167 & 173 & 146 & 143 & 164 & 156 & 153 & 111 & 143 \\
\hline 1974 & 79 & 92 & 104 & 117 & 117 & 127 & 101 & 100 & 114 & 108 & 110 & 85 & $105^{3)}$ \\
\hline 1975 & 71 & 78 & 89 & 94 & 105 & 104 & 91 & 90 & 102 & 103 & 105 & 79 & 93 \\
\hline 1976 & 68 & 72 & 87 & 106 & 111 & 111 & 97 & 93 & 109 & 110 & 105 & 77 & 96 \\
\hline 1977 & 66 & 75 & 9்2 & 104 & 107 & 110 & 96 & 90 & 107 & 109 & 104 & 83 & 95 \\
\hline 1978 & 73 & 69 & 91 & 112 & 114 & 114 & 106 & 100 & 120 & 119 & 120 & 90 & 102 \\
\hline 1979 & 56 & 70 & 97 & 118 & 123 & 134 & 116 & 112 & 133 & 126 & 125 & 105 & 110 \\
\hline 1980 & 79 & 95 & 119 & 128 & 136 & 135 & 111 & 112 & 126 & 127 & 124 & 82 & $\left.115^{4}\right)$ \\
\hline 1981 & 62 & 78 & 95 & 122 & 132 & 129 & 109 & 107 & 126 & 124 & 115 & 69 & 106 \\
\hline 1982 & 39 & 62 & 91 & 101 & 100 & 107 & 89 & 91 & 110 & 101 & 97 & 70 & $\left.88^{5}\right)$ \\
\hline 1983 & 55 & 45 & 81 & 93 & 98 & 107 & 91 & 94 & 108 & 103 & 102 & 63 & 87 \\
\hline 1984 & 56 & 61 & 81 & 95 & 105 & 102 & 101 & 91 & 105 & 107 & 96 & 71 & 89 \\
\hline 1985 & 32 & 40 & 71 & 94 & 98 & 101 & 100 & 89 & 105 & 112 & 85 & 67 & 83 \\
\hline
\end{tabular}

1) von Kalenderunregelmäßigkeiten bereinigt.

2) 1972 bis 1973: Basisjahr $1962=100 \quad$ 3) 1974 bis 1979: Basisjahr $1970=100$

4) 1980 bis 1981: Basisjahr 1976 = $100 \quad$ 5) 1982 bis 1985: Basisjahr $1980=100$

Quelle: Statistisches Bundesamt (Hrsg.), Fachserie 4: Produzierendes Gewerbe, Ausgewählte Zahlen für die Bauwirtschaft, Dezember und Jahr 1973-1986.

Abbildung: 49

\begin{tabular}{|c|c|c|c|c|c|c|c|c|c|c|c|c|c|}
\hline \multicolumn{14}{|c|}{ Saisonfaktoren der Nettoproduktion fur das Banhauptgewerbe 1972 - 1985} \\
\hline Jahr & Januar & Februar & Mărz & April & Mal & Junl & Jull & August & September & Oktober & November & Dezember & JD \\
\hline 1972 & 61,0 & 71,2 & 95,9 & 113,0 & 116,4 & 111,6 & 106,2 & 98,6 & 111,0 & 111,0 & 110,3 & 93,8 & 100,0 \\
\hline 1973 & 73,3 & 78,9 & 89,4 & 111,7 & 116,6 & 120,8 & 101,9 & 99,8 & 114,5 & 108,9 & 106,8 & 77,5 & 100,0 \\
\hline 1974 & 75,6 & 88,0 & 99,5 & 112,0 & 112,0 & 121,5 & 96,7 & 95,7 & 109,1 & 103,3 & 105,3 & 81,3 & 100,0 \\
\hline 1975 & 76,7 & 84,2 & 96,1 & 101,5 & 113,4 & 112,3 & 98,3 & 97,2 & 110,2 & 111,3 & 113,4 & 85,3 & 100,0 \\
\hline 1976 & 71,2 & 75,4 & 91,1 & 111,0 & 116,2 & 116,2 & 101,6 & 97,4 & 114,1 & 115,2 & 109,9 & 80,6 & 100,0 \\
\hline 1977 & 69,3 & 78,7 & 96,6 & 109,2 & 112,3 & 115,5 & 100,8 & 94,5 & 112,3 & 114,4 & 109,2 & 87,1 & 100,0 \\
\hline 1978 & 71,3 & 67,4 & 88,9 & 109,4 & 111,4 & 111,4 & 103,6 & 97,7 & 117,3 & 116,3 & 117,3 & 87,9 & 100,0 \\
\hline 1970 & 51,1 & 63,9 & 88,5 & 107,7 & 112,2 & 122,3 & 105,9 & 102,2 & 121,4 & 115,0 & 114,1 & 95,8 & 100,0 \\
\hline 1980 & 69,0 & 83,0 & 103,9 & 111,8 & 118,8 & 117,9 & 96,9 & 97,8 & 110,0 & 110,9 & 108,3 & 71,6 & 100,0 \\
\hline 1981 & 58,7 & 73,8 & 89,9 & 115,5 & 124,9 & 122,1 & 103,2 & 101,3 & 119,2 & 117,4 & 108,8 & 65,3 & 100,0 \\
\hline 1982 & 44,2 & 70,3 & 103,2 & 114,6 & 113,4 & 121,4 & 100,9 & 103,2 & 124,8 & 114,6 & 110,0 & 79,4 & 100,0 \\
\hline 1883 & 63,5 & 51,9 & 93,5 & 107,3 & 113,1 & 123,5 & 105,0 & 108,5 & 124,6 & 118,8 & 117,7 & 72,7 & 100,0 \\
\hline 1984 & 62,7 & 68,3 & 90,8 & 106,4 & 117,6 & 114,3 & 113,2 & 102,0 & 117,6 & 119,9 & 107,6 & 79,6 & 100,0 \\
\hline 1985 & 38,6 & 48,3 & 85,7 & 113,5 & 118,3 & 121,9 & 120,7 & 107,4 & 126,8 & 135,2 & 102,6 & 80,9 & 100,0 \\
\hline SF & 0,63 & 0,72 & 0,94 & 1,10 & 1,16 & 1,18 & 1,04 & 1,00 & 1,17 & 1,15 & 1,10 & 0,81 & 1,00 \\
\hline
\end{tabular}

Queile: Ėigene Berechnungen aus Abbildung 48. 
Abbildung: 50

\begin{tabular}{|c|c|c|c|c|c|c|c|c|c|c|c|c|c|}
\hline \multicolumn{14}{|c|}{ Index ${ }^{1}$ der Nettoproduktion für das Bauhauptgewerbe 1986 - 1992} \\
\hline Jahr & Januar & Februar & März & April & Mal & Junl & Jull & August & September & Oktober & November & Dezember & JD \\
\hline 1986 & 48 & 37 & 66 & 100 & 97 & 101 & 103 & 90 & 108 & 109 & 100 & 73 & $86^{2)}$ \\
\hline 1987 & 34 & 46 & 52 & 94 & 93 & 97 & 96 & 86 & 104 & 105 & 97 & 69 & 81 \\
\hline $\left.1988^{4}\right)$ & 78 & 74 & 87 & 117 & 123 & 126 & 124 & 123 & 133 & 137 & 117 & 88 & $111^{3)}$ \\
\hline 1989 & 93 & 91 & 113 & 122 & 121 & 130 & 126 & 125 & 135 & 144 & 127 & 93 & 118 \\
\hline 1990 & 94 & 97 & 124 & 126 & 133 & 130 & 135 & 126 & 139 & 154 & 132 & 94 & 124 \\
\hline 1991 & 98 & 70 & 132 & 142 & 136 & 141 & 146 & 132 & 151 & 159 & 139 & 98 & 129 \\
\hline 1992 & 98 & 105 & 137 & 146 & 146 & 148 & 148 & 139 & 159 & 162 & 142 & 111 & 137 \\
\hline
\end{tabular}

1) von Kalenderunregelmäßigkeiten bereinigt.

2) 1986 bis 1987: Basisjahr $1980=100$

3) 1988 bis 1992: Basisjahr $1985=100$

4) Ab 1988 Berücksichtigung der Ergebnisse der Arbeitsstättenzählung von 1987

Quelle: Statistisches Bundesamt (Hrsg.), Fachserie 4: Produzierendes Gewerbe, Ausgewählte Zahlen für die Bauwirtschaft, Dezember und Jahr 1987-1992.

Abbildung: 51

\begin{tabular}{|c|c|c|c|c|c|c|c|c|c|c|c|c|}
\hline Januar & Februar & März & April & Mal & Junl & Jull & August & September & Oktober & November & Dezember & JD \\
\hline 55,8 & 43,0 & 76,7 & 116,3 & 112,8 & 117,4 & 119,8 & 104,7 & 125,6 & 126,7 & 116,3 & 84,9 & 100,0 \\
\hline 41,9 & 56,7 & 64,1 & 115,9 & 114,7 & 119,6 & 118,4 & 106,1 & 128,3 & 129,5 & 119,6 & 85,1 & 100,0 \\
\hline 70,5 & 66,9 & 78,7 & 105,8 & 111,2 & 113,9 & 112,1 & 111,2 & 120,3 & 123,9 & 105,8 & 79,6 & 100,0 \\
\hline 78,6 & 76,9 & 95,5 & 103,1 & 102,3 & 109,9 & 106,5 & 105,6 & 114,1 & 121,7 & 107,3 & 78,6 & 100,0 \\
\hline 76,0 & 78,4 & 100,3 & 101,9 & 107,5 & 105,1 & 109,2 & 101,9 & 112,4 & 124,5 & 106,7 & 76,0 & 100,0 \\
\hline 76,2 & 54,4 & 102,6 & 110,4 & 105,7 & 109,6 & 113,5 & 102,6 & 117,4 & 123,6 & 108,0 & 76,2 & 100,0 \\
\hline 71,7 & 76,8 & 100,2 & 106,8 & 106,8 & 108,2 & 108,2 & 101,6 & 116,3 & 118,5 & 103,8 & 81,2 & 100,0 \\
\hline 0,67 & 0,65 & 0,88 & 1,09 & 1,09 & 1,12 & 1,13 & 1,05 & 1,19 & 1,24 & 1,10 & 0,80 & 1,00 \\
\hline
\end{tabular}

Quelle: Eigene Berechnungen aus Abbildung 50.

Die Gegenüberstellung der Saisonfaktoren der Nettoproduktion verdeutlicht die Entwicklung - vor und nach der Einführung der Winterbauförderungsmaßnahmen - getrennt nach den untersuchten Zeiträumen. 
Abbildung: 52

\begin{tabular}{|c|c|c|c|c|c|}
\hline \multicolumn{6}{|c|}{ Saisonfaktoren der Nettoproduktion im Bauhauptoewerbe } \\
\hline Zeitraum & $\mathbf{1 9 5 4 - 1 9 5 9}$ & $\mathbf{1 9 6 0 - 1 9 6 8}$ & $\mathbf{1 9 6 9 - 1 9 7 1}$ & $\mathbf{1 9 7 2 - 1 9 8 5}$ & $\mathbf{1 9 8 6 - 1 9 9 2}$ \\
\hline Januar & 0,55 & 0,59 & 0,59 & 0,63 & 0,67 \\
Februar & 0,50 & 0,65 & 0,60 & 0,72 & 0,65 \\
März & 0,77 & 0,86 & 0,77 & 0,94 & 0,88 \\
April & 1,07 & 1,12 & 1,10 & 1,10 & 1,09 \\
Mai & 1,20 & 1,19 & 1,26 & 1,16 & 1,09 \\
Juni & 1,20 & 1,21 & 1,21 & 1,18 & 1,12 \\
Juli & 1,14 & 1,11 & 1,11 & 1,04 & 1,13 \\
August & 1,15 & 1,07 & 1,10 & 1,00 & 1,05 \\
September & 1,17 & 1,13 & 1,16 & 1,17 & 1,19 \\
Oktober & 1,13 & 1,11 & 1,15 & 1,15 & 1,24 \\
November & 1,16 & 1,12 & 1,14 & 1,10 & 1,10 \\
Dezember & 0,95 & 0,85 & 0,82 & 0,81 & 0,80 \\
\hline JD & 1,00 & 1,00 & 1,00 & 1,00 & 1,00 \\
\hline SA & 0,70 & 0,62 & 0,67 & 0,55 & 0,59 \\
\hline
\end{tabular}

Quelle: Abbildungen 43, 45, 47, 49 und 51 .

Dabei fuhrt eine erste Analyse im Hinblick auf die angestrebte kontinuierliche Bautätigkeit - ohne an dieser Stelle auf die getroffenen gesetzlichen Förderungsmaßnahmen im einzelnen näher einzugehen - zu folgenden Ergebnissen:

- Für den Monat Januar stieg der Index des Saisonfaktors kontinuierlich von 0,55 (1954-1959) bis zuletzt auf 0,67 (1986-1992) an. Dies ist eine Zunahme von insgesamt etwa 22\% seit Inkraftreten der Förderungsmaßnahmen. Ähnliches gilt für den Monat Februar, dessen Saisonfaktor sich sogar um insgesamt 30\% (von 0,50 auf 0,65 ) erhöhte. Interessant ist dabei die Feststellung, daß insbesondere die Zeiträume, in denen wirtschaftspolitsche Ziele - durch die Einführung spezieller produktionsorientierter Förderungsmaßnahmen (Zeitraum 1969-1971 und 1972-1985) - verfolgt wurden, keinen gesonderten Einfluß auf die Erhöhung der Saisonfaktoren dieser beiden Wintermonate ausübten. So beträgt die Zunahme im Januar von 0,59 (1960-1968) auf 0,63 (1972-1985) nur 6,8\%. Für den Februar sind es immerhin noch $10,8 \%(0,72 \mathrm{zu} 0,65) .{ }^{482}$

Vergleicht man nun diese - nach Einführung der Winterbaunovelle - erreichten Steigerungen, mit der Zunahme der Saisonfaktoren bei Einführung der Förderungsmaßnahmen (Januar 7,3\% und Februar 30\%), ${ }^{483}$ so fallen sie deutlich gerin-

482 Anmerkung: Der Zeitraum 1969-1971 soll aufgrund seiner kurzen Dauer hier unberücksichtigt bleiben, d.h. die genannten Prozentzahlen sind das Ergebnis der Förderungsmaßnahmen aus beiden "produktionsorientierten" Zeiträumen. 
ger aus. Es bleibt daher noch zu untersuchen, ob die Einfürung des SWG im Jahr 1959 letztendlich "produktiver" war, als die produktionsorientierten Förderungsmaßnahmen der Jahre 1969 und 1972. Abschließend ist festzuhalten, daß die Saisonfaktoren der Monate Januar und Februar zwar deutlich erhöht werden konnten, aber von einer kontinuierlichen Bautätigkeit - mit erreichten Indices von 0,67 bzw. 0,65 - noch nicht gesprochen werden kann.

- Anders sieht es dagegen im März aus. Dieser letzte Förderungsmonat kommt mit einer Gesamtindexsteigerung von $14 \%$ und einem Saisonfaktor von 0,88 dem Ziel der kontinuierlichen Bautätigkeit erheblich näher. Es bleibt aber noch zu untersuchen, warum der bereits erreichte Saisonfaktor von 0,94 im Zeitraum 1972-1985 auf die genannten 0,88 zurückging.

- Die Saisonfaktoren der Monate Mai bis August dagegen sind seit Inkrafttreten der Förderungsmaßnahmen leicht rückläufig, d.h. die Saisonspitze konnte - wenn auch nur geringfuigig - abgebaut werden. Im September und Oktober ist dann wieder eine leichte Erhöhung mit der Einführung der produktiven Winterbauförderung ab 1969 festzustellen.

- Bei der Betrachtung der beiden Förderungsmonate November und Dezember, scheinen die Förderungsmaßnahmen dem Gedanken der kontinuierlichen Bautätigkeit entgegenzuwirken. So haben sich in beiden Fällen die Saisonfaktoren deutlich verringert. Im November ist der Index um etwa 5\% gesunken und der relativ günstige Saisonfaktor des Dezembers ist von 0,95 - vor Einführung der Förderungsmaßnahmen - um über $15 \%$, auf 0,80 gefallen.

Faßt man die vorliegenden Ergebnisse - obwohl sie noch auf ihre Aussagefähigkeit überprüft werden müssen - hier zusammen, so scheint es, daß man dem angestrebten Ziel des Ausgleichs der Produktionsschwankungen in der Bauwirtschaft insgesamt zwar näher gekommen ist, es aber noch nicht erreicht hat. Dieser Trend wird auch durch die Entwicklung der Saisonausschläge bestätigt, die sich zwar seit Einführung der Förderungsmaßnahmen um etwa 20\% verringert haben, ${ }^{484}$ aber immer noch einen deutlichen Produktionsunterschied zwischen winterlichem Minimum und sommerlichem Maximum aufweisen. Zur Zeit ist die Produktion im Februar $(0,65)$ nur etwa

483 Berechnung: 0,59 (1960-1968) zu 0,55 (1954-1959) $\Rightarrow$ Januar=7,3\%. Für den Februar gilt entsprechend $0,65 / 0,55=30 \%$.

484 Von 0.70 auf 0,55 bzw. 0,59, vgl. Abbildung 52, S. 151 . 
halb so groß, wie die im Oktober $(1,24)$. Insofern kann von einem Ausgleich der Produktionsschwankungen noch nicht die Rede sein. Inwieweit die Erhöhung des Jahresbauvolumens, als ein weiteres wirtschaftpolitisches Ziel erreicht werden konnte, soll das folgende Kapitel aufzeigen.

\subsubsection{Wirkungen auf das Jahresbauvolumen}

Wie bereits erwähnt, fanden wirtschaftspolitische Ziele erst mit der Einführung des AFG 1969 und dann vor allem mit der Winterbaunovelle von 1972 besondere Beachtung. ${ }^{485}$ Daher ist zu erwarten, daß die Wirkungen der Förderungsmaßnahmen auf das Jahresbauvolumen, wenn überhaupt, dann in den Zeiträumen 1969-1971 und 19721985 - im Vergleich zu den anderen Zeiträumen - besonders ausgeprägt sein werden.

Ausgehend von der Annahme, daß eine Erhöhung des Jahresbauvolumens nur möglich wäre, wenn es gelänge, die winterliche Bauproduktion zu steigern, ohne die Produktion in den Sommermonaten wesentlich einzuschränken, soll an dieser Stelle der Versuch unternommen werden, die Veränderungen in der Entwicklung des Jahresbauvolumens aufgrund der getroffenen Förderungsmaßnahmen zu quantifizieren.

Obwohl die statistischen Ergebnisse - bezüglich der geleisteten Arbeitsstunden und der Nettoproduktion ${ }^{486}$ - bereits aufgezeigt haben, daß weder ein starkes Absinken der Produktion in den Sommermonaten (April bis Oktober) noch eine deutliche Produktionserhöhung in den Förderungsmonaten (November bis März) zu beobachten war, darf diese Erkenntnis nicht darüber hinwegtäuschen, daß auch kleine Veränderungen in der Bautätigkeit volkswirtschaftich bedeutsam sind. Daher werden alle Zeiträume, unabhängig von der "Förderungsintensität", auf die Entwicklung des Jahresbauvolumens untersucht.

Als Grundlage der Untersuchung werden die Zeitreihen der geleisteten Arbeitsstunden im Bauhauptgewerbe herangezogen. Unter Berücksichtigung der gemachten Annahme, die Bauproduktion des Winters zu steigern, ohne die des Sommers einzuschränken, wird die Gesamtentwicklung des Jahresbauvolumens in ein Winter- und

\footnotetext{
485 vgl. hierzu ausführlich Kap. 2.4. Zeitlicher Abriß der Förderungsmaßnahmen zur ganzjährigen Beschäftigung, S.64ff. und Kap. 2.5. Vorstellungen der Beteiligten von den Förderungsmaßnahmen zur ganzjăhrigen Beschäftigung, S.79ff.
}

486 vgl. Abbildungen 41 und 52. 
ein Sommerbauvolumen aufgeteilt. Dabei wird das Winterbauvolumen unter dem Durchschnitt der Förderungsmonate von November bis März zusammengefaßt und der Durchschnitt der übrigen Monate - April bis Oktober - bildet dann das Sommerbauvolumen.

Anhand dieser getroffenen Unterteilung versucht der folgende Vergleich der geleisteten Arbeitsstunden im Bauhauptgewerbe, die Veränderungen in der Entwicklung zwischen "Sommer" und "Winter" aufzuzeigen.

Wie die Abbildung 53 zeigt, ist die durchschnittliche Zahl der geleisteten Arbeitsstunden in der Förderungszeit unmittelbar nach Inkraftreten des Zweiten Änderungsgesetzes zum AVAVG - 189.216 Stunden (1960/61) - beachtlich angestiegen. Verglichen mit der Durchschnittszahl des förderungsfreien Zeitraumes 1954-1959 von 163.232 Stunden, bedeutet dies einen Anstieg in der Bauproduktion von fast $16 \%$. Für den gesamten Zeitraum von 1960-1968 liegt der Durchschnitt der geleisteten Arbeitsstunden im Winter allerdings nur noch um 7,5\% (175.545) über dem des Zeitraumes von 1954-1959. Einen gewissen Anteil an dieser Entwicklung haben auch die geringe Zahl der geleisteten Arbeitsstunden in den Rezessionsjahren (1967/68 und 1968/69) und die außergewöhnlichen Witterungsbedingungen im Winter 1962/63. ${ }^{487}$

Betrachtet man die "Sommerzeit", so läßt sich hier eine ganz ähnliche Entwicklung feststellen. Die Befürchtung, daß die gestiegene Zahl der Arbeitsstunden der "Winterzeit" diejenigen in den Sommermonaten entsprechend einschränkt, ist nicht eingetreten, da auch in der "Sommerzeit" eine Steigerung in der Bauproduktion von etwa $7,8 \%$ (252.441 zu 234.109 Stunden) im Vergleich der beiden Zeiträume erzielt werden konnte.

In allen weiteren Zeiträumen - d.h. in den Zeiträumen 1969-1971, 1972-1985 und 1986-1992 - haben sich die durchschnittlich geleisteten Arbeitsstunden sowohl in der "Sommerzeit" als auch in der "Winterzeit" kontinuierlich verringert, so daß die Vermutung nahe liegt, die getroffenen Förderungsmaßnahmen - insbesondere auch die produktionsorientierten Maßnahmen - dieser Zeiträume hätten kontraproduktive Wirkungen gehabt.

487 vgl. Kap. 3.1.4. Witterungsbedingungen, S.101ff. und Abbildung 11, S.104. 
Abbildung: 53

\begin{tabular}{|c|c|c|c|c|c|c|}
\hline \multicolumn{7}{|c|}{$\begin{array}{l}\text { Vergleich der gelesteten Arbeitsstanden in } 1.000 \text { Stumden im } \\
\text { (Bauhaugtgewerbe uvischen "Sommer" und "YWinter": }\end{array}$} \\
\hline \begin{tabular}{|c|} 
Berichts- \\
jahr
\end{tabular} & JD & \begin{tabular}{|c|}
$\begin{array}{c}\text { Sommerzeit } \\
\left.(\mathrm{SZ})^{2}\right)\end{array}$ \\
\end{tabular} & $\begin{array}{c}\text { Winterzeit } \\
(\mathrm{WZ})^{3)}\end{array}$ & $\begin{array}{c}\mathrm{SZ} \text { zu JD } \\
\text { in } \%\end{array}$ & $\begin{array}{c}\text { WZ zu JD } \\
\text { in } \%\end{array}$ & $\begin{array}{c}\text { WZ zu SZ } \\
\text { in \% }\end{array}$ \\
\hline $1954 / 55$ & 188.474 & 220.308 & 148.253 & 16,89 & $-21,34$ & $-32,71$ \\
\hline $1955 / 56$ & 208.133 & 246.714 & 166.690 & 18,54 & $-19,91$ & $-32,44$ \\
\hline $1956 / 57$ & 212.538 & 250.402 & 173.228 & 17,82 & $-18,50$ & $-30,82$ \\
\hline $1957 / 58$ & 198.261 & 221.116 & 144.908 & 11,53 & $-26,91$ & $-34,47$ \\
\hline $1958 / 59$ & 194.966 & 225.684 & 166.644 & 15,76 & $-14,53$ & $-26,16$ \\
\hline $1959 / 60$ & 210.526 & 240.431 & $179.668^{4)}$ & 14,20 & $-14,66$ & $-25,27$ \\
\hline 1954-1959 & 202.150 & 234.109 & 163.232 & 15,79 & $-19,31$ & $-30,31$ \\
\hline $1960 / 61$ & 210.244 & 233.614 & 189.216 & 11,12 & $-10,00$ & $-19,00$ \\
\hline $1961 / 62$ & 216.303 & 238.539 & 172.447 & 10,28 & $-20,28$ & $-27,71$ \\
\hline $1962 / 63$ & 220.059 & 253.700 & 139.343 & 15,29 & $-36,68$ & $-45,08$ \\
\hline $1963 / 64$ & 221.627 & 275.245 & 186.916 & 24,19 & $-15,66$ & $-32,09$ \\
\hline $1964 / 65$ & 242.316 & 276.703 & 190.126 & 14,19 & $-21,54$ & $-31,29$ \\
\hline $1965 / 66$ & 233.310 & 270.186 & 192.940 & 15,81 & $-17,30$ & $-28,59$ \\
\hline $1966 / 67$ & 232.772 & 261.453 & 182.714 & 12,32 & $-21,51$ & $-30,12$ \\
\hline $1967 / 68$ & 206.228 & 229.501 & 165.346 & 11,29 & $-19,82$ & $-27,95$ \\
\hline $1968 / 69$ & 205.973 & 233.025 & 160.859 & 13,13 & $-21,90$ & $-30,97$ \\
\hline 1960-1968 & 220.981 & 252.441 & 175.545 & 14,18 & $-20,52$ & $-30,31$ \\
\hline $1969 / 70$ & 203.367 & 238.703 & 145.048 & 17,38 & $-28,68$ & $-39,24$ \\
\hline $1970 / 71$ & 210.464 & 247.070 & 177.705 & 17,39 & $-15,57$ & $-28,07$ \\
\hline $1971 / 72$ & 212.828 & 239.860 & 182.404 & 12,70 & $-14,29$ & $-23,95$ \\
\hline 1969-1971 & 208.886 & 241.878 & 168.386 & 15,82 & $-19,51$ & $-30,42$ \\
\hline $1972 / 73$ & 210.355 & 231.132 & 180.584 & 9,88 & $-14,15$ & $-21,87$ \\
\hline $1973 / 74$ & 195.967 & 217.432 & 159.520 & 10,95 & $-18,60$ & $-26,63$ \\
\hline $1974 / 75$ & 172.503 & 185.193 & 138.696 & 7,36 & $-19,60$ & $-25,11$ \\
\hline $1975 / 76$ & 152.529 & 165.942 & 124.403 & 8,79 & $-18,44$ & $-25,03$ \\
\hline $1976 / 77$ & 148.607 & 164.513 & 129.975 & 10,70 & $-12,54$ & $-20,99$ \\
\hline $1977 / 78$ & 138.718 & 150.486 & 114.982 & 8,48 & $-17,11$ & $-23,59$ \\
\hline $1978 / 79$ & 141.000 & 158.286 & 109.086 & 12,26 & $-22,63$ & $-31,08$ \\
\hline $1979 / 80$ & 143.687 & 165.856 & 130.488 & 15,43 & $-9,19$ & $-21,32$ \\
\hline $1980 / 81$ & 145.413 & 162.085 & 108.189 & 11,47 & $-25,60$ & $-33,25$ \\
\hline $1981 / 82$ & 134.496 & 155.205 & 99.985 & 15,40 & $-25,66$ & $-35,58$ \\
\hline $1982 / 83$ & 126.889 & 143.010 & 102.348 & 12,70 & $-19,34$ & $-28,43$ \\
\hline $1983 / 84$ & 123.361 & 140.241 & 103.025 & 13,68 & $-16,48$ & $-26,54$ \\
\hline $1984 / 85$ & 121.729 & 136.473 & 83.215 & 12,11 & $-31,64$ & $-39,02$ \\
\hline $1985 / 86$ & 105.788 & 126.428 & 76.256 & 19,51 & $-27,92$ & $-39,68$ \\
\hline 1972-1985 & 147.217 & 164.449 & 118.625 & 12,05 & $-19,92$ & $-28,44$ \\
\hline $1986 / 87$ & 106.607 & 125.731 & 75.827 & 17,94 & $-28,87$ & $-39,69$ \\
\hline $1987 / 88$ & 103.046 & 123.009 & 87.447 & 19,37 & $-15,14$ & $-28,91$ \\
\hline $1988 / 89$ & 104.772 & 118.163 & 94.836 & 12,78 & $-9,48$ & $-19,74$ \\
\hline $1989 / 90$ & 109.422 & 119.240 & 98.810 & 8,97 & $-9,70$ & $-17,13$ \\
\hline $1990 / 91$ & 112.216 & 122.329 & 91.780 & 9,01 & $-18,21$ & $-24,97$ \\
\hline $1991 / 92$ & 110.883 & 124.557 & 97.380 & 12,33 & $-12,18$ & $-21,82$ \\
\hline $1992 / 93$ & 114.674 & 124.818 & 97.149 & 8,85 & $-15,28$ & $-22,17$ \\
\hline 1986-1992 & 108.803 & 122.549 & 91.890 & 12,75 & $-15,55$ & $-24,92$ \\
\hline
\end{tabular}

1) Berichtsjahr jeweils vom 1.4. bis 31.3.

2) Sommerzeit (SZ): Monatsdurchschnittszahlen der Monate April bis Oktober.

3) Winterzeit (WZ): Monatsdurchschnittszahlen der Monate November bis März.

4) Beeinflußt durch den Beginn der Förderungsmaßnahmen zur ganzjährigen Beschäftigung in der Bauwirtschaft.

Quelle: Eigene Berechnungen nach AbbildungenAbbireqụ Schade - 978-3-631-75046-9 
Anhand einer derartigen Betrachtungsweise sowie durch die zuvor gemachten Feststellungen bezüglich der Produktionserhöhungen, ist jedoch eine gesicherte Aussage über die Effektivität der getroffenen Förderungsmaßnahmen nicht möglich; da die Entwicklung der Zahl der geleisteten Arbeitsstunden untrennbar mit der Entwicklung der Beschäftigtenzahl und der wöchentlichen Arbeitszeit im Bauhauptgewerbe verbunden ist.

Aufgrund dieser Tatsache werden, um die beiden Einflußfaktoren hinreichend genau zu eliminieren, die einzelnen auf das Berichtsjahr bezogenen Verhältnisse betrachtet. Das heißt, die während der "Winterzeit" eines Jahres durchschnittlich geleisteten Arbeitsstunden werden den entsprechenden Durchschnittszahlen der vorangegangenen "Sommerzeit" gegenübergestellt. ${ }^{488}$ Die gleichen Verhältnisse werden zwischen "Sommerzeit" bzw. "Winterzeit" und Jahresdurchschnitt untersucht.

Die Abbildung 53 zeigt, daß vor Inkraftreten der Förderungsmaßnahmen in der "Winterzeit" durchschnittlich 30,31\% weniger Arbeitsstunden als in der "Sommerzeit" und 19,31\% weniger Arbeitsstunden als im Jahresdurchschnitt geleistet wurden, bzw. $\mathrm{da} ß$ in der "Sommerzeit" 15,79\% mehr Arbeitsstunden als im Jahresdurchschnitt geleistet wurden.

Betrachtet man nun den ersten Förderungszeitraum von 1960-1968, so ist festzustellen, daß sich der Überhang über dem Jahresdurchschnitt bei den sommerlichen Bauleistungen um etwa 10\% verringert hat. ${ }^{489}$ Dies entspricht einem Rückgang in der Produktion während der "Sommerzeit" von ca. 1,4\%. ${ }^{490}$ Die winterliche Bautätigkeit ist ebenfalls zurückgegangen, wie die Steigerung der negativen Abweichung vom Jahresdurchschnitt um 6\% ${ }^{491}$ beweist. Daraus resultierte, daß auch das Verhältnis von "WZ/SZ" mit Einführung des SWG nicht verbessert werden konnte, sondern nur rechnerisch rein zufällig - den genau gleichen Wert des förderungsfreien Zeitraumes $(30,31 \%)$ erreichte.

488 Anmerkung: Das Verhältnis $W Z$ zu SZ in \% gibt die prozentuale Verringerung der monatsdurchschnittlich geleisteten Arbeitsstunden an, vgl. Abbildung 53, S. 155.

489 Berechnet aus dem Verhältnis von $14,18 \mathrm{zu} 15,79$

490 Berrechnet aus 115,79 (= 100\%) zu 114,18 (= 98,6\%).

491 Berechnet aus dem Verhältnis von 20,52 zu 19,31. 
Die Analyse der einzelnen Berichtsjahre des Zeitraumes 1960-1968 - ausgenommen das Jahr 1962/63492 - zeigt, daß unmittelbar nach Einführung der Förderungsmaßnahmen erhebliche positive Veränderungen in der Entwicklung der Bautätigkeit zu verzeichnen waren. So konnte im Berichtsjahr 1960/61 die "Überlastung in der Sommerzeit" 493 auf $11,12 \%$ reduziert werden, die winterliche Bauproduktion deutlich erhöht - nur noch 10\% unter Jahresdurchschnitt - und somit die Differenz zwischen "Winterzeit" und "Sommerzeit" auf 19\% verringert werden. Doch schon in den Folgejahren, ${ }^{494}$ die von einem kunjunkturellen Aufschwung in der Bauwirtschaft begleitet waren, ${ }^{495}$ traten wieder. Verhältnisse ein, wie sie von 1954 bis 1959 zu beobachten waren.

Damit stellt sich die Frage, ob die ersten Maßnahmen zur Förderung der ganzjährigen Beschäftigung in der Bauwirtschaft - insbesondere die Einführung des SWG - nach einem positiven Anfangseffekt (1960/61) eher kontraproduktive Wirkungen verursachten. Hierbei ist allerdings zu berücksichtigen, daß der Förderungszeitraum 19601968 primär sozial- und arbeitsmarktpolitische Zwecke verfolgte, ${ }^{496}$ dennoch kann es nicht im Sinne des Gesetzgebers gelegen haben, einen bereits erreichten Stand an winterlicher Bauproduktion nach Einführung von Förderungsmaßnahmen - egal welcher Art - um 6\% (20,52 zu 19,31) zu verringern.

In den beiden folgenden Zeiträumen 1969-1971 und 1972-1985 wurden nun bewußt wirtschaftspolitische Ziele durch die Einführung der sogenannten PWF verfolgt. ${ }^{497}$ Für den Zeitraum 1969-1971 zeigt sich jedoch, daß die getroffenen Förderungsmaßnahmen kaum nennenswerte Steigerungen in der Bauproduktion bewirkt haben. Es

492 Die ungünstigen Witterungsbedingungen dieses Winters haben die Ergebnisse sehr negativ beeinflußt, vgl. Kap. 3.1.4. Witterungsbedingungen, S.101ff.

493 Anmerkung: Es bleibt noch zu klären, inwieweit die Kapazität im Sommer ausgelastet ist und welcher Anteil des jeweiligen Überhanges aus dem Verhältnis $S Z z u J D$ auf geleisteten Überstunden beruht.

494 Dies sind insbesondere die Jahre 1961/62, 1963/64, 1964/65, 1965/66, 1966/67.

495 Anmerkung: So fiel in diese Zeit, um eine "Überhitzung" der Baukonjunktur zu vermeiden, das Gesetz vom 8. Juni 1962 zur Einschränkung der Bautătigkeit, welches am 27. Juni 1963 bis zum 31. Dezember 1973 verlängert wurde, vgl. auch Kap. 2.1.3. Baukonjunkturelle Entwicklung und Prognose, S.42ff.

496 Anmerkung: Wie bereits beschrieben, haben die Förderungsmaßnahmen bezüglich der Einschränkung der Saisonarbeitslosigkeit und der ganzjăhrigen Beschäftigung erhebliche Erfolge erzielt, vgl. hierzu ausfuhrlich Kap. 3.3.1. Arbeitsmarktpolitische Effekte der getroffenen Förderungsmaßnahmen, S.117ff.

497 Laut BT-Drs. V/2291 ist die PWF "ausschließlich produktionsorientiert", vgl. Kap. 2.5.1.2. AFG, S.83ff. 
sind zwar im Vergleich zum vorherigen Zeitraum 1960-1968, leichte Produktionserhöhungen sowohl im Sommer (15,82\% über JD) als auch im Winter (19,51\% unter JD) festzustellen. Beispielsweise konnte die vorherige winterliche Steigerung der negativen Abweichung vom Jahresdurchschnitt von $6 \%$, jetzt rückgängig gemacht werden und dadurch der ursprüngliche Wert vor Einführung der Förderungsmaßnahmen, der nur 19,31\% unter dem Jahresdurchschnitt lag, fast wieder erreicht werden. Dennoch kann von einem Erfolg der Förderungsmaßnahmen nicht gesprochen werden, weil der Saisonausschlag "WZ/SZ" nach wie vor $30 \%$ beträgt und damit dem Ziel der kontinuierlichen Bautätigkeit keinen Schritt näher gekommen ist.

Ähnlich gering ist der Erfolg nach Einführung der Winterbaunovelle am 19. Mai 1972. Wie die einzelnen Ergebnisse des Zeitraumes 1972-1985 zeigen, konnte zwar im Berichtsjahr 1972/73, d.h. unmittelbar nach der Einführung dieser produktionsorientierten Förderungsmaßnahmen, ${ }^{498}$ eine erhebliche Steigerung der winterlichen Bautätigkeit erzielt werden, weil sich die negative Abweichung vom Jahresdurchschnitt um über fünf Prozentpunkte - im Vergleich zum Durschnitt 1969-1971 - von 19,51 auf nur noch $14,15 \%$ reduzierte. Gleichzeitig verringerte sich auch der Überhang in der "Sommerzeit" um fast sechs Prozentpunkte $(9,88 \mathrm{zu} 15,82)$. Aufgrund dieser beiden Ergebnisse konnte auch das Verhältnis "WZ/SZ" um fast neun Prozentpunkte auf $21,87 \%$ reduziert werden, so daß man dem Ziel der kontinuierlichen Bautätigkeit erheblich näher gekommen war.

Doch schon im Folgejahr wurde diese positive Entwicklung wieder umgekehrt und man näherte sich den Werten bzw. Verhältnissen, der bereits beschriebenen Zeiträume von 1954 bis 1971. Mit Ausnahme der Berichtsjahre 1976/77 und 1979/80 konnte das winterliche Produktionsergebnis des Jahres 1972/73 in keinem der verbleibenden Berichtsjahre dieses Zeitraumes auch nur annähernd erreicht werden. Häufig fielen die Einzelergebnisse sogar wesentlich negativer aus - insbesondere in den Jahren 1978/79, 1980/81, 1981/82, 1984/85 und 1985/86 - als die Durchschnitte der Zeiträume 1954-1959, 1960-1968 und 1969-1071, die in allen drei gebildeten Verhältnissen (SZ/JD, WZ/JD, WZ/SZ) nur geringfügig voneinander abwichen.

In dieser zuletzt beschriebenen Entwicklung liegt die Ursache dafür, daß die winterliche Bauproduktion des Zeitraumes 1972-1985 - bezogen auf den Jahresdurchschnitt und im Vergleich zum vorherigen Zeitraum - um etwa $2 \%$ gesunken ist, d.h. der ne-

498 vgl. Kap. 2.4.1.4. 1972-85: Die Winterbaunovelle, S.71ff. 
gative Saisonausschlag des Winters ist auf $19,92 \%$ gestiegen. ${ }^{499}$ Der Überhang in der "Sommerzeit" wurde von 1972-1985 um etwa 24\% erheblich abgebaut und liegt nur noch $12 \%$ über dem Jahresdurchschnitt. ${ }^{500}$ Aufgrund dieses deutlichen Rückganges im Sommer hat sich auch das Verhältnis "WZ/SZ" - trotz der gestiegenen negativen Abweichung im Winter - insgesamt leicht verringert und beträgt nur noch $28,44 \%$.

Hieraus läßt sich allerdings keinesfalls die Schlußfolgerung ziehen, daß man durch die erreichte Verringerung des Saisonausschlages "WZ/SZ", dem angestrebten Ziel der kontinuierlichen Bautätigkeit näher gekommen ist. Zumal die Verringerung des Verhältnisses "WZ/SZ" nicht mit einer Erhöhung, sondern einer Einschränkung des Jahresbauvolumens verbunden ist. ${ }^{501}$ Betrachtet man die zu Beginn des Kapitels geäußerte Erwartung, daß insbesondere durch die produktionsorientierten Förderungsmaßnahmen der Zeiträume 1969-1971 und 1972-1985, die winterliche Bauproduktion steigen würde, ohne die des Sommers wesentlich einzuschränken, so ist jetzt aufgrund der Zahlenergebnisse festzustellen, daß die Wirkungen auf die Produktionsschwankungen, d.h. speziell die erhoffte Erhöhung des Jahresbauvolumens, sich nicht erfullt haben. Die Beantwortung der Frage, inwieweit man dem Ziel der kontinuierlichen Bautätigkeit näher gekommen ist, soll - trotz der bereits geschilderten Ergebnisse im Rahmen des folgenden Kapitels noch einmal eingehend untersucht werden.

\subsubsection{Wirkungen auf die Verstetigung der Bautätigkeit}

Anhand der nachfolgenden Berechnung sollen etwaige Fortschritte in puncto saisonaler Verstetigung der Bautätigkeit und hier insbesondere nach Inkrafttreten der Winterbaunovelle zum AFG vom 19. Mai 1972 quantifiziert werden. Dabei ist zu berücksichtigen, daß die ermittelten Ergebnisse durch Konjunktur und/oder Witterungseinflüsse in den einzelnen Jahren mitbeeinflußt werden und dadurch die exakte Berechnung erschweren bzw. unmöglich machen. Dessen ungeachtet wird der Versuch unternommen, anhand der Entwicklung der geleisteten Arbeitsstunden und der Beschäftigtenzahlen sowie der anzusetzenden Arbeitstage, eine einigermaßen abgesicherte Aussage über die saisonale Verstetigungsentwicklung zu bekommen.

\footnotetext{
499 Berechnet aus dem Verhältnis 19,92 zu 19,51.

500 Berechnet aus dem Verhältnis $12,05 \mathrm{zu} 15,82$.

501 Dies zeigt die Entwicklung der Jahresdurchschnittszahlen für die einzelnen Förderungszeiträume: 220.981, 208.886, 147.217 und 108.803, vgl. Abbildung 53, S.155.
} 
Ausgehend von der Annahme, daß sich die Wirkungen im Hinblick auf eine kontinuierliche Bautätigkeit am besten anhand eines Vergleiches der Entwicklung von "Maximaldifferenzen" über den gesamten Untersuchungszeitraum (1954-1992) erklären lassen, beschränkt sich der Verfasser in der folgenden Berechnung auf die Förderungszeit ${ }^{502}$ und die Monate Juli bis Oktober. Das heißt, es werden die Monate mit den wenigsten geleisteten Arbeitsstunden (Dezember bis März) und der umfangreichsten Winterbauförderung ${ }^{503}$ zusammengefaßt und denjenigen mit den meisten geleisteten Arbeitsstunden (Juli bis Oktober) gegenübergestellt. ${ }^{504}$

Die Berechnung geht weiter davon aus, daß die je Baustellenbeschäftigten geleisteten Arbeitsstunden in den Monaten Juli bis Oktober nicht durch außergewöhnliche Witterungsbedingungen beeinflußt werden, ${ }^{505}$ so daß die Veränderungen der Sommermonatsdurchschnitte zwischen den verschiedenen Jahren primär auf die Entwicklung der tariflichen Wochenarbeitszeit während des Untersuchungszeitraumes ${ }^{506}$ sowie auf konjunkturelle und/oder tendenzielle Verschiebungen zwischen Sommer- und Winterbautätigkeit zurückgeführt werden können.

Die nachfolgende Abbildung 54 zeigt den Vergleich zur Bestimmung der Wirkungen der Förderungsmaßnahmen auf die Verstetigung der Bautätigkeit. Dabei ist die Tatsache, daß die in Spalte "1)" gebildete Summe der geleisteten Arbeitsstunden ${ }^{507}$ nicht auf denselben statistischen Erhebungsumfang wie der in Spalte "2)" gebildete Durchschnitt der Beschäftigten ${ }^{508}$ zurückgreift, zu vernachlässigen. Denn der Unterschied

502 Die Förderungszeit umfaßt den Zeitraum: 1. Dezember bis 31. März.

503 Anmerkung: Der Monat November fällt in die Schlechtwetterzeit (1. November bis 31. März) der Winterbauförderung und nicht in die Förderungszeit, d.h. im November wird kein "produktives" WG sondern nur "unproduktives" SWG gezahlt. Aus diesem Grund bleibt der November in der Vergleichsrechnung zur Entwicklung der kontinuierlichen Bautätigkeit unberücksichtigt.

504 vgl. Kap. 3.3.2.1.1. Geleistete Arbeitsstunden, S.141ff.

505 Anmerkung: Für die Monate April und Mai ließe sich diese Annahme nicht so ohne weiteres treffen, da hier die Bautätigkeit - im April normalerweise mehr als im Mai - häufig noch durch Witterungseinflüsse beeinträchtigt werden kann. Das heißt, eine Berücksichtigung der beiden Monate im "Vergleich der Berechnung der geleisteten Arbeitsstunden je Beschäftigten" hätte zur Folge, daß zwar die Statistik der Beschäftigten nach wie vor unverändert bliebe, denn im April und Mai wird niemand aus Witterungsgründen entlassen, die geleisteten Arbeitsstunden aber aufgrund der Witterungsausfalle reduziert und dadurch die Ergebnisse beeinträchtigt würden.

506 Hinweis: Zu Beginn des Untersuchungszeitraumes 1954 betrug die tarifliche Wochenarbeitszeit noch 48 Arbeitsstunden. Sie ist dann kontinuierlich bis zum Jahr 1992 auf 39 Wochenstunden gesunken, vgl. auch Die Deutsche Bauindustrie (Hrsg.), Baustatistisches Jahrbuch 1992, S.52.

507 Anmerkung: Hierbei handelt es sich um die tatsächlich geleisteten Arbeitsstunden entsprechend der Definition in Kap. 3.3.2.1.1. Geleistete Arbeitsstunden, S. 141, Fußnote 469. 
liegt darin, daß in den geleisteten Arbeitsstunden auch die von Inhabern und Familienangehörigen erbrachten Arbeitsstunden berücksichtigt werden. Diese sind allerdings nicht zu quantifizieren und nach Ansicht der Tarifpartner als vernachlässigbar gering einzuschätzen. Aus diesem Grund verzichtet der Verfasser auf die Berücksichtigung der Inhaber und Familienangehörigen in der Zahl der Beschäftigten der Abbildung 54.

Es zeigt sich, daß die Zahl der im Durchschnitt der Monate Juli bis Oktober je Baustellen-Beschäftigten und Arbeitstag geleisteten Arbeitsstunden relativ kontinuierlich abgenommen hat, und zwar von 8,93 als Mittelwert des forderungsfreien Zeitraumes über 8,31 (1960-1968), 8,21 (1969-1971) und 7,15 (1972-1985) bis auf zuletzt 6,75 (1986-1992) Arbeitsstunden pro Tag. Das ist ein Rückgang der je Mann geleisteten Arbeitsstunden im Sommer um insgesamt $24,4 \%$.

Parallel dazu hat sich die Wochenarbeitszeit im gesamten Untersuchungszeitraum um fast $20 \%$ von 48 auf 39 Wochenstunden reduziert, so daß der Grund für den Rückgang in den betrachteten "Sommermonaten" (Juli bis Oktober) in erster Linie auf die Entwicklung der tariflichen Wochenarbeitszeit zurückzuführen ist. ${ }^{509}$ Hinzu kommen die erwähnten konjunkturellen Einflüsse sowie strukturelle Veränderungen im Sinne von Abbau der sommerlichen Beschäftigungsspitzen und der technische Fortschritt.

Bei den in den Wintermonaten Dezember bis März geleisteten Arbeitsstunden schlägt neben der Konjunktur sowie eventuellen strukturellen Veränderungen in der Verteilung auf Sommer und Winter auch die in den einzelnen Wintern unterschiedliche Witterung zu Buche. ${ }^{510}$ Die Abbildung 54 zeigt, daß die Zahl der je Baustellen-Beschäftigten und Arbeitstag geleisteten Arbeitsstunden in den Monaten Dezember bis März ebenfalls kontinuierlich von Zeitraum zu Zeitraum zurückgegangen ist. So werden im förderungsfreien Zeitraum von 1954-1959 noch durchschnittlich 7,90 Stunden

508 Anmerkung: Im Gegensatz zu den geleisteten Arbeitsstunden beinhalten die Beschäftigtenzahlen auch Urlaubs- oder Krankheitstage, d.h. die Beschäftigtenzahlen repräsentieren zwar die im Arbeitsverhältnis stehenden Beschäftigten, aber nicht die tatsächlich produktiv Tătigen. Insofern ist den ermittelten Ergebnissen ein Fehler in Höhe der nicht produktiv Tătigen Beschäftigten inhärent. Da jedoch nicht zu erwarten ist, daß sich einerseits die Krankheitstage auf einen bestimmten Monat konzentrieren oder andererseits vom traditionellen Rhythmus der Urlaubsnahme abgewichen wird, stellt der Verfasser in Absprache mit den Tarifpartnern fest, daß sich diese Ungenauigkeit relativ gleichmaßig auf den gesamten Untersuchungszeitraum verteilt d.h. einen gleichmäßigen jährlichen Verlauf hat - und daher vernachlässigt werden kann.

509 vgl. Hauptverband der Deutschen Bauindustrie (Hrsg.), Baustatistisches Jahrbuch 1992, S.52.

510 vgl. Kap. 3.1.4. Witterungsbedingungen, S.101ff. 
Abbildung: 54

\begin{tabular}{|c|c|c|c|c|c|c|c|c|c|c|c|}
\hline \multicolumn{12}{|c|}{$\begin{array}{l}\text { Vergleich der geleisteten Arbeitsstunden je Beschäftigten und Tag in } \\
\text { Bauhauptgewerbe }\end{array}$} \\
\hline \multirow[b]{2}{*}{ Zeitraum } & \multicolumn{5}{|c|}{ Juli bis Oktober ("Sommer") } & \multicolumn{5}{|c|}{ Dezember bis März ("Winter") } & \multirow[b]{2}{*}{ 6) } \\
\hline & 1) & 2) & 3) & 4) & 5) & 1) & 2) & 3) & 4) & 5) & \\
\hline $1954 / 55$ & 929.332 & 142.979 & 13,08 & 87 & 9,35 & 20.738 & 777.203 & 670,02 & 86 & 7,79 & 1,55 \\
\hline $1955 / 56$ & 1.024 .745 & 1.252 .870 & 817,92 & 87 & & 93.147 & 822.285 & 21,34 & 85 & 49 & 0,91 \\
\hline $1956 / 57$ & 1.012 .445 & 1.245 .753 & 812,72 & 89 &, 13 & 642.212 & 893.094 & 719,09 & 83 & 3,66 & 0,47 \\
\hline $1957 / 58$ & 891.767 & 1.174 .956 & 758,98 & 90 & 8,43 & 513.264 & 768.438 & 667,93 & 83 &, 05 & 0,39 \\
\hline $1958 / 59$ & 942.922 & 1.228 .615 & 767,47 & 89 & 8,62 & 617.392 & 951.552 & 648,83 & 84 &, 72 & 0,90 \\
\hline $1959 / 60$ & 984.139 & 1.288 .523 & 763,77 & 88 & 8,68 & 673.440 & 1.121 .154 & 600,67 & 86 & 6,98 & 1,69 \\
\hline 1954-1959 & 964.225 & 1.222.283 & 788,87 & 88,3 & 8,93 & 593.366 & 888.954 & 667,49 & 84,5 & 7,90 & 1,03 \\
\hline $0 / 61$ & 95 & 368 & 37,74 & 87 & & 193 & 93 & & 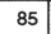 & 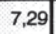 & \\
\hline $1 / 62$ & & 1 & & 87 & & 335 & 310 & & & 27 & \\
\hline $1962 / 63$ & 1.030 .952 & 1.382 .512 & 745,71 & 88 & 8,47 & 460.274 & 1.276 .415 & 60,60 & 82 & 40 & 4,08 \\
\hline $1963 / 64$ & & 132 &, 02 & 90 & & 282 & & & 82 & 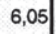 & \\
\hline $1964 / 65$ & 1.111 .874 & 1.506 .537 & 738,03 & 88 & 8,39 & 696.166 & 801 & 511,59 & 84 &, 09 & 2,30 \\
\hline $1965 / 66$ & 1.0 & 1.502 .981 & 724,39 & 87 & 8,33 & .953 & & & 86 & 23 & \\
\hline $1966 / 67$ & 1.039 .634 & 1.454 .170 & 714,93 & 87 & 8,22 & 676.363 & 884 & 62,28 & 85 & 62 & 1,60 \\
\hline $1967 / 68$ & & & 05,84 & 87 & & 306 & 59 & & 82 & 1 & \\
\hline $1968 / 69$ & 954.405 & 1.335 .801 & 714,48 & 89 & 8,03 & 577.491 & 1.237 .165 & 466,79 & 83 & 62 & 2,40 \\
\hline $1960-1968$ & 1.019 .283 & 1.396 .852 & 729,70 & 87,8 & 8,31 & 42.596 & 1.268 .996 & 506,38 & 83,6 & 6,06 & 2,25 \\
\hline $1969 / 70$ & & & 27,61 & 89 & 8,18 & 254 & & & 84 & 1 & \\
\hline $1970 / 71$ & 1.006 .407 & 1.374 .434 & 732,23 & 88 & & 657.490 & 1.270 .866 & & 85 & & \\
\hline $1971 / 72$ & 969.778 & 1.369 .622 & 708,06 & 87 & 8,14 & 691.234 & 1.247 .805 & 553,96 & 87 & 3,37 & 1,77 \\
\hline 1969-1971 & 984.855 & 1.362 .903 & 722,62 & 88,0 & 8,21 & 618.993 & 1.250 .885 & 494,84 & 85,3 & 0,00 & 2,41 \\
\hline & & & & 07 & & & & & & & \\
\hline $1973 / 74$ & 981 & 1.31 & 661,41 & 8 & 7,52 & 411 & 1.15 & & 82 & & \\
\hline $1974 / 75$ & 735.891 & 1.140 .153 & 645,43 & 90 & 7,17 & 519.746 & 985.656 & 27,31 & 81 & ,51 & 0,66 \\
\hline $1975 / 76$ & .588 & 1.03 & 653,42 & 89 & 7,34 & 164 & & & 83 & & \\
\hline $1976 / 77$ & 660.360 & 1.025 .957 & 643,65 & 87 & 7,40 & 484.410 & 924.960 & 23,71 & 84 & 23 & 1,16 \\
\hline $1977 / 78$ & 597.916 & 964.508 & 619,92 & 87 & 7,13 & 433.896 & 917.262 & 473,03 & 85 & & \\
\hline $1978 / 79$ & 629.741 & 1.016 .388 & 619,59 & 87 & 7,12 & 385.141 & 973.008 & 395,83 & 83 & 77 & 2,35 \\
\hline $1979 / 80$ & 664.567 & 1.058 .103 & 628,07 & 88 & 7,14 & 490.611 & 1.016 .580 & 482,61 & 82 & 5,89 & \\
\hline $1980 / 81$ & 652.058 & 1.065 .094 & 612,21 & 87 & 7,04 & 396.440 & 991.977 & 399,65 & 84 & 1,76 & 2,28 \\
\hline $1981 / 82$ & 618.151 & 1.025 .951 & 602,52 & 88 & 6,85 & 359.219 & 902.089 & 398,21 & 85 & 4,68 & 2,16 \\
\hline $1982 / 83$ & 574.222 & 966.283 & 594,26 & 87 & 6,83 & 370.839 & 844.915 & 438,91 & 86 & 5,10 & 1,73 \\
\hline $1983 / 84$ & 573.308 & 960.938 & 596,61 & 87 & 6,86 & 374.763 & 862.364 & 434,58 & 85 & 0,11 & 1,74 \\
\hline $1984 / 85$ & 555.256 & 933.381 & 594,89 & 89 & 6,68 & 286.471 & & 361,05 & 83 & 4,35 & 2,33 \\
\hline $1985 / 86$ & 526.279 & 863.534 & 609,45 & 90 & 6,77 & 276.646 & 755.002 & 366,42 & 83 & 4,41 & 2,36 \\
\hline 1972-1985 & 661.034 & 1.051.219 & 628,83 & 87,9 & 7,15 & 437.086 & 951.274 & 459,47 & 83,5 & 5,50 & 1,65 \\
\hline & & & & 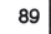 & & & & & 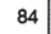 & & 2,68 \\
\hline $1987 / 88$ & 507.837 & 827.662 & 613,58 & 88 & 6,97 & 319.114 & 736.389 & 433,35 & 86 & 5,04 & 1,93 \\
\hline $1988 / 89$ & .967 & 808.617 & 593,57 & 87 & 6,82 & 363.376 & 762.256 & 476,71 & 86 & 5,54 & 1,28 \\
\hline $1989 / 90$ & 481.816 & 817.628 & 589,29 & 87 & 6,77 & 376.228 & 787.902 & 477,51 & 83 & 5,75 & 1,02 \\
\hline $1990 / 91$ & 497.457 & 847.771 & 586,78 & 87 & 6,74 & 340.449 & 811.055 & 419,76 & 82 & 5,12 & 1,63 \\
\hline $1991 / 92$ & 504.016 & 867.999 & 580,66 & 89 & 6,52 & 370.984 & 828.247 & 447,91 & 84 & 5,33 & 1,19 \\
\hline $1992 / 93$ & 505.077 & 873.173 & 578,44 & 88 & 6,57 & 368.140 & 826.462 & 445,44 & 85 & 5,24 & 1,33 \\
\hline $986-1992$ & 499.226 & 841.800 & 593,05 & 87,9 & 6,75 & 342.833 & 785.409 & 436,50 & 84,3 & 5,18 & 1,57 \\
\hline
\end{tabular}

1) Summe der tatsächlich geleisteten Arbeitsstunden in 1.000

2) Beschäftigte im Durchschnitt der Monate Juli bis Oktober bzw. Dezember bis März

3) Tatsächlich geleistete Arbeitsstunden je Beschäftigten im "Sommer" bzw. "Winter"

4) Summe der Arbeitstage ${ }^{511}$ von Juli bis Oktober bzw. Dezember bis März

5) Tatsächlich geleistete Arbeitsstunden je Beschäftigten und Arbeitstag ("Sommer" bzw. "Winter")

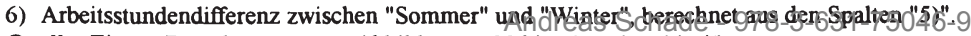

Quelle: Eigene Berechnungen aus Abbildungen 29 bis-33 und 36 bis 49.1/2019 08:54:32AM 
pro Tag und Beschäftigten geleistet. Diese geleistete Arbeitsstundenzahl je Beschäftigten und Arbeitstag verringerte sich dann auf 6,06 (1960-1968), von 1969-1971 auf 5,80 und im Zeitraum 1972-1985 nach Einführung der Winterbaunovelle auf durchschnittlich 5,50 Arbeitsstunden pro Tag und Beschäftigten. Das zuletzt ermittelte Ergebnis (1986-1992) beträgt 5,18 Stunden pro Tag, so daß ein Gesamtrückgang innerhalb des Untersuchungszeitraumes von $34,4 \%$ zu verzeichnen ist.

Die Reduzierung der geleisteten Arbeitsstunden je Beschäftigten und Tag fällt damit in den Wintermonaten um $10 \%$ höher aus als in den Monaten Juli bis Oktober, wie sich aus der Differenz von 34,4\% (Winter) und 24,4\% (Sommer) ergibt. Auf den ersten Blick liegt hier die Vermutung nahe, daß dieser um $10 \%$ gesteigerte Rückgang der Arbeitsstunden je Beschäftigten des "Winters" - im Vergleich zum "Sommer" auf Witterungseinflüsse zurückzuführen ist. Diese Annahme setzt allerdings die Tatsache voraus, daß sich die Witterungsverhältnisse während der Schlechtwetterzeit im Verlauf des gesamten Untersuchungszeitraumes von 1954-1992 kontinuierlich verschlechtert und dadurch die winterliche Bautätigkeit zunehmend negativ beeinflußt haben müßten.

Die "Tage mit Witterungserscheinungen, die die Fortführung der Bauarbeiten sehr erschweren", zeigen jedoch mit durchschnittlich 15 Schlechtwettertagen in der Zeit von 1960-1968, bzw. 14 Schlechtwettertagen in den Zeiträumen 1969-1971 und 1972 1985 sowie zuletzt (1986-1992) erreichten 13 Schlechtwettertagen $^{512}$ eine eher gleichmäßige bzw. leicht positive Witterungsentwicklung im Verlauf des gesamten Untersuchungszeitraumes, so daß der gesteigerte Rückgang der täglich geleisteten Arbeitsstunden je Beschäftigten im "Winter" nicht mit Witterungseinflüssen begründet werden kann.

Es bleibt daher festzuhalten, daß Witterungseinflüsse zwar negative Auswirkungen auf die winterliche Bautätigkeit ausgeübt haben, allerdings nicht in steigender sondern in gleichbleibender Form. Diese Tatsache wird sowohl anhand der Entwicklung der Schlechtwettertage nach Abbildung 15 bestätigt, als auch durch die in jedem Jahr (1954-1992) existierende Differenz - zwischen "Juli bis Oktober" und "Dezember bis März" - in der täglich geleisteten Zahl von Arbeitsstunden je Beschäftigten. ${ }^{513}$

511 Die Anzahl der Arbeitstage variiert aufgrund kalendarischer Verschiebungen (z.B. Februar 28 oder 29 Tage, wechselnder Zusammenfall von Feiertagen und Wochenenden).

512 vgl. Abbildung 15: Vergleich der Witterungserscheinungen in Zeiträumen, S. 106.

513 vgl. Abbildung 54, Ergebnis der Spalte "6)" ermittelt aus der Differenz der Spalten "5)". 
Inwieweit die getroffenen Winterbauförderungsmaßnahmen die ermittelten Ergebnisse der Abbildung 54 beeinflußt haben könnten, soll durch eine nähere Analyse der einzelnen Zeiträume aufgezeigt werden. Dabei konzentriert sich die Analyse insbesondere auf die Entwicklung der Differenz zwischen geleisteten Arbeitsstunden je Beschäftigten von "Sommer" zu "Winter" im Verlauf des gesamten Untersuchungszeitraumes. ${ }^{514}$ Denn bei einer Betrachtung der einzelnen Jahresergebnisse $-d$.h. jeweiliger Vergleich der Monate Juli bis Oktober mit den darauffolgenden Monaten Dezember bis März können die durch Konjunkturschwankungen verursachten Einflüsse erheblich reduziert werden. ${ }^{515}$

\section{4-1959: Der Zeitraum "Vorher"}

Betrachtet man zunächst den förderungsfreien Zeitraum, so ist festzustellen, daß eine durchschnittliche Differenz von 1,03 täglich geleisteten Arbeitsstunden zwischen "Sommer" und "Winter" dem Ziel einer kontinuierlichen Bautätigkeit gegenüberstehen. Oder anders ausgedrückt: Die täglich geleisteten Arbeitsstunden im "Winter", liegen um 11,5\%516 unter denen des "Sommers".

Dabei ist zu berücksichtigen, daß der Untersuchungszeitraum des Jahres 1959/60 durch den Beginn der gesetzlichen Regelungen zur Förderung der ganzjährigen Beschäftigung in der Bauwirtschaft im Dezember 1959 beeinflußt wurde. Diese Tatsache, zeigt sich auch in der deutlichen Abweichung des Einzelergebnisses von 1959/60 für die Monate Dezember bis März im Vergleich zu den übrigen Ergebnissen des förderungsfreien Zeitraumes.

So wurden in den Wintermonaten 1959/60 lediglich noch 6,98 Arbeitsstunden pro Mann und Tag geleistet. Dies entspricht einem Rückgang gegenüber 1958/59 um fast $10 \% .^{517}$ Eine derartig starke Reduzierung innerhalb eines Jahres läßt sich im gesamten Zeitraum 1954-1959 sowohl während des "Winters" als auch während des "Sommers" nicht mehr feststellen. Im Gegenteil, in den ersten drei Jahren (1954/55, 1955/56, 1956/57) wurde die täglich geleistete Arbeitszeit je Beschäftig-

514 vgl. Abbildung 54, Spalte "6)".

515 Anmerkung: Da die Konjunkturschwankungen den mittelfristigen periodischen Schwankungen mit einer Zykluslänge von vier bis sieben Jahren zuzurechnen sind, vertritt der Verfasser die Ansicht, daß ein Vergleich von im Zeitablauf direkt hintereinander liegenden Monaten, konjunkturelle Einflüsse bzw. Verzerrungen bestmöglich reduziert, vgl. auch Kap. 2.2.1. Saisonschwankung, S.50ff. und Vosgerau, H.-J., Konjunkturtheorie, S.478ff.

516 Berechnet aus dem Verhältnis von 7,90 zu 8,93.

517 Berechnet aus dem Verhältnis von 6,98 zu 7,72. 
ten in den Monaten Dezember bis März sogar von 7,79 auf 8,66 Arbeitsstunden pro Tag erhöht. ${ }^{518}$

Die darauffolgende Verringerung im Jahr 1957/58 auf 8,05 tägliche Arbeitsstunden, läßt sich mit der Reduzierung der tariflichen Wochenarbeitszeit von 48 auf nunmehr 45 Arbeitsstunden ab 1. April 1957 begründen. Zumal sich diese Reduzierung auch in den "Sommermonaten" Juli bis Oktober in fast gleicher Höhe beobachten läßt, wie die folgende Vergleichsrechnung der Zeiträume 1957/58 zu 1956/57 zeigt:

$$
\begin{array}{ll}
\text { Reduzierung der Wochenarbeitszeit }(45 / 48): & 6,3 \% \\
\text { Reduzierung Juli bis Oktober }(8,43 / 9,13): & 7,7 \% \\
\text { Reduzierung Dezember bis März }(8,05 / 8,66): & 7,0 \%
\end{array}
$$

Doch selbst dieser etwa 7prozentige Rückgang in den täglich geleisteten Arbeitsstunden zwischen 1956/57 und 1957/58, verursacht durch eine deutliche Reduzierung der tariflichen Wochenarbeitszeit, fällt noch geringer aus, als der Rückgang 1959/60 nach Einführung der Winterbauförderungsmaßnahmen. Hier liegt daher die Vermutung nahe, daß der Beginn der gesetzlichen Förderungsmaßnahmen im Dezember 1959 für die relativ geringe Zahl von 6,98 täglich geleisteten Arbeitsstunden in den Monaten Dezember bis März primär verantwortlich ist. ${ }^{519}$

Aufgrund der gewonnnenen Erkenntnisse müßte das Jahr 1959/60 zur Bestimmung der durchschnittlichen Differenz der täglich geleisteten Arbeitsstunden zwischen "Sommer" und "Winter" ausgeschlossen werden. Zumal der Wert von 1,69 Stunden der Spalte "6)" deutlich oberhalb der anderen Differenzen liegt und dadurch das Gesamtergebnis erheblich beeinflußt. Ohne Berücksichtigung des Jahres 1959/60 ergibt sich für den dann tatsächlich förderungsfreien Zeitraum (1954/55 bis 1958/59) ein durchschnittlicher Differenzwert von nur noch 0,84 Stunden; im Vergleich zu den 1,03 Stunden vorher. Dieser Wert kommt dem angestrebten Ziel

518 Hinweis: Die tarifliche Wochenarbeitszeit betrug wăhrend der Zeit von 1954 bis 1957 konstant 48 Wochenarbeitsstunden. Sie wurde erst am 1. April 1957 im Rahmen der jährlichen Tarifverhandlungen auf 45 Wochenstunden verringert; vgl. Die Deutsche Bauindustrie (Hrsg.), Baustatistisches Jahrbuch 1992, S.52.

519 Anmerkung: Die Aussage wird durch die in dieser Zeit ermittelten Ergebnisse in den Monaten Juli bis Oktober unterstützt, da sie sich nur unwesentlich ăndern; 8,62 bzw. 8,68 und 8,48; vgl. Abbildung 54, Spalte "5)". 
einer kontinuierlichen Bautätigkeit schon erheblich nahe und dies trotz der Tatsache, daß es sich hier um eine förderungsfreie Zeit handelt.

Interessanterweise wurde eine derartig geringe Abweichung in den täglich geleisteten Arbeitsstunden je Beschäftigten zwischen "Sommer" und "Winter" in keinem der nachfolgenden Förderungszeiträume mehr erreicht. Betrachtet man die durchschnittlichen Differenzen dieser Zeiträume, so ist festzustellen, daß insbesondere in der Zeit von 1960-1968 und 1969-1971 deutliche Steigerungen zu verzeichnen waren. Daher stellt sich die Frage, ob die Förderungsmaßnahmen die Verstetigungsentwicklung der Bautätigkeit negativ beeinflußt haben. Die folgende Analyse der Förderungszeiträume soll hierüber Auskunft geben.

\section{0-1968: Das zweite Änderungsgesetz zum AVAVG}

Die Einzelergebnisse der Spalte "6)" dieses ersten Förderungszeitraumes weisen durchweg größere Unterschiede zwischen "Sommer" und "Winter" aus, als dies noch in der förderungsfreien Zeit der Fall war. Die Folge davon ist, daß die durchschnittliche Differenz von 1960-1968 mit 2,25 geleisteten Arbeitsstunden pro Tag und Beschäftigten um 1,22 (bezogen auf 1,03) bzw. 1,41 (bezogen auf 0,84) Stunden angestiegen ist.

Die nähere Betrachtung der jährlichen Einzelergebnisse zeigt, daß sich die ermittelten Stundendifferenzen in einer relativ engen Bandbreite - hauptsächlich Schwankungen zwischen 2,10 und 2,40 - bewegen. Eine absolute Ausnahme bildet allerdings die Differenz von 4,08 Stunden zwischen "Sommer" und "Winter" im Jahr 1962/63, die mit einem äußerst ungünstigen Witterungsverlauf begründet werden kann, wie die folgenden Ausführungen noch zeigen werden. ${ }^{520}$

So ist die Tatsache, daß der Gesetzgeber als Voraussetzung zur Einführung der Förderungsmaßnahmen - speziell der SWG-Regelung - von den Tarifpartnern ein tarifvertraglich fixiertes Kündigungsverbot während der Schlechtwetterzeit für den Fall des Arbeitsausfalles aus Witterungsgründen forderte, ${ }^{521}$ primär für die gestiegenen Differenzen zwischen "Sommer" und "Winter" dieses Zeitraumes verantwortlich.

520 vgl. Kap. 3.1.4. Witterungsbedingungen, S. 101.

521 vgl. Kap. 2.4.2. Tarifvertragliche Leistungen und Regelungen, S.74. 
Statistisch belegen läßt sich diese Aussage anhand der deutlichen Steigerung in den durchschnittlichen Beschäftigtenzahlen der Monate Dezember bis März. ${ }^{522}$ Denn aufgrund der SWG-Regelung im Dezember 1959, erhöhte sich die Zahl der durchschnittlich im "Winter" Beschäftigten sprunghaft um 170.000 auf $1.121 .154 \mathrm{Be}-$ schäftigte 1959/60. Bis 1961/62 stieg sie dann nochmals um rund 100.000 auf 1.220.310 Beschäftigte im Durchschnitt der Monate Dezember bis März. Der Anstieg im "Sommer" fiel dagegen im gleichen Zeitraum mit einer Gesamtsteigerung um etwa 10.000 Beschäftigte von 1.288 .523 (1959/60) auf 1.299.909 (1961/62), erheblich geringer aus.

Diese gestiegenen Beschäftigtenzahlen, verbunden mit der Tatsache, daß der Bauunternehmer jetzt witterungsbedingten Arbeitsausfall aufgrund der SWG-Regelung anmelden konnte, führten zu dem Ergebnis, daß sich die geleisteten Arbeitsstunden je Beschäftigten und Tag in den Monaten Dezember bis März reduzierten und demzufolge sich die Differenzen der Spalte "6)" in Abbildung 54 erhöhten. Die direkte Abhängigkeit der Ergebnisse von den Witterungseinflüssen - d.h. je mehr "Tage mit Witterungserscheinungen, die die Fortführung der Bauarbeiten sehr erschweren", desto mehr Ausfallstunden und desto größer die Differenz zwischen "Sommer" und "Winter" - zeigt die folgende Abbildung:

Abbildung: 55

\begin{tabular}{|c|c|c|c|c|c|}
\hline \multicolumn{5}{|c|}{ Zusammenhang zwischen Arbeitsstundendifferenz und } \\
\hline Zeitraum & 3) & 4) & Zeitraum & 3) & 4) \\
\hline $1960 / 611)$ & 1,19 & 9 & $1966 / 67$ & 1,60 & 9 \\
$1961 / 62$ & 2,22 & 15 & $1967 / 68$ & 2,10 & 12 \\
$1962 / 63$ & 4,08 & 35 & $1968 / 69$ & 2,40 & 12 \\
\cline { 5 - 6 } $1963 / 64$ & 2,23 & 18 & $\left.1969 / 70^{2}\right)$ & 3,27 & 21 \\
$1964 / 65$ & 2,30 & 13 & $1970 / 71$ & 2,23 & 17 \\
$1965 / 66$ & 2,09 & 17 & $1971 / 72$ & 1,77 & 7 \\
\hline
\end{tabular}

1) Förderungszeitraum $1960-1968$.

2) Förderungszeitraum 1969-1971.

3) Ergebnisse der Spalte "6)" aus Abbildung 54.

4) Tage mit Witterungserscheinungen, die die Fortführung der Bauarbeiten sehr erschweren, Jahresdurchschnitt aus Abbildung 11 und Abbildung 12.

Quelle: Abbildung 11, 12 und 54.

Anhand der Spalten "3)" und"4)" der Abbildung 55 läßt sich der Zusammenhang zwischen der Entwicklung der Arbeitsstundendifferenzen in Abhängigkeit von der 
Witterung unschwer erkennnen. Es bleibt daher festzuhalten, daß die hauptsächlich sozial- und arbeitsmarktpolitischen Ziele der Winterbauförderungsmaßnahmen von $1959^{523}$ und hier insbesondere die SWG-Regelung für den Zeitraum 1960-1968 eine deutliche Verschlechterung im Hinblick einer Verstetigung der Bautätigkeit bewirkt haben.

\section{9-1971: Das Arbeitsförderungsgesetz}

Die Winterbauförderungsmaßnahmen dieses Zeitraumes sind prinzipiell mit denen des Zeitraumes 1960-1968 vergleichbar. Zwar wurde mit der sogennanten PWF eine grundsätzlich neuartige Form der Förderungsmaßnahmen während der Winterperiode eingeführt ${ }^{524}$ und die Bundestagsdrucksache V/2291 betont in diesem Zusammenhang sogar den "ausschließlich produktionsorientierten" Charakter der PWF; ${ }^{525}$ dennoch muß festgestellt werden, daß sich die durchschnittliche Differenz zwischen den täglich geleisteten Arbeitsstunden pro Beschäftigten des "Sommers" und "Winters", nicht wie vielleicht erwartet verringert hat, sondern auf einen Unterschied von 2,41 Stunden im Durchschnitt des Zeitraumes 1969-1971 angestiegen ist.

Diese Zunahme im Vergleich zum Zeitraum 1960-1968 um 0,16 Stunden ${ }^{526}$ fällt allerdings äußerst gering aus und läßt sich wiederum mit der direkten Abhängigkeit der Ergebnisse von den Witterungseinflüssen begründen. ${ }^{527}$ So trägt insbesondere die schlechte Witterung des Winters 1969/70 maßgeblich zu dem berechneten Durchschnittswert von 2,41 Stunden des Zeitraumes 1969-1971 bei.

$\mathrm{Fa} \mathrm{At}$ man die bis hier ermittelten Ergebnisse kurz zusammen, so ist festzuhalten, da $\beta$ die SWG-Regelung als Schwerpunkt der Förderungsmaßnahmen der Zeiträume 19601968 und 1969-1971 maßgeblich zu einer kontinuierlichen Verschlechterung der Verstetigungsentwicklung beigetragen hat. Inwieweit sich diese negative Entwicklung mit Inkraftreten der Winterbaunovelle am 19. Mai 1972 umkehren konnte werden die beiden folgenden Zeiträume aufzeigen.

523 vgl. Kap. 2.5.1.1. AVAVG, S.80ff.

524 vgl. Kap. 2.4.1.3. 1969-71: Das Arbeitsförderungsgesetz, S.70.

525 vgl. Kap. 2.5.1.2. AFG, S.84.

526 Differenz aus 2,41 und 2,25.

527 vgl. Abbildung 55 . 


\section{2-1985: Die Winterbaunovelle}

Betrachtet man zunächst den ermittelten Durchschnittswert des Zeitraumes 19721985 von 1,65 Differenzstunden zwischen "Sommer" und "Winter", so hat sich dieser im Vergleich zum vorherigen Zeitraum erheblich reduziert und damit die kontinuierliche Bautätigkeit entsprechend verbessert.

Zur Erklärung dieser Verringerung zwischen "Sommer" und "Winter" um insgesamt 0,76 Stunden ${ }^{528}$ werden die Ergebnisse der Periode 1971/72 (vor Inkraftreten der Winterbaunovelle) mit denen der Perioden 1972/73, 1973/74 und 1974/75 (nach Inkraftreten der Winterbaunovelle) verglichen. In diesen vier Wintern waren die witterungsbedingten Störungen - zumindest nach Tagen mit Witterungserscheinungen, die die Fortführung der Bauarbeiten sehr erschweren ${ }^{529}$ - ähnlich groß, d.h der Vergleich wird demnach nicht durch gravierende witterungsbedingte Veränderungen gestört.

Die tarifliche Wochenarbeitszeit ändert sich ebenfalls von 1971 bis 1975 und auch in den weiteren Jahren des Förderungszeitraumes bis 1985 nicht, ${ }^{530}$ so daß die ermittelten Ergebnisse hierdurch unbeeinflußt bleiben und die Vermutung nahe liegt, daß die Förderungsmaßnahmen einen maßgeblichen Anteil an der Reduzierung der Differenz zwischen den täglich geleisteten Arbeitsstunden je Beschäftigten der Monate Juli bis Oktober und Dezember bis März gehabt haben. Zumal sich auch die konjunkturellen Einflüsse aufgrund der jährlichen Differenzenbildung weitgehend reduzieren lassen. ${ }^{531}$

Zur Quantifizierung der Fortschritte in puncto saisonaler Verstetigung der Bautätigkeit werden die Ergebnisse der Perioden von 1971/72 bis 1974/75 und deren prozentuale Veränderungen im Vergleich zum Vorjahr in der folgenden Abbildung 56 gegenübergestellt.

528 Berechnet aus der Differenz von 1,65 und 2,41.

529 vgl. Kap. 3.1.4. Witterungsbedingungen, S.105, Abbildung 13; 1971/72: 7 Tage, 1972/73: 8 Tage, 1973/74: 7 Tage, 1974/75: 5 Tage.

530 Hinweis: Die tarifliche Wochenarbeitszeit wurde am 1. Oktober 1969 von 42 auf 40 Wochenarbeitsstunden reduziert und blieb bis zum 1. Januar 1990 unverändert. Seit Januar 1990 beträgt sie 39 Wochenarbeitsstunden, vgl. Die Deutsche Bauindustrie (Hrsg.), Baustatistisches Jahrbuch 1992, S.52.

531 vgl. auch Kap. 2.2.1. Saisonschwankung, S.50ff. 
Abbildung: 56

\begin{tabular}{|c|c|c|c|c|c|c|}
\hline \multicolumn{7}{|c|}{ Tägliche Arbeitszeitentwicklung ie Beschäftigten } \\
\hline Zeitraum & "Sommer" & $\%^{3)}$ & "Winter" & $\%^{3)}$ & "Differenz" & $\left.\%^{3}\right)$ \\
\hline $\left.1971 / 72^{1}\right)$ & 8,14 & $X X X$ & 6,37 & $X X X$ & 1,77 & $X X X$ \\
\hline $\left.1972 / 73^{2}\right)$ & 7,86 & $-3,44$ & 6,54 & 2,67 & 1,32 & $-25,42$ \\
\hline $1973 / 74$ & 7,52 & $-7,84$ & 6,33 & $-3,21$ & 1,19 & $-9,85$ \\
\hline $1974 / 75$ & 7,17 & $-4,65$ & 6,51 & 2,84 & 0,66 & $-44,54$ \\
\hline
\end{tabular}

1) Förderungszeitraum 1969-1971.

2) Förderungszeitraum 1972-1985.

3) Veränderung in Prozent im Vergleich zum Vorjahr.

Quelle: Eigene Berechnung ausAbbildung 54.

Die Ergebnisse der Abbildung 56 - in prozentualen Veränderungen zum Vorjahr zeigen stets einen positiven Unterschied zugunsten des Winters; mit anderen Worten: Während die Arbeitszeit im Sommer eingeschränkt wurde, ist die Arbeitszeit im Winter seit Einführung der Winterbaunovelle zum AFG relativ ausgedehnt worden, d.h. entweder absolut gestiegen oder zumindest weniger eingeschränkt worden als im Sommer.

Nach diesen Zahlen ist also davon auszugehen, daß mit der Einführung der Winterbaunovelle zum AFG vom 19. Mai 1972 ein positiver Beitrag zur saisonalen Verstetigung der Bautätigkeit geleistet wurde. Der Aussage der Bundesregierung, daß die Zahl der Arbeitslosen und verkürzt arbeitenden Bauarbeiter in der Schlechtwetterzeit ohne das Förderungssystem höher gewesen wäre, kann somit zugestimmt werden. ${ }^{532}$

\section{6-1992: Aussetzung der Förderung von IKZ und MKZ}

Bei der Betrachtung dieses letzten Förderungszeitraumes von 1986-1992 ist festzustellen, daß sich die Einzelergebnisse - d.h. sowohl die der Monate Juli bis Oktober als auch die der Monate Dezember bis März und die daraus gebildeten Differenzen - kaum von denen des vorherigen Zeitraumes unterscheiden. Demzufolge weicht auch der durchschnittliche Differenzwert zwischen "Sommer" und "Winter" dieses Zeitraumes mit 1,57 Stunden nur unwesentlich von dem des Zeitraumes $1972-1985(1,65) \mathrm{ab}$.

Die Erklärung der Einzelergebnisse, insbesondere die für diesen Zeitraum außergewöhnlich hohe Differenz mit 2,68 Stunden in 1986/87, kann primär auf Witte- 
rungseinflüsse zurückgeführt werden. Die folgende Abbildung 57 belegt den $\mathrm{Zu}$ sammenhang.

Abbildung: 57

\begin{tabular}{|c|c|c|c|c|c|}
\hline \multicolumn{6}{|c|}{ 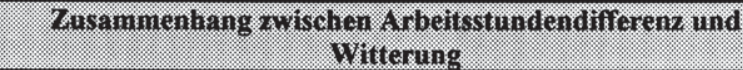 } \\
\hline Zeitraum & 3) & 4) & Zeitraum & 3) & 4) \\
\hline $1983 / 841)$ & 1,74 & 13 & $1988 / 89$ & 1,28 & 5 \\
\hline $1984 / 85$ & 2,33 & 28 & $1989 / 90$ & 1,02 & 8 \\
\hline $1985 / 86$ & 2,36 & 26 & $1990 / 91$ & 1,63 & 15 \\
\hline $\left.1986 / 87^{2}\right)$ & 2,68 & 23 & $1991 / 92$ & 1,19 & 11 \\
\hline $1987 / 88$ & 1,93 & 7 & $1992 / 93$ & 1,33 & 10 \\
\hline
\end{tabular}

1) Förderungszeitraum 1972-1985

2) Förderungszeitraum 1986-1992

3) Ergebnisse der Spalte "6)" aus Abbildung 54.

4) Tage mit Witterungserscheinungen, die die Fortführung der Bauarbeiten sehr erschweren, Jahresdurchschnitt aus Abbildung 13 und Abbildung 14

Quelle: Abbildung 13, 14 und 54.

Es zeigt sich abermals, daß die extrem ungünstigen Witterungsverhältnisse zu Beginn des Zeitraumes 1986-1992 und gegen Ende des vorherigen Zeitraumes (1972-

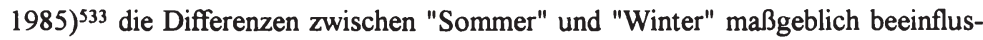
sen und auf Maximalwerte ansteigen ließen. Für den umgekehrten Fall, d.h. bei relativ günstigen Witterungsverhältnissen, verringerten sich dann die Differenzen zwischen "Sommer" und"Winter" entsprechend.

Aufgrund der ermittelten Ergebnisse bleibt abschließend festzuhalten, daß die in den Monaten Dezember bis März des Zeitraumes 1986-1992 geleisteten Arbeitsstunden je Beschäftigten durch die eingeschränkte Förderung (Aussetzung von IKZ und MKZ) nicht reduziert worden sind und daher kein negativer Einfluß auf die Entwicklung der kontinuierlichen Bautätigkeit ausgeübt worden ist.

Insgesamt läßt sich somit das Förderungsprogramm nach Inkraftreten der Winterbaunovelle im Mai 1972 wie folgt charakterisieren:

Die negative Entwicklung bezüglich der kontinuierlichen Bautätigkeit seit Inkraftreten der ersten Förderungsmaßnahmen 1959, konnte mit Einführung der Winterbaunovelle nicht nur gestoppt, sondern sogar umgekehrt werden. Die nach wie vor gültige SWG-Regelung, wirkt allerdings einer Verbesserung bzw. dem angestrebten Ziel einer Verstetigung der Bautätigkeit deutlich entgegen.

533 vgl. Kap. 3.1.4. Witterungsbedingungen, Abbildung 13 und 14, S.105-106. 


\subsubsection{Einkommenswirksame Effekte der getroffenen Förderungs- maßnahmen}

Zu den Primärzielen der IG Bau-Steine-Erden - als Interessenvertreter der Arbeitnehmer - gehört die materielle Sicherheit der Bauarbeiter. Dieses sozialpolitische Ziel der wirtschaftlichen Absicherung der Bauarbeiter bei Arbeitsausfall ${ }^{534}$ verfolgte auch der Gesetzgeber mit seinen getroffenen Maßnahmen zur Förderung der ganzjährigen Beschäftigung in der Bauwirtschaft und zwar - mehr oder weniger deutlich - in allen Förderungszeiträumen. ${ }^{535}$ Erreicht werden sollte diese wirtschaftliche Absicherung des Bauarbeiters vor allem durch ein ganzjährig gesichertes Jahreseinkommen.

Inwieweit dies gelungen ist - bzw. ob als Folge einer eventuellen Verstetigung auch eine Erhöhung des Einkommens der Bauarbeiter erzielt werden konnte - soll der folgende Vergleich der monatlichen Bruttolohnsummen ${ }^{536}$ im Bauhauptgewerbe getrennt nach Förderungszeiträumen aufzeigen.

\subsubsection{Wirkungen auf das Einkommen der Bauarbeiter}

Wie die folgende Abbildung 58 anhand der errechneten Saisonfaktoren ausweist, sind die Schwankungen, denen die Bruttolohnsumme im Jahresverlauf vor Einführung der Förderungsmaßnahmen unterliegt, beachtlich. So beträgt der Saisonausschlag zwischem dem Maximalwert des Saisonfaktors im Juli $(1,20)^{537}$ und dem Minimum im Februar $(0,49)$ 0,71. Das heißt, das Einkommen der Bauarbeiter schwankt in der Zeit von 1954 bis 1959 im Jahresverlauf um fast $60 \%$.

534 vgl. Kap. 2.5.3. Ziele der IG Bau-Steine-Erden, S.90ff.

535 vgl. Kap. 2.5. Vorstellungen der Beteiligten von den Förderungsmaßnahmen zur ganzjährigen Beschäftigung in der Bauwirtschaft, S.79ff.

536 Definition: Als Bruttolohnsummen gelten die Summen der lohnsteuerpflichtigen Bruttobezüge (Bar- und Sachbezüge). Diese Beträge verstehen sich ohne Arbeitgeberanteile zur Kranken-, Renten- und Arbeitslosenversicherung, ohne Beiträge zu den Sozialkassen des Baugewerbes. ohne Winterbau-Umlage, ohne Aufwendungen für die betriebliche Alters-, Invaliditäts- und Hinterbliebenenversorgung und ohne gezahites Vorruhestandsgeld. Die Entgelte für Poliere, Schachtmeister und Meister sind in der Bruttolohnsumme enthalten; vgl. Statistisches Bundesamt (Hrsg.), Fachserie 4: Produzierendes Gewerbe: Ausgewählte Zahlen für die Bauwirtschaft, Dezember und Jahr 1992.

537 Anmerkung: Ähnlich hohe Saisonfaktoren, die sich nur unwesentlich von dem des Juli $(1,20)$ unterscheiden, sind in den Monaten August, September und Oktober $(1,19$ bzw. 1,18) zu beobachten. 
Abbildung: 58

\begin{tabular}{|c|c|c|c|c|c|c|c|c|c|c|c|c|c|}
\hline \multicolumn{14}{|c|}{ Bruttolohnsumme in MTo. DM im Bauhauptgewerbe 1954 - 1959} \\
\hline Jahr & Januar & Februar & März & April & Mat & Junt & Jull) & August & September & Oktober & November & Dezember & J \\
\hline 1954 & 159,1 & 116,2 & 265,9 & 318,0 & 349,1 & 374,5 & 392,5 & 398,9 & 410,3 & 400,8 & 390,0 & 355,9 & 327,6 \\
\hline 1955 & 194,3 & 184,3 & 227,3 & 387,7 & 446,3 & 462,1 & 476,3 & 498,9 & 488,0 & 475,9 & 464,3 & 407,8 & 392,8 \\
\hline 1956 & 317,9 & 132,8 & 319,2 & 450,0 & 518,3 & 518,6 & 519,2 & 528,9 & 492,6 & 510,1 & 468,3 & 399,4 & 431,3 \\
\hline 1957 & 259,2 & 298,3 & 395,4 & 471,3 & 508,7 & 472,2 & 512,1 & 508,1 & 479,0 & 505,1 & 482,5 & 399,7 & 441,0 \\
\hline 1958 & 271,7 & 261,8 & 303,8 & 455,0 & 525,7 & 532,7 & 583,1 & 560,6 & 573,8 & 582,8 & 535,4 & 505,5 & 474,3 \\
\hline 1950 & 306,3 & 283,1 & 492,6 & 568,7 & 585,1 & 617,0 & 653,4 & 626,4 & 651,0 & 649,4 & 609,4 & $573,6^{2)}$ & 551,3 \\
\hline MD & 251,4 & 212,7 & 334,0 & $\mathbf{4 4 1 , 8}$ & 488,9 & 496,2 & 522,8 & 520,3 & 515,8 & 520,7 & 491,7 & 440,3 & 436,4 \\
\hline $\mathbf{S F}$ & 0,58 & 0,49 & 0,77 & 1,01 & 1,12 & 1,14 & 1,20 & 1,19 & 1,18 & 1,19 & 1,13 & 1,01 & 1,00 \\
\hline
\end{tabular}

1) Ab Juli 1959 einschließlich Saarland.

2) Beeinflußt durch den Beginn der gesetzlichen Regelungen zur Förderung der ganzjährigen Beschäftigung in der Bauwirtschaft.

Quelle: Statistisches Bundesamt (Hrsg.), Zahlen aus der Bauwirtschaft, Ergebnisse der monatlichen Bauberichterstattung für Betriebe, 1955-1960.

Inwieweit die einzelnen Förderungszeiträume eine Verringerung der Einkommensschwankungen bei den Bauarbeitern bewirken konnten, sollen die folgenden Abbildungen 59 bis 62 aufzeigen.

Betrachtet man den ersten Förderungszeitraum nach Einführung der gesetzlichen Regelungen, so ist festzustellen, daß die Bruttolohnsummen - im Vergleich zum förderungsfreien Zeitraum 1954-1959 - insbesondere in den Monaten Januar, Februar und März deutlich angestiegen sind. Im einzelnen betragen die Steigerungen in der Bruttolohnsumme im Januar 3,4\%, im Februar 26,5\% und im März 10,4\%. Auch die Maximalwerte in den Monaten Juli bis Oktober sind leicht zurückgegangen. Beide Ergebnisse trugen daher maßgeblich zur Verringerung des Saisonausschlages von 0,71 auf 0,57 (Abbildung 63) bei und haben die Bruttolohnsummenschwankungen der Bauarbeiter dadurch im Jahresverlauf auf knapp 50\% reduziert.

Diese positiven Ergebnisse - mit Ausnahme des erheblichen Absinkens der Bruttolohnsumme im Dezember um fast $13 \%^{538}$ - legen die Schlußfolgerung nahe, daß die getroffenen Maßnahmen zur Förderung der ganzjährigen Beschäftigung in der Bau-

538 Berechnet aus dem Verhaltnis der Saisonfaktoren für Dezember von 0,88 (1960-68) zu 1,01 (1954-59). 
Abbildung: 59

\begin{tabular}{|c|c|c|c|c|c|c|c|c|c|c|c|c|c|}
\hline \multicolumn{14}{|c|}{ Bruttolohmsumme in Mio. DM im Bauhauptgewerbe 1960 - 1968539} \\
\hline Jahr & Januar & Februar & März & April & Mal & Juni & Jull & August & September & Oktober & November & Dezember & JD \\
\hline 1960 & 383,7 & 88,2 & 578,5 & 612,2 & 677,4 & 688,3 & 695,2 & 712,4 & 644,1 & 657,2 & 672,1 & 595,4 & 608,7 \\
\hline 1961 & 452,5 & 547,0 & 708,8 & 694,3 & 774,5 & 820,6 & 810,1 & 858,8 & 822,8 & 832,0 & 801,8 & 621,3 & 728,7 \\
\hline 1962 & 578,5 & 516,9 & 609,6 & 850,0 & 961,8 & 940,0 & 970,9 & 983,7 & 934,7 & 1017,0 & 930,4 & 682,4 & 831,3 \\
\hline 19631) & 310,9 & 253,8 & 692,7 & 1038,0 & 1171,7 & 1121,1 & 1218,8 & 1153,2 & 1142,4 & 1199,7 & 1110,4 & 813,4 & 935,5 \\
\hline 1964 & 632,5 & 719,7 & 873,5 & 1232,1 & 1243,9 & 1329,8 & 1334,3 & 1224,0 & 1317,8 & 1284,2 & 1203,0 & 1097,1 & 1124,3 \\
\hline 1965 & 811,2 & 636,8 & 894,2 & 1312,0 & 1343,1 & 1412,0 & 1408,3 & 1364,2 & 1413,7 & 1375,6 & 1189,1 & 1106,5 & 1188,9 \\
\hline 1966 & 680,7 & 901,0 & 1235,7 & 1348,4 & 1439,0 & 1477,0 & 1399,6 & 1440,1 & 1458,7 & 1389,2 & 1319,5 & 1114,2 & 1266,9 \\
\hline 1967 & 831,1 & 784,8 & 1086,9 & 1112,2 & 1232,7 & 1250,8 & 1234,0 & 1273,0 & 1273,7 & 1316,8 & 1287,1 & 923,6 & 1133,9 \\
\hline 1968 & 740,1 & 836,1 & 972,4 & 1229,8 & 1367,6 & 1292,5 & 1403,0 & 1355,4 & 1349,9 & 1451,7 & 1353,8 & 1016,7 & 1197,4 \\
\hline MD & 602,4 & 620,5 & 850,3 & 1047,7 & 1134,6 & 1148,0 & 1163,8 & 1151,6 & 1150,9 & 1169,3 & 1096,4 & 885,6 & 1001,7 \\
\hline SF & 0,60 & 0,62 & 0,85 & 1,05 & 1,13 & 1,15 & 1,16 & 1,15 & 1,15 & 1,17 & 1,09 & 0,88 & 1,00 \\
\hline
\end{tabular}

1) Ab 1963 einschließlich Berlin (West).

Quelle: Statistisches Bundesamt (Hrsg.), Fachserie 4: Produzierendes Gewerbe: Ausgewählte Zahlen für die Bauwirtschaft, Ergebnisse der monatlichen Bauberichterstattung für Betriebe, Dezember und Jahr 1961-1970

wirtschaft im Hinblick auf eine Verstetigung der Bauarbeiterlöhne zumindest einen Teilerfolg erzielt haben. Ob sich diese Entwicklung in den weiteren Förderungszeiträumen fortsetzen ließ, sollen die Abbildungen 60 bis 62 zeigen.

Abbildung: 60

\begin{tabular}{|c|c|c|c|c|c|c|c|c|c|c|c|c|c|}
\hline \multicolumn{14}{|c|}{ 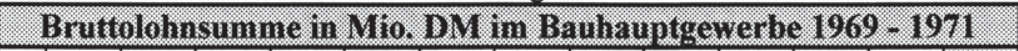 } \\
\hline Jahr & Januar & Februar & März & April & Mal & Junl & Jull & August & September & Oktober & November & Desember & JD \\
\hline 1969 & 895,7 & 639,2 & 960,5 & 1382,4 & 1487,7 & 1484,7 & 1567,1 & 1458,5 & 1568,5 & 1643,7 & 1446,1 & 982,0 & 1293,0 \\
\hline 1970 & 765,1 & 760,6 & 1141,5 & 1645,4 & 1810,3 & 1997,5 & 2027,4 & 1879,5 & 2028,7 & 1994,2 & 1869,4 & 1649,7 & 1630,8 \\
\hline 1971 & 1109,1 & 1272,3 & 1427,3 & 1879,2 & 2043,2 & 2153,2 & 2164,2 & 2062,1 & 2210,3 & 2125,8 & 1996,2 & 1822,9 & 1855,5 \\
\hline MD & 923,3 & 890,7 & 1176,4 & 1635,7 & 1780,4 & 1878,5 & 1919,6 & 1800,0 & 1935,9 & 1921,2 & 1770,6 & 1484,9 & 1593,1 \\
\hline SF & 0,58 & 0,56 & 0,74 & 1,03 & 1,12 & 1,18 & 1,20 & 1,13 & 1,22 & 1,21 & 1,11 & 0,93 & 1,00 \\
\hline
\end{tabular}

Quelle: Statistisches Bundesamt (Hrsg.), Fachserie 4: Produzierendes Gewerbe: Ausgewählte Zahlen für die Bauwirtschaft, Ergebnisse der monatlichen Bauberichterstattung für Betriebe, Dezember und Jahr 1970-1972.

539 Hinweis: Eine im Jahr 1961 durchgeführte Arbeitsstättenzählung brachte das Ergebnis, daß die Beschăftigtenzahl für das Bauhauptgewerbe um etwa $2 \%$ zu niedrig angesetzt war. Daher ist die Vergleichbarkeit des Zahlenmaterials von 1962 an mit den Zahlen der Vorjahre eingeschrănkt; vgl. auch Wirtschaft und Statistik, 2/1963, S.102ff. 
Abbildung: 61

\begin{tabular}{|c|c|c|c|c|c|c|c|c|c|c|c|c|c|}
\hline \multicolumn{14}{|c|}{ 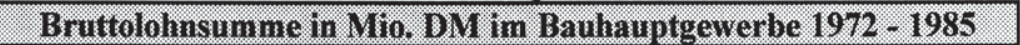 } \\
\hline Jahr & uar & ruar & arz & pril & Mai & Junl & 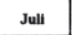 & ugust & nber & ctober & ovember & Dezember & JD \\
\hline & s. & & 0 & 9 & 6 & 2 & 1 & 3 & & & & & Tד \\
\hline & 380,3 & 568,4 & 906,8 & 111,4 & 2548,9 & 2460,1 & 2004,0 & 2396,5 & 2361,9 & 2592,7 & 2304,5 & -1 & \\
\hline 4 & 18,5 & 71,0 & 370,4 & 98,1 & 350,8 & 175,8 & 278,5 & 122,8 & 205,5 & 422,4 & 167,7 & 59,1 & \\
\hline 75 & 1671,1 & 1517,3 & 1674,1 & 1946,4 & 2051,4 & 2088,4 & 2121,1 & 1992,0 & 2216,0 & 356,7 & 2106,6 & 765,9 & \\
\hline 0 & (1) & 00,0 & 1700,0 & 2066,2 & 168,4 & $2<0$, & 2100,0 & $210<, 2$ & 2314,3 & 2339,6 & 2344,6 & 1000 & \\
\hline T & 1317,2 & 36,5 & 1961 & 1947,1 & 2197,2 & 2206,8 & 1951,4 & 2124,3 & 2 & 2161,0 & 2236,4 & 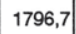 & \\
\hline 78 & 1548,5 & 1090,0 & 1984,6 & 2046,4 & 2312,7 & 2551,0 & 2171,4 & 2322,7 & 2358,1 & 2519,7 & 2782,2 & 761,1 & \\
\hline & ' & 0 & 2099,0 & 2 & 5 & 2659,0 & 2600,1 & 2601,7 & 2637,5 & 2957,0 & 3 & 2233,2 & \\
\hline - & 1606,0 & 71 & 2462 & 2730,0 & 2901,0 & 2837,0 & 2863,8 & 2527,0 & 3 & 5 & 3126,9 & 2005,8 & \\
\hline 1981 & 1461,2 & 1646,3 & 2465,2 & 2897,7 & 2906,5 & 2975,4 & 2877,3 & 2642,7 & 3003,9 & 2944,9 & 3346,0 & 1843,9 & \\
\hline 82 & 1178,0 & 4 & 2442,5 & 2714,4 & 2 & 2804,2 & 2698,7 & 2697,0 & 29 & 2787,7 & 54,2 & 80,7 & , \\
\hline 283 & 1708,4 & 1291,7 & ?2 & 2513,4 & 2753,0 & 29 & 2687,0 & $2 \varepsilon$ & 2 & 3 & 375 & ,9 & \\
\hline 1984 & 1708,4 & 7 & 2 & 25 & 74 & 2753,3 & 2923 & & & 3028,7 & 3 & 2276,8 & \\
\hline 85 & 1139,8 & 1150,2 & 1832,7 & 2351,7 & 2586,6 & 2422,0 & 2736,2 & 2472,3 & 2640,7 & 2892,8 & 3116,6 & 2171,5 & 290, \\
\hline W & 27,0 & 79,4 & 9 & 1782,2 & 1953,8 & 1956,9 & 1874,5 & 1848,0 & 74,1 & 44,7 & 112,4 & 1503,9 & \\
\hline SF & 04 & & 00 & 1,02 & & 12 & 1,07 & 1,06 & , & 1,11 & 1,21 & ),86 & , \\
\hline
\end{tabular}

1) Ab 1976 neue Berichtskreisabgrenzung nach der Systematik der Wirtschaftszweige (SYPRO). ${ }^{540}$

Quelle: Statistisches Bundesamt (Hrsg.), Fachserie 4: Produzierendes Gewerbe: Ausgewählte Zahlen für die Bauwirtschaft, Ergebnisse der monatlichen Bauberichterstattung für Betriebe, Dezember und Jahr 1973-1986.

Abbildung: 62

\begin{tabular}{|c|c|c|c|c|c|c|c|c|c|c|c|c|c|}
\hline \multicolumn{14}{|c|}{ Bruttolohnsumme in Mto. DM im Baulauptgewerbe $1986-1992$} \\
\hline Jahr & Januar & ruar & lärz & pril & fal & inl & Jull & Igust & eptember & ktober & November & Dezember & JD \\
\hline 286 & 579,8 & 03,8 & 384,8 & 374,7 & 161,1 & 483,3 & 720,6 & 197,5 & 669,5 & 768,2 & 3169,7 & 422,7 & 32 \\
\hline 1987 & 1297,0 & 1230,8 & 1525,3 & 2350,4 & 2403,2 & 2554,1 & 2710,8 & 2530,9 & 2664,3 & 2667,3 & 3260,0 & 2383,1 & 298,1 \\
\hline 988 1) & 1791,5 & 1625,5 & 1810,3 & 2277,9 & 2539,9 & 2589,0 & 2548,3 & 2743,9 & 2663,0 & 2605,9 & 3249,3 & 2365,7 & 400,9 \\
\hline 1989 & 2140,4 & 1919,6 & 2295,7 & 2355,6 & 2691,7 & 2700,7 & 2648,7 & 2866,9 & 2658,4 & 2825,0 & 3557,2 & 2409,1 & 2589 \\
\hline 1990 & 2286,2 & 2055,8 & 2518,1 & 2695,8 & 3039,1 & 2825,9 & 3024,6 & 3093,0 & 2826,4 & 3208,3 & 4177,4 & 2619,1 & 2864,1 \\
\hline 1901 & 2505,1 & 1662,1 & 2753,9 & 130,5 & 255,8 & 2997,6 & 3405,7 & 3247,1 & 3193,1 & 3482,5 & 4622,3 & 2978,0 & 0102,0 \\
\hline 1992 & 2603,5 & 2308,3 & 3080,5 & 3147,3 & 3305,1 & 3419,7 & 3594,5 & 3335,9 & 3490,3 & 3486,1 & 5112,7 & 3430,5 & 3 \\
\hline MD & 2029,1 & 1700,8 & 2238,4 & 2618,9 & 2813,7 & 2795,8 & 2950,5 & 2902,2 & 2880,7 & 3006,2 & 3878,4 & 2658,3 & 2706,1 \\
\hline SF & 0,75 & 33 & 0,83 & 7 & 4 & 3 & 1,09 & , & & & 1,43 & 88 &, \\
\hline
\end{tabular}

1) Ab 1988 Berücksichtigung der Ergebnisse der Arbeitsstättenzählung von 1987.

Quelle: Statistisches Bundesamt (Hrsg.), Fachserie 4: Produzierendes Gewerbe: Ausgewählte Zahlen für die Bauwirtschaft, Ergebnisse der monatlichen Bauberichterstattung für Betriebe, Dezember und Jahr 1987-1993.

540 vgl. Kap. 1.1.3. Bauhaupt- und Ausbaugewerbe, S.9 
Die Statistiken für die Förderungszeiträume 1969-1971, 1972-1985 und 1986-1992 zeigen, daß sich der positive Trend des Zeitraumes 1960-1968 nicht fortgesetzt hat, sondern im Gegenteil teilweise wieder Werte erreicht wurden, wie sie vor Einführung der Förderungsmaßnahmen bestanden haben. Begünstigt wurde diese negative Entwicklung der Schwankungen vor allem durch den starken kontinuierlichen Anstieg der Bruttolohnsumme im Monat November aufgrund des im November ausbezahlten Weihnachtsgeldes. Hier lag der Saisonfaktor zuletzt bei 1,43. Das heißt, das Einkommen der Bauarbeiter war im November um $43 \%$ höher als im Jahresdurchschnitt. Die folgende Gegenüberstellung (Abbildung 63) der Saisonfaktoren nach Förderungszeiträumen, zeigt den Anstieg der Saisonausschläge und verdeutlicht die Entwicklung.

Abbildung: 63

\begin{tabular}{|c|c|c|c|c|c|}
\hline \multicolumn{6}{|c|}{ Saisonaktoren der Bratsolohnsumane im Bawhangsererbe } \\
\hline Zeitraum & $1954-1959$ & $1960-1968$ & $1969-1971$ & $1972-1985$ & $1986-1992$ \\
\hline Januar & 0,58 & 0,60 & 0,58 & 0,64 & 0,75 \\
\hline Februar & 0,49 & 0,62 & 0,56 & 0,67 & 0,63 \\
\hline März & 0,77 & 0,85 & 0,74 & 0,93 & 0,83 \\
\hline April & 1,01 & 1,05 & 1,03 & 1,02 & 0,97 \\
\hline Mai & 1,12 & 1,13 & 1,12 & 1,12 & 1,04 \\
\hline Juni & 1,14 & 1,15 & 1,18 & 1,12 & 1,03 \\
\hline Juli & 1,20 & 1,16 & 1,20 & 1,07 & 1,09 \\
\hline August & 1,19 & 1,15 & 1,13 & 1,06 & 1,07 \\
\hline September & 1,18 & 1,15 & 1,22 & 1,13 & 1,06 \\
\hline Oktober & 1,19 & 1,17 & 1,21 & 1,17 & 1,11 \\
\hline November & 1,13 & 1,09 & 1,11 & 1,21 & 1,43 \\
\hline Dezember & 1,01 & 0,88 & 0,93 & 0,86 & 0,98 \\
\hline JD & 1,00 & 1,00 & 1,00 & 1,00 & 1,00 \\
\hline SA & 0,71 & 0,57 & 0,66 & 0,57 & 0,80 \\
\hline
\end{tabular}

Quelle: Eigene Berechnungen aus Abbildungen 58 bis 62 .

Eine derartige Interpretation des statistischen Zahlenmaterials beinhaltet allerdings eine gewisse Ungenauigkeit, die in der Außerachtlassung der Beschäftigtenzahlen begründet ist. Trotz der Tatsache, daß das Ausmaß der Schwankungsbreite bei den Beschäftigtenzahlen mit Einführung der ersten Förderungsmaßnahmen erheblich reduziert werden konnte ${ }^{541}$ und seitdem eine fast gleichmäßige Beschäftigung der Baurbeiter im Jahresverlauf zu beobachten war, bleibt eine "Restungenauigkeit" in der Höhe der noch verbliebenen Beschäftigungsschwankungen bestehen. Außerdem ist der Saisonausschlag der Beschäftigten im förderungsfreien Zeitraum 1954-1959 mit 0,52 sehr ausgeprägt, ${ }^{542}$ so daß einerseits die gewonnenen Erkenntnisse über die Höhe der

541 vgl. Kap. 3.3.1.2. Wirkungen auf die Beschäftigtenzahlen, S.128ff.

542 vgl. Abbildung 34, S.131. 
Einkommensschwankungen des einzelnen Bauarbeiters in dieser Zeit sehr fragwürdig sind und andererseits dieser Zeitraum keine Vergleichsbasis mehr darstellt.

Aus diesen Gründen werden, um eine exaktere Aussage über die Höhe der Einkommensschwankungen beim einzelnen Bauarbeiter machen zu können, die relativen Veränderungen der monatlichen Bruttolohnsummen mit der Zahl der jeweils Beschäftigten im Bauhauptgewerbe ins Verhältnis gesetzt. ${ }^{543}$ Die Ergebnisse dieser Verhältnisse zeigen die Abbildungen 64 bis 68 - getrennt nach Förderungszeiträumen - auf.

Abbildung: 64

\begin{tabular}{|c|c|c|c|c|c|c|c|c|c|c|c|c|c|}
\hline \multicolumn{14}{|c|}{ Bruttolohnsumme in BMUBeschartigten im Bawhamptgewerbe 1954 . 1959} \\
\hline Jahr & Januar & Februar & März & April & Mal & Junl & Jull & August & September & Oktober & November & Dezember & ID \\
\hline 1954 & 305,04 & 226,18 & 300,69 & 325,88 & 336,64 & 345,62 & 350,79 & 349,05 & 354,30 & 347,93 & 352,14 & 375,25 & 337,62 \\
\hline 1955 & 295,70 & 306,85 & 251,90 & 341,24 & 371,71 & 375,43 & 379,18 & 395,26 & 389,26 & 383,87 & 387,79 & 401,05 & 363,85 \\
\hline 1956 & 380,95 & 301,65 & 320,03 & 376,66 & 414,46 & 410,46 & 408,29 & 420,44 & 398,22 & 419,42 & 411,08 & 444,68 & 398,07 \\
\hline 1957 & 365,89 & 334,06 & 368,56 & 417,21 & 438,83 & 410,62 & 434,47 & 430,08 & 410,16 & 431,03 & 421,64 & 479,79 & 413,72 \\
\hline 1958 & 406,75 & 369,42 & 351,55 & 409,73 & 448,96 & 445,23 & 473,50 & 456,23 & 466,26 & 476,30 & 446,91 & 500,02 & 443,22 \\
\hline 1950 & 389,32 & 328,83 & 429,33 & 456,61 & 463,29 & 479,95 & 502,21 & 484,71 & 505,71 & 509,95 & 490,29 & 489,76 & 467,32 \\
\hline MD & 357,28 & 311,17 & 337,01 & 387,80 & 412,31 & 411,22 & 424,74 & 422,63 & 420,65 & 428,08 & 418,31 & 448,42 & 403,97 \\
\hline sr & 0,88 & 0,77 & 0,83 & 0,96 & 1,02 & 1,02 & 1,05 & 1,05 & 1,04 & 1,06 & 1,04 & 1,11 & 1,00 \\
\hline
\end{tabular}

Quelle: Eigene Berechnungen aus Abbildungen 29 und 58.

Anhand der Abbildung 64 ist festzustellen, daß sich unter Berücksichtigung der Beschäftigtenzahlen die monatlichen Einkommensschwankungen der Bauarbeiter im Jahresverlauf des förderungsfreien Zeitraumes von 1954-1959 - im Vergleich zur Abbildung 58 - deutlich reduziert haben. Zwar liegen die geringsten Einkommen nach wie vor in den Monaten Januar, Februar und März und die höchsten Einkommen werden wiederum in den Monaten Juli bis Oktober erzielt, ${ }^{544}$ wie sich anhand der Saisonfaktoren erkennen läßt; jedoch schwankt das Einkommen der Bauarbeiter im Jahresverlauf jetzt nur noch etwa um $30 \% .545$

543 Hinweis: Um den Bruttolohn des Bauarbeiters in DM/Monat zu bestimmen, ist zu gewährleisten, daß das gebildete Verhältnis aus Bruttolohnsumme und Beschäftigten auf denselben Erhebungsumfang zurückgreift. Da die Entgelte für Poliere, Schachtmeister und Meister in der Bruttolohnsumme und nicht in der Gehaltsumme enthalten sind (vgl. Fußnote 536, S.172) und in den Beschäftigtenzahlen dieser Personenkreis ebenfalls enthalten ist (vgl. Kap. 3.3.1.2. Wirkungen auf die Beschăftigtenzahlen, S.128ff.) läßt sich das Verhăltnis aus monatlicher Bruttolohnsumme und Beschäftigten im Bauhauptgewerbe ohne Einschränkungen bilden.

544 Eine Ausnahme ist der Monat Dezember mit dem absolut höchsten Saisonfaktor von 1,11; zur Erklärung vgl. Kap. 3.3.3.2. Erklărungsmöglichkeiten, S.181ff. 
In den Abbildungen 65 bis 68 wird die weitere Entwicklung der Monatseinkommen der Bauarbeiter nach Einführung der Förderungsmaßnahmen aufgezeigt.

Abbildung: 65

\begin{tabular}{|c|c|c|c|c|c|c|c|c|c|c|c|c|c|}
\hline \multicolumn{14}{|c|}{ Bruttolohnsumme in 3 WBeschatigten im Bamhapptgewerbe 1960 - 1968} \\
\hline Jahr & Januar & Februar & Mărz & April & Mal & Junl & Jull & August & September & Oktober & November & Dezember & ID \\
\hline 1960 & 362,29 & 366,01 & 484,66 & 494,69 & 536,02 & 542,62 & 537,97 & 655,81 & 510,39 & 530,26 & 547,47 & 505,38 & 601,65 \\
\hline 1961 & 411,14 & 474,58 & 579,16 & 553,56 & 610,82 & 635,97 & 615,95 & 656,53 & 636,93 & 647,69 & 632,04 & 507,26 & 583,64 \\
\hline 1962 & 485,76 & 429,66 & 482,91 & 644,23 & 711,90 & 689,21 & 694,31 & 708,15 & 680,05 & 743,35 & 692,27 & 529,99 & 629,30 \\
\hline 1963 & 251,67 & 207,78 & 508,74 & 716,46 & 786,61 & 746,52 & 804,36 & 765,22 & 767,50 & 814,04 & 766,52 & 583,47 & 657,05 \\
\hline 1964 & 478,71 & 537,34 & 619,62 & 828,63 & 827,81 & 874,55 & 874,74 & 807,60 & 875,96 & 867,17 & 828,87 & 787,89 & 773,15 \\
\hline 1965 & 612,86 & 485,09 & 632,28 & $\mathbf{8 8 7 , 5 5}$ & 898,87 & 937,69 & 930,86 & 901,19 & 940,69 & 927,93 & 821,71 & 799,83 & 821,27 \\
\hline 1966 & 516,63 & 662,29 & 855,88 & 915,08 & 972,28 & 994,81 & 948,82 & 980,59 & 1005,24 & 977,11 & 962,53 & 866,46 & 892,55 \\
\hline 1967 & 712,90 & 688,21 & 891,16 & 882,64 & 961,44 & 963,07 & 940,45 & 957,42 & 959,03 & 990,70 & 979,79 & 732,90 & 892,85 \\
\hline 1968 & 625,53 & 704,55 & 785,09 & 955,00 & 1046,73 & 982,37 & 1051,75 & 1011,28 & 1011,72 & 1087,69 & 1028,03 & 797,59 & 929,84 \\
\hline MD & 495,28 & 506,17 & 648,83 & 764,20 & 816,94 & 818,54 & 822,13 & 815,98 & 820,83 & 842,88 & 806,58 & 678,08 & 742,36 \\
\hline sF & 0,67 & 0,68 & 0,87 & 1,03 & 1,10 & 1,10 & 1,11 & 1,10 & 1,11 & 1,14 & 1,09 & 0,91 & 1,00 \\
\hline
\end{tabular}

Quelle: Eigene Berechnungen aus Abbildungen 30 und 59.

Abbildung: 66

\begin{tabular}{|c|c|c|c|c|c|c|c|c|c|c|c|c|c|}
\hline \multicolumn{14}{|c|}{ Bruttolohnsumme in BMHBeschaftigten im Bavhauptgewer be 1969.1971} \\
\hline Jahr & Januar & Februar & März & April & Mal & Junl & Jull & August & September & Olctober & November & Dezember & JD \\
\hline 1969 & 736,73 & 532,24 & 764,02 & 1054,03 & 1118,39 & 1106,65 & 1157,63 & 1079,39 & 1166,51 & 1236,72 & 1105,54 & 775,16 & 093,03 \\
\hline 1970 & 633,95 & 633,86 & 904,23 & 1244,01 & 1347,94 & 1466,12 & 1469,75 & 1361,31 & 1472,18 & 1466,70 & $\mid 1396,61$ & 1266,12 & 1235,71 \\
\hline 1971 & 895,38 & 1031,41 & 1090,96 & 1391,68 & 1501,60 & 1575,07 & 1575,91 & 1496,12 & 1611,14 & 1568,83 & 1503,61 & 1420,65 & 396,17 \\
\hline MD & 756,36 & 732,50 & 919,74 & 1229,91 & 1322,64 & 1382,61 & 1401,10 & 1312,28 & 1416,61 & 1424,09 & 1335,25 & 1163,98 & 1208,60 \\
\hline sF & 0,62 & 0,61 & 0,76 & 1,02 & 1,00 & 1,14 & 1,16 & 1,00 & 1,17 & 1,18 & 1,10 & 0,95 & 1,00 \\
\hline
\end{tabular}

Quelle: Eigene Berechnungen aus Abbildungen 31 und 60.

545 Berechnet aus dem Saisonausschlag von 0,34 für den Zeitraum 1954-1959, d.h. 0,77/1,11; vgl. Abbildung 69, S.180. 
Abbildung: 67

\begin{tabular}{|c|c|c|c|c|c|c|c|c|c|c|c|c|c|}
\hline \multicolumn{14}{|c|}{ Bruttolohnsumme in DM/Beschaftigten im Bauhauptgewerbe 1972 . 1985} \\
\hline Jahr & Januar & Februar & März & April & Mal & Juni & Julli & August & September & Oktober & November & Dezember & JD \\
\hline 1972 & 1044,33 & 1186,70 & 1525,85 & 1512,19 & 1736,75 & 1734,37 & 1633,55 & 1680,06 & 1717,16 & 1802,52 & 1760,17 & 1557,37 & 1682,81 \\
\hline 1973 & 1375,41 & 1293,46 & 1493,10 & 1615,09 & $\mid 1929,46$ & 1858,23 & 1772,15 & 1813,92 & 1806,44 & 2015,72 & 1836,88 & 1357,83 & 1686,97 \\
\hline 1974 & 1510,43 & 1498,34 & 1626,13 & 1804,67 & 2026,09 & 1885,09 & 1971,59 & 1848,73 & 1939,21 & 2164,08 & 1994,22 & 1682,10 & 1830,06 \\
\hline 1975 & 1711,34 & 1607,28 & 1714,59 & 1940,99 & 2031,49 & 2049,15 & 2053,40 & 1917,93 & 2124,53 & 2294,40 & 2084,35 & 1794,12 & 1948,30 \\
\hline 1976 & 1491,36 & 1378,75 & 1846,14 & 2075,78 & 2152,47 & 2190,20 & 2065,26 & 2086,93 & 2247,80 & 2286,85 & 2323,15 & 1895,58 & 2013,41 \\
\hline 1977 & 1474,03 & 1622,74 & 2090,74 & 2055,14 & 2311,35 & 2292,42 & 2044,14 & 2188,65 & 2307,41 & 2252,65 & 2363,11 & 1940,04 & 2085,41 \\
\hline 1978 & 1722,51 & 1218,09 & 2091,10 & 2097,19 & 2345,56 & 2528,70 & 2168,36 & 227 & 2299,95 & 24 & 2750,33 & 1769,46 & 2 \\
\hline 1979 & 1009,06 & 1270,62 & 2087,57 & 2316,05 & 2722,71 & 2542,06 & 2482,78 & 2451,10 & 2480,01 & 2789,09 & 3021,73 & 2158,30 & 2297,53 \\
\hline 1980 & 1615,63 & 2081,15 & 2362,28 & 2591,06 & 2747,72 & 2669,71 & 2703,35 & 2364,33 & 2805,91 & 2952,27 & 2990,32 & 1959,90 & 2494,89 \\
\hline 1981 & 1497,23 & 1718,37 & 2439,64 & 2824,39 & 2829,67 & 2881,46 & 2798,70 & 2553,63 & 2912,42 & 2917,47 & 3389,33 & 1930,51 & 2 \\
\hline 1982 & 1339,14 & 1879,66 & 2667,30 & 2876,70 & 2900,97 & 2972,65 & 2801,10 & 2766,93 & 3037,04 & 2920,78 & 3909,45 & 2632,48 & 2741,05 \\
\hline 1983 & 2082,62 & 1613,60 & 2661,50 & 2782,09 & 2986,13 & 3090,50 & 2841,86 & 2908,10 & 3075,66 & 3021,12 & 3971,38 & 2414,79 & 2813,58 \\
\hline 1984 & 2048,21 & 2042,95 & 2599,14 & 2819,70 & 3232,20 & 2978,67 & 3138,99 & 2954,85 & 2889,21 & 3291,76 & 4056,57 & 2604,57 & 2903,66 \\
\hline 1985 & 1458,93 & 1555,58 & 2352,89 & 2856,72 & 3089,38 & 2858,58 & 3194,47 & 2852,23 & 3032,47 & 3363,76 & 3691,49 & 2659,67 & 2772,89 \\
\hline MD & 1527,16 & 1569,09 & 2111,28 & 2297,70 & 2503,00 & 2466,56 & 2404,98 & 2333,17 & 2476,80 & 2610,40 & 2867,32 & 2025,48 & 2278,40 \\
\hline SF & 0,67 & 0,6 & 0,93 & 1,01 & 1,10 & 1,08 & 1,06 & 1,02 & 1,09 & 1,16 & 1,26 & 0,89 & 1,00 \\
\hline
\end{tabular}

Quelle: Eigene Berechnungen aus Abbildung 32 und 61.

Abbildung: 68

\begin{tabular}{|c|c|c|c|c|c|c|c|c|c|c|c|c|c|}
\hline \multicolumn{14}{|c|}{ 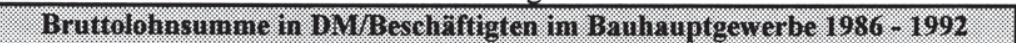 } \\
\hline Jahr & Januar & bruar & Aärz & prill & fal & uni & Jull & ugust & September & ktober & November & Dezember & JD \\
\hline 1986 & 119,31 & 1544,28 & 2266,49 & 2948,07 & 2996,88 & 2977,83 & 3223,81 & 2927,33 & 3115,14 & 3276,02 & 3809,24 & 2991,12 & 2878,40 \\
\hline 1987 & 1770,78 & 1760,08 & 2059,75 & 2958,25 & 2967,25 & 3126,80 & 3287,75 & 3040,57 & 3199,18 & 3249,04 & 4016,30 & 3009,06 & 2900,47 \\
\hline 1988 & 2474,69 & 2309,95 & 2493,67 & 2924,82 & 3202,03 & 3235,16 & 3166,27 & 3373,22 & 3274,93 & 3244,96 & 4079,82 & 3035,15 & 3085,85 \\
\hline 1989 & 2843,14 & 2575,84 & 2975,52 & 2974,31 & 3362,04 & 3347,75 & 3261,76 & 3491,77 & 3236,19 & 3462,19 & 4363,88 & 2995,06 & 3250,26 \\
\hline 1990 & 2962,03 & 2676,53 & 3119,05 & 3285,33 & 3667,32 & 3389,84 & 3594,16 & 3637,39 & 3320,11 & 3783,73 & 4952,03 & 3143,24 & 3472,37 \\
\hline 1991 & 3122,96 & 2114,66 & 3346,87 & 3706,97 & 3833,23 & 3510,79 & 3941,92 & 3733,24 & 3658,45 & 4023,94 & 5367,73 & 3505,46 & 3671,49 \\
\hline 1992 & 3187,78 & 2871,64 & 3654,57 & 3685,33 & 3843,79 & 3954,70 & 4134,33 & 3812,30 & 3974,36 & 4006,89 & 5922,96 & 4029,42 & 3933,38 \\
\hline MD & 2640,10 & 2264,71 & 2845,13 & 3211,87 & 3410,36 & 3363,27 & 3515,71 & 3430,83 & 3396,91 & 3678,11 & 4644,57 & 3244,07 & 3313,18 \\
\hline sF & 0,80 & 0,68 & 0,86 & 0,97 & 1,03 & 1,02 & 1,06 & 1,04 & 1,03 & I, & 1,40 & 0,98 & 1,00 \\
\hline
\end{tabular}

Quelle: Eigene Berechnungen aus Abbildung 33 und 62.

Betrachtet man zunächst die Entwicklung der Einkommen im Jahresdurchschnitt, so läßt sich hier ein kontinuierlicher nominaler Anstieg von 1954 bis 1992 feststellen. Dieser Anstieg des jahresdurchschnittlichen Einkommens wird nur einmal im Jahr 1985, mit einem Rückgang um knapp 5\% auf 2.772,89 DM, unterbrochen. Auffallend bei den Monatswerten ist vor allem die Einkommensentwicklung im November. Diese 
hat seit Einführung der Förderungsmaßnahmen überdurchschnittlich zugenommen und bereits im Zeitraum 1972-1985 mit einem Saisonfaktor von 1,26 den Maximalwert im Jahresverlauf erreicht. In der Zeit von 1986-1992 stieg das Novembereinkommen nochmals deutlich an, so daß der hier erzielte Maximalwert sogar um $40 \%$ über dem Jahresdurchschnitt lag. Dieser zuletzt genannte starke Anstieg, ist vor allem auf die Tarifabschlüsse bezüglich des 13. Monatseinkommens zurückzuführen.

Für die übrigen Förderungsmonate Dezember, Januar, Februar und März ließen sich allerdings seit Einführung der gesetzlichen Regelungen 1959 keine Einkommenssteigerungen mehr erzielen. Im Gegenteil, hier sind deutliche Rückgänge im Vergleich zu den Saisonfaktoren des förderungsfreien Zeitraumes 1954-1959, zu verzeichnen. Die folgende Gegenüberstellung der "Saisonfaktoren der Bruttolohnsumme in DM/Beschäftigten" zeigt die Einkommensentwicklung - getrennt nach Förderungszeiträumen - auf einen Blick.

Abbildung: 69

\begin{tabular}{|c|c|c|c|c|c|}
\hline \multicolumn{6}{|c|}{ Saisonfaktoren der Bruttolohnsumme in DM/Beschäfigten } \\
\hline Zeitraum & $1954-1959$ & $1960-1968$ & $1969-1971$ & $1972-1985$ & $1986-1992$ \\
\hline Januar & 0,88 & 0,67 & 0,62 & 0,67 & 0,80 \\
Februar & 0,77 & 0,68 & 0,61 & 0,69 & 0,68 \\
März & 0,83 & 0,87 & 0,76 & 0,93 & 0,86 \\
April & 0,96 & 1,03 & 1,02 & 1,01 & 0,97 \\
Mai & 1,02 & 1,10 & 1,09 & 1,10 & 1,03 \\
Juni & 1,02 & 1,10 & 1,14 & 1,08 & 1,02 \\
Juli & 1,05 & 1,11 & 1,16 & 1,06 & 1,06 \\
August & 1,05 & 1,10 & 1,09 & 1,02 & 1,04 \\
September & 1,04 & 1,11 & 1,17 & 1,09 & 1,03 \\
Oktober & 1,06 & 1,14 & 1,18 & 1,15 & 1,08 \\
November & 1,04 & 1,09 & 1,10 & 1,26 & 1,40 \\
Dezember & 1,11 & 0,91 & 0,95 & 0,89 & 0,98 \\
JD & 1,00 & 1,00 & 1,00 & 1,00 & 1,00 \\
\hline SA & 0,34 & 0,47 & 0,57 & 0,59 & 0,72 \\
\hline
\end{tabular}

Quelle: Abbildungen 64 bis 68 .

Die Vermutung, daß mit der Einführung der Maßnahmen zur Förderung der ganzjährigen Beschäftigung in der Bauwirtschaft eine Verringerung der monatlichen Bruttolohnsummenschwankungen erzielt werden könne, die dann zu einer Verstetigung der Bauarbeiterlöhne führen würde, läßt sich aufgrund der statistischen Ergebnisse nicht nachvollziehen. Statt dessen differieren die Bauarbeiterlöhne im Jahresverlauf seit Inkraftreten der Winterbauförderung im Dezember 1959 erheblich stärker als zuvor, wie die Entwicklung der Saisonausschläge der Abbildung 69 zeigt. 
Das folgende Kapitel versucht daher zu klären, ob die getroffenen Förderungsmaßnahmen für diese Einkommensentwicklung maßgeblich verantwortlich sind, oder ob auch andere Einflüsse entscheidend zu den dargestellten statistischen Ergebnissen beigetragen haben.

\subsubsection{Erklärungsmöglichkeiten}

Die Ursachen für die negative Entwicklung der Bruttolohnsumme (Abbildung 63) und der Bauarbeiterlöhne (Abbildung 69) im Monat Dezember, läßt sich paradoxerweise mit den getroffenen Winterbauförderungsmaßnahmen erklären. Insbesondere die vom Gesetzgeber gestellte Forderung nach einem Lohnausgleich für einen zusammenhängenden Ausgleichszeitraum, der mindestens die Zeit vom 25. Dezember bis 1. Januar umfassen sollte, ${ }^{546}$ trägt maßgeblich zu dieser statistischen Einkommensentwicklung im Dezember bei. Denn der Gesamtbetrag der Lohnausgleichszahlung, die die Bauarbeiter in der Weihnachtswoche erhalten, ist zwar als solcher im Gesamtvolumen der Bruttolohnsumme enthalten, jedoch nicht als einmalige Zahlung im Dezember, sondern als laufende Beitragszahlung an die Sozialkassen des Baugewerbes während des ganzen Jahres.

Aufgrund dieses statistischen Modus der Bruttolohnsummenerfassung ist zu schließen, daß sich das tatsächliche Einkommen des Bauarbeiters im Dezember um den Lohnausgleichsbetrag erhöht und sich die Bauarbeitereinkommen der übrigen Monate um den Lohnbestandteil, der der Lohnausgleichskasse zufließt, aber erst im Dezember ausbezahlt wird, verringern. Insofern sind die Bruttolohnsummenschwankungen bzw. die Schwankungen der monatlichen Bruttolöhne pro Beschäftigten kleiner, als sie sich in den vorangegangenen Abbildungen 58 bis 69 darstellen. Diese Tatsache wird auch durch die durchweg leichten Erhöhungen der Saisonfaktoren in den Monaten März bis November des Zeitraumes 1960-1968547 - im Vergleich zu 1954-1959 - bestätigt, die demnach zum Teil auf den der Lohnausgleichskasse zufließenden Lohnbestandteil, zurückzuführen sind.

Zur Erklärung der deutlich negativen Einkommensentwicklung seit Einführung der Förderungsmaßnahmen in den Monaten Januar und Februar - im Vergleich zum Jah-

546 vgl. hierzu TV Lohnausgleich, Kap. 2.4.2. Tarifvertragliche Leistungen und Regelungen, S.75f. 547 vgl. Abbildung 69, S. 180. 
resdurchschnitt - ist anzumerken, daß das seit dem Winter 1972 zur Auszahlung kommende $W_{G}^{548}$ ebenfalls als Lohnbestandteil anzusehen ist, der über die Winterbau-Umlage während des gesamten Jahres an die Lohnausgleichskasse fließt aber erst in der Förderungszeit von November bis März ausgezahlt wird. ${ }^{549}$ Insofern sind auch hier die tatsächlichen Einkommensschwankungen um das ausbezahlte WG in den Förderungsmonaten und dem Prozentsatz der auf die Bruttolohnsumme berechneten Winterbau-Umlage zu reduzieren. ${ }^{550}$ Dies gilt allerdings nur für die beiden letzten Förderungszeiträume von 1972-1985 bzw. 1986-1992, da das WG erst im Rahmen der Winterbaunovelle von 1972 eingeführt wurde.

In den beiden Förderungszeiträumen von 1960-1968 und 1969-1971 hingegen dürfte der deutliche Rückgang der Saisonfaktoren der Monate Januar und Februar - im Vergleich zum förderungsfreien Zeitraum 1954-1959 - und der daraus resultierende Einkommensrückgang - im Verhältnis zum Jahresdurchschnitt - im wesentlichen auf die Einführung der SWG-Regelung von 1959, bzw. der aus ihr resultierenden Erhöhung der Beschäftigtenzahlen, zurückzuführen sein. Anhand der folgenden Berechnung läßt sich diese gemachte Aussage sehr gut belegen:

Betrachtet man die Saisonfaktoren der Beschäftigten im Bauhauptgewerbe, ${ }^{551}$ so steigt der Saisonfaktor des Januars von 0,65 vor, auf 0,90 nach Einführung der SWG-Regelung (Zeitraum 1960-1968). Dies ist eine Zunahme um 38,5\%. Eine noch deutlichere Erhöhung ist im Februar festzustellen. Hier steigt der Saisonfaktor von 0,62 auf 0,91 , d.h. um $46,8 \%$ an. Für den darauf folgenden Zeitraum 19691971 konnten die Saisonfaktoren für Januar und Februar nochmals leicht auf 0,93 bzw. 0,92 erhöht werden.

Im Vergleich dazu haben sich die Saisonfaktoren der Bruttolohnsumme im Bauhauptgewerbe ${ }^{552}$ nach Einführung der ersten gesetzlichen Förderungsmaßnahmen (1960-1968) im Januar nur leicht, d.h. um 3,4\% $(0,60 / 0,58)$ und im Februar um

548 Für jede in der Förderungszeit geleistete Arbeitsstunde werden zusätzlich 2,- DM Wintergeld gezahlt.

549 Hinweis: Ausgezahlt wird das WG auf der Basis der geleisteten Arbeitsstunden in den Förderungsmonaten, vgl. hierzu ausführlich Kap. 2.4.1.4. 1972-85: Die Winterbaunovelle, S.71ff.

550 vgl. Anhang III, S.255.

551 vgl. Abbildung 34, S. 131.

552 vgl. Abbildung 63, S. 176. 
$26,5 \%(0,62 / 0,49)$ erhöht. In der Zeit von 1969-1971 sind sogar beide Saisonfaktoren der Bruttolohnsumme - Januar $(0,58)$ und Februar $(0,56)$ - wieder gefallen.

Aufgrund dieser Ergebnisse läßt sich die Schlußfolgerung ziehen, daß durch die überproportionalen Steigerungen der Beschäftigtenzahlen im Verhältnis zur Bruttolohnsumme die Einkommenszuwächse bei weitem überkompensiert wurden und dadurch der einzelne Bauarbeiter in den Monaten Januar und Februar von 1960-1971 weniger verdiente, als vor der Winterbauförderung. Zurückzuführen ist diese überproportionale Steigerung der Beschäftigtenzahlen auf die Tatsache, daß aufgrund der SWGRegelung wesentlich weniger Bauarbeiter im Winter entlassen wurden, ${ }^{553}$ weil der Bauunternehmer jetzt bei witterungsbedingtem Arbeitsausfall auf das SWG zurückgreifen konnte.

In der förderungsfreien Zeit von 1954-1959 hingegen wurde ein Großteil der Bauarbeiter entlassen, um die Lohnansprüche insgesamt, die sich aus der Arbeitsbereitschaft einerseits und der Arbeitsmöglichkeit andererseits ergaben, zu reduzieren. ${ }^{554}$ Für die verbliebenen Arbeitskräfte lag das Arbeitseinkommen, wie sich anhand der Saisonfaktoren für die Monate Januar $(0,88)$ und Februar $(0,77)$ im Zeitraum 1954-1959 unschwer erkennen läßt, entsprechend hoch, denn ausgefallene Arbeitstunden konnten und wurden damals ohne Mehrarbeitszuschläge größtenteils nachgeholt. ${ }^{555}$

Unterstützt werden diese Aussagen beispielsweise durch die Tatsache, daß der Bruttolohn des Bauarbeiters von 389,32 DM im Januar 1959, auf 362,29 DM im Januar 1960 gesunken ist, obwohl der jahresdurchschnittliche Lohn von 467,32 DM auf 501,55 DM gestiegen ist. ${ }^{556}$ Noch deutlicher sind die Einkommensrückgänge in den Monaten Januar und Februar des Jahres 1963. Ausgelöst durch einen besonders ungünstigen Witterungsverlauf in der Schlechtwetterzeit 1963/64557 sinken die Bruttolöhne auf 251,67 DM im Januar bzw. auf 207,78 DM im Februar. ${ }^{558}$ D.h. die

553 vgl. Kap. 3.3.1.1. Wirkungen auf die Arbeitslosenzahlen, S.117ff. und Kap. 3.3.1.3. Erklärungsmöglichkeiten, S.132ff.

554 Hinweis: Lohnanspruch bestand nur für die wirklich geleistete Arbeitszeit.

555 vgl. RTV für das Baugewerbe vom 17. April 1950 in der Fassung vom 8. Februar 1952, §3 Arbeitszeit Abs. Al.

556 vgl. Abbildung 64, S.177 und Abbildung 65, S.178.

557 vgl. Abbildung 11, S.104.

558 Anmerkung: Im Januar und Februar 1963 wurden die niedrigsten Bruttolöhne je Bauarbeiter des gesamten Untersuchungszeitraumes (1954-92) gezahlt. Diese Tatsache ist umso erstaunlicher, weil in der Zeit von 1960-63 der Tarifstundenlohn (1.5.1960: 5,6\%, 1.6.1961: 10,3\%, 
Bauarbeiter befinden sich zwar in einem Beschäftigungsverhältnis; sie beziehen aber für witterungsbedingte Ausfallstunden keinen Lohn.

In den weiteren Jahren des Zeitraumes 1960-1971 sind die Bruttolöhne der Monate Januar und Februar - im Vergleich zum Vorjahr - auch mehrmals angestiegen. Dabei ist jedoch zu berücksichtigen, daß der Tarifstundenlohn sowohl kontinuierlich als auch deutlich erhöht worden ist und sich der Bruttolohnanstieg somit entsprechend relativiert. $^{559}$

Faßt man die gewonnenen Erkenntnisse für die Monate Januar und Februar in der Zeit von 1960-1971 zusammen, so läßt sich festhalten, daß durch die Einführung der Förderungsmaßnahmen, insbesondere der SWG-Regelung, einerseits deutlich mehr Arbeitnehmer des Baugewerbes auf ein Arbeitseinkommen zurückgreifen konnten, als dies früher der Fall war und daß andererseits dieses Einkommen geringer ausfiel als in der förderungsfreien Zeit von 1954-1959. Dieser Zustand wurde dann mit Einführung des WG im Rahmen der Winterbaunovelle von 1972 erheblich verbessert. ${ }^{560}$

Ein weiterer positiver Effekt, der den Bauarbeitnehmern aufgrund der Förderungsmaßnahmen geboten wurde, lag auf dem Gebiet der Sozialversicherung. So haben sich beispielsweise als Folge der Winterbauförderung die finanziellen Bezüge, die die während der Winterperiode erkrankten Bauarbeiter aus der Krankenversicherung erhielten, wesentlich erhöht. Bezogen sie als Arbeitslose lediglich ein Krankengeld in Höhe des Arbeitslosengeldes, so steht ihnen heute im Krankheitsfalle - als im Arbeitsverhältnis verbleibende SWG-Bezieher - ein Krankengeld in Höhe des normalen Nettolohnes zu. ${ }^{561}$

Auch die Ansprüche aus der Rentenversicherung sind durch die SWG-Regelung positiv beeinflußt worden. Denn ursprünglich wurden Zeiten der Arbeitslosigkeit überhaupt nicht angerechnet. Doch mit Einführung der Rentenreform des Jahres $1957^{562}$

1.4. und 1.10. 1962: $6,1 \%$ bzw. 3,0\%, 1.5.1963: 4,9\%) mehrfach erhöht worden ist; vgl. Abbildung 65, S.178 und Hauptverband der Bauindustrie (Hrsg.), Baustatistisches Jahrbuch 1992, S.52.

559 vgl. Hauptverband der Bauindustrie (Hrsg.), Baustatistisches Jahrbuch 1992, S.52.

560 vgl. Abbildung 69, S.181.

561 vgl. Schneider, G., Der Winterbau als sozialpolitischer Erfolg, in: Die Bauwirtschaft, 17. Jg., Heft 46, 1963, S.1417ff.

562 gemäß $\$ 1259$ Abs. 1 der Reichsversicherungsordnung (RVO). 
änderte sich diese Regelung und nach Ablauf der 6. Woche galt auch die Arbeitslosigkeit als anrechnungsfähige Versicherungszeit.

Die Schlechtwetterzeiten dagegen sind aufgrund der SWG-Regelung den anrechnungsfähigen Versicherungsjahren hinzuzurechnen. Zunächst zwar nur dann, wenn der Arbeitsausfall nicht länger als einen Monat andauerte. Mit Inkraftreten der sogenannten "Härtenovelle"563 von 1965 - gemäß Art. 1 §1 Nr.22 b RentenversicherungsÄnderungsgesetz - aber schließlich in vollem Umfang.

Als Ergebnis der durch die gesetzlichen und tariflichen Förderungsmaßnahmen hervorgerufenen Entwicklung bei den Bauarbeitereinkommen läßt sich somit festhalten, daß vornehmlich die Regelungen bezüglich des Wintergeldes die materielle Sicherheit und Situation der Bauarbeiter insgesamt gesehen positiv beeinflußt haben. Im Gegensatz dazu sind die durch das Schlechtwettergeld und die Lohnausgleichsregelung erzielten Verbesserungen vor allem in der sozialen Stellung des Bauarbeitnehmers zu sehen.

Allerdings ist ein auf Arbeit beruhendes Einkommen hinsichtlich seiner sozialen und materiellen Sicherheit als vollwertiger anzusehen, als ein im wesentlichen auf Gesetz bzw. Tarif und nicht auf wirtschaftlicher Notwendigkeit beruhendes Einkommen. Insofern ist die soziale Situation des Bauarbeitnehmers nach wie vor nicht mit der des Industriearbeitnehmers vergleichbar.

563 vgl. Gesetz zur Beseitigung von Härten in den gesetzlichen Rentenversicherungen und zur Änderung sozialrechtlicher Vorschriften (Rentenversicherungs-Änderungsgesetz - RVÄndG), vom 9. Juni 1965, BGBI. I, S.476ff. 


\subsection{Zusammenfassung der Ergebnisse der Wirkungsanalyse}

Bezugnehmend auf die Zielvorstellungen der Beteiligten ${ }^{564}$ und den aus diesen Zielvorstellungen formulierten Untersuchungskriterien ${ }^{565}$ wurden die Auswirkungen der Maßnahmen zur Förderung der ganzjährigen Beschäftigung in der Bauwirtschaft auf die in den Abschnitten 3.3.1. bis 3.3.3. genannten wirtschaftlichen Bewegungsgrößen - wie z.B. Arbeitslosen- und Beschäftigtenzahlen, geleistete Arbeitsstunden, Bruttolohnsummen etc. - untersucht.

Die folgenden Ausführungen fassen daher die in diesen Abschnitten ermittelten Ergebnisse der Wirkungsanalyse, d.h. sowohl die quantitativen Effekte bezüglich der Primärkriterien ${ }^{566}$ als auch deren qualitative Folgeerscheinungen, ${ }^{567}$ noch einmal kurz zusammen:

\section{Arbeitsmarktpolitische Effekte:}

- Im sozialpolitischen Bereich ist das angestrebte Ziel der Beseitigung der Saisonarbeitslosigkeit in der Bauwirtschaft weitgehend erreicht worden. Einerseits konnten die einzelnen monatlichen Saisonfaktoren im Zeitablauf mehr und mehr dem Idealwert von 1,00 angenähert und damit auch die Saisonausschläge um insgesamt $55 \%$ - von 3,20 über 3,12 auf 1,47 - kontinuierlich verringert werden. ${ }^{568}$ Andererseits hat sich die hinter dem Saisonausschlag verbergende absolute Zahl der Arbeitslosigkeit, von durchschnittlich etwa 650.000 Arbeitslosen im Zeitraum 19541959, auf durchschnittlich etwa 120.000 Arbeitslose nach Einführung der Förderungsmaßnahmen reduziert, wie der folgende Vergleich zeigt: 569

$\begin{array}{rrrr}\text { 1954-1959: } & 643.732 & 1972-1985: & 117.193 \\ \text { 1960-1968: } & 122.624 & 1986-1992: & 113.092 \\ 1969-1971: & 75.034 & & \end{array}$

564 vgl. Kap. 2.5. Vorstellungen der Beteiligten von den Förderungsmaßnahmen zur ganzjăhrigen Beschäftigung, S.79ff.

565 vgl. Kap. 3.2. Formulierung der Untersuchungskriterien aus den Zielvorstellungen, S.113ff.

566 vgl. Kap. 3.2.1. Primarkriterien, S.114-115.

567 vgl. Kap. 3.2.2. Sekundärkriterien, S.115.

568 vgl. Abbildung 28, S. 127.

569 vgl. ausführlich Kap. 3.3.1.1. Wirkungen auf die Arbeitslosenzahlen, S.117ff. und Abbildungen $17,24,25,26$ und 27. 
Entscheidenden Anteil an der Beseitigung der Saisonarbeitslosigkeit hatte die im Dezember 1959 eingeführte gesetzliche SWG-Regelung in Verbindung mit den vom Gesetzgeber geforderten tarifvertraglichen Regelungen, die als flankierende Maßnahmen eine Umgehung der SWG-Regelung verhindern sollten. ${ }^{570}$ Sonstige wirtschafts- oder sozialpolitische Förderungsmaßnahmen sowie die allgemeine konjunkturelle Entwicklung konnten keinen nennenswerten Einfluß auf die Beseitigung der Saisonarbeitslosigkeit ausüben.

- Durch das Fortbestehen der Arbeitsverhältnisse infolge der SWG-Regelung haben sich auch die Beschäftigtenzahlen im Jahresverlauf seit 1959 weitgehend stabilisiert. So ist das Ausmaß der Schwankungsbreite zwischen höchstem und niedrigstem Beschäftigtenstand mit Einführung der Förderungsmaßnahmen entscheidend verringert worden. Dies belegt die folgende Gegenüberstellung der Saisonausschläge nach Zeiträumen:571

$\begin{array}{llll}\text { 1954-1959: } & 0,52 & 1972-1985: & 0,11 \\ \text { 1960-1968: } & 0,15 & 1986-1992: & 0,12 \\ 1969-1971: & 0,12 & & \end{array}$

Ein weiterer positiver Effekt liegt darin, daß diese Stabilisierung der Saisonausschläge auf einem hohen Beschäftigungsniveau erreicht werden konnte. ${ }^{572}$ Das heißt, die Steigerung der Beschäftigten in den Wintermonaten ist nicht auf eine Verringerung der Beschäftigten in den Sommermonaten zurückzuführen. Daraus ist zu schließen, daß die genannten Zielvorstellungen bezüglich der Stabilisierung der Arbeitsverhältnisse auf einem hohen Beschäftigungsniveau und die damit verbundene Verringerung der Fluktuation bei den Bauarbeitskräften sich weitgehend erfullt haben.

- Die beschriebenen quantitativen Effekte auf dem Arbeitsmarkt haben unmittelbare qualitative Folgewirkungen. D.h. "...der Übergang von der Saisonarbeit zum ständigen Arbeitsverhältnis, wie es früher nur Meister, Poliere und bewährte Stammkräfte aufzuweisen hatten, hat die gesellschaftiche bzw. soziale Stellung und das Sozialprestige der Bauarbeiter sowohl innerhalb der Betriebe wie in der Öffent-

570 z.B. witterungsbedingtes Kündigungsverbot, vgl. ausführlich Kap. 2.4.2. Tarifvertragliche Leistungen und Regelungen, S.74ff.

571 vgl. Abbildung 34, S.131.

572 vgl. ausfuihrlich Kap. 3.3.1.2. Wirkungen auf die Beschäftigtenzahlen, S.128ff. 
lichkeit spürbar angehoben. Hier hat sich eine Wandlung vollzogen, die rational schwer zu erfassen, aber deshalb keineswegs bedeutungslos ist." 573 Das Image vom Arbeitslosen bzw. Saisonarbeiter in der Bauwirtschaft hat sich daher deutlich verbessert. Dennoch erreicht der soziale Status des Bauarbeiters nicht das Niveau von Arbeitnehmern in anderen Wirtschaftszweigen, weil sein Arbeitsverhältnis während der Winterperiode teilweise auf Gesetz bzw. Tarif und nicht auf wirtschafticher Notwendigkeit beruht.

\section{Wirtschaftspolitische Effekte:}

- Vom wirtschaftspolitischen Standpunkt aus betrachtet, haben die Maßnahmen zur Förderung der ganzjährigen Beschäftigung in der Bauwirtschaft, bezüglich ihrer Zielvorstellungen, mehr oder weniger versagt. Die Entwicklung der Produktionsschwankungen zeigen die folgenden Saisonausschläge der "Geleisteten Arbeitsstunden" und der "Nettoproduktion":574

$\begin{array}{ccc} & \text { SA Arbeitsstunden } & \text { SA Nettoproduktion } \\ \text { 1954-1959: } & 0,72 & 0,70 \\ \text { 1960-1968: } & 0,56 & 0,62 \\ \text { 1969-1971: } & 0,62 & 0,67 \\ 1972-1985: & 0,55 & 0,55 \\ 1986-1992: & 0,57 & 0,59\end{array}$

Seit Einführung der Förderungsmaßnahmen konnten die Produktionsschwankungen im Jahresverlauf bis 1985 - d.h. sowohl die "Geleisteten Arbeitsstunden" als auch die "Nettoproduktion" - zwar um etwa $20 \%$ (0,55/0,72 bzw. 0,55/0,70) reduziert werden; dennoch ist es insgesamt nicht gelungen, die Produktionsschwankungen im Baugewerbe zu beseitigen und dadurch eine kontinuierliche Bautätigkeit zu verwirklichen. Im "Förderungszeitraum" 1986-1992 ist sogar wieder ein Anstieg der Produktionsschwankungen zu verzeichnen. Die Produktion des Februars ist mit $52 \%{ }^{575}$ nur etwa halb so groß wie die des Oktobers. Dieser An-

573 vgl. Ifo-Institut für Wirtschaftsforschung, Soziale und wirtschaftliche Auswirkungen der Winterbauförderung, S.24.

574 vgl. ausführlich Kap. 3.3.2.1. Wirkungen auf die Produktionsschwankungen, S.138ff. und Abbildungen 41 und 52 .

575 vgl. Abbildung 52: 0,65/1,24=52\% bzw. SA: 0,59. 
stieg der Schwankungen, läßt sich mit der Aussetzung der IKZ und MKZ begründen. 576

- Das angestrebte Ziel der Erhöhung des Jahresbauvolumens - gemessen in insgesamt geleisteten Arbeitsstunden - konnte nur einmal im Zeitraum 1960-68 verwirklicht werden. In dieser Zeit stieg die jahresdurchschnittliche Arbeitsstundenzahl um etwa $9 \%$ an. ${ }^{577}$ Dabei ist jedoch zu berücksichtigen, daß dieser Anstieg von der Beseitigung der Saisonarbeitslosigkeit begleitet war und sich aufgrund der gestiegenen Beschäftigungszahlen relativiert. ${ }^{578}$ Alle weiteren Förderungsmaßnahmen sind mit einer Einschränkung des Jahresbauvolumens verbunden. 579

- Die Ursachen für den wirtschaftspolitischen Mißerfolg sind nicht im klimatischen Bereich zu suchen, ${ }^{580}$ sondern im Versagen der gesetzlichen Förderungsmaßnahmen. Insbesondere die nach wie vor gültige SWG-Regelung wirkt kontraproduktiv und damit den genannten wirtschaftspolitischen Zielen entgegen. So ist beispielsweise die Differenz in Stunden - zwischen tatsächlich geleisteten Arbeitsstunden je Beschäftigten und Arbeitstag von "Sommer" zu "Winter" - im Zeitraum 1960-68, auf durchschnittlich 2,25 (1954-59: 1,03) Arbeitsstunden angestiegen. ${ }^{581}$

Auch im darauffolgenden Förderungszeitraum (1969-71) erhöhte sich die tägliche Arbeitsstundendifferenz zwischen "Sommer" und "Winter" nochmalig auf nun insgesamt 2,41 Stunden. Als Ergebnis läßt sich daher festhalten, daß mit der Einführung der SWG-Regelung im Dezember 1959 die Verstetigung der Bautätigkeit um etwa 1 Arbeitsstunde 582 je Beschäftigten und Arbeitstag - im Vergleich "Sommer" zu "Winter" - verschlechtert wurde. Die nach Aussage des Gesetzgebers "ausschließlich produktionsorientierte" Winterbauförderung des AFG von $1969^{583}$ konnte demnach keine wirtschaftspolitischen Erfolge aufweisen.

576 Anmerkung: Unterstützt wird diese Aussage vor allem durch den Rückgang der winterlichen Bautătigkeit in den Fördenungsmonaten Februar und Mărz, vgl. Abbildung 41, S.145 und Abbildung 52, S.151.

577 berechnet aus 220.981/202.150, vgl. Abbildung 53, S.155.

578 vgl. auch Kap. 3.3.2.3. Wirkungen auf die Verstetigung der Bautătigkeit, S.159ff.

579 vgl. ausführlich Kap. 3.3.2.2. Wirkungen auf das Jahresbauvolumen, S.153ff.

580 Hinweis: Die Witterungseinflüsse haben zwar negative Auswirkungen auf die winterliche Bautätigkeit, allerdings nicht in steigender sondern in gleichbleibender Form, vgl. Kap. 3.3.2.3. Wirkungen auf die Verstetigung der Bautătigkeit, S.163.

581 vgl. Abbildung 54, S.162.

582 berechnet aus 2,41 bzw. 2,25 abzüglich 1,03 . 
- Ein in wirtschaftspolitischer Hinsicht positiver Effekt und hier insbesondere bezüglich der Verstetigungsentwicklung der Bautätigkeit, wurde erst mit Einführung der PWF im Rahmen der Winterbaunovelle von 1972 erzielt. Maßgeblich verantwortlich für diesen wirtschaftspolitischen Teilerfolg ist dabei das bis heute unverändert gezahlte Wintergeld von 2,- DM je geleisteter Arbeitsstunde in den Monaten Dezember bis März. Mit der Winterbaunovelle konnte die negative Entwicklung bezüglich der kontinuierlichen Bautätigkeit nicht nur gestoppt sondern sogar umgekehrt werden. Dies zeigen die verringerten Arbeitsstundendifferenzen von 1,65 (1972-85) bzw. 1,57 (1986-92) zwischen "Sommer" und "Winter". 584

\section{Einkommenspolitische Effekte:}

- Die Wirkungen der getroffenen Förderungsmaßnahmen auf die materielle Situation der Bauarbeiter, d.h. Verstetigung und Erhöhung der Bauarbeitereinkommen, sind unterschiedlich zu bewerten. Dies gilt insbesondere für die SWG-Regelung. Aufgrund des Fortbestehens der Arbeitsverhältnisse wird einerseits wesentlich mehr Arbeitnehmern des Baugewerbes ein Arbeitseinkommen ermöglicht. Auf der anderen Seite aber fallen diese Arbeitseinkommen unter Umständen erheblich geringer aus, als dies noch in der förderungsfreien Zeit der Fall war. ${ }^{585}$

Das heißt: im Extremfall erhält der Bauarbeiter während der Schlechtwetterzeit ein monatliches Arbeitseinkommen in Höhe des Arbeitslosengeldes. Dies ist dann der Fall, wenn alle Arbeitsstunden eines Monats aus Witterungsgründen ausfallen. Die Ursache hierfür liegt darin, daß die witterungsbedingten Ausfallstunden nur in Höhe des Arbeitslosengeldes vergütet werden. In der förderungsfreien Zeit von 1954-1959 hingegen wurden ausgefallene Arbeitsstunden größtenteils nachgeholt und damit voll entlohnt. Unterstützt wird diese Aussage durch die entsprechend hohen Saisonfaktoren für die Monate Januar $(0,88)$ und Februar $(0,77)$ des förderungsfreien Zeitraumes 1954-1959. ${ }^{586}$

- Ein positiver Effekt bezüglich der Verstetigung und Erhöhung des Bauarbeitereinkommens geht von dem seit 1972 gezahlten Wintergeld (WG) aus. Die Höhe des WG beträgt 2,- DM je geleisteter Arbeitsstunde in den Monaten Dezember bis

583 vgl. BT-Drucks. V/2291 und auch Kap. 2.5.1.2. AFG, S.84.

584 vgl. Abbildung 54, S. 162.

585 vgl. ausführlich Kap. 3.3.3.2. Erklärungsmöglichkeiten, S.181ff.

586 vgl. Abbildung 69, S. 180 . 
März. Da es sich bei dem WG um eine Sozialleistung der BA handelt, ist es lohnsteuerfrei. ${ }^{587}$

- Der gezahlte Lohnausgleich ${ }^{58}$ in der Weihnachtswoche (d.h. vom 25. Dezember bis 1. Januar) soll die Einkommensverluste aufgrund der SWG-Regelung ausgleichen. Inwieweit der gezahlte Lohnausgleich an den Bauarbeiter die bestehende Differenz aus dem "Winterlohn" - d.h. Schlechtwettergeld 589 und normalem Stundenlohn - und dem tariflichen Monatslohn tatsächlich reduziert, ausgleicht oder sogar überzahlt, wird im Rahmen des Abschnitts 4.1.1.1. noch näher untersucht.

Der Erfolg einzelner Maßnahmen zur Förderung der ganzjährigen Beschäftigung in der Bauwirtschaft, ist also - je nach Gesichtspunkt, unter dem man ihn betrachtet durchaus unterschiedlich zu bewerten.

587 vgl. ausführlich Anhang III, S.252.

588 TV Lohnausgleich, vgl. Kap. 2.4.2. Tarifvertragliche Leistungen und Regelungen, S.75.

589 Angefallene Schlechtwetterausfallstunden multipiziert mit dem Arbeitslosengeldsatz. 


\section{KAPITEL 4}

\section{Diskussion alternativer Maßnahmen zur Förde- rung der ganzjährigen Beschäftigung}

Nachdem die Wirkungsanalyse zumindest das partielle Scheitern der Förderungsmaßnahmen zur ganzjährigen Beschäftigung in der Bauwirtschaft bewiesen hat, sollen im Rahmen des vierten Kapitels mögliche Alternativen und deren Auswirkungen auf die ganzjährige Beschäftigung in der Bauwirtschaft aufgezeigt werden.

Die in den folgenden Ausführungen stattfindende Diskussion darüber, welche Maßnahmen an die Stelle der bisherigen treten bzw. wie die bisherigen Maßnahmen verbessert und gegebenenfalls erweitert werden können, bezieht sich wiederum auf die angestrebten Zielvorstellungen der Beteiligten ${ }^{590}$ und den aus diesen Zielvorstellungen formulierten Untersuchungskriterien. ${ }^{591}$

Dabei wird die Tatsache, daß die Problematik der Förderung der ganzjährigen Beschäftigung in der Bauwirtschaft in eine besonders aktuelle politische Diskussion ausgelöst durch die geplante Streichung des SWG zum 1. Januar 1996 - eingebunden ist, die entsprechenden Handlungsbedarf bei den Tarifvertragsparteien erfordert, ${ }^{592}$ im Rahmen der Ausführungen dieses Kapitels berücksichtigt. Das heißt, es werden die verschiedenen Berechnungen der Beteiligten ${ }^{593} \mathrm{zu}$ den Folgen einer Streichung des SWG analysiert, die in der Diskussion befindlichen Modelle zur Arbeitszeitflexibilisierung aufgezeigt und alternative Förderungsmaßnahmen untersucht.

590 vgl. Kap. 2.5. Vorstellungen der Beteiligten von den Förderungsmaßnahmen zur ganzjährigen Beschäftigung, S.79ff.

591 vgl. Kap. 3.2. Formulierung der Untersuchungskriterien aus den Zielvorstellungen, S.113ff.

592 Die ersatzlose Streichung des SWG zum 1. Januar 1996 hat die Tarifvertragsparteien veranlaßt, über ein ganzjährig gesichertes Einkommen, dessen Verstetigung sowie über bauspezifische Lösungen der Wochen- und Jahresarbeitszeit, zu verhandeln (sog. Leipziger-Erklärung); vgl. Kap. 1.4. Zielsetzung, S. 32.

$593 \mathrm{Zu}$ nennen sind im wesentlichen die folgenden Studien der Beteiligten: "Gesamtwirtschaftliche Folgen einer Streichung des SWG" von Reinhard Hujer und Gerd Hassel, "Der Angriff auf das Schlechtwettergeld, Daten/Fakten/Auswirkungen" vom Bundesvorstand der IG Bau-Steine-Erden und "Geplanter Wegfall des SWG im Baugewerbe" von Erhard Knechtel (Hauptverband der Bauindustrie). 
Aufgrund der ausführlichen Analyse und der ermittelten Ergebnisse bezüglich der getroffenen Förderungsmaßnahmen zur "Ganzjährigen Beschäftigung" beschränkt sich der Verfasser vor allem auf diejenigen Änderungen der gesetzlichen und tariflichen Förderungsmaßnahmen, die die arbeitsmarkt-, wirtschafts- und einkommenspolitischen Zielsetzungen zur Verwirklichung der kontinuierlichen Bautätigkeit bzw. ganzjährigen Beschäftigung unterstützen. ${ }^{594}$ Dabei ist es durchaus möglich, daß die Alternativen des Verfassers manchmal im Gegensatz zu den Vorstellungen der Tarifpartner stehen. Den Abschluß dieses Kapitels bildet ein in Ansätzen vorgestelltes Tarifmodell, bei dem die wesentlichen Rahmenbedingungen, wie Arbeitszeit und Förderung, aufgezeigt werden sollen.

In Anlehnung an die konzeptionellen Möglichkeiten zur Förderung bzw. Realisierung der ganzjährigen Beschäftigung in der Bauwirtschaft - d.h. analog der Gliederung des Abschnitts 2.4. - wird in der Vorgehensweise zwischen gesetzlichen, tarifvertraglichen und sonstigen Alternativen unterschieden. ${ }^{595}$ Dabei ist in der folgenden Diskussion zu berücksichtigen, daß vor allem die gesetzlichen und tariflichen Förderungsmaßnahmen häufig aneinander gekoppelt sind. Dies zeigte sich beispielsweise bei der Einführung der gesetzlichen SWG-Regelung in Verbindung mit den geforderten tarifvertraglichen Regelungen. 596

\subsection{Gesetzliche Alternativmaßnahmen}

Um die Effektivität der derzeit gültigen und seit Dezember 1959 getroffenen Maßnahmen insgesamt beurteilen zu können, werden die im Rahmen der Förderung zur ganzjährigen Beschäftigung in der Bauwirtschaft geleisteten "Zahlungen" den damit verbundenen "Stunden" gegenübergestellt. ${ }^{597}$ Die folgende Abbildung 70 zeigt alle Förderungsmaßnahmen des Zeitraumes 1959 bis 1992 auf, die aufgrund ihres Umfanges für die Förderung der ganzjährigen Beschäftigung von Bedeutung sind.

594 vgl. Kap. 3.2.1. Primärkriterien, S.114-115 und Kap. 3.4. Zusammenfassung der Ergebnisse der Wirkungsanalyse, S.186ff.

595 vgl. Kap. 2.3. Die konzeptionellen Möglichkeiten zur Förderung der ganzjăhrigen Beschäftigung in der Bauwirtschaft, S.60ff. und Kap. 2.4. Zeitlicher AbriB der Förderungsmaßnahmen zur ganzjăhrigen Beschättigung, S.64ff.

596 BRTV für das Baugewerbe vom 20. August 1959 und TV Lohnausgleich, vgl. Kap. 2.4.2. Tarifvertragliche Leistungen und Regelungen, S.75.

$597 \mathrm{Zu}$ den immateriellen Förderungsmaßnahmen, die nicht in die Kategorie der gesetzlichen oder tariflichen Regelungen fallen, vgl. ausführlich Kap. 2.4.3. Sonstige Maßnahmen, S.76ff. 
Abbildung: 70

\begin{tabular}{|c|c|c|c|c|c|c|c|c|c|c|}
\hline \multicolumn{11}{|c|}{ 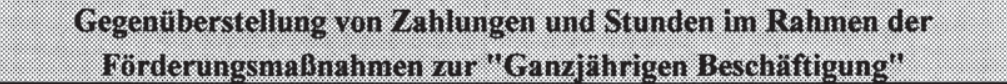 } \\
\hline \multicolumn{7}{|c|}{ Geleistete Zahlungen in Millionen DM } & \multicolumn{4}{|c|}{ Stunden in Millionen } \\
\hline Zeitraum & SWG1) & $\begin{array}{c}\text { Lohnaus- } \\
\left.\text { gleich }^{2}\right)\end{array}$ & $\left.W_{G}{ }^{3}\right)$ & MKZ4) & IKZ5) & $\begin{array}{c}\text { WB- } \\
\text { Umlage }\end{array}$ & Zeitraum & $\begin{array}{c}\text { SWG- } \\
\text { Stunden?) }\end{array}$ & $\begin{array}{c}\text { WG- } \\
\text { Stunden }^{8}\end{array}$ & $\begin{array}{c}\text { MKZ } \\
\text { Stunden } 9) \\
\end{array}$ \\
\hline $1959 / 60$ & 120,4 & 184,0 & & 20,4 & & & $1959 / 60$ & nicht erfa Bt & & \\
\hline $1960 / 61$ & 136,8 & 163,0 & & 40,3 & 18,1 & & $1960 / 61$ & nicht erta Bt & & \\
\hline $1961 / 62$ & 384,9 & 242,8 & & 44,3 & 32,2 & & $1961 / 62$ & 219,0 & & \\
\hline $1962 / 63$ & 859,5 & 280,4 & & 14,5 & 22,2 & & $1962 / 63$ & 425,1 & & \\
\hline $1963 / 64$ & 536,2 & 311,8 & & 46,7 & 18,8 & & $1963 / 64$ & 253,6 & & \\
\hline $1964 / 65$ & 492,8 & 341,0 & & 48,0 & 12,8 & & $1964 / 65$ & 219,2 & & \\
\hline $1965 / 66$ & 472,3 & 302,5 & & 60,4 & 9,6 & & $1965 / 66$ & 194,9 & & \\
\hline $1966 / 67$ & 281,4 & 283,3 & & 67,4 & 2,8 & & $1966 / 67$ & 104,4 & & \\
\hline $1967 / 68$ & 678,4 & 327,0 & & 60,6 & 3,4 & & $1967 / 68$ & 185,7 & & \\
\hline $1968 / 69$ & 813,0 & 356,1 & & 39,0 & 4,5 & & $968 / 69$ & 230,4 & & \\
\hline $1960-68$ & 477,6 & 279,2 & & 44,2 & 12,4 & & $1960-68$ & 229,0 & & \\
\hline $1969 / 70$ & $1.229,7$ & 404,1 & & 6,6 & 10,0 & & $1969 / 70$ & 318,2 & & 5,9 \\
\hline $1970 / 71$ & 817,7 & 485,1 & & 12,4 & 31,4 & & $1970 / 71$ & 204,4 & & 11,3 \\
\hline $1971 / 72$ & 642,7 & 446,9 & & 14,2 & 48,6 & 282,5 & $1971 / 72$ & 147,4 & & 12,1 \\
\hline $1969-71$ & 896,7 & 445,4 & & 11,1 & 30,0 & & $1969-71$ & 223,3 & & 9,8 \\
\hline $1972 / 73$ & 489,0 & 585,4 & 777,6 & 46,8 & 87,2 & $1.110,0$ & 197273 & 107,5 & 388,8 & 37,6 \\
\hline $1973 / 74$ & 554,8 & 588,9 & 789,7 & 64,3 & 23,9 & 931,2 & $1973 / 74$ & 118,8 & 394,9 & 32,8 \\
\hline $1974 / 75$ & 386,1 & 582,0 & 657,2 & 51,7 & 16,2 & 821,7 & $1974 / 75$ & 76,8 & 328,6 & 25,5 \\
\hline $1975 / 76$ & 683,3 & 675,4 & 514,1 & 49,9 & 19,7 & 774,8 & $1975 / 76$ & 138,9 & 257,1 & 25,5 \\
\hline $1976 / 77$ & 559,1 & 615,2 & 702,1 & 67,1 & 21,3 & 754,3 & $1976 / 77$ & 110,3 & 351,1 & 35,3 \\
\hline $1977 / 78$ & 767,4 & 528,4 & 650,5 & 63,4 & 28,6 & 729,5 & $197 / 78$ & 136,3 & 325,3 & 33,7 \\
\hline $1978 / 79$ & $1.590,6$ & 695,7 & 504,0 & 62,0 & 40,2 & 786,4 & $1978 / 79$ & 264,2 & 252,0 & 33,8 \\
\hline $1979 / 80$ & 936,3 & 906,9 & 857,3 & 87,8 & 41,7 & 906,1 & $1979 / 80$ & 148,9 & 428,7 & 48,6 \\
\hline $1980 / 81$ & $1.747,0$ & $1.014,5$ & 670,3 & 83,2 & 39,9 & 880,5 & $1980 / 81$ & 256,5 & 335,2 & 46,7 \\
\hline $1981 / 82$ & $1.380,4$ & 974,7 & 614,2 & 220,4 & 38,1 & 848,4 & $1981 / 82$ & 196,6 & 307,1 & 53,0 \\
\hline $1982 / 83$ & 593,1 & 801,5 & 639,9 & 282,1 & 39,0 & 873,6 & $1982 / 83$ & 84,7 & 320,0 & 62,7 \\
\hline $1983 / 84$ & 684,2 & 698,4 & 652,3 & 242,9 & 47,9 & 879,9 & $1983 / 84$ & 88,5 & 326,2 & 70,9 \\
\hline $1984 / 85$ & 719,4 & 942,1 & 486,6 & 160,6 & 27,2 & 808,6 & $984 / 85$ & 91,8 & 243,3 & 55,1 \\
\hline $1985 / 86$ & 747,6 & 607,7 & 467,6 & 151,8 & 35,8 & 808,3 & $1985 / 86$ & 94,4 & 233,8 & 54,8 \\
\hline $1972-85$ & 845,6 & 729,8 & 641,7 & 116,7 & 36,2 & 851,0 & $1972-85$ & 136,7 & 320,8 & 44,0 \\
\hline $1986 / 87$ & 770,5 & 625,3 & 446,8 & 6,8 & 10,7 & 622,8 & $1986 / 87$ & 96,2 & 223,4 & 2,3 \\
\hline $1987 / 88$ & 422,9 & 632,9 & 569,1 & 0,6 & 2,9 & 590,8 & $1987 / 88$ & 53,9 & 284,6 & \\
\hline $1988 / 89$ & 277,5 & 461,6 & 656,4 & 0,8 & 0,2 & 621,3 & $1988 / 89$ & 34,0 & 328,2 & \\
\hline $1989 / 90$ & 340,1 & 581,0 & 691,9 & 0,2 & 0,3 & 682,4 & $1989 / 90$ & 39,0 & 346,0 & \\
\hline $1990 / 91$ & 868,9 & 754,0 & 611,5 & 0,3 & 0,1 & 817,4 & $1990 / 91$ & 84,5 & 305,8 & \\
\hline $1991 / 92$ & 719,7 & 818,6 & 983,4 & 0,7 & 26,9 & $1.022,2$ & $1991 / 92$ & 75,0 & 491,7 & \\
\hline $1992 / 93$ & 798,2 & & $1.010,5$ & 0,4 & 69,3 & $1.099,7$ & $1992 / 93$ & 82,0 & 505,3 & \\
\hline $1986-92$ & 599,7 & 645,6 & 709,9 & 1,4 & 15,8 & 79,5 & 1986-92 & 66,4 & 355,0 & \\
\hline Durchochnitt & 691,2 & 552,1 & 664,4 & 98,1 & 35,1 & 802,4 & Durchechnitt & 152,5 & 332,2 & 38,0 \\
\hline
\end{tabular}

Anmerkungen:

- Ergebnisse ab 1990/91 für Geamtdeutschland, d.h. einschließlich neue Bundesländer.

- Der Durchschnitt ist berechnet aus der Summe aller Einzelergebnisse dividiert durch die Anzahl.

- Durchschnitte für MKZ und IKZ beziehen sich nur auf den Zeitraum 1972-86.

- MKZ-Beträge von 1960-68 sind auf die Bauherrenförderung (§143a AVAVG) zurückzuführen.

- Die Beträge für IKZ und MKZ im Zeitraum 1986-92 (Aussetzung der Förderung), sind primär auf Ansprüche aus Gerichtsverfahren bzw. auf noch bestehende Förderungsanträge zurückzuführen. 
Zum besseren Verständnis werden an dieser Stelle die in der Abbildung 70 aufgelisteten Zahlungen und Stunden in Kurzform - siehe auch Kap. 2.4. und Anhang - beschrieben.

\section{Erläuterungen zur Abbildung 70:}

1) Insgesamt gezahltes Schlechtwettergeld (SWG) in der jeweiligen Schlechtwetterzeit, d.h. vom 1. November bis 31. März. ${ }^{598}$

2) Insgesamt gezahlter Lohnausgleichsbetrag, der als Ausgleich für Lohnausfall im Zeitraum 24. Dezember bis 1. Januar durch Arbeitgeberbeiträge aufgebracht werden muß. Der Anspruch des Arbeitnehmers auf Lohnausgleich ist Voraussetzung für die Gewährung des gesetzlichen Schlechtwettergeldes. ${ }^{599}$ Die durchschnittliche Höhe dieses Pauschalbetrages für den einzelnen Arbeitnehmer berechnet sich aus dem gesamtem Lohnausgleichsbetrag dividiert durch die Anzahl der Leistungsempfänger. 600

3) Insgesamt gezahltes Wintergeld an Arbeitnehmer in der Förderungszeit, d.h. ab 1976/77 vom 1. Dezember bis 31. März. ${ }^{601}$ Das im Rahmen der Winterbaunovelle 1972 eingeführte WG beträgt nach wie vor 2,- DM je geleisteter Arbeitsstunde auf Baustellen. 602

4) Insgesamt gezahlte Mehrkostenzuschüsse (MKZ), die den Arbeitgebern des Baugewerbes zu den witterungsbedingten Mehrkosten des Bauens in der Schlechtwetterzeit gewährt werden bzw. wurden. Die Förderung ist seit 1986 ausgesetzt. ${ }^{603}$

5) Insgesamt gezahlte Investitionskostenzuschüsse (IKZ), die dem Arbeitgeber für den Erwerb oder die Miete von Winterbaugeräten und -einrichtungen gewährt werden. Die Förderung ist seit 1986 ausgesetzt. ${ }^{604}$

6) Die Winterbau-Umlage (WB-Umlage) ist die Umlage für die Leistungen der Produktiven Winterbauförderung, d.h. WG, MKZ und IKZ. Die WB-Umlage ist für die Produktive Winterbauförderung, einschließlich der Verwaltungskosten und der

598 vgl. Bundesanstalt für Arbeit, Winterbauförderung, Erfahrungsberichte, Nürnberg.

599 vgl. Kap. 2.4.2. Tarifvertragliche Leistungen und Regelungen, TV Lohnausgleich, S.75.

600 vgl. Grünewald, H., Zusammenstellung der Lohnausgleichszahlungen der Urlaubs- und Lohnausgleichskasse der Bauwirtschaft (ULAK), 1994 und Abbildung 71, S.198.

601 Fördenungszeit von 1971/72 bis 1975/76: 16. Dezember bis 31. März., vgl. auch Anhang III, S.250.

602 vgl. Bundesanstalt für Arbeit (Referat IVa2), Übersicht über die Einnahmen aus der WinterbauUmlage und Ausgaben für die Förderung der ganzjährigen Beschäftigung in der Bauwirtschaft, Nürnberg, 18. Januar 1993.

603 vgl. Bundesanstalt für Arbeit, Winterbauförderung, Erfahrungsberichte, Nürnberg.

604 vgl. Bundesanstalt für Arbeit, Winterbauförderung, Erfahrungsberichte, Nürnberg. 
sonstigen Kosten die mit der Gewährung der genannten Leistungen (WG, MKZ und IKZ) zusammenhängen, von den Arbeitgebern des Baugewerbes aufzubringen. 605

7) Insgesamt in der Schlechtwetterzeit ausgefallene und bezahlte Schlechtwettergeldstunden. 606

8) Im Winter geleistete Arbeitsstunden (WG-Stunden), berechnet aus der Summe des Wintergeldes (WG) dividiert durch zwei.

9) Insgesamt geförderte Stunden durch Mehrkostenzuschüsse. ${ }^{607}$

Betrachtet man die seit Dezember 1959 getroffenen gesetzlichen Förderungsmaßnahmen, so sind aufgrund der "Zahlungen" und "Stunden"608 vor allem die SWG-Regelung vom Dezember 1959 und die PWF (IKZ, MKZ, WG) der Winterbaunovelle von 1972 hervorzuheben. Auch die derzeitige Diskussion zwischen Tarifpartner und Gesetzgeber bezieht sich vor allem auf Änderungsvorschläge bezüglich dieser bedeutenden Maßnahmen im Rahmen der Förderung der "Ganzjährigen Beschäftigung". Die folgenden Ausführungen befassen sich daher mit möglichen Alternativen zur SWGRegelung und zur PWF.

\subsubsection{Die SWG-Regelung}

Im Rahmen dieses Kapitels sollen neben möglichen Änderungen der SWG-Regelung beispielsweise bezüglich der Dauer und Höhe ${ }^{609}$ - vor allem die von den Tarifpartnern und der Bundesregierung prognostizierten Folgen einer Streichung des SWG analysiert werden. Die Grundlage für diese Analyse bilden dabei die ermittelten Ergebnisse der Wirkungsanalyse, die verschiedenen Berechnungen der Beteiligten ${ }^{610}$ und die im

605 vgl. Bundesanstalt für Arbeit (Referat IVa2), Übersicht über die Einnahmen aus der WinterbauUmlage und Ausgaben für die Förderung der ganzjährigen Beschäftigung in der Bauwirtschaft, Nürnberg, 18. Januar 1993 und Anhang III, S.255.

606 vgl. Bundesanstalt für Arbeit (Referat IIIa5), Winterbauförderung, Erfahrungsberichtsberichte, Nürnberg.

607 vgl. Bundesanstalt für Arbeit, Winterbauförderung, Erfahrungsbericht für den Winter 1985/86, S.11, Nürnberg.

608 vgl. Abbildung 70, S. 194.

609 vgl. Kap. 2.3. Die konzeptionellen Möglichkeiten zur Fördenung der ganzjährigen Beschäftigung in der Bauwirtschaft, S.61.

610 IG Bau-Steine-Erden, Hauptverband der Deutschen Bauindustrie und Bundesregierung. 
Rahmen der SWG-Regelung geleisteten Zahlungen (Schlechtwettergeld und Lohnausgleich) bzw. ausgefallenen Arbeitsstunden.

Wie bereits erwähnt, hat die SWG-Regelung neben ihren unbestrittenen sozialpolitischen Erfolgen vor allem wirtschaftspolitische Nachteile mit sich gebracht. ${ }^{611}$ Diese Erkenntnis läßt sich anhand der Entwicklung der aus Witterungsgründen ausgefallenen Arbeitsstunden durchaus bestätigen. Betrachtet man hierzu die in der Abbildung 70 aufgelisteten SWG-Stunden, so zeigt sich, daß in den Förderungszeiträumen 196068 und 1969-71 keine spürbaren Veränderungen in den durchschnittlichen SWGStunden (229,0 bzw. 223,3 Mio. Stunden) zu verzeichnen sind.

Erst mit Einführung der PWF im Rahmen der Winterbaunovelle von 1972 verringern sich die durchschnittlichen SWG-Stunden des Zeitraumes 1972-85 auf 136,7 Mio. Ausfallstunden pro Jahr. Diese Entwicklung setzt sich auch im Förderungszeitraum von 1986-92 weiter fort und erreicht schließlich einen durchschnittlichen Wert von 66,4 Mio. Ausfallstunden pro Jahr. ${ }^{612}$ Dabei ist zu berücksichtigen, daß die Winterbauförderungsmaßnahmen dieses Zeitraumes insofern erheblich eingeschränkt wurden, weil die Zuschüsse zu den witterungsbedingten Mehrkosten des Bauens in der Schlechtwetterzeit (MKZ) bzw. die Zuschüsse für den Erwerb oder die Miete von Winterbaugeräten und -einrichtungen $(\mathrm{IKZ})^{613}$ gestrichen wurden. Aufgrund dieser Tatsache wäre ein Rückgang bei den Winterbauschutzmaßnahmen und damit ein Anstieg der Schlechtwetterausfallstunden zu vermuten gewesen.

Eine derartige Betrachtungsweise läßt jedoch keine abgesicherte Aussage zu, weil weder die Entwicklung der Beschäftigtenzahlen noch die der Witterungsverhältnisse berücksichtigt wurde; d.h. die geringen SWG-Stunden des Zeitraumes 1986-92 sind unter Umständen auf gute Witterungsbedingungen und/oder geringe Beschäftigtenzahlen zurückzuführen. Die folgende Abbildung 71 bildet daher auf den einzelnen Bauarbeiter bezogene Verhältnisse ab, anhand derer auch die Einkommenseffekte der SWG-Regelung quantifiziert werden können.

611 vgl. hierzu ausführlich Kap. 3.3.1. Arbeitsmarktpolitische Effekte der getroffenen Förderungsmaßnahmen, S.116ff. und auch Kap. 3.4. Zusammenfassung der Ergebnisse der Wirkungsanalyse, S. 186ff.

612 vgl. Abbildung 70, S.194.

613 vgl. Kap. 2.4.1.5. 1986-92: Aussetzung der Förderung von IKZ und MKZ und auch Anhang III, S.248-249. 
Abbildung: 71

\begin{tabular}{|c|c|c|c|c|}
\hline \multicolumn{5}{|c|}{ Ausfallstunden und Lohnausgleich je Bauarbeiter } \\
\hline Zeitraum & $\begin{array}{c}\text { Baustellen- } \\
\text { beschäftigte }{ }^{1)}\end{array}$ & $\begin{array}{c}\text { SWG-Ausfall- } \\
\left.\text { stunden in Mio. }{ }^{2}\right)\end{array}$ & $\begin{array}{c}\text { Ausfallstunden je } \\
\left.\text { Bauarbeiter }{ }^{3}\right)\end{array}$ & $\begin{array}{c}\text { Lohnausgleich je } \\
\text { Bauarbeiter } 4\end{array}$ \\
\hline $1960 / 61$ & 1.136 .578 & nicht erfaßt & $x x x x x$ & 121,00 \\
\hline 1961/62 & 1.189 .970 & 219,0 & 184,0 & 172,00 \\
\hline $1962 / 63$ & 1.249 .921 & 425,1 & 340,1 & 189,88 \\
\hline $1963 / 64$ & 1.342 .623 & 253,6 & 188,9 & 203,83 \\
\hline $1964 / 65$ & 1.338 .913 & 219,2 & 163,7 & 220,32 \\
\hline $1965 / 66$ & 1.350 .471 & 194,9 & 144,3 & 197,24 \\
\hline $1966 / 67$ & 1.196 .475 & 104,4 & 87,2 & 200,41 \\
\hline $1967 / 68$ & 1.196 .459 & 185,7 & 155,2 & 242,11 \\
\hline 1968/69 & 1.213 .114 & 230,4 & 189,9 & 253,62 \\
\hline 1960-1968 & 1.246 .058 & 229,0 & 181,7 & 200,05 \\
\hline $1969 / 70$ & 1.208 .805 & 318,2 & 263,2 & 284,71 \\
\hline $1970 / 71$ & 1.244 .392 & 204,4 & 164,3 & 330,16 \\
\hline $1971 / 72$ & 1.223 .760 & 147,4 & 120,5 & 302,46 \\
\hline 1969-1971 & 1.225 .653 & 223,3 & 182,7 & 305,78 \\
\hline $1972 / 73$ & 1.224 .280 & 107,5 & 87,8 & 396,66 \\
\hline $1973 / 74$ & 1.131 .992 & 118,8 & 104,9 & 428,96 \\
\hline $1974 / 76$ & 965.923 & 76,8 & 79,5 & 460,82 \\
\hline $1975 / 76$ & 921.694 & 138,9 & 150,7 & 547,50 \\
\hline $1976 / 77$ & 901.813 & 110,3 & 122,3 & 521,77 \\
\hline 1977778 & 883.083 & 136,3 & 154,4 & 458,26 \\
\hline $1978 / 79$ & 940.723 & 264,2 & 280,9 & 584,71 \\
\hline $1979 / 80$ & 982.833 & 148,9 & 151,5 & 746,76 \\
\hline $1980 / 81$ & 962.715 & 256,5 & 266,5 & 806,88 \\
\hline $1981 / 82$ & 879.114 & 196,6 & 223,7 & 839,10 \\
\hline $1982 / 83$ & 822.874 & 84,7 & 103,0 & 740,90 \\
\hline $1983 / 84$ & 838.828 & 88,5 & 105,5 & 632,06 \\
\hline $1984 / 85$ & 775.110 & 91,8 & 118,4 & 910,58 \\
\hline $1985 / 86$ & 732.855 & 94,4 & 128,9 & 928,56 \\
\hline $1972-1985$ & 925.988 & 136,7 & 148,4 & 643,14 \\
\hline $1986 / 87$ & 722.866 & 96,2 & 133,1 & 952,24 \\
\hline $1987 / 88$ & 711.450 & 53,9 & 75,8 & 977,74 \\
\hline $1988 / 89$ & 729.091 & 34,0 & 46,6 & 721,48 \\
\hline $1989 / 90$ & 753.350 & 39,0 & 51,8 & 895,83 \\
\hline $1990 / 91$ & 777.558 & 84,5 & 108,7 & $1.113,26$ \\
\hline $1991 / 92$ & 794.823 & 75,0 & 94,3 & $1.184,00$ \\
\hline $1992 / 93$ & 793.809 & 82,0 & 103,3 & \\
\hline 1986-1992 & 754.707 & 66,4 & 87,7 & 974,09 \\
\hline Durchschnitt & 1.004 .190 & 152,5 & 146,6 & 648,92 \\
\hline
\end{tabular}

Anmerkungen: Der Durchschnitt ist berechnet aus der Summe aller Einzelergebnisse dividiert durch die Anzahl.

\section{Erläuterungen zur Abbildung 71:}

1) Baustellenbeschäftigte im Durchschnitt der Monate November bis März, ${ }^{614}$ abzüglich der in diesen Monaten Beschäftigten Poliere und Schachtmeister. ${ }^{615}$

614 vgl. Abbildungen 30 bis 33, S. 129-131. 
2) Insgesamt in der Schlechtwetterzeit ausgefallene und bezahlte Schlechtwettergeldstunden. ${ }^{616}$

3) Ausfallstunden je Bauarbeiter in der jeweiligen Schlechtwetterzeit, berechnet aus der Zahl der SWG-Ausfallstunden dividiert durch die durchschnittlichen Baustellenbeschäftigten.

4) Durchschnittlicher Lohnausgleichsbetrag je Bauarbeiter. Berechnet aus dem gesamtem Lohnausgleichsbetrag und der Zahl der jeweiligen Leistungsempfänger. ${ }^{617}$

Betrachtet man zunächst die Entwicklung der Beschäftigtenzahlen - d.h. der Baustellenbeschäftigten -, so ist festzustellen, daß sich diese seit Einführung der SWG-Regelung von Zeitraum zu Zeitraum kontinuierlich verringert haben. Der Gesamtrückgang von durchschnittlich 1.246.058 (1960-68) auf 754.707 (1986-92) Baustellenbeschäftigten beträgt etwa $40 \%$. Im gleichen Zeitraum hat sich die SWG-Ausfallstundenzahl jedoch um über $70 \%$ reduziert. ${ }^{618}$ D.h. durch die Entwicklung zu geringeren Beschäftigtenzahlen ist auch die Reduzierung der auf den einzelnen Bauarbeiter bezogenen Ausfallstunden von 1960 bis 1992 abgeschwächt worden.

Insgesamt sind die Ausfallstunden je Bauarbeiter von durchschnittlich 181,7 (196068), auf 87,7 Stunden pro Jahr im Zeitraum 1986-92 zurückgegangen. Da dieser Rückgang um über $50 \%$ die Entwicklung der Baustellenbeschäftigten bereits berücksichtigt, könnte er demnach nur auf eine entsprechend kontinuierliche Verbesserung der Witterungsverhältnisse zurückzuführen sein. Ein Vergleich der Witterungserscheinungen in Zeiträumen hat jedoch ergeben, daß die durchschnittlichen Schlechtwettertage der einzelnen Zeiträume nur geringfügige Unterschiede aufweisen. ${ }^{619}$

Desweiteren läßt sich eine parallele Entwicklung bei den "Tagen mit Witterungserscheinungen, die die Fortfuhrung der Bauarbeiten sehr erschweren" und den entsprechenden SWG-Ausfallstunden feststellen. Diese Aussage gilt vor allem für die Zeit vor Einführung der PWF, als mit 181,7 (1960-68) bzw. 182,7 (1969-71) Ausfallstunden je Bauarbeiter fast identische Durchschnittsergebnisse erzielt wurden. Die

615 Hinweis: Für versicherungspflichtige Arbeitnehmer im Angestelltenverhältnis (z.B. Poliere und Schachtmeister) besteht kein Anspruch auf SWG, vgl. Anhang III, S.253.

616 vgl. auch Abbildung 70, S. 194.

617 vgl. Grünewald, H., Zusammenstellung der Lohnausgleichszahlungen der Urlaubs- und Lohnausgleichskasse der Bauwirtschaft (ULAK), 1994 und Abbildung 70, S.194.

618 Berechnet aus dem Verhältnis von 66,4 zu 229,0, vgl. Abbildung 71, S. 198.

619 vgl. Abbildung 15, S.106. 
folgende Gegenüberstellung zeigt den Zusammenhang zwischen SWG-Ausfallstunden je Bauarbeiter und Witterungsverlauf, in den von der SWG-Regelung bestimmten Förderungsjahren auf:

Abbildung: 72

\begin{tabular}{|c|c|c|c|c|c|}
\hline \multicolumn{6}{|c|}{$\begin{array}{l}\text { Zusammenhang zwischen Ausfallstunden je Bauarbeiter un } \\
\text { Witterungsverlauf }\end{array}$} \\
\hline Zeitraum & 3) & 4) & Zeitraum & 3) & 4) \\
\hline $1960 / 61^{11)}$ & nicht erfaßt & 9 & $1966 / 67$ & 87,2 & 9 \\
\hline $1961 / 62$ & 184,0 & 15 & $1967 / 68$ & 155,2 & 12 \\
\hline $1962 / 63$ & 340,1 & 35 & $1968 / 69$ & 189,9 & 12 \\
\hline $1963 / 64$ & 188,9 & 18 & $\left.1969 / 70^{2}\right)$ & 263,2 & 21 \\
\hline $1964 / 65$ & 163,7 & 13 & 1970/71 & 164,3 & 17 \\
\hline $1965 / 66$ & 144,3 & 17 & $1971 / 72$ & 120,5 & 7 \\
\hline
\end{tabular}

1) Förderungszeitraum 1960-1968.

2) Fördenungszeitraum 1969-1971.

3) SWG-Ausfallstunden je Bauarbeiter, vgl. Abbildung 71.

4) Tage mit Witterungserscheinungen, die die Fortführung der Bauarbeiten sehr erschweren, Jahresdurchschnitt aus Abbildung 11 und Abbildung 12.

Quelle: Abbildungen 11, 12 und 71.

Die Spalten "3)" und "4)" der Abbildung 72 verdeutlichen die direkte Abhängigkeit der Höhe der Ausfallstunden je Bauarbeiter vom Witterungsverlauf. So sind beispielsweise in der bauungünstigsten Schlechtwetterzeit 1962/63 - seit Einführung der SWG-Regelung - sowohl die meisten Schlechtwettertage (35) als auch die höchsten jemals in einem Jahr angefallenen Ausfallstunden je Bauarbeiter $(340,1)$ zu registrieren. ${ }^{620}$ Entsprechendes gilt für den umgekehrten Fall, d.h. günstige Witterungsverläufe haben geringe SWG-Ausfallstunden zur Folge wie die Schlechtwetterzeiten 1966/67 (87,2 Ausfallstunden je Bauarbeiter bzw. 9 Schlechtwettertage) und 1971/72 (120,5 bzw. 7) beweisen. 621

Die hier aufgezeigte Abhängigkeit zwischen SWG-Ausfallstunden und Witterungsverlauf bestätigt zusätzlich, daß die im Rahmen des Abschnitts 3.1.4. getroffene Einteilung bezüglich der "Tage mit Witterungserscheinungen, die die Fortführung der Bauarbeiten sehr erschweren" auch tatsächlich als Kriterium für witterungsbedingten Arbeitsausfall herangezogen wird. ${ }^{622}$

620 vgl. Abbildung 71, S. 198.

621 vgl. Abbildung 72, S.200.

622 vgl. ausführlich Kap. 3.1.4. Witterungsbedingungen, S.102ff. 
Abbildung 73 zeigt nun den Zusammenhang zwischen Ausfallstunden je Bauarbeiter und Witterungsverlauf seit Einführung der PWF im Rahmen der Winterbaunovelle, an einigen Jahren beispielhaft auf.

Abbildung: 73

\begin{tabular}{|c|c|c|c|c|c|}
\hline \multicolumn{6}{|c|}{$\begin{array}{l}\text { Zusammenhang wischen Ausfalksunden fo Banarbeiter the } \\
\text { Witterungsverlauf }\end{array}$} \\
\hline Zeitraum & 3) & 4) & Zeitraum & 3) & 4) \\
\hline \begin{tabular}{|l|}
$1973 / 741)$ \\
\end{tabular} & 104,9 & 7 & $1987 / 88$ & 75,8 & 7 \\
\hline $1981 / 82$ & 223,7 & 21 & $1988 / 89$ & 46,6 & 5 \\
\hline $1982 / 83$ & 103,0 & 7 & 1989/90 & 51,8 & 8 \\
\hline $1983 / 84$ & 105,5 & 13 & 1990/91 & 108,7 & 15 \\
\hline $1985 / 86$ & 128,9 & 26 & 1991/92 & 94,3 & 11 \\
\hline $1986 / 872)$ & 133,1 & 23 & 1992/93 & 103,3 & 10 \\
\hline
\end{tabular}

1) Beispiele aus dem Forderungszeitraum 1972-1985.

2) Förderungszeitraum 1986-1992.

3) SWG-Ausfallstunden je Bauarbeiter, vgl. Abbildung 71.

4) Tage mit Witterungserscheinungen, die die Fortführung der Bauarbeiten sehr erschweren, Jahresdurchschnitt aus Abbildung 13 und Abbildung 14

Quelle: Abbildung 13, 14 und 71.

Ein Vergleich der Einzelergebnisse zwischen Abbildung 72 und 73 beweist, daß nicht die Entwicklung des Witterungsverlaufes, sondern die produktionsorientierten Förderungsmaßnahmen von 1972 maßgeblich für die Reduzierung der witterungsbedingten Ausfallstunden je Bauarbeiter verantwortlich sind. Betrachtet man beispielsweise die Schlechtwetterzeiten 1964/65 und 1983/84 mit ihren identischen Schlechtwettertagen (13), so zeigen sich in deren SWG-Ausfallstunden je Bauarbeiter mit 163,7 (1964/65) und 105,5 (1983/84) deutliche Differenzen. Ähnliche Unterschiede der Ausfallstunden sind auch zwischen Schlechtwetterzeiten mit gleichen Witterungsverläufen, aber wesentlich höheren (1969/70 und 1981/82) bzw. geringeren (1971/72 und 1973/74, 1982/83, 1987/88) Schlechtwettertagen, festzustellen. ${ }^{623}$

Die Tatsache, daß sich die Ausfallstunden je Bauarbeiter - trotz der Aussetzung der produktionsorientierten Förderungsmaßnahmen von IKZ und MKZ - im Zeitraum 1986-92 von 148,4 (1972-85) auf 87,7 Ausfallstunden pro Mann und Jahr weiter deutlich reduziert haben, bedarf einer gesonderten Untersuchung. Wie bereits erwähnt, hat der Vergleich der Witterungserscheinungen nach Zeiträumen ergeben, daß nur geringfügige Unterschiede in den Witterungsverläufen bestehen. Dennoch kann ein Teil des Rückganges der Ausfallstunden je Bauarbeiter in der Zeit von 1986-92

623 vgl. Abbildung 72 und 73. 
auf den Witterungsverlauf zurückgeführt werden, weil dieser insgesamt etwas günstiger war, als in den übrigen Zeiträumen. So fällt beispielsweise sowohl einer der mildesten Winter des 20. Jahrhunderts (1987/88) als auch die Schlechtwetterzeit (1988/89) mit den geringsten durchschnittlichen Schlechtwettertagen (5) seit Einführung der SWG-Regelung in diesen Zeitraum. Dadurch reduziert sich die durchschnittliche Anzahl der Schlechtwettertage von 14 (1972/85) auf 13 (1986-92). ${ }^{624}$ Dies entspricht einem Rückgang um fast 10 Prozentpunkte. Im Vergleich dazu haben sich die Ausfallstunden je Bauarbeiter allerdings um etwa $40 \%{ }^{625}$ verringert. ${ }^{626}$

Es bleibt daher festzuhalten, daß der Witterungsverlauf im Zeitraum 1986-92 den Rückgang der Ausfallstunden je Bauarbeiter zwar beeinflußt hat, aber für den Gesamtrückgang nicht verantwortlich gemacht werden kann. Die Möglichkeit, daß hier die Entwicklung der tariflichen Wochenarbeitszeit einen entscheidenden Einfluß ausgeübt haben könnte, ist ebenfalls auszuschließen, weil sie in der Zeit von 1986 bis 1992 nur um 1 Stunde bzw. 2,5\% - von 40 auf 39 Wochenarbeitsstunden - gekürzt worden ist. ${ }^{627}$

Betrachtet man im Vergleich dazu die Entwicklung der tariflichen Wochenarbeitszeit während der SWG-Regelung von 1960-68 und 1969-71, so verringert sie sich dort um insgesamt 4 Stunden - von 44 auf 40 Wochenarbeitsstunden -, d.h. um fast $10 \%$. Dennoch ist durch diese deutliche Reduzierung kein Einfluß auf die Entwicklung der Ausfallstunden je Bauarbeiter zu erkennen. Selbst im Zeitraum 1969-71, in dem die wöchentliche Arbeitszeit zu Beginn ${ }^{628}$ um 2 Stunden gekürzt wurde und die durchschnittliche Zahl der Schlechtwettertage auf 14 - gegenüber 15 (1960-68) ${ }^{629}$ - gesunken ist, ändern sich die Ausfallstunden je Bauarbeiter $\left(182,7\right.$ und 181,7) nicht. ${ }^{630}$

624 vgl. ausführlich Kap. 3.1.4. Witterungsbedingungen, S. 105-106.

625 Berechnet aus 87,7 zu 148,4, vgl. Abbildung 71, S. 198.

626 Hinweis: Die Darstellung in Prozentpunkten soll hier nur den Größenunterschied zwischen der Reduzierung der Ausfallstunden je Bauarbeiter und dem Rückgang der Schlechtwettertage verdeutlichen. Die exakte Rechnung mit Witterungswerten ist aufgrund der Vielfaltigkeit von Witterungserscheinungen und deren tatsächlichen Auswirkungen auf die Bautätigkeit nicht möglich, vgl. auch Kap. 3.1.4. Witterungsbedingungen, S.102-103.

627 vgl. Deutsche Bauindustrie (Hrsg.), Baustatistisches Jahrbuch 1992, S.52.

628 Zur Entwicklung der tariflichen Wochenarbeitszeit: 1.4.1969: 42 Stunden, 1.10.1969: 40 Stunden, vgl. Deutsche Bauindustrie (Hrsg.), Baustatistisches Jahrbuch 1992, S.52.

$629 \mathrm{vgl}$. ausführlich Kap. 3.1.4. Witterungsbedingungen, S.106.

630 vgl. Abbildung 71, S.198. 
Die gemachten Ausführungen bezüglich der SWG-Regelung - d.h. der Nachweis das weder die Entwicklung der Beschäftigtenzahlen noch die der Witterungsverhältnisse oder unter Umständen auch technische Innovationen ${ }^{631}$ für den Rückgang der SWGAusfallstunden seit der Einführung der PWF verantwortlich sind - bestätigen abermals die bereits gewonnene Erkenntnis, daß die SWG-Regelung den angestrebten wirtschaftspolitischen Zielsetzungen, wie beispielsweise Verstärkung der winterlichen Bautätigkeit und Verringerung der bauwirtschaftlichen Produktionsschwankungen, entgegenwirkt.

Es hat sich gezeigt, daß insbesondere die PWF von 1972 einen echten Anreiz zum Winterbau bietet, ${ }^{632}$ da seitdem die SWG-Ausfallstunden kontinuierlich zurückgehen, obwohl die Witterungsbedingungen konstant geblieben sind bzw. sich nicht verbessert haben. Aufgrund dieser Tatsache kann man daher auch von "unechten" witterungsbedingten Saisonschwankungen sprechen, ${ }^{633}$ die einen "...Arbeitsausfall ausschließlich durch zwingende Witterungsgründe"634 nur vortäuschen und damit den gesetzlichen Anspruch des bei witterungsbedingtem Arbeitsausfall zu gewährenden Schlechtwettergeldes ${ }^{635}$ in Frage stellen. Diese Feststellung wird durch ein Schreiben des Präsidenten der BAVAV unterstützt, in dem es heißt: "...es dürfe nicht verkannt werden, $\mathrm{da} ß$ in allen Schlechtwetterzeiten SWG bewilligt worden ist, obwohl bei Anlegung objektiver Maßstäbe die Fortführung der Arbeit sicher möglich gewesen wäre." 636

Die Höhe dieser "mißbräuchlichen"637 Inanspruchnahme des SWG in den Zeiträumen 1960-68 und 1969-71 läßt sich anhand der gemachten Ausführungen in diesem Kapi-

631 Anmerkung: Entsprechende Innovationen bei den Bauverfahren, die die Abhängigkeit von Witterungseinflüssen derart reduzieren, daß witterungsbedingte Ausfallstunden faktisch ausgeschlossen werden, hat es seit Einführung der Winterbauförderungsmaßnahmen im Dezember 1959 nicht gegeben, d.h. sowohl Technik als auch Schutzmaßnahmen waren bereits zu Beginn der Förderungsmaßnahmen bekannt. Die Ursache dafür liegt vor allem in der Erforschung der technischen Winterbauproblematik während der Zeit vor Einführung der Förderungsmaßnahmen von 1954-59, vgl. ausführlich Kap. 2.4.1.1. 1954-59: Der Zeitraum "Vorher", S.65ff. und auch Kap. 3.1.2. Technik des Winterbaues, S.97 und Kap. 3.1.3. Schutzmaßnahmen, S.98ff.

632 vgl. auch Kap. 3.3.2.3. Wirkungen auf die Verstetigung der Bautätigkeit, S. 169-171.

633 vgl. Kap. 2.2.2.1. Marktbedingte Saisonschwankungen, S.56.

634 vgl. §84 Abs.1 AFG und auch Anhang III, S.253.

635 vgl. $\S 83$ AFG.

636 vgl. Schreiben des Präsidenten der Bundesanstalt für Arbeitsvermittlung und Arbeitslosenversicherung vom 9. Juli 1963 (Az.: IIa5/Ia4-7143d/5520/62), S.2.

637 Anmerkung: Von Mißbrauch im Sinne von unrechter Verwendung, kann an dieser Stelle nicht gesprochen werden, da das SWG vom Arbeitsamt - auf Stellung eines schriftlichen Antrages des Betriebes - gewährt wird. Der Verfasser vertritt jedoch die Ansicht, daß ein Teil des gezahl- 
tel bzw. mit Hilfe der Abbildungen 70 und 71 in etwa quantifizieren. Für diese als Überschlagsrechnung zu verstehende Quantifizierung kann durchaus die zuletzt d.h. im Zeitraum 1986-92 - erreichte durchschnittliche Ausfallstundenzahl je Bauarbeiter herangezogen werden. Zumal der um etwa $10 \%$ günstigere Witterungsverlauf dieses Zeitraumes durch die Aussetzung der Förderung von IKZ und MKZ in etwa ausgeglichen wird. Bei dieser Annahme geht der Verfasser davon aus, daß die im Zeitraum 1972-85 mit MKZ geförderten Arbeitsstunden von durchschnittlich 44,0 Mio. ${ }^{638}$ - das sind $10 \%$ der tatsächlich in der Förderungszeit dieses Zeitraumes geleisteten Arbeitsstunden (437.086.000)639 - aufgrund des Wegfalles der produktionsorientierten Förderung von IKZ und MKZ zu einer erhöhten Inanspruchnahme des Schlechtwettergeldes geführt hätten und damit auch zu mehr SWG-Ausfallstunden.

Grundlage der Überschlagsrechnung sollen dennoch nicht die erreichten 87,7 (198692), sondern 100,0 SWG-Ausfallstunden je Bauarbeiter sein. Danach ergibt sich folgendes Einsparungspotential an SWG für die Zeiträume 1960-68 und 1969-71:640

1960-68: Die Multiplikation der 100,0 Ausfallstunden je Bauarbeiter mit den durchschnittlichen Baustellenbeschäftigten dieses Zeitraumes (1.246.058) ergibt 124,6 Mio. SWG-Ausfallstunden. Dies ist ein Rückgang um 45,6\% gegenüber den tatsächlich abgerechneten Ausfallstunden von 229,0 Mio. Entsprechend verringern sich dadurch die jährlichen SWG-Zahlungen von durchschnittlich 477,6 Mio. DM auf 259,8 Mio. DM.

1969-71: Die gleiche Rechnung führt hier zu folgenden Ergebnissen:

- 122,6 Mio. SWG-Ausfallstunden, d.h. ein Rückgang um 45,1\% gegenüber den tatsächlich abgerechneten Ausfallstunden von 223,3 Mio.

- Rückgang der jährlichen SWG-Zahlungen von durchschnittlich 896,7 Mio. DM auf 492,3 Mio. DM.

ten Schlechtwettergeldes einer objektiven Überprüfung der "Zwingenden Wittenungsgründe" nicht standhält.

638 Anmerkung: Die produktiven Auswirkungen aufgrund der geleisteten Zahlungen für die IKZ lassen sich, im Gegensatz zu den MKZ nicht in Stunden quantifizieren. Sie bleiben daher in dieser Überschlagsrechnung unberücksichtigt, vgl. Abbildung 70, S.194 und Anhang III, S.249.

639 vgl. Abbildung 54, S.162.

640 zur Berechnung vgl. Abbildung 70 und 71. 
Die Berechnung zeigt, daß mit den produktionsorientierten Förderungsmaßnahmen der Winterbaunovelle jährlich etwa 200 Mio. DM (1960-68) bzw. 400 Mio. DM (1969-71) hätten eingespart werden können. ${ }^{641}$

Die Bemühungen des Gesetzgebers, mit der Einführung der SWG-Regelung "...sofort einen nachhaltigen Einbruch in die bisherigen Gewohnheiten $\mathrm{zu}$ erzielen und eine kontinuierliche Bautätigkeit zu verwirklichen"642, haben sich nicht erfüllt. Zwar betont der Gesetzgeber, daß "...das SWG die Arbeitslosenunterstützung nicht einfach ersetzen, sondern die Voraussetzung dafür schaffen sollte, die im Winter verfügbaren $\mathrm{Ka}$ pazitäten der Bauindustrie rationeller auszunutzen."643 Diese Hoffnung wird mit der gefundenen Gesetzeskonstruktion begründet, die einerseits dem Arbeitnehmer des Baugewerbes eine gewisse Sicherstellung des Arbeitsplatzes und andererseits eine permanente Arbeitsverfügbarkeit des Bauarbeiters gewährleistet. Dadurch kann in witterungsgünstigen Zeiten die Arbeit unverzüglich wieder aufgenommen werden.

Aufgrund der ermittelten Ergebnisse kann sich der Verfasser diesem eher "theoretischen Vorteil" - der verschiedentlich sehr hoch bewertet wird ${ }^{644}$ - der SWGRegelung nicht anschließen. Auch andere Autoren sehen die SWG-Regelung durchaus kritisch, wenn sie äußern, "...daß die SWG-Regelung zu einem Stück sozialen Besitzstandes im Baugewerbe geworden ist und sich im Laufe der Jahre die Auffassung gebildet hat, dem Bauarbeiter stehe als Äquivalent für die harte Arbeit eines Jahres das gute Recht zu, bei Beginn der Winterperiode erst einmal Schlechtwettergeld zu beziehen, gleichgültig ob weitergearbeitet werden könnte oder nicht. Die zur Selbstverständlichkeit gewordene Inanspruchnahme der SWG-Regelung als eine Art spezifischen Bauarbeiter-Sonderurlaubs hat dazu geführ, daß auch gut eingerichtete Winterbaustellen mit Vollschutz für eine gewisse Zeit zum Erliegen kamen. "645

641 Hinweis: Die gestiegenen Ausgaben an SWG im Zeitraum 1969-71 ließen an der Effizienz dieser Winterbaufordenung zweifeln, vgl. Kap. 2.5.1.3. Winterbaunovelle, S.84ff.

642 vgl. BT-Drucks. IIL/1211, S.2.

643 vgl. Bulletin des Presse- und Informationsamtes der Bundesregierung, Fünf Jahre Winterbauförderung des Bundes, Bonn, den 3. Dezember 1964, Nr.177, S. 1640.

644 "Das SWG hat den Verlust vieler Hunderttausend Tagewerke verhindert", vgl. hierzu auch Gerland, E., Die sozialen, volkswirtschaftlichen und betriebswirtschaftlichen Auswirkungen der gesetzlichen Schlechtwetter-Regelung im Baugewerbe, Diss., S.117. und auch Ifo-Institut für Wirtschaftsforschung, Soziale und wirtschaftliche Auswirkungen der Winterbauforderung, S.15 und 39.

645 vgl. Brocksiepe, C., Winterbau - Förderung durch Arbeitgeber, in: der arbeitgeber, 24.Jg., Nr.19. 1972, S.741. 
Ähnlich äußert sich Günter Kranz, wenn er die SWG-Regelung als eine "nur sozialpolitische Regelung mit wenig wirtschaftichem Effekt"646 bezeichnet und die BA bereits in ihrem Erfahrungsbericht 1962/63 darauf hinweist, daß die Arbeitnehmer "verschiedentlich gegen den Willen des Arbeitgebers das Ruhen der Arbeit wegen schlechter Witterung durchsetzen."647

Der aufgrund dieser Zitate vermittelte Eindruck, daß die negative Entwicklung im Rahmen der SWG-Regelung - 1960-68 und 1969-71 - maßgeblich auf das Verhalten der Bauarbeitnehmer zurückzuführen ist, entspricht jedoch nicht der Tatsache. Denn über die Fortsetzung, Einstellung oder Wiederaufnahme der Arbeit entscheidet letztendlich der Arbeitgeber, ${ }^{648}$ während das Arbeitsamt über die Anerkennung der gestellten SWG-Anträge befindet.

Vielmehr ist zu vermuten, daß auch die Bauunternehmer nicht sonderlich an einer Winterbautätigkeit interessiert waren. Diese Aussage wird durch die Forderung der Arbeitgeberverbände der Bauwirtschaft aus dem Jahr 1963 unterstützt, wonach die Bauherrenförderung durch eine die "...Produktivität besser anregende Maßnahme"649 zu ersetzen sei. Vergleicht man in diesem Zusammenhang die durchschnittlich geleisteten Zahlungen (1960-68) im Rahmen der Bauherrenförderung von 44,2 Mio. DM mit den durchschnittlichen Zuschüssen an die Unternehmen des Baugewerbes von 12,4 Mio. DM, ${ }^{650}$ so wird das Mißverhältnis der Förderung deutlich. Hinzu kommt die Tatsache, daß die Bauherren nicht bereit waren, sich an den Winterbaumehrkosten des Bauunternehmers zu beteiligen. ${ }^{651}$.

Die Ausführungen haben mehrfach aufgezeigt, daß durch die SWG-Regelung in den Zeiträumen 1960-68 und 1969-71, "unechte" Saisonschwankungen im Produktionsbereich nicht beseitigt, sondern geschaffen wurden. Im Rahmen des folgenden Kapitels

646 vgl. Kranz, G., Die wirtschaftliche Notwendigkeit des Bauens im Winter, in: StraßenbauTechnik, 24.Jg., Nr.22, 1971, S.1413.

647 vgl. Schreiben des Präsidenten der Bundesanstalt für Arbeitsvermittlung und Arbeitslosenversicherung vom 9. Juli 1963 (Az.: IIa5/Ia4-7143d/5520-2236/62), S.2.

648 vgl. BRTV-Bau, $\$ 4$ Abs.5. Arbeitsausfall infolge ungünstiger Witterung, Satz. 5.3.

649 vgl. o.V., Jetzt schon vorsorgen!, in: Die Bauwirtschaft, 17.Jg., Heft 13, 1963, S.364.

650 vgl. Abbildung 70, S.194.

651 vgl. Schreiben des Präsidenten der Bundesanstalt für Arbeitsvermittlung und Arbeitslosenversicherung vom 16. August 1966 (Az.: Ila5/la4-7143d/5520-2273/65), Betr.: Maßnahmen zur Förderung der ganzjăhrigen Beschäftigung in der Bauwirtschaft, Erfahrungsbericht für den Winter $1965 / 66$, S.3. 
sollen nun die finanziellen Zuwendungen der SWG-Regelung analysiert und damit die Einkommenseffekte bei den Bauarbeitern quantifiziert werden.

\subsubsection{Einkommenseffekte}

Zur Ermittlung der Einkommenseffekte ist an dieser Stelle nochmals darauf hinzuweisen, daß die im Rahmen der gesetzlichen SWG-Regelung geleisteten Zahlungen in einem Zusammenhang mit der tarifvertraglichen "...Anwartschaft auf Lohnausgleich für einen zusammenhängenden Ausgleichszeitraum, der mindestens die Zeit vom 25. Dezember bis 1. Januar umfaßt..."652, gesehen werden müssen. Dieser als Pauschalbetrag zu zahlende Lohnausgleich, dessen Höhe sich nach dem Bruttostundenverdienst und der Anzahl der auszugleichenden Arbeitsstunden richtet, belastet im Unterschied zum SWG nicht das Budget der BA, da er von den Arbeitgebern des Baugewerbes aufgebracht wird.

Allerdings belastet er - was in diesem Zusammenhang besonders wichtig ist - die wirtschaftspolitischen Zielvorstellungen, wie beispielsweise Verringerung der bauwirtschaftlichen Produktionsschwankungen und Verstärkung der winterlichen Bautätigkeit, erheblich. Denn seit der Einführung dieses - vom Gesetzgeber ausdrücklich geforderten - Lohnausgleichs im Winter 1959/60 haben sich sowohl die Saisonfaktoren der geleisteten Arbeitsstunden von 0,92 (1954-59) auf 0,79 (1986-92) als auch die der Nettoproduktion von 0,95 (1954-59) auf 0,80 (1986-92), des Monats Dezember deutlich reduziert. ${ }^{653}$ Inwieweit diese vom Gesetzgeber "bewußt" oder "unbewußt" in Kauf genommene negative Auswirkung auf die Bauproduktion des Dezembers lediglich Schachtmeister, Poliere und kaufmännische Angestellte sind in der Weihnachtswoche tätig, da sie keine Lohnausgleichszahlungen erhalten - die Einkommenssituation der Bauarbeiter beeinflußt hat, ist Ziel der anschließenden Untersuchung.

Mit Hilfe der folgenden Gegenüberstellung sollen die Einkommenseffekte - bezogen auf den einzelnen Bauarbeiter - quantifiziert werden. Dabei stellt der Verfasser die im Rahmen der gesetzlichen SWG-Regelung und des tarifvertraglichen Lohnausgleichs geleisteten Zahlungen den Lohnausfällen infolge "witterungsbedingter" Ausfallstunden gegenüber.

652 vgl. $\S 83$ AFG und Kap. 2.4.2. Tarifvertragliche Leistungen und Regelungen, S.74-76.

653 vgl. Abbildung 41, S.145 und Abbildung 52, S.151. 
Abbildung: 74

\begin{tabular}{|c|c|c|c|c|c|c|c|c|}
\hline \multicolumn{9}{|c|}{ Binkommenserfekte der SWO-Regelung } \\
\hline \multirow[b]{2}{*}{ Zeitraum } & \multicolumn{4}{|c|}{ Zahlungen an SWG und Lohnausgleich } & \multicolumn{3}{|c|}{ Berechnung des Lohnausfalles } & \multirow[b]{2}{*}{$\begin{array}{c}\text { Ergeb- } \\
\text { nis } 8)\end{array}$} \\
\hline & \begin{tabular}{|c|} 
Baustellenbe- \\
schäftigte
\end{tabular} & $\begin{array}{c}\text { SWG in } \\
\text { Mio.2) }\end{array}$ & \begin{tabular}{|l|} 
SWG je Be- \\
schäntigten
\end{tabular} & $\begin{array}{c}\text { Ausgleich je } \\
\text { Bauarb.4) }\end{array}$ & $\begin{array}{l}\text { Ausfallstd. je } \\
\left.\text { Bauarbeiter }{ }^{5}\right)\end{array}$ & $\begin{array}{c}\text { Eck- } \\
\text { lohn6) }\end{array}$ & $\begin{array}{c}\text { Lohnaus- } \\
\text { fall7) }\end{array}$ & \\
\hline $1961 / 62$ & 1.189 .970 & 384,9 & 323,45 & 172,00 & 184,0 & 3,11 & 572,36 & $-76,90$ \\
\hline $1962 / 63$ & 1.249 .921 & 859,5 & 687,64 & 189,88 & 340,1 & 3,40 & $1.156,23$ & $-278,71$ \\
\hline $1963 / 64$ & 1.342 .623 & 536,2 & 399,37 & 203,83 & 188,9 & 3,57 & 674,37 & $-71,17$ \\
\hline $1964 / 65$ & 1.338 .913 & 492,8 & 368,06 & 220,32 & 163,7 & 3,90 & 638,54 & $-50,16$ \\
\hline $1965 / 66$ & 1.350 .471 & 472,3 & 349,73 & 197,24 & 144,3 & 4,23 & 610,34 & $-63,37$ \\
\hline $1966 / 67$ & 1.196 .475 & 281,4 & 235,19 & 200,41 & 87,2 & 4,45 & 388,18 & 47,42 \\
\hline $1967 / 68$ & 1.196 .459 & 678,4 & 567,01 & 242,11 & 155,2 & 4,60 & 713,85 & 95,27 \\
\hline $1968 / 69$ & 1.213 .114 & 813,0 & 670,18 & 253,62 & 189,9 & 4,76 & 903,88 & 19,92 \\
\hline $1960-68$ & 1.259 .743 & 564,8 & 448,36 & 200,05 & 181,7 & 4,00 & 727,12 & $-78,72$ \\
\hline $1969 / 70$ & .805 & $1.229,7$ & $1.017,29$ & 284,71 & 263,2 & 5,19 & $1.366,19$ & $-64,20$ \\
\hline $1970 / 71$ & 1.244 .392 & 817,7 & 657,11 & 330,16 & 164,3 & 5,91 & 970,88 & 16,39 \\
\hline $1971 / 72$ & 1.223 .760 & 642,7 & 525,18 & 302,46 & 120,5 & 6,38 & 768,50 & 59,14 \\
\hline $1969-71$ & 1.225 .653 & 896,7 & 731,61 & 305,78 & 182,7 & 5,83 & $1.064,27$ & $-26,89$ \\
\hline $1972 / 73$ & 280 & 489,0 & 42 & 6,66 & 87,8 & 6,79 & 596,06 & 200,02 \\
\hline $1973 / 74$ & 1.131 .992 & 554,8 & 490,11 & 428,96 & 104,9 & 7,39 & 775,57 & 143,50 \\
\hline $1974 / 75$ & 965.923 & 386,1 & 399,72 & 460,82 & 79,5 & 8,22 & 653,22 & 207,32 \\
\hline $1975 / 76$ & 921.694 & 683,3 & 741,35 & 547,50 & 150,7 & 8,76 & $1.319,97$ & $-31,12$ \\
\hline $1976 / 7$ & 901.813 & 559,1 & 619,97 & 521,77 & 122,3 & 9,22 & $1.127,44$ & 14,30 \\
\hline $1977 / 78$ & 883.083 & 767,4 & 869,00 & 458,26 & 154,4 & 9,81 & $1.514,20$ & $-186,94$ \\
\hline $1978 / 79$ & 940.723 & $1.590,6$ & $1.690,83$ & 584,71 & 280,9 & 10,87 & $3.053,04$ & $-777,50$ \\
\hline $1979 / 80$ & 982.833 & 936,3 & 952,65 & 746,76 & 151,5 & 11,63 & $1.761,42$ & $-62,01$ \\
\hline $1980 / 81$ & 962.715 & $1.747,0$ & $1.814,66$ & 806,88 & 266,5 & 12,69 & $3.381,51$ & $-759,97$ \\
\hline $1981 / 82$ & 879.114 & $1.380,4$ & $1.570,22$ & 839,10 & 223,7 & 13,20 & $2.952,54$ & $-543,23$ \\
\hline $1982 / 83$ & 822.874 & 593,1 & 720,77 & 740,90 & 103,0 & 13,75 & $1.415,80$ & 45,87 \\
\hline $1983 / 84$ & 838.828 & 684,2 & 815,66 & 632,06 & 105,5 & 14,16 & $1.494,06$ & $-46,34$ \\
\hline $1984 / 85$ & 775.110 & 719,4 & 928,13 & 910,58 & 118,4 & 14,63 & $1.732,81$ & 105,89 \\
\hline $1985 / 86$ & 732.855 & 747,6 & $1.020,12$ & 928,56 & 128,9 & 14,98 & $1.930,27$ & 18,41 \\
\hline $1972-85$ & 925.988 & 845,6 & 913,18 & 643,11 & 148,4 & 11,15 & $1.654,79$ & $-98,51$ \\
\hline $1986 / 87$ & 722.866 & 770,5 & $1.065,90$ & 952,24 & 133,1 & 15,43 & $2.053,02$ & $-34,88$ \\
\hline $1987 / 88$ & 711.450 & 422,9 & 594,42 & 977,74 & 75,8 & 15,91 & $1.206,18$ & 365,98 \\
\hline $1988 / 89$ & 729.091 & 277,5 & 380,61 & 721,48 & 46,6 & 16,48 & 768,20 & 333,89 \\
\hline $1989 / 90$ & 753.350 & 340,1 & 451,45 & 895,83 & 51,8 & 17,02 & 881,10 & 466,18 \\
\hline $1990 / 91$ & 777.558 & 868,9 & $1.117,47$ & $1.113,26$ & 108,7 & 18,47 & $2.007,20$ & 223,53 \\
\hline $1991 / 92$ & 794.823 & 719,7 & 905,48 & $1.184,00$ & 94,3 & 19,76 & $1.863,52$ & 225,96 \\
\hline $1986-92$ & 748.190 & 566,6 & 757,29 & 974,09 & 85,0 & 17,18 & $1.460,82$ & 270,57 \\
\hline
\end{tabular}

Anmerkungen: Aufgrund fehlender Erhebungen in den Schlechtwetterzeiten 1959/60, 1960/61 (SWG-Ausfallstunden nicht erfaßt) und 1992/93 (Lohnausgleich), konnten diese zur Ermittlung der Einkommenseffekte nicht herangezogen werden. Dadurch ändern sich auch die Durchschnitte der Zeiträume 1960-68 bzw. 1986-92, im Vergleich zu denen der Abbildungen 70 und $71 .{ }^{654}$

\section{Erläuterungen zur Abbildung 74:}

1) Baustellenbeschäftigte entsprechend Abbildung 71 .

2) Insgesamt gezahltes Schlechtwettergeld (SWG) entsprechend Abbildung 70.

654 vgl. auch Abbildung 70 und 71. 
3) SWG je Baustellenbeschäftigten in DM/Schlechtwetterzeit, berechnet aus "2)" dividiert durch "1)".

4) Lohnausgleichsbetrag je Bauarbeiter entsprechend Abbildung 71.

5) Ausfallstunden je Bauarbeiter und Schlechtwetterzeit entsprechend Abbildung 71.

6) Ecklohn ist der Tarifstundenlohn des Spezialbaufacharbeiters gemäß Berufsgruppe III. Der Ecklohn bildet die Lohngrundlage für die Regelung der Löhne und Ausbildungsvergütungen im Baugewerbe. Er wird von den Tarifpartnern festgesetzt. ${ }^{655}$

7) Lohnausfall je Bauarbeiter in DM/Schlechtwetterzeit, berechnet aus "5)" multipliziert mit "6)".

8) Ergebnis: Einkommenseffekt je Bauarbeiter in DM/Schlechtwetterzeit, berechnet aus den Zahlungen an SWG und Lohnausgleich, abzüglich des ermittelten Lohnausfalles, d.h. "3)"+"4)"-"7)".

Die Ergebnisse der Abbildung 74 zeigen, daß die Schwankungen in den Bauarbeitereinkommen tendenziell von den angefallenen SWG-Ausfallstunden abhängig sind. Das heißt Schlechtwetterzeiten mit hohen (geringen) Ausfallstunden haben einen im Ergebnis negativen (positiven) Einkommenseffekt zur Folge.

Betrachtet man zunächst den Zeitraum 1960-68, so wird die eben gemachte Aussage prinzipiell bestätigt. In der Schlechtwetterzeit 1962/63, die mit 35 Schlechtwettertagen den mit Abstand ungünstigsten Witterungsverlauf seit Einführung der SWG-Regelung aufweist, ${ }^{656}$ ist auch das negativste Einkommensergebnis (-278,71 DM) dieses Förderungszeitraumes zu verzeichnen. Vergleicht man allerdings die im Witterungsverlauf bzw. in den Ausfallstunden je Bauarbeiter ähnlichen Schlechtwetterzeiten 1961/62 und 1963-66 mit denen von 1967-69,657 so ist eine Änderung von negativen zu positiven Einkommenseffekten festzustellen.

Dieser Trend zu positiven Ergebnissen gegen Ende des Förderungszeitraumes 196068 bedeutet, daß die Zahlungen an SWG und Lohnausgleich den tatsächlichen Lohnausfall übersteigen. D.h. das Bauarbeitereinkommen liegt bei Inanspruchnahme von SWG über dem normalen Arbeitslohn. Erklären läßt sich dieser Anstieg mit der am 6. Dezember 1967 beschlossenen Erhöhung des SWG, die bis zum Inkraftreten des

655 vgl. Zentralverband des Deutschen Baugewerbes (Hrsg.), Entwicklung des Bundesecklohnes, S.311, in: Jahrbuch des Deutschen Baugewerbes, Baujahr '92, Bonn, 1993 und Karthaus/Müller, Bundesrahmentarifvertrag für das Baugewerbe, Text und Erlauterung, S.156.

656 vgl. Kap. 3.1.4. Witterungsbedingungen, S.103-104.

657 vgl. Abbildung 11, S. 104 und Abbildung 74, S.208. 
Haushaltsstrukturgesetzes am 1. Januar 1976 einen Zuschlag von 0,30 DM58 für jede Ausfallstunde gewährte, so daß das SWG insgesamt stets über dem Arbeitslosengeld lag. Dieser Zuschlag, der seit dem 1. Januar 1968 bestand, sollte die erhöhten finanziellen Belastungen (Fahrtkosten u.ä.) ausgleichen, die dem Bauarbeiter durch seine ständige Arbeitsbereitschaft auf der Baustelle entstanden. ${ }^{659}$ Die folgende Berechnung verdeutlicht die eben beschriebene Entwicklung.

Abbildung: 75

\begin{tabular}{|c|c|c|c|c|c|}
\hline \multicolumn{2}{|c|}{ Entwicklung von SW ie A asfallstunde zum Ecklohn in \% } \\
\hline Zeitraum & $\begin{array}{c}\text { SWG je Aus- } \\
\text { fallstunde1) }\end{array}$ & $\begin{array}{c}\text { in \% vom } \\
\text { Ecklohn2) }\end{array}$ & Zeitraum & $\begin{array}{c}\text { SWG je Aus- } \\
\text { fallstunde1) }\end{array}$ & $\begin{array}{c}\text { in \% vom } \\
\text { Ecklohn') }\end{array}$ \\
\hline $1961 / 62$ & 1,76 & 56,5 & $1967 / 68$ & 3,65 & 79,4 \\
$1962 / 63$ & 2,02 & 59,5 & $1968 / 69$ & 3,53 & 74,1 \\
$1963 / 64$ & 2,11 & 59,2 & $1969 / 70$ & 3,86 & 74,5 \\
$1964 / 65$ & 2,25 & 57,6 & $1970 / 71$ & 4,00 & 67,7 \\
$1965 / 66$ & 2,42 & 57,3 & $1971 / 72$ & 4,36 & 68,3 \\
$1966 / 67$ & 2,70 & 60,6 & $1972 / 73$ & 4,55 & 67,0 \\
\hline
\end{tabular}

1) Berechnet aus dem Verhältnis von "3)" zu "5)" der Abbildung 74.

2) Berechnet aus dem Verhältnis von SWG je Ausfallstunde (Abbildung 75) und Ecklohn (Abbildung 74).

Es zeigt sich, daß sich seit der Einführung des Zuschlages zum SWG 1967/68 der Abstand zwischen Tarifstundenlohn (Ecklohn) und SWG spürbar verringert hat. Der Anteil des SWG von etwa $60 \%$ des Ecklohnes vor der Erhöhung ist auf fast $80 \%$ in der Schlechtwetterzeit 1967/68 gestiegen. In den folgenden Jahren ist der erhöhte Anteil des SWG am Tarifstundenlohn mit ähnlichen Ergebnissen zu beobachten. ${ }^{660}$ Damit erklären sich die fortgesetzten positiven Einkommenseffekte von 1969-71661 und zu Beginn des Förderungszeitraumes 1972-85. Zu dieser Erkenntnis kommt auch die BA, wenn sie betont, daß es "...insbesondere seit der am 6. Dezember 1967 beschlossenen Erhöhung des SWG vorkommen konnte, daß Bauarbeiter, die SWG in Anspruch nahmen, ein höheres Einkommen als ihren üblichen Vollohn erzielten, und das ohne Schwarzarbeit." 662

$658 \S 86$ Abs. 1 AFG.

659 vgl. Deutscher Bundestag, 5. Wahlperiode, Stenographischer Bericht der 130. Sitzung vom 27. Oktober 1967, S.6593ff.

660 vgl. Abbildung 75: 1968/69 bis 1972/73.

661 Anmerkung: Eine Ausnahme ist die Schlechtwetterzeit 1969/70. Das negative Ergebnis von 64,20 DM ist auf den extrem ungünstigen Witterungsverlauf mit 263,2 Ausfallstunden zurückzuführen. Dennoch fällt dieser negative Einkommenseffekt, aufgrund des Zuschlages zum SWG, verhältnismäßig gering aus, vgl. Abbildung 74, S.208. 
Die Höhe der hier aufgezeigten finanziellen Zuwendungen im Rahmen der SWG-Regelung, d.h. insbesondere in den Zeiträumen 1960-68 und 1969-71, in denen dem Bauarbeiter keinerlei produktionsorientierte finanzielle Anreize geboten wurden, trägt sicherlich nicht dazu bei, die Arbeitsbereitschaft der Bauarbeiter während der für sie unangenehmen Witterungszeit zu steigern. Ähnlich charakterisiert Olgred Aule die SWG-Regelung. Er geht allerdings einen Schritt weiter, wenn er sagt, es ist eine "...wirtschaftliche und soziale Anomalie, daß viele Arbeiter den Empfang von Unterstützung der Arbeit vorziehen. Der Fehler liegt nicht in der Mentalität der Arbeiter, sondern in den sozialpolitischen Maßnahmen."663

Die Ausführungen bezüglich der Einkommenseffekte in den Förderungszeiträumen von 1960-68 und 1969-71 unterstützen die mehrfach aufgezeigte Erkenntnis, daß vor allem durch die SWG-Regelung in der Zeit von 1960 bis 1971 die Saisonschwankungen im Produktionsbereich verstärkt wurden. ${ }^{664}$ Im darauffolgenden Förderungszeitraum von 1972-85 wurden dem Bauarbeiter durch das Wintergeld erstmalig nennenswerte produktionsorientierte Zahlungen gewährt, ${ }^{665}$ die den in der Abbildung 74 ermittelten Einkommenseffekten hinzuzurechnen sind. Dadurch relativieren sich die besonders negativen Einkommenseffekte in den Schlechtwetterzeiten 1978/79, 1980/81 und 1981/82 des Förderungszeitraumes 1972-85. Diese sind größtenteils anhand der ungünstigen Witterungsverläufe zu erklären. ${ }^{666}$ Lediglich die Schlechtwetterzeit 1980/81 stellt sich mit 15 Schlechtwettertagen - im Vergleich zu 20 (1978/79) und 21 (1981/82) - etwas günstiger dar. ${ }^{667}$

662 vgl. Sabel, A., (Präsident der BA), Zur Erhöhung des Schlechtwettergeldes, in: Arbeit, Beruf und Arbeitslosenhilfe, 19.Jg., Heft 1, 1968, S.20.

663 vgl. Aule, O., Was hălt der Bauarbeiter vom Winterbau?, in: Das Baugewerbe, 56.Jg., Nr.9, 1972, S.20ff.

664 vgl. ausführlich Kap. 3.3.2.3. Wirkungen auf die Verstetigung der Bautätigkeit, S.159ff. und auch Kap. 3.4. Zusammenfassung der Ergebnisse der Wirkungsanalyse, S. 189.

665 Anmerkung: Auf die Förderung der Arbeitnehmer des Baugewerbes nach §143c AVAVG bestand kein Rechtsanspruch. Außerdem handelte es sich hier um vergleichsweise geringe Beträge, weil nur Zuschüsse zur Beschaffung von Schutzkleidung und zu Fahrtkosten gewährt wurden, vgl. auch Anhang I, S.243.

666 vgl. Abbildung 13, S. 105

667 Anmerkung: Der Versuch, die hohe Ausfallstundenzahl von 266,5 in 1980/81 - trotz eines im Ergebnis etwas günstigeren Witterungsverlauf - mit der starken Rezession zu Beginn der 80er Jahre (Rückgang des Bauvolumens um 4,7\%) zu erklären, ist nicht nachvollziehbar. Zumal schon in der folgenden Schlechtwetterzeit 1981/82 der Witterungsverlauf deutlich ungünstiger ist, die Rezession anhält aber die Ausfallstunden auf 223,7 gesunken sind. Ähnliches gilt auch für die Schlechtwetterzeit 1985/86; vgl. Kap. 2.1.3. Baukonjunkturelle Entwicklung und Prognose, S.42ff. und Abbildungen 7 und 74. 
Der letzte Förderungszeitraum 1986-92 verzeichnet die geringsten Ausfallstunden je Bauarbeiter und daher auch die höchsten positiven Einkommenseffekte. Insgesamt wird ein durchschnittliches Ergebnis von 270,57 DM erreicht. Der negative Einkommenseffekt von 34,88 DM in der Schlechtwetterzeit 1986/87 ist wiederum mit einem äußerst ungünstigen Witterungsverlauf dieses Winters - 23 Schlechtwettertage - zu begründen. ${ }^{668}$

Faßt man die Ausführungen bezüglich der Einkommenseffekte an dieser Stelle zusammen, so läßt sich festhalten, daß die Zahlungen an SWG und Lohnausgleich den durch witterungsbedingte Ausfallstunden entstandenen Lohnausfall ${ }^{669}$ prinzipiell ersetzen. Die Ausnahmen bilden hier nur Schlechtwetterzeiten mit extrem ungünstigen Witterungsverläufen. ${ }^{670}$ Neben den bereits geschilderten ist allerdings noch ein weiterer Grund für die Reduzierung der negativen Einkommenseffekte zu benennen. Dieser liegt in der Art der Berechnung des SWG. Als Berechnungsgrundlage wird das durchschnittliche Arbeitsentgelt der letzten dreizehn Wochen vor dem ersten Arbeitsausfall herangezogen. ${ }^{671} \mathrm{Da}$ dieses Arbeitsentgelt aufgrund der im Herbst üblichen Überstunden - wie die verschiedenen Saisonfaktoren der Arbeitsstunden, der Nettoproduktion und der Bruttolohnsumme in den Monate September, Oktober und November bewei$\operatorname{sen}^{672}$ - überdurchschnittlich hoch ist, trägt es ebenfalls dazu bei, die Bauarbeitereinkommen im Rahmen der SWG-Regelung zu verbessern.

Die soeben beschriebene Berechnungsmethode bezüglich des SWG besaß bereits in der förderungsfreien Zeit von 1954-1959 Gültigkeit. ${ }^{673}$ In dem auf diese Weise bemessenem und entsprechend hohem Arbeitslosengeld sieht Semler die "...Förderung der Nichtarbeit"674, da der Bauarbeiter in Kenntnis seines geringen Verdienstes - als Folge der nicht entlohnten Ausfallstunden während der Schlechtwetterzeit - seine Entlassung einforderte.

668 vgl. Abbildung 14, S. 106.

669 Hinweis: Bei bestehendem Arbeitsverhältnis des Bauarbeiters entfällt der Lohnanspruch für ausgefallene Arbeitsstunden infolge ungünstiger Witterung, vgl. ausführlich Kap. 1.2.1. Die sozialpolitische Sichtweise, S.14.

670 vgl. Abbildung 74, S.208.

671 vgl. ausführlich Anhang III, S.253ff.

672 vgl. Abbildung 41, S.145, Abbildung 52, S. 151 und Abbildung 69, S. 180.

$673 \S 90$ AVAVG in der Fassung vom 3.4.1957.

674 vgl. Semler, R., Laßt uns nicht von Winterbau sprechen, S.478. 


\subsubsection{Fiskalische Effekte}

Nachdem die auf den einzelnen Bauarbeiter bezogenen Einkommenseffekte der SWGRegelung von 1960 bis 1992 quantifiziert worden sind, soll im Rahmen dieses Abschnitts untersucht werden, welche Wirkungen die Förderungsmaßnahmen in finanzpolitischer Hinsicht gehabt haben. Zwar stehen die mit Hilfe der Maßnahmen zur Förderung der ganzjährigen Beschäftigung in der Bauwirtschaft verfolgten finanzpolitischen Absichten in ihrer Bedeutung hinter den sozial- und wirtschaftspolitischen Zielsetzungen zurück; sie dürfen jedoch keineswegs vernachlässigt werden. 675

In diesem Zusammenhang forderte vor allem die Bundesanstalt für Arbeit, von der die wirkungsvolle Durchführung der Förderungsmaßnahmen weitgehend abhängt, ${ }^{676}$ eine für sie günstige finanzielle Entwicklung. So hat sie immer wieder darauf hingewiesen, daß nicht nur der Aufwand, den sie für die Bauwirtschaft zu leisten habe, entschieden zu hoch sei, sondern daß auch die Leistungen "...dem Baugewerbe in einem Maße zufließen, das in keinem Verhältnis ... zur Höhe seiner Beitragsleistung zur Arbeitslosenversicherung steht." 677 Vor diesem Hintergrund befassen sich die folgenden Ausführungen primär mit den zwei Aspekten:

- Entwicklung des Aufwandes der BA für die Bauwirtschaft bzw. Entwicklung der Relation zwischen Beitragszahlungen und Leistungen der BA und der Bauwirtschaft.

- Mögliche Auswirkungen auf das Steueraufkommen. ${ }^{678}$

675 vgl. Kap. 3.2.1. Primärkriterien, S.114-115.

676 Anmerkung: Bezüglich der Durchführung der Förderungsmaßnahmen ist zwischen der SWGRegelung und der PWF (seit der Winterbaunovelle 1972) zu unterscheiden. Die Leistungen im Rahmen der SWG-Regelung (SWG und Beitragszuschüsse zur Rentenversicherung der SWGBezieher) werden von der BA aus den allgemeinen Beitrăgen zur Arbeitslosenversicherung gewährt. Die Mittel für die Leistungen der PWF (WG, IKZ und MKZ) werden durch die Winterbau-Umlage, d.h. ausschließlich von den Betrieben der Bauwirtschaft aufgebracht (\$186a AFG und die hierzu ergangene Winterbauumlageverordnung). Der Einzug dieser Mittel für die PWF geschieht über die Sozialkassen der Bauwirtschaft.

677 vgl. BAVAV (Presseinformation): Schlechtwettergeldregelung reformbedürtig?, in Bau-Markt, 62.Jg., Nr.8, 1963, S.359.

678 Hinweis: Eine exakte Quantifizierung der Steuerausfalle und einnahmen im Zusammenhang mit den Winterbauförderungsmaßnahmen stöBt auf erhebliche Schwierigkeiten, daher sollen diese hier nur in Ansätzen, d.h. in überschlägigen Berechnungen, bestimmt werden; zu den Schwierigkeiten vgl. auch Braun, G., Der Wohnungsbau im Winter. Die Bilanz der seit sechs Jahren in Berlin anhaltenden Winterbauförderung im Wohnungsbau, in: Das Baugewerbe, 45.Jg., Nr.3, 1965, S.142ff. 
Dem ersten Aspekt mißt die BA vor allem deshalb eine große Bedeutung bei, weil mit einer Verringerung des Aufwandes für die Bauwirtschaft eine erhebliche Entlastung ihres Haushaltes verbunden wäre. Die folgende Abbildung 76 zeigt daher die anteilige Entwicklung der Ausgaben der BA, getrennt nach Wirtschaftszweigen, für den Zeitraum von 1955 bis 1975 auf. ${ }^{679}$

Abbildung: 76

\begin{tabular}{|c|c|c|c|c|c|}
\hline \multicolumn{6}{|c|}{ 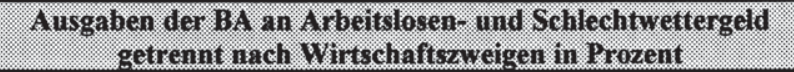 } \\
\hline $\begin{array}{l}\text { Zeitraum } \\
(1.7 .-30.6 .)\end{array}$ & Baugewerbe & \begin{tabular}{|c|} 
Land- und \\
Forstwirtschaft \\
\end{tabular} & $\begin{array}{l}\text { Energie- } \\
\text { wirtschaft }\end{array}$ & \begin{tabular}{|c|}
$\begin{array}{c}\text { Verarbeitendes } \\
\text { Gewerbe }\end{array}$ \\
\end{tabular} & $\begin{array}{c}\text { Dienst- } \\
\text { leistungen }\end{array}$ \\
\hline $1955 / 56$ & 42,1 & 4,7 & 6,7 & 24,3 & 22,2 \\
\hline $1956 / 57$ & 38,3 & 4,2 & 5,8 & 27,5 & 24,2 \\
\hline $1957 / 58$ & 43,8 & 4,6 & 6,3 & 24,4 & 20,9 \\
\hline $1958 / 59$ & 38,3 & 4,3 & 7,2 & 27,7 & 22,5 \\
\hline $1959 / 60$ & 41,7 & 5,8 & 8,5 & 20,6 & 23,4 \\
\hline $1954-1959$ & 40,8 & 4,7 & 6,9 & 24,9 & 22,6 \\
\hline $1960 / 61$ & 43,6 & 5,4 & 6,2 & 19,8 & 25,0 \\
\hline $1961 / 62$ & 62,2 & 4,0 & 4,8 & 14,5 & 14,5 \\
\hline $1962 / 63$ & 73,8 & 3,7 & 4,4 & 9,6 & 8,5 \\
\hline $1963 / 64$ & 66,9 & 3,1 & 4,5 & 13,6 & 11,9 \\
\hline $1964 / 65$ & 67,0 & 4,1 & 4,2 & 12,6 & 12,1 \\
\hline $1965 / 66$ & 67,9 & 3,2 & 4,4 & 13,1 & 11,4 \\
\hline $1966 / 67$ & 46,1 & 3,1 & 6,3 & 30,5 & 14,0 \\
\hline $1967 / 68$ & 47,6 & 2,9 & 6,7 & 28,3 & 14,5 \\
\hline $1968 / 69$ & 65,1 & 3,3 & 5,9 & 13,8 & 11,9 \\
\hline $1960-1968$ & 60,0 & 3,6 & 5,3 & 17,3 & 13,8 \\
\hline $1969 / 70$ & 74,5 & 3,0 & 3,4 & 9,3 & 9,8 \\
\hline $1970 / 71$ & 63,7 & 2,7 & 3,6 & 16,5 & 13,5 \\
\hline $1971 / 72$ & 48,5 & 2,8 & 4,2 & 26,8 & 17,7 \\
\hline $1969-1971$ & 62,2 & 2,8 & 3,7 & 17,5 & 13,7 \\
\hline $1972 / 73$ & 38,9 & 3,0 & 2,7 & 32,6 & 22,8 \\
\hline $1973 / 74$ & 37,8 & 1,8 & 1,5 & 34,3 & 24,6 \\
\hline $1974 / 75$ & 27,3 & 1,3 & 1,1 & 38,0 & 32,3 \\
\hline $1972-1975$ & 34,7 & 2,0 & 1,8 & 35,0 & 26,6 \\
\hline
\end{tabular}

Quelle: Bundesanstalt für Arbeit (Hrsg.), ANBA, Sondernummer: Arbeitsstatistik 1971 - Jahreszahlen, S.289 und ANBA, Sondernummer: Arbeitsstatistik 1975 Jahreszahlen, S.234, Tabelle 22.

Die Entwicklung der Ausgabenanteile in den einzelnen Förderungszeiträumen läßt folgendes erkennen:

679 Hinweis: Eine entsprechende Gegenüberstellung der Ausgaben der BA getrennt nach Wirtschaftszweigen für den Zeitraum 1975 bis 1992, ist nach Auskunft der BA aufgrund der Umstellung in der Erhebung nicht verfuigbar. 
1955-59: Mit einem Anteil von durchschnittlich 40,8\% an den Ausgaben für Arbeitslosen- und Schlechtwettergeld während des förderungsfreien Zeitraumes stellt das Baugewerbe für die BA die weitaus größte finanzielle Belastung dar. Selbst das verarbeitende Gewerbe, in dem weitaus mehr Menschen beschäftigt waren, erreichte nur einen Anteil von durchschnittlich 24,9\% an den Ausgaben der BA.

1960-68: Mit Einführung der Maßnahmen zur Förderung der ganzjährigen Beschäftigung in der Bauwirtschaft im Winter 1959/60 ist der von der BA zu tragende Aufwand für das Baugewerbe nicht geringer geworden, sondern in der Regel sowohl absolut als auch relativ (d.h. in Prozent der Gesamtausgaben der BA an Arbeitslosen- und Schlechtwettergeld) gestiegen. Dabei sind die Leistungen an Bauherren, Arbeitgeber und Arbeitnehmer, die von der BA im Rahmen der Förderungsmaßnahmen zur ganzjährigen Beschäftigung zusätzlich zum SWG erbrachte wurden, ${ }^{680}$ noch nicht berücksichtigt. Ihre durchschnittliche Höhe beträgt 44,2 Mio. DM (MKZ) bzw. 12,4 Mio. DM (IKZ). ${ }^{681}$

1969-71: Das 1969 in Kraft getretene AFG konnte auch mit der Einführung der PWF keine Reduzierung des Aufwandes für die Bauwirtschaft herbeiführen. Im Gegenteil stiegen die Ausgaben für die Bauwirtschaft im Durchschnitt der Jahre $1969-1971$ auf $62,2 \%$.

1972-75: Erst mit Inkraftreten der PWF im Rahmen der Winterbaunovelle von 1972 reduzieren sich die Ausgaben für das Baugewerbe deutlich. So schrumpt der Anteil in den drei Jahren von 1972 bis 1975 auf durchschnittlich 34,7\%. Dies ist der bei weitem niedrigste Wert, der während des gesamten Beobachtungszeitraumes überhaupt zu verzeichnen war.

Ein derartiger Vergleich, der die Ausgaben kommentarlos einander gegenüberstellt, läßt allerdings keine abgesicherte Aussage zu. ${ }^{682}$ Daher ist es zunächst erforderlich, die entscheidenden Einflußgrößen - dies sind vor allem die Witterungsverhältnisse und die Beschäftigtenzahlen - bezüglich der Höhe des Arbeitslosen- und Schlechtwettergeldes zu diskutieren, bevor auf die Entwicklung der Ausgaben der BA in den einzelnen Förderungszeiträumen näher eingegangen werden kann.

680 vgl. Unterabschnitt C des 4. Abschnittes des AVAVG ( $\$$ 143a bis c) und auch Anhang I, S.243-244.

681 vgl. Abbildung 70, S.194.

682 vgl. auch Kap. 4.1.1. Die SWG-Regelung, S.197. 
Wie bereits mehrfach erwähnt, weisen die Witterungserscheinungen - gemessen an den durchschnittlichen Schlechtwettertagen ${ }^{683}$ - im Zeitablauf nur geringfügige Unterschiede auf, so daß auf einen Korrekturfaktor bezüglich einzelner Zeiträume verzichtet werden kann. Der Vergleich der Witterungsverläufe mit den Ausgaben für das Baugewerbe zeigt eine direkte Abhängigkeit, d.h. hohe prozentuale Ausgabenanteile (1962/63: 73,8\%, 1969/70: 74,5\%, und 1970/71: 63,7\%) fallen mit Zeiträumen ungünstiger Witterungsverläufe (1962/63: 35, 1969/70: 21 und 1970/71: 17 Schlechtwettertage $)^{684}$ zusammen. Für den umgekehrten Fall - d.h. geringer Ausgabenanteil für das Baugewerbe und günstiger Witterungsverlauf - gilt der Zusammenhang entsprechend, wie beispielsweise die Zeiträume 1960/61, 1966/67 und 1967/68 sowie die drei Jahre nach Einführung der Winterbaunovelle beweisen. ${ }^{685}$

Aufgrund dieser beschriebenen Abhängigkeit zwischen Witterungsverlauf und Ausgabenanteil liegt die Vermutung nahe, daß die SWG-Regelung einen entscheidenden Einfluß auf den Aufwand der BA für das Baugewerbe ausübt bzw. ausgeübt hat. Inwieweit sich diese Vermutung bestätigt, soll anhand des Einflusses der Beschäftigtenzahlen auf die Entwicklung der Ausgabenanteile für die Bauwirtschaft in der Zeit von 1955 bis 1975 untersucht werden. Eine derartige Untersuchung der Beschäftigtenentwicklung muß sowohl die gesamten Baustellenbeschäftigten als auch deren Anteil an den Erwerbstätigen in der Gesamtwirtschaft berücksichtigen. ${ }^{686}$

Wie die Entwicklung der Baustellenbeschäftigten bereits aufgezeigt hat, konnte hier eine kontinuierliche Reduzierung seit Einführung der SWG-Regelung im Durchschnitt der Förderungszeiträume - mit Ausnahme einzelner Jahresergebnisse - festgestellt werden. ${ }^{687}$ Für den förderungsfreien Zeitraum von 1954-59 dagegen liegen die durchschnittlichen Beschäftigtenzahlen in den Monaten November bis März mit etwa 1.000.000 Baustellenbeschäftigten ${ }^{688}$ deutlich unter dem Durchschnittswert des ersten Förderungszeitraumes 1960-68 (1.246.058). Diese Beschäftigtenzahl sagt allerdings wenig aus, da in der förderungsfreien Zeit noch kein Anspruch auf SWG bestand, so

\footnotetext{
683 vgl. Abbildung 15, S.106.

684 vgl. Abbildungen 11 und 12, S.104.

685 vgl. Abbildung 11, S.104, Abbildung 13, S. 105 und Abbildung 76, S.214.

686 vgl. Kap. 2.1.1. Die Bauwirtschaft im Rahmen der Gesamtwirtschaft, S.37ff.

687 vgl. Kap. 4.1.1. Die SWG-Regelung, Abbildung 71, S.198 und S.199.

688 Hinweis: Berechnet aus dem Durchschnitt der Beschäftigten für die Monate Dezember bis März (888.954) und dem Novemberdurchschnitt der Beschäftigten für 1954-59 (1.171.592), vgl. Abbildung 29, S.128 und Abbildung 54, S.162.
} 
daß der Ausgabenanteil für das Baugewerbe von durchschnittlich 40,8\% im Zeitraum 1954-59 mit der hohen Saisonarbeitslosigkeit und entsprechenden Arbeitslosengeldzahlungen erklärt werden muß.689

Betrachtet man jetzt die Entwicklung der in der Bauwirtschaft Beschäftigten in Abhängigkeit von den Erwerbstätigen der Gesamtwirtschaft, so lassen sich für den Zeitraum von 1960 bis 1975 keine spürbaren Veränderungen erkennen. Insgesamt schwankt das Verhältnis von Erwerbstätigen im Baugewerbe zu denen in der Gesamtwirtschaft zwischen 7,5\% im Jahr 1960 und 8,7\% im Jahr 1970. Dieser leichte Anstieg um 1,2 Prozentpunkte ist jedoch bis 1976 wieder zurückgegangen. Die Ergebnisse relativieren die Ausgabenanteile für das Baugewerbe von rund $60 \%$ im Zeitraum 1960 bis 1971 jedoch nur geringfügig, da mit einem Anstieg der Bau-Beschäftigten an den Gesamtbeschäftigten von 1,2 Prozentpunkten nicht eine Aufwandserhöhung von etwa $20 \%$ erklärt werden kann. Entsprechendes gilt für den Rückgang der Ausgaben für das Baugewerbe in der Zeit von 1972 bis 1975.

$\mathrm{Faßt}$ man die gemachten Ausführungen an dieser Stelle zusammen, so ist festzuhalten, $\mathrm{da} ß$ der gestiegene Aufwand fur das Baugewerbe - so wie er sich in den prozentualen Ausgaben der BA an Arbeitslosen- und Schlechtwettergeld getrennt nach Wirtschaftszweigen der Abbildung 76 darstellt - mit Einführung der Förderungsmaßnahmen im Winter 1959/60 weder auf die Entwicklung der Beschäftigten- bzw. Arbeitslosenzahlen ${ }^{690}$ noch auf die Witterungsverhältnisse zurückgeführt werden kann.

Die Möglichkeit, daß überproportionale Tariflohnerhöhungen für das Baugewerbe im Vergleich $\mathrm{zu}$ anderen Wirtschaftszweigen die Steigerungen bei Arbeitslosen- und Schlechtwettergeldanteilen - beide hängen unmittelbar von der jeweiligen Lohnhöhe ab - hervorgerufen haben, kann ebenfalls ausgeschlossen werden, da die Entwicklung der Bruttostundenverdienste von "Gesamter Industrie" und "Bauwirtschaft", in der Beobachtungszeit keine nennenswerten Unterschiede aufweist. ${ }^{691}$

689 vgl. ausführlich Kap. 3.3.1.1. Wirkungen auf die Arbeitslosenzahlen, S.117ff.

690 Das Problem der Saisonarbeitslosigkeit wurde mit Einführung der Förderungsmaßnahmen gelöst. So ist beispielsweise die absolute Zahl der Arbeitslosigkeit von durchschnittlich 650.000 Bauarbeitslosen im Zeitraum 1954-59 auf durchschnittlich 120.000 Arbeitslose in den Förderungszeitrăumen zuruckgegangen, vgl. hierzu Kap. 3.3.1.1. Wirkungen auf die Arbeitslosenzahlen, S.127-128.

691 vgl. Die Deutsche Bauwirtschaft (Hrsg.), Baustatistisches Jahrbuch 1992, Arbeiterverdienste und Arbeitszeit, S.49. 
Es bestätigt sich die Vermutung, daß mit der Einführung der SWG-Regelung im Winter 1959/60 der Aufwand der BA für das Baugewerbe erheblich gestiegen ist und sogar "...weit über das hinausging, was der SWG-Regelung ursprünglich zugedacht war."692 Die maßgeblichen Ursachen für diesen Anstieg der Ausgaben im Baugewerbe sind bereits in den vorangegangenen Kapiteln diskutiert worden. Beispielhaft aufgeführt werden hier nochmals:

- die am 6. Dezember 1967 beschlossene Erhöhung des SWG, damit lag das SWG über dem Arbeitslosengeld,

- die Berechnungsmethode bezüglich des SWG bzw. Arbeitslosengeldes, d.h. als Berechnungsgrundlage wird das überdurchschnittlich hohe Arbeitsentgelt der letzten dreizehn Wochen vor dem Arbeitsausfall herangezogen,

- die kontraproduktive Wirkung der SWG-Regelung.

Die wirklich positiven Effekte im Rahmen der Winterbauförderungsmaßnahmen gingen vor allem von der Winterbaunovelle 1972 aus. Diese Tatsache scheint sich auch bei den Aufwendungen furr die Bauwirtschaft zu bestätigen, die mit der Einführung dieser produktionsorientierten Förderungsmaßnahmen deutlich reduziert worden sind und mit durchschnittlich $34,7 \%$ den niedrigsten prozentualen Aufwandsanteil des gesamten Beobachtungszeitraumes erreichten. ${ }^{693}$

Mit der PWF von 1972 sollte die Bauwirtschaft an den Kosten der Förderungsmaßnahmen zur ganzjährigen Beschäftigung beteiligt werden. Als Instrument wurde die sogenannte Winterbau-Umlage (WB-Umlage) eingeführt, die von den Betrieben des Baugewerbes in Höhe eines Prozentsatzes der Bruttolohnsumme zu entrichten ist. ${ }^{694}$ Damit kam man insbesondere der immer wieder gestellten Forderung nach, die Relation zwischen Beitragszahlungen und Leistungen der BA und der Bauwirtschaft zu verbessern.

Inwieweit die geleisteten Zahlungen der Baubetriebe im Rahmen der Winterbau-Umlage tatsächlich ausreichten, um die Ausgaben für WG, MKZ und IKZ zu finanzie-

692 vgl. Sabel, A., Winterbau und Schlechtwettergeld aus der Sicht der Bundesanstalt für Arbeitsvermittlung und Arbeitslosenversicherung, S.2797.

693 vgl. Abbildung 76, S.214.

694 vgl. auch Anhang III, S.255. 
ren, ${ }^{695}$ soll die folgende Gegenüberstellung der Einnahmen und Ausgaben aus der Winterbau-Umlage aufzeigen. ${ }^{696}$

Abbildung: 77

\begin{tabular}{|c|c|c|c|c|c|}
\hline \multicolumn{6}{|c|}{ 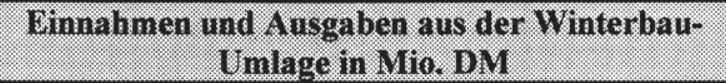 } \\
\hline \multirow[b]{2}{*}{ Zeitraum } & \multirow{2}{*}{$\begin{array}{c}\text { Einnahmen } \\
\text { WB- } \\
\text { Umlage }\end{array}$} & \multicolumn{3}{|c|}{ Ausgaben } & \multirow[b]{2}{*}{$\begin{array}{c}\text { Saldo pro } \\
\text { Jahr1) }^{-}\end{array}$} \\
\hline & & WG & MKZ & IKZ & \\
\hline $1971 / 72$ & 282,5 & & 14,2 & 48,6 & 219,7 \\
\hline $1972 / 73$ & $1.110,0$ & 777,6 & 46,8 & 87,2 & 198,4 \\
\hline $1973 / 74$ & 931,2 & 789,7 & 64,3 & 23,9 & 53,3 \\
\hline $1974 / 75$ & 821,7 & 657,2 & 51,7 & 16,2 & 96,6 \\
\hline $1975 / 76$ & 774,8 & 514,1 & 49,9 & 19,7 & 191,1 \\
\hline $1976 / 77$ & 754,3 & 702,1 & 67,1 & 21,3 & $-36,2$ \\
\hline $1977 / 78$ & 729,5 & 650,5 & 63,4 & 28,6 & $-13,0$ \\
\hline $1978 / 79$ & 786,4 & 504,0 & 62,0 & 40,2 & 180,2 \\
\hline $1979 / 80$ & 906,1 & 857,3 & 87,8 & 41,7 & $-80,7$ \\
\hline $1980 / 81$ & 880,5 & 670,3 & 83,2 & 39,9 & 87,1 \\
\hline $1981 / 82$ & 848,4 & 614,2 & 220,4 & 38,1 & $-24,3$ \\
\hline $1982 / 83$ & 873,6 & 639,9 & 282,1 & 39,0 & $-87,4$ \\
\hline $1983 / 84$ & 879,9 & 652,3 & 242,9 & 47,9 & $-63,2$ \\
\hline $1984 / 85$ & 808,6 & 486,6 & 160,6 & 27,2 & 134,2 \\
\hline $1985 / 86$ & 808,3 & 467,6 & 151,8 & 35,8 & 153,1 \\
\hline $1972-85$ & 813,1 & 598,9 & 109,9 & 37,0 & 67,3 \\
\hline $1986 / 87$ & 622,8 & 446,8 & 6,8 & 10,7 & 158,5 \\
\hline $1987 / 88$ & 590,8 & 569,1 & 0,6 & 2,9 & 18,2 \\
\hline $1988 / 89$ & 621,3 & 656,4 & 0,8 & 0,2 & $-36,1$ \\
\hline $1989 / 90$ & 682,4 & 691,9 & 0,2 & 0,3 & $-10,0$ \\
\hline $1990 / 91$ & 817,4 & 611,5 & 0,3 & 0,1 & 205,5 \\
\hline $1991 / 92$ & $1.022,2$ & 983,4 & 0,7 & 26,9 & 11,2 \\
\hline $1992 / 93$ & $1.099,7$ & $1.010,5$ & 0,4 & 69,3 & 19,5 \\
\hline $1986-92$ & 779,5 & 709,9 & 1,4 & 15,8 & 52,4 \\
\hline
\end{tabular}

1) Die Berechnung des Saldo beinhaltet die IKZ-Beträge von 1972-1985.

Quelle: Abbildung 70, S.194.

Der Saldo aus Einnahmen und Ausgaben der Winterbau-Umlage belegt, daß die mit 4\% der Bruttolohnsumme bemessene Arbeitgeberumlage zu Beginn der Winterbaunovelle sogar ausgereicht hatte (Überdeckung: 219,7/198,4/53,3/96,6), die IKZ und einen Teil des SWG zu bezahlen. Allerdings war eine derartige Beteiligung der Bauwirtschaft an den Kosten des SWG vom Gesetzgeber nicht vorgesehen.

695 Nach §183a Abs.3 AFG sollten mindestens die Leistungen für MKZ und WG abgedeckt werden. Ab l. Januar 1982 auch die Leistungen für IKZ, vgl. Anhang III, S.255.

696 vgl. Bundesanstalt für Arbeit (Referat IVa2), Übersicht über die Einnahmen aus der WinterbauUmlage und Ausgaben für die Förderung der ganzjährigen Beschäftigung in der Bauwirtschaft, Nürnberg, 18. Januar 1993. 
Im Zeitraum 1975/76 wurde daher die WB-Umlage auf 3,5\% gesenkt. Trotz dieser Reduzierung, hatte die BA einen Überschuß von 191,1 Mio. DM zu verzeichnen. Eine erneute Reduzierung im Zeitraum 1976/77 auf 3\% der Bruttolohnsumme brachte schließlich ausgeglichenere Ergebnisse. Mit dem Aussetzen der Förderung von IKZ und MKZ wurde die WB-Umlage letztmalig verringert. Sie beträgt zur Zeit $2 \%$ der Bruttolohnsumme. ${ }^{697}$

Es hat sich gezeigt, daß mit der Förderung echter Winterbautätigkeit - gemeint ist die PWF im Rahmen der Winterbaunovelle - die BA in ihren Aufwendungen für die Bauwirtschaft erheblich entlastet wurde. Die Gründe liegen sowohl in der Verlagerung eines Teils der Kosten auf die Bauwirtschaft als auch in der Förderungsart. So braucht die BA seit Einführung der PWF von 1972 keine Gelder mehr für die bis dahin geltende PWF im Rahmen des AFG (1969-71) aufzubringen. Desweiteren sind die Aufwendungen fur das SWG, die aus den allgemeinen Beiträgen zur Arbeitslosenversicherung finanziert werden, deutlich zurückgegangen. Letztendlich hat sich die Winterbaunovelle auf die kontinuierliche Bautätigkeit positiv ausgewirkt und damit zur Verringerung der Ausfallzeiten beigetragen. ${ }^{698}$

Wie bereits erwähnt, lassen sich die möglichen Auswirkungen im Bereich Steueraufkommen und Sozialversicherung nicht genau quantifizieren. Aufgrund der ermittelten Ergebnisse ist jedoch die Schlußfolgerung zu ziehen, daß der mit der PWF im Rahmen der Winterbaunovelle von 1972 verbundene Produktionsanstieg bzw. Rückgang der Ausfallstunden sowohl zu Mehreinnahmen als auch zu Minderausgaben geführt hat.

\subsubsection{Folgen der Streichung des SWG}

Aufgrund aller im Rahmen dieser Arbeit gewonnenen Erkenntnisse bezüglich der SWG-Regelung muß hier die Frage - unabhängig von der aktuellen politischen Diskussion um die Streichung des SWG zum Januar 1996 - nach den positiven Auswirkungen dieser Förderungsmaßnahme zur ganzjährigen Beschäftigung in der Bauwirtschaft gestellt werden, da insbesondere die Vermutung nahe liegt, daß mit der SWGRegelung im Grunde genommen nur ein "statistischer Erfolg"699 erzielt werden

697 vgl. Kap. 2.4.1.5. 1986-92: Aussetzung der Förderung von IKZ und MKZ, S.73-74.

698 Bezüglich der Verringerung der Ausfallzeiten vgl. auch Abbildung 71, S.198 und Abbildung 74, S.208. 
konnte, der lediglich eine Verlagerung der Arbeitslosigkeit von den Arbeitsämtern in die Betriebe bewirkt hat. ${ }^{700}$

Dieser statistische Erfolg der SWG-Regelung, d.h. die Beseitigung der Saisonarbeitslosigkeit im Baugewerbe, ${ }^{701}$ könnte allerdings auch als Verwirklichung der "Ganzjährigen Beschäftigung" interpretiert werden. Damit wäre eine der wesentlichen sozialpolitischen Zielsetzungen erreicht, nämlich den Arbeitsplatz des Bauarbeiters zu sichern. Dennoch bleibt fragwürdig, ob mit dieser Art des auf Gesetz und Tarif beruhenden Beschäftigungsverhältnisses ${ }^{702}$ eine gewünschte Verbesserung im Hinblick auf die Zielsetzungen zur ganzjährigen Beschäftigung herbeigeführt werden konnte.

Im Hinblick auf die geplante Streichung des SWG, mit der einige Tarifverträge ihre Rechtsgrundlage verlören, befürchten die Tarifpartner insbesondere einen Anstieg der Saisonarbeitslosigkeit mit allen negativen Folgewirkungen. Daher setzen sie sich vehement furr den Fortbestand der SWG-Regelung ein, wie die folgenden Zitate belegen:

- "...Die Bundesregierung riskiert mit der Streichung des SWG einen Rückfall in die längst überwunden geglaubte Saisonarbeit der 50er Jahre." 703

- "...Auf heftige Kritik von Arbeitgeberverbänden und Gewerkschaft stößt die von der Bundesregierung beabsichtigte Abschaffung des Schlechtwettergeldes. Der Präsident des Zentralverbandes des Deutschen Baugewerbes, Fritz Eichbauer, bezeichnete eine derartige Maßnahme als kontraproduktiv. "704

- "...die IG Bau befürchtet, die Streichung mache den Bauarbeiter wieder zum Saisonier."705

699 vgl. o.V., Winterbau - nur ein statistischer Erfolg, in: Der Arbeitgeber, 12.Jg., Heft 5, 1960, S.103f.

700 vgl. Sabel, A., Reformwünsche zur Arbeitslosenversicherung, in: Arbeit und Sozialpolitik, 18.Jg., Nr.3, 1964, S.67ff.

701 vgl. ausführlich Kap. 3.3.1. Arbeitsmarktpolitische Effekte der getroffenen Förderungsmaßnahmen, S.117ff.

702 Die Forderung des Gesetzgebers die SWG-Regelung nur in Verbindung mit dem tariflichen Verbot der witterungsbedingten Kündigung (BRTV, TV Lohnausgleich) einzuführen, vgl. Kap. 2.4.2. Tarifvertragliche Leistungen und Regelungen, S.74-76.

703 vgl. Küchler, W., (Hauptverband der Deutschen Bauindustrie), Schlechtwettergeld darf nicht gestrichen werden, in: Bauwirtschaft, 47.Jg., Juli 1993, S.51.

704 vgl. Saam, W., Kritik an Streichung des Schlechtwettergeldes, in: Baugewerbe, Heft 15-16, August 1993, S.10. 
Wie bereits zu Beginn des vierten Kapitels erwähnt, wurden von den Tarifpartnern Berechnungen zu den möglichen Auswirkungen einer Streichung des SWG angestellt. $\mathrm{Zu}$ diesen Berechnungen wird in den folgenden Ausführungen kurz Stellung genommen:

Hauptverband der Bauindustrie: In ihren Berechnungen bezüglich der Streichung der SWG-Regelung geht die Bauindustrie davon aus, daß in den alten Bundesländern etwa 250.000 Bauarbeiter für einen Zeitraum von 3 Monaten winterbedingt entlassen würden. Den durchschnittlich eingesparten rund 500 Mio. DM an SWG (1988-1992) stünde damit eine Belastung von 1.737 Mio. DM gegenüber. Bei einer Berücksichtigung von Deutschland-Ost ergibt sich schließlich eine verbleibende Mehrbelastung von 1.444 Mio. DM. ${ }^{706}$

IG Bau-Steine-Erden: Auch die IG Bau gelangt zu einer ähnlichen Mehrbelastung. Bei zusätzlich 300.000 arbeitslosen Bauarbeitern und dreimonatiger Arbeitslosigkeit beträgt diese Mehrbelastung 1,2 Mrd. DM. ${ }^{707}$

Die prognostizierte Mehrbelastung - Mehrausgaben der BA und Steuermindereinnahmen des Staates - im Vergleich zur bestehenden Regelung läßt sich in beiden Berechnungen auf den vermuteten Anstieg der Saisonarbeitslosigkeit zurückführen. Es stellt sich jedoch die Frage, ob bei einer Streichung des SWG tätsächlich mit einer derart gravierenden Zunahme (250.000 bzw. 300.000) an arbeitslosen Bauarbeitern gerechnet werden muß.

Beim gegenwärtigen Stand (Zeitraum 1986-92) von durchschnittlich etwa 750.000 SWG-Baustellenbeschäftigten ${ }^{708}$ in den Monaten November bis März wäre dies ein Anstieg in der Bauarbeitslosigkeit um 33\% (250.000) bzw. 40\% (300.000). Selbst in der förderungsfreien Zeit von 1954-59 lag der durchschnittliche Anstieg der Saisonarbeitslosigkeit "nur" bei etwa 27\%. ${ }^{709}$ Hinzu kommt, daß sich die Ausfallstunden je Bauarbeiter mittlerweile auf etwa 90 Stunden pro Schlechtwetterzeit (1986-92) reduziert haben. ${ }^{710}$ Legt man eine Arbeitszeit von 7,8 Stunden/Tag - die tarifliche Wo-

705 vgl. o.V., IG Bau mobilisiert gegen Streichung des Schlechtwettergeldes, in: FAZ vom 13. Juli 1994.

706 vgl. Knechtel, E., Geplanter Wegfall des SWG im Baugewerbe, Hauptverband der Bauindustrie.

707 vgl. IG Bau-Steine-Erden (Bundesvorstand), Der Angriff auf das Schlechtwettergeld, S.15.

708 Berechnete 754.707 Baustellenbeschäftigte, vgl. Abbildung 71, S.198.

709 Berechnet aus dem Verhältnis von 888.954 zu 1.222.283 (1954-59), vgl. Abbildung 54, S.162. 
chenarbeitszeit beträgt 39 Stunden - zugrunde, wäre dies ein effektiver witterungsbedingter Arbeitsausfall von etwa 12 Arbeitstagen. Infolgedessen läßt sich die Schlußfolgerung ziehen, daß sowohl die Höhe als auch die Dauer des vermuteten Anstiegs der Arbeitslosigkeit in beiden Berechnungen zu hoch angesetzt ist.

Eine weitere Studie zu den Folgen der Streichung des SWG wurde von Hujer erstellt. ${ }^{711}$ Aufgrund mehrerer Simulationsrechnungen, die sich auf die Schlechtwetterperiode 1990/91 stützen - da der Betrag der SWG-Aufwendungen in dieser Periode mit 868,9 Mio. DM der von der Bundesregierung projektierten Ein-sparung von 900 Mio. am nächsten kommt ${ }^{712}$ - zieht auch Hujer die Schlußfolgerung, daß eine ersatzlose Streichung des SWG im Baugewerbe negative arbeitsmarkt-, finanz- und sozialpolitische Wirkungen haben würde.

Als Begründung führt Hujer die Ergebnisse seiner Simulationsrechnungen an. D.h. er vergleicht die Gesamtausgaben für SWG und die übliche Zunahme von Arbeitslosigkeit und Kurzarbeit unter Beibehaltung der SWG-Regelung (Referenz) von annähernd 1,184 Mrd. DM mit den zu erwartenden Gesamtausgaben bei der Streichung des SWG. Dabei liegen die ermittelten Ausgaben für Staatshaushalt und Sozialversicherung in den verschiedenen Szenarien mit 1,356 Mrd. DM (Ausgleichstrategie I) und 1,979 Mrd. DM (Ausgleichstrategie II) jeweils über den Ausgaben bei Beibehaltung der SWG-Regelung (Referenz).

Ein wesentlicher Kritikpunkt des Verfassers an diesen Simulationsrechnungen liegt in der von Hujer getroffenen Annahme, ${ }^{713}$ daß sich die Zahl der zusätzlichen Arbeitslosen und Kurzarbeiter infolge der Freisetzung aufgrund der SWG-Streichung auf die gesamte Dauer der Schlechtwetterzeit (fünf Monate) bezieht. ${ }^{714}$ Aufgrund der ermittelten Ergebnisse im Rahmen dieser Arbeit erscheint eine derartige Annnahme für die Monate November und März der Schlechtwetterzeit unrealistisch. ${ }^{715}$ Setzt man daher

710 Berechnete 87,7, vgl. Abbildung 71, S.198.

711 vgl. Hujer, R./Hassel, G., Gesamtwirtschaftliche Folgen einer Streichung des Schlechtwettergeldes, Frankfurt, 1994.

712 vgl. Günther, H., (Staatssekretär im Bundesministerium für Arbeit und Sozialordnung), Argumentationspapier zum SWG, vom 25. August 1994.

713 vgl. Hujer, R./Hassel, G., Gesamtwirtschaftliche Folgen einer Streichung des Schlechtwettergeldes, S.23.

714 Anmerkung: Die getroffene Annahme einer fünf monatigen Arbeitslosigkeit bezieht sich auf alle Simulationsrechnungen.

715 vgl. beispielsweise Abbildung 41 (52), S.145 (S.151) und ausführlich Kap. 3.3.1. Arbeitsmarktpolitische Effekte der getroffenen Fördenungsmaßnahmen, S.117ff. 
nur drei Monate - entsprechend den Annahmen der IG Bau-Steine-Erden und des Hauptverbandes der Bauindustrie - als zusätzliche Arbeitslosigkeit an, so führen die gleichen Simulationsrechnungen zu verminderten Gesamtausgaben bei Streichung der SWG-Regelung. ${ }^{716}$ Es zeigt sich, daß eine Fütterung des Hujer-Modells mit realistischen Daten die geplante Streichung des SWG unterstützt.

Auf weitere Berechnungen von Mehr- und Minderausgaben bzw. Mehr- und Mindereinnahmen im Zusammenhang mit dem geplanten Fortfall der SWG-Regelung soll an dieser Stelle verzichtet werden. Da insbesondere die Tarifpartner an einer Beibehaltung dieser Unterstützungsleistung ihres Wirtschaftszweiges interessiert sind, darf angenommen werden, daß ihre Berechnungen zur Streichung des SWG entsprechend negative Folgewirkungen aufzeigen. Statt dessen soll auf die im Rahmen dieser Arbeit ermittelten Ergebnisse zurückgegriffen werden, die nach Ansicht des Verfassers und unter Berücksichtigung der genannten Zielvorstellungen des Abschnitts 2.5. eine geeignetere Lösungsmöglichkeit zur Verwirklichung der ganzjährigen Beschäftigung bzw. kontinuierlichen Bautätigkeit bieten.

Der Verfasser ist sich der Tatsache bewußt, daß sich mit dem Fortfall der SWGRegelung die gesamte Problematik zur Förderung der ganzjährigen Beschäftigung in der Bauwirtschaft auf die Tarifvertragsparteien verlagert und wesentliche Änderungen bestehender Tarifverträge erforderlich werden. Aufgrund der positiven Effekte, die mit der Einführung der WB-Umlage - d.h. Beteiligung der Arbeitgeber an den Kosten der PWF - und des WG erzielt werden konnten, wird in Anlehnung an das folgende Zitat in Abschnitt 4.4. ein Tarifmodellansatz aufgezeigt: "...bis zum Jahre 1985 gab es in Schweden eine Schlechtwetterregelung, die es ermöglichte, Bauarbeiter bei schlechtem Wetter nach Hause zu schicken. Die Kosten hierfür trugen die Arbeitslosenkassen und die Bauarbeiter. Nach Abschaffung des Schlechtwettergeldgesetzes zahlt der Bauunternehmer die Bauarbeiter fast voll aus, wenn sie aufgrund von Kälte oder Regen nach Hause gehen. Es besteht daher ein starker Anreiz im Winter durchzuarbeiten."717

716 z.B. Ausgleichstrategie I: Bei dreimonatiger Arbeitslosigkeit betragen die Arbeitslosigkeitskosten pro Arbeitnehmer 6.426,- DM (5 Monate: 10.710,- DM). Daraus errechnen sich Winter-Arbeitslosigkeitsausgaben von 785.552.000 DM (5 Monate: 1.309.306.003 DM). Dies entspricht einer Einsparung von etwa 500 Mio. DM im Vergleich zu fünfmonatiger Arbeitslosigkeit. Hinzu kommt die Berechnung der Mehreinnahmen aufgnund der geminderten Ausfallstunden.

717 vgl. Brännström, A., Neue Chancen für den Winterbau, in: Baugewerbe, Heft 24, 1990, S.20. 


\subsubsection{Die PWF von 1972}

Es ist bereits ausführlich diskutiert worden, daß mit den produktionsorientierten Förderungsmaßnahmen der Winterbaunovelle von 1972 eine positive Entwicklung zur Verwirklichung der kontinuierlichen Bautätigkeit bzw. ganzjährigen Beschäftigung eingeleitet werden konnte. ${ }^{718}$ Die folgenden Ausführungen befassen sich daher in vergleichsweise gekürzter Form mit den drei Schwerpunkten dieser Förderung, d.h. mit den IKZ, MKZ und dem WG.

Mit den IKZ - den Zuschüssen zu Winterbaugeräten und -einrichtungen - sollten vor allem die "echten" witterungsbedingten Saisonschwankungen beseitigt werden. Zur Verringerung "unechter" witterungsbedingter Saisonschwankungen ${ }^{719}$ wurden dem Arbeitgeber einerseits Zuschüsse in Form der MKZ gewährt, andererseits wurde er an den Kosten der PWF mit der WB-Umlage beteiligt. ${ }^{720}$ Der Anreiz für den Arbeitnehmer war das eingefürte WG. Vor diesem Hintergrund zeigen die nun folgenden Ausführungen mögliche Änderungen und Schlußfolgerungen bezüglich dieser einzelnen produktionsorientierten Förderungsmaßnahmen auf.

\subsubsection{Wintergeld}

Nach Ansicht des Verfassers liegt in der Einführung des Wintergeldes eine wesentliche Ursache für die positive Trendwende im Rahmen der Förderungsmaßnahmen zur ganzjährigen Beschäftigung. Die Tatsache, daß diese Förderungsmaßnahme unmittelbar an die Arbeitsleistung gekoppelt ist und die geleisteten Zahlungen an WG um ein Vielfaches über denen von IKZ und MKZ liegen - im Durchschnitt des Zeitraumes 1972-85 sind es $75 \%$ der gesamten WB-Umlage ${ }^{721}$ - sowie die Beobachtung, daß sich im Zeitraum 1986-92 - trotz Aussetzung von IKZ und MKZ, d.h. die Zahlungen aus der WB-Umlage betrafen nur noch das WG - die Ausfallstunden deutlich verringert haben ${ }^{722}$ und die Verstetigung der Bautätigkeit fortgeschritten ist, ${ }^{723}$ begründen eine derartige Annahme.

\footnotetext{
718 vgl. ausführlich Kap. 3.3.2. Wirtschaftspolitische Effekte der getroffenen Förderungsmaßnahmen, S.138ff. und Kap. 4.1.1. Die SWG-Regelung, S.196ff. sowie Abbildung 71, S.198.

$719 \mathrm{Zu}$ "echten" und "unechten" Saisonschwankungen, vgl. Kap. 2.2.2.1. Marktbedingte Saisonschwankungen, S.56.

720 vgl. ausführlich Kap. 4.1.1.2. Fiskalische Effekte, S.218ff.

721 Berechnet aus dem Verhältnis von 641,7 zu 851,0, vgl. Abbildung 70, S.194.
} 
$\mathrm{Zu}$ einer ähnlichen Schlußfolgerung kommt das Ifo-Institut, wenn es betont, daß "...das beste Argument gegenüber den Arbeitern der garantiert höhere Verdienst bei durchgehender Arbeit wäre. Für die Leistungsbereitschaft der Arbeiter gibt es nichts schlechteres als die tägliche Zweifelslage, ob es besser ist zu arbeiten oder nicht zu arbeiten. Hier können falsch angelegte soziale Einrichtungen eine verderbliche Rolle spielen."724 In welcher Höhe das WG je Baustellenbeschäftigten die Einkommenssituation des Bauarbeiters tatsächlich beeinflußt hat zeigt die folgende Abbildung auf.

Abbildung: 78

\begin{tabular}{|c|c|c|c|c|c|}
\hline \multicolumn{6}{|c|}{ 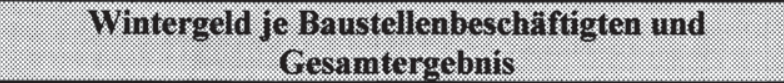 } \\
\hline Zeitraum & $\begin{array}{l}\text { Baustellen- } \\
\text { beschäftigte }\end{array}$ & \begin{tabular}{|c|} 
Wintergeld \\
(WG) in Mio.
\end{tabular} & $\begin{array}{c}\text { WG je Beschäf- } \\
\text { tigten in DM } \\
\end{array}$ & \begin{tabular}{|l|} 
Ergebnis aus \\
Abbildung 74 \\
\end{tabular} & $\begin{array}{l}\text { Gesamter- } \\
\text { gebnis } 1 \text { ) }\end{array}$ \\
\hline $1972 / 73$ & 1.224 .280 & 777,6 & 635,15 & 200,02 & 835,17 \\
\hline $1973 / 74$ & 1.131 .992 & 789,7 & 697,62 & 143,50 & 841,12 \\
\hline $1974 / 75$ & 965.923 & 657,2 & 680,39 & 207,32 & 887,71 \\
\hline $1975 / 76$ & 921.694 & 514,1 & 557,78 & $-31,12$ & 526,66 \\
\hline $1976 / 77$ & 901.813 & 702,1 & 778,54 & 14,30 & 792,84 \\
\hline $1977 / 78$ & 883.083 & 650,5 & 736,62 & $-186,94$ & 549,69 \\
\hline $1978 / 79$ & 940.723 & 504,0 & 535,76 & $-777,50$ & $-241,74$ \\
\hline $1979 / 80$ & 982.833 & 857,3 & 872,27 & $-62,01$ & 810,27 \\
\hline $1980 / 81$ & 962.715 & 670,3 & 696,26 & $-759,97$ & $-63,71$ \\
\hline $1981 / 82$ & 879.114 & 614,2 & 698,66 & $-543,23$ & 155,43 \\
\hline $1982 / 83$ & 822.874 & 639,9 & 777,64 & 45,87 & 823,51 \\
\hline $1983 / 84$ & 838.828 & 652,3 & 777,63 & $-46,34$ & 731,29 \\
\hline $1984 / 85$ & 775.110 & 486,6 & 627,78 & 105,89 & 733,67 \\
\hline $1985 / 86$ & 732.855 & 467,6 & 638,05 & 18,41 & 656,46 \\
\hline 1972-1985 & 925.988 & 641,7 & 692,96 & $-98,51$ & 594,45 \\
\hline $1986 / 87$ & 722.866 & 446,8 & 618,10 & $-34,88$ & 583,21 \\
\hline $1987 / 88$ & 711.450 & 569,1 & 799,92 & 365,98 & $1.165,89$ \\
\hline $1988 / 89$ & 729.091 & 656,4 & 900,30 & 333,89 & $1.234,19$ \\
\hline $1989 / 90$ & 753.350 & 691,9 & 918,43 & 466,18 & $1.384,61$ \\
\hline $1990 / 91$ & 777.558 & 611,5 & 786,44 & 223,53 & $1.009,97$ \\
\hline $1991 / 92$ & 794.823 & 983,4 & $1.237,26$ & 225,96 & $1.463,22$ \\
\hline $1986-1992$ & 748.190 & 659,9 & 881,93 & 263,44 & $1.145,37$ \\
\hline
\end{tabular}

1) Berechnet aus der Summe von WG je Beschaftigten und dem Einkommenseffekt der SWG-Regelung (Ergebnis aus Abbildung 74).

Quelle: Abbildung 70, S.194; Abbildung 74, S.208.

722 vgl. Kap. 4.1.1. Die SWG-Regelung, S.201-202 und Abbildung 71, S.198.

723 vgl. Kap. 3.3.2.3. Wirkungen auf die Verstetigung der Bautătigkeit, S.170-171 und Entwicklung der Differenz in Spalte "6" (1,57 zu 1,65), Abbildung 54, S.162.

724 vgl. Ifo-Institut für Wirtschaftsforschung, Optimaler Winterbau, S.75. 
Es zeigt sich, daß das WG je Beschäftigten vor allem in den Jahren von 1972 bis 1977 deutlich über den Zahlungen an SWG und Lohnausgleich je Bauarbeiter gelegen hat. ${ }^{725}$ Im weiteren Zeitablauf übersteigen sowohl die SWG-Beträge als auch der Lohnausgleich das gezahlte WG je Bauarbeiter mehrfach. Dabei ist zu berücksichtigen, daß die Höhe des WG unverändert blieb, während Lohnausgleich und SWG an die Entwicklung der Bruttostundenverdienste gekoppelt waren. Ähnlich äußern sich auch die Tarifvertragsparteien, die das WG bei seiner Einführung im Jahre 1972 als "...ausreichend hoch erachteten."726 Bis 1977 sind jedoch die Bruttostundenverdienste im Baugewerbe um mehr als ein Drittel - von 6,79 DM (1972/73) auf 9,22 DM $(1976 / 77)^{727}$ - gestiegen, so daß der - wenn auch steuerfreie ${ }^{728}$ - Zuschlag von 2,- DM je geleisteter Arbeitsstunde für den Bauarbeiter in der Förderungszeit, d.h. das WG, hinter den Steigerungen von SWG und Lohnausgleich zurückblieb.

Die Tatsache, daß insbesondere im Förderungszeitraum 1986-92 zeitweilig wieder mehr WG - nach wie vor werden 2,- DM für die in der Förderungszeit geleistete Arbeitsstunde gewährt - als Lohnausgleich bzw. SWG an den einzelnen Bauarbeiter ausbezahlt wurde, ist vor allem mit dem Rückgang der Ausfallstunden zu begründen. So bekam ein Bauarbeiter beispielsweise im Zeitraum 1988/89 durchschnittlich 380,61 DM SWG und 721,48 DM Lohnausgleich sowie 900,30 DM WG. ${ }^{729}$ Ähnliche Ergebnisse sind auch in den Jahren 1989/90 und 1991/92 zu verzeichnen.

Zusammenfassend läßt sich eine positive Einkommensentwicklung bei den Bauarbeitern feststellen. Dies zeigt vor allem das Gesamtergebnis der Abbildung 78 auf. Im Vergleich zu den Ergebnissen der SWG-Regelung sind nur noch in den Zeiträumen 1978/79 und 1980/81 negative Einkommenseffekte im Rahmen der Winterbauförderungsmaßnahmen zu beobachten. Hier konnten mit dem WG die im Ergebnis höchsten jemals vohandenen negativen Einkommenseffekte von 777,50 DM und 759,97 DM

725 vgl. "Geleistete Zahlungen an SWG und Lohnausgleich (Spalte "3" und "4") der Abbildung 74, S.208.

726 vgl. Schreiben des Zentralverbandes des Deutschen Baugewerbes, des Hauptverbandes der Deutschen Bauindustrie und der IG Bau-Steine-Erden vom 1. Februar 1972, An den Vorsitzenden des Ausschusses für Arbeit und Sozialordnung des Deutschen Bundestag, Herrn Prof. Dr. E. Schellenberg, Betr.: Entwurf eines Zweiten Gesetzes zur Änderung und Ergänzung des Arbeitsförderungsgesetzes - Drucksache VI/2689, S.2.

727 vgl. Zentralverband des Deutschen Baugewerbes (Hrsg.), Entwicklung des Bundesecklohnes, S.311, in: Jahrbuch des Deutschen Baugewerbes, Baujahr '92, Bonn 1993 und Abbildung 74, S.208.

728 vgl. Anhang III, S.252.

729 vgl. Abbildung 74, S.208 und Abbildung 78, S.226. 
nicht vollständig ausgeglichen werden. ${ }^{730}$ Äußerst günstig verlief die Einkommensentwicklung im Zeitraum 1986-92, wie das durchschnittliche positive Gesamtergebnis von $1.145,37 \mathrm{DM}$ belegt.

Trotz dieser zuletzt sehr günstig verlaufenen Entwicklung vertritt der Verfasser die Ansicht, daß eine Anpassung des WG an die Lohnentwicklung im Baugewerbe - d.h. eine Erhöhung der seit 1972 unverändert bestehenden 2,- DM pro Arbeitsstunde wünschenswert wäre, um dem Winterbau mit dieser Förderungsmaßnahme neue Impulse zu geben. Dabei müßte man sich allerdings darüber im klaren sein, daß eine Beibehaltung dieser gesetzlichen "Winterbauprämie für Bauarbeiter" - d.h. die steuerfreie Gewährung des WG - eine Subventionierung der Bauwirtschaft auf Kosten der Steuerzahler bedeuten würde.

Eine andere Möglichkeit bestünde darin, dem Bauarbeiter einen Lohnzuschlag für Winterarbeit zu gewähren, um somit den Arbeitsanreiz herbeizuführen. Die Tatsache, daß dieser Lohnzuschlag zu versteuern wäre, würde sich allerdings negativ auf die Einkommenssituation der Arbeitnehmer auswirken. Der Zuschlag müßte daher entsprechend hoch bemessen sein. Eine derartige Lösung hätte den Vorteil, daß das "Zuschlagsproblem" auf die Tarifvertragsparteien verlagert würde. Dadurch könnte der Zuschlag leichter modifiziert und den jeweiligen Verhältnissen auf dem Arbeitsmarkt besser angepaßt werden als die vergleichsweise starre gesetzliche Regelung. Hinzu kommt, daß jeglicher Verwaltungsaufwand bei der BA, der mit der Abrechnung des WG zu tun hatte, entfallen würde. Diese Verwaltungskosten beliefen sich im Jahr 1992 immerhin auf 67,4 Mio. DM. ${ }^{731}$

\subsubsection{IKZ und MKZ}

Nachdem aufgezeigt wurde, daß das WG als Förderungsmaßnahme im Rahmen der PWF grundsätzlich beibehalten bzw. ausgebaut werden sollte, ist diese Frage bezüglich der IKZ und MKZ zu klären. Neben vielen durchaus positiven Stimmen ${ }^{732}$ finden sich jedoch auch kritische wie das folgende Zitat beweist:

730 vgl. ausführlich Kap. 4.1.1.1. Einkommenseffekte, S.211 und Abbildung 74, S.208.

731 Inklusive der Verwaltungskosten für die neuen Bundesländer, vgl. Robl/Brocksiepe, Ganzjährige Beschäftigung in der Bauwirtschaft. Einnahmen und Ausgaben der Bundesanstalt für Arbeit, in: Rundschreiben des Zentralverbandes des Deutschen Baugewerbes vom 26. Juli 1993, S.2. 
"...man könne sich des Erfolges dieser Maßnahmen durchaus nicht sicher sein, da 50 bis $60 \%$ der Winterbaugerätekosten weiterhin von den Unternehmern selbst zu tragen seien. Das hat dann zur Folge, daß zukünftig große Firmen auch die Winterfestmachung aller jener Winterbauprojekte hälftig subventioniert bekommen, die sie bisher auch ohne Subventionen durchgefürt haben, während kleinere und mittlere Firmen, die das Gros der Bauwirtschaft ausmachen, nicht einmal die Mittel für die selbst zu zahlende Hälfte der Aufwendungen zur Winterfestmachung ohne weiteres riskieren können. Denn sie wissen gar nicht, ob sie in genügendem Umfang für diesen Winter sowie für die kommenden Winterhalbjahre ausreichend Aufträge erhalten, die eine Armortisierung ihrer selbst aufgewandten Mittel sichern. So bewirkt die neueste Konstruktion der Winterbausubventionierung weitere Konzentration und eine $\mathrm{Be}$ günstigung der Großunternehmen - und das kann doch weder im Interesse des Gesetzgebers noch im Interesse der Branche insgesamt liegen." 733

$\mathrm{Da}$ die mit diesem Zitat angebrachte Kritik bezüglich der IKZ nicht völlig abwegig ist, zeigt allein schon die Tatsache, daß der Gesetzgeber in $§ 77$ Abs. 2 Satz 2 AFG der Produktiven Winterbauförderung eine Sonderregelung für Kleinbetriebe eingebracht hat. Mit dieser Sonderregelung erhielten Betriebe, in denen Ende Oktober nicht mehr als 20 Arbeiter beschäftigt waren, einen um $10 \%$ erhöhten Zuschuß. ${ }^{734}$ Der Gesetzgeber hatte also die Problematik durchaus erkannt und war damit der kleinbetrieblichen Struktur des Baugewerbes ${ }^{735}$ in gewisser Weise gerecht geworden. Es stellt sich allerdings die Frage, ob die Zuschußhöhe von $10 \%$ richtig bemessen ist bzw. ob die erweiterte Förderung auf Betriebe mit bis zu 20 Beschäftigten - immerhin werden hierdurch die ca. $20 \%$ Mittelstandsbetriebe nicht erfaßt ${ }^{736}$ - dem Mittelstand gerecht wird.

Die MKZ, die den Arbeitgebern zu den witterungsbedingten Mehrkosten des Bauens in der Schlechtwetterzeit gewährt wurden, lagen in der Gesamtsumme ihres Förderungsumfanges deutlich höher als die IKZ. Wie bereits im Abschnitt 4.1. ${ }^{737}$ aufgezeigt, betrugen die im Durchschnitt des Zeitraumes 1972-85 geleisteten Zahlungen an

732 Beispielhaft seien genannt: Röthig, H., Baurationalisierung: Frostige Zeiten für den Winterbau, S.634 und Kranz, G., Der Winterbau bleibt die Chance, in: Bautechnik 10/80, S.92.

733 vgl. o.V., Deutsches Wintermärchen, in: Hoch- und Tiefbau, 26.Jg., Nr.10, 1973, S.14.

734 vgl. Anhang III, S.249.

735 vgl. Kap. 2.1.2. Betriebsstrukturelle Entwicklung, S.41.

736 vgl. Abbildung 5, S.41.

737 vgl. Abbildung 70, S.194. 
MKZ 116,7 Mio. DM. Das ist rund dreimal soviel, wie die im gleichen Zeitraum geleisteten Zahlungen für die IKZ (36,2 Mio. DM).

Mit den MKZ wurden während der Zeit von 1972-85 durchschnittlich 44,0 Mio. Arbeitsstunden gefördert. Dies ist zwar im Vergleich zu den 320,8 Mio. durchschnittlich geförderten WG-Stunden nur ein geringer Anteil, dennoch können die MKZ-Stunden bei der Untersuchung der positiven Effekte im Rahmen der Winterbaunovelle von 1972 nicht gänzlich vernachlässigt werden. Zumal auch die steigende Zahl der einzelnen MKZ-Beträge gegen Ende des Zeitraumes 1972-85 und die damit verbundene Steigerung der bewilligten MKZ-Anträge - von 1972-76 waren es noch ca. 20.000 Anträge pro Jahr, von 1982-86 aber schon $120.000^{738}$ - auf eine zunehmende Akzeptanz dieser Förderungsmaßnahme bei den Arbeitgebern schließen läßt.

Die im Zusammenhang mit den MKZ getroffene Differenzierung der Förderungssätze nach $\S 79$ Abs. $3 \mathrm{AFG}^{739}$ wirt jedoch einige Probleme auf. Zwar scheint es auf den ersten Blick durchaus sinnvoll bzw. selbstverständlich, daß eine Bauleistung entsprechend ihrer Winterbaumehrkosten bezuschußt wird. Dennoch warnt beispielsweise das Ifo-Institut vor einer solchen Differenzierung, weil unter Umständen besonders schlecht geeignete Winterbaubereiche aufgrund der bevorzugten Förderung zu unrationellen Produktionsbereichen hochgezüchtet würden. ${ }^{740}$ Das bedeutet der Arbeitgeber könnte versuchen, nicht dort zu arbeiten wo am meisten geleistet würde, sondern nur dort, wo er die meisten Zuschüsse bekäme. Eine mögliche Lösung dieser Problematik könnte in dem Vorschlag des Battelle-Instituts liegen, der die "...relativ teuren Sparten (z.B. Einfamilienhäuser, wasserwirtschaftlicher Tiefbau) nicht in demselben Maß fördert, wie die dafür geeigneteren Sparten." 741

Aufgrund der ermittelten Ergebnisse im Rahmen dieser Arbeit vertritt der Verfasser die Ansicht, daß von den IKZ und MKZ durchaus positive produktionsorientierte Effekte ausgegangen sind, ohne sie genau quantifizieren zu können. Allerdings hat sich die Aussetzung dieser Förderungsmaßnahmen im Zeitraum 1986-92 in keinster Weise negativ ausgewirkt. Im Gegenteil, die positive Entwicklung zur kontinuierlichen Bau-

738 vgl. Bundesanstalt für Arbeit, Winterbauförderung, Erfahrungsbericht für den Winter 1985/86, S.11, Nürnberg.

739 vgl. Anhang III, S.250-251.

$740 \mathrm{vgl}$. Ifo-Institut furr Wirtschaftsforschung, Optimaler Winterbau, S.124.

741 vgl. Battelle Institut, Untersuchung der Möglichkeiten sowie der wirtschaftlichen und sozialen Auswirkungen einer vermehrten Winterbautătigkeit, S.12. 
tätigkeit bzw. ganzjährigen Beschäftigung hat sich fortgesetzt. Die Arbeitsstundendifferenz zwischen "Sommer" und "Winter" hat sich auf 1,57742 und die Ausfallstunden je Bauarbeiter haben sich auf $87,7^{743}$ reduziert.

Als Schlußfolgerung läßt sich festhalten, daß die IKZ und $\mathrm{MKZ}$ von einigen Baubetrieben gern in Anspruch genommen wurden. Diese Betriebe sahen in der Aussetzung der Förderung natürlich einen entsprechenden "Rückschlag für den Winterbau"744 der sich, wie bereits beschrieben, in keinster Weise eingestellt hat. Beide Förderungsmaßnahmen haben sich letztendlich als überflüssig erwiesen. Daher plädiert der Verfasser für die grundsätzliche Streichung der IKZ und MKZ im Rahmen der Winterbauförderungsmaßnahmen. Neben den diskutierten gesetzlichen Regelungen, ist ebenso an eine Modifizierung der tarifvertraglichen Regelungen zu denken. Diese sollen in dem nun folgenden Abschnitt diskutiert werden.

\subsection{Tarifvertragliche AlternativmaBnahmen}

In Anlehnung an die in Abschnitt 2.3. aufgezeigten konzeptionellen Möglichkeiten zur Förderung der ganzjährigen Beschäftigung in der Bauwirtschaft gilt es nun zu klären, inwieweit die Tarifpartner in der Lage sind, ihren Beitrag zur Förderung der kontinuierlichen Bautätigkeit bzw. ganzjährigen Beschäftigung zu erhöhen. Entsprechend dem Motto, daß das, was sie selber regeln können, nicht vom Staat durch ein Gesetz geregelt werden soll, ${ }^{745}$ haben sie mit der sog. "Leipziger Erklärung vom 10. März 1994"746 ihre Bereitschaft signalisiert, nach eigenen Lösungen zur Sicherung eines ganzjährigen Einkommens und der Arbeitszeit zu suchen.

Die folgenden hier aufzuzeigenden tarifvertraglichen Möglichkeiten zur Förderung der ganzjährigen Beschäftigung in der Bauwirtschaft erheben keinen Anspruch auf Vollständigkeit. Sie werden auch keiner abschließenden Beurteilung unterzogen, denn letztendlich muß die Diskussion um die jeweiligen Vor- und Nachteile, die mit den

742 vgl. Kap. 3.3.2.3. Wirkungen auf die Verstetigung der Bautätigkeit, S.170-171 und Entwicklung der Differenz in Spalte "6" (1,57 zu 1,65), Abbildung 54, S.162.

743 vgl. Kap. 4.1.1. Die SWG-Regelung, S.201-202 und Abbildung 71, S.198.

744 vgl. Kap. 2.4.1.5. 1986-92: Aussetzung der Förderung von IKZ und MKZ, S.73 (1. Absatz).

745 vgl. Kap. 2.3. Die konzeptionellen Möglichkeiten zur Förderung der ganzjährigen Beschäftigung in der Bauwirtschaft, S.62.

746 vgl. auch Kap. 1.4. Zielsetzung, S.32. 
einzelnen Maßnahmen für Arbeitnehmer bzw. Arbeitgeber verbunden sind, der tarifvertraglichen Auseinandersetzung der Sozialpartner überlassen werden. Prinzipiell tragen jedoch alle folgenden tarifvertraglichen Gestaltungsmöglichkeiten mehr oder weniger zur Förderung der kontinuierlichen Bautätigkeit bzw. ganzjährigen Beschäftigung bei. Im wesentlichen handelt es sich dabei um verschiedene Arbeitszeitverteilungen, deren Vor- und Nachteile hier kurz skizziert werden:

- Zweimonatige Arbeitsruhe im Winter: Dieser von Ernst Schlieder bereits im Jahr 1970 gemachte "Lösungsvorschlag zum Winterbauproblem"747 ist in Baufachkreisen bereits diskutiert worden. Aufgrund seiner radikalen Arbeitszeitflexibilisierung - d.h. die Arbeitszeit würde von März bis Dezember 48 Wochenstunden betragen, dagegen ruht die Arbeit im Januar und Februar - spielt dieser Vorschlag im Rahmen der tarifvertraglichen Änderungsmöglichkeiten keine Rolle. Außerdem unterstützt ein derartiger Vorschlag die Verwirklichung der kontinuierlichen Bautätigkeit in keinster Weise. Statt dessen wird die bestehende Differenz zwischen Winter- und Sommerbautätigkeit vergrößert. Desweiteren ist es fraglich, ob wirklich eine größere Arbeitsleistung erwartet werden kann, wenn unter insgesamt günstigeren Witterungsbedingungen gearbeitet wird. Im Gegensatz zu Schlieder kann durchaus vermutet werden, daß eine derart hohe Arbeitsbelastung in den Sommermonaten sowohl die Unfallgefahr als auch die Gesundheitsgefährdung der Bauarbeiter ansteigen und folglich auch die Arbeitsleistung sinken läßt. Die Gefahr, daß die Bauarbeiter in den beiden Wintermonaten in andere Wirtschaftszweige abwandern besteht ebenfalls.

Die Vorteile einer derartigen Arbeitszeitregelung liegen vor allem in der finanziellen Entlastung der BA, da das SWG nur noch in den Monaten November, Dezember und März gezahlt werden müßte. Entsprechend der anfallenden Ausfalltagewerke während des Schlechtwetterzeitraumes - im Januar und Februar jeweils etwa $30 \%{ }^{748}$ der gesamten Ausfalltagewerke - würden sich die Zahlungen an SWG um rund $60 \%$ reduzieren. Daraus ist zu schließen, daß zumindest die Arbeitspause (Januar und Februar) von Schlieder richtig gewählt wurde.

747 vgl. Schlieder, E., Lösungsvorschlag zum Winterbauproblem: Winterpause am Bau - dafür längere Arbeitszeit im Sommer, in: Baumarkt, 69.Jg., Nr.46, 1970, S.2263ff.

748 vgl. Anhang IV, Abbildungen 80 bis 83. 
- Verlängerter Lohnausgleichszeitraum: Bei diesem, schon im Jahr 1964 gemachten Vorschlag des Ifo-Instituts geht es darum, eine über den Lohnausgleichszeitraum hinausgehende sog. "Ruhezeit" einzuführen. ${ }^{749}$ Danach könnte der Lohnausgleichszeitraum - d.h. 24. Dezember bis 1 . Januar ${ }^{750}$ - beispielsweise um sechs Arbeitstage verlängert werden. Je nach Lage der Sonn- und Feiertage würde sich dadurch die arbeitsfreie Zeit bis maximal zum 12. Januar verlängern. Als Ausgleich sollte auf eine weitere Verkürzung der wöchentlichen Arbeitszeit verzichtet werden. Dieser Vorschlag des Ifo-Instituts beinhaltet im Prinzip die gleichen Vor- und Nachteile, wie die, die bereits in der von Schlieder geforderten zweimonatigen Arbeitsruhe aufgezeigt worden sind. Allerdings werden hier die Zielvorstellungen zur kontinuierlichen Bautätigkeit in einer entsprechend abgeschwächten Form negativ beeinflußt.

Beide so eben beschriebenen tarifvertraglichen Möglichkeiten werden von Böhler treffend und kritisch zusammengefaßt: "Wer die Möglichkeit einer Januarproduktion von vornherein zu einem guten Teil ausschließen und dafür das traditionelle SaisonHoch bewußt weit oben belassen will, dürfte zu sehr von einem Teilaspekt des kontinuierlichen Bauens gefangen sein, nämlich vom Teilaspekt der Produktionsausweitung überhaupt, ohne den ebenso wichtigen Aspekt der Ausgeglichenheit gebührend im Auge zu behalten." 751

- Änderung der Urlaubsregelung: Neben den Möglichkeiten der tarifvertraglichen Gestaltung der Arbeitszeit kommt auch eine Änderung der Urlaubsregelung in Betracht. Die ermittelten Ergebnisse im Rahmen der Wirkungsanalyse haben aufgezeigt, daß ausgerechnet in den baugünstigsten Monaten des Jahres ein deutlicher Rückgang der Bautätigkeit - sowohl in den geleisteten Arbeitsstunden als auch in der Nettoproduktion ${ }^{752}$ - aufgrund der sommerlichen Urlaubszeit zu verzeichnen ist. Dieser unter volkswirtschaftlichen Gesichtspunkten höchst unerwünschte Ef-

749 vgl. Ifo-Institut für Wirtschaftsforschung, Soziale und wirtschaftliche Auswirkungen der Winterbauforderung, S.78.

750 Anmerkung: Nach $\S 3$ Abs. 6 TV Lohnausgleich besteht zwar die Möglichkeit, daß wăhrend des Ausgleichszeitraumes gearbeitet wird, da die Entscheidung darüber letztendlich der Arbeitgeber triff. Dennoch ist es in der Praxis üblich, daß im Ausgleichszeitraum die Arbeit ruht. Dies bestätigt auch die Entwicklung der Saisonfaktoren der Arbeitsstunden (Abbildung 41, S.145).

751 vgl. Böhler, H., Zur Beurteilung von Winterbau-Förderungsmaßnahmen. Was sagt uns das IfoGutachten?, in: Architekt und Ingenieur, 16.Jg., Heft 2, 1965, S.33.

752 vgl. Saisonfaktoren der Arbeitsstunden, Abbildung: 41, S.145 und Saisonfaktoren der Nettoproduktion, Abbildung 52, S.151. 
fekt könnte durch eine entsprechende tarifvertragliche Vereinbarung reduziert werden, bei der zumindest ein Teil des Jahresurlaubs in die Schlechtwetterzeit gelegt würde. ${ }^{753}$

Aus volkswirtschaftlicher Sicht wären mit einer derartigen Regelung durchaus positive Effekte in Form von Produktivitätssteigerungen zu erwarten, da eine zusätzliche Möglichkeit der Bautätigkeit in einer witterungsgünstigen Zeit geschaffen und gegen eine ungünstigere eingetauscht würde. Aus sozialpolitischer Sicht könnte durch eine Verlegung von Teilen des Jahresurlaubs in die Schlechtwetterzeit unter Umständen ein höheres Bauarbeitereinkommen erzielt werden. Dies wäre dann möglich, wenn in die Zeit der winterlichen Urlaubsnahme SWG-Ausfallstunden fielen, die bekanntlich nur in Höhe des Arbeitslosengeldsatzes vergütet werden. Aufgrund der Tatsache, daß etwa $60 \%$ der Ausfalltagewerke in den Monaten Januar und Februar angezeigt werden, ${ }^{754}$ müßte sich eine entsprechende Urlaubsregelung für die Schlechtwetterzeit auf diese beiden Monate beschränken. Letztendlich würde sich auch der Aufwand für das gezahlte SWG reduzieren.

Der Nachteil einer tarifvertraglich festgelegten Urlaubsregelung läge vor allem in der Beeinträchtigung der freien Urlaubswahl des Arbeitnehmers. Alternativ könnte eine Vereinbarung getroffen werden, die dem Arbeitnehmer zwar die freie Wahlmöglichkeit überläßt, aber seine Entscheidung durch ein zusätzliches Urlaubsgeld bei Urlaubsnahme in der Schlechtwetterzeit beeinflußt. ${ }^{755}$ Dieses zusätzliche Urlaubsgeld müßte jedoch so ausreichend bemessen sein, daß zumindest das erhöhte Einkommen aufgrund des lohnsteuerfreien WG - von 2,- DM je geleisteter Arbeitsstunde in der Förderungszeit - kompensiert wird. Anderenfalls würde der Bauarbeiter keine Änderung seiner gewohnheitsmäßigen Urlaubsnahme in Erwägung ziehen.

- Lohnzuschläge für Winterarbeit: Der Vorschlag eines Prämiensystems, ähnlich dem bestehenden WG, beruht auf der von Kranz gestellten Forderung: "Grundsatz für die Gestaltung aller sozialen Leistungen müßte sein, daß derjenige, der während

753 Anmerkung: Die Möglichkeit, den Jahresurlaub ganz in die Schlechtwetterzeit zu verlegen, ist aus sozialpolitischen Gründen auszuschließen. Denn in mehreren Gesprächen haben die Baubeteiligten geäußert, daß es der traditionelle Wunsch des Bauarbeiters sei, einen Teil seines Jahresurlaubs in den Sommermonaten zu nehmen.

754 vgl. Anhang IV, Abbildungen 80 bis 83.

755 vgl. IG Bau-Steine-Erden, Arbeitsprogramm zur Verbesserung der Arbeitsbedingungen und der Leistungsfăhigkeit der Bauwirtschaft, abgedruckt in: Bau-Markt, 68.Jg., Nr.46, 1969, $2454 f$. 
der Wintermonate arbeitet, sich materiell bessersteht als der Arbeitslose. "756 Hier geht es vor allem darum, die Differenz zwischen Arbeitslosen- bzw. Schlechtwettergeld und dem Arbeitslohn zu vergrößern. ${ }^{757}$ Außerdem soll die Bereitschaft der Bauarbeiter, unter den erschwerten Witterungsbedingungen zu arbeiten, gesondert honoriert werden. Analog zu den in §6 BRTV aufgeführten Erschwerniszuschlägen, wäre auch an einen tarifvertraglich vereinbarten Lohnzuschlag für Winterarbeit zu denken. ${ }^{758}$

Inwieweit eine Flexibilisierung der Arbeitszeitgestaltung, d.h. beispielsweise der Ausbau der geltenden tariflichen Regelungen bezüglich der Wochenarbeitszeit oder eine Ausdehnung des Ausgleichszeitraumes von jetzt 2 auf 12 Monate $^{759}$ sowie andere tarifvertragliche Möglichkeiten tatsächlich erforderlich werden, um die ganzjährige Beschäftigung in der Bauwirtschaft zu fördern, soll im Rahmen des Abschnitts 4.4. aufgezeigt werden.

\subsection{Sonstige Alternativmaßnahmen}

Neben den bereits in Abschnitt 2.3. und Abschnitt 2.4.3. genannten Maßnahmen, ${ }^{760}$ die weder in die Kategorie der gesetzlichen noch in die der tariflichen Regelungen zur Förderung der ganzjährigen Beschäftigung fallen, sollen an dieser Stelle der Vollständigkeit halber einige weitere Alternativmaßnahmen angeführt werden. Aufgrund der Tatsache, daß der Schwerpunkt dieser Arbeit vor allem in der Analyse gesetzlicher und tariflicher Förderungsmaßnahmen bestanden hat, da diese größtenteils quantifizierbar waren, beschränkt sich die folgende Aufzählung auf eine bloße Darstellung dieser sonstigen Alternativmaßnahmen:

756 vgl. Kranz, G., Die Problematik der Winterarbeitslosigkeit in der Bauwirtschaft und die Bemühungen um die Lösung des Problems, S.29.

757 vgl. auch die Ergebnisse im Rahmen des Kap. 4.1.1.1. Einkommenseffekte, S.207ff.

758 vgl. auch Kap. 4.1.2.1. Wintergeld, S.228.

759 vgl. $\$ 3$ Arbeitszeit, Abs. 1.1. Allgemeine Regelung BRTV.

760 Hinweis: An dieser Stelle, ist noch der Vorschlag einer Produktiven Winterbauförderung des Ifo-Instituts aus dem Jahr 1967 (vgl. Kap. 2.3, S.61) zu erwähnen. Dieser Vorschlag, der eigentlich den gesetzlichen Alternativmaßnahmen zuzuordnen ist, wurde aufgrund seiner pauschalierten Zuschüsse und der Finanzierung von Anfang an abgelehnt. Der Aufwand der BA, der in dieser Zeit "...weit über das hinausging, was der SWG-Regelung ursprünglich zugedacht war" (vgl. Kap. 4.1.1.2. Fiskalische Effekte, S.218), wäre aufgrund des Vorschlages nicht verringert worden. 
- Verbesserte Arbeitsbedingungen: In Anlehnung an die im Rahmen der Winterbaunovelle eingefuhrte Arbeitsschutz-Verordnung für Winterbaustellen muß eine kontinuierliche Verbesserung des Arbeitsschutzes und der Arbeitsplatzbedingungen fortgefürt werden. Bei allen diesbezüglichen Überlegungen muß der Bauarbeiter im Mittelpunkt der Betrachtung stehen. Auf diese Weise können Aversionen gegen die winterliche Bautätigkeit abgebaut werden und sozialer und technischer Fortschritt sich gegenseitig ergänzen. ${ }^{761}$

- Koordinierung der öffentlichen Auftragsvergabe: Hier geht es primär um die immer wieder gestellte Forderung an die öffentliche Hand, ihre Bautätigkeit besser zu koordinieren. In diesem Zusammenhang wird vor allem eine stärkere antizyklische Auftragsvergabe gefordert, bei der entsprechend mehr Winterbauaufträge ausgeschrieben werden. Dabei wird jedoch allzuoft vergessen, daß es sich bei der sog. "öffentlichen Hand" um eine Vielzahl von Stellen handelt, die an der Vergabe beteiligt sind. Desweiteren fehlen dem Bund für seine Bauvorhaben letztendlich die rechtlichen Möglichkeiten zur Koordinierung. ${ }^{762}$ Dickert fordert daher die Einführung einer "Obersten Baubehörde" die das "...Durcheinander der Kompetenzen in der öffentlichen Vergabepolitik" reduziert. ${ }^{763}$

- Erstellung von Winterbauleistungsverzeichnissen: Entsprechend der Vorgehensweise in Schweden sollen unter Verwendung von sog. Winterbauleistungsverzeichnissen frühzeitig winterliche Bauobjekte ausgeschrieben werden. Diese Leistungsverzeichnisse, mit ihren Angaben über Baustandort und Bauart sowie zu verwendende Baustoffe, sind bindender Bestandteil des Bauauftrages.

Als weitere Maßnahmen können noch eine Verstärkung der Öffentlichkeitsarbeit entsprechend dem niederländischen Vorbild der Informationszentralen ${ }^{764}$ oder die Einführung eines speziellen Winterbau-Wetterdienstes angeführt werden. Die hier aufgezeigten Verbesserungsmöglichkeiten zur Förderung der ganzjährigen Beschäftigung

761 vgl. o.V., "Mitten im Sommer: Winterbau vorbereiten!", und "Macht die Baustellen rechtzeitig winterfest!", in: Der Grundstein, 17.Jg., Nr.17 (19), 1966, S.3 (4).

762 So stellt die Bundesregierung in ihrem Winterbau-Bericht 1974 fest, daß "...aufgrund fehlender rechtlicher und organisatorischer Voraussetzungen keine Möglichkeit einer winterbaugerechten Baukoordinierung besteht," vgl. BT-Drucks. 7/3508, S.6 und Art.109 GG (Finanzhoheit der Länder).

763 vgl. Dickert, D., Oberste Baubehörde in Niedersachsen: Ein Beitrag zur Reform der staatlichen Bauverwaltung, in: Bau-Markt, 69.Jg., Nr.26. 1970, S.1309f.

764 vgl. Ifo-Institut für Wirtschaftsforschung, Optimaler Winterbau, S.63. 
in der Bauwirtschaft tragen vor allem dazu bei, die vielfach vorhandenen psychologischen Hemmnisse zu verringern, die einer Winterbautätigkeit bei Arbeitgebern, Arbeitnehmern und Bauherren entgegenstehen. ${ }^{765}$

\subsection{Fazit und Tarifmodellansatz}

Den Abschluß der Arbeit bildet eine Zusammenfassung aller im Rahmen der Untersuchung gewonnenen Erkenntnisse über die von 1960 bis 1992 getroffenen Maßnahmen zur Förderung der ganzjährigen Beschäftigung in der Bauwirtschaft. Zusätzlich werden einige Vorschläge für künttige tarifliche Regelungen aufgezeigt. Vor dem Hintergrund der Zielvorstellungen nach Abschnitt 2.5. und den entsprechenden Ergebnissen der Wirkungsanalyse des Abschnitts 3.3. sowie den Ergebnissen der "Zahlungen/Stunden-Rechnung" des Abschnitts 4.1. lassen sich folgende Schlußfolgerungen für die einzelnen Förderungsmaßnahmen ziehen:

- Die SWG-Regelung hat maßgeblich zur Verschlechterung der kontinuierlichen Bautätigkeit beigetragen, d.h. die Differenz der geleisteten Arbeitsstunden zwischen "Sommer" und "Winter" ist mit ihrer Einfürung um etwa eine Arbeitsstunde je Beschäftigten und Arbeitstag angestiegen. Der Aufwand der BA für das Baugewerbe hat sich aufgrund der Einführung der SWG-Regelung ebenfalls deutlich erhöht. Zusätzlich dazu beigetragen haben die Höhe - von 1967 bis 1976 lag das SWG über dem Arbeitslosengeld - und auch die Berechnungsmethode des SWG. Der sozialpolitische Erfolg der SWG-Regelung liegt in der Verbesserung der materiellen Sicherheit des Bauarbeiters. Die Beseitigung der Saisonarbeitslosigkeit dagegen ist vornehmlich ein statistischer Erfolg, der in einer Verlagerung der Arbeitslosigkeit von den Arbeitsämtern in die Betriebe besteht. Aufgrund der kontinuierlichen Verringerung der witterungsbedingten Ausfallstunden je Bauarbeiter auf durchschnittlich 85,0 Ausfallstunden pro Schlechtwetterzeit im Zeitraum 19861992, ist die Streichung der SWG-Regelung in Verbindung mit tariflichen Neuregelungen zu befürworten.

- Der im Zusammenhang mit der SWG-Regelung eingeführte Lohnausgleichszeitraum in der Zeit vom 25. Dezember bis 1 . Januar wirkt den produktionsorientierten Zielsetzungen einer kontinuierlichen Bautätigkeit entgegen. Der meßbare so-

765 vgl. auch Kap. 2.2.2.1. Marktbedingte Saisonschwankungen, S.54-56. 
zialpolitische Erfolg liegt in der Verbesserung der Einkommenssituation des Bauarbeiters aufgrund des pauschalen Lohnausgleichs.

- Mit den Zuschüssen und Darlehen an Bauherren und Bauunternehmern im Rahmen der Förderung nach §143 AVAVG (Zeitraum 1960-68), die in der witterungsungünstigen Jahreszeit bauen wollten, konnten die produktionsorientierten Zielsetzungen nicht verwirklicht werden. Die Ursachen liegen vor allem in der Unverbindlichkeit dieser Förderungsmaßnahmen - d.h. kein Rechtsanspruch - und der Tatsache, daß primär die Bauherren (44,2 Mio. DM) und nicht die Winterbaumehrkosten der Bauunternehmer (12,4 Mio. DM) bezuschußt wurden.

Ähnlich negative Erfahrungen sind im Förderungszeitraum 1969-71 zu verzeichnen, obwohl erstmalig produktionsorientierte Zuschüsse mit Rechtsansprüchen für die Unternehmen in Form der PWF des AFG gewährt wurden. In dieser Zeit haben sich jedoch die Saisonschwankungen im Produktionsbereich nicht verringert, sondern weiter verstärkt, wie der Anstieg der Arbeitsstundendifferenz zwischen "Sommer" und "Winter" bewiesen hat. Die Entwicklung im Förderungszeitraum 1969-71 wird allerdings auch von negativen Einflüssen der SWG-Regelung überlagert.

- Mit der Einführung der Winterbaunovelle zum AFG vom 19. Mai 1972 haben sich die Verhältnisse bezüglich der Verwirklichung der genannten Zielvorstellungen zur ganzjährigen Beschäftigung in der Bauwirtschaft kontinuierlich verbessert. Diese positive Entwicklung ist vor allem auf die bereits mehrfach gestellte Forderung zurückzufuhren, die Arbeitgeber an den Kosten der Förderungsmaßnahmen zur ganzjährigen Beschäftigung zu beteiligen. Die hierfür eingeführte WB-Umlage, die von der Bauwirtschaft furr die Leistungen WG, IKZ und MKZ aufgebracht wird, hat nicht nur die Ausgaben der BA reduziert, sondern auch ein Umdenken zu produktionsorientierten Zielsetzungen ausgelöst.

- Das seit 1972 unverändert gezahlte WG hat vor allem eine Verstetigung und Erhöhung der Bauarbeitereinkommen bewirkt. Nach Ansicht des Verfassers ist das WG durch die Kopplung an die geleistete Arbeitsstunde im wesentlichen für die positive Entwicklung bezüglich der kontinuierlichen Bautätigkeit verantwortlich.

- Von den IKZ und MKZ sind nach Ansicht des Verfassers durchaus positive produktionsorientierte Effekte ausgegangen. Die IKZ werden jedoch der mittelständi- 
schen Struktur des Baugewerbes nicht gerecht und begünstigen die Großunternehmen. Problematisch bei den MKZ ist die sinnvolle Differenzierung der Förderungssätze. Aufgrund der ermittelten Ergebnisse des Förderungszeitraumes 198692, in der beide Förderungsmaßnahmen ausgesetzt wurden und keine negativen Auswirkungen auf die Entwicklung der kontinuierlichen Bautätigkeit bzw. ganzjährigen Beschäftigung festgestellt werden konnte, erweisen sich beide Förderungsmaßnahmen letztendlich als überflüssig.

Aufgrund der Tatsache, daß es sich bei den Berechnungen in dieser Arbeit um Durchschnittsrechnungen handelte, konnte auf extreme Witterungsverhältnisse einzelner Regionen, die entsprechende Differenzen bei den durchschnittlich ermittelten Ausfallstunden je Bauarbeiter bewirken können, keine Rücksicht genommen werden. Gleiches gilt für diejenigen Bauzweige (Straßenbau, wasserwirtschaftlicher Tiefbau), die nach Ansicht der Baubeteiligten für den Winterbau relativ ungeeignet erscheinen. Derartige Sonderregelungen müssen den Tarifpartnern überlassen bleiben.

Die Tarifvertragsparteien haben in der sog. "Leipziger-Erklärung" vom 10. März 1994 vereinbart, unmittelbar nach den Tarifabschlüssen 1994 mit den Verhandlungen über ein ganzjährig gesichertes Einkommen und die Möglichkeiten seiner Verstetigung sowie über bauspezifische Lösungen der Wochen- und Jahresarbeitszeit zu beginnen. ${ }^{766}$ Bis zum gegenwärtigen Zeitpunkt wurden jedoch von den Tarifpartnern noch keine "...konkreten Modelle zur tariflichen Regelung eines ganzjährigen Einkommens vorgelegt." 767

Die folgenden Ausführungen sollen daher vor allem mögliche Änderungen der Rahmenbedingungen Arbeitszeit und Förderung stichpunktartig aufzeigen. Dabei werden die im Rahmen dieser Arbeit gewonnenen Erkenntnisse und ermittelten Ergebnisse bezüglich der Förderungsmaßnahmen zur ganzjährigen Beschäftigung in der Bauwirtschaft berücksichtigt.

766 vgl. Kap. 1.4. Zielsetzung, S.32.

767 o.V., IG Bau kritisiert Illegalität und Werkverträge: Auf dem 16. ordentlichen Gewerkschaftstag der IG Bau in Dresden wurde in der Debatte zum Geschäftsbericht kritisiert, daß man es bisher versäumt hätte, "...konkrete Modelle zur tariflichen Regelung eines ganzjährigen Einkommens vorzulegen. In der IG Bau konnte bislang offenkundig kein Konsens erreicht werden, wie ein solcher Tarifvertrag gestaltet werden soll. Eine Mehrheit plädiert dafür, daß der gesamte Witterungsausfall von den Sozialkassen des Baugewerbes kompensiert werden müsse. ... Eine Minderheit der Gewerkschaft sähe es lieber, wenn eine Jahresarbeitszeit vereinbart würde, die allerdings Obergrenzen der wöchentlichen Arbeitszeit und entsprechende Ausgleichszeiträume festlegen sollte," in: FAZ vom 11. Oktober 1994. 


\section{Tarifmodellansatz:}

- Streichung der SWG-Regelung nur in Verbindung mit tariflichen Regelungen. ${ }^{768}$

- Streichung des TV Lohnausgleich.

- Erhöhung des WG auf 4,- DM (lohnsteuerfrei) je geleisteter Arbeitsstunde in der Förderungszeit.

- Urlaubsverlegung in die witterungsungünstigste Zeit, d.h. in die Monate Januar und Februar. ${ }^{769}$

Aufgrund der ermittelten Ergebnisse des Förderungszeitraumes 1986-92 - durchschnittlich 85,0 bzw. 87,7 witterungsbedingte Ausfallstunden je Bauarbeiter und Schlechtwetterzeit ${ }^{770}$ - wird in dem folgenden Vorschlag einer tariflichen Lösung von 90 SWG-Ausfallstunden ausgegangen, die im Falle einer Streichung der SWGRegelung kompensiert werden müssen. Mit einer entsprechenden Urlaubsregelung würde ein Teil der Ausfallstunden kompensiert, wie die in Abbildung 79 getroffenen Annahmen aufzeigen:

Abbildung: 79

\begin{tabular}{|c|c|c|c|c|}
\hline Verteilung des witterungsbedingten Arbeitsausfalles von 90 \\
Stunden aur die Monate November bis Marz.
\end{tabular}

1) Die Prozentzahlen entsprechen in etwa der Verteilung der Ausfalltagewerke im Baugewerbe auf die Monate November bis März, vgl. Anhang IV, Abbildungen 80 bis 83 .

2) Verteilung der Ausfallstunden entsprechend der prozentualen Anteile.

768 Anmerkung: In der Diskussion un die SWG-Regelung wird häufig von einer "ersatzlosen" Streichung des SWG gesprochen (vgl. z.B. Hujer, R./Hassel, G., Gesantwirtschaftliche Folgen einer Streichung des Schlechtwettergeldes, S.29.) Hierunter muß die "ersatzlose" Streichung bezüglich der Förderungsmaßnahmen des Gesetzgebers verstanden werden. Eine "ersatzlose" Streichung des SWG ohne entsprechende tarifliche Regelungen würde die Arbeitnehmer aufgrund der bestehenden Tarifverträge einseitig benachteiligen. Daher betrachtet der Verfasser die Streichung des SWG immer im Zusammenhang mit tariflichen Änderungen, entsprechend der "Leipziger Erklärung".

769 vgl. Anhang IV, S.257-258.

770 vgl. Abbildung 71, S. 198 und Abbildung 74, S.208. 
Die Abbildung 79 zeigt in der Spalte "2" die rein rechnerisch ermittelte Verteilung der 90 Ausfallstunden auf die Monate der Schlechtwetterzeit. Der Verfasser geht weiterhin davon aus, daß die Ausfallstunden pro Ausfalltag in den Monaten Januar und Februar höher sind als in den übrigen Monaten. Daher werden die rechnerisch ermittelten SWG-Ausfallstunden je Monat entsprechend auf- bzw. abgerundet (Spalte "3"). ${ }^{771}$ Bei einer Urlaubsverlegung von drei Wochen in die Monate Januar oder Februar würden also rein statistisch 23 SWG-Ausfallstunden kompensiert. 772

Für eine weitere Kompensation der Ausfallstunden schlägt der Verfasser eine Änderung der tariflichen Wochenarbeitszeit vor, d.h. eine Erhöhung der tariflichen Wochenarbeitszeit in den Monaten März bis November um 1 Stunde auf 40 Wochenarbeitsstunden. Von Dezember bis März bleibt die tarifliche Arbeitszeit von 39 Wochenstunden bestehen. Die Erhöhung der tariflichen Wochenarbeitszeit für den Zeitraum von 9 Monaten - d.h. 39 Wochen - um 1 Stunde, bewirkt eine weitere Reduzierung der Ausfallstunden um zusätzliche 39 Stunden.

Mit beiden hier aufgezeigten Maßnahmen, d.h. der Urlaubsverlegung und der Erhöhung der tariflichen Wochenarbeitszeit um 1 Stunde von März bis November, haben sich die SWG-Ausfallstunden um insgesamt 62 von anfangs 90 auf noch verbleibende 28 Ausfallstunden reduziert. Der Verfasser geht jedoch davon aus, daß bei einer gleichzeitigen Erhöhung des WG auf 4,- DM je geleisteter Arbeitsstunde sich diese restlichen 28 SWG-Ausfallstunden automatisch weiter verringern, weil ein ähnlicher produktionsorientierter Effekt eintritt, wie der, der bei Einfuhrung des WG im Jahr 1972 einen deutlichen Rückgang in den Ausfallstunden je Bauarbeiter ausgelöst hat. ${ }^{773}$ Für den Fall noch verbleibender Ausfallstunden werden die bestehenden tariflichen Regelungen zur Arbeitszeit angewendet, d.h. die ausgefallenen Arbeitsstunden durch Witterungseinflüsse können innerhalb von 24 Werktagen nachgeholt werden.

Die Finanzierung des erhöhten WG obliegt den Arbeitgebern im Rahmen der WBUmlage. Vergleicht man dazu die geleisteten Zahlungen an Lohnausgleich und WG im

771 Anmerkung: Über die Verteilung der Ausfallstunden je Ausfalltag in der Schlechtwetterzeit gibt es keine statistischen Erhebungen. Aufgrund der normalerweise ungünstigeren Witterungsverhältnisse in den Monaten Januar und Februar erscheint diese Vorgehensweise gerechtfertigt.

772 Ermittlung des Ausfallstundenanteils aus dem Verhältnis von Urlaubstagen zu Arbeitstagen des Monats.

773 vgl. Abbildung 71, S.198 und Abbildung 74, S. 208. 
Durchschnitt des Zeitraumes 1986-92 so ist nur ein geringfügiger Unterschied festzustellen. An WG ergeben sich durchschnittlich 660 Mio. DM und an Lohnausgleich 645 Mio. DM. ${ }^{774}$ Daraus ist zu schließen, daß die Arbeitgeber aufyrund dieser Umverteilung finanziell nicht stärker belastet werden. Hinzu kommt, daß ihnen jetzt, im Vergleich zum Lohnausgleich, die Arbeitsleistung des Arbeitnehmers zur Verfügung steht.

Betrachtet man abschließend die Einkommenseffekte der Arbeitnehmer, so ist festzustellen, daß sich das Bauarbeitereinkommen wesentlich erhöht. Die noch bestehende Regelung mit SWG, Lohnausgleich, Lohnausfall und WG führte im Zeitraum 1986-92 zu einem durchschnittlichen Einkommensergebnis von 1.145 DM. ${ }^{775}$ Bei der Streichung der SWG-Regelung und einer Verdopplung des WG würde sich ein durchschnittliches Einkommensergebnis von 1.764 DM ergeben. ${ }^{776}$ Dieser positive Einkommenseffekt ist allerdings etwas zu relativieren, da angenommen werden kann, daß einige der Ausfallstunden im Rahmen der SWG-Regelung nachgeholt worden sind.

Die in dieser Arbeit gewonnenen Erkenntnisse über die Förderungsmaßnahmen zur ganzjährigen Beschäftigung in der Bauwirtschaft haben aufgezeigt, daß mit der Einführung der Arbeitgeberbeteiligung an den Kosten der PWF in Form der WB-Umlage eine von konjunkturellen Einflüssen weitgehend unabhängige kontinuierliche $\mathrm{Re}$ duzierung der Ausfallstunden festgestellt werden konnte. Die Ansätze möglicher tariflicher Änderungen, die sich auch auf die neuen Bundesländer übertragen lassen, haben daher eine entsprechend produktionsorientierte Ausrichtung.

Vor dem Hintergrund des prognostizierten Baubedarfs nach Abschnitt 2.1.3. für Gesamtdeutschland vertritt der Verfasser die Ansicht, daß mit der dargestellten Lösung der Ausfallstundenproblematik (Urlaubsverlegung, Differenzierung der Wochenarbeitszeit) eine Möglichkeit zur Verstetigung und Erhöhung der Bauarbeitereinkommen, zur Verbesserung der kontinuierlichen Bautätigkeit und zur Sicherung der ganzjährigen Beschäftigung aufgezeigt worden ist.

774 Der Durchschnitt von 660 Mio. DM für das WG errechnet sich aus dem Zeitraum 1986-92 ohne Berücksichtigung des Zeitraum 1992/93, vgl. Abbildung 70, S.194.

775 vgl. Abbildung 78, S.226.

776 Berechnet aus der Verdopplung des durchschnittlichen WG je Beschaftigten (1986-92) von 881,93 DM, vgl. Abbildung 78, S.226. 


\section{Erläuterungen zu den gesetzlichen Vorschriften von 1960-68}

Die folgenden Beschreibungen und Erläuterungen der gesetzlichen Vorschriften geben einen Überblick über die umfassenden Neuerungen der Förderung in der Bauwirtschaft. Hierbei erhoffte sich der Gesetzgeber durch die Einbeziehung aller am Baugeschehen unmittelbar Beteiligten in die Förderung, die Beseitigung der saisonalen Beschäftigungsschwankungen. Die Förderungsmaßnahmen des AVAVG im einzelnen:777

\section{§ 143 a: Förderung der Bauherren}

Bauherren, die in der witterungsungünstigen Jahreszeit bauen wollten, konnten $\mathrm{Zu}$ schüsse oder Darlehen von der BAVAV erhalten. Auf diese Förderung bestand allerdings kein Rechtsanspruch. Bemessungsgrundlage für die Höhe der Zuschüsse an private Bauherren (öffentliche Bauherren erhielten keine Förderung) war die vom 1.Dezember bis 31.März angefallene Bruttolohnsumme. Die Förderung stieg im Zeitraum 1959/60-67/68 von 7,5\% im Winter 1959/60, über 10,5\% auf schließlich 11\% in 1967/68 der angefallenen Bruttolohnsumme an. Förderungswürdig waren nur Bauten des öffentlich sozialen Wohnungsbaues und zwar dann, wenn Bauherr und Bauunternehmer vertragliche Vereinbarungen über Winterbauschutzvorkehrungen getroffen hatten.

\section{§ 143 b: Förderung der Unternehmen des Baugewerbes}

Hierbei handelt es sich ebenfalls um Leistungen ohne Rechtsanspruch, die dem Bauunternehmer auf Antrag Zuschüsse - später auch zinsgünstige Darlehen - für die für den Winterbau notwendigen Maschinen und Geräte (z.B. Heizaggregate, Dampferzeuger) sowie Abdeckungsmaterial (Zeltplanen, Folien etc.) gewährten.

\section{§ 143 c: Förderung der Arbeitnehmer des Baugewerbes}

Auch auf diese Leistungen bestand kein Rechtsanspruch. Sie wurden nur dann von der Bundesanstalt gewährt, wenn der Arbeitgeber sie nicht übernahm. Im einzelnen bewilligte die Bundesanstalt den Arbeitnehmern des Baugewerbes Darlehen oder Zinszuschüsse zur Beschaffung von Schutzkleidung für die Schlechtwetterzeit, desweiteren eine Trennungsbeihilfe für die Arbeitnehmer, die infolge auswärtiger

777 vgl. Unterabschnitt C des 4. Abschnittes des AVAVG ( $\S 143 a$ bis 143n). 
Beschäftigung einen getrennten Haushalt führen mußten und schließlich Fahrtkostenzuschüsse für Heimfahrten des Arbeitnehmers an seinen Hauptwohnsitz.

\section{§§ 143 d-n: Schlechtwettergeldregelung (SWG-Regelung) für Bauarbeiter}

Im Gegensatz zu den drei erstgenannten Leistungen bestand und besteht für das SWG ein Rechtsanspruch. Dieses erhält der Bauarbeiter von der Bundesanstalt immer dann, wenn er, ohne aus dem Arbeitsverhältnis ausgeschieden zu sein, aufgrund von Witterungsumständen seine Arbeit nicht aufnehmen kann und daher einen Lohnausfall erleidet. Das SWG unterscheidet sich vom Arbeitslosengeld in den folgenden Punkten:

- Der Arbeitnehmer muß, um SWG zu erhalten, in einem Arbeitsverhältnis stehen (im Gegensatz zum Arbeitslosengeld).

- Das SWG kann nur für die Zeit gewährt werden, in der zwingende witterungsbedingte Gründe die Arbeit unmöglich machen. ${ }^{778}$

- Die Berechnung und die Auszahlung des SWG erfolgt durch den Arbeitgeber, der seine Ausgaben erst nachträglich von der Bundesanstalt erstattet bekommt.

- Die Höhe des SWG lag etwas über dem Arbeitslosengeld. Erst seit Inkraftreten des Haushaltsstrukturgesetzes am 1. Januar 1976 sind Arbeitslosen- und Schlechtwettergeld gleich hoch.

- Das SWG wird ausschließlich in der sogenannten Schlechtwetterzeit vom 1. November bis 31. März gezahlt.

In der Finanzierung unterscheiden sich Arbeitslosen- und Schlechtwettergeld nicht voneinander. Sie erfolgte durch die Beiträge aller bei der BAVAV versicherten Personen.

778 Anmerkung: Eine Definition der zwingenden Witterungsgründe wird in Kap. 3.1.4. Witterungsbedingungen, S.101ff. gegeben. 


\section{Erläuterungen zu den gesetzlichen Vorschriften von 1969-71}

Wie bereits erwähnt, wurde das alte AVAVG durch das AFG abgelöst. ${ }^{779}$ Mit der sogenannten Produktive Winterbauförderung (PWF) wurde eine grundsätzlich neuartige Form der Bezuschussung von Bauten während der Winterperiode geschaffen. Die folgenden Erläuterungen geben einen Überblick über die neuen Förderungsmaßnahmen:

\section{\$§ 74 - 81: SWG-Regelung}

Die Vorschriften der $\S \S 143$ d-n zum SWG, die noch im AVAVG mehrfach geändert und verbessert wurden, ${ }^{780}$ sind in ihren Grundzügen übernommen worden. ${ }^{781}$

\section{§§ 82 - 87: Produktive Winterbauförderung (PWF)}

Ein neuer Förderungsansatz der Bundesanstalt für Arbeit (BA) ${ }^{782}$ bestand darin, nicht mehr den Bauherren, sondern den Unternehmern des Baugewerbes Zuschüsse zu den witterungsbedingten Mehrkosten des Bauens während der Schlechtwetterzeit zu gewähren. Außerdem wurden jetzt alle Bauten, ${ }^{783}$ einschließlich die der öffentlichen Hand, die vorher von der Förderung ausgeschlossen waren, bezuschußt. Ein Rechtsanspruch auf PWF bestand ebenfalls, wenn die folgenden Voraussetzungen erfüllt wurden: ${ }^{784}$

- $§ 82$ Abs.1 AFG: Die Zuschüsse wurden nur an Unternehmen des Baugewerbes für Bauarbeiten während der sogenannten Förderungszeit ${ }^{785}$, d.h. Januar und Februar, geleistet.

779 vgl. Kap. 2.4.1.3. 1969-71: Das Arbeitsforderungsgesetz, S.70.

780 vgl. Drittes Änderungsgesetz zum AVAVG und Kap. 2.4.2. Tarifvertragliche Leistungen und Regelungen, S.74ff.

781 vgl. hierzu ausführlich Krebs, H., Arbeitsforderungsgesetz (AFG), Kommentar zu §§74-81 und Schiekel, H., Arbeitsförderungsgesetz (AFG), Kommentar zu §§74-81.

782 Früher: Bundesanstalt für Arbeitsvermittlung und Arbeitslosenversicherung (BAVAV).

783 Anmerkung: Vorher nur der öffentlich soziale Wohnungsbau.

784 vgl. im Gegensatz dazu die Zuschüsse nach §143 a AVAVG.

785 Hinweis: Der Gesetzgeber unterscheidet zwischen Förderungszeit und Schlechtwetterzeit (November bis Mărz). 
- 882 Abs.2 AFG: Es wurden ausschließlich die auf der Baustelle verrichteten Arbeiten gefördert und zwar dann, wenn ausreichende Schutzvorkehrungen (in wirtschaftlich vertretbarem Maß) getroffen worden waren.

- §83 AFG: Zuschüsse wurden nur dann gewährt, wenn innerhalb der Förderungszeit mindestens 800 Arbeitsstunden geleistet worden waren. Auf diese Weise sollten sogenannte "Bagatellfälle", die die Verwaltungsarbeit erschwert hätten, von der Förderung ausgeschlossen bleiben.

- $§ 84$ AFG: Der Zuschuß für die gesamte Förderungszeit war dann zu versagen, wenn für die Bauarbeiter der geförderten Baustelle eine Anzeige wegen Arbeitsausfalles infolge ungünstiger Witterung beim Arbeitsamt erstattet wurde. Der Unternehmer konnte also nicht zwischen PWF und SWG wählen, sondern mußte sich für eines von beiden entscheiden.

- §85 AFG: Die Förderungshöhe errechnete sich aus dem gesetzlich festgelegten Förderungssatz multipliziert mit der Zahl der in der Förderungszeit geleisteten Arbeitsstunden (einschließlich Überstunden).

\section{\$§ 88 - 90: Sonstige Leistungen}

Darlehen und Zinszuschüsse konnten jetzt auch für die Miete, statt wie bi her nur für den Erwerb von Winterbaugeräten, gewährt werden. Ansonsten entsprachen diese Regelungen denen der $\S \S 143 \mathrm{~b}$ und $\mathrm{c}$ des AVAVG. ${ }^{786}$

786 vgl. hierzu ausführlich Krebs, H., Arbeitsförderungsgesetz (AFG), Kommentar zu §§88-90 und Schiekel, H., Arbeitsförderungsgesetz (AFG), Kommentar zu §§88-90. 


\section{Erläuterungen zu den gesetzlichen Vorschriften von 1972-85}

Im Rahmen der gesetzlichen Vorschriften der sogenannten Winterbaunovelle, sollten die produktionsorientierten Förderungsleistungen verbessert werden. Diese Aussage wird durch die neue gesetzliche Gliederung der Maßnahmen zur "Förderung der ganzjährigen Beschäftigung in der Bauwirtschaft" in Allgemeine Vorschriften (§§74-76), PWF (§§77-82) und SWG ( $\S 83-89)$ unterstützt. Die folgenden Erläuterungen beschreiben die Förderungsmaßnahmen im einzelnen:

\section{\$§ 74 - 76: Allgemeine Vorschriften}

Die allgemeinen Vorschriften der $§ \S 74-76$ geben einen Überblick über die Aufgaben und Leistungen der $\mathrm{BA},{ }^{787}$ den Förderungszeitraum ${ }^{788}$ und die in die Winterbauförderung einbezogenen Betriebe. ${ }^{789}$ Als Förderungszeit, d.h. als Zeitraum, in dem PWF gewährt wird, galt seit Einführung der Winterbaunovelle bis einschließlich des Winters 1975/76 die Zeit vom 16. Dezember bis 15. März. ${ }^{790}$ Durch das 19. Rentenanpassungsgesetz ist die Förderungszeit seit der Winterperiode 1976/77 auf den 1. Dezember vorverlegt worden. Als Schlechtwetterzeit, d.h. als Zeitraum, in dem SWG gewährt wird, gilt wie bislang die Zeit vom 1. November bis 31 . März. Die Frage, welche Betriebe leistungsberechtigt im Sinne der Winterbauforderung sind, ist im Vergleich zum alten Recht eindeutig geklärt. Bis auf eine Ausnahme (Fertigteilbauarbeiten sind nur beschränkt förderungsfähig) deckt sich $\S 1$ Abs.1 Nr.1 der Baubetriebe-VO mit dem fachlichen und betrieblichen Geltungsbereich des Bundesrahmentarifvertrages für das Baugewerbe; d.h. alle Betriebe und Betriebsabteilungen, furr die dieser Tarifvertrag maßgebend ist, sind zur Winterbauförderung zugelassen. Damit wurde ein Zustand der Rechtsunsicherheit beseitigt. ${ }^{791}$

787 vgl. $\$ 74$ AFG: Die Förderung beschränkt sich auf Arbeitgeber und Arbeitnehmer des Baugewerbes, die Bauherren werden, wie schon im bisherigen AFG, nicht gefördert.

788 §75 Abs. 2 AFG.

$789 \S 76$ AFG.

790 Im "alten" AFG war die Förderungszeit auf die Monate Januar und Februar beschränkt.

791 vgl. Kranz, G., Produktive Winterbauförderung und Zulassung von Betrieben des Baugewerbes zum Schlechtwettergeld, S.1196ff. 


\section{§§7 - 82: Produktive Winterbauförderung}

Die Winterbauförderungsmaßnahmen, die hier in der Winterbaunovelle unter dem Begriff "Produktive Winterbauförderung" aufgeführt werden, sind wesentlich umfangreicher als die Maßnahmen der Produktiven Winterbauforderung des alten AFG und müssen daher voneinander unterschieden werden. ${ }^{792}$ Die $\$ \S 81$ und 82 beinhalten Verfahrens- und Anordnungsfragen zur neuen PWF. In den folgenden Ausführungen soll der Leistungsumfang der $\$ \S 77$ bis 80 näher beschrieben werden. Hierbei ist zwischen Leistungen an Arbeitgeber des Baugewerbes ${ }^{793}$ ( $§ \S 77-79$ AFG) und Leistungen an Arbeitnehmer des Baugewerbes ( $§ 80$ AFG) zu unterscheiden:

Investitionskostenzuschuß (IKZ) gem. §77 AFG: Bei dieser Arbeitgeberleistung handelt es sich um Zuschüsse für den Erwerb oder die Miete von Winterbaugeräten und -einrichtungen. ${ }^{794} \mathrm{Sie}$ ist zwar keine grundsätzlich neue Form der Winterbauförderung, geht aber doch weit über die bisherigen Förderungsmaßnahmen hinaus, da nunmehr bei Erfüllung gewisser Voraussetzungen ein Rechtsanspruch besteht. ${ }^{795}$ Auch die Höhe liegt entschieden über den bisherigen Leistungen, wie die $§ \S 3-9$ der Winterbau-AO belegen: ${ }^{796}$

Kaufpreiszuschuß bei Ersterwerb gestaffelt nach Gruppen: ${ }^{797}$

- Gruppe 1 mit 50\%: selbsttragende Winterbauschutzhallen, Dachbinder, Seitenverkleidungen, Heizaggregate, Lufterhitzer, etc.

- Gruppe 2 mit 40\%: Dampfstrahlreiniger, Heizmatten, etc.

- Gruppe 3 mit 30\%: Kleinere Schneeräumgeräte, Geräte/Einrichtungen zur Warmwasserbereitung und zur Kleidertrocknung

792 vgl. BT-Drucks. VI/2689, S.9.

793 Arbeitgeber des Baugewerbes sind laut Defonition des $\$ 75$ Abs.1 Nr.1 AFG "natürliche und juristische Personen, Personenvereinigungen oder Personengesellschaften, die als Inhaber von Betrieben des Baugewerbes auf dem Baumarkt gewerblich Bauleistungen anbieten."

$794 \$ 77$ AFG tritt somit an die Stelle des alten $\S 88$ AFG bzw. des davor geltenden $\S 143$ b AVAVG.

795 §2 Winterbau-AO: Die Geräte und Einrichtungen, für die Zuschüsse beantragt werden, müssen für den Winterbau zusätzlich erforderlich sein. Hierzu gehören in jedem Fall die in $\S 3$ Winterbau-AO aufgeführten Gerăte und Einrichtungen. Sie müssen weiterhin für den Einsatz während der Schlechtwetterzeit bestimmt sein, und zwar auf Baustellen im Geltungsbereich des AFG. Schließlich müssen die Geräte und Einrichtungen dem "Gesetz über technische Arbeitsmittel" vom 24. Juni 1968 (BGBl. I, S.717ff.) sowie $\$ 4$ Abs.2 Arbeitsschutz-VO für Winterbaustellen entsprechen.

$796 \$ 77$ Abs.2 AFG gibt hinsichtlich der Höhe des Zuschusses lediglich bestimmte Richtwerte an.

797 Die Geräte wurden nach ihrer Bedeutung für den Winterbau in drei verschiedene Gruppen eingeteilt und unterschiedlich bezuschußt. 
Allerdings dürfen die IKZ für das einzelne Gerät bzw. die einzelne Einrichtung 100.000,- DM nicht übersteigen.

Mietkostenzuschuß wird für die gesamte Mietdauer gewährt, soweit diese in die Schlechtwetterzeit fällt. Es gilt die gleiche Gruppeneinteilung mit denselben Prozentsätzen wie für den Ersterwerb. Die Obergrenze des Zuschusses liegt bei 20.000,- DM je Gerät bzw. Einrichtung.

"Second-hand-Zuschuß": Es konnte unter bestimmten Voraussetzungen auch der Erwerb aus zweiter Hand bezuschußt werden. ${ }^{798}$ Diese neue Regelung sollte vor allem kapitalschwächeren Betrieben, für die nur der Erwerb gebrauchter Geräte in Frage kam, die Möglichkeit auf Zuschüsse geben. Im Zusammenhang damit steht auch die Sonderregelung für Kleinbetriebe. ${ }^{799}$ Diese Betriebe, bei denen Ende Oktober vor Stellung des Anerkennungsantrages nicht mehr als 20 Arbeiter beschäftigt waren, ${ }^{800}$ wurden mit einem noch höheren Zuschuß gefördert; d.h. die genannten Prozentsätze wurden um jeweils $10 \%$ erhöht, unabhängig davon, ob es sich um Kauf oder Miete handelte ${ }^{801}$ Als Kannleistung waren schließlich noch sogenannte zusätzliche Darlehen $^{802}$ in Ausnahmefällen vorgesehen, wenn der Förderungszweck durch besondere Umstände mit den Zuschüssen nicht erreicht werden konnte.

MehrkostenzuschuB (MKZ) gem. $\$ 78$ und 79 AFG: Dies sind Zuschüsse, die den Arbeitgebern des Baugewerbes zu den witterungsbedingten Mehrkosten des Bauens in der Schlechtwetterzeit gewährt werden. ${ }^{803}$ In Bezug auf den Rechtsanspruch des Zuschusses sind mit dieser neuen Regelung einige Unsicherheiten beseitigt worden. So werden die MKZ nur an Arbeitgeber des Bauge-

\footnotetext{
798 vgl. $\$ 4$ Winterbau-AO.

799 vgl. $\$ 77$ Abs. 2 Satz 2 AFG.

800 Von den 58.468 Betrieben des Bauhauptgewerbes, die bei der Totalerhebung am 30. Juni 1975 gezăhlt wurden, waren über 44.000 , das sind etwa $75 \%$ Kleinbetriebe in diesem Sinne, vgl. Hauptverband der Deutschen Bauindustrie (Hrsg.), Baustatistisches Jahrbuch 1976, S.16.

801 vgl. 66 Abs. 1 Winterbau-AO.

802 vgl. $\$ 77$ Abs. 1 Satz 3 AFG.

803 Anmerkung: Die Mehrkostenzuschüsse sind bis auf einige wesentliche Ausnahmen mit der "alten" PWF der früheren $\S \S 82-87$ identisch.
} 
werbes $^{804}$ (bisher: Unternehmen des Baugewerbes) geleistet, weil dieser Begriff im Gegensatz zum Unternehmen keine Abgrenzungsschwierigkeiten bereitet.

Nach wie vor werden ausschließlich die auf der Baustelle geleisteten Arbeiten ${ }^{805}$ gefördert. Hierunter sind allerdings, im Gegensatz zum alten Recht, auch in der Nähe gelegene, der Baustelle zugeordnete Arbeitsstätten zu verstehen. Voraussetzung ist wie bisher, daß ausreichende Schutzvorkehrungen ${ }^{806}$ gegen Witterungseinflüsse getroffen werden, so daß die Fortführung der Arbeit auch bei ungünstiger Witterung möglich ist. Die Förderungszeit ${ }^{807}$ ist jetzt auf die Zeit vom 16. Dezember bis 31. März ausgedehnt worden. ${ }^{808}$ Seit der Winterperiode 1976/77 beginnt sie sogar schon am 1. Dezember.

Desweiteren werden $\mathrm{MKZ}$ nur für Arbeitsstunden gewährt, die von Arbeitern geleistet ${ }^{809}$ worden sind. Hierzu gehören auch die Überstunden. Arbeitsstunden von Angestellten (Schachtmeister, Poliere) und Lehrlingen bleiben unberücksichtigt. Wesentlich dabei ist, daß im Gegensatz zur bisherigen Regelung nicht mehr mindestens 800 Arbeitsstunden innerhalb der Förderungszeit geleistet werden müssen. $\$ 84$ AFG a.F. wurde ersatzlos gestrichen, wonach der Zuschuß für die gesamte Förderungszeit bei Anzeige von witterungsbedingtem Arbeitsausfall zu versagen war. ${ }^{810}$

Die Höhe des MKZ errechnete sich nach wie vor durch Multiplikation der Zahl der während der Förderungszeit geleisteten Arbeitsstunden mit dem sogenannten Förderungssatz. ${ }^{811}$ Die Zuschüsse sollten mindestens ein Drittel und höchstens zwei Drittel der im allgemeinen zu erwartenden Winterbaumehrkosten dekken. ${ }^{812}$ Sie sind je nach Art der durchzuführenden Bauarbeiten unterschiedlich hoch und betragen nun nach der Förderungssätze-Verordnung ${ }^{813}$ gemäß $§ 1: 814$

\footnotetext{
$804 \S 78$ Abs. 1 AFG.

805 \$78 Abs.2 Satz 1, 1. Halbsatz AFG.

806 \$78 Abs.2 AFG.

807 \$78 Abs. 1 AFG.

808 vorher: Januar und Februar.

809 \$79 Abs.2 AFG.

810 vgl. Kap. 2.4.1.3. 1969-71: Das Arbeitsförderungsgesetz, S.70.

$811 \$ 79$ Abs. 2 und Abs.3 AFG.

812 Gemäß Art.2 Winterbaunovelle galten die Förderungssătze des §85 Abs.2 AFG a.F.

813 BGBI. 1, S. 841 .
} 


\begin{tabular}{|lll|}
\hline $\begin{array}{l}\text { Hochbau } \\
\text { Rohbau } \\
\text { Ausbau }\end{array}$ & $2,50 \mathrm{DM}$ & $(1,50 \mathrm{DM})$ \\
\hline Tiefbau & $1,00 \mathrm{DM}$ & $(0,60 \mathrm{DM})$ \\
Erschließungsarbeiten im Straßenbau & $3,60 \mathrm{DM}$ & $(2,70 \mathrm{DM})$ \\
Brückenbauten & $3,20 \mathrm{DM}$ & $(2,70 \mathrm{DM})$ \\
offener Tunnel- und Untergrundbahnbau & $2,00 \mathrm{DM}$ & $(1,20 \mathrm{DM})$ \\
Ausbau & $1,00 \mathrm{DM}$ & $(0,60 \mathrm{DM})$ \\
\hline Sonstige Arbeiten & $2,00 \mathrm{DM}$ & $(1,20 \mathrm{DM})$ \\
\hline
\end{tabular}

Anmerkung: In Klammern bisherige Förderungssätze.

Wintergeld (WG) gem. $§ 80$ Abs.1 AFG: Das Wintergeld ist, wie bereits erwähnt, eine völlig neuartige Leistung an Arbeitnehmer in Betrieben des Baugewerbes. Laut offizieller Begründung sollen damit die Mehraufwendungen, die die Arbeitsleistung in der witterungsungünstigen Jahreszeit für die Bauarbeiter mit sich bringt, pauschal abgegolten werden. ${ }^{815}$ Durch die Wintergeld-Regelung wird einerseits die Einkommenslage der Bauarbeiter während der Wintermonate verbessert und somit ein Beitrag zu der von der Gewerkschaft geforderten materiellen Absicherung geleistet. Andererseits werden durch das Vergrößern der Differenz zwischen Nettoeinkommen und SWG dem Arbeitnehmer verstärkte Anreize zur Weiterarbeit bei ungünstiger Witterung gegeben. ${ }^{816}$ Voraussetzung für die Gewährung von WG ist:

- WG wird nur in der Förderungszeit gewährt. Ausgenommen ist der Lohnausgleichszeitraum vom 24. Dezember bis 1 . Januar. ${ }^{817}$

- Nur Arbeitnehmer, die in Betrieben des Baugewerbes beschäftigt sind, können WG beanspruchen. ${ }^{818}$

814 vgl. "Verordnung über die Förderungssätze für den Mehrkostenzuschuß der Produktiven Winterbaufördenung (Förderungssätze-Verordnung)" vom 16. Juli 1973.

815 BT-Drucks. VI/3261, S.4.

816 vgl. Bundesministerium für Städtebau und Wohnungswesen, Ganzjähriges Bauen - Winterbau, Rundschreiben vom 6. Juli 1972, S. 439f.

817 vgl. Kap. 2.4.2. Tarifvertragliche Leistungen und Regelungen: Lohnausgleichsregelung in der Bauwirtschaft, S.74ff.

818 Betriebe, die nach der Baubetriebe-VO zur Winterbauförderung zugelassen sind. 
- WG erhalten nur Arbeiter, nicht aber Angestellte (Schachtmeister, Poliere) ${ }^{819}$ oder Lehrlinge.

- Die Arbeiter müssen auf einem witterungsabhängigen Arbeitsplatz beschäftigt sein und bei witterungsbedingtem Arbeitsausfall Anspruch auf SWG haben. ${ }^{820}$

- WG wird nur für in der Förderungszeit geleistete Arbeitsstunden, also auch für Überstunden, nicht aber für Zeiten des Urlaubs, der Krankheit etc. gewährt. ${ }^{821}$

- Die Höhe des WG beträgt 2,- DM je geleisteter Arbeitsstunde. Das WG ist lohnsteuerfrei, ${ }^{822}$ weil es sich um eine Sozialleistung der BA handelt, die nicht als Lohnbestandteil (kein Entgelt i.S. der Sozialversicherung) anzusehen ist. ${ }^{823}$

- WG wird auf Antrag des Arbeitgebers oder Betriebsrates, der spätestens innerhalb von 3 Monaten nach dem Ende der Schlechtwetterzeit zu stellen ist, an diesen zur Auszahlung an die Arbeitnehmer überwiesen.

Sonstige Leistungen an Arbeitnehmer des Baugewerbes, ${ }^{824}$ wie die Trennungsbeihilfe und der Fahrtkostenzuschuß sind mit Inkraftreten des Haushaltsstrukturgesetzes am 1. Januar 1976 ersatzlos gestrichen worden. ${ }^{825}$

819 Gemäß "Tarifvertrag über einen Wintergeldausgleich für die Poliere und Schachtmeister des Baugewerbes im Gebiet der Bundesrepublik Deutschland" vom 23. November 1972 i.d.F vom 8. Oktober 1976 erhalten jedoch Poliere und Schachtmeister in den Monaten Dezember, Januar und Februar zusätzlich zu ihrem Monatsgehalt einen sog. Winterausgleich in Höhe von 175,DM brutto.

820 vgl. Bundesanstalt für Arbeit, RdErl.346/72.

821 Hinweis: Förderungszeit (1. Dezember bis 31. März) und Schlechtwetterzeit (1. November bis 31. März).

$822 \S 80$ Abs. 1 AFG.

$823 \S 3$ Ziff. 2 EStG i.V.m. §6 Nr.1 LStDV.

824 vgl. $\$ 80 \mathrm{Abs} .2 \mathrm{AFG}$, die hier aufgeführten Leistungen stimmen im wesentlichen mit den früheren $\$ 143$ c AVAVG bzw. \$89 AFG a.F. überein.

825 Die Zuschüsse für Arbeitsausrüstung, wie sie das AFG von 1969 noch vorgesehen hatte, waren schon mit Inkrafttreten der Winterbaunovelle entfallen. Danach ist die Arbeitsausrüstung als "einfache Schutzvorrichtung" im Sinne des $\$ 84$ Abs.2 Nr.1 AFG vom Arbeitgeber zu stellen. 


\section{$\S \S 83$ - 89: Schlechtwettergeld}

Wenn auch das SWG dem Willen des Gesetzgebers gemäß "nunmehr als subsidiäre Winterbau-Förderungsleistung erscheint" 826 und daher gliederungsmäßig hinter die Vorschriften über die PWF gerückt ist, dürfte ihm dennoch im Rahmen der Förderungsmaßnahmen weiterhin entscheidende Bedeutung zukommen. Der folgende Überblick über die jetztige SWG-Regelung, die in ihren Grundzügen gleichgeblieben ist, zeigt auch die vorhandenen Detailänderungen auf. ${ }^{827}$ Zur Gewährung von SWG gelten die folgenden Voraussetzungen:

- SWG wird nur bei witterungsbedingtem Arbeitsausfall auf Baustellen in der Schlechtwetterzeit (01.11.-31.03.) und nur in Betrieben des Baugewerbes, in denen nach der Baubetriebe-Verordnung die ganzjährige Beschäftigung zu fördern ist, gewährt. ${ }^{828}$

- Die Gewährung von SWG ist zulässig, wenn der Arbeitsausfall ausschließlich durch zwingende Witterungsgründe ${ }^{829}$ verursacht ist, und an einem Arbeitstag mindestens eine Stunde der regelmäßigen betriebsüblichen Arbeitszeit innerhalb der tariflichen Arbeitszeit ausfällt. Die Ausfallstunde kann sich auch aus Teilzeiten zusammensetzen. ${ }^{830}$

- Anspruchsvoraussetzung des Arbeitnehmers ist, ${ }^{831}$ daß er bei Beginn des Arbeitsausfalles auf einem witterungsabhängigen Arbeitsplatz als Arbeiter in einer die Beitragspflicht begründeten Beschäftigung steht ${ }^{832}$ und infolge des Arbeits-

826 BT-Drucks. VI/2689, S.10.

827 vgl. $\S 143$ d-n AVAVG bzw. $\$ \$ 74-81$ AFG a.F.

828 vgl. $\$ 83$ AFG

$829 \$ 84$ Abs.1 AFG. Anmerkung: Zwingende Witterungsgründe werden nach $\$ 84$ Abs.2 AFG definiert als "atmosphärische Einwirkungen (Regen, Schnee, Frost, usw.) oder deren Folgeerscheinungen (z.B. unpassierbares Gelände), die so stark auftreten müssen, daß eine Weiterarbeit technisch unmöglich, wirtschaftlich nicht vertretbar oder fur den Arbeitnehmer unzumutbar ist. Zur Beurteilung der Frage, wann zwingende Witterungsgründe i.S. von §84 Abs.2 AFG im einzelnen vorliegen vgl. Kap. 3.1.4. Witterungsbedingungen, S.101ff.

830 vgl. $\$ 84$ Abs.1 Nr.2 AFG. Diese Regelung ist neu. Vorher mußte ein voller Arbeitstag ausfallen.

831 vgl. $\S 85$ AFG.

832 Anspruchsberechtigt sind nur Arbeitnehmer, die im Sinne des $\$ 168$ Abs.1 AFG beitragspflichtig zur BA sind, d.h. keine Poliere und Schachtmeister. 
ausfalles für die Ausfallstunde kein Arbeitsentgelt bezieht ${ }^{833}$ oder arbeitsunfähig infolge von Erkrankung ist und Anspruch auf Lohnfortzahlung hat. ${ }^{834}$

- Die Höhe des SWG ${ }^{835}$ richtet sich nach dem Bemessungsentgelt. Für Arbeitnehmer, die ohne den Arbeitsausfall Zeitlohn (Stundenlohn) erhalten hätten, ist der tariflich oder vertraglich vereinbarte Brutto-Stundenlohn zugrunde zu legen. Hinzu kommen bestimmte Zuschläge (z.B. Mehrarbeits- und Erschwerniszuschläge) sofern sie regelmäßig gezahlt worden sind.

Für Arbeitnehmer, die ohne den Ausfall Leistungslohn (Akkordlohn) erhalten hätten, ist das Arbeitsentgelt ohne Mehrarbeitszuschläge zugrunde zu legen, das in den letzten mindestens 13 Wochen vor dem ersten Arbeitsausfall in der Schlechtwetterzeit durchschnittlich in der Arbeitsstunde erzielt wurde. ${ }^{836}$

Desweiteren hängt die Höhe einerseits von der maßgeblichen Leistungsgruppe (A-E) ab, die sich aus der in der Lohnsteuerkarte eingetragenen Steuerklasse (IVI) zum jeweils maßgeblichen Abrechnungszeitraum ergibt und andererseits vom Leistungssatz (1 oder 2). Für Arbeitnehmer beträgt das zu gewährende SWG aufgrund des errechneten durchschnittlichen Stundenlohnes, ebenso wie das Arbeitslosen- und Kurzarbeitergeld, 68\% des sonst zu erzielenden Nettolohnes (Leistungssatz 1). Für die übrigen Arbeitnehmer sind es $63 \%$ des Nettolohnes (Leistungssatz 2). ${ }^{837}$ Die Berechnung des SWG erfolgt durch Multiplikation mit der Zahl der wegen Schlechtwetters innerhalb der tariflichen Arbeitszeit ausgefallenen Arbeitsstunden. ${ }^{838}$ Überstunden bleiben demnach unberücksichtigt.

$833 \mathrm{Zu}$ den Ausnahmen vgl. 885 Abs.1 Nr.2 AFG.

834 Anmerkung: Für Urlaubszeiten, gesetzliche Feiertage etc., d.h. für Zeiten in denen ein Anspruch auf Arbeitsentgelt besteht wird kein SWG gewăhrt.

835 vgl. §86 AFG, der an die Stelle des §143g AVAVG bzw. \$77 AFG a.F. getreten ist.

836 In BT-Drucks. VI/2689, S.9 heißt es hierzu in der Begründung zu $\$ 86$ Abs.2 AFG: "Es hat sich herausgestellt, $\mathrm{da} B$ das Arbeitsentgelt, daB Akkordarbeiter im letzten abgerechneten Lohnabrechnungszeitraum vor dem ersten Arbeitsausfall in der Schlechtwetterzeit erzielen (bisherige Bemessungsgrundlage), häufig nicht typisch für ihr durchschnittliches Arbeitsentgelt ist."

837 Anhand der vom Bundesminister für Arbeit und Sozialordnung jeweils für ein Kalenderjahr aufgestellten Verordnung über Leistungssätze (SWG-Tabelle) ist abzulesen welcher SWG-Betrag dem Arbeitnehmer pro Ausfallstunde zusteht.

838 gemäß $§ 3$ Nr. 1.1 BRTV zur Zeit 39 Stunden. 
- Ein Zuschlag zu dem sich aus der Tabelle ergebenden SWG wurde bis zum Inkraftreten des Haushaltsstrukturgesetzes gewährt. ${ }^{839} \mathrm{Er}$ betrug 0,30 DM pro Ausfallstunde. ${ }^{840}$ Mit dieser Höherstellung des SWG im Vergleich zum Arbeitslosengeld sollten die größeren finanziellen Belastungen der Bauarbeitnehmer durch deren Anwesenheitspflicht auf der Baustelle ausgeglichen werden.

- Das SWG ist wie das WG eine Sozialleistung der BA und daher nicht lohnsteuerpflichtig. ${ }^{841}$

Das Verfahren, daß der Arbeitgeber bei Erstattung der Anzeige sowie bei der Antragstellung auf Gewährung und Auszahlung des SWG zu beachten hat, regelt $§ 88$ AFG. Auf seine verfahrensrechtlichen Vorschriften, d.h. formale Fragen hinsichtlich Inhalt und Form der Anzeige, soll hier nicht näher eingegangen werden.

Abschließend soll an dieser Stelle kurz auf die schon genannte Winterbau-UmlageVerordnung ${ }^{842}$ eingegangen werden, mit der der Gesetzgeber einer seit vielen Jahren von der Bundesanstalt gestellten Forderung gefolgt war, die Arbeitgeber an den Leistungen, die die BA für das Baugewerbe aufzubringen hat, zu beteiligen. ${ }^{843}$ Dabei soll die Beteiligung so festgelegt werden, daß sie mindestens die Leistungen (ohne Verwaltungskosten) für MKZ und WG deckt (ab 1982 auch für die IKZ). Die WinterbauUmlage-Verordnung regelt neben der Höhe der Umlage auch die Zahlungs- und Abführungsmodalitäten. Im einzelnen gilt:

\section{Winterbau-Umlage (WB-Umlage):}

- Die Höhe der Umlage bemißt sich nach einem Prozentsatz der lohnsteuerpflichtigen Bruttoarbeitslöhne der Arbeiter in Betrieben, in denen die ganzjährige Beschäftigung durch Leistungen der Produktiven Winterbauförderung zu fördern ist. Dieser Prozentsatz wird vom Bundesminister für Arbeit und Sozialordnung durch Rechtsverordnung festgelegt. ${ }^{844}$ Er beträgt z.Z. 2\% (bis 31. Dezember 1975 waren es $4 \%$ Arbeitgeberumlage, bis 31 . Dezember 1986 3\% und ab 1. Januar 1987 2\%).

839 vgl. §86 Abs. 1 AFG.

840 Anmerkung: Davor waren es 5\% des jeweils geltenden Bundesecklohnes.

$841 \S 3$ Ziff. 2 EStG i.V.m. §6 Nr. 1 LStDV.

$842 \S 186$ a Abs. 3 AFG.

843 Begründet durch die Tatsache, daß die Leistungen der BA an die Bauwirtschaft die Beitragseinnahmen aus diesem Wirtschaftszweig um ein Mehrfaches überschreiten.

844 Gemäß §1 Winterbau-Umlage-Verordnung. 
- Die Umlage wird jeweils am 15. des Monats fällig, der dem Monat folgt, für den der Lohn zu zahlen ist. ${ }^{845}$ Für den Einzug der Umlagebeträge nutzen die Arbeitgeber im Regelfall die gemeinsame Einrichtung ihres Wirtschaftszweiges, die sogenannte Zusatzversorgungskasse des Baugewerbes in Wiesbaden. Dadurch werden Verwaltungskosten gespart, die sonst bei einer direkt geleisteten Zahlung an das Landesarbeitsamt anfallen würden. Die Winterbau-Umlage ist von den Arbeitgebern des Baugewerbes im Wege der Selbstveranlagung (Meldung und Zahlung), d.h. ohne vorherige besondere Aufforderung, zu entrichten.

$845 \S 3$ der Winterbau-Umlage-Verordnung. 


\section{Witterungsbedingter Arbeitsausfall nach Ausfalltagewerken}

Die folgenden Abbildungen 80 bis 83 zeigen die Entwicklung der "Zahl der angezeigten witterungsbedingten Ausfalltagewerke" auf. Als Ausfalltagewerk gilt ein Tag, an dem aus Witterungsgründen für eine Person mindestens eine Stunde der Arbeitszeit ausgefallen ist. Die Ausfallstunde kann sich aus Teilzeiten zusammensetzen. Entsprechend der vorgehensweise in dieser Arbeit wird diese von der Bundesanstalt für Arbeit im Rahmen der Winterbauförderungsberichte gefürte Statistik nach Förderungszeiträumen getrennt.

Abbildung: 80

\begin{tabular}{|c|c|c|c|c|c|c|}
\hline \multicolumn{7}{|c|}{ Witterungsbedingter Arbeitsausfall 1960-1968 } \\
\hline \multirow[b]{2}{*}{ Zeitraum } & \multicolumn{6}{|c|}{ Ausfalltagewerke im Baugewerbe (in 1000) } \\
\hline & November & Dezember & Januar & Februar & März & Insgesamt \\
\hline $1959 / 60$ & 0,0 & 579,1 & 5796,4 & 4941,1 & 606,9 & 11923,5 \\
\hline $1960 / 61$ & 202,5 & 1912,3 & 7542,8 & 2064,4 & 445,5 & 12167,5 \\
\hline $1961 / 62$ & 1172,1 & 5363,0 & 7645,1 & 8358,3 & 8684,4 & 31222,9 \\
\hline $1962 / 63$ & 2080,2 & 6801,4 & 22461,0 & 21190,8 & 8175,7 & 60709,1 \\
\hline $1963 / 64$ & 1074,7 & 7791,4 & 14017,1 & 7293,5 & 7346,9 & 37523,6 \\
\hline $1964 / 65$ & 982,1 & 2741,0 & 7188,1 & 12070,8 & 9543,5 & 32525,5 \\
\hline $1965 / 66$ & 5907,7 & 3136,0 & 13502,8 & 4697,0 & 2987,9 & 30231,4 \\
\hline $1966 / 67$ & 1414,8 & 2407,1 & 6521,5 & 4548,5 & 1176,4 & 16068,3 \\
\hline $1967 / 68$ & 1164,2 & 6645,8 & 10835,8 & 5408,5 & 3929,5 & 27983,8 \\
\hline 1968/69 & 721,6 & 5273,5 & 8706,8 & 13532,7 & 6414,2 & 34648,8 \\
\hline Durchschnitt & 1635,6 & 4265,1 & 10421,7 & 8410,6 & 4931,1 & 29500,4 \\
\hline$\%$ & 5,4 & 14,4 & 36,3 & 28,5 & 16,4 & 100,0 \\
\hline
\end{tabular}

Abbildung: 81

\begin{tabular}{|c|c|c|c|c|c|c|}
\hline \multicolumn{7}{|c|}{ Witterungsbeingter irbeitsausfall 1969 - 1971 } \\
\hline \multirow[b]{2}{*}{ Zeitraum } & \multicolumn{6}{|c|}{ Ausfalltagewerke im Baugewerbe (in 1000) } \\
\hline & November & Dezember & Januar & Februar & März & Insgesamt \\
\hline $1968 / 69$ & 721,6 & 5273,5 & 8706,8 & 13532,7 & 6414,2 & 34648,8 \\
\hline $1969 / 70$ & 2354,1 & 12273,4 & 14797,4 & 13203,4 & 9089,2 & 51717,5 \\
\hline $1970 / 71$ & 1536,5 & 2609,3 & 12441,8 & 4901,0 & 10283,5 & 31772,1 \\
\hline 1971/72 & 4066,4 & 1381,9 & 10110,4 & 5735,5 & 1646,3 & 22940,5 \\
\hline Durchschnitt & 2169,7 & 5384,5 & 11514,1 & 9343,2 & 6858,3 & 35269,7 \\
\hline$\%$ & 6,2 & 15,3 & 32,6 & 26,5 & 19,4 & 100,0 \\
\hline
\end{tabular}


Abbildung: 82

\begin{tabular}{|c|r|r|r|r|r|r|}
\hline \multirow{2}{*}{ Witterangs beaingter Arbeitsausfall 1972-1985 } \\
\hline \multirow{5}{*}{ Zeitraum } & \multicolumn{5}{|c|}{ Ausfalltagewerke im Baugewerbe (in 1000) } \\
\cline { 2 - 7 } & November & Dezember & \multicolumn{1}{|c|}{ Januar } & \multicolumn{1}{|c|}{ Februar } & \multicolumn{1}{c|}{ März } & Insgesamt \\
\hline $1971 / 72$ & 4066,4 & 1381,9 & 10110,4 & 5735,5 & 1646,3 & 22940,5 \\
$1972 / 73$ & 2326,1 & 1248,5 & 6251,3 & 6115,2 & 2957,0 & 18898,1 \\
$1973 / 74$ & 4302,5 & 7748,2 & 4611,5 & 3059,7 & 2187,9 & 21909,8 \\
$1974 / 75$ & 1882,5 & 3584,2 & 3192,4 & 3397,6 & 3173,3 & 15230,0 \\
$1975 / 76$ & 2031,6 & 3336,1 & 7385,3 & 7890,5 & 3649,2 & 24292,7 \\
$1976 / 77$ & 1763,0 & 4389,7 & 8023,2 & 4755,9 & 2274,3 & 21206,1 \\
$1977 / 78$ & 3720,0 & 3252,0 & 6024,7 & 10132,1 & 2996,5 & 26125,3 \\
$1978 / 79$ & 946,6 & 5974,5 & 15428,6 & 10847,8 & 4724,8 & 37922,3 \\
$1979 / 80$ & 1998,8 & 2914,7 & 11184,3 & 4390,7 & 2485,5 & 22974,0 \\
$1980 / 81$ & 2878,7 & 8527,3 & 11669,8 & 9359,3 & 4241,9 & 36677,0 \\
$1981 / 82$ & 2655,4 & 8109,5 & 9748,3 & 5403,7 & 2648,0 & 28564,9 \\
$1982 / 83$ & 833,4 & 2359,4 & 3438,1 & 6269,7 & 1942,9 & 14843,5 \\
$1983 / 84$ & 1097,2 & 4636,5 & 5116,3 & 5135,4 & 1788,1 & 17773,5 \\
$1984 / 85$ & 699,0 & 864,3 & 7444,8 & 5369,7 & 2438,6 & 16816,4 \\
$1985 / 86$ & 3709,2 & 1424,3 & 4593,8 & 6159,6 & 2493,1 & 18380,0 \\
\hline Durchschnitt & $\mathbf{2 3 2 7 , 4}$ & $\mathbf{3 9 8 3 , 4}$ & $\mathbf{7 6 1 4 , 9}$ & $\mathbf{6 2 6 8 , 2}$ & $\mathbf{2 7 7 6 , 5}$ & $\mathbf{2 2 9 7 0 , 3}$ \\
\hline \% & $\mathbf{1 0 , 1}$ & $\mathbf{1 7 , 3}$ & $\mathbf{3 3 , 2}$ & $\mathbf{2 7 , 3}$ & $\mathbf{1 2 , 1}$ & $\mathbf{1 0 0 , 0}$ \\
\hline
\end{tabular}

Abbildung: 83

\begin{tabular}{|c|c|c|c|c|c|c|}
\hline \multicolumn{7}{|c|}{ Witterangs bedingter Arbeitsaus fall 1986 - 1992} \\
\hline \multirow[b]{2}{*}{ Zeitraum } & \multicolumn{6}{|c|}{ Ausfalltagewerke im Baugewerbe (in 1000) } \\
\hline & November & Dezember & Januar & Februar & März & Insgesamt \\
\hline $1985 / 86$ & 3709,2 & 1424,3 & 593,8 & 159,6 & 2493,1 & 18380,0 \\
\hline 1986/87 & 336,6 & 966,4 & 6800,2 & 5257,8 & 5123,9 & 18484,9 \\
\hline $1987 / 88$ & 964,4 & 2195,0 & 2004,5 & 3205,3 & 4146,6 & 12515,8 \\
\hline $1988 / 89$ & 2266,2 & 2229,9 & 1157,4 & 1414,3 & 1381,8 & 8449,6 \\
\hline $1989 / 90$ & 938,1 & 2588,9 & 2629,1 & 2293,7 & 1137,9 & 9587,7 \\
\hline $1990 / 91$ & 1471,0 & 3397,4 & 3659,3 & 8436,6 & 854,5 & 17818,8 \\
\hline $1991 / 92$ & 1294,5 & 3103,9 & 4127,1 & 4052,7 & 1800,8 & 14379,0 \\
\hline Durchschnitt & 1568,6 & 2272,3 & 3567,3 & 4402,9 & 2419,8 & 14230,8 \\
\hline$\%$ & 11,0 & 16,0 & 25,1 & 30,9 & 17,0 & 100,0 \\
\hline
\end{tabular}




\section{LITERATURVERZEICHNIS}

Adamy / Steffen: Finanzierungsprobleme des Sozialstaates in der Beschäftigungskrise. Sozialpolitik zwischen solidarischer Sicherung und marktkonformer Funktionalität, Regensburg, 1989

Anderson, Oskar: Trend, in: Handwörterbuch der Sozialwissenschaften, hrsg. von Erwin von Beckerath, Stuttgart/Tübingen/Göttingen, 1956-1965, S.405-408

Angermann, Oswald: Zur Neuberechnung der Produktions- und Produktivitätsindizes im Produzierenden Gewerbe auf Basis 1985, in: Wirtschaft und Statistik, 3/1988, S.182ff.

Anliker, Markus: Unternehmung und Saisonschwankungen unter besonderer Berücksichtigung ihrer Erfassung und Auswertung durch das Rechnungswesen, Diss., Zürich, 1950

Arbeitsschutz-Verordnung für Winterbaustellen: Verordnung über besondere Arbeitsschutzanforderungen bei Arbeiten im Freien in der Zeit vom 1. November bis 31. März, vom 1. August 1968 (BGBl. I, S.901 f.) i.d.F. der "Ersten Verordnung zur Änderung der Verordnung über besondere Arbeitsschutzanforderungen bei Bauarbeiten in der Zeit vom 1. November bis 31. März", vom 23. Juli 1974 (BGBl. I, S. 1569) und der Arbeitsstättenverordnung (ArbStättV) vom 20. März 1975 (BGBl. I, S. 729 ff.)

Aule, Olgred: Was hält der Bauarbeiter vom Winterbau?, in: Das Baugewerbe, 56.Jg., Nr.9, 1972, S.20ff.

Ausschuß "Kontinuierliches Bauen - Bauen im Winter", in: Bundesbaublatt, 8.Jg.; Heft 9, 1959

Bäcker, Gerhard / Bispinck, Reinhard / Hofemann, Klaus / Naegele, Gerhard: Sozialpolitik und soziale Lage in der Bundesrepublik Deutschland, Band 1: Arbeit, Einkommen, Qualifikation, 2. Aufl., Köln, 1989

Bäcker, G. / Welzmüller, R. Materielle Sicherung durch Arbeits- und Sozialeinkommen - Strukturelle Veränderungen und verteilungspolitische Konsequenzen, in: Perspektiven der Vollbeschäftigung, S.23ff, WSI-Studie 58, Köln, 1987

Batelle-Institut: Untersuchung der Möglichkeiten sowie der wirtschaftlichen und sozialen Auswirkungen einer vermehrten Winterbautätigkeit; Frankfurt am Main, Juli 1967

Baubetriebe-Verordnung: Verordnung über die Betriebe des Baugewerbes, in denen die ganzjährige Beschäftigung zu fördern ist, vom 19. Juli 1972 (BGBl. I, 
S:1257ff.) i.d.F. der ersten Verordnung zur Änderung der Baubetriebe-VO vom 30. April 1975 (BGBl. I, S. 1056)

Baukoordinierungsausschüsse, in: Bundesbaublatt, 8.Jg. Heft 9, 1959

Beckerath, Erwin von (Hrsg.): "Wirtschaftspolitik", in: Handwörterbuch der Sozialwissenschaften, Bd.12, Stuttgart, 1965.

Beckermann, Thomas: Die Bauwirtschaft, in: Schriftenreihe des Rheinisch-Westfälischen Instituts für Wirtschaftsforschung Essen, Heft 36, Berlin, 1976

Beidatsch, Alfred: Der Einfluß des Winterwetters auf die Bautätigkeit im Wohnungsbau und die kostenmäßigen Auswirkungen für die Bauwirtschaft Winter 1967/1968, in: Bau und Bauindustrie, Heft 10, 1968

Bellingen, Knut: Die Effektivität der wirtschafts- und sozialpolitischen Maßnahmen zur Förderung der ganzjährigen Beschäftigung in der Bundesrepublik Deutschland, Diss., Köln, 1975

Betriebswirtschaftliches Institut der Westdeutschen Bauindustrie: Bauunternehmen und Baumarkt in der Statistik. Stand und Probleme, Düsseldorf, 1969, S.17

Bibliographisches Institut (Hrsg.): Duden, Bd.7: Etymologie, Mannheim 1963, S. 305

Bieback, K.J.: Das Sozialleistungssystem in der Krise, in: Zeitschrift für Sozialreform, $10-12 / 1985$

Bieback, K.J.: Die Sozialversicherung und ihre Finanzierung, Frankfurt, 1986

Biffar, M.: Die Kosten der Fluktuation, in: Der Arbeitgeber, 11.Jg., Heft 10, 1959, S.293ff.

Bihn, Willi R.: Kurzfristige Indexziffern der Bauproduktion, Diss., Heidelberg, 1961, S. 107

Birkenfeld, Wolfgang: Methode zur Analyse von kurzen Zeitreihen, Basel/Stuttgart, 1977, S.7

Blüm, Norbert: Bericht über die Förderung der ganzjährigen Beschäftigung in der Bauwirtschaft (Winterbauförderung) nach dem Arbeitsförderungsgesetz, in: Schreiben des Bundesministers für Arbeit und Sozialordnung an den Vorsitzenden des Bundestags-Ausschusses für Raumordnung, Bauwesen und Städtebau, Werner Dörflinger, vom 12. Juni 1992

Böhler, Hermann: Zur Winterbauterminologie, in: Der Querschnitt, 5.Jg., Nr.10, 1961, S.298f.

Böhler, Hermann: Zur Beurteilung von Winterbau-Förderungsmaßnahmen. Was sagt uns das Ifo-Gutachten?, in: Architekt und Ingenieur, 16.Jg., Heft 2, 1965, S.33. 
Bombach, G.: "Wirtschaftswachstum und Stabilität", in: Wachstum und Konjunktur, Darmstadt und Opladen, 1960, S.9

Boot, John C.G./ Cox, Edwin B.: Statistical Analysis for Managerial Decisions, 2. Aufl., New York, 1974, S.446

Bopp, Eduard/ Willeke, Rainer: Konjunktursteuerung durch Bauwirtschaft?, in: Sonderdienst Bauindustrie, Folge 10, 1975, S.7 (264)ff.

Brännström, Anders: Neue Chancen für den Winterbau, in: Baugewerbe 24/90

Braun, Gerhard: Der Wohnungsbau im Winter. Die Bilanz der seit sechs Jahren in Berlin anhaltenden Winterbauforderung im Wohnungsbau, in: Das Baugewerbe, 45.Jg., Nr.3, 1965, 142ff.

Brocksiepe, Carl: Mehr Arbeitslose durch Verteuerung des Winterbaus, in: Magazin/Schlechtwettergeld, Baugewerbe 13/83

Brocksiepe, Carl: Winterbau - Förderung durch Arbeitgeber, in: der arbeitgeber, 24.Jg., Nr.19, 1972, S.741

Brüggemann, H.; Baumarkt - Enfant terrible der Marktwirtschaft?, Küpper, Th. (Hrsg.) in: Baupreis und Baumarkt, Schriftenreihe Baubetrieb und Bauwirtschaft, Wiesbaden 1962, S.16

Brümmerhoff, Dieter: Volkswirtschaftliche Gesamtrechnungen, 4.Aufl., München 1992, S. 171

Brunner, Hermann: Wirtschaftspolitische Forderungen der Deutschen Bauindustrie, in: Architekt und Ingenieur, 21.Jg., Nr.7, 1970

Brunner, Manfred: Planung in Saisonunternehmen, Köln/Opladen 1962

Bulletin des Presse- und Informationsamtes der Bundesregierung: Arbeitslosenquote: 1,9\% - Vollbeschäftigung, Bonn, 5. November 1957, Nr.205, S.1888ff.

Bulletin des Presse- und Informationsamtes der Bundesregierung: Die Winterarbeitslosigkeit im Baugewerbe, Bonn, den 18. Okt. 1957, Nr.195, S.1793f

Bulletin des Presse- und Informationsamtes der Bundesregierung: Schlechtwettergeld, Bonn, den 23. Juni 1959, Nr.109, S. 1103

Bulletin des Presse- und Informationsamtes der Bundesregierung: Fünf Jahre Win-terbauförderung des Bundes, Bonn, den 3. Dezember 1964, Nr.177, S. 1640.

Bundesanstalt für Arbeitsvermittlung und Arbeitslosenversicherung (Hrsg.): Schreiben des Präsidenten vom 9. Juli 1963, Az.: Ila5/Ia4-7143d/5520/62

Bundesanstalt für Arbeitsvermittlung und Arbeitslosenversicherung (Hrsg.): Presseinformation, Schlechtwettergeldregelung reformbedürftig?, in: Bau-Markt, 62.Jg., Nr.8, 1963, S.359

Bundesanstalt für Arbeitsvermittlung und Arbeitslosenversicherung (Hrsg.): Schreiben des Präsidenten vom 16. August 1966, Az.: IIa5/Ia4-7143d/5520/65 
Bundesanstalt für Arbeit (Hrsg.): ANBA, Ergebnisse der Arbeitsstatistik: Die Arbeitslosen im Bundesgebiet nach Berufsgruppen, 1955ff.

Bundesanstalt für Arbeit (Hrsg.): ANBA, Ergebnisse der Arbeitsstatistik: Die Arbeitslosen aus den Bauberufen, 1969ff.

Bundesanstalt für Arbeit (Hrsg.): ANBA, Ergebnisse der Arbeitsstatistik: Die Arbeitslosen aus den Bauberufen, 1971ff.

Bundesanstalt für Arbeit (Hrsg.): ANBA, Ergebnisse der Arbeitsstatistik: Die Arbeitslosen aus den Bauberufen, 1986ff.

Bundesanstalt für Arbeit (Hrsg.): ANBA, Sondernummer: Arbeitsstatistik 1970 Jahreszahlen, 19.Jg., 1971, S.263f.

Bundesanstalt für Arbeit (Hrsg.): ANBA, Sondernummer: Arbeitsstatistik 1971 Jahreszahlen, 20.Jg., 1972, S.84f.

Bundesanstalt für Arbeit (Hrsg.): Hauptergebnisse der Arbeits- und Sozialstatistik, 1955-1959

Bundesanstalt für Arbeit (Hrsg.): Bauen im Winter, Erfahrungsbericht, Nürnberg, 1966

Bundesanstalt für Arbeit (Hrsg.): RdErl.346/72, abgedruckt in: Günter Kranz, Winterbau. Förderung der ganzjährigen Beschäftigung in der Bauwirtschaft, Handkommentar, 4. Aufl., St. Augustin, Januar 1977.

Bundesanstalt für Arbeit (Hrsg.): Winterbauförderung, Erfahrungsbericht für den Winter 1984/85, Anlage 4, Bericht zu den RdErl. vom 23.2.1976 und 24.5.1985 IIIa5 - 7238, Nürnberg

Bundesanstalt für Arbeit (Hrsg.): Referat IVa2, Übersicht über die Einnahmen aus der Winterbau-Umlage und Ausgaben für die Förderung der ganzjährigen Beschäftigung in der Bauwirtschaft, Nürnberg, 18. Januar 1993

Bundesanstalt für Arbeit (Hrsg.): Winterbau-Information, Erfahrungsbericht für den Winter 1992/93, Anlage 4, Bericht zu den RdErl. vom 23.2.1976 und 24.6.1991 -IIIa5 - 7238, Nürnberg

Bundesanstalt für Arbeit (Hrsg.): Winterbauforderung, Winterbau-Information, Nürnberg, 1989/90

Bundesanstalt für Arbeit (Hrsg.): Winterbauförderung, Erfahrungsberichte, Nürnberg

Bundesministerium für Arbeit: Abteilung Statistik (Hrsg.), Analyse der westdeutschen Arbeitslosigkeit, Bonn, September 1952, S.13

Bundesministeriums für Städtebau und Wohnungswesen: Ganzjähriges Bauen Winterbau, Rundschreiben vom 6. Juli 1972, abgedruckt in: Bundesbaublatt, 21. Jg., H.9, 1972 
Deutscher Bundestag: 3. Wahlperiode, Drucksache IIL/495. Große Anfrage der Fraktion der SPD betr. Verbesserung der Verhältnisse in der Bauwirtschaft, vom 30. Juni 1958.

Deutscher Bundestag: 3. Wahlperiode, Drucksache III/1211. Bericht der Bundesregierung betr. Verbesserung der Verhältnisse in der Bauwirtschaft, vom 29. Juni 1959

Deutscher Bundestag: 3. Wahlperiode, Drucksache III/1240. Entwurf eines Gesetzes über Maßnahmen zur Förderung der ganzjährigen Beschäftigung in der Bauwirtschaft und weitere Änderungen und Ergänzungen des Gesetzes über Arbeitsvermittlung und Arbeitslosenversicherung (Zweites Änderungsgesetz zum AVAVG), vom 29. August 1959.

Deutscher Bundestag: 3. Wahlperiode, Drucksache III/1294. Schriftlicher Bericht des Ausschusses für Arbeit über den von der Bundesregierung eingebrachten Entwurf eines Gesetzes über Maßnahmen zur Förderung der ganzjährigen Beschäftigung in der Bauwirtschaft und Zweites Änderungsgesetz zum AVAVG, vom 16. Oktober 1959

Deutscher Bundestag: 3.Wahlperiode, Stenographischer Bericht der 51. Sitzung vom 27.November 1958

Deutscher Bundestag: 4. Wahlperiode, Drucksache IV/643. Bericht der Bundesregierung über die Auswirkungen der Vorschriften zur Förderung der ganzjährigen Beschäftigung in der Bauwirtschaft nach Artikel VI des Zweiten Änderungsgesetzes zum AVAVG vom 7. Dezember 1959 (Bundesgesetzbl. I, S.705), vom 27. September 1962.

Deutscher Bundestag: 5. Wahlperiode, Drucksache V/2291, Entwurf eines Arbeitsförderungsgesetzes (AFG), vom 16. November 1967

Deutscher Bundestag: 5. Wahlperiode, Stenographischer Bericht der 14. Sitzung vom 13. Januar 1966

Deutscher Bundestag: 5. Wahlperiode, Stenographischer Bericht der 52. Sitzung vom 29. Juni 1966

Deutscher Bundestag: 5. Wahlperiode, Stenographischer Bericht der 130. Sitzung vom 27. Oktober 1967

Deutscher Bundestag: 6. Wahlperiode, Drucksache VI/1549, Entwurf eines Gesetzes über Maßnahmen zur Verbesserung des Mietrechts und der Begrenzung des Mietanstiegs, vom 4. Dezember 1970

Deutscher Bundestag: 6. Wahlperiode, Drucksache VI/2689. Entwurf eines Zweiten Gesetzes zur Änderung und Ergänzung des Arbeitsförderungsgesetzes, vom 12. Okt. 1971 
Deutscher Bundestag: 6. Wahlperiode, Drucksache VI/3261. Schriftlicher Bericht des Ausschusses für Arbeit und Sozialordnung (10. Ausschuß) über den von der Bundesregierung eingebrachten Entwurf eines Zweiten Gesetzes zur Änderung und Ergänzung des Arbeitsförderungsgesetzes, vom 2. März 1972

Deutscher Bundestag: 6. Wahlperiode, Stenographischer Bericht der 180. Sitzung vom 12. April 1972, S.10456ff.

Deutscher Bundestag: 7. Wahlperiode, Drucksache VIV/1623. Unterrichtung durch die Bundesregierung. Bericht der Bundesregierung nach $\$ 238$ des Arbeitsförderungsgesetzes (Winterbau-Bericht 1973), vom 29. Januar 1974, S. 1

Deutscher Bundestag: 7. Wahlperiode, Drucksache VIV/4621. Unterrichtung durch die Bundesregierung. Bericht der Bundesregierung nach $\$ 238$ des Arbeitsförderungsgesetzes (Winterbau-Bericht 1975), vom 22. Januar 1976, S.4

Deutscher Bundestag: 10. Wahlperiode, Drucksache X/5771. S.26 zu Art.12

Deutscher Bundestag: 11. Wahlperiode, Drucksache XI/2990. S.23 zu Nr.28

Deutscher Bundestag: 12. Wahlperiode, Drucksache XII/3211. Änderungsgesetz zum AFG

Deutsches Institut für Wirtschaftsforschung (DIW): Revidierte Zeitreihen für das Bauvolumen in der Bundesrepublik Deutschland 1960-1985 und "DIW-Wochenberichte", Berlin, 1989

Donner, Otto: Die Saisonschwankungen als Problem der Konjunkturforschung, Vierteljahreshefte zur Konjunkturforschung, hrsg. vom Institut für Konjunkturforschung, Sonderheft 6, Berlin, 1926, S.10

Dickert, Dietrich: Oberste Baubehörde in Niedersachsen: Ein Beitrag zur Reform der staatlichen Bauverwaltung, in: Bau-Markt, 69.Jg., Nr.26, 1970, S.1309f.

Dressel/Dietel: Der betriebswirtschaftliche Nutzen des Winterbaues - Anleitung zur betrieblichen Berechnung, RG-Bau im RKW, Merkblatt 69.

Dürr, E.: Wachstumspolitik, Bern, 1977

Ebel, H.J.: Der Winterbau. Betriebswirtschaftiche Grundlage, Meisenheim/Glan, 1966.

Ewald, Norbert: Der Angriff auf das Schlechtwettergeld, in: Rundschreiben der IG Bau-Steine-Erden, Abteilung Bundesvorsitzender vom 10.8.93.

Ehrler, Karl: Die statistische Erfassung der Bauwirtschaft, Diss., Leipzig, 1940, S.10

Eyerich, J./ Lenz, J./ Witschel, K.: Einsparungen beim Bauen im Winter, in: Das Baugewerbe, Heft 21, 1973

Finck von Finckenstein, Graf, Hans-Wolfram: Saisonschwankungen, in: Handwörterbuch der Sozialwissenschaften, hrsg. von Erwin von Beckerath, Stuttgart/ Tübingen/Göttingen, 1956-1965, S.84-85 
Fischer, Martin: Saisonarbeitslosigkeit und die Überwindung ihrer Folgen, Diss., Köln, 1966

Fischer, W.: Soziale Unterschichten im Zeitalter der Frühindustrialisierung, in: Wirtschaft und Gesellschaft im Zeitalter der Industrialisierung, Göttingen, 1972, S.242ff.

Förderungssätze-Verordnung: Verordnung über die Förderungssätze für den Mehrkostenzuschuß der Produktiven Winterbauförderung vom 16. Juli 1973

Frank, Peter: Winterbau. Anforderungen und Bewertungskriterien, in: Das Baugewerbe, Heft 21, 1973

Fricke, Roland: Die Ursachen der Arbeitslosigkeit, Berlin, 1931

Fricke, Wolfgang: Kosten und Kostenrechnung im Saisonbetrieb, Europäische Hochschulschriften/05, Frankfurt/Main, 1991

Fürst, Gerhard / Spilker, Hans: Störungen der kurzfristigen Wirtschaftsbeobachtung durch jahreszeitliche und andere wiederkehrende Einflüsse, in: Wirtschaft und Statistik, 9. Jg., n.F., Heft 4, 1975, S.199ff.

Geerling, C.: "Bauen im Winter - sozialpolitisch gesehen", in: Der Bau und die Bauindustrie, Heft 18, 1955, S.546.

Geerling, C.: Winterbau und winterliche Arbeitslosigkeit, in: Der Bau und die Bauindustrie, 11.Jg., Nr.22, 1958, S.615.

Geerling, C.: Der neue Tarifvertrag zur Förderung der Aufrechterhaltung der Arbeitsverhältnisse im Winter, in: Die Bauwirtschaft, 13. Jg., Heft 39, 1959

Gerland, Eberhardt: Die sozialen, volkswirtschaftlichen und betriebswirtschaftlichen Auswirkungen der gesetzlichen Schlechtwetter-Regelung im Baugewerbe, Diss., Frankfurt/Main, 1962

Gluch, E. / Söffner, F.: Auswirkungen der Baunachfrage auf die Struktur der bauausführenden Wirtschaft, Gutachten im Auftrag des Bundesministeriums für Raumordnung, Bauwesen und Städtebau, Mai 1969, S.51

Goldack, Günter: Die Saisonnormale, in: Jahrbuch der Absatz- und Verbrauchsforschung, 3.Jg., Heft 2, 1957, S.173ff.

Göppl, Hermann / Kranz, Otto: Statistik, betriebliche, in: Handwörterbuch der Betriebswirtschaft, 4.Aufl., Stuttgart, 1974, Sp.3713

Grünewald: Zusammenstellung der Lohnausgleichszahlungen der ULAK der Bauwirtschaft, 1994

Gudat, W.: Bauwirtschaftliche Erfahrungen mit dem Schlechtwettergeldgesetz, in: Die Bauwirtschaft, 14.Jg., Heft 6, 1960, S.106ff.

Günther, Horst: Argumentationspapier zum SWG, Bonn, 25. August 1994

Haberler, G.: Wirtschaftswachstum und Stabilität, München 1975, S.46-64 
Hampe, Karl-Heinz: Winterbau-Technologie, Planung, Vergabe, Ausführung; RGBau im RKW, 1992

Hauptausschuß "Bauen im Winter": Erwägungen zum Winterbau, Diskussionsvorschrift zusammengestellt vom "Arbeitskreis Winterbau" im Bundesministerium für Wohnungsbau, in: Bundesbaublatt, 4.Jg. Heft 11, Bad Godesberg, 1955

Hauptverband der Deutschen Bauindustrie (Hrsg.): Zur marktkonformen Gestaltung des Baumarktes. 32 Vorschläge der Bauindustrie, Frankfurt/Main 1961, S.20

Hauptverband der Deutschen Bauindustrie (Stellungnahme): Winterbau-Vorsorge im Für und Wider, in: Bau und Bauindustrie, 17.Jg., Nr.2, 1964, S.36

Hauptverband der Deutschen Bauindustrie (Hrsg.): Baustatistisches Jahrbuch 1976, Wiesbaden, 1976

Hauptverband der Deutschen Bauindustrie (Hrsg.): Forschung und Entwicklung in der Bauwirtschaft - Beispiele moderner Spitzentechnik, S.14ff., Wiesbaden/ Bonn, 1987

Hauptverband der Deutschen Bauindustrie (Hrsg.): Baustatistisches Jahrbuch 1992; Wiesbaden/Bonn/Berlin/Brüssel, Dezember 1992

Hauptverband der Deutschen Bauindustrie (Hrsg.): Systematik der Wirtschaftszweige für das Baugewerbe", in: Baustatistisches Jahrbuch, Erläuterungen Abschnitt D, Wiesbaden, 1992

Hauptverband der Deutschen Bauindustrie (Hrsg.): Tarifsammlung für die Bauwirtschaft 1992/93, Wiesbaden, 1992

Hauptverband der Deutschen Bauindustrie (Hrsg.): Bauwirtschaft im Zahlenbild 1993, Wiesbaden/Bonn/Berlin/Brüssel, Juni 1993

Heberer, Ottmar / Kuhn, Artur / Wagner, Hans-Georg: Kurzarbeitergeld/Winterbauforderung, in: Aufgaben und Praxis der Bundesanstalt für Arbeit, Heft 20a, 3.neubearbeitete Auflage, 1988

Heinen, E.: Grundlage betriebswirtschaftlicher Entscheidungen, 2. Aufl., Wiesbaden, 1972

Heinrichsmeyer, Wilhelm/ Gans, Oskar/ Evers, Ingo: Einführung in die Volkswirtschaftslehre, 9. Aufl., Stuttgart, 1991, S.319

Hennig, Werner/ Kühl, Horst/ Heuer, Ernst: Arbeitsförderungsgesetz (AFG), Kommentar, Frankfurt/Main, 1969

Hensel, K.P.: Grundformen der Wirtschaftsordnung, S.36ff., 3. Aufl. München, 1976

Herbel, Norbert: Erfahrungen mit dem neuen System der Produktionsindizes, in: Wirtschaft und Statistik, 5/1986, S.374

Hesser, Werner: Beschäftigung und Beschäftigungsgrad des Baugewerbes, Diss. Nürnberg, 1960, S.11 
Hujer, Reinhard / Hassel, Gerd: Gesamtwirtschaftliche Folgen einer Streichung des Schlechtwettergeldes im Baugewerbe, Johann Wolfgang Goethe-Universität, Frankfurt/Main, 1994

Ifo-Institut für Wirtschaftsforschung: Die konjunkturelle Schüsselstellung der Bauwirtschaft, in: Wirtschaftskonjunktur, 10. Jg., Heft 4, München, 1958, S.17ff

Ifo-Institut für Wirtschaftsforschung: Soziale und wirtschaftliche Auswirkungen der Winterbauförderung, Gutachten, München 1964

Ifo-Institut für Wirtschaftsforschung: Bauwirtschaft und öffentliche Hand - Partner am Baumarkt, Gutachten im Auftrag des Hauptverbandes der Deutschen Bauindustrie, München 1965

Ifo-Institut für Wirtschaftsforschung: Volkswirtschaftliche Ausstrahlungen der Bauwirtschaft, Gutachten im Auftrag des Hauptverbandes der Deutschen Bauindustrie, München 1967.

Ifo-Institut für Wirtschaftsforschung: Optimaler Winterbau, München, 1968.

Ifo-Institut für Wirtschaftsforschung: Rationalisierung aus der Sicht der Baubeteiligten, Gutachten, München, 1976.

Ifo-Institut für Wirtschaftsforschung: Rationalisierung aus der Sicht der Baubeteiligten, in: ifo-Schnelldienst 18/87, München, 1987

Ifo-Institut für Wirtschaftsforschung: Baubedarf-Perspektive bis 2000, Gutachten im Auftrag des Hauptverbandes der Deutschen Bauindustrie von Karin Behring, München, 1989.

Ifo-Institut für Wirtschaftsforschung: Baubedarf in den neuen Bundesländern bis 2005 von Erich Gluch, ifo studien zur Bauwirtschaft 18, München, 1992

IG Bau-Steine-Erden: Arbeitsprogramm zur Verbesserung der Arbeitsbedingungen und der Leistungsfähigkeit der Bauwirtschaft, abgedruckt in: Bau-Markt, 68.Jg., Nr.46, 1969, 2454f.

IG Bau-Steine-Erden: Rahmenkonzept zur Durchsetzung eines "Ganzjährig gesicherten Einkommens" für Bauarbeiter, Abteilung Tarifpolitik, Frankfurt 13. Juni 1989

IG Bau-Steine-Erden: Verstärkte Winterbautätigkeit bei öffentlichen Bauvorhaben, Frankfurt/Main, 12. Februar 1991

IG Bau-Steine-Erden: Der Angriff auf das Schlechtwettergeld, Daten/Fakten/Auswirkungen, Mitteilung des Bundesvorstandes, S. 15

Institut für Arbeits- und Baubetriebswissenschaft (ifA): Betriebswirtschafticher Nutzen des Winterbaues, Anhang, Januar 1984

Interministerieller ArbeitsausschuB Bauwirtschaft (IAB), in: Bundesbaublatt, 4.Jg., Heft 11, 1955 
Karthaus/Müller: Bundesrahmentarifvertrag für das Baugewerbe, Text und Erläuterung BRTV, 3.Auflage, 1991

Kellerer, Hans: Statistik im modernen Wirtschafts- und Sozialleben, Hamburg/ Reinbek, 1960

Kießling, Achim: Untersuchung der Wirtschaftlichkeit von Bauunternehmungen beim Bauen mit und ohne Winterpause, in: Rationeller Bauen, Heft 10, S.27-30, September 1972

Kießling, Achim: Winterbau steigert die Wirtschaftlichkeit, in: Das Baugewerbe, Heft 21, 1973, S.33

Kießling, Achim: Winterbau lohnt sich - Wirtschaftlichkeit spielt die wichtigste Rolle, in: Beratende Ingenieure, Heft 12, 1974, S.4

Kieselbach/Wacker (Hrsg.): Individuelle und gesellschaftliche Kosten der Arbeitslosigkeit, Weinheim/Basel, 1985

Kirner, W. / Guicciardi, R. / Menkhoff, H. / Zinkhahn, W.: Enquete über die Bauwirtschaft, i.A. des Bundesministers für Wirtschaft, Stuttgart 1973, S.727ff

Knechtel, Erhard: Das sozialpolitische Rahmenprogramm der Bauindustrie, in: Die Bauwirtschaft, 24.Jg., Heft 23, 1970, S.709ff.

Knechtel, Erhard: Geplanter Wegfall des Schlechtwettergeldes im Baugewerbe, Hauptverband der Bauindustrie, 1994

Köbele, Bruno: Konzeption zur Überwindung der Engpässe im Wohnungsbau durch ganzjährige Bautätigkeit/Winterbau, in: Rundschreiben Nr.22/1992 der IG BauSteine-Erden, Abteilung Bundesvorsitzender, S.3

Kondratieff, Nikolaj Dimitrievic: Die langen Wellen der Konjunktur, in: Archiv für Sozialwissenschaften und Sozialpolitik, Tübingen 1926, S.573-609.

Kosiol, Erich (Hrsg.): Handwörterbuch des Rechnungswesens, 2.Aufl., Stuttgart, Poeschel Verlag, 1981

Krämer, Klaus: Der Winterbau; Gesamt- und einzelwirtschaftliche sowie soziale Probleme seiner Förderung zur Ausschaltung der saisonalen Produktionsschwankungen im Baugewerbe Westdeutschlands, Diss., Essen, 1967

Kranz, Günter: Die Problematik der Winterarbeitslosigkeit in der Bauwirtschaft und die Bemühungen um die Lösung des Problems, in: Bundesarbeitsblatt, 10.Jg., 1959

Kranz, Günter: Der Weg zum Gesetzentwurf über die Förderung der ganzjährigen Beschäftigung in der Bauwirtschaft, in: Arbeit, Beruf und Arbeitslosenhilfe, 10.Jg., Heft 7, 1959

Kranz, Günter: Die Auswirkungen der Maßnahmen zur Förderung des Winterbaues, in: Bundesarbeitsblatt, 11.Jg., Nr.8, 1960, S.276ff. 
Kranz, Günter: Die jüngsten Bemühungen um ein kontinuierliches ganzjähriges Bauen (einschließlich Winterbau), in: Bundesarbeitsblatt, 12.Jg., Nr.3, 1961

Kranz, Günter: Der Winterbau im Widerstreit der Meinungen, in: Arbeit, Beruf und Arbeitslosenhilfe, 15.Jg., Heft 12, 1964, S.281ff.

Kranz, Günter: Produktive Winterbauförderung und Zulassung von Betrieben des Baugewerbes zum Schlechtwettergeld, in: Die Bauwirtschaft, 23. Jg., H.48, 1969

Kranz, Günter: Die wirtschaftliche Notwendigkeit des Bauens im Winter, in: Straßenbau-Technik, 24.Jg., Nr.22, 1971, S.1413

Kranz, Günter: Winterbau. Förderung der ganzjährigen Beschäftigung in der Bauwirtschaft, Handkommentar, 4. Aufl., St. Augustin, Stand: 14. Lieferung, Januar, 1977

Kranz, Günter: Der Winterbau bleibt die Chance, in: Bautechnik 10/80, S.92.

Krebs, Heinrich: Arbeitsförderungsgesetz (AFG), Kommentar, Bonn/Bad Godesberg, Mai 1976

Kresling, Hans: Bauwirtschaft, in: Handwörterbuch der Sozialwissenschaften, Bd.1, Stuttgart-Tübingen-Göttingen 1965, S. 687ff

Küchler, Wilhelm: Schlechtwettergeld darf nicht gestrichen werden, in: Bauwirtschaft, 47.Jg., Juli 1993, S.51

Lampert, Heinz: Lehrbuch der Sozialpolitik, Berlin/Heidelberg, 1985

Leber, Georg: Bauen ohne Winterpause, in: Der Querschnitt, 1959

Leber, Georg: Ganzjähriges Bauen aus sozialer Sicht, in: Der Grundstein, 10.Jg., Nr.13, 28. Juni 1959, S.3

Leiner, Bernd: Einführung in die Zeitreihenanalyse, 2. Aufl., München, 1986

Meffert, Heribert: Marketing, 7. Aufl., Wiesbaden, 1986, S.222

Mellerowicz, Konrad: Beschäftigungspolitik, in: Handwörterbuch der Betriebswirtschaft, 3. völlig neu bearb. Auflage, Bd. 1, Stuttgart, 1956, Sp. $719 \mathrm{ff}$.

Mellerowicz, K.: Kosten und Kostenrechnung, Bd.1: Theorie der Kostenrechnung, 4. Aufl., Berlin 1963, S.310

Mellerowicz, Konrad: Kosten und Kostenrechnung, Bd.2: Verfahren, Teil 1: Allgemeine Fragen der Kostenrechnung und Betriebsabrechnung, 5. Aufl., Berlin/New York, 1974.

Monschaw, Bernd von: Perspektiven für das deutsche Baugewerbe, Teil 1: Bauwirtschaft im Rahmen der Gesamtwirtschaft, Untersuchung des Ifo-Instituts für Wirtschaftsforschung im Auftrage des Zentralverbandes des Deutschen Baugewerbes e.V., München 1970

Nolte, Roland: Eine Chance zum Überleben. Winterbau verbessert Rentabilität und Wirtschaftlichkeit, in: Bauwirtschaft, Heft 41, S.1409-1410, 1984 
o.V.: Die Bundestagsdebatte, in: Die Bauwirtschaft, 12.Jg., Heft 49, 1958

o.V.: Das erreichte Deine Gewerkschaft für Dich. Zumutbarkeit in der Winterperiode, in: Der Grundstein, 10.Jg., Nr.24, 29. November 1959, S.4ff.

o.V.: Winterbau - nur ein statistischer Erfolg, in: Der Arbeitgeber, 12.Jg., Heft 5, 1960, S.103f.

o.V.: An der Schwelle des Winters 1961/62, in: Die Bauwirtschaft, 15. Jg., Heft 43, 1961, S.1105

o.V.: Jetzt schon vorsorgen!, in: Die Bauwirtschaft, 17.Jg., Heft 13, 1963, S.364

o.V.: Drei Jahre Schlechtwettergeld, in: Das Baugewerbe, 43.Jg., Nr.1, 1963, S.12ff.

o.V.: "Mitten im Sommer: Winterbau vorbereiten!", in: Der Grundstein, 17.Jg., Nr.17, 1966, S.3

o.V.: "Macht die Baustellen rechtzeitig winterfest!", in: Der Grundstein, 17.Jg., Nr.19, 1966, S.4

o.V.: Produktive Winterbauförderung statt Schlechtwettergeld, in: Straßenbau-Technik, 19.Jg., Nr.21, 1966

o.V.: Vollbeschäftigung durch Arbeitsförderung sichern helfen, in: Sozialpolitische Information, 1.Jg., Nr.5, 1967, S.1ff.

o.V.: Wer rechnet, baut auch im Winter. Bessere Kapazitätsauslatung durch Kontinuität, in: Baumarkt, Heft 46, S.2152-2154, 1971

o.V.: Mehrkosten-Zuschüsse für die kalten Monate, in: Handelsblatt vom 6.12.1984

o.V.: Winterbau - eine Frage der Wirtschaftlichkeit, in: Bauwirtschaft, Heft 37, S.1323, 1986

o.V.: Bauarbeit muß sich immer lohnen - im Sommer und im Winter, in: Der Grundstein, Ausgabe 2/89, S.2

o.V.: Auch in Deutschland soll rund ums Jahr gebaut werden, in: FAZ vom 16. Februar 1993

o.V.: Winterbau in Schweden ist selbstverständlich, in: FAZ vom 16. Februar 1993

o.V.: IG Bau mobilisiert gegen Streichung des Schlechtwettergeldes, in FAZ vom 13. Juli 1994

o.V.: IG Bau kritisiert Illegalität und Werkverträge, in: FAZ vom 11. Oktober 1994

Patsch, M.: Prinzipien und Formen sozialer Sicherung in nichtindustriellen Gesellschaften, Berlin, 1983

Pause, Hans: Argumente zur wirtschaftspolitischen Situation der Bauwirtschaft, in: Sonderdienst Bauindustrie, Folge 9, 1975, S.7 (227)ff.

Pause, Hans: Die Folgen winterbedingter Produktionsausfalle im Bauhauptgewerbe, im Auftrag der Wirtschaftsvereinigung Bauindustrie, Betriebswirtschaftliches Institut der Westdeutschen Bauindustrie GmbH, Düsseldorf, 1979, S.2 
Pesch, Heinz Josef: Finanzplanung in Saisonindustrien, Diss. Köln, 1955

Petz: Lohnausgleich bei Arbeitsausfall im Winter, in: Bundesbaublatt, 4. Jg., Heft 11, 1955, S. $511 \mathrm{ff}$.

Preiser, E.: Wirtschaftspolitik heute, 6. Aufl., München, 1978

Rationalisierungs-Gemeinschaft Bauwesen im RKW (Hrsg.): Optimaler Winterbau, Gutachten im Auftrag des Bundesministeriums für Wohnungswesen und Städtebau, Frankfurt/Main, 1967

Rationalisierungs-Gemeinschaft Bauwesen im RKW (Hrsg.): Der betriebswirtschaftliche Nutzen des Winterbaues, Merkblatt 69, Eschborn, Juli 1984, S.5ff.

Rentenversicherungs-Änderungsgesetz: Gesetz zur Beseitigung von Härten in den gesetzlichen Rentenversicherungen und zur Änderung sozialrechtlicher Vorschriften vom 9. Juni 1965, BGBl.I, S.476ff.

Riebel, Paul: Die Elastizität des Betriebes, Köln/Opladen, 1954

Riester, Friedrich: Die Verhütung und Überwindung saisonaler Arbeitslosigkeit, insbesondere im Baugewerbe, als arbeitsmarktpolitische Aufgabe, Diss. Köln, 1959

Robl/Brocksiepe: Ganzjährige Beschäftigung in der Bauwirtschaft. Einnahmen und Ausgaben der Bundesanstalt für Arbeit, in: Rundschreiben des Zentralverbandes des Deutschen Baugewerbes vom 26. Juli 1993, S.2.

Rocholl, E.: Im Blickfeld der Bauwirtschaft, in: Das Baugewerbe, 45.Jg., Nr.2, 1965, S.53ff.

Rösinger, Friedrich: Die Frage der Saisonschwankungen im Bauwesen, Diss. Erlangen, 1958

Röthig, Horst: Winterbau auf neuen Wegen, in: Straßenbau-Technik, 25. Jg., Nr.20, 1972

Röthig, Horst: Interessante Daten aus dem Winterbau-Bereich, in: Magazin/Winterbau, Baugewerbe 20/80, S.33ff.

Röthig, Horst: Das kontinuierliche Bauen mit Hilfe von Winterbau-Schutzmaßnahmen (Teil 1), in: Baumarkt, Heft 22, 1980, S.1512-1516

Röthig, Horst: Das kontinuierliche Bauen mit Hilfe von Winterbau-Schutzmaßnahmen (Teil 2), in: Baumarkt, Heft 23, 1980, S.1571-1574

Röthig, Horst: Baurationalisierung: Frostige Zeiten für den Winterbau, in: Baumarkt, Nr.12, 1986, S.634-635

Ruckgaber, Helmut: Probleme der sozialen Sicherheit im Baugewerbe unter besonderer Berücksichtigung der winterlichen Arbeitslosigkeit, Diss., Mannheim 1965, S. 23

Saam, Wolfgang: Kritik an Streichung des Schlechtwettergeldes, in: Baugewerbe, Heft 15-16, August 1993, S.10 
Sabel, Anton: Winterarbeit in der Bauwirtschaft, in: Bau-Markt, 57.Jg., Nr.48, 1958, S.1689f.

Sabel, Anton: Winterbau und Schlechtwettergeld aus der Sicht der BAVAV, 1963

Sabel, Anton: Reformwünsche zur Arbeitslosenversicherung, in: Arbeit und Sozialpolitik, 18. Jg, Nr.3, 1964, S.67ff.

Sabel, Anton: Zur Erhöhung des Schlechtwettergeldes, in: Arbeit, Beruf und Arbeitslosenhilfe, 19. Jg, Heft 1, 1968, S.20.

Sartorius, Rolf: Die arbeitspolitische Problematik des saisonabhängigen Berufes unter besonderer Berücksichtigung der Größenordnungen in Rheinland-Pfalz, Diss., Mainz 1954, S.59

Schäfer, Erich / Knoblich, Hans: Grundlagen der Marktforschung, 5. Aufl., Stuttgart 1978

Schäfer, Erich: Der Industriebetrieb, 2. Aufl., Wiesbaden, 1978

Schattenberg, Horst Henner: Öffentlicher Bauherr und kontinuierliche Bautätigkeit, in: Bau und Bauindustrie, 12. Jg., Nr.11, 1959, S.284f.

Schepsky, Johannes: Erfahrungen aus den Winterbauten der Jahre 1955/59, in: Bundesbaublatt, 9. Jg., Heft 4, 1960

Schiekel, Horst: Arbeitsförderungsgesetz (AFG), Kommentar, Percha/Kempfenhausen, Oktober 1970

Schleicher, Eugen: Ratgeber für das Bauen im Winter, Berlin/Wiesbaden, 1956

Schleicher, Eugen: Winterbau - Eine Tagung und eine Reise, in: Die Bauwirtschaft, 10.Jg., Heft 23, 1956

Schleicher, Eugen: Ist das Thema Winterbau noch aktuell?, in: Bau-Markt, 57.Jg., Nr.42, 1958

Schleicher, Eugen: Der Winterbau und der Bauunternehmer, in: Das Baugewerbe, 45.Jg., Nr.5, 1965, S.272ff.

Schleicher, Eugen: Kostenermittlung von Winterbauarbeiten, Heft 1 der Schriftenreihe der Rationalisierungsgemeinschaft Bauwesen, 2. Aufl., Berlin, Köln, Frankfurt/Main 1972

Schlieder, Ernst: Den Bauunternehmen wird zuviel zugemutet - Noch kann vom wirtschaftlichen Erfolg des Winterbaues nicht die Rede sein, in: bau-zentralblatt, Nr.11, November 1968, S.4

Schlieder, Ernst: Lösungsvorschlag zum Winterbauproblem: Winterpause am Bau dafür längere Arbeitszeit im Sommer, in: Baumarkt, 69.Jg., Nr.46, 1970, S.2263ff.

Schlittgen, Rainer/ Streitberg, Bernd: Zeitreihenanalyse, 4. unveränd. Aufl., München/Wien/Oldenbourg, 1991 
Schmidbauer, H: Allokation, technischer Fortschritt und Wettbewerbspolitik, Tübingen 1974, S.127-129.

Schmidt, Friedrich: Wandlung der deutschen Arbeitslosenversicherung?, in: Arbeit, Beruf und Arbeitslosenhilfe, 19.Jg., Heft 2, 1968, S.37ff.

Schmidt, Robert: Neue Vorschriften über die Winterbauförderung, in: Bundesarbeitsblatt, 20.Jg., Nr.6, 1969, S.346ff.

Schmidt, Robert: Der Winterbau lebt; Winterbaubericht 1984/85; in: Bundesarbeitsblatt 2/1986, S.8ff.

Schmidt, Robert: Geringfügig behindert; Winterbau 1987/88, in: Bundesarbeitsblatt $3 / 1989$

Schmidt, Robert: Im konjunkturellen Aufwind; Winterbau 1988/89, in: Bundesarbeitsblatt $2 / 1990$

Schmidt, Robert: Die Förderung der ganzjährigen Beschäftigung in der Bauwirtschaft - eine Hilfe der Arbeitsförderung für Bauarbeiter, in: Wege zur Sozialversicherung, 46.Jahrgang, Heft 10, Oktober 1992, Asgard Verlag, Sankt Augustin

Schneider, Gottfried: Der Winterbau als sozialpolitischer Erfolg, in: Die Bauwirtschaft, 17.Jg., Heft 46, 1963, S.1417ff.

Schneider, Hans Karl: Struktur und volkswirtschaftiche Bedeutung der Bauwirtschaft, in: Der Baumarkt. Beiträge und Untersuchungen des Instituts für Siedlungs- und Wohnungswesen der Westfälischen Wilhelms-Universität Münster, Band 67, Münster/Westf. 1967, S.7ff.

Schönberg, G. / Dobler, M. / Werthwein, R.: Die Wirtschaftlichkeit wird positiv beeinflußt. Untersuchung über Winterbauschutzmaßnahmen, in: Hoch- und Tiefbau, Heft 10, 1978, S.13-16

Schönfelder, Erwin: Das Arbeitsförderungsgesetz - Instrument der Beschäftigungspolitik, in: Arbeit, Beruf und Arbeitslosenhilfe, 20.Jg., Heft 6, S.157ff.

Schreiben des Zentralverbandes des Deutschen Baugewerbes, des Hauptverbandes der Deutschen Bauindustrie und der IG Bau-Steine-Erden vom 1. Februar 1972: An den Vorsitzenden des Ausschusses für Arbeit und Sozialordnung des Deutschen Bundestag, Herrn Prof. Dr. E. Schellenberg, Drucksache VI/2689, S.2.

Schriftenreihe des Bundesministers für Raumordnung, Bauwesen und Städtebau: Bau- und Wohnforschung: Winterbau-Schutzmaßnahmen bei verschiedenen Witterungsbedingungen, Heft 04.043, Bonn, 1978, S.99

Schriftenreihe des Bundesministers für Raumordnung, Bauwesen und Städtebau: Bau- und Wohnforschung: Saisonale Verstetigung der Bautätigkeit, Heft 04.040, Bonn, 1978 
Schriftenreihe des Bundesministers für Raumordnung, Bauwesen und Städtebau: Bau- und Wohnforschung: Möglichkeiten zur Verstetigung der Baunachfrage durch Konjunkturprogramme, Heft 04.062, Bonn, 1980

Schultz, Karl Heinz: Die Ökonomik des Saisonbetriebes, Diss., Nürnberg, 1953, S. 1

Schumpeter, Joseph Alois: Konjunkturzyklen, Bd.1, Göttingen, 1961

Schwarzfischer, J.: "Aufgaben, Möglichkeiten und Grenzen der betrieblichen Sozialpolitik" in: Betriebliche Sozialpolitik und soziale Betriebspolitik", Olten, 1962, S. 53

Seewald, O.: Beitrag zur Frage der Verstetigung öffentlicher Bauinvestitionen, in: Schriftenreihe des Bundesministers für Raumordnung, Bauwesen und Städtebau, S.60, Hamburg, 1977

Semler, Rudolph: Laßt uns nicht von Winterbau sprechen, in: Berliner Bauwirtschaft, 9. Jg., Nr.23, 1958, S.477f.

Sommer, Michael: Winterbau - Kriterium ist die Wirtschaftlichkeit, in: bau-zentralblatt, Heft 21, 1981, S.82

Sperner, Rudolf: IG Bau fordert gesichertes Jahreseinkommen, in: Bau-Markt, 70.Jg., Nr.3, 1971, S.63ff.

Statistisches Bundesamt Wiesbaden (Hrsg.): Zahlen aus der Bauwirtschaft, Ergebnisse der monatlichen Bauberichterstattung für Betriebe, 1955-1960

Statistisches Bundesamt (Hrsg.): Wirtschaft und Statistik, 2/1963, S.102ff.

Statistisches Bundesamt Wiesbaden (Hrsg.): Ausgewählte Zahlen für die Bauwirtschaft, Ergebnisse der monatlichen Bauberichterstattung für Betriebe, Dezember und Jahr 1961-1970, in: Fachserie 4 Produzierendes Gewerbe

Statistisches Bundesamt Wiesbaden (Hrsg.): Ausgewählte Zahlen für die Bauwirtschaft, Ergebnisse der monatlichen Bauberichterstattung für Betriebe, Dezember und Jahr 1970-1974, in: Fachserie 4 Produzierendes Gewerbe

Statistisches Bundesamt Wiesbaden (Hrsg.): Ausgewählte Zahlen für die Bauwirtschaft, Ergebnisse der monatlichen Bauberichterstattung für Betriebe, Dezember und Jahr 1973-1987, in: Fachserie 4 Produzierendes Gewerbe

Statistisches Bundesamt Wiesbaden (Hrsg.): Ausgewählte Zahlen für die Bauwirtschaft, Ergebnisse der monatlichen Bauberichterstattung für Betriebe, Dezember und Jahr 1987-1993, in: Fachserie 4 Produzierendes Gewerbe

Statistisches Bundesamt Wiesbaden (Hrsg.): Volkswirtschaftliche Gesamtrechnungen, Fachserie 18, Konten und Standardtabellen 1979, S. 185.

Statistisches Bundesamt Wiesbaden (Hrsg.): Ausgewählte Zahlen für die Bauwirtschaft, August 1992, in: Fachserie 4 Produzierendes Gewerbe, Einzelveröffentlichungen 
Statistisches Bundesamt Wiesbaden (Hrsg.): Beschäftigung, Umsatz und Gerätebestand der Betriebe im Baugewerbe 1992, in: Fachserie 4 Produzierendes Gewerbe, Reihe 5.1., 1993

Statistisches Bundesamt Wiesbaden (Hrsg.): Statistisches Jahrbuch 1992 für die Bundesrepublik Deutschland, Wiesbaden, 1993

Statistisches Bundesamt Wiesbaden (Hrsg.): Volkswirtschaftliche Gesamtrechnungen, Fachserie 18, Reihe 1.2, Konten und Standardtabellen, Vorbericht 1993

Statistisches Bundesamt Wiesbaden (Hrsg.): Produktion ausgewählter industrieller Erzeugnisse, Index der industriellen Produktion, Fachserie D, Reihe 2

Steinbiss, Max: Untersuchungen über Winterarbeiten im Hochbau und Ergebnisse der vergleichenden Bauforschung, in: Der Querschnitt, 5. Spezialheft: Bauen ohne Winterpause, Frankfurt/Main, 1960

Stier, Winfried: Konstruktion und Einsatz von Digitalfiltern zur Analyse und Prognose ökonomischer Zeitreihen, Forschungsbericht Nr.2760 des Landes Nordrhein-Westfalen, Bochum, 1978

Streit, M.E.: Theorie der Wirtschaftspolitik, Düsseldorf 1979, S.26-38

Strohm, Wolfgang: Zur Aussage der Indizes der Nettoproduktion für das produzierende Gewerbe - Möglichkeiten und Grenzen, in: Wirtschaft und Statistik, 1/1985, S.21ff.

Strohm, Wolfgang: Zur Frage der Kalenderbereinigung von Zeitreihen, in: Wirtschaft und Statistik, 6/1986, S.421ff.

Strube, E.: Kostenremanenz und Beschäftigungsschwankungen, in: Zeitschrift für handelswissenschaftliche Forschung, 30.Jg., Heft 10, 1963, S.505ff.

Tennstedt, F.: Sozialgeschichte der Sozialpolitik in Deutschland, Göttingen, 1981, S.47ff.

Teschke, Frank: Kostenreduzierung durch Winterbau bei bereits gedeckten Fixkosten, S.103, in: Bauwirtschaft, Heft 4, Januar 1980

Tönnies, F.: Die Entwicklung der sozialen Frage, Leipzig, 1907, S.7

Unkelbach, Ludwig: Gesetzliche Schlechtwettergeldregelung, in: Die Bauwirtschaft, 14.Jg., H.46, 1960

van Gries, Hans-Alo: Die Auswirkungen der Saisonschwankungen im Wohnungsbau auf die Gesamtwirtschaft. Eine Multiplikatoranalyse, Schriften des Instituts für Wohnungsrecht und Wohnungswirtschaft an der Universität Köln, Tübingen, 1960

Vittali, Walter: Saisonschwankungen im Baugewerbe und ihre Auswirkungen auf die deutsche Volkswirtschaft, Diss., München, 1931, S.21

Vosgerau, Hans-Jürgen: Konjunkturtheorie, in: Handwörterbuch der Wirtschaftswissenschaften, hrsg. von Willi Albers, Stuttgart, 1977-1982, S.478-507 
Walper, Karl Heinz: Bauen im Winter, Taschenbuch des Deutschen Verbandes für Wohnungswesen, Städtebau und Raumplanung e.V., Bd.12, Bonn 1970

Weber, Helmut Kurt: Industriebetriebslehre, Berlin, 1985

Weddigen, Walter: Die Behandlung der saisonalen Arbeitslosigkeit im Rahmen des Versicherungsschutzes gegen Arbeitslosigkeit, Sozialpolitische Schriften, Heft 8, Berlin, 1957

Werner, Karl: Der Beitrag des Baugewerbes zum Sozialprodukt, in: Die Bauwirtschaft, 17.Jg., Heft 50, 1963, S.1561ff.

Widmaier, H.P.: Klassifikation sozialpolitischer Bedürfnisse, in: Sozialpolitik im Wohlfahrtsstaat, Hamburg, 1976

Willeke, Eduard: "Arbeitslosigkeit. (I) Allgemeines", in: Handwörterbuch der Sozialwissenschaften, Band 1, Stuttgart - Tübingen - Göttingen 1956, S.305ff.

Willeke, Rainer: Möglichkeiten zur Verstetigung der Baunachfrage durch Konjunkturprogramme, in: Schriftenreihe des Bundesministeriums für Raumordnung, Bauwesen und Städtebau, Bonn, 1980, S. 11.

Winterbau-Anordnung: Anordnung des Verwaltungsrates der Bundesanstalt für Arbeit über die Förderung der ganzjährigen Beschäftigung in der Bauwirtschaft vom 4. Juli 1972 (ANBA, 20. Jg., Nr.9, 1972, S.511ff.) i.d.F. der 1. ÄnderungsAO vom 18. Dezember 1975 (Rd.Erl. der BA 61/76, S.338) und der 2.ÄnderungsAO vom 15. Juni 1976 (ANBA, 24. Jg., Nr.9, 1976, S.869)

Winterbau-Umlageverordnung: Verordnung über die Umlage zur Aufbringung der Mittel für die Produktive Winterbauförderung vom 13. Juli 1972 (BGBl. I, S.1102f.) i.d.F. der Verordnung zur Änderung der Winterbauumlage-VO vom 30. April 1975 (BGBl. I, S.1102f.)

Zentralamt des Deutschen Wetterdienstes, Offenbach.

Zentralverband des Deutschen Baugewerbes (Hrsg.): Winterbau 73/74, Grundlage/Möglichkeiten/Kosten, ZDB-Schriften, Heft 5, S.17, Bonn, 1973

Zentralverband des Deutschen Baugewerbes (Hrsg.): Baujahr '92, Jahrbuch des Deutschen Baugewerbes, Ausgabe 1993, Band 43 


\section{SOZIALÖKONOMISCHE SCHRIFTEN}

Herausgegeben von Professor Dr. Dr. h.c. Bert Rürup

Band 1 Marietta Jass: Erfolgskontrolle des Abwasserabgabengesetzes. Ein Konzept zur Erfassung der Gesetzeswirkungen verbunden mit einer empirischen Untersuchung in der $\mathrm{Pa}$ pierindustrie. 1990.

Band 2 Frank Schulz-Nieswandt: Stationäre Altenpflege und "Pflegenotstand" in der Bundesrepublik Deutschland. 1990.

Band 3 Helmut Böhme, Alois Peressin (Hrsg.): Sozialraum Europa. Die soziale Dimension des Europäischen Binnenmarktes. 1990.

Band 4 Stephan Ruß: Telekommunikation als Standortfaktor für Klein- und Mittelbetriebe. Telekommunikative Entwicklungstendenzen und regionale Wirtschaftspolitik am Beispiel Hessen. 1991.

Band 5 Reinhard Grünewald: Tertiärisierungsdefizite im Industrieland Bundesrepublik Deutschland. Nachweis und politische Konsequenzen. 1992.

Band 6 Bert Rürup, Uwe H. Schneider (Hrsg.): Umwelt und Technik in den Europäischen Gemeinschaften. Teil I: Die grenzüberschreitende Entsorgung von Abfällen. Bearbeitet von: Thomas Kemmler, Thomas Steinbacher. 1993.

Band 7 Mihai Nedelea: Erfordernisse und Möglichkeiten einer wachstumsorientierten Steuerpolitik in Rumänien. Dargestellt am Beispiel der Textil- und Bekleidungsindustrie. 1995.

Band 8 Andreas Schade: Ganzjährige Beschäftigung in der Bauwirtschaft - Eine Wirkungsanalyse. Analyse und Ansätze für eine Reform der Winterbauförderung. 1995. 
Andreas Schade - 978-3-631-75046-9

Downloaded from PubFactory at 01/11/2019 08:54:32AM

via free access 